Slavistische Beiträge · Band 429

(eBook - Digi20-Retro)

\title{
Markus Eberharter
}

\section{Der poetische Formismus Tytus Czyżewskis}

\section{Ein literarischer Ansatz der frühen polnischen Avantgarde und sein mitteleuropäischer Kontext}

Verlag Otto Sagner München · Berlin · Washington D.C.

Digitalisiert im Rahmen der Kooperation mit dem DFG-Projekt „Digi20“

der Bayerischen Staatsbibliothek, München. OCR-Bearbeitung und Erstellung des eBooks durch den Verlag Otto Sagner:

http://verlag.kubon-sagner.de

( $)$ bei Verlag Otto Sagner. Eine Verwertung oder Weitergabe der Texte und Abbildungen, insbesondere durch Vervielfältigung, ist ohne vorherige schriftliche Genehmigung des Verlages unzulässig. 


\title{
SLAVISTISCHE BEITRÄGE
}

\author{
Herausgegeben von \\ Peter Rehder
}

\author{
Beirat: \\ Tilman Berger - Walter Breu • Johanna Renate Döring-Smirnov \\ Walter Koschmal • Ulrich Schweier • Miloš Sedmidubský • Klaus Steinke
}

BAND 429

\section{VERLAG OTTO SAGNER MÜNCHEN 2004}




\section{Markus Eberharter}

Der poetische Formismus Tytus Czyżewskis Ein literarischer Ansatz der frühen polnischen Avantgarde und sein mitteleuropäischer Kontext

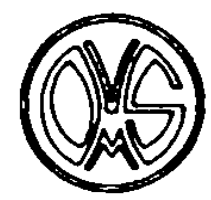

VERLAG OTTO SAGNER

MÜNCHEN 2004 
ISBN 3-87690-878-7

(1) Verlag Otto Sagner, München 2004 Abteilung der Firma Kubon \& Sagner D-80328 München

Gedrucks auf alierungsbeständigem P'apjer

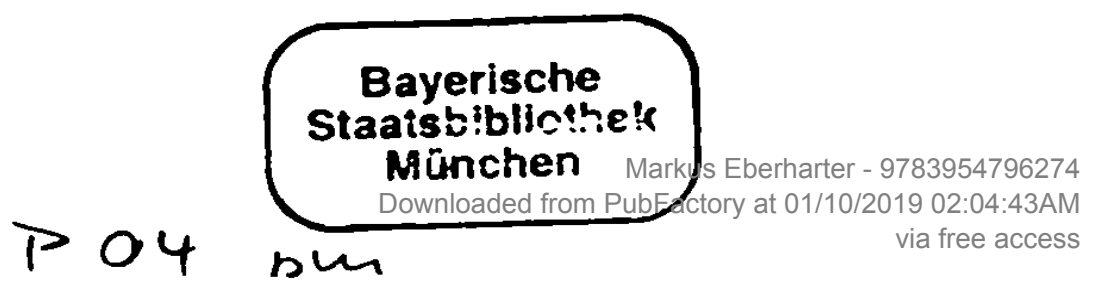




\section{Vorbemerkung}

Die vorliegende Arbeit wurde im Wintersemester 2003/2004 von der Kulturwissenschaftlichen Fakultät der Europa-Universität-Viadrina in Frankfurt (Oder) als Inaugural-Dissertation angenommen.

Ich möchte besonders meiner wissenschaftlichen Betreuerin. Frau Prof. Dr. Bożena Chołuj, für ihr Engagement für die Fertigstellung dieser Arbeit sowie ihre anregende und hilfreiche Kritik danken. Mein besonderer Dank gilt auch Herrn Prof. Dr. Alois Woldan. der mich beim Schreiben dieser Arbeit ebenso fördernd wie tatkräftig unterstützte. Ich danke auch der Europa-Universität-Viadrina. die mir durch ein Stipendium das Verfassen dieser Arbeit ermöglichte.

Ich danke schließlich Herm Prof. Dr. Peter Rehder für die Aufnahme dieser Arbeit in die Reihe ,.Slavistische Beiträge“. 
Markus Eberharter - 9783954796274 


\section{Inhaltsverzeichnis}

1. Einleitung

2. Zur Geschichte des polnischen Formismus

2.1 Die Grundlagen des Formismus

2.2 Das Entstehen des Formismus und der

Gruppe „Polnische Expressionisten“

2.3 Die „Blütezeit” des Formismus: Die Jahre 1917 bis 1922

3. Ästhetik und Kunsttheorie des Formismus

3.1 Die "visionäre Wirklichkeit“ des Formismus

(zum Verhältnis: Kunst und Wirklichkeit)

50

3.2 Zu Form, Komposition und Inhalt des Kunstwerks

61

3.2.1 Witkacy und die "Reine Form"

3.2.2 Die Form als Ausdruck des künstlerischen

Schaffens (zum Begriff der Form)

3.2.3 „Unwesentlich aber notwendig“ - zur Rolle

des Inhalts im Kunstwerk

3.3 Zusammenfassung - eine Theorie des Formismus?

4. Die formistische Literaturtheorie (Texte der

Formisten zur Literatur)

4.1 Zur Erneuerung der Literatur - Literatur und

(ihre) Gegenwart

4.2 Der "mehrdeutige Inhalt“ und die "Reine Form“-

zum Verhältnis zwischen Form und Inhalt im

literarischen Kunstwerk

4.3 Zusammenfassung

5. Die formistische Poesie Czyżewskis

5.1 Die "neue Zeit" in den formistischen Gedichten Czyżewskis

5.1.1 „Nie koniec a początek” - Der Erste Weltkrieg 
und der Beginn der neuen Zeit $\quad 114$

5.1.2 Das Antlitz der neuen Zeit (1): Die Großstadt 127

5.1.3 Das Antlitz der neuen Zeit (2): Die Technik und $\begin{array}{ll}\text { das neue Leben } & 137\end{array}$

5.1.4 Die neue Kunst 144

5.2 Das „Formistische“ in Czyżewskis Dichtung 154

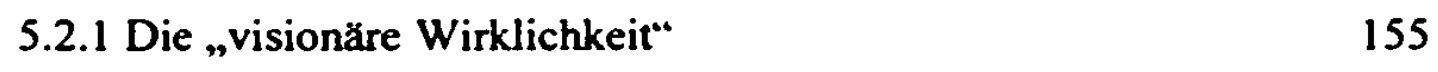

5.2.2 Die Form des Kunstwerks und die Überwindung des Inhalts 158

5.2.3 Literatur und Malerei im Schaffen Czyżewskis $\quad 174$

5.2.4 Zusammenfassung: Ist Czyżewskis Lyrik "formistisch“? 182

5.3 Czyżewski und die europäische Avantgarde 186

6. Der Formismus und die mitteleuropäische Avantgarde 197

6.1 Die Herausbildung des Formismus im Kontext

der mitteleuropäischen A vantgarde $\quad 200$

6.2 Mitteleuropäische Entwürfe einer ,neuen Kunst““ 212

$\begin{array}{ll}6.3 \text { Zusammenfassung } & 220\end{array}$

$\begin{array}{ll}\text { 7. Ausblick } & 223\end{array}$

$\begin{array}{lr}\text { 8. Bibliographie } & 227\end{array}$ 


\section{Einleitung}

Die ursprüngliche Idee dieser Arbeit bestand in einer vergleichenden Studie der frühen mitteleuropäischen Avantgarde am Beispiel der polnischen, tschechischen und ungarischen Literatur, die unmittelbar nach dem Ersten Weltkrieg entstand.

Als eine für diese Zeit charakteristische Strömung der polnischen literarischen Avantgarde sollte dabei der Formismus untersucht werden. Die entsprechenden Recherchen zeigten aber, dass der Formismus in seiner Charakteristik einige Besonderheiten aufweist, die bei seiner Beschreibung als Strömung der literarischen Avantgarde berïcksichtigt werden müssen, was in der bestehenden Sekundärliteratur nicht bzw. nur teilweise der Fall ist. Zum Beispiel kann der Formismus, aufgrund seiner immanenten Verbindung zur bildenden Kunst, nicht nur allein aus der Literatur heraus erfasst werden kann. Wie in dieser Arbeit beschrieben wird, spielten gerade die Malerei von Cézanne und der Kubismus eine entscheidende Rolle bei seiner Herausbildung noch vor dem Ersten Weltkrieg. Gleichermaßen vereinte auch die Gruppe der „Polnischen Formisten“ Künstler unterschiedlicher Bereiche, nämlich Bildhauer, Maler und Schriftsteller. Zu letzteren gehörten Stanisław Ignacy Witkiewicz (genannt: Witkacy), der in den frühen zwanziger Jahren vor allem als Dramatiker bekannt war und Tytus Czyżewski, der einzige "formistische Lyriker" in Polen. Beide traten gleichermaßen auch als Maler in Erscheinung, weshalb in ihrem Falle von sogenannten „Doppelbegabungen“ gesprochen werden kann.

Bei den Studien zum Formismus wurde außerdem klar, dass sich die einzelnen ästhetischen Ansätze nicht als Einheit, gewissermaßen im Sinne einer „Theorie des Formismus” erfassen lassen. Die formistische Gruppe verstand sich von Beginn an mehr als ein loser Verband von Künstlern, die sich in ihrem stilistischen Ausdruck deutlich voneinander unterscheiden. Was sie einte, waren weniger gemeinsame Programme, sondern die Idee einer an der Form orientierten Kunst und Literatur. Auf dieser Idee beruhen auch die von einzelnen Formisten verfassten kunst- und literaturtheoretischen Texte, die aber ebenfalls, wegen des pluralistischen Charakters der Gruppe, in erster Linie als individuelle Äußerungen ihrer Autoren und nicht als "Bausteine“ zu einer gemeinsamen formistischen Theorie gelesen werden sollen. In diesem Zusammenhang kommt hinzu, dass die Formisten, die am Beginn der polnischen Avantgarde stehen, viele neue ästhetische Ansätze zum ersten Mal formulierten und dadurch den Weg für neue Ausdrucksformen in Kunst und Literatur schufen, die anschließend jedoch nicht immer in vollem Umfang künstlerisch realisien 
wurden bzw. erst in späteren Strömungen wieder aufgegriffen wurden: So blieb zum Beispiel Czyzewski der einzige "formistische“ Dichter und Chwistek selbst bemerkt in seinem Text "Tytus Czyżewski und die Krise des Formismus“ („Tytus Czyżewski a kryzys formizmu“), in dem er die Auflösung der formistischen Gruppe quasi offiziell verkündet, dass der Formismus keine eigene Theorie, die in einigen Worten zusammengefasst werden könnte, hervorgebracht habe $(1922 b, 108)$.

Ungewöhnlich, vor allem wegen ihrer Einmaligkeit innerhalb der europäischen Avantgarde der zwanziger Jahre, erscheinen nicht zuletzt auch die Namen „Formisten“ („Formisci“) bzw. „Formismus“ („formizm“) selbst. Dabei handelt es sich, auch für das Polnische, um Neuschöpfungen, zur Bezeichnung einer an der Form orientierten Ästhetik - und darum genau ging es ja den Formisten - existiert an sich der Begriff „formalizm“ („Formalismus“)'. Wer diesen Namen erfand ist ebenso unklar, wie die Frage, warum sich die Gruppe anfangs noch „Polnische Expressionisten“ (.Ekspresjoniści Polscy“) nannte und aus welchem Grund sie sich nach einem halben Jahr für „Formisten“ entschied. Eine gewisse Rolle spielte dabei das Verhältnis des Formismus zu den anderen Gruppen der frühen polnischen Avantgarde, nämlich insofern, dass es den Formisten in diesem Zusammenhang auch um die Behauptung einer eigenen Position ging.

Dieser zuletzt angesprochene Aspekt, das heißt die Erfassung des Formismus als eigenständige Richtung der polnischen Avantgarde, ist gewissermaßen die größte Hürde, die es bei dessen Beschreibung zu überwinden gilt. Das resultiert vor allem aus dem angesprochenen Fehlen einer gemeinsamen ästhetischen Theorie und bezieht sich weniger auf die bildende Kunst der Formisten, sondern in erster Linie auf die formistische Poesie.

Was den Bereich der bildenden Kunst betrifft, so existieren hier bereits zahlreiche Untersuchungen in polnischer Sprache, die den Formismus in dieser Hinsicht ziemlich umfassend beschreiben. Dazu zählen. neben kleineren Aufsätzen verschiedener Autoren, vor allem die Arbeiten von Joanna Pollakówna, insbesondere ihre Monographie „Die Formisten“ („Formisci“, 1972). Der Formismus wird in diesen Studien als die erste Richtung in der polnischen Malerei beschrieben. für die eine nicht-mimetische, formale Kunst charakteristisch ist. Gleichermaßen wird auf die für dessen Herausbildung wichtige Rolle der zeitgenössischen europäischen Avantgarde in Gestalt von Kubismus, Expressionismus und Futurismus verwiesen, in deren Spannungsfeld die formistische Kunst interpretien wird.

\footnotetext{
'Anna Schmidt stellt in ihrer Arbeit zu Witkacy fest (1992, 44). dass "formistisch" (.,formistyczny”) dic eigentlich morphologisch korrekte Ableitung zum Substantiv ..Form" sei, wăhrend "formalistiscli" (.formalistyczny“) sich aus ..Formalismus“" (.,formalizm“) bzw. dem Adjektiv ..formal” (..formalny") herleite.
} 
Allerdings wurden bislang kaum Arbeiten veröffentlicht, die explizit die "formistische Lyrik“ Czyżewskis betreffen. Zwar gibt es viele Aufsätze zu Czyżewski, der mittlerweile einen festen Platz im „Kanon“ der polnischen Avantgarde einnimmt, in denen jedoch die Frage nach dem „Formistischen“ in Czyżewskis Lyrik nicht eigens behandelt wird. Eine Ausnahme bilden hier zwei Texte von Alicja Baluch (1985 und ihr Vorwort zu: Czyżewski 1992), die auch die erste Gesamtausgabe von Czyżewskis Gedichten veröffentlichte (1992). Zum ersten Mal untersuchte aber Helena Zaworska den literarischen Formismus Czyżewskis (1975). Wenngleich in diesen Arbeiten viele treffende Erkenntnisse formuliert werden. können sie doch - auch aufgrund ihrer Kürze - das Problem des „Formistischen“ bei Czyzzewski nicht erschöpfend behandeln. So fehlt etwa eine gemeinsame Darstellung der Gedichte Czyżewskis und der im Kontext des Formismus entwickelten theoretischen Ansätze Chwisteks oder Witkacys. aus der eine verwandte Auffassung vom Schaffensprozess sowie ähnliche Formen der künstlerischen Darstellung erkennbar wären, ohne dass dabei Czyżewskis Lyrik als "literarische Umsetzung“ dieser Theorien interpretiert wird.

In anderen Arbeiten zu Czyżewskis Lyrik wird im Zusammenhang mit der Frage nach dem „Formistischen“ auf die Schwierigkeit verwiesen, die vorwiegend am Material der bildenden Kunst entwickelten Theorien des Formismus auf die Literatur zu übertragen (zum Beispiel: Hutnikiewicz 1965, 174-179).

Häufig wird Czyżewski aber auch im Kontext der Literatur des polnischen Futurismus untersucht, was vor allem durch die zahlreichen stilistischen Parallelen zwischen Czyżewskis Lyrik und der futuristischen Poetik sowie durch seine intensiven persönlichen Kontakte zu den polnischen Futuristen motiviert wird (zum Beispiel: Lam 1969, Gazda 1974 und Drews 1983). Wenngleich eine solche Analyse durchaus von einer soliden Grundlage aus argumentieren kann, stellt sich doch die Frage, ob es durch sie wirklich möglich ist, Czyżewskis Poesie hinsichtlich ihrer Stilistik und der Besonderheiten der poetischen Darstellung umfassend zu beschreiben, oder ob durch die Fokussierung auf den futuristischen Hintergrund nicht andere, für diese Poesie wichtige Impulse, vernachlässigt werden.

Somit kristallisierte sich eine neue Aufgabenstellung für diese Arbeit heraus: die Beschreibung des Formismus als eigenständigen Ansatz im Bereich der Lyrik. Dabei scheint es zielfuhrend zu sein, von der Lektüre jener theoretischen Texte einzelner Formisten auszugehen, in denen Probleme der bildenden Kunst behandelt werden (Kapitel 3). Der Formismus ist durch eine Gruppe bildender Künstler entstanden und in diesen Texten zur bildenden Kunst, die vor allem von Chwistek und Witkacy stammen. werden die für die formistische Ästhetik zentralen Ideen zum ersten Mal formuliert. Diese Texte, die sich zum 
Teil erheblich von einander unterscheiden, weshalb nicht von einer kohärenten formistischen Theorie gesprochen werden kann, bilden zusammen jedoch eine Grundlage, auf der es mogglich ist, das „Formistische” - im Sinne eines gemeinsamen Nenners - in der bildenden Kunst herauszuarbeiten und zu beschreiben. Dieses „Formistische" besteht insbesondere in der Idee einer nicht-mimetischen Kunst, deren ästhetischer Wert auf der Form eines Kunstwerks, vor allem auf dessen in sich geschlossener Komposition beruht. Im Hinblick auf die literaturwissenschaftliche Fragestellung dieser Arbeit geht es bei der Lektüre dieser Texte allerdings weniger um Probleme, die explizit die bildende Kunst betreffen, als vielmehr darum, ăsthetische Ideen herauszuarbeiten, die gleichermaßen für die Literatur von Bedeutung sind. Dazu zählt zum Beispiel die Vorstellung von Kunst selbst, das heißt die Bestimmung dessen, was als ästhetisch "wertvoll” gilt. Gleichermaßen spielt auch das Verständnis vom künstlerischen Schaffensprozess eine Rolle, in dessen Zentrum der Künstler steht. Diese zentrale Position nimmt er wegen der Bedeutung ein, die die Formisten der individuellen Verarbeitung der Wahrnehmung von Eindrücken einer außerkünstlerischen Wirklichkeit zuschreiben. Außerdem verstehen sie die künstlerische Darstellung in gewissem Sinne als handwerkliche Tătigkeit, in der die kreative und in stilistischer Hinsicht individuelle schopferische Leistung des Künstlers zum Ausdruck kommt. Auch der Begriff der „Form” wird in diesen Texten näher bestimmt, ebenso wie das Verhältnis zwischen Form und gegenständlichem Inhalt im Kunstwerk. Da die Formisten den Schwerpunkt eindeutig auf die Form legen, stellt sich in diesem Zusammenhang auch die Frage, wie der Inhalt in einem Kunstwerk der Form „untergeordnet” werden kann. Diese sogenannte bewusste „Deformation” von Gegenständen spielt schließlich vor allem für die Komposition des Kunstwerks, deren Geschlossenheit die Formisten als ein zentrales Kriterium für den ästhetischen Ausdruck eines Kunstwerks begreifen, eine wesentliche Rolle.

An die Lektüre dieser Texte schließt sich im vierten Kapitel die Untersuchung der literaturtheoretischen Schriften von Czyżewski, Chwistek und Witkacy an, die meist zu einem spatteren Zeitpunkt als die allgemein theoretischen Texte entstanden sind. Es gilt daher danach zu fragen, ob und in welcher Form die für das formistische Kunstverständnis wichtigen Ideen. die zuvor aufgezählt wurden, auf den Bereich der Literatur übertragen werden. Gerade an diesen literaturtheoretischen Texten wird die Pluralität der innerhalb des Formismus vertretenen ästhetischen Ansätze deutlich, ebenso wie der zum Teil inkohärente Charakter der formistischen Theorie(n). Durch das gewählte analytische Vorgehen wird dieser Tatsache insofern entgegengetreten, als dass die literaturtheoretischen Schriften zusammen mit den kunsttheoretischen Texten gelesen werden, in deren Fall ja von einer gemeinsamen 
ästhetischen Grundlage gesprochen werden kann. Dadurch ist es möglich, das "Formistische” auch für die Literatur besser herauszuarbeiten.

Im funften Kapitel schließlich folgt die Interpretation der formistischen Gedichte Czyzewskis. Dabei geht es auch um ihre Beschreibung im allgemeinen Kontext ihrer Entstehungszeit, das heißt der Jahre um den Ersten Weltkrieg. Zu dieser Zeit kommt es in ganz Europa zum Entstehen neuer sozialer und politischer Lebensformen, es findet eine Revolutionierung der Technik statt und es setzt sich die Überzeugung durch, an der Schwelle zu einer neuen historischen Epoche zu stehen. Kunst und Literatur reagieren in vielfacher Hinsicht auf diese Veränderungen. Etwa durch die Suche nach neuen künstlerischen Ausdrucksformen, die dem "Geist" dieser neuen Zeit entsprechen, ebenso wie durch die Einführung neuer Themen und Motive in die Literatur. Die literarischen und künstlerischen Strömungen, die in vielen europăischen Ländem unter diesen Vorzeichen entstanden sind, werden gemeinsam oft als „Avantgarde” bezeichnet. Miklós Szabolcsi definiert diesen Begriff so:

\footnotetext{
.Unter Avantgarde verstehe ich Stromungen und Tendenzen mit einem klaren Programm auf asthetischer, philosophischer und in vielen Fallen politischer Ebene. Diese Stromungen finden sich meist in Kanstlergemeinschaften zusammen und treten in den ersten Jahren des Jahrhunderts auf: der italienische Futurismus. der franzosische Kubismus (sowohl in der bildenden Kunst als auch in der Literatur) und der deutsche Expressionismus in bildender Kunst und Literatur. Sie erreichen einen ersten Hohepunkt im ersten Jahrzehnt des 20. Jahrhunderts; eine zweite Welle ist zu Beginn der zwanziger Jahre zu beobachten (Dada. Surrealismus, Konstruktivismus); eine fuhlbare Veränderung ihrer Gestalt und ihres Einflusses schließlich erfolgt etwa 1935 bis 1938. Die erste große Periode der Avantgarde erstreckt sich also zwischen 1905 und 1938." (1979, 27).
}

Szabolcsi beschreibt hier, dass unter "Avantgarde“ mehrere Strömungen zusammengefasst werden. die sich in etwa zur selben Zeit - Szabolcsi unterscheidet hier zwei Phasen - in unterschiedlichen europäischen Ländern herausgebildet haben. Diese Strömungen erfuhren im Anschluss auch eine Verbreitung in anderen Ländern: so entstanden etwa nach dem italienischen oder russischen Futurismus, futuristische Gruppen auch in Polen, ăhnlich wie sich der Surrealismus, neben der französischen, zum Beispiel auch in der tschechischen Literatur etablierte. Auf diesem Verständnis der europăischen Avantgarde, das heißt als Sammelbegriff für einige zentrale Strömungen (Futurismus, Expressionismus, Kubismus, Dadaismus, Surrealismus und Konstruktivismus), die nicht nur in jenen Literaturen, in denen sie entstanden sind, sondern auch in anderen Literaturen Verbreitung fanden, beruhen viele Untersuchungen und Beschreibungen (zum Beispiel: Weisgerber 1984). Es scheint, dass sich in der polnischen Avantgarde, die sich im Unterschied zu den von Szabolcsi genannten Strömungen der ersten Periode, erst um 1917/1918 herausbildet bzw. in Form von Zeitschriften. Gruppen etc. institutionalisiert, mehrere Formen dieser Verbreitung feststellen lassen: unter gleichem Namen (Fxpressionismus) oder aher in jener Form, dass 
unterschiedliche Einflüsse miteinander kombiniert werden. So finden sich etwa im polnischen Futurismus viele Elemente, die eher mit dem Dadaismus, als mit dem italienischen oder russischen Futurismus, verwandt sind. Gleichermaßen steht auch der Formismus dem Kubismus, dem Expressionismus und dem Futurismus nahe, sowohl was den Bereich der bildenden Kunst, als auch den der Lyrik betrifft. Diese besondere Beziehung zwischen dem Formismus und der gesamteuropäischen Avantgarde findet in zweifacher Hinsicht Eingang in die vorliegende Arbeit: zum einen bei der Beschreibung von Parallelen zwischen Czyżewskis Gedichten und Apollinaire, dem Futurismus und dem Expressionismus. Zum anderen bildet diese Beziehung auch den Ausgangspunkt für die vergleichende Untersuchung der mitteleuropäischen Avantgarde, da es scheint, dass sich auch das Verhältnis zwischen der tschechischen bzw. der ungarischen und der gesamteuropäischen Avantgarde in einer ăhnlichen Weise gestaltete.

Die Beziehung zwischen dem Formismus bzw. der formistischen Lyrik Czyżewskis und anderen zeitgenössischen literarischen Strömungen spielt letztendlich auch eine Rolle für die Untersuchung der zentralen Fragestellung dieser Arbeit, nämlich. ob von einer eigenständigen "formistischen Poetik“, von spezifisch "formistischen" Verfahrensweisen in der Literatur gesprochen werden kann. Die Untersuchung stützt sich dabei vor allem auf die Lektüre der theoretischen Texte der Formisten in den Kapiteln drei und vier, wodurch gezeigt werden soll. wie bestimmte, für die formistische Konzeption von Kunst charakteristische Ansätze, auch in die lyrische Praxis Eingang finden können. Zentral ist in diesem Zusammenhang etwa die Beziehung von Form und Inhalt im Gedicht, die Chwistek mit der Formel von der „Überwindung des Inhalts durch die Form“ beschreibt. Obwohl es im Falle eines einzelnen Dichters schwer ist, von einer Strömung zu sprechen, kann dadurch dennoch sichtbar gemacht werden, dass die formistische Lyrik Czyżewskis durchaus als eine eigenständige Erscheinung - auch innerhalb der polnischen und europäischen avantgardistischen Literatur - angesehen werden kann.

Allerdings kann das Verhältnis Formismus-Avantgarde in dieser Arbeit nicht zur Gänze beschrieben werden. Aufgrund der Komplexität mancher damit im Zusammenhang stehender Fragen wären dafür eigene Untersuchungen notwendig. Dies betrifft insbesondere die strukturelle Eingliederung des Formismus in die europäische Avantgarde, wobei es zum Beispiel um die Frage nach der Rolle der Kunst im gesellschaftlichen Kontext. um die Auffassung von Kunst und vom Kunstwerk selbst sowie um die Bestimmung von künstlerischen Verfahren geht, die für die unterschiedlichen avantgardistischen Strömungen, das heißt auch für den Formismus, eine zentrale Rolle spielen. Als Ausgangspunkt einer 
solchen Beschreibung könnte dabei die Arbeit „Theorie der Avantgarde“ von Peter Bürger (1974) dienen. Ebenso wăren die von Szabolcsi im zuvor angeführten Zitat genannten (literatur-)soziologischen Faktoren für den Formismus in Bezug auf die gesamteuropäische Avantgarde noch genauer zu untersuchen: die Gestalt und Konzeption der formistischen Gruppe oder das Problem (des Fehlens) eines formistischen Programms. Schließlich wäre auch die Bedeutung des Begriffs "Avantgarde" speziell in Polen noch genauer zu differenzieren und danach zu fragen, ob der Begriff gleich oder unterschiedlich wie in anderen europäischen Ländern gebraucht wird (vgl. Jaworski 1992, 6-7).

Die ursprüngliche Idee einer vergleichenden Studie zur mitteleuropäischen Avantgarde, sollte, wie angedeutet. nicht zur Gänze aufgegeben werden. Daher wird im letzten Kapitel der Versuch unternommen, am Material des Formismus sowie paralleler Erscheinungen aus der frühen tschechischen und ungarischen Avantgardeliteratur, beispielhaft einige Gemeinsamkeiten herauszuarbeiten, die für die Beschreibung der mitteleuropäischen Avantgarde fruchtbar gemacht werden können. Die Avantgarde ist eine gesamteuropäische Erscheinung, es kann daher nicht darum gehen. einzelne Strömungen aus diesem Kontext herauszulösen, sondern vielmehr auf die entsprechenden Besonderheiten im mitteleuropäischen Raum hinzuweisen. Dadurch wird auch an eine Diskussion über diesen Teil Europas angeknüpft, die besonders seit den achtziger Jahren geführt wird, ebenso wie an eine Forschungstradition der Komparatistik.

Es gibt bislang nur vereinzelt Darstellungen des Formismus und seiner Kunst in deutscher Sprache. Lam und Drews behandeln im Rahmen ihrer Arbeiten zur polnischen bzw. slawischen literarischen Avantgarde auch den Formismus (1990 bzw. 1983). Sie informieren dabei ubber die wichtigsten Daten aus der Geschichte des Formismus und erwähnen auch einige theoretische Ansătze, vor allem von Chwistek. Da beide Autoren in ihren Arbeiten ein breites Thema behandeln, nămlich die gesamte frühe polnische (Lam) bzw. die polnische, tschechische und russische Avantgarde (Drews) müssen sie sich in ihrer Darstellung des Formismus notgedrungen kurz fassen. Daher steht am Anfang der vorliegenden Arbeit ein chronologischer Überblick über die Geschichte des Formismus mit den wichtigsten Ereignissen und Fakten².

Die vorliegende Arbeit beschränkt sich bei der Untersuchung des Formismus auf die Krakauer Gruppe. Diese entstand als erste und ihr gehorten auch die wichtigsten Theoretiker

\footnotetext{
${ }^{2}$ Zwei karzere Darstellungen zum Formismus auf deutsch finden sich in: Dedecius 1996-2000, V/293-304 und in: Wilhelmi 2001, 143-145. In dem von Dedecius herausgegebenen Werk finden sich außerdem
} 
des Formismus an: Tytus Czyżewski, Leon Chwistek, Zbigniew Pronaszko und Witkacy. Formistische Gruppen bildeten sich in der Folge auch in Warschau und in Lemberg. Da die Mitglieder dieser beiden Gruppen keine größeren theoretischen Schriften verfassten, werden sie in dieser Arbeit nicht berücksichtigt. Gerade was die Lemberger Gruppe betriff, so existieren bislang auch nur vereinzelte Hinweise auf ihre Tătigkeit, es ist aber durchaus möglich, dass zukünftige Untersuchungen hier neue Ergebnisse vorlegen werden.

Alle Übersetzungen der aus polnischen Texten entnommenen Zitate stammen von mir. Da diese Texte das Material und die Grundlage meiner Beschreibung darstellen, finden sie auch in der von mir verwendeten Form, das heißt im polnischen Original, Eingang in den Text dieser Arbeit. Ihre Übersetzung ist in einer Fußnote angeführ. Im Falle der Zitate aus Czyżewskis Gedichten sei an dieser Stelle betont, dass es sich dabei um wörtliche Übersetzungen handelt, in denen nicht versucht wird, auch Metrum und Reim sowie andere Stilfiguren des Originals wiederzugeben. Ansonsten werden im Sinne der Lesbarkeit des deutschen Textes möglichst viele polnische Titel (Aufsătze, Bücher usw.) und Bezeichnungen, sofern dies vertretbar ist, in ihrer deutschen Übersetzung gebraucht, bei ihrer erstmaligen Nennung ist das polnische Original in Klammern angeführt.

Einzeldarstellungen von Chwistek, Czyzewski und Witkacy (vgl. IV/122-126, 143-147 bzw. 945-952) sowie einige formistische Gedichte Czyzewskis in deutscher Übersetzung ( $(1 / 1 / 335-342)$. 


\section{Zur Geschichte des polnischen Formismus'}

\subsection{Die Grundlagen des Formismus}

Als entscheidend für die Herausbildung des Formismus können die Jahre 1910 bis 1914 angesehen werden. In dieser Zeit (zwischen 1910-1912) schlossen viele der späteren Formisten ihr Studium $a^{2}$, in den polnischen Kunst- und Literaturzeitschriften wurde ausführlich über die neuesten Erscheinungen in der europäischen Kunst geschrieben und immer deutlicher war auch die Krise der Generation des „Jungen Polens" (,Młoda Polska“) ${ }^{3}$ und ihrer Ästhetik zu spüren, was ebenfalls das Entstehen von Neuem begünstigte. Die meisten der späteren Formisten studierten an der Krakauer Akademie der Schönen Künste, an der mit Mehoffer oder Malczewski einige der wichtigsten Künstler des „Jungen Polens" unterrichteten. Nicht zuletzt aus diesem Grund war ihre anfängliche Suche nach eigenen ästhetischen Positionen auch von der konstruktiven Auseinandersetzung mit der Kunst ihrer Lehrer, das heißt der des „Jungen Polens“ geprăgt, die eine wichtige Grundlage ihrer eigenen Überlegungen bildete. Aus diesem Grund muss der in vielen späteren Texten so vehement artikulierten Opposition, die den Wunsch der Formisten nach einem radikalen

\footnotetext{
' Zur Geschichte des Formismus liegen in polnischer Sprache bereits viele Arbeiten vor (vor allem: Pollakówna 1972), die das Thema erschopfend beschreiben. Da in deutscher Sprache eine entsprechende lăngere Darstellung bislang fehlt. ist es das primäre Ziel des vorliegenden Kapitels diese Lucke zu fullen. wenngleich ich mich dabei auf die wichtigsten Zusammenhănge beschranke.

2 Eine Ausnahme bildet Czyzewski, der sein Studium bereits 1907 beendete.

3 Der Begriff ..Mloda Polska" (..Das junge Polen“), der die polnische Variante der europäischen Moderne bezeichnet, wurde vom Schriftsteller und Literaturkritiker Arnur Górski gepragt. der unter diesem Titel in der Krakauer Zeitschrift .Życie“" (..Das Leben“) 1898 einen Zyklus von Feuilletons veroffentlichte, in denen er zum ersten Mal die Ideen und das Lebensgefuhl derer beschrieb, die um 1870 geboren wurden. Der Begriff wurde so bald auf die ganze Generation ubertragen. Für die Literatur formulierte das Programm des "Jungen Polens“" darauf aufbauend Stanislaw Przybyszewski, der 1898 nach Krakau kam und die Redaktion von ..Zycie" ubernahm. Kazimierz Wyka (vgl. Stichwort: „Mloda Polska” in: Krzyzanowski'Hemas 1984, 1/676-678) sieht das Lebensgefuhl. das die Grundlage von Kunst und Literatur bildete. geprägt vor allem vom Bewusstsein der Krise (zum Beispiel: Verlust allgemeinverbindlicher Wahrheiten), vom Misstrauen gegenuber lechnischen Errungenschaften und gegenüber dem Fortschritt der Naturwissenschaften des 19. Jahrhunderts. Dies trug zui Abkehr vom Realismus und zum Aufkommen metaphysischer und irrationaler Haltungen bei und fuhrte schließlich vom Protest gegenúber der imperialistischen Politik der europäischen Großmáchte zum Erstarken nationaler Unabhăngigkeitsbestrebungen. In Polen war die Wiederentdeckung der Romantik ein wichtiges Element dieses Prozesses. Im asthetischen Bereich wurde die Kunst als autonome, oberste Wahrheit erachtet. Dem Kunstler wurde eine, im Vergleich zum gemeinen Büger. besondere und tiefergehende Wahmehmung zugestanden: seine weltabgewandte und dekadente, zum Teil exzentrische Lebenshaltung unterschied ihn von seiner Umwelt. Durch ihre verschiedenen Zentren (Warschau, Krakau und Lemberg) und ihrer Akzentuierung politischer Werte (staatliche Souveranitat Polens) wirkte das .Junge Polen“ uber die drei Teilungsgebiete hinweg integrierend im Sinne einer polnischen Kunst. Gleichzeitig war es, aufgrund ahnlicher Erfahrungen sowic eines gemeinsamen asthetischen Kanons, Teil der europäischen Moderne. Aus diesem Grund ist das .Junge Polen" in typologischer Hinsicht auch mit zeitgleichen Erscheinungen wie .Jung-Wien“ oder ..Jung-Berlin" verwandt. hatte jedoch nichts mit der in Deutschland zwischen 1830 und 1840 entstandenen Bewegung des ..Jungen Deutschlands" gemein.
} 
Neubeginn zum Ausdruck bringt, doch eher mit Zurückhaltung entgegengetreten werden ${ }^{4}$. In diesem Zusammenhang sei auch auf die Ausführungen von Kryszak zum literarischen Schaffen Czyżewskis vor dem Ersten Weltkrieg verwiesen. Er beschreibt nämlich (1981, 29 33), wie Czyżewski in einigen Gedichten bzw. in seinem Drama „Der Tod eines Fauns“ („Śmierć fauna“) von 1907, bestimmte, mit dem „Jungen Polen“ verbundene literarische Konventionen aufruft, um diese dann in denselben Werken, etwa durch Einfuhrung von unerwarteten Elementen, die nicht in eine bestimmte Konvention passen, zu konterkarieren.

Eine wichtige Rolle für die Suche nach neuen, eigenen künstlerischen Ausdrucksformen spielte die Kenntnis der neuesten Strömungen der europäischen Kunst und Literatur. Gelegenheit, um sich mit ihnen bekannt zu machen, bot sich zum Beispiel auf Reisen, vor allem nach Paris. Den Anfang machten Zbigniew Pronaszko (mehrere Male zwischen 1907 und 1910) und Czyżewski (1907-1909 und 1910-1912), etwas später verbrachte auch Chwistek zwei Jahre in Paris (1912-1914) . Paris hatte seinen Rang als Hauptstadt der Kunst des beginnenden 20. Jahrhunderts vor allem drei Erscheinungen zu verdanken: erstens der Malerei Cézannes, die unter anderem 1907 auf einer großen Ausstellung gezeigt wurde. zweitens dem Kubismus, der, nach Picassos "Les Demoiselles d'Avignon“ von 1907, zwischen 1909 und 1912 in Gestalt des sogenannten analytischen Kubismus seinen Höhepunkt fand (die wichtigste Ausstellung fand im Oktober 1912 statt) und drittens dem Futurismus, dessen erstes, von Marinetti verfasstes „Manifest des Futurismus“ („Manifeste du futurisme“) am 20. Februar 1909 in der Tageszeitung "Le Figaro" erschien". Es waren vor allem die Malerei Cézannes und die vom Kubismus vorgeschlagene neue Ar, die Wirklichkeit künstlerisch zu erfassen, die den stärksten Eindruck bei Pronaszko, Chwistek und Czyzewski hinterließen.

Die neuesten Strömungen der europäischen Kunst und Literatur wurden, etwa ab 1909, aber auch in Polen selbst rezipier'. Allgemein kann festgestellt werden, dass die meisten Artikel,

\footnotetext{
4 Zum Beispiel: Winkler 1927 sowic: Czyzewski 1938 und Z. Pronaszko 1938. Vgl. zum Verhaltnis der Formisten zur Kunst des .Jungen Polens“ auch: Pollakowna 1963, 247-248.

'Vgl. zu Zbigniew Pronaszko: Blumówna 1958, 6-7; zu Chwistek: Estreicher 1971, 87-94; zu Czyzewski: Pollakówna 1963, 249-251 bzw. Baluch. in: Czyzewski 1992, XV-XVI. Auch Witkacy verbrachte 1911 cine langere Zeit in Frankreich, und zwar in der Bretagne auf Einladung des dort ansăssigen polnischen Malers Wradysław Slewiniski (vgl. Estreicher 1971, 81-82).

- Vgl. zu Cézanne: Borghesi 1999, besonders 130-131; zum Kubismus: Richter 1998, 46-54 sowie zum Futurismus: Schmidt-Bergmann 1993.

$7 \mathrm{Zu}$ diesem Thema liegen vor allem auf polnisch sowohl vonseiten der Kunstgeschichte. als auch der Literaturwissenschaft bereits zahlreiche Untersuchungen vor. Statt einer falle von Details verweise ich daher nur auf einige grundlegende Zusammenhange, wobei ich mich auf folgende Arbeiten stutze: Pollakowna 1966, 6266. Lam 1969, 1/66-73, Prokop 1970, 38-52, Estreicher 1971, 67-70 und 82-85, Kuzma 1976. 22-25, Drews 1983, 180-182, 194-195 und 204-205. Malinowski 1991, 15-22 sowic Lukaszewicz/Malinowski 1996, $221-229$. Es scheint jedoch, dass das Thema einer neuen, grundlegenden Aufarbeitung bedarf. da die Angaben und
} 
die in Polen vor dem Ersten Weltkrieg über Kubismus oder Futurismus berichten, in erster Linie über diese informieren wollen, nur vereinzelt lässt sich eine kritische Auseinandersetzung mit deren Theorien beobachten. Der Wert der Informationen ist dabei von unterschiedlicher Qualität: neben Übersetzungen zentraler programmatischer Texte und fundierten Studien, finden sich auch Beiträge, deren Autoren sich mehr über die neue Kunst lustig machen, ja diese sogar verspotten. Oftmals wurden nämlich Berichte zum Beispiel über eine kubistische Ausstellung nicht von Fachleuten geschrieben, sondern von Laien, die nicht fähig waren, das Phänomen adäquat zu erfassen. Dieser Umstand erklărt wohl auch ein weiteres Manko vieler Texte, das in der verwirrenden Terminologie besteht: allein dem Begriff „Expressionismus“ können zumindest drei unterschiedliche Bedeutungen zugeschrieben werden: als dem Impressionismus entgegengesetzte "Ausdruckskunst“, als neueste deutsche Kunst und als Oberbegriff für alle Strömungen der zeitgenössischen Kunst. Da außerdem relativ wenige Reproduktionen von einzelnen Kunstwerken abgedruckt wurden. kam es oft wirklich auf die Beschreibungskunst des jeweiligen Autors an. Dennoch - und das ist das Entscheidende - war es in Polen möglich, sich gut über die zeitgenössische Kunst zu informieren und die wesentlichen Diskussionen zu verfolgen.

Über den Kubismus wurde bereits ab 1909 geschrieben. zu nennen ist vor allem die ausfuthrliche Studie von Adolf Basler ${ }_{n}$ Alte und neue Konventionen in der Malerei (Von Cézanne zum Kubismus)“ („Stare i nowe konwencje w malarstwie - Od Cézann'a do kubizmu“) aus dem Jahre $1913^{8}$. Er rekonstruiert darin die Entwicklung der neuesten Malerei. von Cézanne über Matisse bis hin zu den Kubisten. Sie sind für ihn die ersten, die die Kunst von ihrer abbildenden Funktion befreiten und sich mehr formalen Fragen zuwandten, etwa einer neuen Bildkonstruktion durch das Bemühen, unterschiedliche Ansichten eines Gegenstandes simultan darzustellen'.

Auch der Futurismus wurde in Polen im Prinzip seit seinen Anfängen rezipien, wenngleich dies eher über Paris, als über Italien geschah. Doch gerade ihm, was vielleicht in der

Bewertungen in den einzelnen Studien zum Teil erheblich divergieren. Dabei ist folgendes festzustellen: Wahrend altere Arbeiten die Informationen uber die europaische Kunst in Polen vor dem Ersten Weltkrieg sowohl qualitativ, als auch quantitativ - als schlecht einschatzen (das extremste Beispiel ist: Zaworska 1963. 24. 26. die eine weitgehenden Unkenntnis der europaischen Kunst feststelit), konnen Arbeiten neueren Datums in ihrer Argumentation auf immer mehr Texte zurlickgreifen: Lukaszewicz und Malinowski sprechen daher in ihrem Aufsatz (1996, 224) von „vielen detaillierten Informationen und Interpretationen [...] ab 1912“* (.sporo szczególowych informacji $i$ interpretacji $[. .$.$] od roku 1912.")$

- Ausfuhrlich gehen auf diese Studie Pollakowna (1966, 63-64) sowie Estreicher (1971, 83-85) ein. Estreicher weist auch darauf hin, dass Chwistek diesen Aufsatz kannte. Vgl. auch: Lukaszewicz/Malinowski 1996. 228.

- Vgl. dazu das von Pollakówna zitierte Fragment aus Baslers Aufsatz (1966, 64). Estreicher erwăhn (1971, 115-117), dass, aufgrund der seit dem 19. Jahrhundert intensiven kulturellen Beziehungen zwischen Krakau und 
Außergewöhnlichkeit der futuristischen Postulate begründet ist, begegnete man anfangs oft mit Spott und Unverständnis, bestenfalls mit verhaltener Sympathie. Letztere resultierte meist aus der Bewunderung für den futuristischen Aktivismus und Vitalismus, dessen Begeisterung an den Erscheinungen der Gegenwart sowie der von den Futuristen gepriesenen und geforderten Dynamisierung des Lebens, was sich alles in allem gegen die modernistische Dekadenz und Passivität richtete. In dieser Hinsicht sahen Kritiker wie Wilhelm Feldman oder Anna Limprechtówna im Futurismus sogar einen möglichen Impuls für die polnische Unabhängigkeitsbewegung und die Realisierung ihrer Ziele sowie für die allgemeine Entwicklung Polens hin zu einem modernen Staat. Beides sollte Hand in Hand mit einer Neubewertung des Verhältnisses zur eigenen Tradition gehen ${ }^{10}$. Insgesamt wurde dem Futurismus zugestanden, belebend und erneuernd für die zeitgenössische Kunst und Literatur wirken zu können, in formaler, wie in thematischer Hinsicht. Dennoch dachte keiner der Autoren. die in Polen über ihn schrieben, wirklich an einen polnischen Futurismus noch vor dem 1. Weltkrieg". Dies triff auch auf die erschöpfendste Studie zum Futurismus „Über den Futurismus als kulturelles und künstlerisches Phänomen“ (,O futuryzmie jako zjawisku kulturalnym i artystycznym", 1914) von Aleksander Kołtoński zu. der neben den ideellen Grundlagen des Futurismus auch alle Manifestationen futuristischer Kunst untersucht ${ }^{12}$. Doch gerade der Futurismus sollte in Jerzy Jankowski einen ersten Vertreter in Polen finden. Jankowski veröffentlichte noch vor dem Ersten Weltkrieg einige futuristische Gedichte (zum Beispiel: „Brand des Fliegers“ - „Spłon lotnika“ und „Maggi“ - „Maggi“), doch erst 1920 erschien sein einziger Gedichtband "Tram kwer zur Straße. Prosa-Auszüge und Poeme“ („Tram wpopszek ulicy. Skruty prozy i poemy“) im „Verlag Polnischer Futurismus unter der Leitung von Jeschi Jankofski“ (,Wydawnictwo Futuryzm Polski pod wodza Yeżego

Prag, auch der vor dem Ersten Weltkrieg entstandene tschechische Kubismus der Kanstler Otto Gutfreund, Bogumil Kubišta und Emil Filla der polnischen Offentlichkeit bekannt gewesen sein könnte.

${ }^{10}$ Zu Feldman: vgl. Lam 1969, 1/67-68. Zu Limprechtówna: vgl. Prokop 1970, 42-43.

"Ignacy Grabowski schreibt in seinem Text "Die neuesten Strömungen in der europäischen Literatur. Der Futurismus" („Najnowsze prady w literaturze europejskiej. Futuryzm”) unter anderem: „W jakim stosunku stanąc moze ten ruch do naszej literatury? Stosowanie tych słów bombastycznego manifestu signora Marinettiego, gdzie mówi się o zniszczeniu muzeów i zatopieniu bibliotek [...] do nas byloby gorzką ironia, do nas, gdzie w ogóle tych ,zacnych trupów' jest w dziesięckroć. jezeli nie o stokroć za malo." (in: PodrazaKwiatkowska 1973, 698). ..In welcher Beziehung kann diese Bewegung zu unserer Literatur stehen? Es wăre bittere Ironie, die Worte des bombastischen Manifestes von Signore Marinetti, in dem von der Zerstorung der Museen und dem Versinken von Bibliotheken [...] die Rede ist, auf Polen zu abertragen, wo es uberhaupt zehn-. wenn nicht hundertmal zu wenig dieser ,ehrenhaften Leichen' gibt."

12 Vgl. dazu besonders: Lam 1969, 1/68-72. Auch Drews betont $(1983,182)$. dass die eigentliche inhaltliche Auseinandersetzung mit dem Futurismus in Polen erst nach dem Ersten Weltkrieg stattgefunden habe, also zu einer Zeit, als der italienische Futurismus seine Glanzzeit bereits hinter sich hatte. Der russische Futurismus wurde erst nach dem Ersten Weltkrieg in Polen stärker rezipien, vermittelnd wirkten hier vor allem die polnischen Futuristen Bruno Jasienski und Stanisław Mlodozeniec. die 1918 aus Russland nach Krakau zuruckkehrten. 
Yankowskiego"). Wie die Schreibweise der Titel verrăt, versuchte auch Jankowski die polnische Orthographie zu verfremden, wenn auch nicht so radikal, wie es später Jasieński vorschlagen sollte. Jankowski hielt in Warschau um 1919/1920 auch Kontakt zu den Futuristen, schrieb auch futuristische Manifeste, die allerdings als verschollen gelten und trat auch einige Male bei futuristischen Abenden auf. Durch eine psychische Krankheit war ihm aber eine weitere aktive Teilnahme am polnischen Futurismus nach 1921 nicht mehr möglich (vgl. Jarosiński/Zaworska 1978, XV-XVIII).

Im Vergleich zu Kubismus und Futurismus waren die Informationen über den Expressionismus vor dem Ersten Weltkrieg äußerst spärlich, wenngleich, wie Prokop zeigt (1970, 58-61), die polnische Kritik durchaus in der Lage war, ihn in seiner Ästhetik differenziert zu erfassen. Im Jahre 1911 wurde der Begriff in einer Rezension einer Berliner Ausstellung zum ersten Mal verwendet, zwei Jahre später erwăhnt auch Basler in seinem oben genannten Text den Expressionismus, den er - parallel zum Kubismus in Frankreich - als die deutsche Variante der zeitgenőssischen Kunst bestimmt, die ihre Wurzeln in der Malerei Cézannes hat. $\mathrm{Da}$ es vor dem Ersten Weltkrieg keine Versuche gegeben hat, den Expressionismus in der polnischen Kunst und Literatur zu verankern (vgl. Kużma 1976, 25), ist es umso erstaunlicher, dass sich die beiden ersten polnischen avantgardistischen Künstlergruppen, die 1917 entstehen, explizit auf den Expressionismus beziehen: die Posener Gruppe um die Zeitschrift „Zdrój” („Die Quelle“) und die mit ihr verbundene Gruppe bildender Künstler „Bunt“ (,Rebellion“) sowie die Krakauer Formisten, die sich zu Beginn ja noch „Polnische Expressionisten“"(,Ekspresyoniści Polscy“) nennen.

Gerade am Expressionismus wird deutlich, dass die Nachrichten über die neueste europăische Kunst, die in Polen vor dem Ersten Weltkrieg erschienen, in erster Linie die bildende Kunst und nicht die Literatur betrafen, nur selten ist von expressionistischer Dichtung die Rede. In ähnlicher Weise wurde auch die franzosische avantgardistische Literatur vor 1914 in Polen kaum rezipiert; Apollinaire war in dieser Zeit vor allem als Theoretiker des Kubismus bekannt und wurde erst nach 1918 ubersetzt. Und schließlich wurde ja auch der Futurismus weniger als literarische Erscheinung, sondern vielmehr als neues, aktivistisches Lebensmodell interpretiert.

In welcher Hinsicht nun beeinflussen Cézanne, der Kubismus, der Futurismus und der Expressionismus die jungen polnischen Künstler und wo gibt es Berührungspunkte im ästhetischen Denken mit den spăteren Formisten?

Cézanne und seiner Malerei wird allgemein entscheidende Bedeutung für die Entwicklung der Kunst im 20. Jahrhundert zugemessen, und auch die Formisten bezogen ihre Kunst auf ihn. 
Winkler, der Cézannes Malerei durch Czyżewski kennen lernte, beschreibt seinen ersten Kontakt folgendermaßen:

„W tym czasie, a byl to rok 1907, Czyzewski nawiazawszy lącznośc z Paryzem pokazal mi po raz pierwszy jednobarwne reprodukcje z obrazów Cézann'a - nad którymi ślęczeliśmy godzinami, nic z począku nie rozumicjąc. Dopiero po pewnym czasie domyślilismy się, o co tu chodzi. A więc przede wszytkim o formę i konstrukcje obrazu - o budowę planowa w przeciwieństwie do chaosu i przypadkowości w naturze." (1947, $13)^{13}$

Bei Cézanne geht es also zum ersten Mal nicht wie im Impressionismus um das Festhalten eines bestimmten Moments, sondern um eine originär künstlerische Aneignung der Wirklichkeit, die Winkler im Zitat "Natur“ nennt. Diese Aneignung besteht für Winkler in der Erfassung der „chaotischen“ Eindrücke von der Wirklichkeit durch klare Formen, die auch an geometrische Figuren erinnern können sowie in einer konzipierten und einheitlichen Komposition des Kunstwerks (vgl. auch: Winkler 1921, 20-21 und 1927, 9-12). Diese beiden Aspekte sollten die Vorstellung der Formisten, was Kunst sei, entscheidend beeinflussen, wie in ihren theoretischen Schriften deutlich sichtbar wird. Somit liegt die Bedeutung Cézannes für sie insgesamt in der Betonung formaler und konstruktiver Aspekte der Kunst, was zur Folge hat, dass die dargestellten Gegenstände deformiert werden (können) und auf eine die "Realităt" suggerierende Anordnung der einzelnen Elemente auf der Leinwand gemäß einer einheitlichen Perspektive verzichtet wird (vgl. auch: Lukaszewicz/Malinowski 1996, 226). Die Idee der Kunst wird nicht mehr in der Nachahmung, sei es im Erfassen nur eines bestimmten Momentes, sei es in beschreibender Detailtreue, gesehen. Künstlerisches Schaffen wird nun als Umgang mit dem Material, in dessen Erfassung und Bearbeitung sowie im Streben nach einer harmonischen und geschlossenen Komposition. die von der Beziehung zwischen ihren Einzelteilen lebt, verstanden.

Wenngleich auch der Kubismus eine wichtige Rolle für die Herausbildung der avantgardistischen polnischen Kunst spiclte. sahen die Formisten in ihm weniger einen Vorläufer, sondern eine zu ihnen parallele Strömung der zeitgenössischen Kunst (vgl. Kostyrko 1996, 204-206). Diese Auffassung liegt einigen theoretischen Texten, zum Beispiel von Chwistek oder Winkler, zugrunde ${ }^{4}$. Der Kubismus wirkte in mehrerer Hinsicht inspirierend für den Formismus. Dazu zählt erstens erneut die Auffassung, dass sich

\footnotetext{
${ }^{13}$.Zu jener Zeit, im Jahre 1907, zeigte mir Czyzewski. nachdem er Kontakt nach Paris geknupft hatte, zum ersten Mal einfarbige Reproduktionen von Bildern von Cézanne - aber denen wir stundenlang bruteten, ohne. dass wir anfangs etwas verstanden hătten. Er nach einer gewissen Zeit kamen wir darauf, worum es hier geht. Nămlich vor allem um die Form und die Konstruktion des Bildes - um den planmåßigen Aufbau im Gegensatz zum Chaos und zur Zufalligkeit in der Natur."
} 
künstlerisches Schaffen nicht mehr in der Nachahmung und Abbildung, sondern im kreativen Umgang mit Eindrücken ăußert. Die Kubisten zăhlten zu den ersten, die nicht mehr nach der Natur, sondern aus dem Gedächtnis malten. Damit zusammen hängt die Aufgabe einer an Themen und Inhalten orientierten Kunst; der künstlerische Ausdruck wird in der, zum Beispiel von der Geometrie beeinflussten, formalen Erfassung der Bildelemente sowie im Aufbau und in der Komposition des Kunstwerkes gesucht. Durch die Dekonstruktion und Zerlegung des Gegenstandes und die simultane Darstellung verschiedener Ansichten eines Gegenstandes aus unterschiedlichen Blickwinkeln unter Aufgabe einer "wirkliche" Raumverhältnisse vortăuschenden Perspektive, wird die Wiedererkennung des Dargestellten erschwert. Nicht zuletzt offnete sich der Kubismus der sogenannten primitiven Kunst und fuhrte in seinen Collagen, deren Ziel es ist, anstatt abzubilden, ein Bild neu zu schaffen, auch neue Materialien (Karton, Knöpfe etc.) in die Kunst ein ${ }^{15}$.

Das Verhăltnis zwischen dem Formismus und dem Futurismus gestaltet sich ähnlich wie jenes zum Kubismus. Wie erwähnt, wurde in den verschiedenen Berichten, die über die Theorien und die Kunst des Futurismus erschienen, immer wieder auf die für die futuristische Ästhetik so zentralen Aspekte wie „Dynamik“ und .Bewegung“ verwiesen. Außerdem erscheint es im Falle des Futurismus wichtig, dass er sich als erste Kunstrichtung intensiv mit den technischen und zivilisatorischen Neuerungen seiner Zeit auseinander setzte, was insbesondere die polnische Poesie vor und nach dem Ersten Weltkrieg beeinflusste (zum Beispiel: Jankowski, Czyżewski). Es wurde außerdem erwăhnt. dass mit dem Futurismus auch Abkehr vom Alten und Emeuerung in Verbindung gebracht wurde. In dieser Hinsicht ist es interessant zu bemerken, dass Chwistek die Bezeichnung „Futurismus“ in seinem Text „Die Vielfalt der Wirklichkeiten in der Kunst“ („Wielość rzeczywistości w sztuce“) auf die neueste Kunst anwendet, und zwar mit der Begründung, dass diese erst im Entstehen und somit eine Sache der Zukunft sei $(1918,45)^{16}$.

\footnotetext{
14 So orientiert sich zum Beispiel der Aufbau von Winklers Studie .Der Formismus vor dem Hintergrunci zeitgenossischer Richtungen in der Kunst" (.Formizm na tle wspótczesnych kierunków w szuuce", 1921) an dieser Auffassung. Vgl. zum Verhaltnis Formismus-Kubismus auch: Chwistek 1920a. 103-104.

is $\mathrm{Vgl}$. zu den Ausfuhrungen uber den Kubismus: Kostyrko 1996, 204-205 sowie Richter 1998. 46-54. Vgl. auch: Lukaszewicz/Malinowski 1996, 224.

${ }^{16}$ Nach 1920 sollte sich außerdem eine enge Zusammenarbeit zwischen den Formisten und den polnischen Futuristen ergeben. wovon im weiteren Verlauf dieses Kapitels noch die Rede sein wird. Zur deutschen Öbersetzung von Chwisteks „Wielośc rzeczywistosci w sztuce" (1918 und 1924) bzw. "Wielosć rzeczywistosci” (1921): Da die Genitivform "rzeczywistosci“ bezaglich ihres Numerus uneindeutig ist. ist von der Form her sowohl eine Übersetzung mit "Vielfalt der Wirklichkeit (in der Kunst)" bzw. ..der Wirklichkeiten (in der Kunst)" moglich. Beide Varianten finden sich auch im Deutschen: „Die Vielfalt der Wirklichkeit“" (Dedecius 1996-2000. IV/123) oder .Die Vielheit der Wirklichkeit in der Kunst“ (Lam 1990, 43). Zutreffender scheinen aber jene Öbersetzungen zu sein, in denen die Pluralform verwendet wird. da Chwistek in seinen Texten vier eigenstăndige Wirklichkeiten unterscheide! (vg!. Kap. 3.1): ..Die Vie!falt der Kunstwitk!ichkeiten“* (Folga-
} 
Die Suche junger polnischer Künstler nach neuen Ausdrucksformen fand in den Jahren vor dem Ersten Weltkrieg also nicht unabhängig von den neuesten Entwicklungen in der europäischen Kunst statt ${ }^{17}$. Deren wichtigste Erscheinungen wurden rezipiert und vereinzelt ist den Kunstwerken jener Jahre der Versuch zu spüren, die Impulse der zeitgenössischen Kunst zu verarbeiten ${ }^{18}$. Besondere Aufmerksamkeit verdienen in diesem Zusammenhang die von Zbigniew Pronaszko mitorganisierten „Ausstellungen der Unabhängigen“ („Wystawy Niezależnych"), die insgesamt dreimal stattfanden: 1911, 1912 und 1913. Sie wurden. so Pronaszko $(1938,32)$, vor allem in der Absicht veranstaltet. junge Kunst zu zeigen und dieser zum Durchbruch zu verhelfen. Insgesamt lässt sich an vielen der gezeigten Arbeiten. die Auseinandersetzung mit Cézanne. Gauguin oder dem Kubismus bemerken. Ebenso sichtbar ist vielerorten aber auch noch der Einfluss der Meister, zum Beispiel von Wyspiański oder Malczewski. Dennoch gibt es, gerade von Czyżewski und Pronaszko einige Arbeiten. in denen sich der Formismus bereits anzukündigen scheint. wenngleich alles in allem diese Jahre vor dem Ersten Weitkrieg vor allem eine Zeit des Übergangs und der Orientierung sind ${ }^{19}$.

Charakteristisch für diese Zeit vor dem Formismus ist auch der Text ..Vor dem großen Morgen“ („Przed wielkim jutrem“), den Zbigniew Pronaszko knapp vor Ausbruch des Ersten Weltkrieges veröffentlichte. Zwar kann noch nicht von einem im engeren Sinne programmatischen Text des Formismus gesprochen werden, dennoch formulier Pronaszko darin, wenn auch nur vorsichtig, bereits einige Ideen und Ansätze, die nach 1917 wieder aufgegriffen werden sollten. Pronaszko war $1918 \mathrm{mit}$ „Über den Expressionismus“ („O ekspresyoniżmie“) der Autor des ersten theoretischen Textes des Formismus.

Pronaszko bezieht seine Ausführungen in „Vor dem großen Morgen“ nicht nur auf die Malerei, sondern auch auf Musik und Literatur. All diesen Kunstformen sei in ihren neuesten Erscheinungen gemeinsam, dass sie sich vom nachahmenden, nur auf das Äußerliche der

\footnotetext{
Januszewska 1984, 39) bzw. dies. auf englisch: ..Leon Chwistek's multitude of realities“ (1982, 2) oder .Multiple Realities in Ar" (Gryglewicz 2002. 331). In der vorliegenden Arbeit wird der Vorschlag von Heinrich Kunstmann "Die Vielfalt der Wirklichkeiten (in der Kunst)” ubernommen (1962, 222). der die beste Öbertragung in Deutsche darstellt. Diese Übersetzungsvariante ist letztendlich auch jener von FolgaJanuszewska vorzuziehen, da Chwistek im Prinzip keine ..Kunstwirklichkeiten" unterscheidet. sondern .Wirklichkeiten", die er anschließend mit einem bestimmten Typ von Malerei in Verbindung zu bringen sucht. also auf die Kunst ubertragt. Auf einem Tippfehler (..wielkosć” - ..die Große“ statt: ..wielosć”) beruht offensichtlich die von Drews verwendete Übersetzung ..Die Große der Realităt in der Kunst“ (1983. 164).

"Wie Estreicher betont $(1971,178)$, hane auch die russische Kunst einen, wenn auch bescheidenen Einfluss auf die polnische Kunst, er nennt vor allem die Begeisterung Witkacys fur die Malerei Kandinskijs.

18 Vgl. dazu Pollakównas Analyse von Czyżewskis Aquarell .Baume“" (.Drzewa”) und der Zeichnung .Madonna" (1963, 250-251). Den Einfluss des Kubismus auf sein Schaffen betont Czyzewski auch selbst, und zwar in einem Interview mit Jan Śpiewak $(1939,5)$.

$19 \mathrm{Vgl}$. zu den erwăhnten Arbeiten spăterer Formisten aus den Jahren vor dem Ersten Welckrieg: Pollakówna 1972. 18-29. Speziell zu Zbigniew Pronaszko: Blumówna 1958, 9-12.
} 
Dinge beschränkten Realismus oder Naturalismus gelöst hätten. In der zeitgenössischen Kunst geht es daher um Folgendes:

.Gdy patrzymy na rzeczy zywe, czy martwe, budza się w nas wrazenia, uczucia, przezycia, myśli, - chodzi o to, aby nie malować (powtarzac) rzeczy samej, lecz owe przeżcia, na które ona wpłyneła, które w nas wywotała. Czyli ukszałować swoje wrazenia, uczucia (tworzenie form dla nich) spowodowane, wywołane dana rzecza. Otóz to dązenie od materyalnej formy przezyć do duchowej jest owym istotnym szlakiem Szuki.

Tu dopiero rzeczywiste Jej stanowisko.

Tem stoi na tak wielkiej wyzynie Muzyka. Poezya (ta prawdziwa), tem ma tez być Malarstwo i Rzeżba, jeśli nie chca być interpretacya lecz twórczością." (Z. Pronaszkc 1914, 128-129)

Eine so verstandene Kunst geht von einem anderen Verhältnis zu den Dingen, der Umwelt aus. Sei, so Pronaszko, dieses Verhältnis im Falle von realistischer und naturalistischer Kunst rein optisch und nur auf das Ziel der möglichst getreuen Nachahmung begrenzt gewesen, so nehme die heutige Kunst gegenüber der Umwelt eine schőpferische Haltung ein:

.Pewien mysliciel francuski mówi stuszanie: ,Szuuka - to dalszy ciąg Natury - a Natura jest Tworzeniem'. Natura jest Natchnieniem - przykładem da tworzenia nowych form. nowych dalszych ksztatów - a zrobiono z niej... modela!" $(1914,126)^{21}$

Es ist wahrscheinlich, dass Pronaszko hier auf Bergson anspielt, dessen Philosophie die gesamte europăische Avantgarde beeinflusste. Besonders die von Bergson beschriebene Form der intuitiven Erkenntnis, die der intellektuell-rationalistischen Weltsicht entgegengesetzt wird, erlaubt eine neue Sicht der Dinge, losgelöst zum Beispiel von ihrem aktuellen Gebrauchswert. In Polen waren Bergsons Ideen vor allem dank der Essayistik Boleslaw Leśmians bekannt. Lam betont den zeitlichen Kontext von Leśmians Essays, das heißt die Übergangszeit zwischen dem ,Jungen Polen“ und der sich herausbildenden Avantgarde und sieht die Bedeutung von Leśmian in der Überwindung der Geisteshaltung der Moderne, also der Wendung von melancholischer Dekadenz und jenseitiger Metaphysik hin zu einem künstlerischen Schaffen, das mit der diesseitigen Wirklichkeit in enger Verbindung steht ${ }^{22}$.

Auch Pronaszko fordert in dem angeführten Zitat ein produktives Verhăltnis zur Natur, das heißt zur außerkünstlerischen Wirklichkeit: Sie ist für den Künstler Vorbild und Inspiration

20 "Wenn wir auf Lebewesen oder Gegenstănde blicken, entstehen in uns Eindrocke, Gefuhle, Erlebnisse, Gedanken - es geht darum, nicht den Gegenstand selbst zu malen (zu wiederholen), sondem jene Erlebnisse, die er hervorgerufen hat, die er in uns entstehen ließ. Das heißt, die eigenen Eindrucke, Gefuhle, die von jenem Gegenstand verursacht, hervorgerufen wurden, zu gestalten (fur sie Form zu schaffen). Dieses Streben von der materiellen Form der Erlebnisse hin zur geistigen ist der eigentliche Weg der Kunst. Das ist Ihr wirklicher Standpunkt. Deshalb ist die Musik, die Poesie (die echte) weit erhaben, so sollten auch Malerei und Plastik sein. wenn sie nicht Interpretation, sondern Schaffen sein wollen.“

${ }^{21}$.Ein gewisser franzosischer Denker sagt richtig: ,Die Kunst - ist die Fortsetzung der Natur - und die Natur ist Schopfung'. Die Natur ist Inspiration - ein Vorbild fur die Schopfung neuer Formen, neuer weiterer Gestalten und man machte aus ihr: bloß ein Modell!"

$22 \mathrm{Vgl}$. zu Bergson, dessen Bedeutung far die europaische Avantgarde sowie zur Vermittlung in Polen durch I.esmians Essayistik: Lam 1969. 1/43-51 und Drews 1983. 119-121 sowie 126-131. 
und er will schaffen wie sie. Denn wir lebten, wie Pronaszko weiter feststellt, nicht in einem Chaos oder Äther, sondern seien organisch von unserer Welt abhängig. Dieser letzte Satz kann auch als gegen die Moderne gerichtet gelesen und verstanden werden.

Wie im ersten Zitat aus Pronaszkos Text erwähnt. bildet eine so verstandene Kunst die Dinge nicht mehr ab („nie malować (powtarzać) rzeczy samej“), sondern versucht diese in ihrer Idee zu erkennen und die Gefühle oder Eindrücke. die beim Betrachten hervorgerufen werden. zum Ausdruck zu bringen. ,[...] dajemy wyobrażenie rzeczy - właśnie przez syntezę formy uczuciowej." (Z. Pronaszko 1914, 125) 23. Für diese nicht-realistische, nicht-mimetische Kunst verwendet Pronaszko in seinem Text die Bezeichnung ..dekorative Malerei” (,malarstwo dekoracyjne"), einen, für den frühen Formismus, nicht unwichtigen Begriff. Dieser verweist, und in diesem Sinne gebraucht ihn auch Pronaszko, auf die Ordnung, also auf den Aufbau des Bildes. Grundlagen einer so verstandenen Malerei seien. so Pronaszko. Farbe und Linie, denn durch Farbharmonien bzw. -kontraste sowie durch expressive Konturlinien könnten die einzelnen Elemente der Komposition eines Bildes deutlicher sichtbar gemacht werden ${ }^{24}$. Diese Bedeutung von „dekorativ" kommt auch in einem Zitat von Matisse zum Ausdruck, das die Formisten drei Jahre später im Katalog zu ihrer ersten Ausstellung abdrucken sollten und in dem es heißt: ,.Sztuka kompozycji polega na dekoracyjnem uporządkowaniu różnorodnych elementów, jakimi rozporządza malarz, chcący wyrażić swe uczucia." (Katalog 1. Wystawy Ekspresyonistów Polskich. 1) ${ }^{25}$.

Aus Pronaszkos Text werden so die Konturen einiger für die neue Kunst wesentlicher Ideen sichtbar, die auch bei der Rezeption der zeitgenössischen europäischen Kunst eine Rolle spielten. Die Kunst, und das scheint für alle ihre Ausdrucksformen zu gelten, wendet sich zunehmend vom gegenständlichen Inhalt ab und konzentriert sich auf die Form. Der Künstler will nicht mehr abbilden, er nimmt zwar Anregungen und Inspirationen von der Umwelt auf, sucht diese aber gemäß seinem Willen zu gestalten. Dies ist auch eine Verschicbung des Schwerpunkts vom Zufälligen hin zum Dauernden: Die Kunst konzentriert sich nicht mehr auf einen bestimmten kurzen Moment, sondern versucht, die Dinge in ihrem Wesen, in ihrer Idee zu sehen. Die Arbeit des Künstlers, wie der künstlerische Ausdruck im allgemeinen. beruhen auf der Komposition des Kunstwerks, im Erfassen ihrer einzelnen Elemente und in den Harmonien und Kontrasten. die zwischen diesen bestehen.

23 ......] wir geben die Vorstellung einer Sache - und zwar durch die Synthese der Gefuhlsform."

$24 \mathrm{Vgl}$. auch: Pollakówna 1963, 247 und 1972, 33-35 die in diesem Zusammenhang auf die Parallelen zur sezessionistischen Kunst verweist bzw. allgemein auf das Verhaltnis Formismus-Sezession eingeht.

${ }^{23}$..Die Kunst der Komposition beruht auf der dekorativen Anordnung verschiedener Elemente, uber die der Maler, bestrebt seine Gefuhle zum Ausdruck zu bringen, verfügt." 


\title{
2.2 Das Entstehen des Formismus und der Gruppe „Polnische Expressionisten“
}

In einem Text von 1938 konfrontien Zbigniew Pronaszko die Erfahrung von Kubismus oder Futurismus mit der Situation der polnischen Malerei vor dem Ersten Weltkrieg:

\begin{abstract}
.Jezeli sie wam przypomni i wyraznie ukaze przed oczami obraz przedwojennego malarstwa u nas zozumie się odruch młodych. który 2 protestu, stał się walką o nową estetykę.

Malarstwo przedwojennego czasu u nas - poza bardzo nielicznymi wyjątkami - bylo echem minionego impresjonizmu - przede wszystkim niemieckiego, w sosie naturalizmu, akademizmu. symbolizmu. lub, co gorsza, secesji wiedeńskiej ( $Z$ Zielony Balonik» z siedziba 」 Michalika). Nie mozna się więc dziwic, jesli mlody malarz, po powrocie $z$ najblizszej chocby granicy, po ujrzeniu wielkiej sztuki w muzeach - musiał odczuwac bunt przeciw temu wszytkiemu, co widzial wokó siebie. Zwłaszcza, gdy w tejze zagranicy powstaty nowe ruchy artystyczne, jak kubizm we Francji, futuryzm we Wloszech. czy ekspresjonizm w Niemczech. Paliło się więc naokoło... ." $(1938,31-32)^{26}$
\end{abstract}

Um es vorwegzunehmen: Die Formisten wollten keinen absoluten Bruch mit der Vergangenheit, sondern begriffen sich und ihre Kunst vielmehr als weitere Etappe der kunstgeschichtlichen Entwicklung. Das ist vor allem in ihren späteren Schriften klar ersichtlich: „Dzisiejszy ekspresyonizm bierze swój początek we wczorajszym swym poprzedniku: neoimpresyonizmie, ten zaś w impresyonizmie“, schreibt Pronaszko (1918, 15), wobei er „Expressionismus“ als Oberbegriff für die zeitgenössische Kunst allgemein verwendet $^{27}$. Die Abgrenzung zum Impressionismus ist vor allem durch ein neues Verständnis von Kunst geprägt, es soll in der Kunst nicht mehr um das Verewigen eines einzelnen Momentes, sondern um die (dauerhafte) Form des Kunstwerkes selbst gehen ${ }^{28}$.

Das angeführte Zitat von Pronaszko drückt weniger die radikale Abkehr von Traditionen, sondem vielmehr eine gewisse Unzufriedenheit angesichts der Lage der polnischen Kunst vor dem Ersten Weltkrieg aus. Wie ist dies zu verstehen?

In stilistischer Hinsicht steht die Malerei des .Jungen Polens" Strömungen wie Impressionismus, Jugendstil/Sezession und Symbolismus nahe, die zu jener Zeit in ganz

\footnotetext{
${ }^{26}$.Wenn ihr euch das Bild unserer Vorkriegsmalerei in Erinnerung bringt und deutlich vor Augen fuhrt - wird die Reaktion der Jungen verstăndlich. die vom Protest zum Kampf um eine neue Ästhetik wurde. Unsere Malerei der Vorkriegszeit war - mit sehs wenigen Ausnahmen - ein Echo des vergangenen Impressionismus - vor allem des deutschen, in der Sauce von Naturalismus. Akademismus. Symbolismus, oder, noch schlimmer, der Wiener Sezession ("Der Grune Ballon" mit seinem Sitz bei Michalik [gemeint ist das Krakauer Kaffeehaus und Kanstlertreffpunkt .Jama Michalika” - „Die Hohle Michaliks"; M.E.]). Man darf sich daher nicht wundern. wenn ein junger Maler, nach seiner Ruckkehr schon aus dem năchstgelegenen Ausland, Gefuhle der Rebellion gegen alles hegen musste, was er um sich herum sah. Insbesondere. wenn im besagten Ausland neue kunstlerische Bewegungen. wie der Kubismus in Frankreich. der Futurismus in Italien oder der Expressionismus in Deutschland, entstanden. Es brannte sozusagen rundherum... ."

27 .Der heutige Expressionismus nimmt seinen Anfang in seinem gestrigen Vorganger: im Neoimpressionismus, dieser hingegen im Impressionismus."

Vgl zum Verhaltnis der Fermisten zum Impressionismus: Winkler 1927. 9 sowie 1938. 39.
} 
Europa verbreitet waren ${ }^{29}$. Der Impressionismus ist besonders in den ersten Jahren dominierend (etwa 1893-1900), auf ihn folgt die eigentliche Blütezeit des "Jungen Polens“, zwischen 1900 und 1907, in der die bedeutendsten literarischen und künstlerischen Werke entstehen. Die Malerei ist geprägt von Jugendstil und Sezession, die herausragende Persönlichkeit in Kunst und Literatur ist Stanisław Wyspiański. Mit seinem Tod im Jahre 1907 tritt allerdings im künstlerischen Leben des "Jungen Polens“ eine gewisse Stagnation $e^{30}{ }^{30}$. Insgesamt fehlte es an Ideen, die neuen Strömungen wurden vorwiegend skeptisch betrachtet. Viele Künstler passten sich darüber hinaus vor allem dem Geschmack des breiten Publikums an, das eine leicht verständliche, stimmungsvoll-patriotische Malerei schätzte ${ }^{31}$. Winkler schreibt rückblickend über diese Kunst: „W Polsce ów naturalistyczny pseudoimpresjonizm, dostrajal się znakomicie do współczesnych u nas hasel «unarodowienia sztuki» [...].“(1927,6)

Die Situation der polnischen Kunst vor dem Ersten Weltkrieg schien den jungen Künstlern für ihre Suche nach Neuem nicht geeignet:

.Sławna krakowska "Szzuka» z Mehofferem i Axentowiczem, osiadła juz od wielu lat spokojnie na laurach. [...] Atmosfera stawała się coraz bardziej ponura dla młodych malarzy. My wówczas mlodzi rwaliśmy się do nowych form malarskich i rzeżbiarskich." (Czyzewski 1938, 12)

In dieser Atmosphäre nahm die Idee, eine Gruppe junger Künstler zu gründen, langsam Gestalt an, wie sich Zbigniew Pronaszko erinnert:

.Ze byli mlodzi plastycy, którzy gdzieś, w ciszy pracowni, trudzili się nad tymi problemami ${ }^{i 4}$ - nie budzilo wạtpliwości. Chodziłó tylko o to, zeby ich skontaktowac [...]. Będąc nowym członkiem Związku Artystów Plastyków, przekonalem wydzial tego zwiazku, aby urzadzil, na wzór paryskich - salon "niezaleznych». [...] W rok pózniej. znowu urządziliśmy taka wystawę w pawilonie po jakiejś czasowej imprezie. na Placu Ducha.

29 Die Ausfuhrungen zur bildenden Kunst und zu Kunstlern des .Jungen Polens" in diesem Abschnitt stalzen sich - sofern nicht anders vermerkt - auf: Dobrowolski 1976, 119-125, Kębłowski 1987, 195-199 sowie auf Ostrowski 1989, 103-146.

$10 \mathrm{Zu}$ den beiden erwăhnten Abschnitten der Geschichte des .Jungen Polens", die Estreicher bestimmt (1973, 561) ließe sich noch ein dritter hinzurugen, zwischen 1907 und dem Ersten Weltkrieg: die Jahre der Krise und des Niedergangs.

${ }^{31}$ Vgl. Estreicher 1971, 71-72. Vgl. auch Prokop 1970, 5-21, der ausfuhrlich auf die Popularitat der ..nationalen Thematik" in der polnischen Kunst und Literatur nach 1905 eingeht.

${ }_{32}$.In Polen passte sich jener naturalistische Pseudoimpressionismus hervorragend an die bei uns gegenwartigen Schlagworter von der "Nationalisierung der Kunst" an."

${ }^{33}$.Die berohmte Krakauer "Szzuka» mit Mehoffer und Axentowicz ruhte sich schon seit vielen Jahren ruhig auf ihren Lorbeeren aus. [...] Fur die jungen Maler wurde die Atmosphäre zunehmend traber. Wir damals Jungen drängten nach neuen Formen in der Malerei und Plastik." Die im Zitat genannte Kunstlervereinigung ..Szauka” (..Die Kunst") wurde 1897 in Krakau gegrundet. Ihr gehorten die bedeutendsten Kunstler des ..Jungen Polens" an. Auch sie geriet nach 1907 in eine Krise.

${ }^{34}$ Die Probleme, die die jungen Kunstler in jenen Jahren beschăttigten, benennt Pronaszko an anderer Stelle dieses Textes (1938, 32), aus dem auch das vorliegende Zitat stammt, so: .,Problemy: formy ściśle sprzęgniętej kolorem i kolorem budowanej, scislej kompozycji i tej wielkiej dyscypliny i porzadku obrazu [...]. - ..Probleme: der Form zusammengehalten durch die Farbe und durch die Farbe gebaut. [Probleme] einer strengen Komposition, jener großen Disziplin und der Ordnung des Bildes." 
Tam juz pokazały sie obrazy Tytusa Czyzewskiego. W nastepnym roku, tuz przed wojna wystawa niezaleznych odbyła sie w salach pałacu Spiskiego, gdzie przybyły nam obrazy Jacka Mierzejewskiego. Wybuchnela wojna i kontakt nasz został zerwany." $(1938,32)^{\text {s }}$

Es scheint, dass Pronaszko in diesem Zitat ein wenig vereinfacht. Die umfassende Chronik des polnischen Kunstgeschehens vor dem Ersten Weltkrieg „Polskie życie artystyczne w latach 1890-1914" führ an (Wojciechowski 1967, 105), dass Czyżewski nicht nur auch auf der ersten Ausstellung der „Unabhängigen“ vertreten war, sondern dass diese Ausstellung auf Initiative der Brüder Pronaszko und Czyzewskis ilberhaupt erst zustande kam. Außerdem finden sich in dieser Chronik noch Hinweise auf vier weitere Ausstellungen, an denen Zbigniew Pronaszko und Czyżewski vor der Gründung der formistischen Gruppe gemeinsam teilnahmen (Wojciechowski 1967, 110 bzw. 1974, 13, 20-21 und 22): im April 1912 in Posen („Wystawa w Salonie Stowarzyszenia Artystów"), im Dezember 1915 und im Juni 1916 in Krakau (,XIX Wystawa ,Sztuki' i VI Wystawa ,Rzeżby““ sowie: „XX Wystawa Towarzystwa Sztuki“) und schließlich im September 1916 in Zakopane („Wystawa Sztuki w sali Bazaru Krajowego"). Im Lichte der bisherigen Ausführungen in diesem Abschnitt scheint gerade die Teilnahme Czyżewskis und Pronaszkos an der 20. Ausstellung der Gruppe "Sztuka“ bemerkenswert. Überhaupt liest sich die Liste der Teilnehmer dieser Ausstellung wie eine Mischung von Künstlern des „Jungen Polens“ und späterer Formisten, unter anderem: Czyżewski, Fałat. Hrynkowski, Mehoffer, Mierzejewski, Niesiołowski, Zbigniew Pronaszko. Weiss, Wyczółkowski. Es mag darin ein weiterer Beleg dafür gesehen werden, dass die Formisten nicht radikal mit der Kunst ihrer Lehrer brechen wollten bzw. dass die Ereignisse in der Erinnerung nicht immer so dargestellt waren, wie sie in der Tat geschahen.

Die erwăhnte Ausstellung in Zakopane ist für das Entstehen des Formismus wichtig. Zu den Organisatoren gehörte wiederum Zbigniew Pronaszko und die Idee dieser Ausstellung bestand ăhnlich wie zuvor bei den Ausstellungen der „Unabhăngigen“ darin, jungen Künstlem eine Plattform zu bieten ${ }^{36}$. So waren in Zakopane sieben Kunstler zu sehen, die im November 1917 auch an der ersten Ausstellung der Formisten teilnehmen sollten: Czyzewski,

33 .Dass es junge bildende Kanstler gab, die sich irgendwo, in der Stille ihrer Ateliers mit diesen Problemen abmuhten - daruber bestand kein Zweifel. Es ging nur darum, mit ihnen Kontakt aufzunehmen. [...] Als neues Mitglied des Verbands bildender Kunstler, aberzeugte ich eine Sektion dieses Verbandes, einen Salon der "Unabhängigen" nach Pariser Vorbild zu organisieren. [...] Ein Jahr spater organisierten wir wieder, in einem Pavillon nach einer vorubergehenden Veranstaltung, am Plac Swiętego Ducha, eine solche Ausstellung. Dorn zeigten sich schon die Bilder von Tytus Czyzewski. Im năchsten Jahr, kurz vor dem Krieg, fand die Ausstellung der Unabhangigen in den Salen des Spiski-Palais statt, wo die Bilder von Jacek Mierzejewski zu den unsrigen kamen. Es brach der Krieg aus und unser Kontakt wurde abgebrochen." Witkacy war wałhrend des Krieges in Petersburg. zum Teil im Dienste der russischen Armee. Chwistek, anfangs noch an der Front, spater in Wien, kehrte erst 1917 wieder nach Krakau zuruck. Auch Czyzewski verbrachte einen Teil des Krieges in Wien, die Brader Pronaszko hingegen in Zakopane. 
Gwozdecki, Mierzejewski, Niesiołowski, Andrzej und Zbigniew Pronaszko, Skoczylas ${ }^{37}$. Dass die Einladung, an der Ausstellung teilzunehmen aber auch an Mehoffer und andere Künstler des „Jungen Polens“ ging, zeigt, dass es Pronaszko nicht um eine Abgrenzung zu dieser Künstlergeneration ging, sondern um eine gemeinsame Anstrengung nach einem neuen künstlerischen Ausdruck. Er wollte durch die Ausstellung Künstler zusammenführen, die dieses Streben eint, deren Kunst sich in stilistischer Hinsicht aber deutlich unterscheiden $k^{k a n n}{ }^{38}$. Hier klingt bereits die Idee einer Künstlergruppe konkret an, zu deren Gründung es ein Jahr später kommen sollte. Czyżewski und Pronaszko nennen dafür zwei Gründe:

„Pewnego wieczoru skomunikowali sie ze mna dwaj malarze. bracia Zbigniew i Andrzej Pronaszkowie. Postanowiliśmy we trzech zalozyć Towarzystwo skrajnych modemistów i przeciwstawiać się tępocie i ogólnej śpiązce jaka panowała wówczas w sztuce polskiej." (Czyżewski 1938, II) ${ }^{39}$

\section{Und Pronaszko:}

.Grupa polskich ekspresyonistów otwarla swa pierwsza wspólną wystawę. Zjednoczyli siẹ i oddzielili od reszay malarstwa polskiego nie dlatego, aby uwazali się za bezwzględnie lepszych. Przyczyna tkwi gdzieindziej - jest nia potrzeba zbiorowego wysilku w sztuce." $(1918.15)^{40}$

Die Idee Czyżewskis und der Brüder Pronaszko, eine Künstlergruppe zu gründen, entstand demnach, um sich dem Stillstand in der polnischen Kunst entgegenzusetzen und um gemeinsam für die Sache einer neuen Kunst einzutreten - nun doch in gewisser Abgrenzung vom „Rest“ der polnischen Kunst. Diese Gruppe nahm bei den Vorbereitungen zu ihrer ersten Ausstellung. die am 4. November 1917 eröffnet werden sollte, immer mehr Gestalt an ${ }^{41}$. Winkler schreibt in seiner Monographie (1927, 7), dass die Gruppe Ende 1917 mit Leon Chwistek. Tytus Czyżewski. Jan Hrynkowski, Jacek Mierzejewski. Tymon Niesiołowski, Andrzej und Zbigniew Pronaszko. Stanislaw Ignacy Witkiewicz und August Zamoyski bereits

\footnotetext{
${ }^{36}$ Vgl. ausfohrlich zu dieser Ausstellung: Pollakówna 1972, 32-33, auf die ich meine Ausfuhrungen zu dieser Ausstellung stutze.

${ }^{37}$ Estreicher $(1971,102)$ weist außerdem darauf hin. dass auch Chwistek sich im September 1916, also zur Zeit der Ausstellung, in Zakopane aufhielt, schreibt aber nicht, ob sich Chwistek auch an der Ausstellung beteiligte.

${ }^{38}$ Dieser Aspekt scheint für die Gruppe der Formisten insofern charakteristisch, als dass sie stets ihre stilistische Individualităt betonen und lediglich die Orientierung an einer formal orientienten Ästhetik als gemeinsam erachten. Daraus resultien nicht zuletzt auch die Schwierigkeit, von einem gemeinsamen formistischen Programm sprechen zu kónnen.

39. .An einem gewissen Abend setzten sich mit mir zwei Maler, die Bruder Zbigniew und Andrzej Pronaszko, in Verbindung. Wir beschlossen zu dritt die Gesellschaft extremer Modemisten zu grunden und uns der Stumpfsinnigkeit und allgemeinen Schlafrigkeit, die damals in der polnischen Kunst herrschte, entgegenzusetzen."

to „Die Gruppe der polnischen Expressionisten eroffnete ihre erste gemeinsame Ausstellung. Sie schlossen sich zusammen und trennten sich vom Rest der polnischen Malerei nicht deshalb, weil sie sich für absolut besser hielten. Es gibt dafur einen anderen Grund - sie braucht eine gemeinsame Anstrengung in der Kunst."

"Chwistek erinnen sich daran wie folgt (zit. n.: Estreicher 1971, 120): „Zeszlej soboty (6.X.1917) odwiedzil mnie p. Pronaszko i zaprosil do wzięcia udzialu w wystawie ekspresjonistów." - „Am letzten Samstag (6.X.1917) besuchte mich Herr Pronaszko und lud mich ein, an der Ausstellung der Expressionisten teilzunehmen."
} 
neun Mitglieder zählte. Im darauffolgenden Jahr hätten sich noch Henryk Gotlieb und er selbst der Gruppe angeschlossen ${ }^{42}$. In dieser sind somit Künstler unterschiedlicher Bereiche vereint: neben den beiden Bildhauem Zbigniew Pronaszko und Zamoyski sind es vor allem Maler. Einige dieser Künstler beschäftigen sich noch mit anderen künstlerischen Ausdrucksformen, wie mit dem Theater (Czyżewski, Andrzej Pronaszko, Witkacy) oder der Poesie (Czyżewski). Chwistek und Witkacy treten außerdem noch als Autoren philosophischer bzw. philosophisch-ăsthetischer Texte hervor. Auch in stilistischer Hinsicht bringen die Künstler dieser Gruppe einen gewissen Pluralismus zum Ausdruck und nähern sich in ihrem künstlerischen Schaffen unterschiedlichen Strömungen der europăischen Avantgarde an bzw. verbinden deren Impulse miteinander: dem Kubismus (zum Beispiel: Czyzewski, Andrzej und Zbigniew Pronaszko, Winkler), dem Futurismus (Chwistek) oder dem Expressionismus (Gotlieb, Witkacy).

In „Über den Expressionismus“ konkretisiert Pronaszko die Absichten, die mit der Gründung einer Gruppe verbunden waren $(1918,15)$. Diese begriff er, ăhnlich wie dies bei der Zakopaner Ausstellung von 1916 zum Ausdruck kam, vor allem als losen Zusammenschluss von Künstlern. Es gehe daher auch nicht, so Pronaszko, um künstlerisches Schaffen nach einer im Vorhinein festgelegten Doktrin, sondern um eine intensive Form der Zusammenarbeit und des Austausches. Das Ziel dieser Arbeit sei ein gemeinsamer Stil in der Art sich künstlerisch zu artikulieren, worin für Pronaszko auch das Vermächtnis der Gruppe besteht. Zwar entsprechen die Formisten durch ihren Zusammenschluss als Gruppe einer allgemeinen Tendenz in der europäischen Kunst und Literatur des frühen 20. Jahrhunderts, als es hăufig zur Bildung von Künstlergruppen oder -vereinigungen kam, dennoch unterscheiden sie sich doch erheblich gerade von vielen avantgardistischen Gruppen ${ }^{43}$. Insbesondere nämlich dadurch, dass die Formisten es stets ablehnten ein „formistisches Programm“ zu verfassen, etwa im Sinne der Manifeste Marinettis oder des Surrealismus, ebenso wie sie keine Anstrengungen unternahmen, eine einheitliche Theorie ihrer Kunst zu entwerfen. Der notwendige innere Zusammenhalt, der für die Existenz einer Gruppe wesentlich scheint. wurde vielmehr in anderer Form zum Ausdruck gebracht: durch die Ausstellungen, durch eine gemeinsame Zeitschrift oder durch ein geschlossenes Auftreten nach außen, zum Beispiel gegenüber der Kunstkritik. Das wichtigste Element des Zusammenhalts der Gruppe war aber eine ăhnliche Auffassung ihrer einzelnen Mitglieder in Bezug auf das Wesen der Kunst. Im

\footnotetext{
${ }^{42} \mathrm{Zu}$ erganzen ist, dass Witkacy, obwohl von Winkler, als auch von Zbigniew Pronaszko $(1938,32)$ unter den ersten Mitgliedern erwăhnt, erst Anfang Juni 1918 aus Petersburg zuruckkehre (vgl. J. Witkiewicz 1977, 73).

${ }^{43} \mathrm{Vgl}$. allgemein zum Phanomen der Kanstlergruppe: Kawn 1946 sowie Glowinski 1998.
} 
angefuhren Zitat verwendet Pronaszko außerdem noch die ursprüngliche Bezeichnung der Gruppe: „Polnische Expressionisten“. Erst ein halbes Jahr später änderte die Gruppe diese Bezeichnung und nahm ihren eigentlichen Namen „Polnische Formisten“ („Formiści Polscy“) an, wovon noch die Rede sein wird.

Auffallend für die Herausbildung des Formismus ist die entscheidende Rolle der bildenden Kunst. Vor allem Cézanne und der Kubismus beeinflussten die jungen polnischen Künstler bei ihrer Suche nach neuen künstlerischen Ausdrucksformen. Die Bedeutung der bildenden Kunst ist im Übrigen für die ganze europäische Avantgarde entscheidend, oftmals werden Kunst und Literatur durch eine gemeinsame Ästhetik eng miteinander verbunden, wie die Beispiele von Expressionismus, Futurismus oder Surrealismus zeigen.

Der Formismus entstand somit als neuer Ansatz in der bildenden Kunst und in diesen Kontext sind auch die meisten theoretischen Schriften einzuordnen. Erst drei Jahre nach der Gründung der Gruppe veröffentlichte Czyzewski seinen Gedichtband „Das grüne Auge. Formistische Dichtungen. Elektrische Visionen“ („Zielone oko. Poezje formistyczne. Elektryczne wizje“) und auch Chwistek und Witkacy verfassten ihre literaturtheoretischen Arbeiten erst Anfang der zwanziger Jahre. Da somit angenommen werden kann, dass die Formisten ihre ästhetischen Ansichten in erster Linie in Bezug auf die bildende Kunst entwickelten. stellt sich für diese Arbeit zentral die Frage, wie einzelne Positionen auf die Literaturtheorie übertragen werden, das heißt in welcher Form die bildende Kunst die Literatur beeinflusst.

Parallel zur Herausbildung des Formismus, kam es in den Jahren vor dem Ersten Weltkrieg auch innerhalb der polnischen Literatur zu wichtigen Neuerungen. Leśmians Überwindung der Weltanschauung der Generation der Jahrhundertwende wurde bereits erwähnt und in der Literaturkritik, wie zum Beispiel die Schriften Karol Irzykowskis zeigen (vgl. Lam 1969, V36-42), wurden Ansätze formuliert, die sich mehr und mehr von der Ästhetik des ,Jungen Polens“* 18sten. Auch in der Literatur selbst ließen sich zunehmend Ausdrucksformen bemerken, die in stilistischer Hinsicht zum Beispiel mit dem Expressionismus verwandt sind (vgl. Prokop 1970, 63-71).

Wenngleich sich die polnische Avantgarde in institutionalisierter Form (Künstlergruppen. Ausstellungen. Zeitschriften etc.) erst ab 1917 manifestiert, sind ihre Anfänge noch vor dem Ersten Weltkrieg zu beobachten ${ }^{4+}$. Charakteristisch. gerade für den Formismus, ist dabei die

\footnotetext{
4 Oftmals wird daher der Beginn der polnischen Avantgarde explizit in die Zeit vor dem Ersten Weltkrieg gelegt: vgl. etwa: Winkler 1927, 7. Pollakówna 1963, 253, Kużma 1976, 23 sowie Lukaszewicz'Malinowski 1996. 226. Einige Autoren verweisen in diesem Zusammenhang aber auch darauf, das die ..Verspătung" der polnischen Avantgarde - im Vergleich zu den westeuropaischen oder russischen Strömungen - auch mit der besonderen Entwicklung der polnischen Kunst und Literatur bis 1918 zusammenhăngt. Scheint es doch. dass die
} 
konstruktive Auseinandersetzung mit dem ,Jungen Polen ${ }^{45}$. Der Formismus ist somit keine Avantgarde der Stunde Null, worin er sich von anderen Strömungen unterscheidet ${ }^{46}$.

\subsection{Die „Blütezeit" des Formismus: Die Jahre 1917 bis 1922}

Die erste Ausstellung der Formisten wurde am 4. November 1917 in Krakau als „Erste Ausstellung Polnischer Expressionisten“ („Pierwsza Wystawa Ekspresjonistów Polskich“) eröffnet. In ihr wurden insgesamt 124 Werke gezeigt, davon 28 volkstümliche Hinterglasmalereien aus der Podhale-Region sudlich von Krakau, was die Sympathie der jungen Avantgardisten für die heimische Volkskunst zum Ausdruck bringen sollte - eine Sympathie, die sie mit ihrer Vorgängergeneration, der des „Jungen Polens“, teilten. Neben den Mitgliedern der frisch gegründeten Künstlergruppe, nahmen an dieser Ausstellung auch Künstler teil, die deren ästhetischen Ideen nahe standen ${ }^{47}$. Diese Ideen, also ihre Vorstellung von Kunst, suchte die Gruppe im Katalog zur Ausstellung zu verdeutlichen, in dem sie aphorismusartige Textfragmente unterschiedlicher Autoren, wie Mickiewicz, Ingres oder Matisse, abdruckte ${ }^{48}$. Von den Mitgliedem der Gruppe veröffentlichte einzig Zbigniew Pronaszko einen kurzen Beitrag. Aus diesen Fragmenten ist herauszulesen, dass es den Formisten in ihrer Kunst nicht um die Nachahmung der außerkünstlerischen Wirklichkeit geht, sondern darum, ein schöpferisches Verhältnis dieser gegenuber einzunehmen. Diese Absicht sehen die Formisten vor allem in ihrem Streben verwirklicht, die zahlreichen Ansichten zum Beispiel eines Gegenstandes durch vom Künstler entwickelte Formen zu erfassen - ein Gedanke, der auch in den theoretischen Texten, vor allem von Zbigniew Pronaszko, immer wieder betont wird - um diese anschließend in einer in sich geschlossenen Komposition harmonisch zusammenzufügen. Diesen Aspekt betont auch Stanisław Mróz in seiner Rezension der Ausstellung, indem er schreibt, dass die künstlerische Form für die Expressionisten sich nicht aus der Nachahmung der Natur ergebe. Vielmehr sei diese das Ergebnis der Arbeit des Künstlers und daher auch das wichtigste Element in dessen

Forderung nach deren nationalem Engagement wenig Platz fur radikale, vor allem formal orientierte. Experimente ließ. Vgl. dazu: Zaworska 1963, 18-26, Prokop 1970, 102-105 sowie Estreicher 1971, 71.75.

is Vgl. auch: Lam. der allgemein fur die frahe polnische Avantgarde darauf verweist (1969, V/51), dass sie viele asthetische Fragestellungen der Moderne aufgriff und in ihre Oberlegungen mit einbezog.

${ }^{4}$ Zum Beispiel vom italienischen oder auch russischen Futurismus, deren Vertreter die radikale Abkehr von Traditionen lautstark artikulierten.

${ }^{47} \mathrm{Vgl}$. zu den genauen Daten und zu den einzelnen Teilnehmern der Ausstellung: Jakimowicz 1989, 19.

48 Dieser Katalog erschien in mehreren. leicht unterschiedlichen Fassungen: Jakimowicz spricht von zwei (1989, 19-70). Pollakowna, die diesen Aspe!n ausfohr!ich behandelt (1972, 42-45), von drai Versiener des Kataloges. 
künstlerischem Ausdruck (in: Wojciechowski 1974, 35). Auch in anderen Rezensionen wird das neue Verständnis der jungen Künstler in Bezug auf das künstlerische Schaffen thematisiert, wie ebenso der Zusammenhang mit den zeitgenössischen Strömungen der europäischen Kunst betont wird. Wenngleich es auch viel Kritik an den gezeigten Werken gab - insbesondere an Czyżewskis sogenannten „vielebenigen Bildern“ („obrazy wielopłaszczyznowe“" $)^{49}$ - so versuchten doch einige Rezensenten, zum Beispiel die Zeichnung, das heißt den Charakter der einzelnen Elemente des Kunstwerks bzw. dessen kompositorische Gestaltung, unter Bezugnahme auf die beschriebene veränderte Kunstauffassung, herauszuarbeiten ${ }^{50}$.

Im April und Mai 1918 wurde diese Ausstellung in verkleinerter Form in Lemberg gezeigt. auch der Katalog war mit dem aus Krakau identisch und enthielt dieselben Textfragmente. von denen zuvor die Rede war. Nicht mehr zu sehen waren in dieser Ausstellung die volkstümlichen Hinterglasmalereien sowie die Werke jener Künstler, die nicht der Krakauer Gruppe angehörten. Dafür nahmen mit Ludwik Lille und Zofia Vorzimmerówna auch zwei aus Lemberg stammende Künstler teil. Eine eigene, wenn auch kleine Gruppe Lemberger Formisten sollte sich im Jahre 1921 bilden $^{5 !}$.

Im Zusammenhang mit dieser Ausstellung der Formisten schrieb die Lemberger Zeitung „Gazeta Wieczoma“ („Abendzeitung“) am 3. Juli 1918 eine „Umfrage zum Expressionismus“ („Ankieta o ekspresyoniżmie“) unter Künstlem und Kunsthistorikern aus. Die Redaktion der Zeitung wollte dadurch. wie sie in ihrer Ausschreibung betont (,.Ankieta o ekspresyoniżmie“ 1918, 5), dieses neueste Phänomen der polnischen Kunst einem breiteren Publikum verständlicher machen, ohne für oder gegen den Expressionismus Stellung zu nehmen. Am 28. Juli 1918 erschien schließlich eine zehnseitige Sonderausgabe der Zeitung, die nicht nur die einzelnen Beiträge, sondern auch Abbildungen formistischer Kunstwerke von Zbigniew Pronaszko und Chwistek enthielt ${ }^{52}$.

Die Hälfte der Autoren (Kazimierz Chłędowski. Leon H. Piniński, Artur Schröder und Władysław Witwicki) lehnt den Expressionismus ${ }^{\mathbf{5 3}}$, das heißt die neueste Kunst insgesamt.

\footnotetext{
"Bei Czyzewskis „vielebenigen Bildem" handelt es sich um eine Art dreidimensionaler Collage aus zum Teil verschiedenen Materialien. Leider gelten alle „vielebenigen Bilder" Czyzewskis als verschollen. sie sind nur mehr als Photographien erhalten. Vgl. dazu: Pollakowna 1963, 259-264 sowie: Stopczyk 1984, 13-16.

${ }^{30} \mathrm{Vgl}$. dazu: Wojciechowski (1974), 34-36, wo eine repräsentative Auswahl von Rezensionen abgedruckt ist.

s1 Vgl. Winkler 1927, 8 sowie: Terlecki 1922. 47. Dieser Gruppe sollten, neben den beiden genannten Künstlern. noch Stanisław Matusiak und Zygmunt Radnicki angehoren.

$32 \mathrm{Vgl}$. „Ekspresyonizm w sztuce plastycznej. Ankieta Gazety Wieczornej” 1918. 1-10. Alle Zitate der folgenden Beschreibung dieser Umfrage stutzen sich auf diese Quelle.

${ }^{33}$ Wie mehrfach angedeutet, wurde „Expressionismus" in Polen in den Jahren nund um den Ersten Weltkrieg in verschiedener Bedeutung gebraucht. auch die Lemberger Umfrage betrifft eigentlich die neueste Kunst im Allgemeinen. In dieser Hinsicht, als Oberbegriff für alle Stromungen der zeitgenðssischen Kunst, ist auch der
} 
ab. Der hăufigste Vorwurf besteht darin, dass die jungen Künstler das Handwerk des Malers nicht mehr beherrschten, als weitere Gründe für ihre negative Haltung nennen diese Autoren die Missachtung der Tradition sowie die Aufgabe der Gegenständlichkeit, was die expressionistischen Kunstwerke unverständlich mache.

Vorsichtig positiv äußerten sich Władysław Kozicki und Roman Zrębowicz zur expressionistischen Kunst. Letzterer sieht den Expressionismus als konsequente Weiterentwicklung vor allem von Cézanne und dem Kubismus. Auch Kozicki bestimmt den polnischen Expressionismus, wozu er neben den Formisten auch die Gruppe „Bunt” zählt, als Reaktion auf die zeitgenössischen Strömungen in Frankreich, Italien, Russland und Deutschland. Für eine endgültige Einschätzung, so Kozicki sei es noch zu früh, die expressionistische Theorie stecke zwar erst in ihren Anfängen, doch bereits diese wenigen formulierten Ansätze würden die heutigen Künstler dazu zwingen, die Grundlagen der Kunst neu zu überdenken. Als stilistische Merkmale nennt er die Abkehr von Mimesis, die Loslösung der Farbe von gegenständlicher Bedeutung sowie den Verzicht auf konkrete Gegenstände in den Kunstwerken und die Annäherung der verwendeten Formen an die Geometrie.

Zu den positiven Stimmen der Umfrage gehören schließlich die Texte von Stanisław Przybyszewski und von Jan Bołoz-Antoniewicz. Przybyszewskis Beitrag ist ein Fragment aus seinem Text „Die rückflutende Welle. Rund um den Expressionismus“ („Powrotna fala. Naokoło ekspresjonizmu“), den er im März 1918 in der Zeitschrift „Zdrój“ veröffentlichte. Er sieht im Expressionismus keine neue Kunst, sondern vielmehr ein uraltes Prinzip des künstlerischen Schaffens, bei dem es darum gehe. dass der Künstler nicht die äußere Wirklichkeit abbilde, sondern auf seine Eindrücke von dieser Wirklichkeit reagiere, seine eigenen Visionen zum Ausdruck bringe: „Nie ten kamień mnie obchodzi, który wpadł z .zaświata' w jezioro mej duszy, ale te kręgi, które wywołal." (Przybyszewski 1918, 52) ${ }^{54}$. Der Lemberger Kunsthistoriker Jan Bołoz-Antoniewicz stand dem Formismus von Beginn an aufgeschlossen gegenüber und schrieb über ihn im Jahre 1920 eine längere Studie unter denı Titel „Die Grundlagen des Formismus“ („Podstawy formizmu“) widmete Boloz-Antoniewicz sein Gedicht „Für die Kunst und das Leben“ („Dla sztuki i zycia“). In seinem Beitrag zur Umfrage hebt Bołoz-Antoniewicz besonders den Gegensatz

Begriff „Expressionismus" in der Beschreibung der Beiträge zu dieser Umfrage zu verstehen und wird daher nicht weiter differenziert.

"Mich interessiert nicht der Stein, der aus dem ,Jenseits" in den See meiner Seele hineinfiel, sondern die Kreise, die er hervorrief."

${ }^{35}$ Ebenfalls verxffentlicht in der ..Gazeta Wieczoma“ - vgl. dazu im weiteren Verlauf dieses Abschnitts. 
zwischen Expressionismus und Impressionismus hervor. Dieser beruht für ihn darauf, dass der Impressionismus nicht schaffe, sondern lediglich die den Künstler umgebende Materie umgestalte (.,przetwarza“), wohingegen der Expressionismus aus sich selbst heraus schaffen wolle, nach einer im Inneren geborenen Idee. Dieser Gegensatz sei im Übrigen nicht neu. sondern habe sich schon in Bezug auf Klassik und Romantik in ähnlicher Form offenbart. Der Expressionismus ist auch für Bołoz-Antoniewicz eine weitere Etappe einer kunstgeschichtlichen Entwicklung: der Expressionismus baue dabei auf den Leistungen des Neoimpressionismus auf, der sich durch die Suche nach an die Geometrie angelehnten grundlegenden Formen („zasadniczych form"; im Original fett hervorgehoben), vom Naturalismus entfernt habe. Charakteristisch für den Expressionismus ist für BolozAntoniewicz schließlich das Bestreben, die Unterschiede zwischen den einzelnen Künsten aufzuheben und diese im Ausdruck aneinander anzunähern. der Kunst die Fähigkeit zu denken (.zdolność myślenia“) zurückzugeben. die sie in der Ornamentik eingebüßt habe sowie den Menschen in seiner Ganzheit darzustellen. Um den Expressionismus zu verstehen. sei es notwendig. eine ideell-abstrakte Kunst anzuerkennen.

Diese Umfrage über den Expressionismus ist insofern für die ersten Monate des Formismus bzw. für die frühe polnische avantgardistische Kunst insgesamt repräsentativ, da sie zum einen die dezidiert negative Haltung vieler Kritiker dieser gegenüber zeigt und zum anderen offenbart, wie es anfangs selbst für positiv eingestellte Autoren schwierig war, eine Art der Beschreibung zu finden, die den Ausdrucksformen und der Stilistik dieser neuen Kunst gerecht wird.

Kurze Zeit später, im Juni und Juli 1918, fand in Krakau die nächste Ausstellung der Gruppe statt, und zwar als ..II. Ausstellung Polnischer Expressionisten“ (..II. Wystawa Ekspresyonistów Polskich“). Da der Katalog nicht mehr zu existieren scheint, ist über diese Ausstellung wenig bekannt, die Rezensionen verraten. dass etwa Zbigniew Pronaszko (Statue „Sybilla“) oder Czyżewski (,.Selbstportrait“ - „Autoportret“, .,Portrait von Stanisław Mroz“ .Portret Stanisława Mroza“) einige ihrer Werke zeigten. die ihre Auseinandersetzung mit dem Kubismus und ihr Streben nach einer aus klaren Formen gebauten Komposition des Bildes spüren lassen. Von Bedeutung ist aber, dass in einigen Rezensionen dieser Ausstellung schon der Name „Formisten“ auftaucht. die eigentliche Bezeichnung der Gruppe. die diese von nun an tragen wird.

Wer diesen Namen erfand, ist unklar. Czyżewski schreibt $(1938,12)$, es sei der mit den Formisten befreundete Kritiker Emil Breiter gewesen. Chwistek $(1935,5)$ spricht dieses Verdienst Zbigniew Pronaszko zu. Die Notwendigkeit, ihren Namen zu ändern, ergab sich für 
Chwistek daraus, dass die trotz aller Unterschiede zwischen den einzelnen Mitgliedern existierenden Gemeinsamkeiten weder auf den Expressionismus, noch auf den Kubismus allein zurückgeführt werden konnten. Es schien ihm daher, wie er betont $(1935,5)$, notwendig, nach einer neuen. eigenen Bezeichnung für die Gruppe und ihre Kunst zu suchen $^{56}$. Der wichtigste Grund für die Namensänderung ist daher in der Absicht der Formisten zu sehen, eine eigenständige Position, sowohl innerhalb der europäischen, als auch der polnischen Kunst, behaupten zu wollen. Dies betraf vor allem auch ihr Bestreben. sich vom Posener „Zdrój“ und der Gruppe „Bunt“ abzugrenzen, die 1917-1918 ebenfalls als „Expressionisten“ in Erscheinung traten.

Für Zbigniew Pronaszko, der den ersten programmatischen Text der Gruppe mit „Über den Expressionismus“ betitelte, bedeutete „Expressionismus“ zu dieser Zeit die zeitgenössische Kunst im Allgemeinen $(1918,15)^{57}$. Die oftmalige Hinzufügung des Adjektivs ,polnische“ (,polscy“ in: „Ekspresjoniści Polscy“ oder „Formiści Polscy“) sollte dabei auf den spezifisch nationalen Charakter einer im europäischen Kontext stehenden Erscheinung verweisen. Rund ein Jahr später, im August 1919, schreibt Chwistek in seinem Aufsatz ..Der Formismus“ (,Formizm“) noch einmal über die verschiedenen Bezeichnungen der Kunst bzw. der Krakauer Gruppe selbst:

\begin{abstract}
.Dażenie to [=zmierzanie ku nowemu stylowi w sztuce; $M . E$.$] skupilo nas przed dwoma laty pod haslem$ ekspresjonizmu, które uzyte było jedynie jako symbol protestu przeciwko szuuce oficjalnej. W krótkim czasie okazalo się jednak. ze nazwa ta łaczy nas w przekonaniu ogołu z sztuka niemiecka która pozostaje ciagle w okresie eksperymentowania, nie cofając sie w wielu wypadkach przed niesmacznym dziwactwem. W tych warunkach okazała się koniecznośc zaznaczenia naszej odrębnosci przez wprowadzenie nazwy nowej. W ten sposób doszlišmy do nazywania się formistami." (1919a, 98)
\end{abstract}

Unterschiedlich zu der von Chwistek in diesem Zitat vertretenen Meinung verweist Irena Jakimowicz darauf (1978, 7), dass beide Bezeichnungen „Expressionismus“ und „Formismus“ gleichermaßen zutreffend sein können. Zeigten doch, so Jakimowicz, sowohl

\footnotetext{
" Estreicher weist noch darauf hin, dass Chwistek mit der Bezeichnung "Expressionismus", den er fur zu mystisch hielt, ohnehin nie glacklich gewesen sei (1971, 127).

${ }^{37}$ Wie am Beispiel der Rezeption des deutschen Expressionismus in Polen erwăhnt, wurde .Expressionismus“ in der polnischen Kunstkritik vor 1917 nicht einheitlich verstanden. Estreicher schreibt außerdem (1971, 120), dass Pronaszko der Name ..Expressionisten“ aus jenem Grund besser als ..Futuristen” oder „Kubisten“ passte. da dieser in der Kunstoffentlichkeit weniger Widerstand als jene hervorrief, ohne dabei jedoch den neuartigen Charakter der expressionistischen Malerei zu verbergen.

33 „Dieses Streben [ =nach einem neuen Stil in der Kunst; M.E.] fuhre uns vor zwei Jahren unter dem Schlagwort des Expressionismus zusammen, das allein als Symbol des Protestes gegen die offizielle Kunst gebraucht wurde. Nach kurzer Zeit stellie sich jedoch heraus, dass uns dieser Name in der allgemeinen Öberzeugung mit der deutschen Kunst verbindet, die sich immer noch im Stadium des Experimentierens befindet und in vielen Fallen auch vor geschmackloser Skurrilitat nicht zurlckschreckt. Unter diesen Bedingungen stellte es sich als notwendig heraus, unsere Eigenstăndigkeit durch die Einfuhrung eines neuen Namens hervorzuheben. Auf diese Weise kamen wir dazu, uns Formisten zu nennen." Ausfuhrlich beschătigt sich Pollakówna (1972, 57-58 sowie
} 
die künstlerische Praxis, als auch die theoretischen Schriften der Formisten, dass diese in ihrer Vorstellung von Kunst stets zwischen zwei Polen schwankten: Kunst als Ausdruck des Inneren bzw. als Streben nach einem rein formalen Ausdruck.

Im Jahre 1919 intensivierten die Formisten ihre Tătigkeit. In Zakopane wurde im November die „Freie Schule der Schönen Künste“ (,Wolna Szkoła Sztuk Pięknych“) eröffnet, an der mit Gotlieb, Niesiołowski, Zbigniew Pronaszko und Zamoyski einige Formisten unterrichten sollten. Zamoyski und seine Frau Rita Sacchetto führten in Posen und Lemberg den von ihnen konzipierten formistischen Tanz vor (vgl. Pollakówna, 1972, 85-86). Die Formisten bzw. einzelne ihrer Mitglieder organisierten in diesem Jahr vier Ausstellungen in großen polnischen Städten: Warschau. Krakau und Posen. Außerdem erschien im Oktober die erste Nummer ihrer eigenen Zeitschrift „Formisci“ („Die Formisten“).

Nach der Ausstellung von Niesiolowski, Witkacy und Zamoyski, die im Februar in Krakau stattfand, wurde am 21. April 1919 in Warschau die „I. Ausstellung Polnischer Formisten” („I. Wystawa Formistów Polskich“) eröffnet. Neben den Krakauer Formisten, nahmen an dieser Ausstellung auch Künstler aus Warschau teil, ähnlich wie in Lemberg, sollte sich später auch in der Hauptstadt eine eigene formistische Gruppe bilden (vgl. Winkler 1927, 8). Der Katalog zur Ausstellung enthält neben kürzeren Fragmenten zur Kunst. die zum Teil bereits im Katalog zur ersten Krakauer Ausstellung 1917 abgedruckt waren. zwei Beiträge von Witkacy und Zamoyski. Witkacy, der 1919 auch seine Studie „Die neuen Formen in der Malerei und die daraus entstehenden Missverständnisse“ („Nowe formy w malarstwie $i$ wynikające stąd nieporozumienia“) veröffentlicht, wiederholt in seinem Text zum Katalog (1919b, o.S.) seine darin entwickelte Hauptthese. Dieser zufolge beruht die Aufgabe der Malerei nicht in der möglichst getreuen Nachahmung irgendwelcher Gegenstände, sondern einzig darin, eine in sich geschlossene Komposition zu schaffen, eine Komposition der sogenannten „Reinen Form“ ("Czysta Forma“). Auch der Rezipient eines Kunstwerks, so Witkacy, müsse versuchen, dic Idee und die Einheit dieser Komposition zu verstehen und dürfe nicht nach einem gegenständlichen Inhalt suchen ${ }^{59}$.

Im September 1919 fand in Krakau die „III. Ausstellung Polnischer Formisten“ („III. Wystawa Formistów Polskich“) statt, eine eher kleine Ausstellung, an der zum ersten Mal

61-62) mit dem Namen der Gruppe und weiterer, sich aus der Bezeichnung „Expressionisten“ ergebender. Implikationen.

39 Witkacys Theorie der "Reinen Form” wird ausfuhrlich im dritten Kapitel dieser Arbeit dargestellt. Nicht eigens besprochen wird an dieser Stelle der Beitrag von Zamoyski, da dieser dessen wichtigste Gedanken in erweiterter Form nur kurze Zeit spăter noch einmal darlegen sollte. Es handelt sich dabei um seine Einleitung zum Katalog der Posener Ausstellung. die die Formisten zusammen mit der Gruppe „Bunt” im Winter 1919 veranstalteten und von der im weiteren Verlauf noch die Rede sein wird. 
auch Jerzy Fedkowicz und Konrad Winkler teilnahmen. Der längste Beitrag zum Katalog, in dem auch Czyżewski vier Gedichte veröffentlichte, die er im darauffolgenden Jahr 1920 in seine Sammlung „Das grüne Auge. Formistische Dichtungen. Elektrische Visionen“ aufnehmen sollte, stammte von Chwistek, es handelt sich dabei um seinen bereits erwähnten Aufsatz „Der Formismus" von 1919. Chwistek versucht darin zum ersten Mal, Gemeinsamkeiten zwischen den der Gruppe angehörenden Künstlem herauszuarbeiten und somit ein „Programm des Formismus“ anzudeuten. Dadurch sollte auch die Eigenständigkeit des Formismus als Strömung der zeitgenőssischen Kunst stärker betont werden.

Ermutigt von der wohlwollenden Annahme dieses Kataloges, beschlossen die Formisten eine eigene Zeitschrift herauszubringen, die ihrem künstlerischen Schaffen gewidmet sein sollte ${ }^{60}$. Es war geplant, die Zeitschrif, die den Titel „Formiści“ trug, monatlich erscheinen zu lassen, was aber anfangs, wohl aus finanziellen und technischen Gründen, nicht gelang. Die zweite Nummer erschien somit erst im April 1920 und die dritte, die als verschollen gilt, im darauffolgenden November. Die Redaktion dieser ersten drei Nummern übernahmen Czyżewski und Chwistek. Die Nummem vier bis sechs, die Czyżewski und Winkler redigierten, erschienen nun wirklich im Monatsrhythmus, von April bis Juni 1921. Neben eigenen Texten (Chwistek, Winkler, Witkacy), Gedichten (Czyżewski, Hrynkowski) und Abbildungen von Kunstwerken (u.a. Czyżewski, Hrynkowski, Lille, Zbigniew Pronaszko, Zamoyski), druckten die Formisten auch Texte von Autoren, die mit anderen polnischen Künstlergruppen verbunden waren (Wittlin, Młodożeniec, Jasieński) oder anderer zeitgenőssischer polnischer Autoren (Jerzy Tom ${ }^{61}$, Jan Starzewski oder Leopold Zborowski). Viel Platz war auch der europäischen Avantgarde gewidmet, vor allem der französischen. So wurden Apollinaires Gedichte sowohl auf französisch, als auch in der Übersetzung Czyżewskis gedruckt, dazu kamen noch Werke von Reverdy. Ebenso waren in „Formiści“ Texte des Dadaisten Hans Arp, des Futuristen Palazzeschi, von Majakovskij und Chlebnikov (beide in der Übersetzung von Anatol Stem) oder von Iwan Goll zu finden. Außerdem erschienen von Zeit zu Zeit Berichte und Analysen über das künstlerische und literarische Geschehen in Europa (zum Beispiel: Louis Markous „Korrespondenz aus Paris“ „Korespondencja z Paryża“ oder Juljan Rot-Czerwiński „Die neue Poesie und das Drama in Deutschland“ - „Nowa poezja i dramat w Niemczech“). Von der Zeitschrift erschienen insgesamt nur sechs Nummern, die letzte im Juni 1921 bereits zu einer Zeit, in der sich schon

\footnotetext{
${ }^{\infty}$ Dies verrăt der Text: „Von den Formisten“ (.Od formistów"), in: „Formiści“ (1), hintere Umschlagklappe.

${ }^{61}$ Estreicher schreibt $(1971,6)$, dass es sich bei diesem Namen um ein Pseudonym handle, unter dem Chwisteks Schwester Emilianna ihre Gedichte in ..Formisci“ veroffentlichte.
} 
erste Auflösungstendenzen innerhalb der Gruppe zeigten, wovon weiter unten noch die Rede sein wird.

Die vierte und letzte Ausstellung des Jahres 1919 wurde im Dezember in Posen eröffnet und dauerte bis zum Januar 1920. Es handelt sich dabei um die „Ausstellung der Formisten und [der Gruppe; M.E.] Bunt“ („Wystawa Formistów i Buntu“). August Zamoyski geht in seinem Vorwort für den Katalog $(1920$, o.S.) von einer ähnlichen Vorstellung des künstlerischen Schaffens aus, wie sie in den verschiedenen Katalogen der formistischen Ausstellungen schon zum Ausdruck gekommen war. Die Natur, so Zamoyski, sei zwar Inspiration und Quelle, doch anstatt diese nachzuahmen, liege die Aufgabe der Kunst vielmehr darin, selbst „Schönes“ oder „Schönheit“ (,piękno“) zu schaffen. Dieser Ausdruck des Kunstschönen ist für Zamoyski in der Komposition von Linien, Farben sowie in den Formen des Kunstwerks selbst und in deren gegenseitigen Beziehungen zueinander gegeben. Darin bestehe die eigentliche, immer gleiche Aufgabe der Kunst, wenngleich dieses .Schöne“ zu unterschiedlichen Zeiten verschieden verstanden worden sei.

Zamoyski schien der ideale Autor für die Einleitung zum Katalog dieser gemeinsamen Ausstellung zweier Künstlergruppen der frühen polnischen Avantgarde zu sein, da er mit beiden Gruppen gleichermaßen verbunden war $^{62}$. Parallel zur Ausstellung fand auch, wie die Zeitung "Goniec krakowski“ („Krakauer Bote“) schreibt (in: Wojciechowski 1974, 57), ein futuristischer Abend statt, auf dem nicht nur Czyżewski, sondern unter anderem auch die Warschauer Dichter Julian Tuwim und Jaroslaw Iwaszkiewicz lasen. Dass diese beiden Dichter, die der Warschauer Gruppe „Skamander” angehörten, auf einem „futuristischen Abend" auftraten. ist insofern bemerkenswer, da die Lyrik dieser Autoren bzw. dieser Gruppe, unterschiedlich zu Czyżewski, mit dem Futurismus kaum verbunden ist. Diese Zeitungsnotiz zeigt daher den uneinheitlichen Gebrauch von Bezeichnungen in der polnischen Kunstkritik in den Jahren nach dem Ersten Weltkrieg, wie dies schon in ähnlicher Form einige Male in dieser Arbeit angesprochen wurde.

Nach der kleineren „VI. Ausstellung der Formisten” („VI. Wystawa Formistów“), die im April 1920 in Warschau stattfand und an der nur wenige Krakauer Formisten teilnahmen, kam es kurz darauf zu einer weiteren Zusammenarbeit zwischen den Formisten und der Gruppe „Bunt”. Am 2. Mai wurde in Lemberg die „II. Ausstellung der Formisten und [der Gruppe; M.E.] Bunt“ („II. Wystawa Formistów i Buntu“) eröffnet, die bis zum 13. Juni dauerte und auf der Künstler aus Krakau. Posen und Lemberg vertreten waren. Parallel zur Ausstellung

${ }^{62} \mathrm{Vgl}$. außerdem zur Zusammenarbeit zwischen den Formisten und der Gruppe .Bunt” bzw. der Zeitschrift „Zdrojj": Pollakówna 1972, 96. 
fanden, ăhnlich wie zuvor in Posen, Autorenabende statt. Am ersten Abend (12. Mai) las der in Lemberg ansässige, aber mit der Zeitschrift ,Zdrój“ eng verbundene Józef Wittlin, am zweiten Abend (19. Mai) traten Adam Bederski, Jarosław Iwaszkiewicz, Artur Grocholski und noch einmal Wittlin auf. Grocholski hielt an diesem Abend auch eine Einfürung zur neuen Poesie ${ }^{63}$.

$\mathrm{Zu}$ Wort meldete sich erneut auch Jan Bołoz-Antoniewicz, und zwar mit seiner ausfuhrlichen Studie "Die Grundlagen des Formismus", die im Juni 1920 in sieben Folgen in der „Gazeta Wieczorna" erschien ${ }^{64}$. Er stellt darin den Formismus in einen Kontext mit der Malerei Raffaels, deren künstlerischer Ausdruck für ihn ebenfalls auf formalen Qualitäten beruht, nämlich: Form als Art der Gestaltung einer künstlerischen Vision. Die Formen, so BołozAntoniewicz, änderten sich mit dem Verlauf der Weltgeschichte (bei Bołoz-Antoniewicz: "Weltgedanke“ - „myśl światowa“), daher müsse auch die Umbruchsphase, in der sich die Menschheit am Beginn des 20. Jahrhunderts befinde, neue künstlerische Formen hervorbringen, da die Kunst immanenter Ausdruck dieses Weltgedankens sei. Es stelle sich nur die Frage, ob sich mit einer neuen Kunst auch eine neue Weltanschauung durchsetze. Als unmittelbaren Vorläufer des Formismus bestimmt Boloz-Antoniewicz unter anderem die Sezession, und zwar deshalb, da diese Kunst den Schwerpunkt vom Kunstwerk auf das Innere des Künstlers verlagert habe. Außerdem nennt er Hodler, Gauguin und Cézanne, die als erste den Betrachter ihrer Kunstwerke zur aktiven Mitarbeit gezwungen hătten. Sie verlangtem von ihm, das Bild im Rezeptionsprozess zu vervollständigen. Ein Verlangen. das die gegenwärtige Kunst noch in viel stärkerem Maße an den Rezipienten stelle. Und zwar nicht zuletzt deshalb. da sie sich in ihrem künstlerischen Ausdruck auf „Grundfarben“ (.,barwy zasadnicze“) bzw. „grundlegende Formen“ (,ksztahty zasadnicze“), das heißt an die Geometrie angelehnte Formen, stütze. Das, so Bołoz-Antoniewicz, verlange ein Auge, das das Bild wieder zusammensetze.

Diese Studie zeigt, dass der Formismus, rund zweieinhalb Jahre nach seinem Entstehen, als eigenstăndige Erscheinung innerhalb der zeitgenössischen polnischen Kunst akzeptiert wird. unabhängig davon, dass oftmals, zum Beispiel in Rezensionen zu einzelnen Ausstellungen, dezidierte Ablehnung zu spüren ist. Im Text von Bołoz-Antoniewicz kommt diese Akzeptanz gerade dadurch zum Ausdruck, dass der Kunsthistoriker den Formismus im Kontext der Kunstgeschichte verortet, das heißt in ihm eine Weiterentwicklung von Tendenzen des frühen

${ }^{63}$ Diese Daten vermerkt die Lemberger „Gazeta Poranna” (.Morgenzeitung”) - vgl. Nr. $5223(12.05 .1920,6)$ sowie Nr. 5242 (23.05.1920, 3).

* Vgl. Boloz-Antoniewicz 1920. Alle Zitate aus dieser Studie stammen sus dieser Quelle. 
20. Jahrhunderts sieht. Dass auch die Formisten selbst Anstrengungen unternahmen, sich ein eigenes Profil zu verleihen, zeigt Chwisteks erwähnter Aufsatz „Der Formismus“ vom September 1919. Chwistek ließ diesem Text nur einige Monate später, im März 1920, einen weiteren folgen, der nicht nur denselben Titel trug, sondern auch in einer ähnlichen Absicht verfasst wurde. In diesem Aufsatz formuliert Chwistek erstmals das für den Formismus zentrale Postulat von der Überwindung des Inhaltes durch die Form des Kunstwerks, wovon im nächsten Kapitel ausführlich die Rede sein wird.

Zwei große formistische Ausstellungen fanden im darauffolgenden Jahr 1921 statt: die „IV. Ausstellung der Formisten“ („IV. Wystawa Formistów“), die am 23. Januar in Krakau eröffnet wurde und die „Ausstellung der Formisten“ („Wystawa Formistów“), die von April bis Mai in der Warschauer Galerie „Zachęta“ zu sehen war. Es handelte sich dabei im Prinzip zweimal um dieselbe Ausstellung, wenngleich die in Krakau gezeigte Version größer war als die in Warschau (vgl. Jakimowicz 1989, 23). Auch der Katalog war derselbe: er enthielt neben dem Dramolett „Das Genie und der Doppelgänger” (,Geniusz i sobowtór”) von Czyżewski und dem Gedicht „Un dernier chapitre“ („Ostatni rozdzial”) von Apollinaire. ein Fragment aus Winklers Buch „Der Formismus vor dem Hintergrund zeitgenössischer Richtungen in der Kunst“ („Formizm na tle współczesnych kierunków w sztuce“), das ebenfalls 1921 erschien. Verwunderlich ist, dass das von Winkler im Katalog abgedruckte Fragment aus dem Kapitel über den Expressionismus, und nicht, was wohl näher liegend wäre, aus jenem über den Formismus stammt. Außerdem behandelt Winkler darin weniger den polnischen, sondern vor allem den deutschen Expressionismus ${ }^{65}$.

Von den Rezensionen zu diesen Ausstellungen ist besonders jene des Warschauer Kunsthistorikers Mieczysław Wallis hervorzuheben (in: Wojciechowski 1974, 75), der auf die stilistische Heterogenităt in Bezug auf die einzelnen Mitglieder der formistischen Gruppe aufmerksam macht. Er bemüht sich auch, das „Formistische“. das er insbesondere in der Plastik von Zbigniew und Andrzej Pronaszko verwirklicht sieht, im Zusammenhang mit Expressionismus, Kubismus und Futurismus zu beschreiben. Daneben gab es auch viel Kritik. wiederum vor allem an die Adresse Czyżewskis und seiner „vielebenigen Bilder“ (vgl. Pollakówna 1972, 143-144), auf die Witkacy im April 1921, in der vierten Nummer von „Formisci“" reagierte (1921b, 5-8). Es gehe ihm und den Formisten, so Witkacy, nicht um ungeteilte Zustimmung zu ihrer Kunst. Kritik könne angebracht sein, jedoch nur dann, wenn sie sich auf die Kunst selbst konzentriere, das heißt von einem solchen Standpunkt aus

${ }^{63} \mathrm{Vgl}$. dazu auch: Pollakówna 1972, 161, die vermutet, dass es Winkler dabei vor allem um eine Abgrenzung gegenuber dem Futurismus ging. 
argumentiere. Das Fehlen eines solchen Standpunktes sowie fachlicher Kompetenz bei vielen polnischen Kritikem - Witkacys zentraler Vorwurf - führten dazu, dass die Formisten immer noch dafür angegriffen würden, keine gegenstăndliche bzw. mimetische Malerei zu betreiben. Am 12. Mai erschien außerdem im „Kurier Warszawski“ („Warschauer Kurier“) ein Brief von Künstlern der älteren Generation, die dagegen protestierten, dass die Galerie „Zachęta“ den Formisten und ihrer Kunst so viel Ausstellungsfläche zur Verfügung stellt (vgl. Pollakówna 1972, 149-150). Und weiter heißt es in dem Brief:

.Zachęcie nie wolno deprawować ogólu, a przede wszytkim miodzieży naszej za pomoca wystaw podobnych do ostatniej [=wystawa Formistów; M.E.], gdzie się panoszy juz nie tylko brutalne wyuzdanie, lecz nawet petne perfidii bluźnierstwo $i$ gdzie nie tylko estetyczne $i$ etyczne, ale nawet religijne ideały sa zanieczyszczone." (zit. n. Wojciechowski 1974, 76)

Auf diesen Protest reagierte Winkler ebenfalls im Mai, und zwar in einem kurzen Beitrag, der in der fünften Nummer von „Formiści“" veröffentlicht wurde (1921b, 16). Winkler bleibt darin wenig sachlich und beschimpft die Unterzeichner des erwähnten Protestbriefes als „einen Haufen Eunuchen“ und „künstlerisch Zurückgebliebener" („grono eunuchów i niedobitków artystycznych").

Mit den Kritikem ihrer Kunst bzw. des Formismus beschäftigten sich auch Chwistek und Czyżewski. Chwistek tat dies in seinem Text „Die Feinde des Formismus und ihre Psychologie“ („Wrogowie formizmu i ich psychologia“) ${ }^{67}$. Er bestimmt darin (1919b, 89-93) in erster Linie psychologische Gründe dafür, warum der Formismus bei vielen Kritikem auf Ablehnung stößt. Es sei, so Chwistek, Neid und Unzufriedenheit ob des scheinbar leicht errungenen Erfolges und der Anerkennung der jungen Künstler, womit sich das instinktive Streben nach Bewahrung und Verteidigung des Gewohnten verbinde. Daraus resultiere letztendlich die Unfăhigkeit. das Neue zu verstehen, da dieses eben den Horizont des Bekannten überschreite. Für die Formisten bedeute dies, eher nachsichtig mit den Verteidigem der alten Ordnung umzugehen und Mitleid für ihre Unfahigkeit aufzubringen. Denn die Geschichte, schreibt Chwistek, weise viele Beispiele dafur auf, dass der Kampf gegen das Neue letztendlich sinnlos sei.

Einen ähnlich ironischen Unterton weist auch Czyżewskis Text „Tytus Czyżewski über ,Das griune Auge' und seine Malerei. Selbstkritik - Selbstreklame” (.,Tytus Czyżewski o ,Zielonym oku' i swoim malarstwie. Autokrytyka - autoreklama", 1921) auf. Er äußert sich darin zu

\footnotetext{
66 „Die Zachęta darf nicht die Allgemeinheit, vor allem nicht unsere Jugend mit solchen Ausstellungen wie der jungsten [=die der Formisten; M.E] verderben, in der nicht nur brutale Ausschweifung. sondem sogar perfide Blasphemie herrschen und in der nicht nur asthetische und ethische, sondem sogar auch religiose Ideale beschmutzt werden."

${ }^{67}$ Eine deutsche (ibersetzung dieses Textes findet sich in: Lam (1990. 117 121).
} 
seiner Malerei und zu einzelnen Gedichten aus seinem ersten formistischen Gedichtband und nimmt auch zur Meinung einzelner Kritiker Stellung:

„Rózni krytycy pisali o Zielonym oku rózne rzeczy.

Krytycy piszacy w gazetach o poezji' zgadzali sie prawie wszyscy na jedno - ze moje poezje sa złożone $z$ minimum talentu', natomiast malarstwo moje uwazali za rzecz, epokowa'.

Na odwrót - krytycy piszacy w gazetach o .szukach plastycznych' zgadzali się prawie wszyscy na jedno, ze poezje moje sa ,epokowe' (?!), a malarstwo moje jest ,niedolęzne', bez ,rysunku' i ,koloru'." (Czyżewski $1922 \mathrm{c}, 119)^{68}$

Die Schlussfolgerung, die Czyżewski daraus zieht, ist, dass die besten Kunstkritiken nicht von den sogenannten „Fachleuten“, sondem von Rechtsanwälten. Ärzten, Veterinären oder Geologen geschrieben würden.

Das Jahr 1921 brachte eine verstärkte Zusammenarbeit zwischen den Formisten und den Krakauer Futuristen Jasieński und Młodożeniec ${ }^{69}$. Beide waren bereits Ende 1918 nach Krakau gekommen, die Gründung der futuristischen Gruppe und des futuristischen Klubs „Katarynka“ („Leierkasten“) dürfte rund ein Jahr später erfolgt sein. Der von Anfang an enge Kontakt zwischen den Formisten und den Futuristen war vor allem Czyżewski zu verdanken, der nicht nur die jüngeren Kollegen in den Kreis der Formisten einführte, sondern ihnen als Redakteur von „Formisci“ auch eine Publikationsmöglichkeit bot. Im Laufe des Jahres 1920 fanden einige gemeinsame Abende statt, auf denen Gedichte rezitiert oder Vorträge über die neue Kunst und Poesie gehalten wurden. Viele dieser Abende waren von Tumulten, Handgemengen und Polizeieinsätzen begleitet. was die zum Teil ablehnende und feindliche Haltung breiter Teile der Gesellschaft gegenüber der futuristischen Kunst zeigt. Diese Ablehnung des Futurismus wurde durch zwei Publikationen. die 1921 erschienen und an denen unter anderem Czyżewski und Chwistek beteiligt waren. noch verstärkt. Es handelt sich dabei um die beiden futuristischen „Eintagesblätter” (.jednodniówki“): "1Tagesblatt der Futuristen“ (..Jednodnuwaka Futurystuw“, 10. Juni 1921) und ..Das Messa im Bauch" (..Nuż w bżuhu", 13. November 1921) ${ }^{70}$. Es waren vor allem die in einigen Manifesten vertretenen gesellschaftlich-politischen Ansichten bezüglich der ..sofortigen Futurisierung des Lebens“ (zum Beispiel: Jasieński: „Manifest in der Sache der sofortigen Futurisierung des Lebens“-

\footnotetext{
6s "Verschiedene Kritiker schrieben uber Das grüne Auge verschiedene Dinge. Die Kritiker, die in Zeitungen uber die "Poesie' schrieben, stimmten fast alle darin aberein - dass meine Gedichte aus einem Minimum an 'Talent' bestehen, wohingegen sie meine Malerei for epochal hielten. Umgekehr - fast alle Kritiker, die in Zeitungen über die ,bildenden Künste' schrieben, stimmten darin überein, dass meine Gedichte ,epochal' (?!) seien, dafur aber meine Malerei ,unbeholfen', ohne ,Zeichnung' und ,Farbe' sei."

${ }^{\circ}$ Bei meinen Ausfuhrungen zur Geschichte des Krakauer Futurismus stütze ich mich auf: Jarosinski/Zaworska 1978. XLIII-LXVIII.

to Die korrekte Schreibweise ist: „Jednodniówka futurystów” bzw. .Nóz w brzuchu”. Diese verfremdete Orthographie, die ich versuche auch in der deutschen Übersetzung der Titel ansatzweise wiederzugeben, war ein Teil der futuristischen Emeuerung der polnischen Literatursprache (vgl. Jasienski 192 I, 219-22I).
} 
"Mańifest w sprawie natyhmiastowej futuryzacji żyća“), die den Futuristen die größte Gegnerschaft bescherten. Dies schien auch Auswirkungen auf die Formisten gehabt zu haben. Czyżewski und Chwistek steuerten, wie gesagt, Gedichte und Texte zu den beiden Publikationen bei und ein Aufruf aus „Das Messa im Bauch“ an die Bürger, sich, ihre Frauen und Kinder zu bemalen, suggeriert, dass sich die Formisten als Malergruppe begreifen, die sich dem Futurismus verbunden fühlt ${ }^{71}$. Chwistek, dessen Habilitation an der Krakauer Jagiellonen-Universität sich aufgrund seiner Teilnahme an „Das Messa im Bauch“ um einige Jahre verzögem sollte, schreibt 1938 rückblickend auf die formistisch-futuristische Zusammenarbeit:

„Sielanka [...] skończyła się skutkiem wmieszania się w tę sprawę poetów. Dopóki szło o czysta szzukę. krakowianie byli cierpliwi, ale ,Nuz w bżhu" przerazil ich i zmrozil. Zaczęła sie gwałowna reakcja [...]. Formiści stropili się i zaczęli szukać sposobów dystkretnego wycofania się z płonącej budowli." (1938. $117)^{7}$

Es scheint in der Tat, dass die Zusammenarbeit von Chwistek und Czyżewski und den Futuristen einen nicht unbedeutenden Beitrag zum Zerfall der formistischen Gruppe leistete. Oder anders gesagt. dass dem Formismus der enge Kontakt zu den Futuristen schadete. Allerdings gab es auch inhaltliche Differenzen unter den Formisten, etwa zwischen Chwistek und Witkacy, von denen weiter unten noch ausführlich die Rede sein wird. Vorbehalte wurden auch gegenüber Zbigniew Pronaszko laut, der, wie in einer in „Das Messa im Bauch“ abgedruckten Polemik zu lesen ist, in einigen seiner neuesten Bilder scheinbar den Weg der neuen Kunst verlassen habe und nun angeblich die Rückkehr zur gegenständlichen, stimmungsvollen Malerei vollziehe (vgl. Pollakówna 1972, 152). Zum endgültigen Bruch zwischen den Formisten und Pronaszko sollte es im darauffolgenden Jahr 1922 kommen, als dieser im April an einer Ausstellung der Krakauer Vereinigung „Sztuka“ teilnahm. In der Zeitschrift ,Zwrotnica“ findet sich dazu eine nicht namentlich unterzeichnete Notiz.

Ihr Autor, wahrscheinlich Peiper selbst (vgl. Jaworski, in: Peiper 1974, 529), schreibt (Peiper 1922b, 16), dass Pronaszkos formistische Kollegen diesem vorwerfen würden, durch die Ausstellung mit "Sztuka“ den gemeinsamen Weg der neuen Kunst verlassen zu haben. Wären, so der Autor weiter, diese Kollegen aber weniger verbittert, so sảhen sie, dass das Beste an Pronaszkos Malerei weiterhin durch den Formismus beeinflusst sei. Diese

\footnotetext{
"Pollakówna verweist in diesem Kontext (1972, 153-154), dass einige Bilder von Chwistek (zum Beispiel: „Die Stadr" - . Miasto“) durchaus mit der Ästhetik des Futurismus in Verbindung gebracht werden konnen.

7 "Die Idylle [...] endete mit der Einmischung der Dichter in die Sache. Solange es nur um die reine Kunst ging. waren die Krakauer geduldig, aber ,Das Messa im Bauch' erschrak sie und ließ sie erstarten. Es begann eine heftige Reaktion [...]. Die Formisten gerieten aus der Fassung und begannen nach Wegen zu suchen, sich diskret aus dem brennenden Gehalude zurickzuziehen."
} 
Einschätzung bestätigt auch Helena Blumówna (1958, 38-39), die schreibt, dass Pronaszkos Bruch mit den Formisten nur äußerlich gewesen sei, in seiner Kunst hätte Pronaszko stets an den während der formistischen Zeit entwickelten Prinzipien festgehalten.

Somit scheinen also mehrere Faktoren zusammenzuwirken, die die Auflösung des Formismus einleiten. Bestătigt wird dies durch eine Meinung von Chwistek, die dieser in einem Text von 1935 (5) äußert: „W r. 1921 rozpocząl się rozkład formizmu.“73.

1922 folgten noch einige kleinere Ausstellungen in Lemberg und Warschau und vor allem in Paris. Bei letzterer handelte es sich zwar nicht um eine eigene formistische Ausstellung, sondern um eine Schau der jungen polnischen Malerei, an der aber von den in Polen arbeitenden Künstlem vor allem Formisten teilnahmen. Nur ein Monat nach dieser Ausstellung, im März 1922 erschien Chwisteks Text „Tytus Czyżewski und die Krise des Formismus“, dessen erster Satz lautet: „Stowarzyszenie formistów przestało istnieć.“ (1922b, $107)^{74}$. Es scheine ihm richtig, so Chwistek, sich zusammen mit Czyżewski noch wie gewohnt als ..Formisten“ zu bezeichnen, denn die älteren Formisten - Chwistek nennt keine Namen hätten schon den „Weg der Vernunft“ („droga rozsądku“) eingeschlagen. Nach der in „Das Messa im Bauch“ geäußerten Kritik an Zbigniew Pronaszkos neuesten Bildern, kann es sein. dass Chwistek hierbei vor allem an den ehemaligen Initiator des Formismus denkt. Im weiteren Verlauf des Textes wehrt sich Chwistek gegen die Vorwürfe, er und Czyżewski seien in ihrer Kunst zu sehr von den zeitgenössischen Strömungen beeinflusst und wendet sich gegen die seiner Meinung nach ungerechtfertigte Bezeichnung Czyżewskis als „Kubist“ bzw. von ihm selbst als „Futurist”. Nachdem Chwistek noch einmal auf einige zentrale Aspekte der formistischen Ästhetik eingegangen ist, vor allem dem Problem der Neubewertung des Inhalt-Form-Dualismus im Kunstwerk, setzt er sich im zweiten Teil seines Aufsatzes mit Witkacys Buch „Ästhetische Skizzen“ („Szkice estetyczne“) auseinander. Er reagien damit auf den darin abgedruckten Aufsatz Witkacys ..Kritik der Kunsttheorie Leon Chwisteks“ (,Krytyka teorii Sztuki Leona Chwistka“). Wie erwähnt, gab es zwischen Chwistek und Witkacy inhaltliche Differenzen, vor allem, was die Rolle des gegenständlichen Inhalts im Kunstwerk betrifft.

Neben der Mitarbeit an den futuristischen Eintagesblättern. engagierte sich Chwistek schon im November 1921 auch für die in Warschau neu entstandene Zeitschrift ..Nowa Sztuka“ (,Die Neue Kunst“), die, wie Lam betont (1969, 1/182), den Versuch darstellt, die

"3 "Im Jahre 1921 begann der Zerfall des Formismus."

"..Die Vereinigung der Formisten horte auf zu existieren." Alle Zitate der obigen Beschreibung sind aus der angefuhrten Quelle entnommen, der ganze Text ist auf den Seiten 107-112 abgedruckt. 
verschiedenen Gruppen der frühen polnischen Avantgarde durch ein gemeinsames Projekt zusammenzuführen, mit Ausnahme jedoch des Expressionismus. Die Redaktion setzte sich daher unter anderem aus dem Futuristen Anatol Stern, Chwistek und Tadeusz Peiper zusammen. Die Zeitschrift konnte allerdings nur noch ein zweites Mal, im Februar 1922 erscheinen. Chwistek druckte in beiden Nummern einen Artikel ab. In der ersten Nummer erschien „Fragen der zeitgenössischen Architektur“ (,Zagadnienia architektury współczesnej“), in der zweiten: „Die neue polnische Dichtung. Vier Vorträge über die futuristische Dichtung, vorgetragen in literarischen Kursen in Krakau“ („Nowa poezja polska. Cztery wykłady o poezji futurystycznej wygloszone na kursach literackich w Krakowie"). Nur wenige Monate später, im Juli 1922 erschien aber bereits die erste Nummer der von Peiper wieder in Krakau herausgegebenen Zeitschrift „Zwrotnica" ("Die Weiche“), in der viele der ehemaligen Formisten publizierten bzw. Abbildungen formistischer Kunstwerke erschienen (von Zamoyski und Gotlieb) und in der auch allgemein über mit dem Formismus zusammenhängende Entwicklungen berichtet wurde (Peiper 1922a und 1922b, Terlecki 1922 sowie Młodożeniec 1922) ${ }^{75}$. Am meisten veröffentlichten aber Chwistek (1922c), Witkacy (1922-1923 und 1923b) und vor allem Czyżewski in „Zwrotnica“. Letzterer druckte nicht nur zahlreiche Gedichte, sondern schrieb, bereits in Paris weilend, Berichte über das dortige aktuelle Kunstgeschehen (1922b, 1923a). Außerdem erschien in der Zeitschrift sein Text .Monsalvat oder das Bordell“" (,Monsalwat czy lupanar“), in dem er sich noch einmal mit der polnischen Kunstkritik beschäftigt und dieser vorwirft (1922a, 21), unfähig zu sein. neue Entwicklungen in der Kunst zu begreifen und nur die Wiederholung des Alten zu akzeptieren. Unter diesen Vorzeichen habe diese auch diejenigen Künstler angegriffen. die wirklich etwas Neues wagten und diese vor dem „Tribunal des billigen Patriotismus“ (,trybunal taniego patrjotyzmu“) denunziert. Aus diesen Zeilen spricht nicht nur die Enttäuschung über das Scheitern des Formismus, sondern auch die Verbitterung darüber, dass die Anstrengungen. die die Formisten nach 1918 unternahmen, die seit der polnischen Romantik so feste Verbindung von Kunst und Politik aufzulösen und die Kunst auf ihre ästhetischen Probleme zu fokussieren. in der Öffentlichkeit nicht den gewünschten Widerhall fanden.

Nach dem Ende des Formismus schlossen sich einige Formisten anderen Künstlergruppen an bzw. gründen neue. Einige verfolgten auch eigene Projekte: Witkacy widmete sich vor allem dem Theater und Chwistek entwickelte seine Theorie der „sphäristischen Malerei“

\footnotetext{
75 Auch die - ebenfalls nicht namentlich gekennzeichnete - Notiz ..Zerwärfnis im Formismus" (..Rozłam w formizmie" kann Peiper zugeschrieben werden (Ygl. Jaworski, in: Peiper 1974. 528).
} 
(,strefizm“, von: strefa $=$ Zone, Sphäre) ${ }^{76}$. Diese beruhte auf einer besonderen Einteilung des Bildes in verschiedene Sphären, die, obgleich zueinander oft im Kontrast stehend, dennoch durch besondere Kompositionsmittel (zum Beispiel: Farbharmonien) miteinander in Beziehung gebracht wurden, was die Einheit des Kunstwerks gewährleistete ${ }^{77}$. Czyżewski schließlich verließ Polen im Oktober 1922 und ging für mehrere Jahre nach Paris ${ }^{78}$.

\footnotetext{
${ }^{76}$ Estreicher schreibt $(1971,222)$, dass die Bezeichnung .Sphärismus” von Peiper stamme.

$n$ Vgl. genauer zu Chwisteks Spharismus: Estreicher 1971, 219-236 sowie: Jakimowicz 1978, 57-61. Vgl. auch: Tamogórska (1997, 194-204), die anhand zweier Poeme von Adam Wazyk die Art einer (freien) Übertragung von Chwisteks ..sphăristischen" Ideen auf die Literatur beschreibt.

"In Paris war Czyzewski unter anderem als Diplomat tătig und pflegte außerdem Kontakt zu den „Kapisten“" (..Kapisci“), einer in Paris und Krakau tatigen Gruppe junger polnischer Maler. Er kehre erst 1930 wieder nach Polen zuruck. Die dreißiger Jahre und den Zweiten Weltkrieg verbrachte er in Warschau, das er nach dem gescheiterten Warschauer Aufstand in Richtung Krakau verließ. Dort starb Czyzewski am 6. Mai 1945.
} 


\section{3. Ästhetik und Kunsttheorie des Formismus}

Außer Chwistek, Witkacy und auch Winkler, die sich in zum Teil längeren Studien ausführlich mit dem Formismus, seiner Geschichte bzw. mit zentralen Fragen der Kunst beschätigten, nahmen mit Zbigniew Pronaszko, Czyżewski oder Zamoyski auch andere Formisten in kleineren Texten, zum Beispiel in Katalogen oder Zeitschriften, Stellung zu ăhnlichen Fragen. Wenn ich in der folgenden Darstellung vereinzelt auch auf nach 1922 entstandene Texte zurückgreife, so nur dann, wenn diese in einem unmittelbaren Verhältnis zum Formismus stehen'. Das triff vor allem auf die einzelnen Beiträge einer Umfrage zum Formismus zu, die im März 1938, also zwanzig Jahre nach der Gründung der Gruppe, von der Zeitschrift „Glos Plastyköw" („Stimme plastischer Künstler") unter den ehemaligen Formisten ausgeschrieben wurde. Sie hatte zum Ziel, aus Sicht der Protagonisten selbst, ein, wie der Herausgeber der Zeitschrift Jan Cybis schreibt (1938, 5), „repräsentatives Bild“ des Formismus zu vermitteln ${ }^{2}$.

Der Formismus und seine Ästhetik lassen sich an einzelnen zentralen Fragen untersuchen, die in all den Texten, die hier behandelt werden, immer wieder eine wichtige Rolle spielen. Diese Fragen können deshalb als „zentral" bezeichnet werden, weil die Formisten selbst sie als Prämissen für ihren ästhetischen Ansatz beschreiben. Dazu zählen: der Begriff der „Form“, das Verhältnis von Form und Inhalt, das Problem der Komposition sowie der Zusammenhang zwischen Kunst und außerkünstlerischer Wirklichkeit.

Auch im Hinblick auf die primăr literaturwissenschaftliche Themenstellung dieser Arbeit, geht es mir bei der Untersuchung der Texte in diesem Kapitel vor allem darum, welche ästhetischen Strukturen des Formismus ihren Ausdruck gleichermaßen in der bildenden Kunst und der Literatur finden können. Die erwăhnten Fragen ermöglichen einen Vergleich von Literatur und Kunst, weil sie für beide künstlerischen Ausdrucksformen von Bedeutung sind. Denn die Komposition des Kunstwerks oder das Primat der Form über den Inhalt können sowohl in Bezug auf Bilder, als auch auf literarische Werke diskutien werden.

\footnotetext{
"Aus diesem Grund wird etwa Chwisteks „Spharismus" nicht mehr behandelh, ebenso wie jene Schriften Witkacys, die nach 1922/23 entstanden sind.

${ }^{2}$ Cybis schreibt $(1938,5)$ in seiner Einleitung „Der polnische Formismus” (..Polski formizm”) außerdem uber die Intention dieser Umfrage: .,[...] dac obraz formizmu, w przekroju najsluszniejszy, a zarazem stworzyć najautentyczniejsze żodło dla przyszłych badaczy - albowiem pewni jestesmy, ze formizm wejdzie w historį sztuki polskiej jako jedna z kart najbardziej wzruszajacych." - ......] ein Bild des Formismus zu geben. am zutreffendsten im Querschnitt, und gleichzeitig eine am meisten authentische Quelle für zukunftige Forscher zu schaffen - denn wir sind uns sicher, dass der Formismus in die Geschichte der polnischen Kunst als eine der hewrgendsten Karten eingehen wird *
} 
Am Rande sei jedoch darauf hingewiesen, dass es den Formisten nicht um eine Vereinheitlichung ihrer theoretischen Ansätze ging, die für alle Mitglieder der Gruppe gleichermaßen hätte verbindlich sein können. Eine ,gemeinsame“ formistische Ästhetik lässt sich jedoch aufgrund einer vergleichenden Analyse der theoretischen und programmatischen Texte charakterisieren, die sich, wie gesagt, auf die Herausarbeitung der für das Kunstverständnis zentralen Ideen konzentriert.

\subsection{Die „visionäre Wirklichkeit” des Formismus (zum Verhältnis: Kunst und Wirklichkeit)}

In seinem im August 1919 verfassten programmatischen Aufsatz "Der Formismus" unternimmt Chwistek den Versuch. den Formismus als eigenständige Strömung der zeitgenössischen Kunst zu bestimmen, indem er bestehende Gemeinsamkeiten zwischen den einzelnen Mitgliedern der Gruppe zusammenführ und somit vorsichtig die Möglichkeit eines für alle Formisten verbindlichen Programms andeutet. Chwistek betonte dies auch selbst. nämlich in seinem Beitrag „Die schöpferische Kraft des Formismus” ("Twórcza siła formizmu“), den er 1938 für das erwähnte Sonderheft von „Glos Plastyków“" verfasste. Dort schreibt er über seinen Aufsatz von 1919: „Starałem się sformułowac to, co było wspólne wszytkim czlonkom grupy, pomijając swoje osobiste tendencje i teoretyczne koncepje poszczególnych członków." $(1938,118)^{3}$. Dabei interessiert ihn vor allem die Beziehung zwischen bildender Kunst und (außerkünstlerischer) Wirklichkeit:

\footnotetext{
„W przeciwienstwie do muzyki i do szauki omamentacynej, które zajmuja się problemem formy niezaležnie od rzeczywistości, wzoruje siẹ malarstwo i rzeżba wszystkich czasów na otaczajacym nas świecie [...]. Niektórzy z nowszych teoretyków sztuki staraja się odją́ temu zjawisku znaczenie zasadnicze. thumaczac je ta okolicznościa, ze artysta zwraca się do świata rzeczywistego jedynie dlatego, ze świat ten jest mu najblizszy, a więc najlatwiej dosteppny. Wbrew temu twierdzeniu można się latwo przekonac, ze zerwanie z światem rzeczywistym pozbawiloby zarówno malarstwo jak i rzeżbę tych cech istotnych. które odróżniaja je od sztuki omamentacynej." $(1919 a, 94)^{4}$
}

${ }^{3}$.Ich bemahte mich, das zu formulieren, was allen Mitgliedern der Gruppe gemeinsam war, wobei ich meine personlichen Tendenzen ebenso wie die theoretischen Konzepte einzelner Mitglieder uberging." Allgemein mit Chwisteks Rolle als Theoretiker des Formismus beschaftigt sich Kostyrko (1995, 103-115).

4.Im Gegensatz zur Musik und zur ornamentalen Kunst, die sich unabhăngig von der Wirklichkeit mit dem Problem der Form befassen, nehmen sich Malerei und Plastik zu allen Zeiten die uns umgebende Welt zum Vorbild. [...] Einige der jüngsten Kunsttheoretiker versuchen, diesem Phănomen seine grundlegende Bedeutung abzusprechen und begrunden es damit. dass sich der Kanstler nur deshalb zur wirklichen Welt wende, da ihm diese Welt am năchsten, also am leichtesten zugănglich sei. Entgegen dieser Behauptung kann man sich leicht davon aberzeugen, dass der Bruch mit der wirklichen Welt sowohl Malerei, als auch Plastik ihrer wesentlichen Eigenschaften berauben wörde, die diese von der ornamentalen Kunst unterscheiden." 
Chwistek geht hier von einem recht allgemeinen Verständnis von „Wirklichkeit” (die „uns umgebende Welt") aus, etwa im Sinne einer gemeinhin wahrnehm- und erfahrbaren Realităt, die das umfasst, was existiert, im Gegensatz zu dem, was nur scheinbar oder imaginiert ist ${ }^{5}$. Grundlegend ist für ihn dabei, dass sich die Kunst auf diese Wirklichkeit bezieht, diese mittels künstlerischer Verfahren zum Ausdruck bringt. Denn es sei, so Chwistek an anderer Stelle von „Der Formismus“ (1919a, 95), bei jedem gelungenen Kunstwerk möglich, das Dargestellte mit dieser Realität in Verbindung zu bringen, die jeweiligen Formen oder Konturen mit mehreren konkreten Gegenständen zu assoziieren. Der durch die formalen Qualităten bestimmte ästhetische Ausdruck eines Kunstwerks beruht somit auf einer gewissen inhaltlichen Mehrdeutigkeit.

Ausgehend vom Zusammenhang zwischen Kunst und Wirklichkeit sowie vom Phänomen der Mehrdeutigkeit, wendet sich Chwistek in seinem Text dem Problem zu, dass es verschiedene künstlerische Möglichkeiten gibt, die Wirklichkeit darzustellen. Am Beispiel der Photographie zeigt er, dass es selbst hier unterschiedliche Darstellungsverfahren (zum Beispiel durch Retusche) gibt, weswegen sie - im Vergleich zur Malerei, auf die das zuvor Gesagte in gleichem Maße zutriff - für ihn zu unrecht für ein privilegiertes Mittel gehalten wird, die Wirklichkeit abzubilden. Für Chwistek gibt es daher keine festgelegte Art, die Wirklichkeit oder einzelne Gegenstände künstlerisch darzustellen. Im Gegenteil: dies kann auf viele verschiedene Arten geschehen (1919a, 96).

Dieses Problem, das heißt die verschiedenen Möglichkeiten, die Wirklichkeit in der Kunst darzustellen. steht für einen zentralen Aspekt von Chwisteks kunsttheoretischem Denken. Ihn interessient nämlich vor allem, ob der künstlerischen Darstellung eine besondere, charakteristische Erfassung der Wirklichkeit zugrunde liegt. Ebenso entscheidend ist für ihn die Frage, ob überhaupt von einer einzigen, allgemein verbindlichen Definition der Wirklichkeit ausgegangen werden kann oder ob nicht mehrere. gewissermaßen parallel existierende Konzeptionen der Wirklichkeit möglich sind.

Mit diesen Fragen, die die Beziehung „Kunst - Wirklichkeit" betreffen, setzt sich Chwistei explizit in gleich drei Texten auseinander: in den beiden Aufsätzen „Die Vielfalt der Wirklichkeiten in der Kunst“ (1918 und 1924) sowie in der längeren Studie „Die Vielfalt der Wirklichkeiten“ (1921a). In diesen Arbeiten unternimmt er zum einen den Versuch, mehrere

\footnotetext{
"Chwistek hat sich in seinen Schriften nie explizit mit seinem Verständnis des Begriffs "Wirklichkeit" beschaftigt. Dass aber der oben angefuhrte Vorschlag, diese als Gegenteil des Scheinbaren zu verstehen. zutreffend ist, zeigt das folgende Fragment, in dem Chwistek diesen Gegensatz selbst herstellt: $n[\ldots]$ nie mozemy rozstrzy gnąc. czy mamy so czynienia z przedmiotami rzeczywistymi, czy tez z fikcjami [...].“ (1921a. 30). .. [...] wir knnnen nicht entscheiden. ob wir es mit wirklichen Gegenstanden oder mit Fiktionen zu tun haten [...]."
} 
Definitionen der Wirklichkeit zu unterscheiden und zum anderen, diese unterschiedlichen Wirklichkeitsdefinitionen einer bestimmten künstlerischen Darstellungsart zugrunde zu legen. Seine zentrale These, die er anschließend in allen drei Arbeiten zu begründen sucht, formuliert er dabei am Beginn von „Die Vielfalt der Wirklichkeiten“: „Różnice pomiędzy typami malarstwa odpowiadają ściśle różnicom pomiędzy typami rzeczywistości." (1918, 24) ${ }^{6}$. Diese Unterschiede, so versucht er im selben Aufsatz zu zeigen (vgl. 24-34), bestehen für ihn der Art die Wirklichkeit zu erfassen sowie in der sich daran anschließenden Ar, diese künstlerisch darzustellen.

Bei der Unterscheidung der einzelnen Wirklichkeitstypen geht Chwistek von der bekannten Erfahrung aus, dass es möglich ist, von ein und demselben Gegenstand viele unterschiedliche Ansichten zu gewinnen, wenn sich die Lichtverhältnisse, die Perspektive, aus der der Betrachter diesen Gegenstand beobachtet, die Entfernung etc. verändern. Aus dieser Erfahrung, so Chwistek, lasse sich nun zum einen folgern, dass aufgrund sich immer unterschiedlich darbietender Ansichten nicht vom Gegenstand an sich die Rede sein könne. In diesem Fall spricht Chwistek von der „Wirklichkeit der Eindruckselemente“ („rzeczywistość elementów wrażeniowych"), an anderer Stelle (1921a, 34) nennt er sie zutreffender "Wirklichkeit der Eindrücke“ (,rzeczywistość wrażen“). Während Chwistek bei diesem Verständnis den Eindrücken eine gewisse Autonomie zuschreibt, so setzt er bei seinem zweiten Schluss, den er aus der zuvor beschriebenen Erfahrung zieht, den Schwerpunkt auf die Gegenstände selbst. Diese könnten, so Chwistek, nicht allein durch Beobachtung erkannt werden, da sich mit Veränderung der Beobachtungsbedingungen auch ihre Ansicht ändere. Eine Ansicht eines Gegenstandes sei immer das Ergebnis eines bestimmten Verhältnisses zwischen dem Betrachter, der Lichtquelle und dem Gegenstand. Um aber die „wahre“ Eigenheit dieses Gegenstandes erkennen zu können. sei es nötig, sie zum Beispiel durch den Intellekt zu erfassen. Ein alternatives Kriterium hierzu wäre der „common sense“, der "gesunde Verstand", also das auf alltäglicher Praxis basierende Verständnis der Dinge bzw. ihrer Existenz (1921a, 32). Diese Wirklichkeit nennt Chwistek „Wirklichkeit der Dinge“ (,rzeczywistość rzeczy“).

Beide Wirklichkeiten, die für Chwistek gleichberechtigt nebeneinander stehen (1921a, 34), lassen sich weiter differenzieren: Wenn zwischen den Eindrücken von Dingen selbst und Assoziationen, Visionen, ja sogar Halluzinationen unterschieden werde, so zerfalle die „Wirklichkeit der Eindrücke“ in die „Wirklichkeit sinnlicher Eindrücke“ oder „Wirklichkeit

\footnotetext{
- „Die Unterschiede zwischen den Typen der Malerei entsprechen strikt den Unterschieden zwischen den Typen der Wirklichkeit."
} 
der Psychologen“ („rzeczywistość wrazeń zmysłowych“ oder „rzeczywistość psychologistów") und in die „Wirklichkeit reproduzierter Eindrücke“ (,rzeczywistość wrażen reprodukowanych“) oder "visionäre Wirklichkeit" (,rzeczywistość wizjonerów"). Die "Wirklichkeit der Dinge“ hingegen ließe sich laut Chwistek (vgl. 1918, 30 bzw. 38) in die „populäre Wirklichkeit“ (,rzeczywistość popularna“) und in die „physikalische Wirklichkeit“ (,rzeczywistość fizyki“) unterteilen, je nachdem, ob die Frage nach den Dingen selbst oder nach dem Verhältnis zwischen Ding, Lichtquelle und Betrachter als wichtiger angesehen wird. Für die ,physikalische Wirklichkeit" sei es von Bedeutung, dass die Welt aus (unsichtbaren) Atomen besteht. Auf diese Art bestimmt Chwistek 1918 in „Die Vielfalt der Wirklichkeiten in der Kunst“ vier Typen der Wirklichkeit. Drei Jahre später kommt er darauf in seiner längeren Abhandlung „Die Vielfalt der Wirklichkeiten“ wieder zurück. In diesem Text, der von seinem Charakter her einer philosophischen Studie nahe kommt, bemüht sich Chwistek um eine widerspruchsfreiere Definition der vier Wirklichkeiten. Außerdem beschäftigt er sich mit methodologischen Fragen und mit dem Vergleich seines Ansatzes mit anderen philosophischen Wirklichkeitstheorien. Er sucht dabei nach Axiomen und Axiomsystemen, die die vier Wirklichkeiten möglichst eindeutig bestimmen können. Um die bisherige Darstellung von Chwisteks Theorie zu ergänzen, möchte ich an dieser Stelle noch auf drei Aspekte aus „Die Vielfalt der Wirklichkeiten“ (1921) verweisen, ohne seine Argumentation zur Gänze nachzuvollziehen? ${ }^{7}$ Dies betrifft folgende Punkte: Chwisteks Begriff der Wirklichkeit, seine Unterscheidung zwischen den "Wirklichkeiten der Eindrücke“ und denen der "Dinge" sowie die Unterscheidung zwischen den beiden Eindruckswirklichkeiten. Dadurch scheint es im Anschluss daran besser möglich, die Wirklichkeiten, entsprechend Chwisteks zuvor zitierter These, mit den jeweiligen Typen der Malerei in Verbindung zu bringen ${ }^{8}$.

Chwistek operiert in "Die Vielfalt der Wirklichkeiten“ (1921) bei seinem Versuch, die jeweiligen Wirklichkeiten definierende Axiome festzulegen, vor allem mit den Begriffen „unmittelbar gegeben“ (,bezpośrednio dane“) bzw. „sichtbar“ („widzialne“):

„[...] , $x$ jest bezpostrednio dane' jest bardzo ogólnikowe i moze stosować sie do róznych przedmiotów, a w szczególności zarówno do wrazeń, jak do rzeczy. To samo odnosi się do okreslenia ,x jest widzalne', które stosować mozemy zarówno do rzeczy, jako do kompleksów wrazeń względnie stałych." (Chwistek 1921 a. $57)^{9}$

\footnotetext{
${ }^{7} \mathrm{Zu}$ einer Besprechung von Chwisteks Ansatz, mittels bestimmten Axiomen und deren Kombinationen die einzelnen Typen der Wirklichkeit năher zu bestimmen vgl. Kostyrko 1995, 29-38.

Die Ausfuhrungen zu Chwisteks Axiomen statzen sich auf: Chwistek 1921a, 51-56.

'.....],$x$ ist unmittelbar gegeben' ist sehr allgemein und kann sich auf verschiedene Gegenstande beziehen, im Besonderen aber gleichermaßen auf Eindrocke. wie auf Dinge. Dasselbe gilt auch fir die Bezeichnung $x$ ist
} 
Da Chwistek, wie sich auch an dieser Stelle zeigt, "Wirklichkeit“ im Gegensatz zum Scheinbaren begreift, ist das für ihn „wirklich“, was (sinnlich) erfahrbar oder sichtbar (in jeder erdenklichen Form) ist. Dies trifft gleichermaßen auf Gegenstände, als auch auf Gefuhle, Visionen etc. zu.

Bei der Unterscheidung, um nun zum zweiten Aspekt zu kommen, zwischen den beiden "Wirklichkeiten der Eindrücke“ und denen der "Dinge“ bestimmt Chwistek für die "Wirklichkeit sinnlicher Eindrücke“ sowie für die „visionäre Wirklichkeit” folgendes Axiom: In diesen Wirklichkeiten sei wirklich, was erfahrbar (direkt gegeben) oder sichtbar sei. Im Unterschied dazu könne diese Annahme nicht uneingeschränkt auf die beiden „Wirklichkeiten der Dinge“" (,populäre Wirklichkeit“ und ,physikalische Wirklichkeit") bezogen werden, da in diesen Wirklichkeiten gelte, so Chwistek. dass bestimmte wirkliche Gegenstände nicht erfahrbar (direkt gegeben) bzw. nicht sichtbar seien. So wird in ihrem Falle die Existenz der Gegenstände nicht über die visuelle Erfahrung, sondem mittels des Kriteriums des ,.common sense" oder basierend auf dem atomaren Aufbau der Welt bestimmt.

Und drittens sieht Chwistek den Unterschied zwischen den beiden „Wirklichkeiten der Eindrücke“ vor allem darin gegeben, dass für die „visionäre Wirklichkeit” vor allem Visionen. Träume etc. eine Rolle spielen, während die „Wirklichkeit der sinnlichen Eindrücke“ mehr auf Impressionen von konkreten Gegenständen basiert.

Chwistek selbst räumt in „Die Vielfalt der Wirklichkeiten“ (1921) ein, dass es ihm noch nicht gänzlich gelungen sei, den Begriff der „Wirklichkeit” widerspruchsfrei zu bestimmen und dass die vier von ihm erkannten Wirklichkeiten vor allem zeigen sollten. dass es eben auf unterschiedliche Arten möglich sei, diesen Begriff zu erfassen: "Znaczenie powyższych ukladów polega jedynie na tym, że wykazują one niezbicie wielość sposobów pojmowania rzeczywistości." (1921a, 56) ${ }^{10}$. In dieser Formulierung wird deutlich, dass es Chwistek um vier grundlegende Wirklichkeitstypen geht, das heißt im Prinzip um vier eigenständige Wirklichkeiten. Diese vier Typen stehen nicht für eine bestimmte Interpretation einer einzigen Wirklichkeit, sondern sie repräsentieren die vier grundlegenden Möglichkeiten. „Wirklichkeit“ überhaupt zu definieren, je nachdem ob dabei der Schwerpunkt auf die Dinge selbst. die Impressionen oder die Visionen gelegt wird.

Um nun seine These, dass die Unterschiede zwischen den einzelnen Typen der Malerei, den Unterschieden zwischen den einzelnen Wirklichkeiten entsprechen, zu begründen, versucht

sichtbar', die wir gleichermaßen auf Dinge, wie auch auf Komplexe relativ bestăndiger Eindrucke anwenden konnen." Vgl. dazu auch: 52. 
Chwistek in "Die Vielfalt der Wirklichkeiten“ (1918) zu zeigen, dass ein bestimmter Malereityp auf eine bestimmte Wirklichkeit zurückgreift und diese künstlerisch zum Ausdruck bringt ${ }^{\prime \prime}$. Für Chwistek war der Zusammenhang zwischen Kunst und (einer bestimmten) Wirklichkeit, wie zu Beginn dieses Abschnittes ausgeführt, ja grundlegend gegeben. Er versuchte mit dieser Theorie eine Systematik für die gesamte kunstgeschichtliche Entwicklung zu entwerfen, wenngleich es ihm im Besonderen darum ging, die neuesten Strömungen in der Kunst - und damit auch den Formismus - verständlicher zu machen (vgl. 1919a, 96 und 1921a, 35) $)^{12}$.

Chwistek ordnet nun den vier Wirklichkeiten die vier Typen der Malerei: Primitivismus, Realismus, Impressionismus und Futurismus - verstanden als Sammelbezeichnung für die „neueste Kunst”, die noch eine "Sache der Zukunft” sei - zu (vgl. 1918, 34-45). Den primitiven Maler, der sich in der „populären Wirklichkeit“ bewegt, interessieren vor allem die Dinge als solche - die wichtigste Anforderung, die an seine Malerei gestellt wird, ist die Wiedererkennbarkeit des Dargestellten. Der realistische Künstler geht von der „physikalischen Wirklichkeit" aus und will das malen, was er sieht, weiß jedoch zugleich um dessen Unmöglichkeit: zum einen aufgrund der von Licht, Perspektive etc. bewirkten Veränderbarkeit seiner Eindrücke, zum anderen, da die Atome, aus denen die Welt besteht, nicht gesehen werden können und somit auch die Dinge im Prinzip unsichtbar sind, das heißt visuell nicht erfassbar sind. So malt er zwar aufgrund seiner langen Betrachtung. jedoch nicht das, was er sieht (da sich das ja ständig verändert), sondern gewissermaßen die Summe, das Ergebnis davon. Außerdem orientiert er sich nicht, wie etwa der primitive Künstler, an bekannten Darstellungsmustem. Den Impressionisten wiederum interessieren nicht die Dinge als solche, sondem vielmehr seine Eindrücke von ihnen, weshalb dieser Malereityp der "Wirklichkeit der sinnlichen Eindrücke" entspricht. Das Ziel des Impressionisten ist es, einen bestimmten Moment, seinen bestimmten Eindruck von etwas künstlerisch wiederzugeben.

\footnotetext{
10 „Die Bedeutung obiger Systeme beruht einzig darauf, dass sie unwiderlegbar die verschiedene» Moglichkeiten, die Wirklichkeit zu erfassen, beweisen." Vgl. auch: 51-52.

"Chwistek prazisiert dies an manchen Stellen insofern, dass ein bestimmtes Kunstwerk immer nur auf eine Wirklichkeit zurackgreifen kann und knupft daran sogar ein mogliches Kriterium fur die Unterscheidung zwischen Kunst und Nicht-Kunst: „Koniecznym warunkiem, zeby dany utwór byl dziełem sztuki, jest to, azeby jego forma zaczerpnięta była z jednej rzeczywistości." (1921a, 97). „Entscheidendes Kriterium dafur, ob ein bestimmtes Werk als Kunstwerk angesehen werden kann, ist, dass seine Form aus einer Wirklichkeit entnommen wurde."

12 Außerdem schreibt Chwistek zu diesem Aspekt: „Równocześnie [=razem z teoria wielości rzeczywistości; M.E.] bedziemy mogli usprawiedliwić wszystkie wielkie szkoły malarskie, od począku historii do chwili obecnej.” (1921a, 35). .Gleichzeitig [=mit der Theorie der verschiedenen Wirklichkeiten: M.E.] werden wir alle großen Schulen der Malerei, vom Anfang der Geschichte bis zur heutigen Zeit, rechtfertigen konnen." Kostyrko bemerkt $(1995,114)$ in diesem Zusammenhang, dass Chwistek neben: "Theoretiker des Formismus" gleichermaßen als .. Thenretiker der A vantgarde" bezeichnet werden !.రnne.
} 
Der "Wirklichkeit der Visionäre“ ordnet Chwistek schließlich die neueste, die „futuristische“ Malerei zu. Hier geht es in erster Linie um Vorstellungen, Visionen, Träume, psychische Zustände etc., die der „Futurist“" entwickelt (zum Teil inspiriert von der äußeren Welt) und die er künstlerisch darstellen möchte. Chwistek beschreibt damit eine zum Beispiel dem Expressionismus nahe stehende Auffassung von Kunst. Nach dieser beruht das künstlerische Schaffen nicht mehr auf Mimesis, sondern darauf, dass der Künstler seine Reaktion auf bestimmte Eindrücke, seine Gefühle, also sein „Inneres“ zum Ausdruck zu bringen versucht. Es geht also, auch bei Chwistek, der ein so verstandenes künstlerisches Schaffen auf die "visionäre“ Erfassung der Wirklichkeit bezieht, um dessen Rechtfertigung als eine vom Künstler ausgehende schöpferisch-kreative Leistung.

Im Aufsatz „Die Vielfalt der Wirklichkeiten“ (1918) setzt sich Chwistek also zum ersten Mal mit dem Verhältnis zwischen Kunst und Wirklichkeit auseinander und arbeitet auch den Zusammenhang zwischen Formismus und „visionärer Wirklichkeit" aus ${ }^{13}$. Dass er dabei in seinen Ausführungen. gerade was das künstlerische Schaffen. das er auf die „visionäre Wirklichkeit* bezieht, noch sehr allgemein bleibt, begründet er selbst damit, dass sowohl diese Wirklichkeit selbst, als auch die mit ihr zusammenhängende Malerei erst im Entstehen begriffen seien (vgl. 1918, 44-45). In den folgenden Jahren kehrt Chwistek aber immer wieder zu diesen Problemen zurück und versucht die von ihm 1918 entwickelten Ansätze zu prăzisieren, zum Beispiel in der schon angesprochenen Studie „Die Vielfalt der Wirklichkeiten“ von 1921. Im ihrem siebten Kapitel, das wiederum den Titel „Die Vielfalt der Wirklichkeiten in der Kunst" trägt, rekapituliert Chwistek noch einmal die vier Wirklichkeiten und die ihnen entsprechenden Typen der Malerei. Er betont dabei, dass die „visionäre Wirklichkeit“" in ganz Europa an Bedeutung gewinne, wenngleich sie noch nicht vollstăndig entwickelt sei. Chwistek sieht darin jedoch keinen Mangel. sondern die Begründung dafür, dass in der zeitgenössischen Kunst mehrere Strömungen parallel entstehen hătten können. Futurismus, Kubismus, Expressionismus und auch Formismus basieren somit auf einer gemeinsamen Wirklichkeit, konzentrieren sich im Falle der künstlerischen Darstellung jedoch auf jeweils unterschiedliche Aspekte. Während sich zum Beispiel die Futuristen mit der Dynamik beschäftigten, so sei für die Formisten in erster Linie die

\footnotetext{
${ }^{13}$ Ich verwende hier, im Sinne einer einheitlichen Begriffichkeit, die Bezeichnung „Formismus", auch wenn Chwistek in diesem Aufsatz noch von „Futurismus" spricht. Dies hat unter anderem auch damit zu tun. dass Chwisteks Artikel bereits im Januar 1918 erschien, die Gruppe den Namen ..Formisten", wie beschrieben, aber erst einige Monate spăter annahm.
} 
Integration von Visionen, Bildern etc. dieser Wirklichkeit in eine sich an der Form orientierende Kunst von Bedeutung ${ }^{14}$.

Die besondere Bedeutung der "visionären Wirklichkeit“ für die (formistische) Kunst sieht Chwistek vor allem in der unglaublichen Füle der imaginierten Bilder, in der großen Anzahl möglicher Visionen etc. gegeben (1921a, 89). Um zu erklären, wie diese Visionen entstehen können, fuhrt Chwistek den Begriff des „anormalen Sehens“ („widzenie anormalne“) ein und verweist auf das von Hermann Bahr beschriebene „,innere Sehen“ (vgl. 1921a, 67-69 und 89$90)^{15}$.

Bahr, bereits einer der wichtigsten Theoretiker der europäischen Moderne, schreibt darüber in seinem Buch „Expressionismus“. Sehen, so Bahr $(1920,51)$, bestehe immer aus zwei Tătigkeiten. einer äußeren, der bloßen Wahrnehmung und einer inneren, der Verarbeitung der Eindrücke. Im Abschnitt „Das Auge des Geistes“ kommt Bahr genauer auf das innere Sehen zu sprechen und beruft sich dabei auf die Studie von Sir Francis Galton „Inquiries into Human Faculty and its Development" von 1883 sowie auf eine Arbeit von Goethe, die dieser über den Aufsatz „Sehen in subjektiver Hinsicht“ von Purkinjes schrieb. Galton, so Bahr, beschreibe das innere Sehen als die Fähigkeit mancher Menschen, ihnen bekannte Gegenstände auch dann erblicken zu können, wenn diese nicht gegenwärtig seien, auch mit geschlossenen Augen, durch die reine Willenskraft $(1920,78)$. Wenngleich sich diese Eindrücke, was ihre Intensität betreffe, nicht von „normalen“ optischen Eindrücken unterscheiden würden, gebe es doch - und gerade dieser Punkt scheint auch für Chwistek von Bedeutung - einen wesentlichen Unterschied zwischen dem äußeren und dem inneren Sehen:

.....] manche sehen mit dem Auge des Geistes mehr, als das Auge des Leibes jemals sehen kann: das geistige Bild enthălt zuweilen mehr, als ein sinnliches jemals enthaiten kann. Sie kơnnen nămlich mit dem Auge des Geistes auf einmal sehen, was sie sonst bloß nacheinander sehen: sie sehen mit dem Auge des Geistes alle vier Seiten eines Warfels, eine ganze Kugel auf einen Blick. [...] Womit also bewiesen ware, daß dieses geistige Sehen [...] mehr als ein bloßes Erinnern oder ein bloßes Reproduzieren des sinnlichen Sehens, daß es ein eigenes Produzieren ist, daß das geistige Sehen eine schaffende Kraft hat, die Kraft, eine Welt nach anderen Gesetzen zu schaffen als den Gesetzen des sinnlichen Sehens." (Bahr 1920, 83-84)

Was an diesen Zeilen Bahrs für Chwistek wichtig schien, war die Betonung sowohl dei Höherwertigkeit des inneren Sehens gegenüber einer „normalen Wahrnehmung“, da es zu ungleich mehr Eindrücken füren kann, als auch des produktiven Charakters dieser Form der

\footnotetext{
${ }^{14} \mathrm{Vgl.} \mathrm{.....],} \mathrm{formiści} \mathrm{zwrócili} \mathrm{uwage} \mathrm{na} \mathrm{niezwykłą} \mathrm{jej} \mathrm{[=rzeczywistości} \mathrm{wizjonerów;} \mathrm{M.E.]} \mathrm{giętkośc} \mathrm{i} \mathrm{płynąca}$ stad zdolnośc przystosowania sie do problemów czysto formalnych." (1921a, 89-90). „[...], die Formisten achteten vor allem auf ihre [=die Wirklichkeit der Visionare; M.E.] ungewohnliche Biegsamkeit und die daraus resultierende Făhigkeit, sich rein formalen Problemen anzupassen."

is Das .. anormale Sehen" beruht fulr Chwistek nicht auf der bloßen Wahmehmung, sondem auf einem eigentamlichen Verhălmis, im Sinne eines Bezug-Nehmens zu einer Erscheinung („osobliwe odniesienie sie do zjawiska" - 1921a, 67), streicht also auch die individue!le Verabeitung von Sinneseindrucken hervor.
} 
Wahmehmung. Auch für Chwistek beruht die (visionäre) Betrachtung eines Gegenstandes darauf, sich regelrecht in diesen zu vertiefen, sich in diesen „hineinzufuhlen“ - ein Erlebnis, das an die Kontemplation erinnert. Wichtig ist dabei jedoch, dass die dadurch entstehenden Bilder und Visionen nicht mehr unmittelbar an den konkreten Gegenstand gebunden sind, wie dies noch bei den Impressionen der Fall war. Sie sind in einem gewissen Sinn eigenständiger und hängen vor allem stärker vom Betrachter ab. Dies betont auch Bahr: „[...] das geistige Sehen ist mehr individualisiert als das sinnliche, weil ja das Individuum selbst am inneren Sehen mehr beteiligt ist als am äußeren." (1920. 84). Ebenso, so Bahr, produziere das innere Sehen Visionen, Erscheinungen, die nicht mehr dem menschlichen Willen gehorchten, sondern von selbst entstünden $(1920,88)$.

Das künstlerische Schaffen beruht nun für Chwistek auf der Darstellung dieser Visionen oder Bilder: „I on [=futurysta (formista); M.E.] musi notowac to, co znajduje we wrażeniach $[\ldots]^{\omega .16}$, schreibt Chwistek in „Die Vielfalt der Wirklichkeiten in der Kunst“ $(1918.43)$ und sechs Jahre später bezeichnet er in einem Aufsatz mit demselben Titel den Formismus als jene Kunst, die auf einer „konkretisierten Vision“ (.,skonkretyzowana wizja“) beruht (1924, 11). Und in „Tytus Czyżewski und die Krise des Formismus“ geht Chwistek darauf am konkreten Beispiel der Malerei von Czyżewski noch einmal ein:

\begin{abstract}
.Formizm [...] oglosil swoja niezaleznośc od obowiazującej rzeczywistosci, tworzac spontanicznie rzeczywistośc wlasna te wlaśnie, która jako taka nieodparcie narzuca się antyście. Jeśli np. analizować zechcemy takiego Zbójnika lub Madonne Czyżewskiego, zobaczymy, ze jest tak właśnie, a nie inaczej. Ktoss, kto by idac za Witkiewiczem sadzil, ze Czyzewski pojmuje zbojjnika tak, jak to przedstawiaja np. fotografie w Kurierze llustrowanym, a następnie ,deformuje' go dla celów dekoracyjnych, bylby w grubym blędzie. Czyzewski, jak kazdy prawdziwy artysta. jest najzupetniej szczery i maluje zbójnika takiego. jak go sobie wyobraza. innymi stowami, jakiego spotyka w rzeczywistosci. Ale o to właśnie idzie. ze rzeczywistośc Czyzewskiego jest czymś zupelnie innym niz ta, z która mają do czynienia ludzie przeciętni. Može nie jest piękna, moze nawet jest okropna, ale jest inna." $(1922 \mathrm{~b}, 108)^{17}$
\end{abstract}

\footnotetext{
16 "Auch er [=der Futurist (der Formist); M.E.] muss das notieren, was er in den Eindrucken findet [...]."

17 „Der Formismus [...] verkundete seine Unabhangigkeit von der herrschenden Wirklichkeit, indem er spontan seine eigene Wirklichkeit schuf, nămlich jene, die sich als solche dem Künstler unwiderstehlich aufdrăngt. Wenn wir zum Beispiel den Răuber oder die Madonna von Czyzewski analysieren wollen, sehen wir, dass es so und nicht anders ist. Jemand, der der Meinung von Witkiewicz folgend glaubte. Czyzewski erfasse den Rauber so. wie ihn zum Beispiel eine Photographie im Illustrierten Kurier darstellt und .deformiere' ihn anschließend fur dekorative Ziele, ime gewaltig. Czyzewski ist, wie jeder wirkliche Künstler, vőllig ehrlich und malt den Răuber, den er sich vorstellt, mit anderen Worten, den er in der Wirklichkeit triff. Aber genau darum geht es, dass Czyzewskis Wirklichkeit eine vollig andere ist als jene, mit der die durchschnittlichen Leute zu tun haben. Sie ist vielleicht nicht schon, vielleicht sogar schrecklich, aber sie ist anders." Die in diesem Zitat anklingende „Exklusivitat” der „visionăren Wirklichkeit” verneint Chwistek an anderer Stelle (1921a, 78-80), mit der Begrondung, dass, wenn es um eine Form des inneren Erlebens gehe, niemand von sich behaupten konne, tiefer oder intensiver zu fuhlen als andere. Dies fuhre letztendlich nur zu einer extremen Form des Subjektivismus. Diese Bemerkung kann auch als gegen Witkacy gerichtet verstanden werden, der das „metaphysische Gefuhl“" (vgl. dazu in den năchsten Abschnitten) ja nur für eine kleine Gruppe von Menschen, vor allem Kunstler, als erlebbar beschrieb.
} 
Hier streicht Chwistek, stärker als bisher, die Bedeutung der "visionären Wirklichkeit", die er in diesem Zitat im Gegensatz zur alltäglichen - zur „populären“ - begreift, für die Kunst hervor und zeigt am Beispiel von Czyżewskis Malerei, dass die künstlerische Darstellung immer auf der Erfassung dieser Wirklichkeit beruht („Czyżewski malt den Räuber, den er sich vorstellt, den er in der Wirklichkeit triff" ${ }^{18}$. Es geht also um die Darstellung der Visionen oder Vorstellungen des Künstlers, gegenüber denen das Objekt (der Betrachtung) in den Hintergrund tritt und nicht um eine „kalkulierende“, geplante Deformation von ursprünglich realistisch Erfasstem. Einmal bestimmt Chwistek sogar das Finden und Entwickeln von Visionen als das eigentliche künstlerische Schaffen, dem gegenüber er die konkrete Umsetzung dieser Visionen als Bild oder als Plastik als „zweitrangige Tătigkeit“ („czynność drugorzęna") bezeichnet ${ }^{19}$.

Als eine der wesentlichsten Gemeinsamkeiten zwischen den einzelnen Formisten bestimmt Chwistek in "Der Formismus“ (vgl. 1919a, 96-98) ihren Rückgriff auf die „visionäre Wirklichkeit". Denn besonders diese Wirklichkeit, dank der Fülle ihrer Visionen, Bilder etc., erlaubte es ihnen, nach immer neuen Möglichkeiten zu suchen, sie künstlerisch darzustellen. Und gerade die Visionen dieser Wirklichkeit lassen sich, wie zuvor gezeigt, am besten mit den formalen Aufgaben, die sich die Formisten für ihre Kunst stellten, zusammen bringen.

Neben Chwistek, für den die Beziehung zwischen Kunst und Wirklichkeit im Zentrum seiner ästhetischen Überlegungen stand, beschaftigte sich auch Zbigniew Pronaszko mit dieser Frage, und zwar in seinem Text „Über den Expressionismus“, der gemeinsam mit Chwisteks „Die Vielfalt der Wirklichkeiten in der Kunst” im Januar 1918 in der Zeitschrift „Maski“ („Die Masken“) veröffentlicht wurde. Es ging inm dabei explizit um die Frage, wie der „expressionistische Künstler" seine Eindricke, die er beim Betrachten zum Beispiel der Gegenstände gewinnt, künstlerisch verarbeitet. Dabei beschreibt Pronaszko eine ähnliche Form der Wahrnehmung dieser Gegenstände wie zuvor Chwistek: „[...] wystarczy wyobrazić sobie jakiś znany przedmiot: $z$ całą pewnością przypomni on nam się tysiącem swych oblicz.“

\footnotetext{
18 Auch Bahr betont: „Wenn wir, was wir sonst mit den Augen des Leibes sehen, nun mit den Augen des Geistes betrachten, erblicken wir eine Welt. die uns an jener gemessen, deformiert scheint; sie weicht von jener ab." $(1920,84)$.

19 "Twórczosć artysty polega na tym, ze w chaosie danych bezpośrednich, dostarczanych mu przez rzeczywistosć, odnajduje nowe kszzałty i nowe zestawienia tychže. Oddanie tych zestawien na płótnie czy w kamieniu jest juz czynnością drugorzędna, będąca $w$ zwiazku jedynie $z$ mniejsza lub większa wprawa techniczna." (Chwistek 192 la, 96). „Das Schaffen des Kunstlers beruht darauf, dass er im Chaos des ihm unmittelbar von der Wirklichkeit Gegebenen, neue Gestalten und neue Zusammenstellungen von ihnen entdeckt. Die Wiedergabe dieser Zusammenstellungen auf der Leinwand oder im Stein ist bereits eine zweitrangige Tatigkeit, die nur mit einer kleineren oder großeren technischen Fertigkeit zu tun hat." Pollakowna spricht in diesem Zusammenhang treffend davon (1972, 123), dass Chwisteks Modell des Schaffensprozesses auf der "Vereinignng des Knnstlers mit der Wirklishkeir" (.rzjednoczenie artysty z rzeczywistoscia“) beruhs.
} 
$(1918,16)^{20}$. Diese unterschiedlichen, von Licht, Perspektive etc. abhängigen, das heißt insgesamt zufalligen Eindrücke, die Chwistek zum Ausgangspunkt für die Bestimmung der „visionären Wirklichkeit“" macht, nennt Pronaszko „Gestalten“ (,kształty“):

„Forma nazywam konwencyę, w jaką ujmuje dany ksztah: kszaltem: wyglad jakiegokolwiek ciała przestrzeni np. skrawek błękitnego nieba wśród obłoków, plamę światła na czole, drzewo, cień drzewa i t.p. Kształ, jako wyraz natury, jest zależny od okolicznosci i otoczenia, więc przypadkowy; forma jest stała, jako wyraz twơrczosci." (1918. 15)

Die Aufgabe der Kunst sei es nun, diese Gestalten eben durch künstlerische Formen zu erfassen, um sie damit letztendlich in die Komposition des Kunstwerks eingliedern zu können. Da diese Komposition auf der Harmonie ihrer einzelnen Teile beruhe, müssen diese aufeinander abgestimmt sein. Dies sei durch die Zufalligkeit der Gestalten a priori ausgeschlossen und erst durch die vom Künstler entwickelten Formen möglich: „Celem [=malarstwa (sztuki); M.E.] jest wyraz [...] reagując na kształty, jakie się nam narzucają przy rozpatrywaniu przedmiotu. Dla tego wyrazu znaleść formę jest istotnem zadaniem malarstwa [...]." (Z. Pronaszko 1918, 15) 22 .

Die Ausfuhrungen Chwisteks und Pronaszkos machen verständlich. warum sie den Formismus als nicht-gegenständliche, nicht-figurative Kunst begriffen. Chwistek beschreibt dies mit den vom Betrachter (Künstler) entwickelten Visionen, die sich zunehmend von einem konkreten Gegenstand entfernen, Pronaszko bestimmt es als die Aufgabe der Kunst. die Eindrücke durch Formen zu erfassen. wodurch er die Kunst selbst unabhängiger von der Wirklichkeit begreift, als zuvor Chwistek (vgl. Pollakówna 1972. 121). Hierdurch entfernt sich der Formismus von der mimetischen Kunst des Naturalismus und Realismus, der für Chwistek ja auch auf eine andere Wirklichkeit zurückgriff. So betonen die Formisten immer wieder, dass es ihnen nicht darum gehe, die Wirklichkeit nachzuahmen, zu kopieren oder gar zu idealisieren. Im Gegensatz dazu begriffen sie Kunst als produktives Schaffen, das mit der Wirklichkeit zwar zusammenhängt, jedoch auf eigenen Prinzipien beruht, was sich vor allem in der Form und der Komposition des Kunstwerks manifestiert. Pronaszko schreibt bereits in

20 „[...] es genagt, sich irgendeinen bekannten Gegenstand vorzustellen: ganz bestimmt wird er sich uns durch tausend seiner Ansichten in Erinnerung rufen."

21 .Als Form bezeichne ich die Konvention, mit der ich eine bestimmte Gestalt erfasse; als Gestalt: das Aussehen irgendeines Korpers im Raum, zum Beispiel ein Stack blauer Himmel zwischen Wolken, ein Lichtfleck auf der Stim, ein Baum, der Schatten eines Baumes usw. Die Gestalt, als Ausdruck der Natur, ist von der Situation und der Umgebung abhăngig. also zufallig: die Form ist konstant. als Ausdruck des Schaffens."

22 .Das Ziel [= der Malerei (Kunst); M.E.] ist ein Ausdruck [...], der auf die Gestalten reagiert, die sich uns bei der Betrachtung eines Gegenstandes aufdrăngen. Eine Form für diesen Ausdruck zu finden. ist die wichtigste Aufgabe der Malerei [...]." 
„Vor dem großen Morgen": „Natura jest Natchnieniem - przykladem dla tworzenia nowych form, nowych, dalszych kszałtów [...].“ $(1914,126)^{23}$.

\subsection{Zu Form, Komposition und Inhalt des Kunstwerks}

\subsubsection{Witkacy und die „Reine Form"}

Am intensivsten von allen Formisten setzte sich Witkacy mit der "Form" und deren Funktion im Kunstwerk auseinander. Er bestimmt sie dabei auf seine individuelle Weise, was sich vor allem im Begriff der „Reinen Form“ zeigt, der im Zentrum seines ästhetischen Systems steht. Seine Vorstellung vom künstlerischen Schaffensprozess unterscheidet sich aber von der von Chwistek und Pronaszko. Dies betrifft insbesondere den Ursprung des künstlerischen Schaffens:

,$Z$ jednej strony musi artysta być cały takim, jakim jest, $\mathbf{z}$ drugiej - musi być Czysta Forma; $\mathbf{z}$ jednej strony to, co nazywaliśmy metafizycznym uczuciem, z drugiej - czyste jakości złączone jedna idea która zamienia chaos w jednośc nierozerwalna. Co się dzieje między tymi dwoma momentami, jest tajemnica twórców, która na prózno staraja się zgłębić biografowie i krytycy, wprowadzani często w błąd przez zeznania osobiste swoich pacjentów." (Witkiewicz 1919a, 58)

Dieses Zitat stammt aus „Die neuen Formen in der Malerei und die daraus entstehenden Missverständnisse", Witkacys erstem großen kunsttheoretischen Text, den er während seiner Zeit in Petersburg, zwischen 1914 und 1918, verfasst hat. Dass dieser Text in der vorliegenden Arbeit im Zusammenhang mit dem Formismus gelesen wird, ist dadurch begründet, dass sich Witkacy darin theoretisch mit Fragen einer nichtmimetischen, formorientierten Kunst beschăftigt und unter anderem auch wegen dieses Textes den Formisten im Sommer 1918 beitritt bzw. in die Gruppe aufgenommen wird ${ }^{25}$. Besonders in

\footnotetext{
${ }^{23}$ "Die Natur ist Inspiration - ein Vorbild fur die Schopfung neuer Formen, neuer weiterer Gestalten [...]."

24 "Auf der einen Seite muss der Kanstler ganz der sein, der er ist, auf der anderen - muss die Reine Form sein; auf der einen Seite das, was wir das metaphysische Gefuhl nannten, auf der anderen - reine Qualităten, verbunden durch eine Idee, die das Chaos in eine unaufosbare Einheit verwandelt. Was zwischen diesen beiden Momenten passier, ist das Geheimnis der Schaffenden, das Biographen und Kritiker, of durch personliche Bekenntnisse ihrer Patienten in die Irre gefuhrt, vergeblich zu vertiefen suchen." Die Darstellung der Grundlagen von Witkacys Ästhetik muss sich im Rahmen dieser Arbeit auf das Notwendigste beschränken. Zu Witkacy und seiner Ästhetik liegen aber bereits eine Falle von Untersuchungen vor, in deutscher Sprache hat sich zum Beispiel Schmidt (1992, vgl. besonders: 43-119) damit ausfuhrlich befasst. Zu einer neueren polnischen Untersuchung vgl. Soin (1995, besonders: 117-163). Beide Autoren geben auch zahlreiche Hinweise auf weiterfuhrende Literatur.

${ }^{25}$ Mit dem Argument, den Text bereits vor der Grondung der Gruppe verfasst zu haben, reagierte Witkacy (1923c, 420) abrigens auch auf den Vorwurf von Chwistek (1922b, 109-1 10), der beklagte, dass Witkacy in „Die neuen Formen in der Malerej“ den Formismus mit keinem einzigen Wort erwshnt habe.
} 
den beiden ersten Kapiteln, der „Philosophischen Einleitung“ („Wstęp filozoficzny“) und in „Über die Reine Kunst“ („O sztuce czystej“), legt Witkacy sein Verständnis einer mit existenziellen Fragen verknüpften Kunst dar.

Das Modell, mit dem Witkacy das künstlerische Schaffen erfasst, beruht, wie das zuvor angefuhrte Zitat zeigt, im Wesentlichen auf zwei Elementen: auf der einen Seite steht der Künstler selbst bzw. das „metaphysische Gefühl“ (,uczucie metafizyczne“), auf der anderen Seite, gewissermaßen als das Ideal des Schaffens, die Komposition des Kunstwerks, als harmonische Geschlossenheit. Das „metaphysische Gefül” bzw. die "metaphysische Unruhe“ („niepokój metafizyczny“) ist für Witkacy der Ursprung, die Quelle der Kunst, wie auch von Philosophie oder Religion (vgl. 1919a, 16-21). Dieses unmittelbare Gefühl betrifft das Bewusstsein für das eigene Ich und lässt dieses Fragen nach seiner individuellen Existenz stellen, die vor allem die Beziehung seiner „Einzelexistenz“ („Istnienie Poszczególne“) zum „gesamten Sein“ („Całość Istnienia“) berühren ${ }^{26}$. Die an sich zutiefst beunruhigenden Fragen können im Falle der Kunst positiv wirken, das heißt den Impuls für künstlerisches Schaffen geben:

„O ile przeżywanic niepokoju metafizycznego samego w sobie može mieć zabarwienie nieprzyjemne [...], o tyle przezycia tego rodzaju, bezpośrednio wywołując twórczość artystyczna sa pozbawione przez jedność zobiektyzowana $w$ dziele szuuki, tego potwornego $w$ swej istocie uczucia samotności $i$ jedyności lstnienia Poszczególnego w nieskończonej calości lstnienia." (Witkiewicz 1919a. 20) ${ }^{27}$

Im Unterschied zur Religion, die die Schrecken der Existenz zu mildern und abzuschwächen versucht, ermöglicht es die Kunst, sich diesen zu stellen und sich damit auseinander zu setzen $^{28}$. Dabei ist es aber nicht das Ziel, diese Schrecken erträglicher zu machen. sondern dazu beizutragen, sie zu erkennen:

\footnotetext{
${ }^{26}$ Etwa schreibt Witkacy: „To poczucie jedności naszego ja', bezpośrednio dane [...] ležy u podstawy uczucia niepokoju metafizycznego [...]. Z uczucia tego rodzace sį pytania: ,Czemu ja jestem tym właśnie, a nie innym istnieniem? [...] dlaczego w ogóle istnieje? mógłbym nie istnieć wcale; dlaczego w ogóle coś jest?' [... $]^{\prime \prime}$ (1919a. 16-17). „Dieses Gefuhl der Einheit unseres .Ichs' ist unmittelbar gegeben [...] und bildet die Grundlage des Gefuhls der metaphysischen Unruhe. [...] Aus diesem Gefuhl heraus entstehen Fragen wie: ,Warum bin ich gerade diese und keine andere Existenz? [...] warum existiere ich aberhaupt? ich könnte oberhaupt nicht existieren; warum existiert Oberhaupt etwas?' [...]."

${ }^{27}$..So wie das Erleben der metaphysischen Unruhe fur sich selbst eine unangenehme Farbung haben kann [...]. sind Erlebnisse dieser Ar, die unmittelbar kunstlerisches Schaffen hervorrufen, durch die im Kunstwerk objektiviene Einheit von dem in seinem Wesen schrecklichen Gefuhl der Einsamkeit und Einmaligkeit der Einzelexistenz in der unendlichen Gesamtheit des Seins befreit."

28 An anderer Stelle schreibt Witkacy: .Zyjemy bowiem w epoce straszliwej, jakiej nie znala dotad historia [...]. $W$ formach sztuki naszej epoki jest prawda potwornosci naszego istnienia $i$ jest w nich ostatnie, ginące piękno. którego prawdopodobnie nic juz powrócić nie zdoła." (1919a, 37). ..Wir leben in einer schrecklichen Zeit, die die Geschichte bislang nicht kannte [...]. In den Formen der Kunst unserer Epoche ist die wahre Scheußlichkeit unserer Existenz und in ihnen ist auch das letzte, vergehende Schöne. das wahrscheinlich nie wieder zuruckgeholt werden kann."
} 
"Twórzośc arytstyczna jest bezpośrednim potwierdzeniem prawa samotności jako tego, za cenę czego istnienie $w$ ogóle jest mozliwym, $i$ to potwierdzeniem nie tylko dla siebie, ale $i$ dla innych Istnien Poszczególnych, tak jak ono samotnych; jest potwierdzeniem Istnienia w jego metafizycznej okropnosci, a nie usprawiedliwieniem tej okropności przez stworzenie systemu pojęc tagodzacych, jak to jest w religii, lub systemu pojęć wykazującego rozumowo koniecznosć takiego, a nie innego stanu rzeczy dla Calości Istnienia. jak to ma miejsce w filozofii." (Witkiewicz 1919a, 20-21)

Die Kunst kann somit für Witkacy dadurch auf die angesprochenen existenziellen Fragen des Ichs antworten, dass sie der Einzelexistenz das "Gefühl der Einheit in der Vielheit" („poczucie jedności w wielości“) vermitteln kann, wodurch wiederum die metaphysischen Gefühle, in diesem Fall aber positiver und weniger beunruhigend als zuvor, entstehen (vgl. 1919a, 20). Sowohl der Künstler während des Schaffensprozesses, als auch der Betrachter wăhrend seiner Rezeption eines Kunstwerks, können zu diesem „Gefühl der Einheit in der Vielheit", das Witkacy auch als „tiefe ästhetische Befriedigung“ („glębokie zadowolenie estetyczne") bezeichnet (1919a, 20), gelangen. Über die Fähigkeit der Kunst bzw. eines Kunstwerks, beim Schaffenden oder Rezipienten dieses existenzielle „Gefuhl der Einheit in der Vielheit" hervorzurufen, schreibt Witkacy:

Zasadniczym momentem glębszego estetycznego zadowolenia jest samo scałkowanie danej wielości w
jedności; na tym polega (a nie na odczytaniu anegdoty w obrazie [...]) zrozumienia danego dzieła szzuki. [...]
Do pewnej granicy im większa bedzie komplikacja danej konstrukcji elementów, tym większa będzie i
glębsza estetyczna przyjemnośc scałkowania jej, czyli estetycznego zrozumienia; tym silniej bęzzie
odczuwana jedność tączaca te elementy, tym wyrániej wystąpi w naszym trwaniu metafizyczne uczucie."
$(1919 a, 28)^{j 0}$

Wie im Falle der existenziellen Fragen, geht es also auch in der Kunst um das Gefüh der Einheit, der (gelungenen) Integration von „Einzelstücken“ in ein geschlossenes Gesamtes, womit im Falle des Kunstwerks dessen Komposition gemeint ist ${ }^{31}$. Die Komposition eines

29 „Das künstlerische Schaffen ist die direkte Bestătigung des Gesetzes der Einsamkeit, für dessen Preis die Existenz aberhaupt moglich ist, und zwar eine Bestătigung nicht nur fur einen selbst, sondern auch fur andere Einzelexistenzen, die ebenso einsam sind; es ist die Bestătigung der Existenz in ihrer metaphysischen Schrecklichkeit, jedoch nicht die Rechtfertigung dieser Schrecklichkeit durch das Schaffen eines Systems mildernder Begriffe, wie in der Religion, oder eines Begriffssystems, das rational die Notwendigkeit, dieses und keines anderen Zustandes für die Gesamtheit des Seins erklärt, wie dies in der Philosophie der Fall ist."

30. .Der grundlegende Moment einer tieferen asthetischen Befriedigung ist schon alleine die Integration einer bestimmten Vielheit in eine Einheit; darauf beruht (und nicht auf dem Herauslesen einer Anekdote [...]) das Verstehen eines bestimmten Kunstwerks. [...] Je komplizierter - bis zu einer gewissen Grenze - eine bestimmte Konstruktion von Elementen ist, desto großer und tiefer wird das asthetische Vergnugen sein, sie zu integrieren, das heißt sie asthetisch zu verstehen; desto stäker wird die Einheit, die diese Elemente verbindet, empfunden, desto deutlicher entsteht in unserem Dauern das metaphysische Gefuhl.“ Vgl. auch: „Im większa będzie ilosć podzialów i nierównowaga przy jednoczesnej koniecznosci calkowania tej wielości w jednośc, tym silniejsze będzie uzcucie jedności. co jest celem Czystej Szzuki.” (1919a, 44). „Je großer die Anzahl der Unterteilungen und das Ungleichgewicht bei gleichzeitiger Notwendigkeit, diese Vielheit in eine Einheit zu integrieren, sind, desto stäker wird das Gefuhl der Einheit, was das Ziel der Kunst ist.“

${ }^{31}$ Meiner Meinung nach verknopft Witkacy selbst im angefuhren Zitat kunstlerische und existenzielle Fragen. und zwar indem er in beiden Fallen das .Gefuhl der Einheit in der Vielheir" als entscheidend beschreibt. Aus diesem Grund teile ich nicht die Bedenken von Konstanty Puzyna, der diesbezaglich von zwei Kunsttheorien spricht (vgl. 1999, 123-125), nămlich einer „formistisch-ăsthetischen" und einer .expressionistischmetaphysischen" Allerdings komm! Puzyna letzendlich zu dem Schluss, dass es eben die "Reine Form“ sei, die 
Kunstwerks, die durch ihre Geschlossenheit die „metaphysischen Gefühle“, das heißt das "Gefühl der Einheit in der Vielheit" beim Künstler selbst und beim Rezipienten auslösen kann, nennt Witkacy (die) "Reine Form“: „[...] Czysta Forma (jak bęziemy nazywać konstrukcje jakości stanowiąca jedność w wielości).“ $(1919 a, 26)^{32}$. Damit wird nun Witkacys Modell, das zu Beginn dieses Abschnittes zitiert wurde, verständlich: auf der einen Seite das .metaphysische Gefühl“, auf der anderen die „Reine Form“. Dazwischen liegt das Geheimnis der Schaffenden, das Kunsthistoriker und Kritiker fälschlicherweise mit biographischem Wissen zu erklären versuchen, was stets zum Scheitern verurteilt sein muss.

Witkacy selbst erweitert nun sein Modell des Schaffensprozesses um noch zwei weitere Elemente, die mit der Psyche des Künstlers zusammen hängen: die "Lebensgefühle“ (,uczucia życiowe ${ }^{\mu}$ ), das heißt der direkte Bezug zur außerkünstlerischen Wirklichkeit und der Intellekt (intelekt). Dieses Modell veranschaulicht er anhand konzentrischer Kreise, deren innersten Kreis die „metaphysischen Gefühle“ bilden, auf die die „Lebensgefühle“, der Intellekt und schließlich die „Reine Form“ folgen (1919a, 22-23). Ein konkretes Kunstwerk ist nun vom Verhältnis dieser vier Elemente zueinander abhängig: das .metaphysische Gefühl“ des Künstlers muss in den Sphären der ..Lebensgefühle” und des Intellekts reflektiert werden, bevor die „Reine Form“ entstehen kann:

\begin{abstract}
"Wskutek róznorodnosci jednak tych sfer, przez które przejsć musi fala metafizycznego uczucia, aby dostać sie do sfery Czystej Formy, ilość form, które moga powstać. jest teoretycznie nieograniczona. Samo metafizyczne uczucie nie ma wyrazu w Czystej Formie bez uprzedniej polaryzacji w całym świecic psychicznym danego osobnika. Powstanie więc dzieła stuki [...] załeży od proporcji tych 4 elementów." (Witkiewicz 1919a, 23)
\end{abstract}

Dadurch erklärt Witkacy, dass es letztendlich unterschiedliche Kunstwerke gibt, da das Verhältnis der vier Elemente sich von Fall zu Fall unterscheidet, obwohl das „metaphysische Gefühl“ im Prinzip immer dasselbe bleibt ${ }^{34}$, was so auch auf die .Reine Form“" (als gelungene Konstruktion) zutrifft. Ebenso gelingt es ihm, indem er die Sphäre der "Lebensgefühle“ in sein Modell einführt, den Bezug der Kunst zu (außerkünstlerischen) Wirklichkeit herzustellen, ohne diese zum eigentlichen Inhalt der Kunst zu machen. Denn ein Kunstwerk

\footnotetext{
Witkacys ontologisches und asthetisches Denken, wenn auch nur fur einen Moment, zu verbinden vermag. $\mathrm{Vgl}$. zu diesem Aspekt auch: Soin (1995, 120, 122 und 130), der sich an dieser Stelle auch mit Puzyna beschaftigt.

32 ......] Reine Form (so werden wir eine Konstruktion von Qualitaten nennen, die die Einheit in der Vielheit darstellt)." Vgl. auch: Witkiewicz 1922b, 186.

${ }^{33}$..Infolge der Vielfalt dieser Sphăren. durch die die Welle des metaphysischen Gefuhls hindurchlaufen muss. um in den Bereich der Reinen Form zu gelangen, ist die Anzahl der Formen, die entstehen konnen, theoretisch unbegrenza. Das metaphysische Gefuhl selbst findet keinen Ausdruck in der Reinen Form, ohne vorherige Polarisierung in der ganzen psychischen Welt eines bestimmten Individuums. Das Entstehen eines Kunstwerks [...] hăngt daher vom Verhàltnis dieser 4 Elemente ab."

* Vgl. .Uczucie to samo w sobie musimy przyjąc za jednakowe dla wszystkich Istnień Poszczególnych“ (1919a, 22). „Dieses Gefuhl an sich mussen wir als identisch fur alle Einzelexistenzen voraussetzen.”
} 
kann für Witkacy eben nicht allein über die Biographie des Künstlers erklärt werden. Der Rezeptionsprozess hingegen, verlaufe genau umgekehr - indem der Rezipient die „Reine Form" des Kunstwerks, den äußersten der konzentrischen Kreise begreift, erlebt er direkt die „metaphysischen Gefuhle“, wobei eine Reflexion in den übrigen beiden Sphären nicht mehr zwingend notwendig ist (1919a, 23). Ein Bild könne, so Witkacy, dann als gut bezeichnet werden, wenn es zumindest bei einem Rezipienten die ,metaphysischen Gefühle“ durch seine „Reine Form“ entstehen lässt (1919a, 105).

Das ästhetische Erlebnis selbst, das heißt die Erfassung einer Komposition als Einheit und das Entstehen der „metaphysischen Gefuhle“, bleibt für Witkacy letztendlich nicht erklärbar ${ }^{35}$. Als zentral gilt es dabei festzuhalten, dass er dieses ästhetische Erlebnis unmittelbar und nur mit der Form des Kunstwerks verbindet: „[...] forma dzieła sztuki jest jego jedyną treść istotna" (1919a, 21) ${ }^{36}$.

An diesem Punkt kann Witkacys Ansatz nun mit jenen von Chwistek und Pronaszko zusammengefuhn werden. Denn auch wenn sie, was das Entstehen des Kunstwerks betriff, von der Erfassung der Wirklichkeit und nicht von den „metaphysischen Gefühlen“ ausgehen. bestimmen sie, wie Witkacy, die Form als das ästhetisch Wesentliche des Kunstwerks. Alle drei Autoren versuchen außerdem, die Rolle einer außerkünstlerischen Wirklichkeit für die Entstehung eines Kunstwerks adäquat zu bestimmen und auch wenn sie hier unterschiedlich verfahren, so sind sie sich darin einig, dass es beim künstlerischen Schaffen nicht um Nachahmung dieser Wirklichkeit geht und gehen darf. Somit ist im Formalen der Berührungspunkı zwischen den einzelnen ästhetischen Ansätzen von Pronaszko, Witkacy und Chwistek gegeben, obwohl alle drei von unterschiedlichen Voraussetzungen ausgehen. Dieses formale Verständnis der Kunst sowie die sich daraus ergebenden Fragen nach der Komposition, der Form ihrer Einzelteile sowie der Beziehung von Form und Inhalt sind Gegenstand der weiteren Ausführungen. Da diese Fragen eng miteinander zusammenhängen, werden sie innerhalb eines Abschnittes gemeinsam behandelt.

\footnotetext{
3s "Moze to brzmieć parakdoksalnie, als twierdzimy, ze warunkiem glębokiego, estetycznego zadowolenia jest niemozność pojęciowego zdania sobie sprawy, dlaczego dana kombinacja jakości jest jednościa," (1919a, 26). „Es mag vielleicht paradox klingen, aber wir behaupten, dass die Bedingung fur eine tiefe, asthetische Zufriedenheit die Unmøglichkeit ist, sich begrifflich klar zu machen, warum eine bestimmte Kombination von Qualitaten eine Einheit darstellt." An anderer Stelle fuhr Witkacy auch aus, dass das subjektive Gefuhl des Einzelnen allein dafur verantwortlich sei, eine bestimmte Kombination als Einheit erfassen zu können: „Jednosć dzieła szuki jest formalna, niesprowadzalna i subiektywna." (1922a, 178). „Die Einheit des Kunstwerks ist formal, nicht herleitbar und subjektiv."

${ }^{36}$......] die Form des Kunstwerks ist dessen einziger wesentlirher Inhalt "
} 


\subsubsection{Die Form als Ausdruck des künstlerischen Schaffens (zum Begriff der Form)}

Witkacy kommt 1919, ein Jahr nach der Veröffentlichung seiner Studie „Die neuen Formen in der Malerei“ noch einmal ausfürlich auf sein Verständnis des Begriffs der „Form“ zu sprechen. Es handelt sich dabei um den Aufsatz „Über den Begriff der Form“ („O pojęciu formy“), den Witkacy später in sein 1922 veröffentlichtes Buch „Ästhetische Skizzen“ aufnahm, das er im Vorwort selbst als „Ergänzung“ und „Erweiterung“ („dopetnienie i rozszerzenie“) von „Die neuen Formen in der Malerei“ bezeichnet.

Witkacy betont in "Über den Begriff der Form" die Mehrdeutigkeit von „Form" und unterscheidet anschließend vier Bedeutungen des Begriffs (vgl. 1922b, 184-192). Die ersten beiden Bedeutungen bezieht er auf die „Form der Gegenstände der äußeren Welt“ (..forma przedmiotów świata zewnętrznego") und unterscheidet dabei die sogenannte ..Silhouettenform“ („,forma sylwetowa“) von der ",mehrdimensionalen Form“ („forma w wielu wymiarach“), die er auch die „wirkliche Form“ („forma rzeczywista“) der Gegenstände nennt. Die erste ist für Witkacy das Produkt des „einäugigen Sehens“ (,jednooczne patrzenie“), das einen bestimmten Gegenstand nur zweidimensional in seinen Umrissen, das heißt in seiner Kontur zu erfassen vermag. Im Gegensatz dazu bezieht sich die "mehrdimensionale Form" auf die Plastizität eines bestimmten Gegenstandes, wodurch sie ihre Verwendung in der Bildhauerei findet, während die „Silhouettenformen“ in der Malerei auftreten ${ }^{37}$. Als dritte Bedeutung nennt Witkacy die "ästhetische Form“ (,forma estetyczna“), worunter er die Konstruktion oder die Komposition des Kunstwerks versteht ${ }^{38}$. Diese Bedeutung entspricht der "Reinen Form“. Als vierte Bedeutung bestimmt Witkacy die „Erfassung der Form“ (,ujęcie formy“), womit er die Form der Einzelelemente eines Kunstwerks bezeichnet.

Dieser „Erfassung der Form", die für Witkacy, wie er selbst bemerkt (1919a, 39-40), neben Komposition und Farbharmonie, das dritte wichtige Element eines Kunstwerks darstellt. widmet er ein eigenes Kapitel in „Die neuen Formen in der Malerei“. Darin bestimmt er den Begriff auf zwei Arten (vgl. 1919a, 91-105): zum einen bezieht er ihn auf den Charakter und das Aussehen der Einzelelemente einer Komposition, die in einem Kunstwerk möglichst einheitlich sein sollen, als Beispiele nennt er: „scharf” („ostry“), „eckig“ (,kanciasty“),

\footnotetext{
"An anderer Stelle (1919a, 44-46 bzw. 1922c, 205-207) arbeitet Witkacy auch mit dem Begriff der ..Flachheit" (..ptaskosc") - bezogen auf die im Bild dargestelten Gegenstände, mit dem er eben jene dritte Dimension ausschließt, die er mit der Illusion der Wirklichkeit in der naturalistischen oder realistischen Malerei verbindet. Daher bestimmt er diese .Flachheit” zum Teil auch als entscheidendes Kriterium dafur, ob ein Bild zur ..Reinen Form" gehoren kann oder nicht. Auf jeden Fall setz Witkacy das Streben des Kunstlers nach dieser .Flachheit" mit dem Streben nach der „Reinen Form“ gleich.

"Witkacy verwendet zwar beide Begriffe, zieht aber .Komposition" vor (vgl. 1922b, 191).
} 
„abgerundet“ (,zaokraglony“), „fransig“ („,strzępiasty“) oder „glatt“ („gladki“). Zum anderen beschreibt Witkacy mit diesem Begriff die Abgrenzung der einzelnen Bildteile voneinander bzw. die Art des Übergangs zwischen ihnen:

"Glównie jednak ujęcie formy oznacza sposób odgraniczenia od siebie czéści obrazu: czy części te, róznych kolorów, stykaja się bezpośrednio; jaki jest charakter ich zetknięcia: czy płynny, czy poszarpany; jaki jest charakter odgraniczających je waskkich płaszczyzn, tj. linii czy konturów, o ile większe płaszczyzny nie stykają się ze soba bezpośrednio; czy kontury te sa jednakowej barwy w całym obrazie, czy tez zmieniaja barwę zależnie od barwy płaszczyzn, które odgraniczaja." $(1919 \mathrm{a}, 91)^{39}$

Die Bedeutung der „Erfassung der Form" für das Kunstwerk ist für Witkacy darin gegeben, dass sie sich auf die Bausteine einer Komposition, im idealen Fall einer "Reinen Form", bezieht. Und durch die gelungene Integration von „Einzelstücken“ (der Bausteine) in ein geschlossenes Gesamtes kommt für Witkacy das ästhetische Erlebnis (verbunden mit den „metaphysischen Gefühlen“) zustande. Schließlich betont Witkacy, dass die „Erfassung der Form" immer in engem Zusammenhang mit dem Stil des Künstlers stehe, nämlich als das, was ihn von anderen Künstlern unterscheidbar mache.

Puzyna schreibt über Witkacys Definition der „Erfassung der Form“, dass es Witkacy dabei nie ganz gelinge, die rein formalen Fragen völlig losgelöst von den inhaltlichen zu behandeln:

.[Wyrażnie widoczne sa; M.E.] kłopoty Witkacego ze wspomniana juz opozycja ,forma-tresć': chce ja przekreslic, mowiąc tylko o jednym jej czlonie - o formie, z pominięciem drugiego, zamiast odraucic cała te kategorie, totez tresć, drzwiami wyrzucona, oknem powraca." $(1999,116)^{40}$

Und in der Tat stellt sich bei Witkacys Definition der "Erfassung der Form" die Frage, ob es sich bei den Elementen einer Komposition (im Rahmen eines Kunstwerks) um rein abstrakte Figuren (zum Beispiel: rote Quader oder blaue Kreise etc.) oder aber um Formen handelt, die den Betrachter in irgendeinem Sinne an konkrete Gegenstände erinnern. Es scheint, und das spricht auch Puzyna an, dass Witkacy selbst zur mehr „gegenständlichen Variante“ tendier, denn er wandte sich immer gegen eine rein abstrakte Kunst. Außerdem führte er die außerkünstlerische Wirklichkeit über den Schaffensprozess in die Kunst ein, und zwar uber die Sphăre der „Lebensgefühle“, in der das „metaphysische Gefühl“ des Künstlers ja während der Entstehung eines Kunstwerks polarisiert werden muss. Und schließlich ist sich Witkacy

\footnotetext{
39 „Hauptsächlich bezeichnet Erfassung der Form die Art, in der die Einzelteile des Bildes voneinander abgegrenzt sind: ob diese farblich unterschiedlichen Teile einander unmittelbar beruhren; wie der Charakter ihrer Beruhrung ist: fließend oder zerfetza; wie ist der Charakter jener schmalen Ebenen, d.h. Linien und Konturen, die diese Teile voneinander abgrenzen, sofem sich großere Flachen nicht unmittelbar berahren; sind jene Konturen im ganzen Bild in einer Farbe gehalten, oder andern sie ihre Farbe je nach der Farbe der Flächen, die sie begrenzen."

${ }^{40}$.[Deutlich sichtbar sind; M.E.] Witkacys Schwierigkeiten mit der bereits erwahnten Opposition .Form-Inhalt': er will sie streichen, indem er nur aber einen ihrer Teile - die Form - spricht und den zweiten abergeht, anstelle
} 
dessen bewusst, dass er mit der „Erfassung der Form“, verstanden als „Art, die Gegenstände zu interpretieren“ („sposób interpretacja przedmiotów“) bzw. als „Vereinfachung der Gestalten“ („uproszczenie kształtów“), das Problem des gegenständlichen Inhaltes in der Malerei anspricht (vgl. 1919a, 94 und 1922b, 191). Allerdings ist dieses Problem für Witkacy gegenüber der formalen Seite des Kunstwerks zweitrangig bzw. überhaupt ohne Bedeutung. Ihm scheint es in erster Linie darum zu gehen, mit der „Erfassung der Form“ ein bestimmtes künstlerisches Verfahren zu beschreiben, mit dem die außerkünstlerische Wirklichkeit in die Komposition eines auf formalen Prämissen beruhenden Kunstwerks integriert werden kann, wodurch aber nun explizit das Verhältnis zwischen Form und gegenständlichem Inhalt in der Malerei angesprochen wird ${ }^{41}$.

Zusammenfassend zu Witkacys Verständnis von „Form“ sei festgehalten, dass für seinen ästhetischen Ansatz zwei der vier von ihm unterschiedenen Bedeutungen des Begriffs eine wichtigere Rolle spielen: „Form“ als Charakter der einzelnen Bausteine. der Einzelelemente des Kunstwerks und vor allem als dessen Komposition, das heißt: als „Reine Form“.

Mit der Komposition des Kunstwerks, verstanden als „Aufbau des Bildes“ („uklad obrazu“) beschäftigt sich Witkacy ebenfalls in einem eigenen Kapitel von „Die neuen Formen in der Malerei“. Darin unterscheidet er (vgl. 1919a, 43-66) als wesentliche Elemente der Komposition: „Haupt- und Nebenformen, Besonderheiten dieser beiden Formen sowie den Hintergrund mit seinen Details“ (,formy glówne, poboczne, szczegóły obu tych form i tlo z jego szczegölami“). Außerdem führt er den Begriff der „Richtungsspannungen“ (,napięcia kierunkowe“) ein, die den einzelnen Elementen der Komposition eine gewisse Dynamik verleihen können, zum Beispiel dadurch, dass diese Elemente mit Merkmalen von Figuren, Tieren oder Pflanzen (zum Beispiel: Augen etc.) versehen werden können. Dadurch, so Witkacy, würde diesen Elementen eine gewissen Bewegung (zum Beispiel: Blickrichtung) eingeschrieben, wodurch ihre Erfassung als einheitliche Komposition insgesamt erleichtert werde. Schließlich verweist Witkacy auch auf die Möglichkeit der ,.perversen oder tückischen Komposition“ (,kompozycja perwersyjna lub przewrotna“), in der die "Einheit der Vielheit“ nicht über Integration und Gleichgewicht. sondern über das genaue Gegenteil hergestellt werde. Und genau diese Integration der Einzelelemente als ein Gesamtes. dieses Erfassen der Komposition als Einheit, bleibt das entscheidende Moment von Witkacys Verständnis der

diese ganze Kategorie zu verwerfen, folglich dessen kehrt der Inhalt, zur Tar hinausgeworfen. durch das Fenster wieder zuruck."

"Witkacy năhert sich damit zum Teil Zbigniew Pronaszko an. der es, wie gezeigt, auch als die Aufgabe der Malerei beschreibt, fur die .zufalligen“ Gestalten der außerkünstlerischen Wirklichkeit .,Form“ zu finden. 
Komposition. Daran bindet er nicht nur, wie oben dargestellt, das ästhetische Erlebnis selbst, sondern definiert dadurch auch den Begriff des Schönen in der Kunst (1922a, 177-178).

Für Zbigniew Pronaszko manifestiert sich in der Form in erster Linie das künstlerische Schaffen selbst, was sich ebenfalls sowohl in der Form der einzelnen Elemente des Kunstwerks, als auch durch dessen Komposition zeigt. Er geht, wie Witkacy, von einem ähnlichen „doppelten“ Verständnis des Begriffs „Form“ aus und schreibt in „Über den Expressionismus": „Aby obraz mial formę potrzeba: $1^{0}$ zeby wszystkie jego objekty miały formę, $2^{0}$ zeby forma ich byla jednolita, $3^{0}$ aby związek między objektami był ścisły $i$ organiczny.“ $(1918,15)^{42}$. Durch die Form erfasst der Künstler schöpferisch die zufälligen Gegenstănde der Wirklichkeit, die Pronaszko „Gestalten“ nennt. Darauf beruht für ihn auch ihre Bedeutung. Wie zuvor Witkacy - im Falle der „Erfassung der Form“, spricht auch Pronaszko in diesem Zusammenhang von Form als „Erfassung der Gestalt" (,ujęcie kształtu“) ${ }^{43}$. Aus diesem Verständnis heraus bestimmt Pronaszko die Form als eine Konvention, welche die „Gestalten“ in ihrem Charakter gewissermaßen vereinheitlicht ${ }^{4}$. Erst durch diese Vereinheitlichung scheint es für Pronaszko letztendlich möglich, sie in die organische Komposition eines Kunstwerks zu integrieren.

Mittels des Begriffs der „dekorativen Malerei“ als besonderem Merkmal der „neuen Kunst“ hat Pronaszko bereits vor dem Krieg in „Vor dem großen Morgen“ auf die Komposition verwiesen, um die "neue Kunst“ vom Realismus abzugrenzen ${ }^{45}$. In „Über den Expressionismus" kommt er darauf noch einmal zurück und greift dabei die zuvor hergestellte Opposition wieder auf:

\footnotetext{
42 .Damit das Bild Form hat, braucht es: $1^{\circ}$ dass alle seine Objekte Form haben, $2^{\circ}$ dass ihre Form einheitlich ist. $3^{\circ}$ dass die Beziehung zwischen den Objekten eng und onganisch ist." Die Ausfuhrungen zu Pronaszkos Formbegriff stutzen sich auf: Z. Pronaszko 1918, 15-16.

${ }^{43} \mathrm{Vgl}$. dazu: Lipski $(1993,13)$, der auf das artistotelische Verstandnis von „Form” bei den Formisten verweisL. verstanden als die Kraft, die die Materie gestaltet.

4 „Ona [=forma; M.E.] to wlaśnie, jako ujęcie kształtu pewna konwencyą wytwarzając zespoły jednego gatunku i sprowadzając je do jednego mianownika, da moznošc pewnych ich kojarzen." (Z. Pronaszko 1918, 15). „Sie [=die Form; M.E.] gibt gerade, als Erfassung der Gestalt durch eine bestimmte Konvention, indem sie Komplexe eines Charakters hervorbringt und sie auf einen Nenner zurlickfuhr, die Moglichkeit gewisse Verbindungen zu schaffen."

"s "W tych jedynie epokach Sztuki, gdzie dekoracyjne malarstwo (lub rzeźba) miało stosowanie - wredy tylko ratowane było od upadku w swym realizmie - gdyz musiano się rachować $z$ linia $i$ barwa - temi zalozeniami malarstwa.” (Z. Pronaszko 1914, 127). „Einzig in jenen Epochen der Kunst, in denen die dekorative Malerei (oder Plastik) Verwendung fand - nur dann wurde sie vor ihrem Untergang in ihrem Realismus gerettet - da Racksicht auf Linie und Farbe genommen werden musste - diesen Grundlagen der Malerei." Von "Dekorativitat" als Kennzeichen der neuen Malerei sprach Pronaszko auch im Zusammenhang der Zakopaner Ausstellung im Sommer 1916. Zum Begriff der "Dekorativitar" vgl. auch: Pollakówne 1972. 29-35.
} 
"I w istocie: malarstwo nie moze być ,powrotem do natury, malarstwo musi zawsze być powrotem do obrazu. Obrazem zaś jest celowe, logiczne wypełnienie pewnemi określonemi formami pewnej prestrzeni, stanowiącej $w$ ten sposób jednolity, niezmienny organizm." $(1918,15)^{46}$

Die Komposition, verstanden zum einen als Ordnung und Aufbau des Bildes, zum anderen als immanenter Ausdruck der künstlerischen Arbeit, wird von der außerkünstlerischen Wirklichkeit abgegrenzt und dieser sogar gegenübergestellt. Dadurch wird der Bruch mit einem Kunstverständnis vollzogen, das auf der möglichst getreuen Nachahmung dieser Wirklichkeit beruht. Für das Bild gelten nach Pronaszko andere Gesetze, als für die Natur: vor allem sei dessen (innere) Logik, die sich aus der „Verbindung von Formen und Flecken“ („zwiazek form i plam“) ergebe, von Bedeutung $(1918,16)$. Das Leben des Bildes beruhe daher einzig auf dessen Konstruktivităt, sein einziges Thema seien „Form- und Farbprobleme“" (,zagadnienia formy i barwy“).

Auch Chwistek widmete sich in seinen Schriften, wenn auch nur ansatzweise, dem Begriff der „Form“, in der er, ähnlich wie Witkacy und Pronaszko. das Wesen der Kunst sieht: „Cała współczesna sztuka rozwinęła się pod hasłem formy. [...] Forma była i jest istotą wszelkiej sztuki." (192lb, 77) ${ }^{47}$. Am systematischsten stellt Chwistek sein Verständnis des Formbegriffs in seiner Studie "Die Vielfalt der Wirklichkeiten“ (vgl. 1921a, 82-83) dar, wenngleich er an dieser Stelle auch schreibt, dass er den Begriff nicht erschöpfend definieren will. „Form“ bezieht er im Falle der Malerei auf folgende Elemente: die Komposition, verstanden als Beziehung der einzelnen Elemente eines Kunstwerks zueinander und die Ar. sie anzuordnen, auf das Kolorit, das heißt die Anordnung der Farben sowie die im Bild auftretenden Lichtverhältnisse und auf die Technik. das heißt auf das Material (Leinwand. Farben etc.) bzw. auf die Art des Künstlers, mit diesem Material umzugehen. Allerdings, so Chwistek weiter (1921a, 95-96), müsse jeder Versuch, verbindliche Prinzipien für die Komposition im Vorhinein festzulegen, zum Scheitern verurteilt sein, abgesehen von allgemeinen, die etwa die notwendige Geschlossenheit der Komposition beträfen ${ }^{48}$.

Drei Jahre später, in „Die Vielfalt der Wirklichkeiten in der Kunst“ (1924) kommt Chwistek noch einmal auf das Problem der Komposition zu sprechen. Zwar stellt er an dieser Stelle erneut die prinzipielle Unmöglichkeit fest (1924, 16-17), allgemein verbindliche Regeln der

\footnotetext{
${ }^{46}$ „Und tatsăchlich: die Malerei kann keine ,Ruckkehr zur Natur' sein, die Malerei muss immer die Rülckkehr zum Bild sein. Das Bild hingegen ist das bewusste, logische Ausfullen einer bestimmten Fläche mit bestimmten definierten Formen, die auf diese Art einen einheitlichen, unverănderbaren Organismus darstellt."

${ }^{47}$.Die ganze zeitgenossische Kunst entwickelte sich unter dem Schlagwort der Form. [...] Die Form war und ist das Wesen aller Kunst."

${ }^{43}$ Diese Unmoglichkeit beruht fur Chwistek unter anderem darauf, dass die Gestalten und Formen, aus denen der Kunstler sein Bild baut, sich ihm erst wăhrend des Schaffensprozesses ergeben, weshalb er erst dann aber ihre Zusammenstellung im Rahmen einer Komposition entscheiden konne.
} 
Komposition zu finden, räumt aber ein, dass dies innerhalb einer bestimmten Strömung bis zu einem gewissen Grad möglich sei. In diesem Zusammenhang verweist er auf seinen nach 1922, das heißt nach dem Formismus, entwickelten Ansatz der sphäristischen Malerei.

In „Die Vielfalt der Wirklichkeiten“ (1921) geht Chwistek außerdem speziell auf die Bedeutung der Form im Zusammenhang mit seiner Theorie der verschiedenen Wirklichkeiten ein. Dabei schreibt er (1921a, 82-83), dass von diesem theoretischen Standpunkt aus die formalen Kriterien eines Kunstwerks ungleich stabiler seien, als die inhaltlichen, die im Prinzip lediglich von der jeweiligen Wirklichkeit, die dem Kunstwerk zugrunde liegt, abhingen.

Somit formulieren alle drei Autoren das Primat der Form vor dem Inhalt: Zwar spielt dieser für sie eine notwendige Rolle im Kunstwerk bzw. für dessen Entstehen, das künstlerische Schaffen selbst beruht jedoch erst auf der formalen Erfassung und Gestaltung dieses Inhaltes. Chwistek schreibt beispielsweise:

„Bez pojęcia jakiejś rzeczywistości zagadnienie formy jest zupełnie nieokreślone, a priori bowiem wolno wogóle wszystko [...]. Zagadnienie formy zaczyna się dla mnie z chwila kiedy $z$ jednej strony posiadam intuicje kształtów rzeczywistych, a z drugiej zasady komponowania. [...] zadanie artysty polega według mego przekonania [...] na pogodzeniu zasad kompozycji $z$ intuicją kszałtów rzeczywistych." $(1924,16)^{49}$

Zusammenfassend lässt sich sagen, dass die drei Autoren den Begriff der „Form“ sowohl auf die einzelnen Elemente eines Kunstwerks, als auch auf dessen Komposition beziehen. Da sich in beidem explizit die künstlerische Arbeit manifestiert, ist auch die ästhetische Bedeutung des Kunstwerks an die formalen Qualităten gebunden. An sie, und nicht an die Dechiffrierung eines bestimmten gegenständlichen Inhalts, ist schließlich das ästhetische Erlebnis des Rezipienten geknüpft, was besonders bei Witkacy zum Ausdruck kam $^{\text {s0 }}$. So werden, ausgehend von der Bestimmung der „Form" bei allen drei Autoren vor allem zwei Probleme erkennbar, die in ihren Ausführungen eine zentrale Rolle einnehmen: neben der Komposition des Kunstwerks auch die Beziehung zwischen Form und Inhalt.

\footnotetext{
49 ..Ohne den Begriff irgendeiner Wirklichkeit bleibt die Frage der Form vollig unbestimmt, a priori ist uberhaupt alles erlaubt. [...] Die Frage der Form stellt sich fur mich in jenem Moment, wenn ich zum einen die Intuition der wirklichen Gestalten habe und zum anderen die Prinzipien der Komposition. [...] die Aufgabe des Kunstlers beruht gemaß meiner Überzeugung [...] darauf, die Prinzipien der Komposition mit der Intuition der wirklichen Gestalten in Einklang zu bringen."

so Auch Chwistek stellt die Frage, ohne sie allerdings zu beantworten: „[...] czy wolno w dziele, które spetnia wszystkie postulaty doskonałej formy, doszukiwać się jeszcze czegoś innego, co tej formie jest obce." (1921a.
} 


\subsection{3 „Unwesentlich aber notwenig ${ }^{\star}$ - zur Rolle des Inhalts im Kunstwerk}

Für Pronaszko, Witkacy und Chwistek besteht ein immanenter Zusammenhang zwischen Kunst und außerkünstlerischer Wirklichkeit, da Kunstwerke ihrer Meinung nach nie allein nur der reinen Vorstellung des Künstlers entspringen können. Vielmehr spielt diese Wirklichkeit eine wichtige Rolle im konkreten Schaffensprozess, was zur Folge hat, dass sich in jedem Kunstwerk ihre Spuren finden lassen, und zwar in Form von Gegenständen. Figuren etc.. Dieser gegenständliche Inhalt - als "Ergebnis“ der referentiellen Beziehung zwischen den Formen des Kunstwerks und den Dingen einer außerkünstlerischen Wirklichkeit - tritt im Kunstwerk in ein besonderes Verhältnis zur Form, dem, wie gesagt, ăsthetisch eigentlich Wesentlichen. Durch formale Gestaltung verarbeitet der Künstler die Gestalten der äußeren Wirklichkeit und kann sie so in die Komposition des Kunstwerks überführen.

Auf diese Weise wurde der Inhalt zwar der formalen Seite des Kunstwerks gewissermaßen untergeordnet, aber eben nicht völlig eliminiert. Das Verhältnis zwischen beiden soll im Folgenden untersucht werden. Dabei wird ..Inhalt“ hier als gegenständlicher Inhalt verstanden, im Unterschied etwa zum .,formalen Inhalt“ (.treść formalna“). den ja Witkacy als den einzig wesentlichen des Kunstwerks bestimmt.

Witkacy setzt sich vor allem in zwei Aufsätzen explizit mit dem gegenständlichen Inhalt von Kunstwerken auseinander: „Über den «Inhalt» von Bildern. ihre Titel und über das Problem Dreidimensionalităt auf einer Ebene zu imitieren“ (,O «treści» obrazów i ich tytulach i o problemie imitacji trójwymiarowości na płaszczyżnie“) und „Über die scgenannte "Deformation» der Gestalten der äußeren Welt in den Bildern zeitgenössischer Maler” („O tak zwanej «deformacji» kształów świata zewnętrznego na obrazach malarzy wspöłczesnych“). Beide Aufsätze veröffentlicht er in der Sammlung .,Ästhetische Skizzen“, mit der er, wie erwähnt. Unklarheiten aus "Die neuen Formen in der Malerei“ zu beseitigen und zentrale Aspekte zu präzisieren sucht, was sich neben dem Begriff der ..Form“ auch auf den des „Inhaltes“ der Fall bezieht.

In beiden Aufsätzen betont Witkacy (vgl. 1922c und 1922d) noch einmal seine in „Die neuen Formen in der Malerei“ erläuterte Auffassung, dass allein die Form des Kunstwerks im ästhetischen Sinn relevant sei, der gegenständliche Inhalt hingegen unwesentlich. Allein für den Schaffensprozess sei die außerkünstlerische Wirklichkeit von Bedeutung. Außerdem hat Witkacy im Zusammenhang mit der Komposition das Phänomen der „Richtungsspannungen“

82). „[...] ist es erlaubt, in einem Kunstwerk, das alle Anforderungen der vollendeten Form erfullt, noch nach etwas anderem, dieser Form Fremden. zu suchen." 
beschrieben, das in der Angleichung von Kompositionselementen an Gegenstände, Figuren etc. besteht, um diesen - aufgrund kompositorischer Anforderungen - eine gewisse Ausrichtung bzw. Dynamik zu verleihen. So kommt Witkacy zum Schluss:

Jakkolwiek tresć przedmiotowa jest prawie nie do wyeliminowania, jako element nieistotny a konieczny, ze względu na powstanie obrazu przez polaryzację $\mathrm{i}$ indiwidualizację metafizycznego uczucia w świecie uczuć $\mathrm{i}$ wyobrazen [...], jak równiez z powodu tego, ze przedmioty wyobrazone i dowolnie z punktu widzenia rzeczywistości zdeformowane nadaja masom kompozycji niezmierne bogactwo napięć kierunkowych, tresć ta powinna zajmować tyle miejsca $w$ obrazie, aby nie wysuwać się na plan pierwszy jako taka i nie uniemozliwiac czysto formalnego jego pojmowania." $(1922 c, 203)^{31}$

Wird diese Stelle mit dem zuvor angefuhrten Zitat von Puzyna gelesen, der schreibt, dass wenn Witkacy den Inhalt zum Fenster hinauswerfe, dieser bei der Tür wieder hereinkomme, so kann das hier zitierte Fragment gewissermaßen als Witkacys Eingestăndnis interpretiert werden, den Inhalt eben nicht aus seiner Ästhetik eliminier haben zu können ${ }^{52}$. Einzig im Falle der „Richtungsspannungen“, so Witkacy können die inhaltlichen Elemente gezielt für den formalen Ausdruck des Kunstwerks fruchtbar gemacht werden.

Das zweite Problem, das für Witkacy mit dem gegenständlichen Inhalt von Kunstwerken zusammenhängt. ist das der Deformation. Aber dieses Problem. so Witkacy (vgl. 1922d, 208218), sei nur dann interessant, wenn in der Malerei die Widerspiegelung der äußeren Welt gesucht werde, was im Fall der Kunst der „Reinen Form“ genau nicht der Fall sein dürfe. Da es nămlich um die Realisierung einer in sich geschlossenen Komposition, einer Komposition der "Reinen Form“, gehe, sei das Problem der Deformation aus den Anforderungen der Komposition heraus zu erfassen:

„Wtaśnie szukanie sposobów urozmaicenia kompozycji przy stosunkowo wielkiej prostocie jest tym, co zmusza do ,deformacji', raczej wyrazając sie językiem formistycznym, a nie sposobem ludzi, widzacych na obrazach jedynie świat mniej lub wiẹcej zdeformowany, zmusza artystę do nadawania danym formom lub ich kompleksom pewnych cech podobieństwa do kszałtów świata zewnętrznego." (1922d, 213)

si „Obwohl der gegenstăndliche Inhalt als unwesentliches, jedoch notwendiges Element fast nicht eliminien werden kann. [notwendig; M.E.] fur die Entstehung des Bildes durch Polarisation und Individualisierung des metaphysischen Gefuhls in der Welt der Gefuhle und Vorstellungen [...], ebenso wie aus jenem Grund, dass die dargestellten und vom Standpunkt der Wirklichkeit aus beliebig deformierten Gegenstande, deıI Kompositionsmassen den unermesslichen Reichtum der Richtungsspannungen geben, sollte dieser Inhalt gerade so viel Platz im Bild einnehmen, dass er sich als solcher nicht in den Vordergrund drangt und dessen rein formale Erfassung nicht unmoglich macht."

32 Obwohl Witkacy dies immer wieder fordert: .A do zrozumienia ogólnego dojdziemy nigdy, jeśli nie wyeliminujemy raz na zawsze z estetyki pojęcia swiata zewnętranego i przedmiotu. które to pojęcia ciąza nad nia od dawna jak duszaca wszelkie pojmowania zmora i sa przyczna wszystkich nieporozumień." (1922a, 183). „Wir gelangen nie zu einem allgemeineren Verstăndnis, wenn wir nicht ein fur allemal die Begriffe der außeren Welt und des Gegenstandes aus der Ästhetik eliminieren, die diese seit langem wie ein Alptraum belasten, jedes Verständnis ersticken und der Grund fur alle Missverständnisse sind.“

\$3 „Gerade die Suche nach Moglichkeiten, die Komposition zu bereichern, bei verhătnismaßig großer Einfachheit, zwingt zur ,Deformation', im Sinne der formistischen Sprache und nicht gemaß dem Verstandnis jener, die in den Bildern einzig eine mehs oder weniger deformierte Welt sehen und zwingt den Kunstler den jeweiligen Formen oxter ihren Komplexen gewisse Ähnlichkeiten zu den Gestalten der zußeren Welt zs 
Aus dem Zusammenhang von Deformation und kompositorischen Anforderungen ergibt sich für Witkacy noch ein zweiter Aspekt. In der Deformation verwirkliche sich der Zusammenhang zwischen der Kunst und dem Leben, nämlich insofern, dass die für den Künstler spezifische Art der Deformation auch mit seiner Persönlichkeit zusammenhänge, die wiederum von der Zeit, in der er lebt, den vorherrschenden Ideen etc. beeinflusst und gebildet werde. Aufgrund dieses Zusammenhangs zwischen der Persönlichkeit des Künstlers und der Deformation, bezeichnet Witkacy die Frage der Art des Deformierens als eine private, gleich der nach familiären, erotischen oder finanziellen Angelegenheiten des Künstlers. Und so lassen sich für Witkacy schließlich auch die "Seltsamkeiten der Formen der neuen Kunst" ("dziwności form nowej sztuki“) erklären, da nämlich die heutigen Künstler in der modernen, zur Vermassung tendierenden Zeit, gezwungen seien, immer neue Reize in der Kunst zu suchen, was durch kompliziertere Kompositionen und Vervielfäligung der "Richtungsspannungen“ geschehe ${ }^{54}$.

Es scheint, um nun Witkacys Verständnis der Funktion des Inhalts im Kunstwerk zusammenzufassen, dass es ihm wohl nur zum Teil gelingt. diesen in sein ästhetisches System so einzubinden, dass dieser sich der Form unterordnet und die formalen Qualitäten des Kunstwerks stărker hervortreten lässt. Stattdessen muss Witkacy erkennen, dass der Inhalt eine zu dominante Kategorie darstellt, die vor allem, und darauf weist er öfters hin. bei der Rezeption von Kunstwerken für viele noch im Zentrum des Interesses steht. So beklagt er (vgl. zum Beispiel: 1922c), dass sich die Aufmerksamkeit oft allein auf den ,literarischen Inhalt“" richte, statt auf die formale Konstruktion des Kunstwerks und dessen Erfassung als Einheit. Dieses Dilemma Witkacys resultiert daraus, dass er den referentiellen Bezug zwischen den künstlerischen Formen und denen einer außerkünstlerischen Wirklichkeit als fưr die Entstehung eines Kunstwerks als unbedingt notwendig crachtet, dem Ergebnis dieser Beziehung, das heißt dem gegenständlichen Inhalt, jedoch - im Gegensatz zur Form -

verleihen." Dies erinner zum Teil an den von Witkacy ebenfalls gebrauchten Begriff der .Erfassung der Form". Witkacy selbst verweist aber nur zum Teil auf diesen Zusammenhang. wenn er die "Erfassung der Form" auch als "Vereinfachung der Gestalten" (.uproszczenia kształów") bzw. als ..Art. die Gegenstánde zu interpretieren" (.,sposob interpretacji przedmiotów“) bezeichnet (1919a, 94 und 1922b. 191).

\% Dies steht auch in engem Zusammenhang mit Witkacys dezidient pessimistischer Vorstellung. was die zukanftige gesellschaftliche Entwicklung betriff, dargelegt zum Beispiel im Kapitel „Die gesellschaftliche Entwicklung" (.Rozwoj spoteczny") aus "Die neuen formen in der Malerei" (1919a, 119-134). Es würde an dieser Stelle zu weit fuhren, darauf năher einzugehen, erwăhnt sei nur, dass Witkacy, ausgehend von der zunehmenden Bedeutung der (gesellschaftlichen) Masse, den Niedergang des Individuums und damit auch den von Kunst, Religion und Philosophie vermutete. Dieser „Katastrophismus" fand besonders in seinen beiden Romanen „Abschied vom Herbst” (.,Pozegnanie jesieni“) und .Unersătlichkeit” (.Nienasycenie“) seinen literarischen Ausdruck. 
jeglichen ästhetischen Wert abspricht. Doch Witkacy besteht auf dieser Notwendigkeit und wendet sich stets dezidiert gegen eine rein abstrakte Kunst.

Letztendlich bieten sich für Witkacy zwei Auswege aus dem beschriebenen Dilemma. Der erste besteht darin, dass er anerkennt, dass auch der Inhalt eine Quelle ästhetischer Befriedigung sein kann, jedoch nur zusätzlich zur Reinen Form:

„Jeśli dany obraz jest poza ta niezupetnie ścisle dająca się określic granica poza która zaczyna się sfera Czystej Formy, wszystko jedno jest, czy ,przedstawia' taka lub inna historię, czy ma tytul prosty, czy zawily." (1922c, 204)

Der zweite Ausweg bietet sich für Witkacy in der Berufung auf das subjektive Urteil (vor allem des Künstlers) als letzte Instanz an. Dies betrifft sowohl den Umstand, wie stark dieser Inhalt in einem Kunstwerk der „Reinen Form“ repräsentiert sein darf (vgl. 1922a, 178-180), um dessen Einheit nicht zu zerstören, als auch - und vielleicht gerade vor allem - die Frage. welche (deformierten, mit „Richtungsspannungen“ ausgestatteten) Gegenstände in einem Kunstwerk zu sehen sind. Denn wenn es ohnehin nur um die formale Konstruktion gehe, so die von Witkacy angefürte Frage eines Kritikers (vgl. 1920, 268-269), sei es dann nicht einerlei, ob an einer bestimmten Stelle ein Schenkel oder eine auf dem Kopf stehende Flasche zu finden sei, denn vom Formalen her, fuhrten doch beide Varianten im Prinzip zum gleichen Ergebnis? Nein, so Witkacys Antwor, und zwar wegen der für die Einheit der Komposition notwendigen „Richtungsspannungen“. Diese würden nämlich im Falle eines Schenkels unterschiedlich zu denen einer Flasche verlaufen. Außerdem sei, aufgrund der Projektion des „metaphysischen Gefühls" des Künstlers in der "Sphăre der Lebensgefühle“, der gegenständliche Inhalt von Kunstwerken eben auf die individuelle Lebenssituation des Künstlers zurückfuhrbar. Daher komme für den Künstler die Überlegung, ob Schenkel oder Flasche überhaupt nicht in Frage:

„Ten, a nie inny przedmiot, w wieksszej lub mniejszej deformacji na obrazie. jest tak samo dany implicite z konieczna w danym miejscu Czysta Forma w zaleznosci od calosci utworu i wszystkich czynnikow nieistotnych, a koniecznych, które złozyły się na jego powstanie, jak implicite dany jest w kombinacjach dzwiekkowych ich nastroj uczuciowy, taki a nie inny, stanowiący $z$ dźwiękami tymi nierozerwalna całośc. [...] Na koniecznym i nieuniknionym sposobie indiwidualizacji uczuć metafizycznych polega nieczystość nawet najczystszej sztuki $i$ wszelkie nieporozumienia na temat formy i treści, odtworzenia i deformacji." (1920. $276)^{36}$

\footnotetext{
3s .Wenn sich ein bestimmtes Bild jenseits dieser nicht exakt bestimmbaren Grenze, hinter der die Sphăre der Reinen Form beginnt, befindet, ist es egal, ob es diese oder jene Geschichte ,darstellt', ob es einen einfachen oder komplizierten Titel hat."

so „Dieser, und kein anderer Gegenstand, der mehr oder weniger deformiert auf dem Bild zu sehen ist, ist gleichermaßen implizit mit der an der jeweiligen Stelle notwendigen Reinen Form, in Abhăngigkeit von der Ganzheit des Werkes und von allen unwesentlichen aber notwendigen Faktoren, die zu seiner Entstehung beigetragen haben. gegeben, wie in den Klangkombinationen eine bestimmte Gefuhlsstimmung ebenso implizit gegeben ist. die mit den Klangen eine untrennbare Einheit bildet. [...] Auf der netwendigen und unuermeidlichen
} 
Witkacy betont somit noch einmal mit Nachdruck die Subjektivităt des Künstlers, auf die letztendlich das Entstehen eines Kunstwerkes bezogen werden müsse, das aus diesem Grund nie zur Gänze analysiert bzw. erklärt werden kann. Und im Anschluss daran formuliert er indirekt den an die Kunstkritik gerichteten Vorwurf, nicht das Wesentliche im Kunstwerk erkennen zu können bzw. zu wollen:

..Sąd: ,nie lubię Picassa, poniewaz ludzi maluje $w$ postaci kanciastych plam i kolorów, nie odpowiadających naturze' - jest sadem pozbawionym sensu i dowodzacym. ze ten, który go wydaje, nie rozumie istoty malarstwa. Jest to tak, jak gdyby ktos powiedzial: ,nie lubię ryby w majonezie, poniewaz nie jest ona sleepingiem I klasy'." $(1920,276)^{37}$

Auch Chwistek versteht "Inhalt" als das Produkt eines notwendigen referentiellen Zusammenhanges der Kunst bzw. ihrer Formen mit einer außerkünstlerischen Wirklichkeit ${ }^{58}$ (von denen Chwistek allerdings vier unterscheidet) und auch er versucht, ähnlich wie Witkacy den gegenständlichen Inhalt für die formalen Qualitäten des Kunstwerks fruchtbar zu machen. allerdings auf eine andere Weise: Chwistek ist nämlich vielmehr der Meinung, dass durch eine bewusst eingesetzte inhaltliche Uneindeutigkeit der formale Ausdruck des Kunstwerks noch gesteigert werden kann. Der Beschreibung dieses Phänomens widmet sich Chwistek gleich in mehreren Texten: zuerst 1919 und 1920 in den beiden gleichnamigen programmatischen Aufsätzen „Der Formismus“ und später ausführlich in „Die Vielfalt der Wirklichkeiten“" (1921).

In den beiden mit „Der Formismus“ betitelten Aufsätzen, betont Chwistek (vgl. 1919a. 94-99 und 1920a, 100-104 ${ }^{59}$ ) den für ihn notwendigen Zusammenhang zwischen der Malerei und einer bestimmten außerkünstlerischen Wirklichkeit und versucht die Rolle des Inhaltes im Kunstwerk zu bestimmen:

„Natomiast sztuki te [=poezja, malarstwo, rzeżba; M.E.] rozporzadzaja środkami. przy pomocy których mozna tresć tak dobrac. zeby wrazenie artystyczne płynące $z$ doskonalej formy nie tylko nie zostalo umniejszone, ale w swoisty sposób do ostatecznych granic spotęgowane. Pochodzi to stad, ze zarówno sens zdania. który jest treścią w poezji, jak rzeczywistość, która jest treścia w malarstwie i rzezbie, nie sa

Art der Individualisierung der metaphysischen Gefuhle beruhen die Unreinheit auch der reinsten Kunst und alle Missverstăndnisse bezüglich der Form und des Inhalts, der Abbildung und Deformation."

37 „Das Uneil: ,ich mag Picasso nicht, weil er die Menschen in Gestalt eckiger Flecken und Farben malt, die der Natur nicht entsprechen' - ist ein Urteil, das jeglichen Sinns entbehrt und beweist, dass der, der es abgibt. das Wesen der Malerei nicht versteht. Das ist ungefahr so, als ob jemand sagte: ich mag keinen fisch in Mayonnaise, da dieser kein Schlafwagen erster Klasse ist'." Vgl. auch die ausfuhrlichen Bemerkungen Witkacy an dieser Stelle.

"ss In .Die Vielfalt der Wirklichkeiten“ (1921) bestimmt Chwistek drei Arten des Inhalts in der Kunst (1921a. 81), stellt jedoch fest, dass weder die durch das Kunstwerk hervorgerufenen Gefuhle (1. Bedeutung). noch der ,anekdotische Inhalt", im Sinne einer Geschichte etc., die im Bild wiederentdeckt werden kann (2. Bedeutung) wirklich relevant sein konnen. Dies sei allein bei der 3. Bedeutung der Fall: .Jedynym interesującym znaczeniem wyrazu ,trešc dzieła sztuki moga być elementy rzeczywistosci." - ..Die einzige interessante Bedeutung des Begriffs ,Inhalt' eines Kunstwerks konnen die Elemente einer Wirklichkeit sein."

${ }^{59}$ Der Aufsatz von 1920 ist auch in deutscher Übersetzung (in: Lam 1990, 154-157) erschienen. 
jednoznacznie określone i skutkiem tego pozostawiają niezmieme pole do swobodnych odkszalceń." (1920a. $101)^{60}$

Es geht ihm also um eine bewusste Mehrdeutigkeit des gegenständlichen Inhalts, die er mit dem Begriff der „Oszillation des Inhaltes“ („oscylacja treści“) fasst. Diese beruht darauf, dass eine bestimmte in einem Bild verwendete Kontur, das heißt Form, mit mehreren Gegenständen gleichermaßen in Verbindung gebracht werden kann, ohne dass letztendlich eine eindeutige Zuordnung möglich ist. Der Künstler, so Chwistek, müsse den Betrachter genau dazu verleiten, von einer eindeutigen, schnellen Zuordnung Abstand zu nehmen, indem er diese Oszillation bewusst einsetzt und die gewählten Formen in einer Komposition anordnet. Dadurch werden Beziehungen zwischen den einzelnen Formen hergestellt, was wiederum, aufgrund einer wechselseitigen Assoziation, auf die inhaltliche Mehrdeutigkeit zurückwirken kann. Dank dessen werde der Rezipient, so Chwistek, zu einer längeren. tiefergehenden und damit ergiebigeren Betrachtung eines Kunstwerks angehalten:

"Istotna róznica pomiędzy malarstwem i rzeżba a ornamentyka polega na tym, ze obrazy i rzeźby powinny być zbudowane w ten sposób, azeby mogty być jako calosć poddane dhugotrwałej kontemplacji [...]." (1921 a. 92) 61

Dieses Zitat stammt aus Chwisteks längster kunsttheoretischer'Studie „Die Vielfalt der Wirklichkeiten“ (1921). Er geht darin von der Feststellung aus (vgl. 1921a, 81-97), dass aufgrund der notwendigen Präsenz von gegenständlichem Inhalt in der Malerei, meist die falschen Schlüsse gezogen worden seien, was das Wesen der Malerei betreffe: Ihr Ziel wurde darin gesehen, diese außerkünstlerische Wirklichkeit möglichst genau zu kopieren und abzubilden. Erst die Etablierung der „visionären Wirklichkeit“ in der jüngsten Vergangenheit habe hier eine Veränderung bewirken können:

„Musimy natomiast stwierdzic, ze wciagnnięcie rzeczywistosci wyobrazeń [=rzeczywistość wizjonerów; M.E.] do zakresu tresci malarstwa i rzeźby pozwala nam załatwić się z pewnym zasadniczym problemem teorii sztuki, polegającym na pytaniu: do jakiego stopnia tresć $w$ dziele szuki moze byc przezwycięzona." $(1921 \mathrm{a}, 91)^{62}$

${ }^{60}$ „Allerdings verfúgen diese Kunste [=Poesie, Malerei, Plastik; M.E.] aber Mittel, mit deren Hilfe der Inhalt so gewahlt werden kann, dass der auf der vollendeten Form beruhende kunstlerische Eindruck nicht nur nicht geschmaler, sondern auf eigene Weise bis zu den letzten Grenzen gesteigert wird. Dies kommt daher, dass der Sinn eines Satzes, der den Inhalt in der Dichtung darstellt, gleichermaßen wie die Wirklichkeit, die den Inhalt in der Malerei und der Plastik bildet, nicht eindeutig bestimmt sind, wodurch sie ein unermessliches Feld fur freie Deformationen hinterlassen."

6) .Der wesentliche Unterschied zwischen Malerei und Plastik auf der einen und der Omamentik auf der anderen Seite beruht darauf, dass Bilder und Statuen so gebaut sein sollen, dass sie als Ganzes einer langen Kontemplation unterzogen werden konnen."

${ }_{62}$ „Wir mussen allerdings feststellen, dass das Miteinbeziehen der Wirklichkeit der Vorstellungen [=die visionăre Wirklichkeit: M.E.] in den Bereich des Inhalts von Malerei und Plastik uns erlaubt, uns eines gewissen grundlegenden Problems der Kunsttheorie zu entledigen, das auf der Frage beruht: bis zu welchem Grad kann der Inhait in einem Kunstwerk nherwinden werden. “ 
Chwistek nennt explizit keinen Grund, warum eine "Überwindung des Inhaltes", das heißt eine Veränderung seiner dominierenden Rolle, die er im Kunstwerk zuweilen spielt, gerade durch die "visionäre Wirklichkeit" ermöglicht wurde. Es scheint aber, dass dies gerade wegen der geringen Bedeutung der Gegenstände in dieser Wirklichkeit (im Vergleich zu den Visionen, Vorstellungen etc.) der Fall ist, denn Chwistek schreibt: „[...] formiści rozporządzają dzięki rzeczywistości wyobrażeń środkiem [...], polegającym na wyzyskaniu chwiejności granic przedmiotów występujących w tej rzeczywistości.“ $(1921 \mathrm{a}, 93)^{63}$. Damit knüpft Chwistek wieder an sein in den beiden Formismus-Aufsätzen beschriebenes Phänomen der „Oszillation des Inhaltes“ an. Zuvor sprach er von der mehrdeutigen, nicht definitiv einem Gegenstand zuordenbaren Kontur, hier von der Unstetigkeit der Begrenzung eines Gegenstandes, das heißt also ebenfalls von der Kontur. So kommt Chwistek auch in .Die Vielfalt der Wirklichkeiten“ (1921) auf die „Oszillation des Inhaltes“ zu sprechen (1921a. 93 95), differenziert aber, im Unterschied zu den beiden vorherigen Aufsätzen, zwischen "gleichmäßiger“ und „ungleichmäßiger Oszillation“ (,oscylacja równomierna“ bzw. „nierównomierna“). „Gleichmäßige Oszillation“ bezieht Chwistek auf eine solche Kontur, der zwei Gegenstände gleichwertig zugeordnet werden können, was für ihn letztendlich zur Langeweile führen muss. Hingegen gibt es bei der "ungleichmäßigen Oszillation“ eine latente Dominanz eines Gegenstandes, ohne aber, dass die anderen möglichen gänzlich verschwinden, wodurch eine gewisse Dissonanz. die den künstlerischen Wert der Darstellung entscheidend zu beeinflussen vermag, hergestellt wird. Chwistek fasst schließlich zusammen:

\begin{abstract}
"Wydaje się rzecza niewătpliwa ze artystyczna wartosć nieokreślonosci kszahtów jest ściśle zwiazzana z zjawiskiem oscylacji nierównomiemych. Mozna powiedzieć. ze jeśli z cała bezwzględnościa nalež unikać oscylacji ściśle równomiemych, to wystrzegać się należy równiez skrajnej określoności kszzahów. Chwilowe i rzadkie zaburzenia pola widzenia, wykazujące stanowcza przewage jednej strony, odgrywaja role dysonansu, ktorry moze zadecydować o wrazeniu artystycznym." (1921 a. 95)
\end{abstract}

Anders als bei seinen Ausführungen zur Poesie, in deren Fall Chwistek die inhaltliche Mehrdeutigkeit im Sinne einer stärkeren Betonung der Form des Kunstwerks beschreibt, enthält er sich bezüglich der Malerei einer solchen expliziten Feststellung. Er lässt nämlich offen, in welchem Verhältnis der aus der „ungleichmäßigen Oszillation“ des Inhaltes resultierende ästhetische Eindruck zu demjenigen steht. der aus der Form des Kunstwerks

\footnotetext{
${ }^{63}$..[...] die Formisten verfugen dank der Wirklichkeit der Vorstellungen uber ein Mittel [...], das auf der Nutzung der Unbestăndigkeit der Grenzen der in dieser Wirklichkeit vorkommenden Gegenstănde beruht."

ot "Es scheint unzweifelhaft, das der kunstlerische Went der Unbestimmtheit von Gestalten eng mit dem Phănomen ungleichmåßiger Oszillationen zusammenhăngt. Man kann sagen, dass so wie man mit ganzer Entschiedenheit streng gleichmåßige Oszillationen vermeiden soll, es auch gilt, sich vor extremer Bestimmtheit der Gestalten zu haten. Die zeitweiligen und seltenen Storrungen des Sichtfeldes, die die entschiedene
} 
entsteht. Es liegt aber nahe, dass Chwistek dieses Verhältnis analog zur Poesie versteht, das heißt, dass der gegenständliche Inhalt aufgrund seiner Mehrdeutigkeit in den Hintergrund rückt und so dem Rezipienten den Blick auf die Form öffnet ${ }^{65}$. Außerdem steht ein nicht eindeutig festlegbarer Inhalt einer schnellen rezeptiven Erfassung eines Kunstwerks im Wege, wodurch die von Chwistek ebenfalls eingeforderte längere Kontemplation ermöglicht wird. Und schlieBlich bestimmt er, wie gezeigt, die in ihren Konturen unsteten Gestalten der „visionären Wirklichkeit“ als am besten dafür geeignet, in eine von formalen Prämissen ausgehende Kunst (zum Beispiel bezüglich der Komposition) integriert werden zu können. Abschließend verweist Chwistek noch auf folgendes Problem:

„Do jakich granic wolno rozlużniać ksztatty, zeby nie zejść z tego terenu na martwe obszary zmian równomiemych - trudno powiedziec. Jest to rzecza intuicji artysty. Im dalej artysta zapuszcza się na te tereny, tym sztuka jego jest śmielsza, tym donioślejsze sa jego zdobycze." $\left(1921\right.$ a, 95) ${ }^{66}$

Wie im Falle der Poesie, die ebenfalls nicht zur „Gerăuschmusik“ („muzyka szmerów“) werden darf, gebe es also auch für die Malerei eine Grenze, die sie nicht überschreiten darf, um nicht zur selbstreferenziellen formalen Spielerei zu werden. In der maximalen Annăherung an diese Grenze beruht aber die besondere innovative Leistung des Künstlers, dessen Intuition auch von Chwistek hier als das letztendliche Kriterium angefuhrt wird.

Auf diese Weise beschreibt Chwistek, wie der in einem Kunstwerk immer präsente gegenstăndliche Inhalt in den formalen Ausdruck integriert werden kann, wofür vor allem die im letzten Zitat angesprochene „Auflockerung der Gestalten“ fruchtbar gemacht werden kann. Besonders der Formismus, so Chwistek, habe mit dem traditionellen Begriff des Gegenstandes gebrochen (1920a, 103) ${ }^{67}$, aber auch andere zeitgenössische Strömungen hätten durch ihre Bemühungen, die gewohnte getreue Darstellung von Gegenständen zu überwinden, einen neuen Blick auf die formale Gestaltung von Kunstwerken ermöglicht (1919a, 96).

\footnotetext{
Überlegenheit einer Seite zeigen, spielen die Rolle einer Dissonanz die aber den kunstlerischen Eindruck entscheiden kann."

6s Ähnlich bewertet dies Kostyrko (1995, 107). Vgl. dazu auch folgende Bemerkung Chwisteks: „....]. uświadomiona walka $z$ elementami rzeczywistosci i sensu nadaje zagadnieniu formy właściwe znaczenie. nie pozwalając mu zejsć na bezdroza abstrakcyjnej kombinatorki barw i kształtów i prowadzac równocześnie (jako rezultat uboczny) do nowego pojmowania rzeczywistości." (1921b, 78). .[...]. der bewusste Kampf mit den Elementen der Wirklichkeit und des Sinns verleiht der Frage der Form ihre eigentliche Bedeutung. indem er verhindert, dass diese auf die Abwege einer abstrakten Kombinatorik von Farben und Gestalten abgleitet. gleichzeitig fuhrt er (als Nebeneffekt) zur neuen Erfassung der Wirklichkeit."

"Bis zu welchen Grenzen die Gegenstande aufgelockert werden konnen, ohne dass man dabei aus diesem Terrain in die toten Bereiche gleichmaßiger Veränderungen abgleitet - ist schwer zu sagen. Es ist eine Sache der Intuition des Kanstlers. Je weiter sich ein Kanstler in diese Terrains vorwagt, desto kahner ist seine Kunst, desto bedeutender sind seine Leistungen."

${ }^{67} \mathrm{Vgl}$. dazu auch Kostyrko (1995, 104-105), die versucht, Chwisteks „Auflockerung der Gestalten“ im Sinne einer den Formisten gemeinsamen Abkehr vom konkreten gegenstandlichen Inhalt zu beschreiben.
} 
Insgesamt scheint es daher, dass es Chwistek, im Unterschied zu Witkacy, besser gelungen ist, den gegenständlichen Inhalt funktional in die Form des Kunstwerks, auf die es beiden Theoretikern letztendlich ankommt, einzubinden. Beide betonen zwar, dass es unmöglich sei, ein Kunstwerk zusammen mit dessen Konstruktion „kalt“ auszudenken, das heißt rein abstrakt zu kalkulieren (vgl. zum Beispiel: Chwistek 1921a, 96 bzw. Witkiewicz I922d, 208), doch gerade für Witkacy ist dieser Inhalt, wenn auch "notwendig“, so doch "unwesentlich“ („nieistotny a konieczny“). Dadurch gerät er schließlich in das oben beschriebene Dilemma. aus dem der eigentlich einzige Ausweg nur noch im Sich-Berufen auf das subjektive Urteil des Künstlers besteht. Anders für Chwistek: Er geht, mit der Bestimmung der „visionären Wirklichkeit", bereits von einem viel flexibleren Inhaltskonzept aus, das anschließend auch nicht in einem dezidierten Widerspruch zur Form steht. Außerdem betont er, dass Form ohne Bezug zu einer Wirklichkeit fast gar nicht möglich wäre. Daher ist für ihn eine vollendete Form des Kunstwerks immer möglich. egal auf welche der vier von ihm bestimmten Wirklichkeiten dabei zurückgegriffen wird - unter der einzigen Bedingung, dass der Inhalt sich nicht vor die Form schiebt (1921a, 85).

Gerade im Falle des Problems des gegenständlichen Inhalts wird klar, dass die formistischen Theoretiker mit einer bestimmten vorherrschenden Art der Rezeption von Kunstwerken kämpften. Denn sie beklagen in ihren Schriften oft, dass ihre Kunst immer wieder auf Unverständnis treffe, da Kunstkritik und Publikum einzig den ,literarischen Inhalt“ suchten. ohne der Form des Kunstwerks weiter Beachtung zu schenken. Witkacy, der sich in „Die neuen Formen in der Malerei“ in einem eigenen Abschnitt mit der Kunstkritik beschäftigt (1919a, 106-116, vgl. besonders: 110-111), macht diese Konzentration auf den gegenständlichen Inhalt vor allem den Kunstkritikern zum Vorwurf. Gerade ihre Aufgabe, so Witkacy, sei es, zu versuchen, die sicher nicht auf Anhieb verständliche gegenwärtige Kunst. einem breiteren Publikum näher zu bringen. Denn anstatt das Wesen der Kunst zu erklären (das Witkacy in der „Reinen Form" sieht), beschäftige sich die polnische Kunstkritik allein mit in ästhetischer Hinsicht unwesentlichen Fragen ${ }^{68}$.

\footnotetext{
6s Vgl. auch Witkacys zuvor (Kap. 2.3) besprochene Reaktion auf die ..IV. Ausstellung der Formisten". Das enwahnte Kritikkapitel aus ..Die neuen Formen in der Malerei“ lasst ubrigens vermuten. dass Witkacy auch nach seiner Ruckkehr nach Polen (im Fruhjahr 1918) noch an diesem Text arbeitete. Denn gerade in diesem Kapitel scheint sich Witkacy auf konkret gemachte Erfahrungen zu stutzen. die er zum Beispiel als Teilnehmer der zweiten formistischen Ausstellung in Krakau (Juni-Juli 1918) gemacht haben konnte. Außerdem erwahnt Witkacy in diesem Kapitel die im Juli 1918 in Lemberg durchgefuhre „Umfrage zum Expressionismus". Gedruckt wurden ..Die neuen Formen in der Malerei“ ja, wie erwăhnt. erst 1919.
} 


\subsection{Zusammenfassung - eine Theorie des Formismus?}

Mit Czyżewski und Zamoyski äußerten sich auch andere Formisten zu theoretischen Fragen ihrer Kunst. Doch im Unterschied zu den längeren analytischen Studien von Witkacy oder Chwistek sind ihre Texte kürzer und wegen ihres postulierenden Charakters mehr mit Manifesten vergleichbar. Dennoch sind es meist dieselben Fragestellungen, die alle formistischen Theoretiker beschäftigen: Es geht primär um eine nicht-mimetische. formorientierte Kunst, bei der sich das künstlerische Schaffen in der Form, vor allem in der Komposition des Kunstwerks zeigt.

Czyzewski schreibt in „Mein Formismus“ („Mój Formizm“), seinem Beitrag für die erwähnte Umfrage der Zeitschrift „Glos Plastyków“ über die Rolle der Form für sein künstlerisches Schaffen und betont, dass der Formismus nie eine rein gegenstandslose Kunst gewesen sei im Unterschied zum Kubismus mit dessen Hang zur Geometrie. Die Formisten, so Czyżewski, hătten sich vor allem um eine neue Konstruktion des Kunstwerks bemüht, ausgehend von den Einzelformen und den Farbharmonien (1938, 13-14). Mit der Form. verstanden als Manifestation des künstlerischen Schaffens, hat sich Czyzewski in seinem früheren Artikel „Über die neuesten Strömungen in der polnischen Kunst“ („O najnowszych prądach w sztuce polskiej“, 1919) beschäftigt. Er unterscheidet darin zwischen „äußerer“ und „innerer Form“ (forma zewnętrzna bzw. wewnętrzna). Während er mit der ersten jene Formen bezeichnet, die in der alltäglichen Wirklichkeit auftreten, verbindet er die ,innere Form“ unmittelbar mit dem Künstler selbst und mit dessen schöpferischem Vorhaben:

..Idea formy moze być tylko wewnętrzna a nie brana ze swiata zewnętrznego (chociaz moze przypominać "świat zewnętrzny (). Idea formy to określenie moje osobiste i twórcze w stosunku do jakiejbadz formy "zewnętrznej«. Idea formy to stosunek do materyału na mocy ustosunkowania linij, płaszczyzn $\mathrm{i}$ wymiarow. Idea formy to ja sam jako motor twórczy w stosunku do materyah. Idea formy to twór indywidualny stworzony $z$ materyału (tu więc artysta jest twórca a nie naśladowca)." (1919b [dokonczenie], 11)

Damit legt auch Czyżewski, ähnlich wie Pronaszko und Witkacy, das Verhältnis zwischen außerkünstlerischer Wirklichkeit und Kunst fest: Es geht nicht um Nachahmung, sondern u., die kreative Verarbeitung von Eindrücken. Dies geschieht in den vom Künstler individuell entwickelten Formen, was Pronaszko und Witkacy „Erfassung der Form bzw. der Gestalten“ nannten. Darin kommt die stilistische Charakteristik des Künstlers zum Ausdruck. Die

69 "Die Idee der Form kann nur innerlich sein und nicht aus der außeren Welt entnommen werden (obwohl sie an die "ăußere Welt" erinnem kann). Die Idee der Form ist meine personliche und schøpferische Bezeichnung in Bezug auf irgendeine "außere" Form. Die Idee der Form ist die Beziehung zum Material auf der Basis des InBeziehung-Setzens von Linien, Flăchen und Maßen. Die Idee der Form bin ich selbst als schøpferischer Motor in 
Affinităt zwischen ihm und den anderen Formisten sah Czyżewski am Ende von „Über die neuesten Strömungen in der polnischen Kunst" auch selbst, als er über die Formisten schrieb: „Za zasadę swej twórczości powzięli jako idee formy - formę wewnętrzną - wyrazając swą twórczością stosunek artysty wewnętrzny do danej formy." $(1919 \mathrm{~b}, 12)^{70}$.

Auch August Zamoyski streicht in seinem Beitrag zur Umfrage über den Formismus von 1938 die zentrale Rolle der Form für sein Schaffen hervor (vgl. 1938, 43-46): es sei stets sein Bestreben gewesen, mit seiner Kunst eine Form zu schaffen, die auf nichts mehr verweisend, fur sich selbst stehen kann und damit zur Quelle der interesselosen Freude am Schönen werden $\operatorname{kann}^{71}$.

Nicht zuletzt durch diese Texte von Czyżewski und Zamoyski wird deutlich, dass es durchaus Parallelen im Kunstverständnis der Formisten gibt, wie sich zum Teil auch in den Texten von Chwistek und Witkacy zeigte ${ }^{72}$. Es stellt sich somit die Frage, welche Ansätze, die in den einzelnen Texten entwickelt wurden, für den Entwurf einer Theorie des Formismus fruchtbar gemacht werden können.

Zuvor sei an dieser Stelle aber der fast hundertseitige Text „Der Formismus vor dem Hintergrund zeitgenössischer Richtungen in der Kunst" von Konrad Winkler erwähnt, den er 1921 veröffentlichte. Er wollte damit weniger den theoretischen Entwürfen Chwisteks oder Witkacys noch einen weiteren zur Seite stellen, sondern vielmehr eine Bestandsaufnahme des Formismus im fünften Jahr seines Bestehens versuchen, um diesen stärker im Bewusstsein seiner Zeitgenossen zu verankern, wie er im Vorwort verrät:

.Zapoznanie ogółu z tem co się juz dokonało [=w dziejach formizmu; M.E.], co juz skrystalizowało w pewnych formach odmiennych wprawdzie, a przez to dla przeciętnego widza nielatwo dostępnych. lecz równie jak dawne potęznych, jest celem niniejszej ksiązki." $(1921 \mathrm{~d}, 6)^{73}$

Beziehung zum Material. Die Idee der Form ist eine individuelle Schopfung aus Material (hier ist der Kanstler also Schopfer und nicht Nachahmer).“

7o "Als Prinzip ihres Schaffens nahmen sie die Idee der Form - die innere Form - und brachten in ihrem Schaffen das innere Verhăltnis des Kanstlers zu einer bestimmten Form zum Ausdruck.“

"Etwa schreibt Zamoyski: „Przypuszczalem, ze będzie mozna stworzyc «Formę", stworzyć tak oderwany od wszystkiego "Kszałt», któryby sam przez się nieprzypominając niczego, byl pięknym skoniczonym dzielem. dajacym ta radośc bezinteresowna piękna." $(1938,44)$. .Ich nahm an, dass es møglich sein wird, eine "Form" zu schaffen, eine von allem losgeloste "Gestalt», die fur sich genommen an nichts erinnen und ein sch⿰nes. vollendetes Werk darstellt, das die interesselose Freude am Schonen spendet."

$n$ Auch die im zweiten Kapitel besprochenen Einleitungen zu den Katalogen der einzelnen formistischen Ausstellungen können zum Teil als der Versuch gelesen werden. Gemeinsamkeit im Kunstverstăndnis der einzelnen Mitglieder der Gruppe zu betonen.

3 ..Die Offentlichkeit damit bekannt zu machen, was [ $=$ in der Geschichte des Formismus: M.E.] geleistet wurde. was sich bereits in bestimmten Formen kristallisiente, die wohl andersartig und dadurch fur den durchschnittlichen Betrachter nicht leicht zuganglich waren, jedoch von gleicher Gewalt wie die alten, ist das Ziel des vorliegenden Buches.“ 
Damit wollte Winkler den Formismus, neben Kubismus, Expressionismus und Futurismus, denen er jeweils einen eigenen Abschnitt seiner Studie widmete, als eigenständige Strömung der modernen Kunst definieren: zum einen durch die Untersuchung der vor 1921 erschienenen Texte von Zbigniew Pronaszko, Chwistek und Witkacy, zum anderen durch den Versuch, so gut wie alle formistischen Künstler anhand ihres Schaffens vorzustellen und zu charakterisieren $^{74}$.

Winkler greift somit in seinem Text auf dieselben Texte zurück, die auch der in den einzelnen Abschnitten des dritten Kapitels dieser Arbeit durchgeführten Untersuchung zugrunde lagen, weswegen die meisten der von ihm erkannten Aspekte bereits in der einen oder anderen Form erwăhnt bzw. dargestellt wurden. Stärker als andere Formisten, betont Winkler aber die Rolle der formistischen Kunst zwischen traditioneller Ästhetik, womit wohl in erster Linie die an Gegenständlichkeit orientierte Malerei (vor allem die des Naturalismus und Realismus) gemeint ist und der "neuen Kunst”, die den Akzent stärker auf die individuell auf den Künstler bezogene Gestaltung von Eindrücken, Visionen etc. sowie auf die formalen Qualităten der Kunstwerke legt, wodurch sie sich von der besagten Gegenstăndlichkeit zunehmend zu entfernen vermochte. Die Formisten, so Winkler, gehörten einer Generation an, die noch mit dieser traditionellen Ästhetik aufgewachsen sei, weswegen in ihren Werken gerade auch die Konfrontation zwischen dem Alten und dem Neuen spürbar sei (1921d, 7374). Abgesehen davon, verweist auch Winkler auf die nicht-mimetische Funktion der Kunst und darauf, dass das Streben des Künstlers vor allem der Form und der Komposition des Kunstwerkes gelten müsse. Und genau in diesem Streben, so Winkler im Einklang mit den anderen Formisten, in der Suche des Künstlers nach Formen. mittels derer er „die Welt seines inneren ,Ichs'“ (.,świat swego wewnętrznego ,ja”“) zum Ausdruck bringen kann, manifestiere sich die individuelle schöpferische Leistung des Künstlers (1921d, 70).

Die Aspekte, die Winkler hier als den Formisten gemeinsam beschreibt, sind, angesichts der sehr ausführlichen theoretischen Konzepte von Chwistek und Witkacy, im Prinzip nicht viel mehr, als der kleinste gemeinsame Nenner. Ähnlich sieht dies übrigens auch Irena Jakimowicz, die überhaupt nur den gemeinsamen Kampf mit der naturalistischen Konvention sowie die Ablehnung der didaktische Funktion der Kunst (zum Beispiel zur Stärkung des Nationalgefühls) als unstrittig, das heißt für alle Formisten gleichermaßen verbindlich,

\footnotetext{
${ }^{74}$ Pollakówna bemerkte zu dieser Arbeit Winklers: „Za wszystkimi [teoretykami formizmu; M.E.] zaś kroczyl skrzetny, gorliwy Konrad Winkler. Przypadła mu w udziale rola apostola prawd utwierdzanych przez wspohtowarzyszy." (1972, 138). "Hinter allen [Theoretikern des Formismus; M.E.] schritt jedoch der geschaftige, eifrige Konrad Winkler. Ihm fiel die Rolle des Apostels jener Wahrheiten zu, die von den Mitstreitern begrondet und gefestigt wurden."
} 
bestimmt $(1978,7)$. Auch die Formisten selbst blieben in dieser Frage, das heißt bezüglich ihrer theoretischen Gemeinsamkeiten, immer recht allgemein: Für Witkacy waren sie sich, wie er einmal bemerkte $(1921 \mathrm{~b}, 6)$, eigentlich nur darin einig, dass sie "Form" weder als „kubisierte Katze“ („ukubistyczniony kot“) noch als „rundisierte Dame“ (,rondystyczna dama"), sondern einzig allein als Konstruktion des Kunstwerks begriffen. Chwistek unternimmt, wie erwähnt, in „Der Formismus“ (1919) den Versuch, unabhängig von individuellen Ansichten einzelner Formisten, diejenigen Aspekte zu bestimmen, die den einzelnen Mitgliedern der Gruppe gemeinsam waren. Dazu zählt er (vgl. 1919a, 98-99), neben dem Rückgriff auf eine, wie er es nannte, „erweiterte Konzeption des Bildes der wirklichen Welt“ („rozszerzona koncepcja obrazu świata rzeczywistego“), nur noch das formistische Streben mit „nüchternen und einfachen Formen“ („formy surowe i proste“) nach dem „reinen Schönen“ („czyste piękno“), das er einzig dadurch näher bestimmt, dass er es im Gegensatz zu psychologischen, gesellschaftlichen oder literarischen Inhalten, die in der Kunst zum Ausdruck gebracht werden können. begreifi ${ }^{75}$. Damit zeigt sich, dass die von Witkacy und Chwistek hier angeführten Punkte, sich eigentlich nur in sehr allgemeiner Weise auf das Kunstverstăndnis beziehen.

Diese letzten Bemerkungen machen noch einmal besser verständlich, dass es den Formisten selbst nie um eine einheitliche Theorie der „formistischen Kunst“ gehen konnte. Zum einen wegen der zum Teil bedeutenden Unterschiede im Kunstverständnis einzelner Mitglieder der Gruppe, zum anderen wohl auch wegen der prinzipiellen Skepsis gegenüber Programmen, die quasi als Anleitung zum künstlerischen Schaffen verstanden werden können. So schreibt zum Beispiel Witkacy in „Die neuen Formen in der Malerei”: „[...] wszelka programowość wyklucza szczerość, która jest najistotniejszym elementem wszelkiej twórczości [...]." (1919a. 96) ${ }^{76}$. Und Chwistek stellt in "Tytus Czyżewski und die Krise des Formismus" beinahe analog dazu fest: „Niemniej jest faktem, że formizm nie stworzyl do tej chwili tzw. recepty malarskiej, którą można streścić w paru słowach, ale recepta taka nie może być uważana za kryterium prawdziwej sztuki." (1922b, 108) ${ }^{77}$.

Somit bleibt der einzige programmatische Text des Formismus, der alle Formisten gleichermaßen vereint. im Prinzip jener von Konrad Winkler. den er unter dem Titel „Ohne

\footnotetext{
75 Auch Witkacy wirft Chwistek vor (1922e, 250), das Schone an dieser Stelle nicht năher prazisiert zu haben, wodurch wieder neue Missverstândnisse entstehen könnten.

76 . $[. .$.$] jedes Programm schließt Ehrlichkeit aus, die das wichtigste Element jedes Schaffens ist."$

7 "Nicht weniger ist es eine Tatsache, dass der Formismus bis heute kein sog. Rezept der Malerei schuf, das man in einigen Worten zusammenfassen konnte, aber ein solches Rezept kann nie ein Kriterium fur wahre Kunst sein."
} 
Programm“ („Bez programu“) in der vierten Nummer von „Formiści“ veröffentlichte $(1921 a)^{78}$.

Es nimmt daher nicht wunder, wenn auch die Formisten selbst immer wieder betonen, dass die Unterschiede zwischen ihnen zu groß seien, als dass sie sich auf eine gemeinsame Theorie ihrer Kunst hätten einigen können. Witkacy schreibt dazu in „Fortführung der Polemik mit Leon Chwistek“ („Dalszy ciagg polemiki z Leonem Chwistkiem“), dass es zwischen den Formisten immer schon ,gravierende Meinungsverschiedenheiten“" (,jaskrawe różnice zdañ") gegeben habe und dass anfangs höchstens der Wille stärker gewesen sei, diese zu überwinden (1923c, 420). Als Beleg dafür führ Witkacy das Zerbrechen der Gruppe sowie seine Diskussion mit Chwistek an ${ }^{79}$.

Chwistek beschäftigt sich mit Witkacys Schriften unter anderem in "Tytus Czyżewski und die Krise des Formismus" sowie in "Die Vielfalt der Wirklichkeiten in der Kunst“ (1924), Witkacy widmete seiner Kritik an Chwisteks Theorie sogar zwei eigene Aufsătze, die bereits genannt wurden: „Kritik der Kunsttheorie Leon Chwisteks“, den er in „Ästhetische Skizzen“ veröffentlichte und „Fortfuhrung der Polemik mit Leon Chwistek“, der 1923 erschien. Der zentrale Punkt, an dem sich die Meinungen teilten, ist die Beziehung zwischen Kunst und (außerkünstlerischer) Wirklichkeit. Für Chwistek ist dieser Rückgriff auf eine bestimmte WirkJichkeit, wie gesagt, immanent. Witkacy hingegen misst dieser Wirklichkeit (der Sphäre der "Lebensgefühle“) nur insofern Bedeutung zu, als dass in ihr bei der Entstehung eines Kunstwerks die „metaphysischen Gefühle“ projiziert werden, letztendlich aber allein die

\footnotetext{
$"$ Nur Pronaszkos Text „Ober den Expressionismus" kann, aufgrund des Zusammenhangs mit der ersten Ausstellung der Gruppe, ansatzweise die Funktion eines Programms einnehmen. Offen muss jedoch die Einschatzung der Bemerkung Chwisteks aus seinem Tagebuch bleiben, in der er schreibt (in: Estreicher 1971, 202), dass er durch seinen Aufsatz ..Die Vielfalt der Wirklichkeiten in der Kunst“ (1918) einen großen Einfluss auf die Entwicklung der Gruppe genommen habe.

79 Diese Diskussion zwischen den beiden wichtigsten Theoretikem aus dem Kreis der Formisten könnte ohne weiteres zum Gegenstand einer eigenen Untersuchung gemacht werden. Denn Chwistek und Witkacy waren seit ihrer Kindheit, die sie in den neunziger Jahren des 19. Jahrhunderts gemeinsam in Zakopane verbrachten, miteinander befreundet und von dieser Zeit an, bis in die dreißiger Jahre hinein, war ihre Beziehung gepragt von intellektuellen Auseinandersetzungen. Es warde allerdings den Rahmen und auch die Themenstellung diesei Arbeit bedeutend aberschreiten, sich mit dieser Beziehung ersch ̋ppend auseinander zu setzen, erwăhnt seien daher nur jene Differenzen zwischen Chwistek und Witkacy, die sich unmittelbar aus den hier behandelten Texte zum formistischen Kunstverstandnis ergeben. Denn auch in diesen Texten nehmen die beiden Autoren immer wieder explizit Stellung zueinander. Ausfuhrlich schreiben zu diesem Thema: Estreicher (1971, 244-252) und Pollakowna (1972, 116-118 sowie 127-130). Ihren Niederschlag fand diese Beziehung auch in literarischer Form, und zwar in Witkacys Roman „.Die 622 Unglucksfalle Bungas oder die dämonische Frau“ (,622 upadków Bunga czyli Demoniczna Kobieta“), in dem Chwistek als Baron Brummel de Buffadero Bluff auftritt, nicht zuletza als Autor eines .metaphysischen Romans“ mit dem Titel .Kardinal Xylotet“ (.,Kardynal Xylotet”). Witkacys Roman entstand zwischen 1909 und 1911; Chwistek arbeitete in diesen Jahren (1907-1914) in der Tat an seinem Roman „Kardinal Pontiflet“ (,Kardynal Pontifler*), den er allerdings 1919, ohne ihn vorher gedruckt zu haben, vernichtete. Die Figur des Kardinals nahm Chwistek in seinen zweiten Roman .Pałace Boga“ („Die Palăste Gottes“. 1932-33) wieder auf. Vgl. zu Chwisteks Romanen sowie zur Rolle Chwisteks in Witkacys Romanen: Grzeniewski 1968. 5-79
} 
formale Konstruktion entscheidend sei (vgl. auch: Chwistek 1924, 9). An diesem Punkt macht Witkacy auch seine Kritik fest (vgl. zum Beispiel: 1922e, 246-249 und 255 bzw. 258): Für ihn beschäftigt sich Chwistek ausschließlich mit der Beziehung zwischen Kunst und Wirklichkeit, wodurch er das Formale völlig vernachlässige bzw. nur unzureichend behandle. Dies betreffe im Besonderen die Beziehung zwischen den Formen eines Kunstwerks und der Wirklichkeit. Außerdem lehnt es Witkacy ab, die ästhetische Qualität eines Kunstwerkes in irgendeiner Form an den in ihm präsenten gegenständlichen Inhalt zu knüpfen, wie es Chwistek mit dem Phänomen der „Oszillation des Inhalts“ zu beschreiben versucht. Für Witkacy können nämlich nicht eindeutig bestimmte bzw. bestimmbare Gegenstände, niemals zufriedenstellend in die Komposition des Kunstwerks integrier werden.

Ferner kritisiert Chwistek an Witkacys Ansatz, dass sich dieser letztendlich auf das subjektive Urteil des Künstlers beruft bzw. berufen muss, vor allem in der Frage, ob eine bestimmte Komposition gelungen ist, das heißt ob sie die „metaphysischen Gefühle“ zu reflektieren und zu evozieren vermag. Unter anderem schreibt Chwistek darüber in "Fragen der zeitgenössischen Architektur":

„Nie wchodzac $w$ analize tych teorii [m. in. Witkacego; M.E.] zaznaczyć musze, ze teoria sztuki nie moze zalezec od uczuć artysty, a tym samym widza, bez względu na to, czy te uczucia sa niezmiernie wzniosłe (metafizyczne), czy tez pospolite (zyciowe). Jeśli godzimy się na to, ze w sztuce chodzi o forme i tylko o forme, to nie pora nam zastanawiać się nad metafizycznym znaczeniem tego pojęcia ani tez analizować laczace się z nim wzruszenia. [...; Mowiąc o konkretnych problemach sztuki; M.E.] nie potrzeba odwoływać się so tak zawitych i ciemnych zagadnień jak jednosc osobowosci." $(1921 \mathrm{~b}, 77-78)^{20}$

Witkacy antwortet auf diesen Vorwurf des Subjektivismus in „Fortfuhrung der Polemik mit Leon Chwistek“ und betont, dass er eine objektive Theorie der Kunst überhaupt für unmöglich halte, gerade wenn es um Kriterien für die Bewertung von Kunstwerken gehe. Hier müsse, so Witkacy, auch das subjektive Empfinden sowohl des Künstlers, als auch des Rezipienten eine Rolle spielen und eine Theorie der Kunst müsse daher vor allem versuchen, objektive Kriterien für die Beschreibung von Kunstwerken zu finden, von denen ausgehend subjektive Urteile erst möglich und auch berechtigt sind (vgl. 1923c, 411-416).

Gerade Witkacy reagiert in seinen Texten oftmals auch auf konkrete Vorwürfe von Chwistek. Die Polemik zwischen beiden setzte sich bis in die dreißiger Jahre hinein fort - geführt mit

\footnotetext{
${ }^{20}$ "Ohne diese Theorien [=zum Beispiel von Witkacy; M.E.] eingehender analysieren zu wollen, muss ich anmerken, dass die Theorie der Kunst nicht von den Gefuhlen des Konstlers, ebenso wenig wie von denen des Betrachters, abhăngen darf, unabhăngig davon, ob diese Gefühle außerst erhaben (metaphysisch), oder gewðhnlich (lebenspraktisch) sind. Wenn wir darin abereinstimmen, dass es in der Kunst um die Form und nur um die Form geht, ist es nicht an der Zeit, uber die metaphysische Bedeutung dieses Begriffs nachzudenken. noch die mit ihm verbundenen Emotionen zu analysieren. [...; Spricht man aber konkrete Probleme der Kunst; M.E.] ist es unnotig, sich auf so verworrene und dunkle Fragen wie die Einheit der Persornlichkeit zu berufen."
} 
besonderer Leidenschaft von Witkacy ${ }^{81}$. Chwistek hingegen, so Estreicher (1971, 249-250), wollte, zum Teil aus persönlichen Gründen, in den späten zwanziger und in den dreißiger Jahren nicht mehr auf Witkacy reagieren.

Ob die formistische Gruppe auch aufgrund der Differenzen zwischen Witkacy und Chwistek letztendlich zerbrochen ist, wie in der Sekundärliteratur manchmal vermutet wird (vgl. zum Beispiel: Zaworska 1975, 342 sowie - etwas relativierend: Estreicher 1971, 190) muss offen bleiben. Denn es gab in der formistischen Gruppe seit ihrer Gründung immer schon Differenzen, wie dies bereits mehrfach zum Ausdruck kam. Dennoch sei nun abschließend der Versuch unternommen, ausgehend von den in diesem Kapitel untersuchten Texten, die wesentlichsten Aspekte des formistischen Kunstverständnisses festzuhalten.

Zuerst sei in diesem Zusammenhang das Bestreben der Formisten genannt, eine nicht mimetische Kunst zu etablieren, die sich in erster Linie an der Form des Kunstwerks, vor allem an dessen Komposition orientiert. Dieses Ziel versuchen die formistischen Theoretiker zum Teil auf unterschiedlichen Wegen zu erreichen: Pronaszko durch eine vom Künstler entwickelte Art die differenten Eindrücke der äußeren Wirklichkeit zu erfassen, Chwistek durch die Bestimmung der „visionären Wirklichkeit“ und Witkacy durch die Konzeption des Schaffensprozesses als Objektivierung der "metaphysischen Gefühle“ des Künstlers. Am Ende stehen bei allen drei Kunstwerke, deren ästhetischer Wert sich auf deren Form stützt und an diesem Punkt können die einzelnen theoretischen Ansätze auch zusammengefuhrt werden, das heißt vergleichend miteinander betrachtet werden, wenn auch der Begriff der „Form" durchaus verschieden verstanden wird. Dies trifft gleichermaßen auch auf die Auffassung vom Inhalt und dessen Rolle in einem Kunstwerk zu: Alle drei Theoretiker vollzogen aber nicht den Schritt hin zu einer vollig abstrakten Kunst, sondern versuchten den gegenständlichen Inhalt, der auf eine immanente Beziehung zwischen Kunst und einer außerkünstlerischen Wirklichkeit zurückführbar ist. im ästhetischen Sinne fruchtbar zu machen. Witkacy führte in diesem Zusammenhang den Begriff der „Richtungsspannungen“* ein, die die Einheitlichkeit der Komposition des Kunstwerks stärken, Chwistek sprach von der "Oszillation des Inhalts", der die Aufmerksamkeit des Betrachters mehr auf die formalen Qualităten zu lenken vermag. Aus diesem Grund scheint die oftmals geäußerte Kritik an Chwistek und Witkacy, es gehe ihnen um eine vollständige Eliminierung bzw. Entwertung (im ästhetischen Sinne) des Inhaltes im Kunstwerk, ungerechtfertigt. Eine solche Kritik metafizyka” (1922c, 173). „Auf dem Grund bleibt die Lage - als unehrliche. nichtssagende Metaphysik.” 
formuliert zum Beispiel Karol Irzykowski, der sich in zwei Aufsätzen (1922 und 1929) mit den theoretischen Ansätzen beider Autoren beschäftigt und mit ihnen in jener Hinsicht polemisiert, als dass er versucht, auch den gegenständlichen Inhalt, im Falle der Literatur: ein bestimmtes Thema oder eine Handlung, als Quelle ästhetischer Befriedigung zu bestimmen ${ }^{82}$. Auch Wiktor Doda geht in seiner Kritik des Formismus von derselben falschen Annahme aus, wie Irzykowski. So schreibt Doda (1925, 16 und 19) unter anderem vom formistischen Bestreben, eine „Form ohne Inhalt“ (,forma bez treści") zu schaffen, sieht im Formismus daher die Fortsetzung des modemistischen Postulats der l'art pour l'art und versucht, in Berufung auf die beiden Aufsätze von Irzykowski, nachzuweisen. dass Form und Inhalt im Kunstwerk untrennbar miteinander verbunden seien, weswegen es unmöglich sei, einen der beiden Teile zu eliminieren. Zwar bemerkt Doda, dass zum Beispiel Chwistek, gegen den sich der Großteil seiner Kritik richtet, in seinen Schriften immer wieder auch von der Rolle des Inhalts spricht, etwa im Sinne von Elementen einer bestimmten Wirklichkeit, versucht dies aber als Inkonsequenz in Chwisteks ästhetischer Theorie zu beschreiben (1925, 20-21).

Die Neubestimmung des Verhältnisses zwischen Inhalt und Form wird auch in den im nächsten Abschnitt untersuchten literaturtheoretischen Schriften sowie in der Interpretation der formistischen Gedichte Czyżewskis eine zentrale Rolle spielen. An dieser Stelle bleibt noch festzuhalten, dass der Formismus im theoretischen Sinn als eine offene Richtung erscheint, die sich einem „Schaffen nach Programm“ widersetzt. Dem Formismus ist ein bewusster Pluralismus in den theoretischen Ansätzen eigen, für den auch die hier behandelten Texte als Beispiele stehen, da in ihnen stets der individuelle Zugang des Autors zu Fragen der neuen Kunst im Vordergrund steht und weniger der Wunsch, im Namen aller Mitglieder der formistischen Gruppe zu sprechen.

\footnotetext{
"Das beredtste Beispiel dafür ist Witkacys Text: „Leon Chwistek - Dämon des Intellekts" (..Leon Chwistek Demon intelektu“), der in 15 (!) Folgen in der Zeitschrift „Zer" (..Z“) 1933 und 1934 erschien.

* Irzykowskis Artikel uber Witkacy erschien ursprunglich in seinem 1929 veroffentlichten Buch mit dem bezeichnenden Titel: „Der Kampf um den Inhalt. Studien zur literarischen Erkenntnistheorie“ („Walka o treśc.

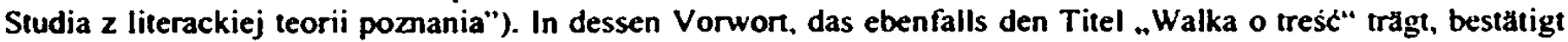
Irzykowski (vgl. 1975, 198), dass es ihm in seinem Artikel zu Chwistek darum ging. das Primat des Inhaltes ober die Form hervorzuheben.
} 


\section{Die formistische Literaturtheorie (Texte der Formisten zur Literatur)}

Von den Mitgliedern der formistischen Gruppe haben sich Chwistek, Czyżewski und Witkacy mit Literatur, das heißt vor allem mit Lyrik beschäftigt. Ähnlich wie im Falle der im vorigen Kapitel besprochenen Texte, geht es ihnen auch hierbei nicht um einen einheitlichen theoretischen Entwurf hinsichtlich einer "formistischen Poesie", sondern darum, die Grundlagen einer von (völlig) neuen Voraussetzurgen ausgehenden Poesie zu beschreiben. Der Formismus steht so auch in diesem Bereich mehr für eine allgemeine, von den Positionen der Avantgarde aus geführte Diskussion über die neue Kunst'.

\subsection{Zur Erneuerung der Literatur - Literatur und (ihre) Gegenwart}

Ein zentraler Punkt, der in fast allen literaturtheoretischen Texten der Formisten zumindest erwähnt wird, betrifft - allgemein gesprochen - die Erneuerung der Literatur. Am ausfuhrlichsten behandelt diesen Aspekt Czyzewski, und zwar in seinem Artikel „Die Poesie der Expressionisten und Futuristen“ („Poezja ekspresjonistów i futurystów“, 1919)². Er stellt darin die neuesten Erscheinungen in der europäischen Literatur zusammen mit ihren Grundlagen dar und erwähnt alle Länder, in denen wichtige Impulse zur Emeuerung der modernen Literatur gegeben wurden: vor allem Frankreich und Italien, aber auch Deutschland und Russland. Ein Ziel Czyzzewskis war es sicher, mit diesem Artikel ein breites, interessiertes Publikum mit den neuesten Tendenzen vertraut zu machen, was der Publikationsort - die Krakauer Tageszeitung „Goniec krakowski“, die relativ einfache Sprache sowie die auf ihre wesentlichsten Elemente reduzierten Zusammenhänge erklären.

Czyżewski gibt in „Die Poesie der Expressionisten und Futuristen“ zunächst einen Überblick über die Entwicklung der europäischen Literatur (vgl. 1919c, 78-80), und zwar am Beispiel Italiens und Frankreichs: Besonders in der französischen Literatur, so fuhrt Czyżewski aus, sei der Schritt hin zu einer neuen Dichtung. schon in der zweiten Hälfte des 19. Jahrhunderts

\footnotetext{
' Als Materialgrundlage fur diese Untersuchung dienen alle theoretischen oder programmatischen Texte von Chwistek, Czyzewski und Witkacy, die wăhrend ihrer Zugehorigkeit zur formistischen Gruppe entstanden sind. Gerade an den literaturtheoretischen Schriften von Chwistek und Witkacy wird deutlich - das sei an dieser Stelle vorausgeschickt, dass die formistischen Theorien zu einem großen Teil ursprunglich am Material der bildenden Kunst entwickelt wurden. Am deutlichsten zeigt sich dies bei Witkacy, der seinen Ansatz der "Reinen Form“ direkt auf die Literatur abertragt. Der Preis einer solchen Obertragung scheint aber auch zu sein, dass bestimmte, eigentlich zentrale Begriffe, nicht (mehr) eigens fur die Literatur definiert werden, was vor allem auf den Begriff der ,Form" zutriff.
} 
getan worden: Von Rimbaud ging zum Beispiel der innovatorische Impuls aus, die Dichtung der Malerei anzunähern. In seinem berühmten Gedicht „Voyelles“ arbeitet Rimbaud nämlich mit den einzelnen Vokalen zugeordneten Farben, die er als Symbole für das Verskolorit verwendet. Die Symbolisten um Mallarmé verfeinerten die Mittel des poetischen Ausdrucks, was ihnen erlaubt, über die Symbole in ihren Werken Farb-, Klang- und sogar Geschmackseindrücke hervorzurufen. Doch waren sie, was die Form ihrer Verse sowie den Bau ihrer Metaphem betriff, traditionell, das heißt im Falle ihrer sprachlichen Bilder, dass diese auf einer gewissen Logik und auf einem „äußeren Realismus“ (,realizm zewnętrzny“) aufbauen. Erst Claudel, vor allem aber Whitman konnten dies durchbrechen: durch die Einführung von „Vergleichsdissonanzen“ („dysonanse porównan“) bzw. durch „unerwartete“ und „plötzliche Wendungen“ (,zwroty nieoczekiwane i nagłe“). Damit erreichte die Dichtung für Czyzewski in ihrer Entwicklung die modernste Zeit, in der sie auf die neuesten Erscheinung der Gegenwart reagieren kann und in der nun zum Beispiel der Futurismus aufritt:

..Szuuka poetycka, rozwijając się z wolna na mocy ewolucji, doszła do uypowiedzenia przez poetę stanów najgłębszych. czasem neurastenicznych $i$ neuropatologicznych. Poeta, będacy przewaznie nerwowym $i$ zdenerwowanym dzjeckiem wielkiego miasta. wchłanial w siebie ten powszechny dynamizm wspótczesnej mechaniki świata cywilizowanego. [...] Na gruzach ,sielankowości’, a raczej po epoce .dekadencji sielankowosici, powstał w Paryzu i we Wloszech, futuryzm, inicjowany i propagowany przez poete Marinettiego." (1919c, 80)

Czyżewski setzt den Zeitpunkt. ab dem es zu einer Erneuerung der französischen Literatur kam, im 19. Jahrhundert mit Rimbaud an. Rimbaud und die Symbolisten begannen, die Dichtung von Realismus und Naturalismus loszulösen, was sich auch die Formisten als Aufgabe setzten. Rimbaud. Mallarmé, Claudel und Whitman erbrachten für Czyżewski jeweils „einzelne Beiträge“ (Entdeckung der Farben. Erweiterung der Möglichkeiten des poetischen Ausdrucks, Einführung von Spontaneität und freien Assoziationen in die Dichtung etc.) für die Erneuerung der Literatur, auf die die gegenwärtige Poesie nun zurückgreifen kann. So lässt sich zum Beispiel im deutschen Expressionismus, den Czyżewski selbst in die Nachfolge des französischen Symbolismus stellt, der Wille des Dichters bemerken, das zum Ausdruck zu bringen. „was innerlich, sinnlich nicht erfassbar und geistig ist" ("co

\footnotetext{
${ }^{2}$ Ein deutsche Übersetzung von Czyzewskis Text findet sich in: Lam 1990, 101-104.

3 .Die poetische Kunst. die sich schrittweise durch die Kraft der Evolution entwickelte, erreichte jenen Punkt, an dem der Dichter die tiefsten, manchmal neurasthenischen und neuropathischen Zustănde zum Ausdruck bringt. Der Dichter, ein vorwiegend nervoses und generves Kind der Großstadt, nahm diesen allgemeinen Dynamismus der gegenwartigen Mechanik der zivilisierten Welt in sich auf. [...] Auf den Ruinen des ,Idyllischen' bzw. eher nach der Epoche der, Dekadenz des Idyllischen', entstand in Paris und in Italien der .Futurismus', der vom Dichter Marinetti initiiert und propagiert wurde."
} 
wewnętrzne, zmysłowo nieuchwytne i duchowe"), und zwar durch die gänzliche Aufhebung der ,logischen Bildlichkeit“ („obrazowość logiczna“) in der Poesie (1919c, 81).

Mit der Situation der polnischen Literatur, im Vergleich zur europäischen, beschäftigt sich Czyżewski im ersten Teil (vgl. 1921a, 175-176) von „Das Begräbnis der Romantik Altersschwäche des Symbolismus - Tod des Programmismus“ („Pogrzeb romantyzmu uwiąd starczy symbolizmu - śmierć programizmu“"): Die polnische Literatur habe keine ähnliche Entwicklung wie zum Beispiel die französische durchlaufen können, da sie sich ausschließlich mit dem "Martyrium der Nation“ (,martyrologia narodu“) beschäftigte und dadurch in „Form und Stimmung völlig der Romantik“ verpflichtet blieb („o formie $\mathrm{i}$ nastrojach zupełnie romantycznych“). Auch Witkacy spricht von dieser Art der polnischen Literatur und nennt sie ,prophetisch“ („wieszczy“):

„Powstanie tego typu [=literatury typu ,wieszczego”; M.E.] zwiazane było z metafizyczna interpretacją klęsk, które spotkały polski naród. [...] Ciśnienie pojęcia Polski, zmuszające do ,wieszczenia' par force, byłoby według nas niepozadane i tamowałoby swobodny rozwój literatury. Dawniej kazdy literat musiał być wieszczem prawie ze obowiazkowo [...]." (1921c, 283-284)

Beide Autoren sind aber der Meinung, dass mit dem Wiederentstehen des polnischen Staates im Jahre 1918 diese Art von Dichtung überflüssig werde. Bei Czyżewski heißt es dazu:

\begin{abstract}
„Naród polski nie moze juz zyć próchnami królów i dziadów. Naród polski nie moze morfinować się koszmarami $z$ Wesela, ale musi poczuc w sobie szuke i poezję odrodzenia współczesnego. Polska uzyskała swoja niezalezność polityczna $w$ tak szczęsliwym czasie $i$ okolicznościach, ze razem $z$ przebudzeniem sie jej do życia - przebudziły się $\mathrm{i}$ narodziły sie w Europie nowe wartości socjalne $i$ estetyczne." (1921a, 176)
\end{abstract}

Es scheint Czyżewski wichtig zu betonen, dass die Emeuerung der polnischen Literatur zwischen 1910 und 1917 im Prinzip von denselben Faktoren bestimmt wurde, wie in anderen europäischen Ländern. An erster Stelle nennt Czyżewski in diesem Zusammenhang (1919c, 78-79) die außereuropäische Kunst Japans, Mexikos oder Polynesiens, die die gesamte europäische Avantgarde, insbesondere die Malerei, nachhaltig beeinflusst habe. Eine wichtige Rolle spielen für Czyżewski auch, wie erwăhnt, die Großstadt sowie die Technik in all ihren neuen Erscheinungsformen: Maschinen, Dynamos, Motoren, Mechanik oder

\footnotetext{
Auf deutsch in: Lam 1990, 179-180.

5 "Das Entstehen dieser Ant von Literatur [=d.h. der ..prophetischen“: M.E.] war mit der metaphysischen Interpretation der Niederlagen verbunden, die die polnische Nation erlitt. [...] Der Druck des Begriffs Polen, der mit Nachdruck zum ,Prophetisieren' zwingt, ware unserer Meinung nach unerwonscht und warde die freie Entwicklung der Literatur behindern. Froher was es fast schon verpflichtend fur jeden Literaten, ein Prophet zu sein [...]." Ein Teil von Witkacys Aufsatz ist in deutscher Obersetzung bei Lam (1990, 203-220) abgedruckt.

6 .Das polnische Volk kann nicht lănger von der Asche der Konige und GroBvăter leben. Das polnische Volk kann sich nicht lănger mit den Alpträumen aus Die Hochzeitsfeier [=Drama von Stanisław Wyspiański; M.E.] betăuben, sondern muss in sich die Kunst und Poesie einer modernen Renaissance fuhlen. Polen erreichte seine
} 
Geschwindigkeit, was nicht nur die Lebensform, sondern auch die psychische Verfassung der modemen Menschen radikal verändere: „W spółczesnym właśnie człowieku ujawnia się ,konflikt pozostałości’ duszy pasterza - z duszą twórcy dynamomaszyny.“ (1919c, 80) ${ }^{7}$. Einen Zusammenhang zwischen der psychischen Verfassung der Menschen (der Künstler) und den neuen Formen in der Kunst sieht übrigens auch Witkacy, wovon weiter unter noch die Rede sein wird. Für Czyżewski geht es somit in der neuen Dichtung vor allem um "Abkürzungen und notwendige synthetische Abrundungen“ (,skróty i potrzebne syntetyczne zaokrąglenia“) sowie insgesamt um ,eine neue Form, geeignet für die zeitgenössischen Menschen, die nach nervösen, synthetischen Reizen verlangen“ („nowa odrębna forma. podatna dla ludzi współczesnych, laknących nerwowych, syntetycznych wzruszeń.“ - 1921 a. 176). Besonders deutlich zeigt sich für Czyżewski der Einfluss der veränderten Wirklichkeit des beginnenden 20. Jahrhunderts in der Kunst des italienischen Futurismus (1919c, 80).

An dieser Stelle sei erwähnt, dass es Czyżewski, im Unterschied beispielsweise eben zum italienischen Futurismus, nicht darum geht, die Maschine zu verabsolutieren - er stellt ihr, ihrem präzisen Funktionieren, den „Instinkt der Tiere“ (,,instynkt zwierząt“) entgegen. Die neue Kunst müsse beide Einflüsse gleichermaßen in sich aufnehmen und vereinen, also sowohl von den Maschinen, als auch von den Tieren „lernen“. Den Vorzug gibt Czyżewski dabei den Tieren und ihrem Instinkt, worüber er in seinem Manifest von $1921 \mathrm{mit}$ dem vielsagenden Titel: „Von der Maschine zu den Tieren - Wer ärgert sich über uns?“ („Od maszyny do zwierzat - Kto sie gniewa na nas?") ${ }^{8}$ schreibt:

.Zywiof - od ogólnego mechanizmu do instynktu zwierzq̨ - będziemy bracmi zwierzą i bẹdziemy się uczyć od nich instynktowej sztuki. kochać będziemy maszyny, gdyz one nasze siostry i zwierzęta bo one nasi nauczyciele i bracia. [...]

Uczymy się muzyki od ptaków. - Architektury, malarstwa i rzeżby od gniazd zwierzęcych. Instynkt mechanizmu $=$,niech kazdy pisze. rzeżbi i maluje jak mu jego instynkt wskazuje'! Szukamy instynktu. który zgubiliśmy doskonaląc się przez tyle wieków w sztuce i nauce.

Niech zyje elektryczny instynkt instynktowna sztuka zwierzat instynkt elektryczny." (1922c, 117$)^{9}$

politische Unabhăngigkeit zu einer so glücklichen Zeit und unter so glücklichen Umstănden, dass gleichzeitig mit seiner Erweckung zum Leben in Europa neue soziale und asthetische Werte erweckt und geboren wurden." ${ }^{7}$.Gerade im gegenwărigen Menschen offenbart sich der .Konflikt der Relikte' der Seele des Hirten - mit der Seele der Schopfers der Dynamomaschine."

- Von diesem Manifest existieren zwei leicht unterschiedliche Versionen. da Czyzewski die ursprünglich in der vierten Nummer von .Formiści“" abgedruckte Fassung noch einmal, in uberarbeiteter und etwas gekurzter Fassung, in seinem zweiten Gedichtband „Noc-Dzien. Mechaniczny instynkt elektryczny“" (1922) veroffentlichte. Wahrend Lam (1969, II/177-178) die erste Fassung abdruckt, ist in dem von Baluch herausgegebenen Band von Czyzewskis Gedichten $(1992,117)$ die aberarbeitete Version zu finden.

9. Element - vom allgemeinen Mechanismus zum Instinkt der Tiere - wir werden Bruder der Tiere sein und wir werden von ihnen die instinktive Kunst lernen, lieben werden wir die Maschinen, da sie unsere Schwestem sind und die Tiere, da sie unsere Lehrer und Brader sind. [...] Die Musik lernen wir von den Vogeln. Architektur, Malerei und Plastik von den Tiemestem. Der Instinkt des Mechanismus $=$.jeder soll schreiben. 
Der Instinkt oder die Intuition, als eine der rational-wissenschaftlichen Analyse entgegengesetzte Art der Welterkenntnis, spielte für die gesamte europäische Avantgarde eine bedeutende Rolle. Diese wird im allgemeinen durch die Philosophie Bergsons erklärt, der die Intuition als eine Möglichkeit, die Welt zu sehen, bestimmt, die frei von bereits vorgegebenen Schemata (zum Beispiel durch eine bestimmte Tradition) und logischen Begriffen ist - also gerade die individuelle, die eigene Weltsicht hervortreten lässt (vgl. auch: Lipski 1993, 13). Gerade hierin liegt der entscheidende Aspekt für die Avantgardisten, die dies auch als Begründung der Notwendigkeit zur Deformation (in der bildenden Kunst) bzw. zur Aufhebung logischer Sinnkategorien (in der Dichtung) verstanden. Es sei daran erinnert, dass auch Chwistek in „Die Vielfalt der Wirklichkeiten in der Kunst“ (1918) auf Bergson im Zusammenhang mit der "futuristischen" Malerei verweist: nämlich dass erst durch dessen Denken die Künstler ihre Visionen so hätten darstellen können, wie sie sich ihnen auch tatsächlich zeigten („oddawać swoje wizje zgodnie z ich właściwym kształtem“-1918, 44) ${ }^{10}$. In diesem Sinne ist „Instinkt“ auch im angefuhrten Zitat bei Czyzzewski zu verstehen: Jeder soll so schaffen, wie es ihm sein Instinkt zeigt, was aber, wie die Zeile "Tylko bez programowych prymitywów" einschränkt (1922c, 117), nicht die Rechtfertigung für ein gänzlich willkürliches künstlerisches Schaffen sein darf ${ }^{11}$. Daher ist es vielleicht hier nun die Präzision der Mechanik, die dem Instinkt als notwendiges Korrelat zur Seite gestellt wird. Somit wird deutlich, dass sich für Czyzewski Instinkt und Maschine, Natur und Technik gegenseitig bedingen und im Falle der neuen Kunst untrennbar zusammenwirken, was er auch in seinen Gedichten häufig thematisien. Auch für den modernen Menschen sind beide gleichermaßen von Bedeutung: „Przyszły czlowiek, to elektryczna maszyna - czuła skomplikowana, a prosta w stylu." $(1922 \mathrm{c}, 119)^{12}$.

Für Czyżewski sind es also, nun zusammenfassend gesprochen, vor allem zwei Erscheinungen, die die Erneuerung der Literatur entscheidend beeinflussen: die modeme Zivilisation und die Hinwendung des Künstlers zum Ursprünglichen (Primitiven). Dazu kommt, dass die Literatur, wie auch die Kunst, nicht mehr im Dienste konkreter politischer

bildhauem und malen wie ihm sein Instinkt zeigt'! Suchen wir den Instinkt, den wir verloren haben, indem wir uns jahrhundertelang in Kunst und Wissenschaft perfektionier haben. Es lebe der elektrische Instinkt - die instinktive Kunst der Tiere - der elektrische Instinkt."

10 "die eigenen Visionen entsprechend ihrer eigentlichen Gestalt wiedergeben".

" "Nur: ohne programmatische Primitive." Vgl. dazu auch die Anmerkung von Baluch zu diesem Text Czyzewskis, die diese Zeile als gegen die Warschauer Futuristen Stem und Wat gerichtet liest (in: Czyzewski 1992. 117). In der Tat werden Stern und $W$ at in der zweiten Version des Manifestes auch namentlich genannt. Czyzewski wirf ihnen darin vor, das wiederholen zu wollen, was die italienischen Futuristen schon vor zehn Jahren gemacht hăten (vgl. Czyzewski, in: Lam 1969, 11/178).

${ }_{12}$ "Der kunftige Mensch ist eine elektrische Maschine empfindsam komplizier, aber einfach im Stil." 
oder gesellschaftlicher Zwecke stehen soll. Der zuletzt genannte Aspekt unterscheidet Czyżewski und den Formismus insgesamt von vielen europăischen Avantgarde-Bewegungen, die die von ihnen angestrebte Emeuerung, in möglichst allen Lebensbereichen durchsetzen wollten $^{13}$. Besonders sichtbar wurde das politische Engagement bei den italienischen und russischen Futuristen (gerade nach der Oktoberrevolution), die teilweise auch aktiv in den politischen Parteien ihrer Länder mitarbeiteten. Die Formisten hingegen wollten ihre Kunst nicht im Zusammenhang mit gesellschaftlichen oder politischen Aktivitäten sehen: „My bez programu dążymy do stworzenia nowej ery wartości estetycznych, tj. wartości sztuki.“ (Czyzewski 1921a, 176) ${ }^{14}$.

Die in diesem Kapitel gewonnenen Erkenntnisse sind mehr allgemeiner Natur und betreffen die Literatur als solche. Ausgehend davon, geht es im folgenden Abschnitt um speziellere Probleme, etwa das Verständnis des Begriffs „Form“ bei den einzelnen Autoren. Zu fragen ist aber auch nach ihrer Funktion für die künstlerische Bedeutung eines Gedichtes und vor allem nach dem Verhältnis zwischen Form und Inhalt im Kontext eines sprachlichen Kunstwerks.

\subsection{Der „mehrdeutige Inhalt" und die „Reine Form ${ }^{\mu}$ - zum Verhältnis zwischen Form und Inhalt im literarischen Kunstwerk}

Chwistek und Witkacy stimmen in der Frage, was Dichtung nicht ist (heute nicht mehr ist). mehr oder weniger überein: Für beide Autoren ist Dichtung kein Trost für Sorgen, keine Stärkung des Mutes, keine Bestätigung des Nationalstolzes, keine Unterhaltung und auch keine Wissenschaft - für all diese Aufgaben stünden geeignetere Mittel zur Verfügung (Chwistek 1920a, 102). Die Kunst ist darüber hinaus keine inhaltliche Ausarbeitung bestimmter Themen oder Ausdruck der "Lebensgefulhle“, wic Witkacy betont. Für ihn geht es, wie in der Malerei auch in der Literatur einzig um die "metaphysischen Gefühle“, also um Fragen der Existenz. Aus diesem Grund bezeichnet er Gedichte auch als „verdichtete Formeln ewiger Gesetze des Seins“ (.,skondensowane formuly wiecznych praw Bytu“ - 1920, 276277).

\footnotetext{
${ }^{13}$ Borger beschreibt dieses Vorhaben der A vantgarde als „Ruckfuhrung der Kunst in Lebenspraxis“ und arbeitet diesen Aspekt als eine der Hauptthesen in seinem Buch „Theorie der Avantgarde“ (1974) aus. Die Avantgarde. so Barger, wollte den Autonomiestatus der Kunst aufheben. um so die Abkehr vom Prinzip des ästhetischen Selbstzwecks zu erreichen.

i4 „Ohne Programm streben wir danach. eine neue Ära asthetischer Werte, d.h. Werte der Kunst, zu schaffen."
} 
Als wesentlichstes Element des ästhetischen Ausdrucks eines literarischen Kunstwerks bestimmen Czyżewski, Chwistek und Witkacy die Form, wenngleich sie den Begriff selbst auf jeweils unterschiedliche Weise definieren.

Für Chwistek ergibt sich die Hinwendung zur formalen Seite der Dichtung, wie erwähnt, aus dem Funktionswandel, den die Literatur insbesondere seit 1918 durchlaufen hat. In der Betonung der Form ist für Chwistek aber das eigentlich Ästhetische der Poesie begründet:

.Ci, którzy pragna poezji naprawdę, wiedz̧, ze znaležć w niej można jedna tylko wartośc wielka $i$ jedno tylko uczucie godne zaspokojenia, a mianowicie: doskonala formę $i$ upojenie się ta forma. Dązenie do poezji pojętej w ten właśnie sposób nazywamy formizmem w poezji." (1920a, 102)

Trotz der hohen ästhetischen Bedeutung, die Chwistek hier der Form zumisst, bleibt er in seinen Texten bei der Bestimmung des Begriffs, gerade in Bezug auf das literarische Kunstwerk, recht allgemein. Unter "Form" versteht er (vgl. 1921a, 82 und 1922/24, 100$102^{16}$ ) in erster Linie die nicht-inhaltliche Seite der Dichtung, bezogen sowohl auf die Art und Weise des künstlerischen Verfahrens, durch das ein bestimmter Inhalt zum Ausdruck gebracht wird, als auch auf den Aufbau eines literarischen Kunstwerkes, das heißt dessen Komposition. Allerdings räumt Chwistek dabei gleich ein, dass es - zu einer Zeit, in der die neuen Formen der Dichtung gerade erst im Entstehen begriffen seien, unmöglich scheine, grundlegende Prinzipien des Gedichtaufbaus zu nennen. Dazu kommt noch, dass sich für Chwistek jedes neue Gedicht um formale Neuerungen bzw. um eine innovative Weiterentwicklung bekannter Formen bemühen soll, was die Existenz von festen Regeln a priori ausschließe. Chwistek bestimmt daher nur einige allgemeine Prinzipien, die er für die Komposition als wesentlich erachtet: das Akzentuieren von Rhythmus, Tempo sowie einzelnen Klängen (Klangfolgen und Reimen), die den Aufbau eines Gedichtes bestimmen. Als Hauptpunkte der Komposition

is „Diejenigen, die wirklich nach Poesie verlangen, wissen, dass man in ihr nur einen großen Wert und nur ein Gefuhl finden kann, das es wern ist, befriedigt zu werden, namlich: die vollendete Form und das Sich-Berauschen an dieser Form. Das Streben nach einer gerade so verstandenen Dichtung nennen wir Formismus in der Poesie."

${ }^{16}$ Hierbei handelt es sich um einen unveroffentlichten Text von Chwistek uber die Poesie, den Estreicher im Rahmen seines Aufsatzes zitiert. Wie dieser einleitend bemerkt (vgl. 99-100), handelt es sich dabei um das Manuskript zu einem Vortrag Chwisteks, das ungefahr zwischen 1922 und 1924 entstanden sein durfte. Es konnte daher sein, dass es sich dabei um einen der vier Vortrage handelt, die Chwistek um 1922 in Krakau hielt und deren erster (Chwistek 1922a), wie erwałhnt, in der zweiten Nummer von .Nowa sztuka“ erschien. Bemerkenswert scheint an beiden Texten, dass Chwistek darin - auch im Falle Czyzewskis - von ..futuristischer" und nicht von .,formistischer" Poesie spricht. Warum dem so ist, daruber kann nur spekulien werden. Beide Texte sind um 1922 entstanden, also zu einer Zeit, als die formistische Gruppe schon im Auflosen begriffen war. In der von Chwistek verwendeten Bezeichnung „Futurismus“ kann auch ein Beleg fur das Naheverhăltnis der Formisten zu den Futuristen, deren Zusammenarbeit ja gerade 1921-22 sehr intensiv war, gesehen werden, wie ebenso dafur, dass Namen und Bezeichnungen fur Stromungen in der frahen polnischen A vantgarde noch nicht so stark im Bewusstsein fundiert und daher austauschbar sind. Auch Chwistek selbst verwendet in ..Die Vielfalt der Wirklichkeiten in der Kunst" (1918) noch „Futurismus" als Oberbegriff fur die neueste Malerei. Dennoch ist es gerade im Falle Chwisteks, der sich in vielen seiner Schriften um die 
nennt Chwistek außerdem einzelne Ausdrücke, die auch typographisch hervorgehoben werden sollen. Die einzelnen Teile eines Gedichtes sollen so nicht mehr über den Inhalt, sondern über den Rhythmus sowie die „Anordnung der Verse“ („rozłozenie wierszy“) miteinander verbunden werden.

Wenngleich Chwistek betont, es gehe ihm nicht um eine erschöpfende Definition von „Form“, sondern nur darum, ansatzweise zu verdeutlichen, in welcher Hinsicht er den Begriff gebrauche (1921a, 82), so ist die Kritik Irzykowskis, Chwistek arbeite in seiner Theorie mit einem ungenügend bestimmten Formbegriff, nicht ganz zu unrecht geäußert:

„Coz to jest ta forma? Mozna by sie spodziewac, ze jezeli od kogo, to od filozofa otrzymamy dokładne wiadomości w tej równie populamej jak zagmatwanej sprawie. Lecz p. Chwistek albo mówi o formie komunały, albo odmawia wyjaśnien, i pod tym względem takze jako filozof jest formista czy oscylacjomista." $(1922,453)^{17}$

Auch für Czyżewski stehen formale Innovationen in der Dichtung in einem engen Zusammenhang mit der Gegenwart, wenngleich er im Unterschied zu Chwistek, weniger einen Funktionswandel der Kunst, als vielmehr gesellschaftliche Veränderungen bzw. neue technische Errungenschaften dafür verantwortlich macht.

Czyzewskis Verständnis von „Form“ vermag insbesondere das Jan Bołoz-Antoniewicz gewidmete Gedicht „Für die Kunst und das Leben“ zu vermitteln. Czyzzewski bestimmt in diesem Gedicht die Bedeutung der Form für die moderne Kunst und Literatur, die Art der Aussage erinnert dabei an den manifestartigen Charakter von programmatischen Texten. Auf der anderen Seite versucht er gerade in diesem Gedicht nicht, formale Innovationen direkt umzusetzen: die zwanzig Verse des Gedichtes sind paarweise durch zweisilbige Endreime miteinander verbunden. Die einzelnen Verse sind für sich abgeschlossen (Zeilenstil) und kurz, sie bestehen aus sieben bzw. acht Silben mit je drei unregelmäßig verteilten Betonungen (tonisches Metrum). Durch diesen recht einfachen formalen Bau des Gedichtes soll aber vielleicht gerade dessen programmatischer Charakter unterstrichen werden.

Das ganze Gedicht ist dem „Neuen“ gewidmet: „Form" wird dabei in den einzelnen Teilen mit verschiedenen Aspekten dieses "Neuen“ in Verbindung gebracht. Gleich in den ersten vier Versen ist dies der Bau neuer Welten, die Konstruktion eines neuen Lebens:

Bestimmung des .Formistischen" bemaht, verwunderlich, dass er in diesen Texten zur Poesie eben von „Futurismus" und nicht von .Formismus" spricht.

i7 "Was ist das, diese Form? Man kठnnte erwarten, dass man, wenn schon, dann von einem Philosophen genaue Auskunft in dieser ebenso verbreiteten wie verwickelten Angelegenheit erhalten wöde. Aber Hert Chwistek sagt aber die Form entweder Banalitäten oder verweigen die Erklärung und ist daher unter diesem Gesichtspunkt auch als Philosoph ein Formist oder ein Oszillationist." Irzykowski spielt hier in geistreicher Weise auf Chwisteks Bestimmung des "oszillierenden Inhalts" an, der aufgrund seiner vom Kunstler ihm bewusst zugeschriebenen Uneindeutigkeit die Form stärker hervortueten lässt. 
„Przez FORME budowa swiatów

Styl zycia sztuki i kwiatów

Mlot bije dom się gotowi

Tna kwarce murarze nowi“* $(1920 a, 57)^{18}$
„Durch die FORM der Bau von Welten

Stil des Lebens der Kunst und der Blumen

Der Hammer schlagt das Haus wird ferig

Neue Maurer schneiden Quarzblocke"

Eingeleitet durch: „Idzie nadwielkie życie“ („Es kommt das übergroße Leben“), erfolgt in den weiteren Zeilen die Beschreibung dieses neuen Lebens. Dies geschieht erstens durch die Bildlichkeit des Gedichts („Rozkwit kwiatu Magnolii“, „Ocean ognia w zenicie“ oder „Pójda gwiezdną ulica“ - „Aufblühen der Magnolienblüte“, „Feuerozean im Zenit“ oder „Sie werden eine Sternstraße gehen“), zweitens durch Beschreibung typischer Bewusstseinszustände des modernen Menschen („dreszczy nerwowych drgan“" - „Schauer nervöser Zuckungen“) und nicht zuletzt drittens durch einen aus der Welt der modernen Technik entlehnten Wortschatz (,atomy“, „prądy radiosiły“ - „Atome“, „Ströme der Radiokraft“), der, an der Entstehungszeit des Gedichtes gemessen, sehr neu und innovativ wirkt. „Form“ wird außerdem mit der neuen Kunst in Zusammenhang gebracht: neben dem Titel des Gedichtes „Für die Kunst und das Leben“ geschieht dies auch im zweiten Vers des angeführten Zitats: „Stil des Lebens der Kunst.“ Bemerkenswert scheint, dass die Verse, in denen „Form“ mit dem Bau neuer Welten, dem neuen Leben verbunden wird, am Anfang des Gedichtes stehen. Hingegen schließen diejenigen Verse, die „Form“ und neue Kunst betreffen, das Gedicht ab, wodurch eine Art Rahmen geschaffen wird. Diese letzten vier Verse lauten:

\footnotetext{
„Od sztuki przez STYL do trwania

Duch ku harmonii sie sktania

Gdzie bezmyśl formy nie zbruka

Gdzie nowa rodzi się sztuka."
}

\author{
„Von der Kunst aber den STIL zur Dauer \\ Der Geist neigt zur Harmonie \\ Wo der Un-Gedanke die Form nicht beschmuta \\ Wo die neue Kunst geboren wird."
}

„Form" wird, wie in den oben zitierten Zeilen, auch hier mit „Stil” assoziiert, beide Begriffe scheinen miteinander identisch zu werden. Als die einzigen des ganzen Gedichts sind sie im Druckbild zusätzlich durch Großbuchstaben hervorgehoben, was ihre besondere Bedeutung unterstreichen soll.

Diese enge Verbindung von „Form" und „Stil“ erinnert an Zbigniew Pronaszkos „Über den Expressionismus". Er hebt darin die Form als den eigentlichen Ausdruck des künstlerischen Schaffens hervor und bringt sie in ihrem Charakter mit einer Konvention. einem Stil in Verbindung: Dieser Stil, das heißt die Art des Künstlers, die Form und Gestalt der einzelnen Elemente seiner Kunstwerke zu bestimmen, sei auch das einzige Ziel, das sich eine Künstlergruppe für ihre Arbeit setzen dürfe, gleichwie er auch ihr einziges Vermächtnis bleibe, so Pronaszko $(1918,15)$. Der Vers „Od sztuki przez STYL do trwania” aus

\footnotetext{
18 Alsch alle weiteren Zitate aus diesem Gedicht im folgenden Text stammen aus dieser Quelle.
} 
Czyżewskis Gedicht kann demnach auch in diesem Sinne verstanden und wie folgt paraphrasiert werden: „Von der Kunst durch Form und Stil zur Dauer, zur Ewigkeit“ - Form und Stil sind das Stabile, Feste, das, was bleibt, das „einzige Vermächtnis“.

Es findet sich noch ein zweiter Gedanke aus Pronaszkos Text in „Für die Kunst und das Leben": Die Form ist kein spontanes Produkt künstlerischen Schaffens, sondern kann nur auf dem Weg intellektueller Anstrengung und Konzentration gefunden werden: „Dzieło rozumu i woli“" ("Werk des Verstandes und Willens“) heißt es in Czyżewskis Gedicht, ebenso wie: "Gdzie bezmyśl formy nie zbruka“, das oben zitiert und mit: „Wo der Un-Gedanke die Form nicht beschmutzt..." übersetzt wurde. Diese Übersetzung bedarf einer genaueren Erklärung: Im Polnischen gibt es das von Czyżewski verwendete „bezmyśl“, das mit "Gedankenlosigkeit“ (polnisch eigentlich: „,bezmyślnośc்“) nur unzureichend übersetzt wäre, an sich nicht. Die Bedeutung dieses Ausdrucks ist aber über seine beiden Teile leicht erschließbar: „myśl“ heißt auf deutsch „Gedanke“ oder „Idee“, das Präfix „,bez-,, (wörtlich: "ohne") bringt das Nicht-Vorhandensein einer im zweiten Teil des Kompositums genannten Sache zum Ausdruck. Worauf es Czyżewski hier ankommt, wird aus der Opposition zum zuvor Gesagten deutlich, als er die Form als Schöpfung der intellektuellen Konzentration und des Verstandes bestimmte. Als deren Gegenteil ist eben „bezmyśl”, das heißt das Fehlen einer Idee, eines konstruktiven Gedankens zu verstehen. Ebenso ist das mit dem Subjekt ,.bezmyśl“* verbundene Prädikat ,nie zbruka“ (,nicht beschmutzt“) nur als Teil einer semantischen Opposition zu begreifen: „beschmutzen“ steht von seiner Bedeutung her der Reinheit und Klarheit einer ansprechenden künstlerischen Form gegenüber. Erst an diesem Punkt ist die wichtigste Feststellung des Gedichts möglich, die im letzten Vers zum Ausdruck kommt: "gdzie nowa rodzi się sztuka.“

Am intensivsten setzt sich aber erneut Witkacy mit der „Form" und deren Funktion im literarischen Kunstwerk auseinander, wenngleich er den zentralen Begriff seines ästhetischen Systems, den der „Reinen Form“, für die Literatur nicht eigens bestimmt, sondern ihn aus der Malerei überträgt und ihn an die Gegebenheiten der Dichtung anpasst:

„Formę będziemy tu [=w poezji; M.E.] rozumieli oczywiscie analogicznie do naszej koncepcji czystej formy $w$ malarstwie, tj. jako konstrukcje calości, czyli pewna jedność $w$ wielośc, $z$ ta róznica, ze o ile elementy tej wielości w malarstwie sa jednorodne. o tyle w poezji będa złożone. Będziemy więc kazdy wiersz, względnie zblizona do wiersza prozę, uwazali za pewien prad, składajacy się ze splatanego pęku róznych pradów. Pierwsza wartościa tego prąu będa wartości dżwiękowo-rytmiczne, następnie pojęciowe jako takie [...]. a następnie obrazowe, jako uboczny skutek znaczeń pojęc lub calych zdan, przedstawienie sobie w fantazji wzrokowej sugestionowanych obrazów." (1921c, 291-292)

19 "Die Form werden wir hier [ = in der Poesie; M.E.] naturlich analog zu unserer Konzeption der Reinen Form in der Malerei verstehen, das heißt als Konstruktion des Ganzen, also als gewisse Einheit in der Vielheit. mit dem Unterschied, dass die Elemente dieser Vielheit in der Malerei einheitlich sind. wohingegen sic in der Poesie 
Unter der „Form“ eines literarischen Kunstwerks versteht Witkacy also auch hier in erster Linie dessen Konstruktion. Handelt es sich dabei im Falle der bildenden Kunst um Formen und Farben, so bestimmt Witkacy hier drei Teilaspekte, aus denen sich das „Bündel“ eines bestimmten Gedichtes als Ganzes prinzipiell zusammensetzt. Es sind dies - entsprechend den Bezeichnungen, die Witkacy an einer anderen Stelle verwendet (vgl. 1921 c, 296): die "Laute im Rhythmus" („dźwięki w rytmie“; im Zitat: „die lautlich-rhythmischen Werte“), der „Sinn“ und die „Bedeutung der Begriffe“ („sens“, „znaczenie pojęç“; im Zitat: „die Begriffe als solche“, das heißt die Ebene der Semantik) sowie die Topik, die „visuellen Bilder“ (,obrazy wzrokowe“), die im Zitat als Assoziationen, Visionen etc., die dem Rezipienten beim Hören/Lesen eines Gedichtes als „Nebeneffekt” entstehen, umschrieben wurden. Witkacy bezeichnet die Poesie auch als eine „zusammengesetzte Kunst“ oder „Mischkunst“ (,sztuka złożona" bzw. "mieszana"), und zwar deswegen, da in einem Gedicht die drei genannten Elemente stets zusammenwirken (vgl. 1920, 276). Der Begriff „zusammengesetzte Kunst“ scheint dabei zutreffender als „Mischkunst“ zu sein, da er besser das Zusammenspiel von Lauten. Bedeutungen sowie den im Text gebrauchten Bildern und Assoziationen bezeichnet. Auch der Rezeptionsprozess selbst wird letztendlich von diesem Zusammenspiel bestimmt, da während der Aufnahme eines Gedichtes immer ein bestimmtes Element in den Vordergrund tritt, das heißt im Bewusstsein des Rezipienten präsent ist. Die beiden anderen Elemente verharren währenddessen im sogenannten „gemischten Hintergrund“ („tlo zmieszane“). In einem nächsten Moment kann sich dieses Verhältnis zwischen den Einzelelementen aber ändern: so tritt einmal stärker der Klang, dann wieder die Bedeutung etc. hervor und wirkt auf den Rezipienten (vgl. 1921c, 286-287 und 295-296). Interessant ist auch die Tatsache. dass Witkacy dieselben drei Elemente auch in Bezug auf einzelne Begriffe bzu: Begriffskombinationen feststellt, wovon weiter unten noch die Rede sein wird. An dieser Stelle sei noch festgehalten, dass Witkacy bei seinen Ausführungen über die „Reine Form“ in der Poesie nicht so sehr ins Detail geht. wie im Falle der bildenden Kunst, was im dritten Kapitel beschrieben wurde. Dies mag damit zu tun haben, dass er seine in „Die neuen Formen in der Malerei“" entwickelte Vorstellung der Form. wie erwähnt, auf die Literatur überträgt. ohne diese noch einmal in umfassender Weise neu zu bestimmen. Somit scheint es, dass die „Reine Form“, auf der schließlich die ästhetische Befriedigung, das heißt das „metaphysische

zusammengesetzt sind. Wir werden daher jedes Gedicht bzw. der Lyrik nahe stehende Prosa, als gewisse Stromung verstehen, die sich aus einem Bandel verschiedener Stromungen zusammensetzt. Der erste Wert dieser Stromung sind die lautlich-rhythmischen Werte, dann die begrifflichen als solche [...] und anschließend die bildlichen, als Nebeneffekt der Bedeutung der Begriffe oder ganzer Sătze, als eine Vorstellung suggerierter Rilder in der visurllen Phantasie." 
Gefühl" beruht, für Witkacy auch in der Dichtung vor allem aus dem Zusammenspiel Jer Einzelelemente im Rahmen der Komposition eines literarischen Kunstwerks zustande kommt. Da Witkacy die „Reine Form“ in der Malerei nicht auf den Inhalt, das heißt die dargestelten Gegenstände, sondern auf die formale Konstruktion (Einzelformen oder Farben) stützt, kann angenommen werden. dass es in der Dichtung in erster Linie die Klänge und Klangstrukturen sind, die das "metaphysische Gefühl“ hervorrufen können. Dies erklärt, warum Witkacy der Rezitation eines Gedichtes so hohe Bedeutung beimisst. wie er am Beispiel von Kazimiera Illakowiczówna und Julian Tuwim betont:

„Moze nie sa oni [=Iłlakowiczówna i Tuwim; M.E] technicznie wykształceni, moze nie maja postawionych głosów, moze nie słychać by ich bylo w promieniu 300 metrów, ale za to. słuchając ich deklamacji. można się przeniesć w świat czysto artystycznych wrazeń, a nie doznawać bebechowych wstrzasów od ryku dzikiej bestii, która zerwała się $z$ tańcucha." (192Ic, 297)

Ein guter Rezitator versucht somit für Witkacy nicht, durch Betonungen oder ähnliche stimmliche Effekte, beim Zuhörer Gefühle wie Trauer oder Sehnsucht zu wecken, sondern bemüht sich einzig und allein darum, die Klangstruktur eines bestimmten Gedichtes adäquat hervortreten zu lassen - nur darin ist letztendlich eine tiefere ästhetische Befriedigung gegeben.

Alle drei Autoren bestimmen die „Form“, verstanden als Art und Weise des poetischen Ausdrucks, als das ästhetisch Wesentliche am Kunstwerk. Dabei wird „Form“ einerseits mit „Komposition“, andererseits mit dem Neuen im Allgemeinen sowie mit der Erneuerung der literarischen Ausdrucksweise im Speziellen in Zusammenhang gebracht. Vor allem in Czyżewskis Gedicht „Für die Kunst und das Leben“ wird dies deutlich, wo es um den „Bau neuer Welten" und um eine "neue Kunst“ geht. Auch bei Chwistek ist der Gedanke von der Erneuerung des poetischen Ausdrucks durch die Form zu finden, wenn er schreibt: „Każdy poemat wielki musi przynosić nową formę, albo przynajmniej pewne wyrażne modyfikacje form dawniejszych.“ (1922/1924, 103) ${ }^{21}$. Von „Form“ im Sinne von „Konstruktion“ bzw. „Komposition“ ist zwar in erster Linie in den Texten von Witkacy die Rede, doch auch Czyżewski unterstreicht die hohe Bedeutung der Komposition. und zwar in Bezug auf den

\footnotetext{
20 ..Sie [=Illakowiczówna und Tuwim: M.E.] besitzen vielleicht keine fachliche Ausbildung, vielleicht haben sic keine ausgebildeten Stimmen, man konnte sie wahrscheinlich im Umkreis von 300 Metern nicht horen, aber dafur kann man, wenn man ihre Rezitationen horn, in eine Welt reiner künstlerischer Eindracke vorstoßen und erfahrt keine Erschütterung der Innereien durch das Geschrei einer wilden Bestie, die sich von der Kette losriss." 21. Jedes große Gedicht muss eine neue Form mit sich bringen oder zumindest gewisse deutliche Modifikationen fruherer Formen."
} 
künstlerischen Schaffensprozess selbst, wenn er über die neue Dichtung schreibt: „Artyści będa jak najmniej używać tematu, a jak najwięcej konstruować.“ $(1921 \mathrm{a}, 177)^{22}$.

In diesem Satz klingt etwas sehr Wesentliches an: Es geht nicht - und darin sind sich alle drei Autoren einig - um eine völlige Preisgabe des Inhaltes ${ }^{23}$. Zwar tritt dieser, was seine künstlerische Bedeutung betriff, gegenüber der Form zurück, doch kann die Dichtung nicht gänzlich auf ihn verzichten. Chwistek schreibt, dass sie ansonsten zur „Geräuschmusik“ verkomme ${ }^{24}$. Doch er räumt ein:

\begin{abstract}
.Natomiast sztuki te [-poezja, malarstwo, rzeźba; M.E.] rozporzadzaja środkami, przy pomocy których mozna tresć tak dobrać, zeby wrazenie artystyczne płynące $z$ doskonałej formy nie tylko nie zostało umniejszone, ale w swoisty sposób do ostatecznych granic spotęgowane. Pochodzi to stąd, ze zarówno sens zdania. który jest treścia w poezji, jak rzeczywistość. która jest treścia w malarstwie i rzezbie, nie sa jednoznacznie określone i skutkiem tego pozostawiaja niezmieme pole do swobodnych odksztalceń." (1920a. $101)^{2 s}$
\end{abstract}

Der künstlerische Ausdruck wird also über das Zusammenspiel von Form und Inhalt hergestellt, in dem der Inhalt die formalen Qualitäten der Dichtung stärker hervorheben soll. Nur ein auf entsprechende Art gewählter Inhalt kann die Form wirklich zur Geltung bringen. Und auch im Zusammenhang mit der Emeuerung der Dichtung ist der Inhalt für Chwistek von Bedeutung: „Jednym słowem, nowa forma nie da się pomyśleć bez nowego sposobu pojmowania treści." $(1922 / 1924,102)^{26}$.

Die Fähigkeit des Inhalts, die formalen Qualitäten eines literarischen Kunstwerks stärker hervortreten zu lassen, stammt, wie Chwistek es im längeren oben angeführten Zitat formuliert, in erster Linie daher, dass der „Sinn eines Satzes“, also sein „Inhalt”, unklar bleibt. Chwistek geht dabei von folgender Annahme aus: Ist der "Sinn eines Satzes" allzu klar, absorbiert er zu schnell die für das Verständnis dieses Satzes aufgebrachte Aufmerksamkeit

\footnotetext{
22 .Die Kunstler werden møglichst wenig ein Thema benutzen und moglichst viel konstruieren.”

${ }^{23}$ Gerade dieser Aspekt wurde, wie zum Teil bereits erwahnt, von den Kritikem des Formismus (zum Beispiel: Irzykowski 1922 und 1929, Doda 1925 oder Baczyński 1923 und 1924) of falsch verstanden, die davon ausgehend oft die Unmoglichkeit betonten (und damit das ..Scheitern" der formistischen literarischen Ästhetik). die Literatur ganzlich von ihrer Bedeutungsebene zu befreien und den literarischen Ausdruck auf sinnentleen. Klangkombinationen zu statzen.

${ }^{24}$ Etwa schreibt Chwistek: .,[...] ze nie moga one [=poezja, malarstwo i rzeżba: M.E.] oderwać sie w zupełności od treści." (1920a, 100). .[...] dass sie [=Poesie, Malerei und Plastik; M.E.] sich nicht gănzlich vom Inhalt loslosen konnen." An anderer Stelle betont er (1921a, 91), dass es keine eindeutige Grenze zwischen der Poesie und der ..Gerauschmusik" gebe.

25. Allerdings verfugen diese Kunste [=Poesie, Malerei, Plastik; M.E.] Ober Mittel, durch deren Hilfe der Inhalt so gewăhlt werden kann, dass der auf der vollendeten Form beruhende kunstlerische Eindruck nicht nur nicht geschmalert, sondern auf eigene Weise bis zu den letzten Grenzen gesteigert wird. Dies kommt daher, dass der Sinn eines Satzes, der den Inhalt in der Dichtung darstellt, gleichermaßen wie die Wirklichkeit, die den Inhalt in der Malerei und der Plastik bildet, nicht eindeutig bestimmt sind, wodurch sie ein unermessliches Feld fur freie Deformationen hinterlassen." Diese Stelle von Chwistek wurde schon im dritten Kapitel zitiert, aus Grunden einer zusammenhăngenden Darstellung wird dieses Zitat hier noch einmal angefuhrt.

${ }^{26}$...Mit einem Wort: die neue Form laxss sirh nhne eine neue Art. den Inhalt zu erfassen. nicht denken.”
} 
des Rezipienten, ohne dass sich dieser näher mit der Form des Satzes oder des ganzen Gedichts, also dem eigentlich Künstlerischen, beschäftigen kann. Dazu schreibt Irzykowski:

\begin{abstract}
„Ale co najwazniejsze: p. Chwistek - i nie tylko on - widocznie nie jest zdolny do stwierdzenia najprostszej oczywistości psychologicznej, inaczej widziałby, ze właśnie rzecz ma się przeciwnie, ze wieloznacznośc, niejasność treści zwraca silnie uwage na te treść, sklania czytelnika nawet pomimo jego woli do odgadywania, domyślania się, w ogóle wyzywa go do pracy intelektualnej, a przez to odwraca jego uwage od spraw formy." $(1922,459)^{29}$
\end{abstract}

Irzykowski hat Recht und nicht Recht zugleich. Ein Gedicht, dessen Inhalt unklar bzw. nicht ganz klar ist, spornt den Rezipienten zweifellos dazu an, den Inhalt ganz zu erfassen. Was Irzykowski jedoch übersieht, ist, dass dieses Verstehen nur über das Sich-Bewusstmachen der formalen Gestaltungsprinzipien dieses Gedichtes führt. Erst wenn die Form, das heißt die Art und Weise, wie die künstlerische Aussage zustande kommt, klar ist, ist auch zu verstehen. was damit gesagt wird bzw. werden kann. In dieser Hinsicht beschreibt Chwistek das Verhältnis zwischen Form und Inhalt im literarischen Kunstwerk und seine Annahme ist insofern richtig, dass durch einen leicht verständlichen Inhalt die Aufmerksamkeit des Rezipienten kaum auf die Form gelenkt wird.

Im Idealfall, so kann Chwisteks Ansatz weitergedacht werden, verschwindet der Inhalt während des Rezeptionsprozesses zunehmend aus dem Bewusstsein des Lesers oder Hörers eines Gedichts. Dessen ganzes Augenmerk gilt von da an nur mehr der Form der künstlerischen Aussage, die durch ihre ästhetische Vollkommenheit begeistert. Dies zeigt die folgende Bemerkung Chwisteks über die beiden Verse: „wdziej ciepłe astrachany // termometr wciąz opada" aus Czyżewskis Gedicht "Miasto w jesienny wieczór (niesielanka)" („Stadt an einem Herbstabend. Nichtidylle“ - Czyżewski 1920a. 41) 28.

„Trudno podać piękniejszy przykład wyzyskania treści wyrazów dla spotęgowania siły rytmu. Wszytko przeciez jedno. ze gdzieś termometr opada, ale ten przedziwny, jakby w nieskończoność skierowany spadek rytmu drugiego wiersza. absorbuje całą uwage. wywołjąc rozkosz i niepokój właściwy wielkiej sztuce." (Chwistek 1920b. 32)

27. Aber was am wichtigsten ist: Herr Chwistek - und nicht nur er - ist offensichtlich nicht fahig. die einfachste psychologische Selbstverstăndlichkeit zu bemerken, ansonsten săhe er, dass es genau umgekehrt ist, dass die Vieldeutigkeit, die Unklarheit des Inhalts die Aufmerksamkeit nachdrucklich auf diesen Inhalt lenkt und den Leser, sogar gegen dessen Willen, dazu verleitet, diesen Inhalt zu entschlusseln, zu mutmaßen, ihn also allgemein zur intellektuellen Arbeit ruft und dadurch seine Aufmerksamkeit von der Form abwendet." Denselben Vorwurf richtet. unter Berufung auf Irzykowski, auch Doda (vgl. 1925, 23) an Chwistek.

${ }^{28}$ "zieh an den warmen Persianer // das Thermometer fallt und fallt". Mit .astrachan“ wird. wie Baluch zu diesem Gedicht anmerkt (in: Czyzewski 1992, 41), der Pelz des Karakulschafes bezeichnet, das aus der Umgebung der Stadt Astrachan an der Wolga stammt. Im Deutschen heißt dieses klein gelockte Fell von den Lammern des Karakulschafes auch .,Persianer".

29. .Man konnte schwer ein schoneres Beispiel dafur finden, wie der Inhalt der Ausdracke fur die Steigerung der Stärke des Rhythmus genutzt wird. Es ist doch eigentlich egal, ob irgendwo ein Thermometer fallt. da dieses seltsame, scheinbar ins Unendliche gerichtete Fallen des Rhythmus des zweiten Verses die ganze Aufmerksamkeit auf sich zieht und ein Glucksgefuhl sowie eine der großen Kunst eigene Unruhe hervorruft." 
Der Inhalt der beiden Verse von Czyżewski ist klar und leicht nachvollziehbar: Bei Käite ist es ratsam, sich warm anzuziehen. Was Chwistek durch seine Bemerkung aber zum Ausdruck bringen will, ist, dass das Sinken der Temperatur im zweiten Vers zwar explizit genannt wird, sich ungleich stärker aber durch dessen formale Gestaltung, das heißt durch den fallenden Rhythmus (dieser Vers kann mit einer einzigen Betonung auf der zweiten Silbe gelesen werden) im Bewusstsein des Rezipienten verankert. Deshalb, so Chwistek, sei es ziemlich egal, ob parallel dazu noch irgendwo ein "Thermometer" auch wirklich "fällt “30. Dieses Beispiel zeigt nicht zuletzt noch einmal, dass es Chwistek, ebenso wie Czyżewski und Witkacy, nicht um die vollständige Eliminierung des Inhaltes, sondern um eine Neubestimmung des Verhältnisses zwischen Form und Inhalt im literarischen Kunstwerk geht.

Die beiden zuletzt besprochenen Verse von Czyżewski stellen insofern eine Besonderheit dar, dass in ihnen die Form auch bei einem völlig klaren Inhalt dominierend hervorzutreten vermag, wodurch dieser Inhalt im Prinzip unwichtig wird. Dieses Moment des Hervortretens der Form über den Inhalt sieht Chwistek, wie angedeutet, aber vor allem dann gegeben, wenn der Inhalt mehrdeutig und schwer verständlich ist, wie er in gleich drei Texten erläutert: „Der Formismus“ (1920), im Vorwort zu Czyżewskis Gedichtband „Das grüne Auge. Formistische Dichtungen. Elektrische Visionen“ und in „Über die Poesie“ („O poezji“, 1921), seinem Beitrag zu „Das Messa im Bauch“. Er zeigt dies am Vergleich zwischen einem Satz aus einem wissenschaftlichen Text und einem Satz aus einem Gedicht. Der Verfasser eines wissenschaftlichen Textes strebt für Chwistek nach Klarheit und Verständlichkeit des Gesagten. Er umschreibt aus diesem Grund denselben Gedanken mit verschiedenen Worten. das heißt er ändert die Form seiner Aussage, um zum eindeutigen Inhalt, das heißt einer

\footnotetext{
${ }^{30}$ Auch zum angefuhrten Zitat Chwisteks nimmt Irzykowski Stellung: „Otóż wbrew temu [=stwierdzeniu Chwistka; M.E.] powiadam: takich wierszy jest setkami, Czyzewski skorzystal tu z formy utartej. będacej własnościa wspólną, nie można więc - i nie trzeba - windykować właśnie jemu jako wynalazku rzeczy, która jest zaczerpnięta ze wspólnego dziedzictwa i jezeli p. Chwistek przy tak drobnej sposobnosci nie moze wyjsć z transu podziwienia, to chyba oszaleje, gdy będzie czytal np. wiersze Tuwima, bo nie starczy mu sil, aby nadziwič się wszytkim zdobyczom powszechnej kultury literackiej, jakie kazdy poeta, lepszy czy gorszy, wplata w swoje utwory." (1922, 461-462). ..Dem [=der Behauptung Chwisteks; M.E.] halte ich jedoch entgegen: solche Gedichte gibt es zu Hunderten. Czyzewski gebrauchte hier eine konventionelle Form, die ein Gemeingut darstellt, man kann und braucht daher nicht ihm die Erfindung einer Sache zuschreiben, die aus einem gemeinsamen Erbe stammt und wenn Herr Chwistek bei einem so kleinen Anlass schon in eine tranceartige Bewunderung verfallt, so dreht er wahrscheinlich durch, wenn er zum Beispiel Gedichte von Tuwim liest, da seine Kraft nicht ausreicht, um alle Errungenschaften der allgemeinen literarischen Kultur zu bewundem, die jeder bessere oder schlechtere Dichter in seine Werke einbaut." Irzykowskis Kommentar ist sicher nicht unberechtigt. berahrt aber nicht den zentralen Punkt von Chwisteks Ausfuhrungen, was sich auch dadurch zeigt, dass Irzykowski im selben Aufsatz vorschlägt, „termometr" im zitierten Vers Czyzewskis durch "majonez" (.Mayonnaise“) zu ersetzen, da doch der Rhythmus gleich bliebe (463). Es geht Chwistek aber eben nicht nur um den Rhythmus allein, sondem um das Zusammenspiel von Rhythmus (Form) und Inhalt, wobei der Schwerpunkt eindeutig auf der Form liegt
} 
klaren Botschaft, zu gelangen. Das Verfahren des Dichters ist genau umgekehrt: Er wählt den Inhalt so, um die formalen Qualitäten stärker zu akzentuieren und um die endgültige und vollendete, nicht mehr veränderbare Form zu finden. Dies geschieht eben durch eine vom Dichter beabsichtigte Mehrdeutigkeit, durch eine bewusste „Verschleierung des Inhaltes“ (,zaciemnieníe treści“). Dank der Mehrdeutigkeit bleibe, so Chwistek (vgl. 1920a, 101-102 und 1920b, 31), der Inhalt im Hintergrund, wodurch die Form der Aussage stärker hervortreten könne. Auch die Aufmerksamkeit des Rezipienten richte sich so länger auf einen Satz, was wiederum ein besseres Erkennen der Form ermögliche.

Aus dem besonderen Verhältnis zwischen Inhalt und Form in einem Gedicht zieht Chwistek folgenden Schluss, der für ihn zugleich ein wichtiges Merkmal der formistischen Auffassung von Lyrik beschreibt: „[...] forma musi opierać się na bezwzględnie koniecznych zestawieniach wyrazów, podczas gdy treść powinna być jak najbardziej płynna." (1920b, $31)^{31}$. Ein ähnliches Verständnis von „Form“ kam auch in Czyżewskis Gedicht „Für die Kunst und das Leben" zum Ausdruck. in dem sie als das Dauerhafte, das Ewige am Kunstwerk bestimmt wurde.

Dieser „fließende Inhalt" kann zum einen durch die erwähnte, bewusste Mehrdeutigkeit charakterisiert sein, zum anderen ist damit aber auch die Einführung von nicht logischen. scheinbar unsinnigen Aussagen in die Dichtung gemeint, was Chwistek in „Über die Poesie“ folgendermaßen beschreibt:

.Jest jasne, ze [...] posuwamy się [...] coraz bardziej do pustego dżwięku wyrazów, czyli do tzw. muzyki szmerów. - Tym samym oddalamy się coraz bardziej od zagadnienia prawdy i falszu. przesuwajac się na teren zagadnień czysto formalnych. - Jest jasne, ze dazenie poezji do oddzielenia się od nauki $i$ innych obcych sztuce dyscyplin musi kierować poezje do tych nieuchwytnych terenów, na których jeszcze nie mamy czystej muzyki szmerów, a które jednak sa juz obce problematowi prawdy i fałszu." (1921c, 235)

Zwar dürfe, so Chwistek, die Dichtung nicht zu reinen Malerei sinnentleerter Laute werden. dennoch müsse sie sich, maximal vom eindeutigen Sinn entfernen (..[gdzie] jeszcze nie mamy czystej muzyki szmerów“), wo die Kategorien „wahr” und „falsch“ ihre Gültigkeit verlieren, wo also keine Urteile über die Richtigkeit von Aussagen, gemessen an den Verhältnissen des

\footnotetext{
" "[...] die Form muss auf absolut notwendigen Zusammenstellungen von Ausdracken basieren. wohingegen der Inhalt moglichst fießend sein soll."

32 .Es ist klar, dass [...] wir uns [...] immer weiter hin zum reinen Klang der Worter, das heißt hin zur sog. Gerauschmusik, bewegen. - Zugleich entfernen wir uns immer mehr von der Frage: ,wahr' oder ,falsch', indem wir uns auf das Terrain rein formaler Fragen begeben. - Es ist klar, dass das Streben der Poesie, sich von der Wissenschaft und anderer der Kunst fremder Disziplinen abzugrenzen, sie in die kaum fassbaren Bereiche fuhrn. in denen wir noch keine reine Gerauschmusik haben, denen aber bereits der Frage: ,wahr' oder .falsch' fremd ist."
} 
täglichen Lebens, mehr möglich sind ${ }^{33}$. Durch diese bewusste Desemiotisierung auf der Inhaltsebene, wird für Chwistek letztendlich wiederum der formale Ausdruck eines literarischen Kunstwerks in den Vordergrund gerückt, entsprechend zur sogenannten Deformation von Gegenständen in der bildenden Kunst.

An diesem Punkt treffen sich Chwisteks Ausfuhrungen mit jenen von Witkacy, der explizit die Frage des Fehlens von Sinn in der Dichtung thematisiert. Damit ist vielmehr die Loslösung der Dichtung von ihren lebenspraktischen Bezügen („Lebensgefühlen“) und weniger völlige Bedeutungslosigkeit, das heißt Sinnlosigkeit (zum Beispiel: Gestammel oder Lallen), gemeint. Gleichermaßen kann dieser Aspekt auch auf die von den Formisten geforderte Loslösung der Dichtung von zum Beispiel patriotisch-politischen Tendenzen bezogen werden.

Es wurde zuvor bereits erläutert, dass Witkacy die Dichtung als „zusammengesetzte Kunst“ betrachtet. Dies gilt für ihn auch im Falle einzelner Begriffe oder Begriffskombinationen, wo ebenfalls lautliche, semantische (das heißt Bedeutungen an sich) und assoziative Elemente, also die durch die Begriffe hervorgerufenen Bilder, zusammenwirken.

Im Kapitel „Die Theorie der Reinen Form in der Poesie“ („Teoria Czystej Formy w poezji“) aus seinem Aufsatz „Nähere Erläuterungen zur Frage der Reinen Form auf der Bühne“ („Bliższe wyjaśnienia w kwestii Czystej Formy na scenie”) widmet sich Witkacy ausführlich den Begriffen. Er versucht dabei diese als ,reine Qualitäten“(,jakości czyste“), das heißt vor allem als Klangstrukturen, zu beschreiben. Er weiß aber auch, dass es im Prinzip nicht möglich ist, die semantische und assoziative Ebene der Begriffe ganz auszuklammern:

\begin{abstract}
.Nas obchodzi tu tylko kwestia znaczenia pojęc jako takich, w pewnym uniezaleznieniu od wizji wzrokowych. Calosć wszytkich tych elementów [dżwiekki, znaczenia oraz obrazy wzokowe: M.E.] moze ponadto sugestionować pewne stany uczuciowe, i to zarówno uczuć zyciowych jak i metafizycznych [...]. Ale sugestia przy pomocy pojęć i obrazów będzie tu pośrednia, nie jak przy pojmowaniu czystej formy, czyli oderwanej konstrukcji elementów, stanowiających jedność. Oprócz tego može być dany wiersz czysto pojęciowym opisaniem $i$ jednych, $i$ drugich uczuc, bez sugestii bezpośredniej. Oba gatunki mozliwych tresci poematów, na równi z zawartymi w nich koncepcjami myślowymi, musimy uznać z punktu widzenia czysto formalnego za nieistotne [...]. Jednak zaznaczamy, ze analizujemy tu pojęcia nie jako elementy nieistotne. tylko jako prawdziwe elementy artystyczne, na równi $z$ jakościami czystymi. Na ten punki zwracamy specjalna uwage. Teoria ta pozwala rozwazac z czysto formalnego punktu widzenia poematy: tzw. z sensem $i$ tzw. bez sensu - može stanowić klucz do rozwiazzania wielu zagadek dzisiejszej sztuki [...]." (192 Ic, 292)
\end{abstract}

${ }^{33}$ Ein Beispiel fulr eine solche Aussage, die allerdings keinen formalästhetischen Wert besitz. gibt Chwistek in „Wielośc rzeczywistości w sztuce“ (1924): „Epimenides powiada: ,Ja klamie." Chodzi o to, czy mówi prawdę. czy nie. Jeśli mówi prawde mówiąc, ze kłamie, to kłamie a więc nie mówi prawdę. Jeśli kłamie mówiąc, ze klamie, to mówi prawde a więc nie kłamie, wypowiada więc zdanie pozbawione sensu.” $(1924,8)$. „Epimenides sagt: ,Ich lage.' Es geht darum, ob er die Wahrheit sagt, oder nicht. Sagt er die Wahrheit, wenn er sagt, dass er luge, so logt er, sagt also nicht die Wahrheit. Lagt er aber, wenn er sagt, dass er luge, so sagt er die Wahrheit, logt also nicht, sagt also einen Satz, der keinen Sinn hat."

${ }^{34}$.Uns geht es hier nur um die Frage der Bedeutung der Begriffe an sich, in gewisser Unabhăngigkeit von visuellen Visionen. Das Gesamt all dieser Elemente [=Klănge, Bedeutungen und visuelle Bilder; M.E.] kann 
Unter „reinen Qualitäten” versteht Witkacy die Einzelelemente eines Kunstwerkes, die keine inhaltliche Bedeutung aufweisen, also zum Beispiel die Farben in der Malerei oder die Töne in der Musik. Als solche möchte er vorrangig auch die Begriffe in der Literatur verstehen ${ }^{35}$. Er ist sich allerdings, wie gesagt, dessen bewusst, dass Begriffe immer einen semantischen Gehalt haben, der auch stets präsent ist, zum Beispiel wenn diese Begriffe in einem Gedicht gebraucht werden. Doch dürfe, so Witkacy, die Funktion dieses Inhaltes nicht missverstanden werden: es gehe nicht um die Beschreibung irgendwelcher Ereignisse, sondern nur um die Verwirklichung der formalen Qualitäten des literarischen Kunstwerks. Ähnlich argumentiert Witkacy auch in jenem Fall, dass in einem Bild immer diese oder jene Gegenstände wiedererkannt werden könnten und versucht, durch Einführung des Begriffs der „Richtungsspannungen“, diese Gegenstände für den formalen Ausdruck des Kunstwerks fruchtbar zu machen, was ihre sogenannte Deformation erfordere. Diese werde aber nur von jenem Standpunkt aus überhaupt als „Deformation“ begriffen. der die Wiedererkennbarkeit der dargestellten Gegenstände in der Malerei fordert und nicht, wie Witkacy es tut, von einer rein formalen Auffassung der Kunst ausgeht.

Ähnlich verhält es sich im Falle der Literatur. Auch hier besteht das eigentlich Künstlerische in der „Reinen Form", das heißt in einer in sich geschlossenen Komposition. Dem Streben nach dieser „Reinen Form“ liegt das Gefühl der „formalen Ungesättigtheit“ (,nienascycenie forma“") zugrunde, das für Witkacy von den Gegebenheiten der modernen Zeit beeinflusst wird $^{36}$. So sei es für die Dichter heute nicht mehr möglich, die Erfüllung der Anforderungen der „reinen Kunst“ mit „,begrifflichem Sinn“(,sens pojęciowy“) zu verbinden:

\footnotetext{
daraber hinaus gewisse emotionale Zustănde suggerieren. und zwar gleichermaßen lebenspraktische wie metaphysische Gefuhle. [...] Allerdings wăre die Suggestion mittels Begriffen und Bildern nur indirekt, nicht wie im Falle der Erfassung der Reinen Form, das heißt einer losgelösten Konstruktion von Elementen. die eine Einheit darstelt. Daruber hinaus kann ein bestimmtes Gedicht eine rein begrifnliche Beschreibung beider Arten von Gefuhlen, ohne direkte Suggestion, sein. Vom rein formalen Standpunkt aus, müssen wir beide Arten des moglichen Inhalts von Gedichten, ebenso wie die in ihnen enthaltenen gedanklichen Konzeptionen, als unwesentlich erachten. [...] Wir betonen aber, dass wir an dieser Stelle die Begriffe nicht als unwesentliche Elemente, sondem als wirkliche künstlerische Elemente. gleich den reinen Qualitaten, analysieren. Auf diesen Punkt weisen wir besonders hin. Diese Theorie erlaubl es uns. Gedichte sowohl mit, als auch ohne Sinn vom rein formalen Standpunkt aus zu betrachten und kann der Schlüssel für die Losung vieler Rătsel der heutigen Kunst sein $[. .] .$.

${ }_{35}$ Vgl. auch die Bemerkung Witkacys: „Elementami malarstwa i muzyki sa czyste. jednorodne jakości; poezji pojęcia w odpowiednich znaczkach widzalnych lub słyszalnych" (192Ic, 283). ..Die Elemente der Malerei und der Musik sind reine, einheitliche Qualităten; der Poesie - Begriffe in entsprechenden visuellen oder akustischen Zeichen."

${ }^{36}$ Witkacy bestimmt damit in den Texten zur Poesie den Impuls for das künstlerische Schaffen auf eine etwas andere An als im Falle der Malerei. Da es ihm aber beide Male letztendlich um die ..Reine Form" geht. kann angenommen werden, dass die ..metaphysische Unruhe" und die ..formale Ungesăttigtheit" einen ungefahr ahnlichen Gefuhlszustand des Kanstlers bezeichnen.
} 
„Niemożność pogodzenia nienasycenia formą z formą rzeczywistych przedmiotów i z sensem określonym, z logika formalna i logika uczuć zyciowych, wyłamywanie się kompozycji spod przesądów naturalizmu jest cecha całej sztuki lat ostatnich [...]." (1921c, 284)

Genau aus diesem Grund, so Witkacy weiter, würden die zeitgenössischen Künstler ihr gegenständliches (Dinge) bzw. begriffliches Material (Wörter) den gegebenen formalen Erfordernissen angleichen, was sich unter anderem in der Deformation der Gegenstände der äußeren Welt in der bildenden Kunst bzw. in der Einführung von (scheinbarem) Unsinn in der Dichtung niederschlage. Erst dies gebe dem Künstler völlige formale Gestaltungsfreiheit:

„Celem naszym nie jest programowy bezsens, raczej tylko rozszerzenie kompozycyjnych mozliwości przez nietrzymanie się w sztuce konsekwencji zyciowej, czyli fanstastycznosć psychologii i działania, dajaca, według nas, zupetna swobode komponowania formalnego." $(1921 \mathrm{c}, 285)^{38}$

Die Einführung von Unsinn in die Dichtung respektive die Abkehr von lebenspraktischen Bezügen ist sowohl für Chwistek als auch für Witkacy ein zentrales Merkmal der zeitgenössischen Literatur. Durch den unklaren Inhalt und den Unsinn sollen letztendlich eben die formalen Ausdrucksmöglichkeiten gesteigert werden. In dieser Hinsicht versucht Witkacy die Begriffe und ihre Bedeutung zu erfassen.

In seiner Theorie bezeichnet Witkacy die Bedeutung als das dritte konstitutive Element eines Wortes - neben dem Klangwert und den durch das rezeptive Erfassen hervorgerufenen Assoziationen. Wie erwähnt, tritt während des Rezeptionsprozesses eines dieser drei Elemente in den Vordergrund, während die beiden anderen den sogenannten „gemischten Hintergrund" bilden. Dieser Hintergrund, oder wie ihn Witkacy auch bezeichnet, dieser „Bereich“ („zakres“) ist jedem Begriff eigen und wird aus allen möglichen Klangfolgen (akustische Ebene), Bedeutungen (semantische Ebene) und Assoziationen (bildliche Ebene), die dieser Begriff hervorrufen kann, zusammengesetzt:

\footnotetext{
„Nie wchodzac $w$ dalsze zwiazane $z$ teoria pojęc problematy, zaznaczamy tylko, ze znak pojęciowy (slowo wypowiedziane lub napisane) jest symbolem mozliwych lub aktualnie zachodzacych następstw kompleksów jakosci, o konturach mniej lub więcej rozwianych, które nazywamy zakresem danego pojęcia i które moga byc realnie wypetnione lub nie." $(1921 \mathrm{c}, 287)^{39}$
}

${ }^{37}$ „Die Unmoglichkeit die formale Ungesătigtheit mit der Form wirklicher Gegenstănde und bestimmtem Sinn. mit formaler Logik und der Logik lebenspraktischer Gefuhle in Einklang zu bringen sowie das Ausbrechen der Komposition aus den Vorurteilen des Naturalismus sind die Eigenschaften der ganzen Kunst der letzten Jahre [...]."

38 „Unser Ziel ist kein programmatischer Unsinn, sondern eher die Erweiterung der kompositorischen Moglichkeiten durch Missachtung lebenspraktischer Konsequenzen in der Kunst, also die Phantastizităt der Psychologie und des Handelns, was unserer Meinung nach vollige Freiheit in der formalen Komposition gewahrt."

39 „Ohne auf weitere Probleme, die mit der Bedeutung der Begriffe verbunden sind, einzugehen, betonen wir nur, dass das begriffliche Zeichen (ausgesprochenes oder geschriebenes Wort) ein Symbol fur mogliche oder gerade stattfindende Abfolgen von Komplexen von Qualităten mit mehs oder weniger verwischten Konturen ist. die wir als Bereich eines bestimmten Begriffs bestimmen und die real ausgefullt sein konnen oder nicht.“ 
Von der Größe dieses „Bereichs“, so Witkacy, hänge auch die Bedeutung eines bestimmten Begriffs für die Kunst ab: diese nimmt mit der Größe des Bereichs zu. Die Größe des „Bereichs“ ist wiederum abhängig von der Art des Begriffs. Hier muss erwähnt werden, dass Witkacy vier Arten von Begriffen, neben zusätzlichen Sonderformen, unterscheidet (vgl. 1921c, 287-288): die sogenannten .,perzeptiven Begriffe“ (,pojęcia percepcyjne“), zum Beispiel „rot“, „empirische Begriffe“ (,pojęcia empiryczne“), etwa „Pferd“, in deren Fall es möglich ist, ein Referenzobjekt zu finden, „real abstrakte Begriffe“ (,pojęcia realnie abstrakcyjne“), zum Beispiel „Tugend“ oder „Liebe“, die mit realen Geschehnissen oder menschlichem Handeln in Verbindung gebracht werden können und schließlich absolut abstrakte Begriffe (,pojęcia absolutnie abstrakcyjne“), zum Beispiel „abstrakte Zeit“ oder „Unendlichkeit", denen im Prinzip keinerlei Erfahrungen zugeordnet werden können. Die bisher genannten vier Arten ordnet Witkacy im Rahmen einer hierarchischen Struktur, an deren Spitze der Begriff des "Seins“ (,pojęcie istnienia“) steht. Zu den Sonderformen zählt Witkacy erstens den Begriff des „absoluten Nichts“: „Pojęcie nicości absolutnej jest jedyne w swoim rodzaju, jako zupełnie określone przez swój absolutny bezsens, negację wszystkiego, co istnieje." (1921c, 288) ${ }^{40}$. Ebenfalls eine Sonderform bilden für ihn Begriffe, deren „Bereich“ nicht bestimmt ist. Dabei handelt es sich um Neuschöpfungen oder scheinbar sinnlose Worte - als Beispiel nennt er: „kalamarapaksa“. Dank ihres lautlichen Inhaltes können diese Begriffe unterschiedliche Bedeutungen annehmen: Sie werden zum Beispiel an bekannte. ähnlich klingende Wörter angenähert. über deren jeweilige Bedeutung(en) ihre möglichen Bedeutungen assoziiert werden. Allerdings ist keine unbegrenzte Anzahl neuer Bedeutungen möglich. da die lautliche Struktur einer bestimmten Neoschöpfung dies auch wieder begrenzt. außerdem müssen diese Bedeutungen in letzter Konsequenz immer unbestimmt bleiben. In dieser Unbestimmtheit liegt jedoch die innere Spannung dieser Begriffe und damit für Witkacy auch ihr künstlerischer Wert (vgl. 1921c, 291-292). Auch die Rezeption solcher Begriffe folgt im Prinzip dem oben beschriebenen Muster, das heißt durch das kurzzeitige Hervortreten eines der drei Teilelemente. Im Falle der Neuschöpfungen ist aber wesentlich, dass diese, dank ihrer inhaltlichen Unbestimmtheit, eine besonders starke assoziative Funktion haben.

Von einer besonderen inneren Spannung leben auch Kombinationen von einzelnen Begriffen (zum Beispiel: Adjektiv plus Substantiv) bzw. ganze Sätze. Bei den Kombinationen unterscheidet Witkacy zwei Arten von Begriffen (vgl. 1921c, 290): „asymptotische Begriffe“

*0 „Der Begriff des absoluten Nichts ist der einzige seiner Art, bestimmt zur Gănze durch seinen absoluten Unsinn und die Negation von allem, was existiert." 
(,pojęcia asymptotyczne“), womit Witkacy Oxymora meint und „Grenzbegriffe“ („pojęcia graniczne") ${ }^{4 !}$. Asymptotische Begriffe" bestehen aus zumindest zwei sich widersprechenden Teilen, etwa „quadratischer Kreis“ („kwadratowe koło“) oder „lebender Leichnam“ (,zywy trup“). Diesen Widerspruch gibt es bei den „Grenzbegriffen“ (zum Beispiel: „lebender Kreis“ - „Żywe koło“) nicht.

Die möglichen Bedeutung(en) solcher Kombination werden aber immer über beide ihrer Teile hergestellt. Bei den ,asymptotischen Begriffen“ nähern sich die beiden Teile zwar einander an, begegnen sich aber aufgrund ihrer (semantischen) Gegensätzlichkeit nicht. Hingegen verschmelzen die Elemente der "Grenzbegriffe“ miteinander, woraus für Witkacy ihre besondere Bedeutung entsteht:

n....] ten moment jest właśnie zrealizowaniem artystycznego znaczenia i nadania wartości slowom tym, $z$ punktu widzenia logiki $i$ zycia, bezsensowym. W granicy (w matematycznym znaczeniu) utozsamiaja się dwa znaczenia poprzednich symbolicznych wyrazeń [...]." (1921c, 291 $)^{42}$

Werden diese Begriffe in grammatikalische Strukturen eingebunden (Subjekt - Prädikat, Adverb - Verb, ganze Sätze usw.), wird die ihnen eigene Spannung durch die Beziehung zu anderen Begriffen zum Teil noch gesteigert. Im Idealfall ist es dabei nicht mehr möglich, einen Bezug zwischen einer konkreten Aussage und einer bestimmten Lebenssituation herzustellen:

\begin{abstract}
„Właśnie dlatego, ze całośc [...; danego; M.E.] zdania nie odpowiada zadnym międzygwiezdnym ani ziemskim stosunkom. ze to, co dzieje się, zachodzi $w$ świecie kompletnie urojonym $i w$ dodatku nieokreslonym. zostaje tylko to napięcie wewnętrzne uzytych pojęc $i$ czysto formalny charakter calego kompleksu, jako taki zupełnie ścisle określony." $(1921 \mathrm{c}, 294)^{43}$
\end{abstract}

Dieses Zitat macht den zentralen Punkt von Witkacys Ausführungen deutlich: erst wenn es in einem Vers oder einem Gedicht keinen lebenspraktischen Inhalt mehr gibt, kann der reine formale Wert dieses Verses oder Gedichtes klar hervortreten. Das Problem, das es auf dem Weg zu dieser Erkenntnis zu lösen galt, war, dass das Material der Dichtung, die Wörter und das war Witkacy bewusst - immer in irgendeiner Form diesen Inhalt in sich tragen, da sie immer auf ein außersprachliches Bezugsobjekt verweisen. Gemäß seiner Theorie der „Reinen Form“, kann das „metaphysische Gefühl“, das heißt die wirkliche ästhetische Befriedigung,

\footnotetext{
"Diese Klassifizierung ergibt sich aus Witkacys Argumentation. Seine Ausfuhrungen sind allerdings etwas widerspruchlich, da er die Bezeichnung ..Grenzbegriff" auf beide von ihm erkannten Typen anwendet.

42 ......] dieser Moment stellt gerade die Verwirklichung der künstlerischen Bedeutung dar und verleiht den vom Standpunkt des Lebens und der Logik aus unsinnigen Wortern ihren Wert. In der Grenze (in ihrer mathematischen Bedeutung) vereinen sich die beiden Bedeutungen der vorigen symbolischen Ausdricke [...]."

43 „Gerade deshalb, da das Gesamt [...; eines bestimmten; M.E.] Satzes keinen kosmischen oder irdischen Verhaltnissen entspricht. da das, was geschieht in einer absolut erdachten und dazu unbestimmten Welt stattfindet. bleibt nur die innere Spannung der verwendeten Begriffe und der rein formale Charakter des ganzen Komplexes. als solcher vollig exakt bestimmt."
} 
nur aus der Form, niemals aber aus dem Inhalt des Kunstwerks entstehen. Dementsprechend versucht Witkacy in seiner hier referierten Theorie der Begriffe, diese nach dem Grad ihrer "semantischen Klarheit" zu definieren, wobei er denjenigen Begriffen und Begriffskombinationen den höchsten ästhetischen, das heißt formalen Wert, zuspricht, die inhaltlich am meisten uneindeutig sind. Das zuletzt Gesagte erklärt auch einen scheinbaren Mangel an Witkacys Argumentation, nämlich, dass er eigentlich nur über den Inhalt, das heißt die Bedeutung der Begriffe, spricht und nicht über die Form, worauf es ihm doch eigentlich ankommt. Doch es scheint, dass sich Witkacy in seinen Ausführungen auf jenen Punkt bezieht, der ihm am schwersten mit seiner Theorie der „Reinen Form“ vereinbar scheint: die a priori in den Begriffen mitschwingende inhaltliche Bedeutung. Ihre Fruchtbarmachung in formaler Hinsicht will Witkacy beschreiben. Dass es ihm letztendlich aber um die Form. verstanden, wie zuvor angedeutet, als Klangstruktur, geht, zeigt das folgende Zitat:

„Cóz dopiero, jeśli wyrazy te [=neologizmy i kombinacje pojęc; M.E.] połaczone sa ze soba w muzyczne calości i całe ich kompleksy, zdania, które otwieraja niezbadane obszary znaczeń, lezących na granicach zupetnego z punktu widzenia zycia bezsensu lub tez wprost wewnątrz tej sfery, gdzie bezsens zyciowy zmienia się w najwyzszy sens formalny." $(1921 \mathrm{c}, 295)^{\text {th }}$

Erst bei maximaler inhaltlicher Uneindeutigkeit, an den „Grenzen des Unsinns“ entstehen also jene „musikalischen Ganzheiten“, die als Klanggebilde nur mehr durch ihre Form wirken ${ }^{45}$.

\subsection{Zusammenfassung}

Witkacys zuletż beschriebene Ausführungen über die Bedeutung der Begriffè stehen denen von Chwistek in einem Punkt sehr nahe: nämlich in der Überzeugung, dass die semantische Unbestimmtheit von Begriffen. Versen oder eines ganzen Gedichtes letztendlich die Form stärker hervortreten lässt. Chwistek zeigt dies am Vergleich zwischen einer

\footnotetext{
* .Was erst, wenn diese Ausdrucke [=Neologismen und Begriffskombinationen: M.E.] miteinander zu musikalischen Ganzheiten und weiter zu ganzen Komplexen verbunden werden, zu Sătzen, die unerforschte Bereiche von Bedeutungen auftun, die an den Grenzen des, vom Standpunkt des Lebens aus betrachtet, volligen Unsinns liegen oder sogar innerhalb dieser Sphăe, in der sich der lebenspraktische Unsinn in den höchsten formalen Sinn verwandelt."

4s Fur die vorliegende Arbeit war es vor allem wichtig. Witkacys literarische Theorien in Hinsicht auf den Formismus zu beschreiben. Aus diesem Grund wurden nur jene Texte von Witkacy in die Untersuchung miteinbezogen, die zwischen 1917 und 1922 entstanden sind. Witkacy arbeitete aber bis in die dreißiger Jahre hinein immer wieder an seinen literarischen Theorien. Vgl. zu einer umfassenden Darstellung von Witkacys literarischen Theorien, die zum Beispiel auch seine Ansichten zum Roman mit einbezieht: Skowroniski 1979 sowie das Kapitel „Theorie der kunstlerischen Sprache" aus: Schmidt 1992, 76-90. Ebenso würde es an dieser Stelle zu weit fuhren. Witkacys literarische Theorien mit seiner Philosophie zu konfrontieren. Vgl. dazu genauer: Szymanska 1971, besonders: 173-176 bzw. 187.
} 
wissenschaftlichen und poetischen Aussage, wobei er von folgender Annahme ausgeht: je klarer der Inhalt einer solchen Aussage ist, desto weniger Aufmerksamkeit richtet ein Rezipient auf deren Form. Da es in der Kunst aber einzig um die Form geht, muss der Dichter den Inhalt bewusst mehrdeutig bzw. unlogisch gestalten. Für Witkacy ist der höchste formale Effekt dann gegeben, wenn mit einem Begriff oder einem Vers kein lebenspraktischer Inhalt mehr assoziierbar ist, wenn diese nur noch akustisch wirken. Die Einführung von Unsinn, von Nicht-Logischem in die Dichtung erklären sowohl Chwistek, als auch Witkacy mit dem Streben des Dichters nach einer möglichst vollkommenen Form des literarischen Kunstwerks $^{46}$. Beide stimmen außerdem darin überein, dass es zwar um eine möglichst weite Entfernung von Sinn und Logik gehe, aber nur um die Form stärker hervorzuheben. Die Dichtung, so Chwistek dürfe nicht zur sinnentleerten ,Geräuschmusik“ verkommen und Witkacy betont (1922f, 317), die Einfuhrung von Unsinn sei kein Selbstzweck ${ }^{47}$.

Auch Czyżewski beschreibt, wie angesprochen, in „Die Poesie der Expressionisten und Futuristen" am Beispiel von Claudel und Whitman die Tendenz der modernen Dichtung, sich von logischer und zusammenhängender Beschreibung zu lösen, vom Standpunkt des täglichen Lebens aus gesehen, Unsinniges in sich aufzunehmen und mit einer den außeren Lebenszusammenhängen entsprechenden literarischen Darstellung zu brechen. Ihnen folgten die italienischen Futuristen, in deren Gedichten Humbug und burlesker Humor anzutreffen sind. Und auch die deutschen Expressionisten entfernten sich von konkretem Sinn und begrifflicher Logik, und zwar in ihrem Bemühen, die innere Verfassung des Menschen zum Ausdruck zu bringen. Dies alles habe, so Czyżewski (vgl. 1919c, 79-81), letztendlich zu einer Bereicherung der künstlerischen Ausdrucksmöglichkeiten, auch in formaler Hinsicht, beigetragen. Die Forderung, dass die Lyrik die Schilderung nachvollziehbarer und zusammenhängender Inhalte aufgeben soll, formuliert Czyżewski auch in seinem programmatischen Text ,.Das Begräbnis der Romantik - Altersschwäche des Symbolismus Tod des Programmismus“: „Skojarzenia myṡlowe będą rzadkie, niespodziewane i nieprzewidziane - forma barwna - wiersz jak najbardziej wolny - kontrasty myślowe jai najbardziej oddalone.“ (192la, 177) ${ }^{48}$. In vielen Gedichten Czyżewskis ist, wie deren Interpretation im nächsten Kapitel zeigen wird, eben genau dieses Bemühen zu spüren.

\footnotetext{
${ }^{46}$ Chwistek spricht in diesem Zusammenhang (vgl. 1922/1924, 102) außerdem von der "Transformation des Worterbuchs" (.transformacja slownika“) im Sinne einer kritischen Überprufung der traditionellen Bedeutung der Begriffe.

${ }^{47}$ Den Vorwurf, Unsinn nur um des Unsinns willen (und nicht zu formalen Zwecken) in ihre Poesie einzufuhren. macht Witkacy an dieser Stelle den polnischen Futuristen.

4. „Gedankliche Assoziationen werden selten, unerwartet und unvorhersehbar sein - die Form farbig - der Vers moglichst frei - die gedanklichen Kontraste moglichst weit entfernt."
} 
nämlich die inhaltlichen Zusammenhänge aufzulösen, das heißt sie zu lockern, aber nicht völlig zu zerstören und an ihrer Stelle neue formale Kohärenzen zu etablieren, die die Einheit des Kunstwerks herstellen.

Diese bewusste Aufgabe des Inhalts ist für alle drei formistischen Autoren auch eine Konsequenz aus einem Funktionswandel, dem die Literatur in den Jahren rund um den Ersten Weltkrieg, gerade in Polen, unterworfen war. Denn nicht zuletzt durch die Wiedererlangung der staatlichen Souveränität sei die Literatur ihrer Meinung nach endlich von der Thematisierung politischer und nationaler Fragen befreit worden und habe sich auf das eigentlich Künstlerische, das für Chwistek, Czyżewski und Witkacy in der Form zu suchen ist, konzentrieren können.

Im Zentrum der behandelten literaturtheoretischen Texte dreier formistischer Autoren steht die Neubestimmung des Verhältnisses zwischen Inhalt und Form, ähnlich wie dies bereits bei den Texten zur bildenden Kunst, die im vorigen Kapitel untersucht wurden, der Fall war. Erst eine Zurückdrängung des Inhaltes öffnet den Blick auf die Form. In der Literatur geht es dabei konkret um die Aufgabe von Diskursivität und ihren beschreibenden Funktionen. Die innere Geschlossenheit eines Gedichtes, das heißt dessen Komposition, soll demnach nicht mehr auf inhaltlichen, sondern primär auf formalen Zusammenhängen beruhen. Dieser Aspekt ist zentral für die Beschreibung des „Formistischen“ in den Gedichten Czyżewskis im nächsten Kapitel. 


\section{Die formistische Poesie Czyżewskis}

Die in diesem Kapitel vorgenommene Untersuchung betrifft jene Gedichte Czyżewskis, die er während seiner Zugehörigkeit zur Gruppe der Formisten veröffentlichte. Dabei handelt es sich um seine beiden Bände: „Das grüne Auge. Formistische Dichtungen. Elektrische Visionen“ (1920) und „Nacht - Tag. Mechanisch-elektrischer Instinkt“ („Noc - Dzień. Mechaniczny instynkt elektryczny", 1922). In beiden Bänden finden sich aber nicht nur Gedichte aus den Jahren 1917 bis 1922, sondern auch solche, die schon viel früher entstanden sind und daher deutliche Anklänge an die modernistisch-symbolistische Poetik des .Jungen Polens“ aufweisen'. Diese Gedichte brachten Czyżewski oft den Vorwurf ein, seine Lyrik sei, gemessen an ihrem avantgardistischen Anspruch. noch viel zu stark in der Moderne verhaftet (vgl. Irzykowski 1922, 463-464, Doda 1925, 29-30 und Wyka 1945/1949, 18 bzw. - zu einer Analyse des Problems: Baluch, in: Czyżewski 1992, XXXII-XXXVI). Für die Themenstellung der vorliegenden Arbeit spielt diese Frage allerdings eine untergeordnete Rolle und wird daher, wie die entsprechenden Gedichte aus den beiden Sammlungen Czyżewskis, nicht näher untersucht. Vielmehr geht es um eine Beschreibung von Czyżewskis Gedichten im Zusammenhang mit den Ansătzen und Theorien, die in den beiden vorigen Kapiteln dargestellt wurden und daran anschließend explizit um die Frage, ob es möglich ist, im Falle Czyżewskis von „formistischer Poesie“ zu sprechen. Dabei soll nicht der Versuch unternommen werden, die Lyrik Czyżewskis von den parallelen Strömungen der Avantgarde, der Lyrik Apollinaires, dem Futurismus oder dem Expressionismus, mit denen sie, wie in einem eigenen Abschnitt gezeigt wird, zahlreiche Beruhrungspunkte aufweist, zu isolieren. Vielmehr ist es das Ziel, durch das Herausarbeiten des „Formistischen“ die Spezifik dieser Poesie sichtbar zu machen und so letztendlich auch einen Beitrag zu ihrer adäquaten Beschreibung im Kontext der polnischen und europäischen Avantgarde zu leisten.

Aus dem Zusammenhang mit der avantgardistischen Kunst, die laut dem Willen ihrer Schöpfer unmittelbarer Ausdruck einer neu angebrochenen Epoche sein soll, ergibt sich noch ein weiterer Interpretationskontext für Czyżewskis formistische Gedichte. Neben dem Epochenwandel, das heißt dem Ende der „alten“ und dem Beginn der "neuen Zeit“, thematisiert er in diesen Gedichten vor allem diese „neue Zeit“ selbst, und zwar in ihren typischen Erscheinungsformen, wie den Großstädten mit ihren Kinos und Kaffeehäusern oder

\footnotetext{
'Aus ..Das grane Auge“ sind etwa zu nennen: „Die Kathedrale“ (.Katedra“), „Der Schlaf der Blumen“ (.Sen kwiatów"). ..Der Regen“" (,Deszcz") oder .Ein trauriger Augenblick“ (.,Smutna chwila“). Die beiden Gedichte
} 
den neuen technischen Gerätschaften, die das Leben zunehmend verändern. Damit steht Czyzewski in einer poetischen Tradition, die mit Whitman begonnen hat und die bis zu den Futuristen und zu Apollinaire reicht, nämlich die Hinwendung des Dichters zu seiner unmittelbaren Gegenwart, aus der er die Themen seiner Lyrik schöpft (vgl. Simonis 1967, 63). Dieses für die europäische Avantgarde an sich charakteristische Bewusstsein, am Beginn eines neuen Zeitalters zu stehen, kommt auch in den theoretischen und programmatischen Texten der Formisten immer wieder zum Vorschein. Es ergibt sich nicht nur aus der Geschichte des Formismus selbst, die ja um 1910, also noch während der Epoche der Modeme, begonnen hat, sondern wohl auch daraus, dass die Gruppe der Formisten zu den ersten Repräsentanten der von ihnen immer wieder thematisierten „neuen Kunst“ gehört.

\subsection{Die „neue Zeit ${ }^{\mu}$ in den formistischen Gedichten Czyżewskis}

\subsection{1 „Nie koniec a początek ${ }^{22}$ - Der Erste Weltkrieg und der Beginn der neuen Zeit}

Die Vorstellung vom Weltende, mit dem gleichzeitig aber eine neue Zeit beginnt, ist ein häufiges Thema expressionistischer Gedichte (vgl. Anz 2002, 44-49). Dementsprechend findet sich auch an erster Stelle der bekanntesten deutschsprachigen expressionistischen Gedichtsammlung. der von Kurt Pinthus herausgegebenen Anthologie „Menschheitsdämmerung“, Jakob van Hoddis” Gedicht „Weltende“, das erstumals 1911 gedruckt wurde. Darin werden in zwei vierzeiligen Strophen kurze Situationen geschildert. die mit dem im Titel angekündigten Ereignis scheinbar in Verbindung stehen. Dabei mischt sich Emstes und Tragisches (zum Beispiel: „In allen Lüften hallt es wie Geschrei“) mit Absurdem oder Groteskem (,Die meisten Menschen haben einen Schnupfen“ - beide in: Pinthus 1920, 39). Diese Art der Darstellung wird durch den von van Hoddis gebrauchten

.Der Tag Maria Himmelfahrt - Idylle” (..Dzien Matki Boskiej Zielnej - Sielanka”) und „.Der Wald” (.Las”) aus „Nacht-Tag" sind überhaupt auf die Jahre 1903 bzw. 1902 datiert.

"Dieser Vers stammt aus Czyzewskis Gedicht ..Elektrische Visionen“ (..Elektryczne wizje“- 1920a, 72). .Nicht Ende sondem Anfang". Vgl. dazu auch den Aufsatz von Balcerzan (1984), der das Bewusstsein fur Anfang und Ende als charakteristisch fur die Generation der polnischen Zwischenkriegszeit beschreibt. Balcerzan bezieht diesen ,Mythos von Anfang und Ende“" (..mit początku i konca") aber nicht nur auf das Jahr 1918, als sich diese Generation am Beginn einer neuen Zeit sah. sondern auch auf das Jahr 1939, als durch den Ausbruch des Zweiten Weltkrieges die Epoche der Zwischenkriegszeit zu Ende ging (gehen musste). Der Gedanke an dieses ihr eigenes - Ende, so Balcerzan, sei in der Literatur der Zwischenkriegszeit ebenso prăsent gewesen wie der vom Neubeginn um 19/8, was sich unter anderem in der Literatur des sogenannten ..Katastrophismus” (..katastrofizm") spătestens gegen Ende der zwanziger Jahre zeige. Zu den bekanntesten Werken dieser 
parataktischen Zeilenstil, den nur ein Enjambement zwischen den ersten beiden Zeilen der zweiten Strophe unterbricht, getragen. So gelingt es dem Dichter, die unterschiedlichen Situationen unmittelbar aneinander zu reihen, die innere Geschlossenheit des Gedichtes wird in diesem Fall zum Beispiel von einem regelmäßigen Reimschema (in „Weltende“: abba cdcd) hergestellt.

Czyżewskis Gedicht „Stadt an einem Herbstabend“, das in der ersten Nummer von „Formisci“" vom Oktober 1919 zum ersten Mal gedruckt wurde, ist in vielerlei Hinsicht mit dem von van Hoddis verwandt. Auch Czyżewski versucht in mehreren kleinen, zum Teil ebenso grotesken Momentaufnahmen eine Art Weltuntergangsstimmung einzufangen. Das Gedicht, das den Untertitel „niesielanka“ („Nichtidylle“) ${ }^{3}$ trägt, lautet:

\author{
(niesielanka) \\ wdziej cieple astrachany \\ termometr wciaz opada \\ od knajpy spiew pijany \\ dysonans serenada \\ w kosciele dzwonia dzwony \\ ktos kogoś kopnal noga \\ $w$ kanale $z$ mgiet opony \\ i psy juz wyć nie moga \\ ni słonce się nie śmieje \\ nad miastem płyna dymy \\ kogut na zmiane pieje \\ $z$ cmentarza kapia rymy \\ mknie autem nierzadnica \\ tramwaj w aleje zmyka \\ wyblanszowane lica \\ pantofle nieboszczyka \\ czuć zapach swiezej ziemi \\ i trzepia stare meble \\ fa so la si do re mi \\ drabiny białe szczeble \\ w ochronce płacza dzieci \\ i chmury mkna powoli \\ purpura zorzy świeci
}

„MIASTO W JESIENNY WIECZÓR

\author{
.STADT AN EINEM HERBSTABEND \\ (Nichtidylle) \\ zieh an den warmen Persianer \\ das Thermometer fallt und fallt \\ aus der Kneipe betrunkener Gesang \\ eine Dissonanz-Serenade \\ in der Kirche lăuten die Glocken \\ jemand tritt jemanden mit dem FuB \\ im Kanal Nebelhülen \\ und die Hunde konnen schon nicht mehr heulen \\ weder lacht noch die Sonne \\ aber die Stadt flieBt Rauch \\ der Hahn kraht zur Schicht \\ aus dem Friedhof tropfeln Reime \\ mit dem Auto dahin eilt eine Hure \\ die Straßenbahn tümnt durch die Allee \\ weiß gepuderte Gesichter \\ die Pantoffeln einer Leiche \\ man riecht den Duft frischer Erde \\ sie klopfen die alten Mrbel \\ fa so la si do re $\mathrm{mi}$ \\ weiße Sprossen einer Leiter \\ im Heim weinen die Kinder \\ und gemachlich eilen die Wolken \\ das Purpur der Dammerung leuchtet
}

katastrophistischen Literatur zahlen ubrigens, wie erwahnt, die Romane „Abschied vom Herbst” und "Unersattlichkeit“ von Witkacy.

${ }^{3}$ Dieser Untertitel kann auch als Infragestellung oder Parodie der literarischen Gattung der „Idylle“" verstanden werden. Die Idylle spielte in der polnischen Literatur vor allem in der vorromantischen Zeit zu Beginn des 19. Jahrhunderts eine wichtige Rolle, unter anderem dank dem Schriftsteller und Literaturtheoretiker Kazimierz Brodziński, der in der Idylle eine zentrale und dem Polnischen am meisten eigene literarische Gattung sah, die es am besten erlaube, das spezifisch "Polnische“, etwa am Beispiel des Charakters des Protagonisten. zum Ausdruck zu bringen (vgl. dazu: den Eintrag „Sielanka“ von Teresa Kostkiewiczowa, in: Slawiniski 1976. 508509). Die Herausgeberin der Anthologie „Idylla Polska“ Alina Witkowska (Wrocław u.a. 1995) kommt in ihrem Vorwon zweimal auf Czyzewski zu sprechen: einmal am Beispiel von Czyzewskis "Weihnachtsliedem" (.,Pastorałki“), die als eigener Band 1925 in Paris veroffentlicht wurden und in denen Czyzewski bewusst auf aus der idyllischen Dichtung bekannte Gestaltungsformen zurackgreift (XXXVI). Gleichzeitig stellt auch Witkowska "Stadt an einem Herbstabend“ in den Kontext der Antijdylle (XLIX), ebenso wie sie dieses Gedicht in ihre Anthologie aufnimmt. 
Die besagte Endzeitstimmung wird von Czyżewski durch unterschiedliche Motive hervorgerufen, die sich ungefähr auf die erste Hälfte des Gedichtes konzentrieren, nämlich auf die ersten zehn von insgesamt 24 Zeilen: Herbst bzw. Abend (Titel), verbunden mit dem Fallen der Temperatur (Zl.1-2), mit dem Gesang Betrunkener, der aus den Kneipen der Stadt dringt ( $\mathrm{Zl} .3$ ), dem abendlichen Läuten der Kirchenglocken ( $\mathrm{Zl} .5$ ), dem Auftauchen von Nebel und Rauch (Zl. 7 und 10) sowie dem Verschwinden der Sonne (Zl. 9). Mit diesen Motiven korrespondiert auch das in mehreren Versen gestaltete Begräbnis (Zl. 12, 15-17). Dazwischen fügt Czyżewski, wie auch van Hoddis, scheinbar unbedeutende Ereignisse ein. die im Gesamtzusammenhang grotesk erscheinen (Zl. 6, 8 oder 13). Und auch in „Stadt an einem Herbstabend" wird die Geschlossenheit des Gedichtes nicht zuletzt durch den konsequent verwendeten Kreuzreim. der bis auf die beiden Ausnahmen in Zl. 17 und 19 immer zweisilbig ist, hergestellt. Unterstützt wird diese Geschlossenheit vom regulären metrischen Bau der Verse, die aus meist sieben Silben mit je drei Hebungen bestehen. Kleinere Einheiten des Gedichtes werden daneben auch klanglich organisiert. zum Beispiel durch Assonanzen (Zl. 1-4 mit „a“, 5-8 mit „o“ oder 22-24 mit „u“) oder Alliterationen (Zl. 5 und 6).

Wenngleich die zeitlichen Bestimmungen „Herbst“ und „Abend“ des Gedichtes vor allem in ihrer übertragenen Bedeutung zu verstehen sind, besitzt das Gedicht in dieser Hinsicht auch eine reale Dimension, das heißt, dass sich auch Hinweise finden. die die dargestellte Szenerie wirklich an einem Abend spielen lassen. So fallt zum Beispiel die Temperatur gegen Abend und auch Kneipen werden für gewöhnlich am Abend aufgesucht, besonders um Alkohol zu trinken. Dadurch, dass sich dieser Abend, durch das Verschwinden der Sonne (Zl. 9), in Nacht und anschließend in den Morgen (vor allem durch den krähenden Hahn in $\mathrm{Zl}$. 11) wandelt, wird aber wiederum die metaphorische Bedeutung des Gedichtes unterstrichen: das Ende der alten Zeit ist zugleich der Beginn der neuen. In dieser Hinsicht ist insbesondere das von Czyżewski verwendete Motiv der Dämmerung zu verstehen, das er, um dessen Bedeutung zu unterstreichen, an den Schluss des Gedichtes setzt (Zl. 23-24). Auch dieses Motiv ist unter anderem aus dem deutschen Expressionismus bekannt, vor allem auch deswegen, da es Pinthus im Titel seiner Anthologie expressionistischer Dichtung gebraucht. Im Vorwort zu „Menschheitsdämmerung“ schreibt er über die Bedeutung dieses Motivs:

\footnotetext{
- Das Gedicht ist, in der Übersetzung von Karl Dedecius, auch auf deutsch mehrfach erschienen. Zuerst als: ..Antiidyll. stadt am herbstabend" (in: Dedecius 1964, 31), spater in uberarbeiteter Form. als ..Stadt am Herbstabend (Antiidyll)", zum Beispiel in: Dedecius 1996-2000, 1/1/335.
} 
„Diese Dichter [=die expressionistischen; M.E.] fuhlten zeitig, wie der Mensch in die Dămmerung versank.... sank in die Nacht des Untergangs..., um wieder aufzutauchen in die sich klärende Dammerung neuen Tags. In diesem Buch wendet sich bewusst der Mensch aus der Dámmerung der ihm aufgedrăngten. ihn umschlingenden, verschlingenden Vergangenheit und Gegenwar, in die erlosende Dammerung einer Zukunft, die er selbst sich schaff." $(1920,25)^{3}$

Im Motiv der Dämmerung verschmilzt somit das Untergehen der alten mit dem Beginn der neuen Zeit. Doch ist der Gebrauch dieses Motivs im Sinne Pinthus', zumindest im deutschpolnischen Sprachvergleich, ein Privileg der deutschen Sprache. „Dämmerung“ im Deutschen kann gleichzeitig sowohl Morgen-, als auch Abenddämmerung bedeuten. Das Polnische besitzt hierfür zwei Begriffe, nämlich „świt“ für Morgen- und „zmierzch“ für Abenddämmerung. Um das Doppeldeutige dennoch, wie es im Deutschen möglich ist, durch ein einzelnes Wort zum Ausdruck zu bringen, gebraucht Czyżewski den Begriff „zorza“. womit das rötliche Licht, das sich zur Zeit der Dämmerung am Himmel zeigt, bezeichnet wird. Allerdings steht „zorza“ im Polnischen für gewöhnlich nicht allein, sondern wird mit „poranna“ (,morgendlich“) bzw. „wieczorna“ („abendlich“) kombiniert, bezeichnet also einmal das Dämmenungslicht am Morgen, einmal am Abend. Und genau dadurch. dass Czyżewski auf eine nähere temporale Bestimmung durch das Adjektiv verzichtet, also „zorza“ allein stehen lässt, erreicht er dieselbe motivische Doppeldeutigkeit, auf die es auch Pinthus ankommt.

Auch in der Gestaltung dieses Dämmerungsmotivs am Ende des Gedichtes lässt Czyżewski noch einmal einen realen Vorgang mit dessen übertragener Bedeutung verschmelzen, wie es zuvor im Falle der in "Stadt an einem Herbstabend" vorkommenden Tageszeit beschrieben wurde. In der drittletzten Zeile verziehen sich nämlich die Wolken (am Himmel) und geben somit den Blick auf die Dämmerung. das Dämmerungsrot frei. Doch um was für eine Dämmerung handelt es sich? In der wörtlichen Übersetzung der letzten beiden Zeilen „leuchtet das Purpur der Dämmerung // den Fetzen des menschlichen Schicksals“. Gerade diese Metapher ist schwer aufzulösen, dennoch scheint sich die Dämmerung doch im positiven Sinne auf das Schicksal der Menschen zu beziehen, vielleicht gerade als der Anbruch einer neuen, besseren Zeit.

Neben dem der Dämmerung, steht auch das Motiv der Auferstehung bzw. des Wiederauferstehens für die Zeitenwende, das heißt für den Anbruch der neuen Zeit. Dieses Motiv ist unmittelbar mit der Person von Jesus Christus verbunden. In Czyżewskis Lyrik findet es sich zweimal: einmal in dem Gedicht „Die Glocke“ („Dzwon“-1920a, 50-51), in dem es aber in erster Linie die im Frühjahr wieder erblühende Natur ist, die mit Christus

"Pinthus' Vorwort tragt den Titel: „Zuvor (Berlin, Herbst 1919)“. Auch Czyzewskis Gedicht wurde ja erstmals 
verglichen wird sowie im zweiten Teil des längeren Gedichts „De profundis“ aus Czyżewskis zweitem Gedichtband „Nacht - Tag“, der im Kontext der bisherigen Ausführungen dieses Abschnittes gelesen werden $\mathrm{kann}^{6}$. Das ganze Gedicht „De profundis“ ist an sich eine fröhliche Schilderung der neuen Zeit, speziell im zweiten Teil, der dazu den Titel „Frühling“ („Wiosna“) trägt, kombiniert Czyżewski Motive des technischen Fortschritts, wie Flugzeuge, Automobile etc. mit Frühlingsszenen auf dem Dorfe, wenn er das Umpflügen der Erde sowie ein Frühlingsfest mit Gesang, Tanz und dem Ertränken der den Winter symbolisierenden Strohpuppe „Marzanna“ schildert (vgl. 1922c, 78-80). In diese Szenerie des Frühlings und des Neubeginns fügt Czyżewski Ereignisse aus dem Leben von Jesus Christus ein: durch die Person des Judas und die Nennung der Summe von 30 Silberlingen den Verrat, der zur Festnahme und zur Kreuzigung Christus führte sowie die Geschichte der beiden Jünger Simon und Kleopas, die dem von den Toten wiederauferstandenen Christus auf dem Weg nach Emmaus begegnen. Diese Geschichte wird von Czyżewski jedoch etwas verfremdet dargestellt, so scheint etwa Judas mit dem Geld aus seinem Verrat Bilder zu kaufen:

„A ja szedłem ulica i myślalem CINQ BIS ( 5 bis) przyjdzie do mnie Judasz i kupi kilka obrazów." (1922c, 80)
.Und ich ging die Straße entlang und dachte CINQ BIS (5 bis)

besucht mich Judas und kauft einige Bilder."

Trotz der Verfremdung mittels einer „unerwarteten Wendung” (im Apollinaireschen Sinne), bleibt der wesentliche Symbolgehalt der Geschichte von Tod und Wiederauferstehung erhalten. Dass sich dieser auf die unmittelbare Gegenwart bezieht, wird durch den Ersten Weltkrieg deutlich, der kurz angedeutet wird. So heißt die Straße, die das lyrische Ich im angeführten Zitat entlanggeht ..Avenue de la grande Armee“, außerdem begegnet es unterwegs „vier Särgen“7.

An kein anderes historisches Ereignis war das Bewusstsein vom Ende der alten sowie vom Beginn der neuen Zeit so eng geknüpft, wie an den Ersten Weltkrieg. Viele Künstler in Italien. Deutschland oder Frankreich sehnten um 1910 dessen Beginn herbei und versprachen sich davon positive Veränderungen, nicht nur in politischer, sondern auch in kultureller Hinsicht ${ }^{8}$. Doch brachte der Krieg auf der anderen Seite sinnloses, grausames Sterben vieler

im Oktober 1919 gedruckt.

" „De profundis" ist auch der Titel einer bekannten Erzahlung von Stanisław Przybyszewski. Die vergleichende Lekture beider Texte zeigt jedoch, dass Czyzewski keinen Bezug zu Przybyszewskis Text herzustellen versucht.

? "i spotkalem po drodze czery trumny" (.,und ich traf unterwegs vier Särge" - 1922c. 80).

- Am bekanntesten ist die Kriegsbegeisterung von Marinetti und der italienischen Futuristen: aber auch die Namen Apollinaires. der sich 1914 freiwillig zur franzosischen Armee meldete bzw. Franz Marcs oder Emst Tollers, die dasselbe in Deutschland taten. können hier genannt werden. Thomas Mann veroffentlichte im November 1914 seine „Gedanken im Krieg”, in denen er schreibt: „Wie hătte der Künstler, der Soldat im 
Zivilisten und Soldaten, Verwüstung, Hunger und Leid. Dies führte insgesamt zu einer ambivalenten Bewertung, die beide Seiten des Ersten Weltkrieges gleichermaßen bewusst werden ließ. Speziell in Polen wurde dieser Krieg nicht nur als Anfang einer neuen zivilisatorischen Epoche verstanden, sondern auch als politischer Neubeginn, da nach über 100 Jahren der Dreiteilung, Polen wieder als ein unabhängiger Staat entstand.

Czyzewski beschäftigt sich in zwei Gedichten aus „Das grüne Auge“ mit dem Krieg: aus der Perspektive eines Soldaten in "Halbschlaf" (,Półsen“) und in „Elektrische Visionen“ (,Elektryczne wizje“). In .Halbschlaf (vgl. 1920a, 36-37) ${ }^{9}$ wird der Fiebertraum - das Gedicht trägt den Untertitel „w gorączce“ (,im Fieber“) - eines Soldaten geschildert, der, auf einem Lager liegend, sich in einem Zustand zwischen Wachsein und Schlaf (,stoi tam żółnierskie łoże //na lożu nie śnię ni czuwam") ${ }^{10}$ befindet. In seinem Traum erlebt das lyrische Ich einen zweifachen Soldatentod: auf dem Schlachtfeld, als schwere Stiefel über ihn trampeln und er das Stöhnen eines im Sterben liegenden Soldaten hört (,po moim brzuchu i piersi // obute stapaja nogi // konającego słyszę jęk") und am Ende des Gedichtes, als Erschießung durch die Gewehre feindlicher Soldaten („pluton baczność z ramienia bron // tarach trach karabin ja śpię.")". Dem wird eine idyllische Vision eines besseren Jenseits entgegengestellt, die zwischen die beiden Todeserlebnisse eingefügt ist und die direkt mit dem „ersten Tod“ beginnt:

„i zimne palce na oczy
złozyła mi nemezis smierć
słońce wyjrzalo z białych chmur
na twarzy mej uczulem dłoń
miękki snieznej lilli [sic!] dzwon
i białych jej piersi pek
pachna zioła zaszumial las
gdzie jestem gdzie jestem ach gdzie
czy On czy Ona woła
uwielbiam cię mój bracie śnie"

,i zimne palce na oczy zlozyła mi nemezis śmierc slonce wyjrzalo $z$ białych chmur miękki śnieznej lilli [sic!] dzwon i białych jej piersi pek pachna zioła zaszumial las czy On czy Ona woła

Durch die positiven Motive dieses Traumes, wie der Sonne, der sanften Berürung des Gesichtes oder dem Duft der Kräuter wird der Gegensatz zu den zuvor angesprochenen Schreckenserlebnissen des Krieges deutlich. Unterstützt wird dies auch durch die Klangstruktur des Gedichtes bzw. der zitierten Passage. In dieser wird das Harmonische,

Kanstler nicht Gott loben sollen fur den Zusammenbruch einer Friedenswelt, die er so satt, so aberaus satt hatte! Krieg! Es war Reinigung. Befreiung. was wir empfanden, und eine ungeheure Hoffnung." (zit. n.: Anz 2002, 133).

Alle im folgenden Text zitierten Passagen beziehen sich auf diese Vorlage.

10 "dort steht ein Soldatenbett // auf dem Bett träume ich nicht und wache ich nicht".

" "aber meinen Bauch und meine Brust "/ stampfen beschuhte Fuße // ich hore das Stohnen eines Sterbenden"* "Zug Achtung legt an // peng peng Karabiner ich schlafe."

i2 Das polnische ..sen" bedeutet zugleich "Schlaf* und "Traum".

"und kalte Finger auf die Augen
legte mir Nemesis Tod
die Sonne schaute aus weißen Wolken hervor
auf meinem Gesicht sparte ich eine Hand
eine weiche Glocke einer Schneelilie
und ein Bandel ihrer weißen Bruste
es duften die Kräter der Wald rauschte
wo bin ich wo bin ich ach wo
ruft Er oder Sie
ich liebe dich mein Bruder Traum (Schlaf) 12


Weiche vor allem durch das zehnmal verwendete „1" noch stärker zum Ausdruck gebracht, unterstützt durch die ebenfalls weich und sanft, etwas rauschend klingenden Linguale , $\Omega(z)$ (", "ć, „s“, „z“, „dz“, „cz“ und „sz“, die in angeführten Zitat ebenso häufig verwendet werden. Zum Teil ergibt sich daraus auch ein gewisser Kontrast zu jenen Passagen des Gedichtes, in

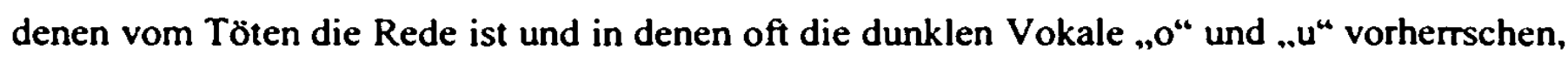
wie die zuvor im Text zitienten Fragmente zeigen.

Zentral für dieses Gedicht ist das bereits im Titel angedeutete Motiv des Schlafes, das sowohl in seiner realen, als auch in einer übertragenen Bedeutung, im Sinne von Tod und Sterben, vorkommt. Das lyrische Ich, der Soldat, liegt zu Beginn des Gedichtes im Halbschlaf auf seinem Soldatenlager, wobei durch die beiden Zeilen „półszept szeleści modlitwy // lęk z twarza upiora przed snem“"13 auch die Möglichkeit angedeutet wird, dass er verletzt ist bzw. im Sterben liegt. Es kann nämlich das Gebet sein, das für den Sterbenden gesprochen wird. dessen Angst vor dem „Schlaf“ wäre somit eine Todesangst. Es könnte aber auch die Angst vor dem fiebrigen Schlaf an sich sein, und zwar deshalb, da in ihm die Schreckensträume vom Tod am Schlachtfeld wieder auftauchen. So zum Beispiel in der letzten Zeile, wo ..tot sein“ darüber hinaus mit „schlafen“ verknüpft wird: „tarach trach karabin ja śpię.“. Eine ganz. andere, positive Bedeutung gewinnt ..Schlaf* in der letzten Zeile des angeführten, längeren Zitats, die durch die Personifikation ,mein Bruder Schlaf“ noch unterstrichen wird. Wenn diese Passage wirklich als Jenseitsvorstellung gelesen wird, was durch die beiden ersten Zeilen motiviert wird. so ist es hier die Todessehnsucht. die zum Ausdruck kommt. Etwas unklar bleibt dabei die Wendung: „nemezis śmierć“. Nemesis steht in der griechischen Mythologie für den ..gerechten Zorn, der sich gegen diejenigen richtet. die eine Ordnung. vor allem die Ordnung der Natur, durchbrochen haben." (Kerényi 1966. 1/85). Ein Bedeutungszusammenhang aus dem Kontext des Gedichtes ergibt sich aus der Abstammung der Nemesis, die eine Tochter der Nacht ist und zu ihren Brüdern unter anderem den Tod (Moros, Ker und Thantos), den Schlaf Hypnos und das Volk der Träume zählt (vgl. Kerényi 1966, V/32). Ob mit der Nennung der Nemesis ein .,gerechter Tod" suggeriert werden soll, muss dahingestellt bleiben. Durch die Zeile „czy On czy Ona wola” scheint allerdings angedeutet, dass diese positiv besetzte Todesvision mit einer höheren Macht in Verbindung steht, was der jeweilige Fettdruck von .nemezis“ bzw. von „On“ und „Ona“. als den einzigen Begriffen im ganzen Gedicht, beweist. Und schließlich ist auch die Lilie ein Symbol für die Gnade Gottes, die Vergebung der Schuld sowie für die von den Sünden gereinigte Seele (vgl.

${ }^{13}$.halbfusternd raschelt ein Gebet "i Angst mit einem Gespentergesicht vor dem Schlaf*. 
Kopaliniski 1990, 200). Somit gewinnt der Tod in „Halbschlaf" endgültig sein doppeltes Antlitz: er steht für die Angst des Soldaten, der ihm täglich ins Auge blicken muss, ist aber gleichzeitig auch dessen Erlösung.

Mit dem Krieg, nun aber auch stärker in seiner zuvor skizzierten Bedeutung als Ende und Neubeginn, beschäftigt sich Czyżewski auch in "Elektrische Visionen“, einem seiner interessantesten Werke. Das Gedicht ist in einzelne Abschnitte unterteilt: auf eine Einleitung folgen drei einzelne Visionen, mit einem Intermezzo zwischen zweiter und dritter Vision. Dieses Gedicht kann, nicht zuletzt wegen seines Titels mit dem apokalyptisch-visionären Erzăhlen in Zusammenhang gebracht werden, für deren Tradition vor allem die „Offenbarung des Johannes" von Bedeutung ist. Diese beschreibt, insbesondere für den Expressionismus, Klaus Vondung so:

„Fur die Offenbarung des Johannes, die der Tradition apokalyptischen Denkens den wichtigsten Anstoß gab. war der Weltuntergang nur eine Durchgangsphase - allerdings eine notwendige - zu einer "neuen Erde«, einem "neuen Jerusalem«. [...] Der Gedanke der Erlosung jedenfalls bestimmte die Apokalypse bis in unser Jahrhundert, auch wenn sie sich von ihrem religiosen Ursprung entfernt hat: Die alte, unvollkommene und verdorbene Welt muß zerstort werden, damit eine neue, vollkommene aufgerichtet werden kann. Stets kam es der Apokalypse auf diese neue Welt an, die Apokalypse war eine Erlosungsvision." (zit. n.: Anz 2002, 45)

Das in diesem Zitat skizzierte Grundmuster liegt auch dem Aufbau von „Elektrische Visionen" zugrunde: Auf die Einleitung, die erste Vision, das Intermezzo und Teile der zweiten Vision, in denen vom "Weltuntergang“, das scheint in diesem Fall besonders die von den Folgen des Ersten Weltkrieges gezeichnete Welt zu sein, die Rede ist, folgt die Schilderung der neuen Welt in der zweiten, und dann vor allem in der dritten Vision. Doch noch in einer anderen Hinsicht kann Czyżewskis Gedicht im Kontext der biblischen Apokalypsen betrachtet werden, und zwar, dass der „Auftrag“ die Vision zu erzählen, von Gott selbst, das heißt von einer höheren Macht gegeben wird, wie dies auch in der „Offenbarung des Johannes“ der Fall ist:

\begin{abstract}
.Am Tag des Herrn wurde ich vom Geist ergriffen und horne hinter mir eine Stimme, laut wie eine Posaune. Sie sprach: Schreib, was du siehst, in ein Buch [...]. Da wandte ich mich um, weil ich sehen wollte, wer zu mir sprach. [...] Als ich ihn sah, fiel ich wie tot vor seinen Fußen nieder. Er aber legte seine rechte Hand auf mich und sagte: Fürchte dich nicht! Ich bin der Erste und der Letzte [...]." (..Die Bibel” 2003, 1385)
\end{abstract}

Auch bei Czyżewski scheint das lyrische Ich, der Erzähler der Visionen, jemand Höherem, der ihm die Visionen erst erschließt, zu begegnen. Dabei klingt das aus der JohannesApokalypse zitierte Fragment wieder an, zum Beispiel durch das Motiv der Stimme. Bei Czyżewski gestaltet sich die Begegnung wie folgt:

"W ciemna noc zbliza sie

Do mego spręzynowego Domu
..In der dunklen Nacht nahert er sich an mein federnes Haus 
Kogut pieje i wola

[...]

Stysze idzie pod drzwi mego domu

czujny pies zaszczekal

Ktoś puka słysze glos zótty
[...]

Ich hore er geht bis an die Tor meines Hauses der wachsame Hund schlug an

Jemand klopft ich horre eine gelbe Stimme

\section{Otwórz" (1920a, 64)}

Mach auf

In diesem Abschnitt ist zuerst wieder die für Czyżewskis Dichtung charakteristische Vermischung von realem und metaphorischem Sprachgebrauch zu bemerken. Der durchaus konkrete Vorgang, dass jemand zum Haus von jemand anderem kommt und dabei etwa der Hund anschlägt, wird durch die Metapher „sprężynowy Dom“ in eine übertragene Sphäre gerückt. Möglich ist es, darin eine Verbindung zum Gehirn zu suchen, da Czyżewski auch in anderen Gedichten das Gehim mit dem Bild von Windungen, das wäre hier die Feder, verbindet $^{15}$. Wer allerdings dem lyrischen Ich begegnet, bleibt unklar, vor allem auch aufgrund des Untertitels der Einleitung: „Gość pomarańczowego cynizmu” (.,Der Gast des orangen Zynismus“). Es muss sich aber wohl, und auch das ist eine Parallele zu Johannes, um jemand Mächtigeren handeln. da dieser Gast sich selbst unter anderem so vorstellt: „Jestem ten którego poznałeś // Dzieckiem // Grywam na wielkiej klawiaturze" bzw. „Ja jestem ten o którym myślałeś // Nie myśląc"16. Die Macht dieses Besuchers wird nicht zuletzt auch dadurch noch unterstrichen, dass er es ist, der dem lyrischen Ich die Visionen ermöglicht und ihn auch vor seinem Tod zu bewahren vermag (.,unikasz śmierci“ - ..du entgehst dem Tod"). Das Erleben der Visionen wird durch das Motiv des Aufbruchs verbildlicht. wenn das lyrische Ich die Aufforderung hört: „Weżmij kij umajony bluszczem // Przepasz biodra i pójdż.."17. Das Motiv des mit Efeu geschmückten Stocks ist aus dem Dionysoskult bekannt. daneben scheint diese Passage aber auch auf eine biblische Vorlage zurückzugehen. nämlich auf die in der „Apostelgeschichte“ geschilderte Befreiung des von Herodes ins Gefängnis geworfenen Petrus, der auf wundersame Weise von einem Engel gerettet wird. Die Parallelen zu Czyżewskis Text sind auffallend. nicht nur allein wegen des Aufbruchs:

„Der Engel aber sagte zu ihm [=Petrus; M.E.]: Güre dich und zieh deine Sandalen an! [...] Dann ging er hinaus und Petrus folgte ihm, ohne zu wissen, dass es in Wirklichkeit war, was durch den Engel geschah; es kam ihm vor, als habe er eine Vision." (..Die Bibel“" 2003, 1235)

\footnotetext{
14 Auch alle weiteren Zitate aus ..Elektrische Visionen“ sind dieser Quelle entnommen. das ganze Gedicht ist auf den Seiten $64-72$ abgedruckt.

is Zum Beispiel in ...Mediumistisch-magnetische Photographic des Dichters Bruno Jasieriski“ (Mediumicznomagnetyczna fotografia poety Brunona Jasieńskiego“), wo es heißt: ..mózg jest pelen węzów (...]” (..das Gehim ist voller Schlangen $\left.[\ldots]^{*}-1922 c, 105\right)$.

${ }^{16}$ "Ich bin der, den du kennen lemtest // als Kind // Ich spiele auf einer großer Tastatur" bzw. .Ich bin der, an den du dachtest // nicht denkend".

".Nimm einen Stock mit Efeu geschmückt // Umgäre deine Hüften und geh."
} 
Auf diese Einleitung folgen in „Elektrische Visionen“ die drei Einzelvisionen. Wohin dabei anfangs die „Reise“ geht, wird durch die Frage des Gastes angedeutet, die er an das lyrische Ich bei ihrer ersten Begegnung richtet:

„Czy chcesz išc w krainę

czamej zorzy

Czerwonej trupiej czaszki grobu grobów"
„Willst du in das Land gehen

des schwarzen Dämmerungslichts des roten Totenkopfes des Grabes der Gräber"

Entsprechend der düsteren Bildlichkeit, insbesonciere des „schwarzen Dämmerungslichtes“, dieser Frage geht es in der ersten Vision um eine vom Krieg verwüstete Welt. In kurzen, elliptischen Sätzen bzw. in für sich allein stehenden Substantiven wird geschildert, wie Angst, Schmerz, Unfreiheit, Verzweiflung die Menschen erfasst haben. Wegkreuze erinnem an die Toten, der Krieg selbst wird aber nur noch kurz erwähnt: „Tańczą trumny ideałów“..18. Diese Stimmung wird durch die Natursymbolik noch verstärkt, neben dem „brennenden Himmel“ (,niebo palące się“), stehen die „zugefrorenen Flüsse“ (,zamarzle rzeki“) für den Winter. Doch ist in dieser ersten Vision auch bereits vom Neubeginn die Rede: auf die „Nacht“ folgt schon die „Dämmerung“ („Noc Zorza“) und auch der Tod von Jesus Christus am Kreuz ist mit dessen Auferstehung verbunden. Doch im Unterschied zur bereits besprochenen Stelle aus „De profundis“, in der die Jünger auf dem Weg nach Emmaus dem wiederauferstandenen Christus begegnen, wird hier in dieser ersten Vision nur auf die Kreuzigung selbst verwiesen. durch die am Kreuz befestigte Tafel mit der Inschrift "INRI“ sowie durch die sich daran anschließende Zeile: „W górze płacze nad miastem“"19.

In der zweiten Vision deutet sich der Neubeginn schon stärker an, was bereits der Untertitel „Wejście w niebieski dzieñ“ sowie die erste Zeile „Przeszła noc dzień codzień się zbliża“ verraten $^{20}$. Nach der dunklen Nacht bricht also der hoffnungsvolle „blaue Tag“ an, der Alltag kehrt wieder in das Leben der Menschen ein. Dieser (neue) Alltag wird in der zweiten Vision durch drei verschiedene Motivbereiche zum Ausdruck gebracht: erstens durch neue technische Erscheinungen, wie der U-Bahn ${ }^{21}$, die mit einem Panther verglichen wird:

.Pregowana pantera ryza

Elektryczne oczy strzaly świecace

Szerokość mózgu metro-dworzec ziemi
.Ein gestreifter rotblonder Panther

Elektrische Augen leuchtende Pfeile

Die Breite des Gehirns Metrobahnhof der Erde

\footnotetext{
18 "Es tanzen die Sarge von Idealen".

19 "Oben das Weinen uber die Stadt."

20 "Eintritt in den blauen Tag" - „Die Nacht verging es nahert sich der Tag Alltag".

21 "Lipski (vgl. 1993, 15) bemerkt zum Gebrauch technischer Motive in ..Elektrische Visionen“", dass Czyzewski in dieser Hinsicht sehr innovativ sei, also oft Dinge und Erscheinungen einführt. die im Polen der fruhen zwanziger Jahre nicht oder nur wenig bekannt waren. Das scheint auch auf das Motiv der Untergrundbahn zuzutreffen, die Czyzewski wohl von seinen Paris-Aufenthalten her kannte.
} 
Czarne petne energii dynamo pedzace Bez ognia koła gorace"
Ein schwarzer rasender Dynamo voll Energie

Ohne Feuer heiße Răder"

Metaphern, die die Bildbereiche der Technik und der Natur miteinander verbinden, sind in Czyżewskis Dichtung häufig anzutreffen, wovon weiter unten noch ausführlich die Rede sein wird. Das zitierte Fragment zeigt auch gut die Dynamik der neuen Zeit. Neben dem schnellen Kommunikationsmittel U-Bahn, sind es die Wörter „energia“ und „pędzič“ sowie die hier häufig verwendeten Partizipien Präsens, die diesen Eindruck vermitteln. Der zweite Motivbereich ist der eines Maskenballs, der wohl für das Amüsement steht, dem nach dem Krieg wieder nachgegangen werden kann. Und drittens ist es das wirkliche alltägliche Leben. das wieder entsteht: so gibt es Geschäfte, die wieder geöffnet haben, Lotterien, Modejournale, Bordelle usw., wodurch auch die Vielfältigkeit und die Intensität des modernen (Großstadt-) lebens gezeigt wird, ebenso wie durch den Vers: „Drżące miasta spracowane ${ }^{.22}$. Gleichzeitig wird in der zweiten Vision auch noch einmal an die Vergangenheit erinnert: auf das Sterben im Krieg folgt nun eine neue Zeit der Fruchtbarkeit: ,Z czaszki trupa // wyrasta // Klos ${ }^{* 23}$.

In der dritten Vision scheint die neue Zeit nun endgültig angebrochen und es ist, wie wieder der Untertitel „Elektryczny świt“ („Elektrische Morgendämmerung“) verrät, auch eine technisierte Zeit. Daher ist von Öfen und Rauch, Uran, Mechanik, Fabriken usw. die Rede. Im Unterschied zur fragmentarisierten Sprache, mit der in der ersten Vision die zerstörte Welt beschrieben wird, sind es nun ganze Sătze, mit denen in oft hymnischem Ton die Gegenwart besungen wird:

„Dzwon dzwon buduje się dom

Mlot Mlot uderzył mlot

Zdrój Zdrój wytrysnał zdrój

Strach strach przeminal strach

$\mathrm{Na}$ lutni wiekom gram

Alleluja Alleluja nam"
„Glocke Glocke das Haus wird gebaut Hammer Hammer es schlug der Hammer Quelle Quelle es entsprang die Quelle Angst Angst es verging die Angst Auf der Leier spiele ich den Jahrhunderten Halleluja halleluja uns"

Das Hymnische, Feierliche wird durch die jeweilige Wiederholung eines Begriffes zu Beginn bzw. am Ende jedes Verses noch gesteigert, ebenso wie durch das freudige „halleluja" im letzten zitierten Vers ${ }^{24}$. In der dritten Vision, in der einzelne Personen auftreten, werden diese Sätze wahrscheinlich von einem Dichter gesprochen. Wahrscheinlich deshalb, da die Person, die diese Zeilen spricht mit „Ten sam“, also „derselbe“ überschrieben sind, also wohl dieselbe Person spricht, die auch zuvor - und das ist eben der Dichter - gesprochen hat. Diese Lesart

22 ,Zitternde, von Arbeit mude Stadte".

23 "Aus dem Totenschădel // wăchst heraus // eine Ähre".

24 Eine Ausnahme bildet der erste zitierte Vers, an dessen Ende sich nicht .,dzwon“ sondern .,dom“ findet. Es wird also nicht der Begriff vom Anfang des Verses wiederholt; die Verbindung zwischen "dzwon" und ..dom” beruht aber auf einer Assonanz. 
ist auch insofern zulăssig, da sich die avantgardistischen Dichter ja als Sprachrohre der neuen Zeit verstanden und diese in all ihren Facetten zum Thema ihrer Lyrik machten. In diesem Sinne interpretiert der Dichter in der dritten Vision mechanische Geräusche von Zahnrädern auch als Gesang der Zukunft:

„Słysze kietkujący śpiew (z dala słychać zebaty jęk)

ty $r$ r r hr r r"
.Ich hore keimenden Gesang

(aus der Ferne ist gezahntes Stohnen zu horen)

kr r r r-chr r r"

Was der Dichter hier positiv interpretiert, ist, wic die in Klammern gesetzte Anmerkung verrät, in Wirklichkeit ein Stöhnen, wodurch sich in die Begeisterung an der Technik auch die Furcht vor ihr mischt. Darin verbirgt sich vielleicht auch eine Kritik am Futurismus, dessen absoluter Verehrung der Maschine Czyżewski, wie erwähnt, skeptisch gegenüber steht: „Człowiek spłodzil i rozpętał machinę, która kiedyś zabije go, albo wywyższy.“ (1922c, $118)^{25}$. In dieser Hinsicht können auch die „eingestürzten Fabriken“ (,Zapadły się fabryki...“) in der dritten Vision verstanden werden und auch Zaworska (1975, 347) spricht, ebenso wie Lipski (1993, 14-15), am Beispiel von "Elektrische Visionen“ von einer darin zum Ausdruck gebrachten ambivalenten Haltung Czyżewskis gegenüber dem technisierten 20. Jahrhundert, das ihm zugleich faszinierend und schrecklich erschien ${ }^{26}$.

Eine weitere Person dieser dritten Vision ist ein Hirte, dessen Dudelsackspiel aus der Ferne zu hören ist. Durch den Hirten, der in dieser neuen technisierten Welt auftritt, wird eine gewisse Spannung zwischen dem alten und dem neuen Menschen verbildlicht, die Czyżewski in seinem Aufsatz „Die Poesie der Expressionisten und Futuristen“ so beschreibt: „W spółczesnym właśnie czlowieku ujawnia się ,konflikt pozostałości’ duszy pasterza - z dusza twórcy dynamomaszyny.“ $(1919 c, 80)^{27}$.

Dieser „neue Mensch“ ist eines der zentralen Themen von ..Elektrische Visionen“, das mittels des lyrischen Ichs in allen drei Einzelvisionen angedeutet bzw. ausgeführt wird, wenngleich letztendlich unklar bleibt, in welcher Beziehung die lyrischen Ichs der einzelnen Visionen zueinander stehen. Im Intermezzo, das zwischen erster und zweiter Vision eingefügt irt, finden sich folgende Zeilen:

\footnotetext{
${ }^{25}$ "Der Mensch zeugte und entfesselte die Maschine, die ihn einmal toten oder erhohen wird."

26 "Zaworska versteht .Elektrische Visionen“" allerdings zur Gänze als katastrophistische Vision des Zusammenbruchs der Welt, eine Lesar, die, wie die hier vorgeschlagene Interpretation zeigt, nicht zur Gănze gerechtfertigt scheint, insbesondere aufgrund der zahlreichen ..positiven" Motive in der dritten Vision. In eine ăhnliche Richtung geht auch die Interpretation von Kryszak (vgl. 1981, 41-44), der aber an einer Stelle (43) doch auf den im Untergang mitgedachten Neubeginn verweist.

${ }^{27}$ "Gerade im gegenwărigen Menschen offenbart sich der ,Konflikt der Relikte` der Seele des Hirten - mit der Seele der Schrpfers der Dynamomaschine."
} 
.Zbliza się moja synteza

A teraz ide do czuciowej

Do przepotęznej Machiny

Mego Rozumu"
„Es năhert sich meine Synthese

Und jetzt gehe ich zur fuhlenden

Zur ubermáchtigen Maschine

Für Czyżewski waren, wie er in „Von der Maschine zu den Tieren“ schreibt, die Maschine und der (animalische) Instinkt die wichtigsten Quellen der modemen Kunst (vgl. 1921b). Im Zitat werden diese beiden Einflüsse auch im „neuen Menschen" synthetisiert. Geboren wird dieser aber erst im letzten Absatz von „Elektrische Visionen“, der mit „Nie koniec a początek ${ }^{1.28}$ eingeleitet wird, das im Druck noch durch Großbuchstaben und Fettdruck hervorgehoben wird. Diese Zeile kann auch als eine Reflexion über das Gedicht als Ganzes gelesen werden. In diesem Absatz werden noch einmal viele mit dem Neubeginn verbundene Motive aufgerufen, zum Beispiel „narodzone slonce“ (,geborene Sonne“) oder .jarzaca dziewica“ (,hell strahlende Jungfrau“). Zugleich wird noch einmal an den vergangenen Krieg erinnert: „Gdy trumny już się zabliżniły“.29. Erst in dieser Situation wird das neue Ich, der

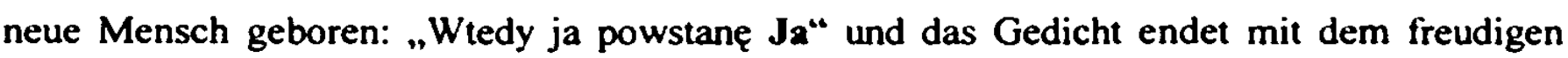
„Hosanna Hosanna Wam. “30.

In „Elektrische Visionen“ werden zum Beispiel mit der neuen Kunst selbst oder der - im Sinne Chwisteks - „visionären“ Erfassung der Wirklichkeit noch weitere Aspekte der neuen Zeit thematisiert. Diese Punkte werden im weiteren Verlauf dieses Kapitels noch eigens diskutiert. An dieser Stelle ging es vor allem darum zu zeigen, wie die neue Zeit selbst Eingang in Czyżewskis Dichtung findet. Wichtig war dabei das Bewusstsein, dass dieser neuen Zeit ein Akt der Zerstörung vorausging bzw. vielleicht sogar vorausgehen musste. Um dies zu verbildlichen, greift Czyżewski an zentralen Stellen in den hier besprochenen Gedichten zum Motiv der Dämmerung bzw. der Auferstehung. wie er auch. gerade in „Elektrische Visionen“, auf die biblische Tradition des apokalyptischen Erzählens zurückgeht. Dadurch ist es möglich, Ende und Neubeginn gemeinsam zu betrachten bzw. sie als zusammengehörig miteinander zu vereinen.

\footnotetext{
28 "Nicht Ende sondern Anfang".

29 "Wenn die Sarge schon vernarbt sind".

30 ".Dann entstehe ich Ich" - .,Hosanna hosanna Euch."
} 


\subsubsection{Das Antlitz der neuen Zeit (1): Die Großstadt}

Als „vorwiegend nervöses und genervtes Kind der Großstad"“ („przeważnie nerwowe i zdenerwowane dziecko wielkiego miasta") bezeichnet Czyżewski einmal den modernen Dichter (1919c, 80). Die Großstadt ist für diesen nicht nur Lebensraum, der ihn beeinflusst und prägt, sondem auch Vorlage und Inspiration für seine Poesie. In der Großstadt erblicken viele Vertreter der Avantgarde die typischste Lebensform der „neuen Menschen“, die auf alle Bereiche seines Lebens, also auch auf die Kunst, abfärbt ${ }^{31}$.

Czyżewski beschäftigt sich in mehreren Gedichten mit der Großstadt bzw. mit dem großstädtischen Leben. Dies geschieht sowohl durch die Thematisierung und Benennung der wichtigsten urbanen Erscheinungsformen, zum Beispiel der Masse, moderner Kommunikationsmittel, Bars, Kaffeehäuser und Kinos, als auch durch den Versuch mittels bestimmter poetischer Gestaltungsmittel der inneren Dynamik und dem Tempo der Großstadt und ihres Lebens zu entsprechen.

Als erstes von Czyżewskis Großstadt-Gedichten ist „Die Stadt“ („Miasto“) aus „Das grüne Auge" zu erwähnen. Durch die Nennung der Seine in der ersten Zeile scheint das Gedicht Paris gewidmet zu sein, weswegen vermutet werden kann, dass Czyżewski es während einem seiner Paris-Aufenthalte 1908-1909 bzw. 1911-1912 verfasst haben könnte. Obwohl die genaue Entstehungszeit dieses Gedichts nicht bekannt ist, kann eine Datierung auf die Zeit vor dem Ersten Weltkrieg auch dadurch näher begründet werden, als dass die von Czyżewski gewählte Art der Darstellung in diesem Gedicht, ebenso wie dessen äußere Form, noch wenig mit Czyżewskis späteren avantgardistischen Gedichten gemein haben. So gebraucht Czyżewski in .,Die Stadt“ konsequent die eher traditionelle metrische Form des Elfsilbers mit einer regelmäßigen Zäsur nach der fünften Silbe, ebenso wie ein einigermaßen regelmäßiges Reimschema: abca dede fgf hgh. Nicht zuletzt beginnt das Gedicht mit einem impressionistisch anmutenden Stimmungsbild:

"Mosty rzucone na mglawa Sekwane
Spajaja miasto niby klamn retawe
Nad zielonawa woda dwa szeregi
Skrywionych domów co jak niewyspane
Mrugaja blaskiem okien

ludzi wozów" (1920a, 42-43)
.Brücken an die nebelige Seine geworfen

Halien die Stadt wie rostige Klammern zusammen

Am grunlichen Wasser =wei Reihen

Schiefer Hauser die wie unausgeschlafen

Blinzeln mit dem Glanz der Fenster

\footnotetext{
${ }^{31}$ Vgl. dazu zum Beispiel auch Peipers Aufsatz (1922d): „Stadt, Masse, Maschine“ (..Miasto. Masa, Maszyna“). auf deutsch abgedruckt in: Olschowsky 1986, 59-81.

32 Das Gedicht ist im Original kursiv gedruckt. Auch alle weiteren Zitate aus .Miasto" sind der angefuhrten Quelle entnommen.
} 
Wenig ist in dieser Passage noch von der Hektik und vom Tempo des großstädtischen Treibens zu spüren, der neblige Morgen, das grünliche Wasser und das langsame Erwachen der Stadt, das mittels einer Personifikation, dem „Blinzeln“ der Häuser mit ihren Fenstern, zum Ausdruck gebracht wird, wirken eher gemächlich. Dennoch geht es im weiteren Verlauf des Gedichtes um die Eile des Stadtlebens und um die Menschenmassen der Großstadi, vor allem in den folgenden Zeilen:

„Tlum sie kotluje przez mosty ulice Citba sklębiona tramwai powozó"
„Die Masse brodelt über die Brücken der Straßen Geballtes Gedrainge der Siraßenbahnen der Wagen"

In diesen beiden Versen finden sich allein vier Ausdrücke, die mit „Masse“ assoziiert werden können (,thum“, „kothuje się“, „ciżba skłębiona“), auch die zu Beginn des vorigen Zitats genannten Brücken der Stadt als Orte der Enge verstärken noch den Eindruck des Gedränges. Daneben geht es in "Die Stadt" um die Stadtbewohner selbst. die ihren unterschiedlichen Tätigkeiten nachgehen. Wenngleich also die Dynamik der Stadt im Vordergrund steht, ist das Gedicht selbst in einem langsamen Tempo gehalten. Czyżewski unternimmt dabei nicht den Versuch, diese Dynamik der Stadt auch in die poetische Gestaltung zu übernehmen. was sich zum Teil wohl dadurch erklärt, dass das Gedicht, wie zuvor erwähnt, wahrscheinlich noch vor dem Ersten Weltkrieg entstanden ist. So besteht „Die Stadt” ausschließlich aus grammatisch vollständigen Sätzen, unterstrichen wird diese distanzierte. langsame Art der Beschreibung noch durch einige Enjambements. Einzig die Zeile: „w takt bije miasta tętno ustawiczne ${ }^{\text {4.33 }}$ bildet eine Ausnahme, da das unablässig pulsierende Stadtleben in den zwei unmittelbar aufeinanderfolgenden betonten Silben am Beginn dieses Verses seine formale Entsprechung findet.

Erst in den späteren Gedichten „Stadt an einem Herbstabend", von dem bereits die Rede war, „Singende Häuser” („Śpiewające domy“) und „Melodie der Menge“ (..Melodia tlumu“) spiegelt sich die innere Bewegung und Dynamik der Großstadt auch in den poetischen Verfahrensweisen wider. Zum Beispiel wird die Simultaneität des großstädtischen Geschehens in "Stadt an einem Herbstabend" durch unmittelbar aufeinanderfolgende, aber nicht miteinander in Verbindung stehende Geschehnisse zum Ausdruck gebracht. Sogar die Schilderung eines einzigen Ereignisses ist nicht mehr in sich geschlossen: so ist vom Begräbnis in den Zeilen 12,16 und 17 die Rede, unterbrochen immer wieder von anderen

33 ,im Takt schlagt der unaufhorliche Puls der Stadt“. 
Ereignissen $^{34}$. In formaler Hinsicht ist diese Gleichzeitigkeit des Geschehens durch den Zeilenstil umgesetzt.

Die innere Bewegtheit der Stadt ist auch das Thema des Gedichts "Singende Häuser". Czyżewski scheint darin jene Form der Wahrnehmung zu gestalten, die zum Beispiel bei einer Fahrt mit dem Auto oder einer Straßenbahn durch eine Stadt entsteht und die beim Blick aus dem Fenster die Gebäude bewegt erscheinen lässt. Allerdings wird in „Singende Häuser“ die Bewegung des Blickes auf die Häuser selbst übertragen:

\begin{tabular}{|c|c|}
\hline $\begin{array}{l}\text { Wda ulica domy } \\
\text { Spiewajace }\end{array}$ & $\begin{array}{l}\text {.Es gehen durch die Straße Hâuser } \\
\text { Singend }\end{array}$ \\
\hline$[\ldots]$ & {$[\ldots]$} \\
\hline Dom bialy & Weißes Haus \\
\hline Skacze z radości & Springt vor Freude \\
\hline Dom fioletowy & Violettes Haus \\
\hline Niski ton & Tiefer Ton \\
\hline Dom zódty smukty & Schlankes gelbes Haus \\
\hline $\begin{array}{l}\text { Wysoki ion } \\
\text { Katdy inm }\end{array}$ & Hoher Ton \\
\hline $\begin{array}{l}\text { Kazdy inny } \\
\text { Pędza i patrza }\end{array}$ & $\begin{array}{l}\text { Jedes anders } \\
\text { Sie eilen dahin und blicken }\end{array}$ \\
\hline Szyby leca na bruk & Die Scheiben gehen zu Bruch \\
\hline Bbyszcza $i$ dżwięcza & Glanzen und klingen \\
\hline$Z$ dala stysze spiewaja & Von weitem höre ich sie singen \\
\hline Domy" (1920a, 49) & \\
\hline
\end{tabular}

Das Subjekt der in diesem Fragment verbildlichten Bewegung sind die Häuser. Durch die drittletzte Zeile wird aber gleichermaßen deutlich, dass diese Bewegung erst in der Beziehung zu einem ebenfalls nicht statischen Betrachter (,minąlem“ bzw. „z dala słyszę") entsteht. So wird die Dynamik der Stadt zweifach zum Ausdruck gebracht: durch die Eindrücke des durch die Stadt gehenden oder fahrenden lyrischen Ichs, wie gleichermaßen dadurch, dass sich die Häuser selbst bewegen bzw. zu bewegen scheinen. Dafür verwendet Czyżewski in „Singende Häuser“ häufig das Stilmittel der Personifikation: Die Häuser „gehen“ und „eilen“ nicht nur .dahin“, sondern ..singen“ auch oder „springen aus Freude ${ }^{.36}$. Die Vielfalt der sich für den Betrachter ergebenden Eindrücke wird durch die zahlreichen Synästhesien des Gedichts noch unterstrichen. Es ist nicht nur die Bewegung, die ins Auge sticht. sondern es sind auch die

\footnotetext{
${ }^{34}$ Es ist außerdem noch moglich die ZI. 5: „w kosciele dzwonia dzwony“ im Zusammenhang mit dem Begrabnis zu lesen, wodurch sich dessen Schilderung noch breiter aber das Gedicht verteilen würde.

35 Auch dieses Gedicht im Original kursiv. Eine deutsche Übersetzung findet sich in: Dedecius 1996-2000. V/1/336.

${ }^{36}$ Stanisław Baczynski schreibt in seiner Studie uber die neueste polnische Lyrik (vgl. 1924, 28-30), dass der zu bemerkende hăufige Gebrauch von Stilfiguren, wie Personifikationen oder Onomatopoesien aus dem neuen Blick des Dichters auf die Wirklichkeit, die er als dynamisch empfinde und als deren Teil er sich fuhle. resultiere. Das Ziel, das der modeme Lyriker dabei verfolge. sei es, die „Belebung der Welr” („ozy'wienie swiata") und die Bewegung zum Ausdruck zu bringen. Als Beispiel für ein Gedicht Czyzewskis nennt Baczyñski unter anderem auch ..Singende Hăuser".
} 
Farben und der Glanz sowie die Klänge der Häuser, die sich für ihn zu einer Art Gesamtkunstwerk Stadt zusammenzufügen scheinen. Die Gestalt der Häuser, ihre Farbe und der ihnen zugeordnete Ton korrespondieren dabei miteinander: so hat zum Beispiel das "schmale, schlanke" Haus eine helle Farbe ("gelb") und steht für einen "hohen Ton", wohingegen der des Hauses mit der gedämpften „violetten“ Farbe „tief" ist.

In „Singende Häuser“ findet, im Unterschied zum vorhin besprochenen Gedicht „Die Stadt“, die thematisierte Bewegung der Stadt auch Eingang in die stilistische Gestaltung: so sind es kurze Sătze, Ellipsen oder sogar manchmal nur mehr einzelne Wörter, die dem Gedicht als Ganzes ein schnelleres Tempo geben und so eine formale Entsprechung zum raschen Wechsel der Eindrücke bilden.

Czyżewski selbst stellt in seinem Text „Tytus Czyżewski über ,Das grüne Auge’ und seine Malerei“ dieses Gedicht noch in einen anderen Kontext:

.spiewajace domy to ,poemat’ krzywości linii i miary. Wszystko tańczy w europejskiej chuci powojennej. Domy śmieja się z ludzi, a ludzie płacza nad swoja ghupota.

Dzieci śmieją sį̧ z rodziców." (1922c, 118$)^{37}$

Dadurch wird die dem Gedicht eigene Fröhlichkeit und Unbekümmertheit, wenn auch in ironischem Ton, auch auf die Nachkriegseuphorie bezogen. Es ist dies die Zeit einer neuen Generation, die den Werten ihrer Eltern bricht. Alles Gewohnte und Etablierte scheint ein wenig aus den Fugen gekommen (,krzywości linii i miary“), sogar die Häuser lachen daher über die Menschen.

Im selben Text schreibt Czyżewski außerdem über „Melodie der Menge“, dem nächsten hier zu behandelnden Gedicht, in dem die Großstadt mit den für sie charakteristischen Erlebnissen thematisiert wird. Das Gedicht, so Czyżewski, sei ein Gedicht über die Unruhe und das nervende Chaos, die auf dem Pariser Boulevard St. Michel herrschen, auf dem er sich einmal befand (vgl. 1922c. 118). Welche Situation genau diese Unruhe hervorruft, wird ganz am Ende von „Melodie der Menge“ gesagt, und zwar in den drei letzten Zeilen:

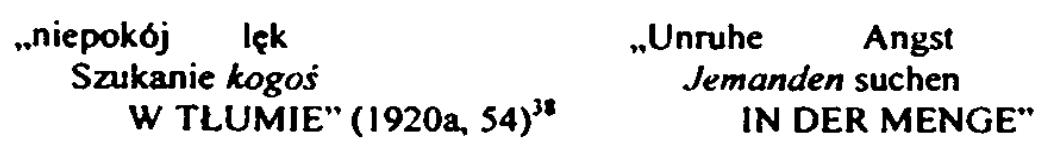

Ob es das lyrische Ich ist, das jemanden in der Menge sucht, bleibt unklar, dennoch wird dieses der Menschenmasse der Großstadt gegenüber gesetzt:

\footnotetext{
'.Singende Hauser ist ein .Poem' der Schiefheit der Linien und des Maßes. Alles tanzt in der europăischen Nachkriegslust. Hăuser lachen aber die Menschen und Menschen weinen aber ihre eigene Dummheit. Kinder lachen uber ihre Eltem."

${ }_{38}$ Alle weiteren Zitate sind dieser Vorlage entnommen, das ganze Gedicht ist auf den Seiten 53-54 abgedruckt.
} 
„Bulwarem phynie rzeka Która staje przede mna Procesja szkieletow"
.Am Boulevard fließt ein Fluss

Der sich vor mich stellt

Eine Prozession von Skeletten"

Nur mehr umrisshaft können die einzelnen Menschen in dieser Masse vom lyrischen Ich wahrgenommen werden, sie erscheinen ihm nur mehr als ein durchgehender Fluss bzw. als Prozession entindividualisierter Skelette. Auch im weiteren Verlauf des Gedichtes wird die charakteristische Form der Wahrnehmung der Großstadt mit ihren vielfaltigen und schnell wechselnden Eindrücken beschrieben:

$\begin{array}{cccc}\text { "Alfonsy panny } & \text { "Zuhalter } & \text { Frăulein } \\ \text { Uliczni hotysze } & \text { Habenichtse von der Straße } \\ \text { Tramwaj omnibus } & \text { auto" } & \text { Straßenbahn Omnibus Auto" }\end{array}$

Das Tempo der Stadt kommt außerdem durch bestimmte Erscheinungsformen des großstädtischen Lebens zum Ausdruck, wie etwa der Bar, in der die Leute schnell ein Sandwich essen (,w barze jedli już sandwich").

Außerdem lässt Czyżewski in ..Melodie der Menge“ diese Dynamik über die poetischen Ausdrucksmittel zum Vorschein kommen. Wie in ,Singende Häuser" geschieht dies auch hier durch eine unvollständige, defekte Syntax. Die kurzen Eindrücke werden durch einzelne Substantive wiedergegeben, fast immer ohne näher beschreibende Adjektive. Im zuletzt angeführen Zitat sind die einzelnen Eindrücke noch miteinander verbunden - zum Beispiel in semantischer Hinsicht - und können außerdem als solche ganzheitlich benannt werden. Durch eine nochmalige Steigerung des Tempos scheint dies aber im weiteren Verlauf des Gedichtes nicht mehr möglich:

\section{.W kawiarni \\ Zielony flet \\ Piers kobiety \\ Atsention}

Kastaniety"

.Jm Kaffechaus
Grüne Flote
Die Brust einer Frau
Attention
Kastagnetten"

Personen und Sachen sind hier nur mehr durch Synekdochen bezeichnet. Die Wahmehmung beruht nicht mehr auf der Betrachtung, sondern nur mehr auf einem schnell erhaschendin Blick, der eben nicht die ganze Frau, sondern nur ihre Brust und nicht mehr die ganze Musikgruppe. sondern nur eine Flöte oder die Kastagnetten zu erfassen vermag. Auch das lyrische Ich scheint in diese Dynamik der Stadt hineingezogen zu werden. die seine Unruhe, angesichts der zuvor angesprochenen Situation, in der Menge jemanden finden zu müssen. bis zum Äußerten steigert: 

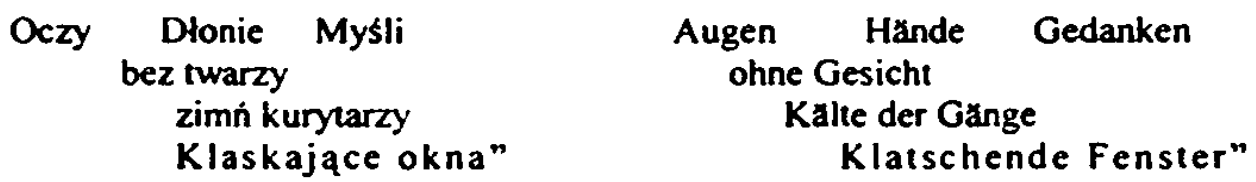

Neben dem schnellen Tempo, das durch eine auf Substantive und Adjektive - bei fast völligem Verzicht auf Verben - reduzierte elliptische Syntax hergestellt wird, verstärken auch die äußeren Umstände, das „nervöse Licht“, das Schlagen (,Klatschen“) der Fenster die Unruhe des Suchenden, dessen Wahrnehmung der Menschen sich nur mehr auf Eindrücke von Körperteilen („oczy“, „dłonie“) beschränkt. Noch einmal wurde dabei das Tempo des Gedichtes gesteigert, die Fülle der Eindrücke ist zu groß, als dass diese noch geordnet und verarbeitet werden können - die Menschen erscheinen daher ohne Gesicht („bez twarzy“), wodurch ein Motiv vom Beginn des Gedichts wieder aufgegriffen wird.

Auch die Szenerie des Gedichtes „Katzenserenade“ („Kocia serenada“) ist in die nervöse Atmosphäre der Großstadt eingebettet. Das Gedicht erzählt vor allem vom nächtlichen Liebeswerben eines Katers, das dem lyrischen Ich, das sich in seinem Hotelbett befindet, den Schlaf raubt:

„Ja słucham ja spać nie moge

Ulice wierci auto

Latarni gazowej blask

Na dachu śpiewa i płacze" $(1920 a, 61)^{39}$
„Ich hore ich kann nicht schlafen

Ein Auto bohrt die Straße

Glanz einer Gaslateme

Singt und weint auf dem Dach"

Durch das Singen der Katze, zu dem noch die Geräusche der Stadt kommen. im Zitat das Dröhnen eines Autos, an anderer Stelle des Gedichtes dringt Lärm aus einer Bar usw. sowie die vom fahlen Schein der Gaslaternen stammende Unstetigkeit der nächtlichen Großstadt. ziehen das lyrische Ich zunehmend in deren Unruhe hinein. Schon in der ersten Hälfte des Gedichts kündigt sich diese an: „Nerwy - ja się uduszę“40 und verstärkt sich kurz vor dem Ende. Doch jetzt scheint das lyrische Ich selbst an dieser nervösen Dynamik teilhaben zu wollen:

Juz północ bija zegary

bom bum bum bom

Mrau mrau tęskne mrau

Ja z lózka skaczé szalony

Ja spać nie moge ja drze

Nerwowo wdziewam pantalony

Miłości - ja biegnę w ulice

Poszukam sobie awantury"
"Schon Mitternacht schlagen die Uhren

bom bum bum bom

Mrau mrau sehnsuchisvolles mrau

Ich springe aus dem Bett verrickt

Ich kann nicht schlafen ich zittere

Nervos ziehe ich meine Hosen an

Liebe! - ich laufe auf die Straße

Ich werde mir ein Abenteuer suchen"

\footnotetext{
${ }^{39}$ Alle Zitate aus „Katzenserenade" sind aus dieser Quelle entnommen, das ganze Gedicht ist auf den Seiten 59 61 abgedruckt.

".Die Nerven - ich ersticke".
} 
Dreimal klingt in diesem Zitat die Nervosităt des lyrischen Ichs an (,ja skaczę szalony“, ,ja drž̨", "nerwowo“), aufgrund derer es in die nächtliche Stadt läuft (,biegnę w ulice“), um sich in Abenteuer zu stürzen. Deutlich werden hier auch die zahlreichen Geräusche der Stadt, das "Schlagen der Uhren“ und eben der Gesang des Katers, die sich durch das ganze Gedicht ziehen. Außerdem ist an diesem Fragment das relativ hohe Tempo des Gedichtes erkennbar, das der dargestellten Szenerie entspricht. Dies wird auch durch den Zeilenstil und durch die metrische Gestaltung des Gedichtes - es handelt sich hier um einen tonischen Vers mit jeweils drei Betonungen (bei unterschiedlicher Silbenanzahl) - unterstrichen.

Mit dem Kino, einer charakteristischen Institution der Großstadt beschäftigt sich Czyżewski zum Beispiel in dem Gedicht "Sensation im Kino“ (,Sensacja w kinie“). Darin wird von einem Kinobesuch erzählt, wobei sich die Eindrücke des Films mit den Erlebnissen des lyrischen Ichs im Kino selbst, zum Beispiel seinen kleineren Streitereien mit dem Nachbar. vermischen. Insgesamt erinnert das Gedicht aber eher an eine spielerische, leichte und ein wenig humoristische Erzählung. Dieser Eindruck wird durch die äußere Form des Gedichtes verstärkt, bei der es sich ohne Ausnahme um einen regelmäßigen Achtsilber mit ebenso konsequenten Paarreimen aa bb cc usw. handelt. Das Gedicht spiegelt so auch ein wenig die Leichtigkeit und Seichtheit der sensationellen Kinounterhaltung - es handelt sich hier um den Film "mord w Bombaju“ („Mord in Bombay“) - wider. Dies verrät auch die letzte Zeile: „Film kurz nerwy trochę błota“ $(1922 c, 86)^{41}$. Außerdem stellt das Publikum dieses Films durch seine Reaktionen und emotionalen Zwischenrufe selbst seine eigene Naivität bloß.

Vielleicht um diesen Eindruck nicht zu zerstören, versucht Czyżewski in „Sensation im Kino“ nur an wenigen Stellen, das Erlebnis der filmischen Wahmehmung auch in die stilistische Gestaltung des Gedichts einfließen zu lassen, wie dies noch bei den Stadtgedichten der Fall war. So wird etwa die vom Film ausgehende Bewegung und der damit verbundene schnelle Wechsel der Eindrücke nur in einem Vers zum Ausdruck gebracht: „morze auto cztery drzewa" $(1922 c, 86)^{42}$. Nur der durchgehend verwendete Zeilenstil, der es, wie im Falle von „Stadt an einem Herbstabend“ erlaubt, unterschiedliche Situationen unmittelbar aneinander $<\mathrm{u}$ reihen, bildet eine formale Entsprechung zu den stetig wechselnden Bildern eines Films.

Dieselbe anekdotenhafte Erzählweise ist auch für das Gedicht .,Ballade über die Kellnerin Kocia“ („Ballada o Koci kelnerce“) charakteristisch. Auch die äußere Form dieses Gedichtes ist mit der von „Sensation im Kino“ identisch: es handelt sich auch hier um einen Achtsilber mit regelmäßigen Paarreimen. Das Gedicht erzählt vom hektischen Treiben in einem

\footnotetext{
"1 "Film Staub Nerven etwas Schlamm".

42 ".Meer Auto vier Baume".
} 
Kaffeehaus, das Czyżewski oft in seinen Stadtgedichten thematisiert und das ebenso als typisches Element des Großstadtlebens angesehen werden kann, wie das $\mathrm{Kino}^{43}$. Die für die Stadt als solche so charakteristische unablässige Bewegung, die Fülle der Reize und der schnelle Wandel der Geschehnisse fmdet sich auch in der Geschäftigkeit eines Kaffeehauses wieder. Im Mittelpunkt des Gedichts steht die Kellnerin mit Namen Kocia, die zwischen Bestellen, Servieren und Kassieren hin- und hereilt, wodurch sich für das Gedicht insgesamt ein recht hohes Tempo ergibt:

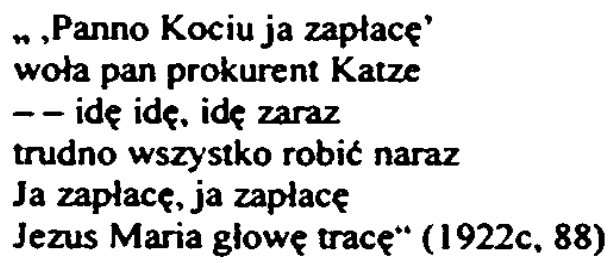

\author{
„,Fraulein Kocia ich bezahle' \\ ruft der Herr Prokurist Katze \\ - - komme komme komme gleich \\ schwer alles zugleich zu tun \\ Ich bezahle, ich bezahle \\ Jesus Maria mir dreht sich der Kopf*
}

Dieses beschwingte Tempo entsteht nicht nur durch die schnell wechselnden Ereignisse, sondern auch, wie im Fragment ersichtlich, durch die Wiederholungen (,ja zapłacę“ und „idę. idę, idę zaraz").

Ganz unterschiedlich dazu ist das im Band „Nacht - Tag“ im Anschluss abgedruckte Gedicht „Ein Schläfchen im Kaffeehaus“ („Drzemka w kawiarni“), vor allem was das Erzähltempo betrifft. Hier scheint das Kaffeehaus eher als eine Oase der Ruhe inmitten der Dynamik der Großstadt begriffen zu werden und nicht als dessen mikrokosmische Widerspiegelung. Es ist der Ort, um Zeitung zu lesen und über aktuelle politische Entwicklungen zu diskutieren, wie auch um Geschäfte zu machen.

In einigen der zuvor besprochenen Gedichte war zu bemerken, dass sich zum Beispiel die Hektik und Dynamik der Stadt auf jemand anders zu übertragen scheint: auf die Unruhe des lyrischen Ichs, das jemanden in der Masse zu finden versucht in .,Melodie der Menge“ oder auf die Nervosität des lyrischen Ichs, das nicht mehr zu schlafen vermag in „Katzenserenade“. In „Ein Schläfchen im Kaffeehaus” scheint sich dieser Prozess umzukehren, da von der schläfrigen Atmosphäre des Kaffeehauses zuerst die Stadt Krakau und schließlich ganz Polen erfasst wird:

\footnotetext{
${ }^{43}$ Czyzewski thematisiert in seinen Gedichten das Kaffeehaus vor allem als typische Einrichtung der modemen Großstadt. Spătestens seit der Moderne gilt das Kaffeehaus aber auch als bevorzugter Treffpunkt und Diskussionsort von Schriftstellem und Kanstlem, wo neue Ideen geboren werden. Vgl. zu einer Beschreibung der Krakauer (literarischen) Kaffeehausszene um 1900: Faron 1995. Ausfuhrlich ist bei Faron vom beruhmtesten Kaffeehaus der Jahrhundertwende ..Jama Michalika" (..Die Hohle Michaliks") die Rede, in dem, wie in dieser Arbeit bereits erwăhnt, ab 1905 das modemistische literarische Kabarett ..Der grüne Ballon" (.Zielony balonik“) auftrat. Auch viele literarische Gruppen der $Z$ wischenkriegszeit trafen sich und lasen regelmaßig in bestimmten Cafés, so zum Beispiel die Mitglieder der Warschauer Gruppe ..Skamander" im ..Pod Picadorem" (..Zum Pikador" (vgl. Zawada 1998. 29-51).
} 
„Wszystko i wszytkich sen bierze

Drzemia widelce i noze

Kawiamia kelnerzy a moze

Krakowa całe ulice

Drzemią i Sukiennice,

Szewska Dhuga i Wolska

I cała zdrzemała się Polska
"Alles und alle uberfallt der Schlaf

Es schlummern Gabeln und Messer

Das Kaffeehaus die Kellner und vielleicht

ganze Straßen Krakaus

Auch schlummern die Tuchhallen

die Straßen: Szewska, Diuga und Wolska

Und ganz Polen schlummerte ein .$^{\prime \prime}(1922 c, 91)^{4+}$ ,

In diesem Fragment ist gut erkennbar, dass die Gemächlichkeit der ganzen Szenerie auch durch die formale Gestaltung des Gedichtes, vor allem über die zwischen den einzelnen Versen eingefügten Leerzeilen, die nur aus Punkten bestehen, vermittelt wird.

Das Motiv des modernen Kaffeehauses kommt schließlich auch im Gedicht „Das gesehene Gesicht“ („Twarz widziana“) vor, das aus Gründen der Anschaulichkeit hier vollständig angefuhrt sei:

„TWARZ WIDZIANA

Naprzeciw - szyba srebmo-sina

Kawiami, -

Raz, dwa, trzy,

Naprzeciw

,Kawa', ,Mazagran', ,Grenadyna'.

Biała ręka trzyma

Gazetę.

Cztery, pięc, sześć. -

Naprzeciw

Widze pod twarzy

Kobiety. -

Błoto bryzga spod kô.

Serce się thucze.

Naprzeciw

To ons

Czyta "Journal des Débats».

Spoglada: siedm, osm,

Widze twarze dwie i por!

Nie!

To nie ona - eh - bah!!

byl to zwid...

Obraca na mnie oczy

Nie - to nie ona.

Biale zęby widze -

- Mózg się mroczy -

\section{„DAS GESEHENE GESICHT}

Gegenuber - eine silber-blaugraue Scheibe

Des Kaffeehauses. -

Eins, zwei, drei,

Gegenaber

,Kaffee', ,Mazagran', ,Grenadine'.

Eine weiße Hand halt

Eine Zeitung.

Vier, funf, sechs, -

Gegenaber

Sehe ich ein halbes Gesicht

Einer Frau. -

Schlamm spritzt von den Rádem,

Das Herz poltert.

Gegenüber

Das ist sie

Sie liest "Journal des Débats".

Schaut: sieben, acht,

Ich sehe zweieinhalb Gesichter!

Nein!

Das ist nicht sie - eh - bah!!

Es war eine Taxuschung...

Sie wendet die Augen zu mir

Nein - das ist nicht sie.

Ich sehe weiße Zahne -

- Das Gehim verfinstert sich -

\footnotetext{
"Der Spott aber das verschlafene Krakau, das von den in die Stadt kommenden Kunstlern des .Jungen Polens” aus seinem Schlaf erweckt wird. ist auch ein zentrales Motiv vieler Feuilletons von Tadeusz Boy Zeleniski (vgl. 1983). Es scheint daher nicht ausgeschlossen, dass Czyzewski in seinem Gedicht bewusst auf dieses Motiv zuruckgreift. wenngleich er sich einer ahnlich expliziten Feststellung - zum Beispiel bezogen auf die Kunstler der jungen A vantgarde - enthalt.
} 
W uśmiechu i zlota plombe,

To nie ona." (1920a, 58-59)
Im Lachen und eine goldene Plombe, Das ist nicht sie.“

Wieder wird in diesem Gedicht ein für die Großstadt typisches Erlebnis thematisiert: der Blick fällt auf jemand scheinbar Bekannten. Das lyrische Ich, das sich auf der gegenüberliegenden Straßenseite („naprzeciw“ und „Błoto bryzga spod kól“) als das Kaffeehaus, in dem die Frau sitzt, befindet, versucht, diese näher zu erkennen. wodurch sein Blick auf ihre einzelnen Körperteile fällt: „biała ręka“, „pół twarzy Kobiety”, „oczy“, „biale zęby“, „złota plomba“. Durch die innere zeitliche Struktur des Gedichtes, die sich auf das Ticken zum Beispiel des Sekundenzeigers einer Uhr stützt (,raz, dwa, trzy“ etc.), wird das Schweifen des Blickes von einem Teil zum anderen suggeriert. Dadurch ergibt sich zwar eine gewisse Zeitspanne, die die dargestellte Handlung des Betrachtens ausgefullt haben muss, dennoch fügen sich im Gedicht die Eindrücke scheinbar zu einem simultanen Gesamtbild zusammen. Diese Gleichzeitigkeit wird formal auch durch die in "Das gesehene Gesicht” verwendeten kurzen Sätze, Ellipsen und einzelnen Wörter, durch die Czyżewski die Unmittelbarkeit der Eindrücke und deren raschen Wechsel wiederzugeben versucht. suggeriert. Das ganze Gedicht ist ein innerer Monolog des lyrischen Ichs, wobei sich dessen Gedanken mit seinen Beobachtungen vermischen. Ebenso scheint sich seine Wahrnehmung der Frau mit seiner Vorstellung, mit der Erinnerung an eine ihm in der Tat bekannte Frau zu vermischen, erst als ihm beide Gesichter zugleich bewusst zu werden scheinen, wird ihm dies deutlich: „Widzę twarze dwie i pól// Nie! // To nie ona... // był to zwid“4ts.

Die Thematisierung des Phänomens "Großstadt" und ihrer "Institutionen" erfolgt in allen untersuchten Gedichten über ihre charakteristischen Erscheinungen, von denen insbesondere die Masse und die Dynamik. die für eine nervöse Atmosphäre sorgt, zu nennen sind. Die Wahrnehmung erscheint beschleunigt, es sind zum Teil nur noch fragmentartige Eindrücke. die möglich sind. Czyżewski versucht auch, in der stilistischen Gestaltung dieser Dynamik gerecht zu werden: mit dem Zeilenstil in "Stadt an einem Herbstabend" und „Katzenserenade“ oder den elliptischen Sätzen und einzelnen Ausdrücken in „Singende Häuser" und in „Melodie der Menge“, wobei in letzterem noch eine Dynamisierung innerhalb des Gedichtes zu erkennen ist. Auffallend ist außerdem, das Czyżewski die innere Bewegung der Stadt in zwei Gedichten (,Singende Häuser“ und „Melodie der Menge“) explizit mit Musikalität in Verbindung bringt: Auch darin kommt letztendlich das Verständnis der Stadt als rhythmischer und sich in ständiger Bewegung befindender Organismus zum Ausdruck.

\footnotetext{
4s Vgl. zu "Das gesehene Gesicht" auch Abschnitt 5.2.3 dieser Arbeit, in dem dieses Gedicht im Kontext der Beziehung zwischen Czyzewskis Lyrik und dem Kubismus besprochen wird.
} 


\subsubsection{Das Antlitz der neuen Zeit (2): Die Technik und das neue Leben}

In der Besprechung des Gedichts „Für die Kunst und das Leben“ im vierten Kapitel dieser Arbeit wurde ansatzweise deutlich, dass die Thematisierung der neuen Zeit in Czyzewskis Gedichten oft über die Attribute des neuen Lebens sowie über eine vorwiegend aus dem Bereich der Technik entlehnte Bildlichkeit erfolgt. Dementsprechend finden sich in vielen Gedichten, zusätzlich zur expliziten Thematisierung neuer Phänomene in den Großstadtgedichten oder zum Beispiel im Gedicht „Die Stille“ („Cisza“), das die Telegraphentechnik beschreibt, zahlreiche entsprechende Motive bzw. Metonymien, Symbole, Metaphern und Vergleiche.

Neben dem häufig gebrauchten Motiv der Maschine oder des Dynamos (zum Beispiel in: „Elektrische Visionen“), vermitteln viele Bilder in Czyżewskis Gedichten unmittelbare Eindrücke der neuen Zeit, zum Beispiel: „nerwowych drgań atomy“ („Atome nervöser Zuckungen“ - 1920a, 57), ..błyskawice telegrafów Morsego“ („Blitze des MorseTelegraphen“ - 1922c. 81) oder „skrzdla aeroplanu szumią“ („die Flügel des Flugzeuges rauschen“- 1922c, 73).

Die im selben Kontext verwendeten Symbole betreffen vor allem zwei Bereiche, erstens den des Morgenanbruchs, der fur der Beginn der neuen Zeit insgesamt steht. So ist in vielen Gedichten vom Anbruch des neuen Tages („po nocy dzień się niebieszczy“*6 - 1920a, 57 bzw. „Wejście w niebieski dzień. ${ }^{47}$ - 1920a, 68) sowie vom Morgen selbst (.,ranna godzina brzaskowa“ - ..morgendliche Dämmerungsstunde” - 1922c, 82 bzw. „Rano Rosa“ - .Morgen Tau" - 1922c. 97) die Rede. Der zweite Bereich ist der der Arbeit. des Bauens etc., wodurch das Entstehen von etwas Neuem und gewissermaßen auch das Ende der Passivität. der Untätigkeit zum Ausdruck gebracht wird. Dies geschieht zum Beispiel durch das Schlagen des Hammers, mit dem die ..neuen Maurer“ das Haus fertig stellen: „Młot bije dom się gotowi // Tna kwarce murarze nowi““8 $(1920 a, 57)$ oder: ..dzwon dzwon buduje się dom // Mlot młot uderzyl mlot" (1920a. 71) $)^{49}$.

Sehr anschaulich wird Czyżewskis Gebrauch der Symbolik des Neuen in dem Gedicht „Nacht-Tag“ („Noc-Dzien““). dem ersten aus dem gleichnamigen Band .Nacht - Tag. Mechanisch-elektrischer Instinkt". Bereits der Titel lässt vermuten, dass hier der Gegensatz zwischen alter, vergangener und neuer, im Anbrechen begriffener Zeit dargestellt werden soll.

\footnotetext{
46 "nach der Nacht erblaut sich der Tag".

47 "Eintritt in den blauen Tag".

48 "Der Hammer schlät das Haus wird fertig // Neue Maurer schneiden Quarzblocke".
} 
Dementsprechend wird im Gedicht der Übergang zwischen „Nacht“ und „Tag“" insgesamt dreimal zur Sprache gebracht:

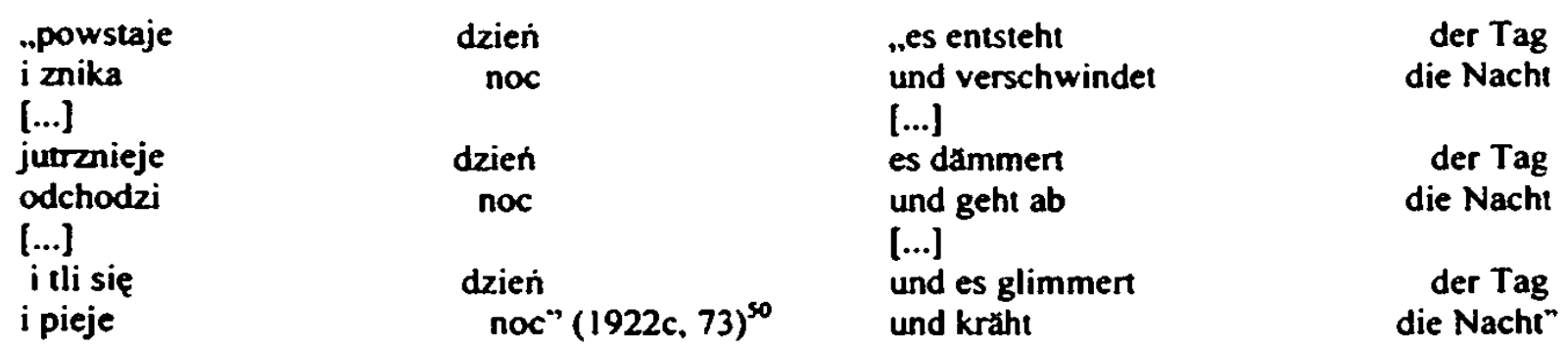

Einmal wird daruber hinaus auch bewertend auf den Gegensatz zwischen Gestern und Heute hingewiesen:

$\begin{array}{lccc}\text { \#olbrzymi } & \text { dzien } & \text {,riesiger } & \text { Tag } \\ \text { i nikła } & \text { noc" } & \text { und winzige } & \text { Nach"” }\end{array}$

Die zitierten Fragmente zeigen, dass das Gedicht eine dialektische Grundstruktur besitzt: Jeder der Verse besteht aus zwei Wörtern, die graphisch am linken bzw. am rechten Rand der Seite platziert werden, wodurch sich zwischen ihnen der größtmögliche räumliche Abstand auftut. Die erwähnte semantische Opposition zeigt sich dabei ausschließlich auf der rechten Seite, wo sich die Begriffe „Tag“ und „Nacht” unmittelbar gegenüberstehen. Im Kontext des ganzen Gedichts sind es nur diese acht Verse, die aus zwei Wörtern bestehen: von den restlichen zwölf Versen bestehen sieben Verse aus drei und vier Verse aus einem Wort. Das Gedicht ist regelmäßig konstruiert. Werden die Verse mit einem Wort mit „A“, die mit zwei Wörtern mit „B“ und die mit drei Wörtern mit „C“ bezeichnet, so lässt sich der Bau des Gedichts wie folgt darstellen: BBC A CBBC A CBBC A CBB A C. Die Verse mit zwei Wörtern stehen also stets unmittelbar nacheinander, in zwei Fällen werden sie von Versen mit drei Wörtern umschlossen. Die Verse, die nur aus einem Wor bestehen. nehmen eine gewisse hervorgehobene Position ein. die durch das Druckbild noch unterstrichen wird: Diese Verse sind in Großbuchstaben gedruckt. Es ist allerdings schwer, die exponierte Position dieser Verse auch in semantischer Hinsicht zu bestätigen, etwa, dass es sich hier um für die Aussage des Gedichtes zentrale Begriffe handeln würde. Dies ist nicht der Fall: Ihre an sich exponierte Position wird dreimal außerdem durch Enjambements relativiert.

Einige der Verse, die aus drei Wörtern bestehen. können im Kontext des zuvor erwähnten zweiten Symbolbereichs, dem der Arbeit, des Bauens etc.. verstanden als Ausdruck des

49 "Glocke Glocke das Haus wird gebaut // Hammer Hammer es schlug der Hammer".

so Auch alle im weiteren Verlauf des Textes angefuhrten Zitate aus diesem Gedicht stammen aus dieser Quelle. 
Entstehens von etwas Neuem sowie der Tătigkeit, gelesen werden. Sie beschreiben so etwa einen charakteristischen Vorgang, zum Beispiel:

$\begin{array}{lccccc}\text {.kota } & \text { obręcze } & \text { wiruja } & \text { „Rader } & \text { Reifen drehen sich } \\ {[\ldots . .]} & \text { rẹce } & \text { się trudza } & \text { pracuja" } & \text { Hănde } & \text { bemahen sich arbeiten" }\end{array}$

Schwierig aufzulösen bleiben dabei die letzten beiden Verse des Gedichtes:

krwawia "GWOŹDZIE

Zwar können auch Nägel im Bildbereich des Bauens verstanden werden, dennoch lässt ihre Verbindung mit Blut. Leid und Kreuz zuerst an die Kreuzigung Jesu Christi denken. Dieses Motiv wurde weiter oben als Motiv der Auferstehung begriffen und beschrieben. Diese Lesart ist in „Nacht - Tag“" schwierig, zum einen, da im ganzen Gedicht zuvor sich die neue Zeit schon materialisiert zu haben scheint, der der Auferstehung notwenig vorhergehende Tod gewissermaßen also zu spät erfolgen würde, zum anderen, da in diesen beiden Versen ausschließlich das Leid zur Sprache gebracht wird und nichts von der anschließenden Freude zu spüren ist. Vielleicht ist es daher angebracht. diese beiden Zeilen im Sinne einer Kritik an der neuen Zeit zu lesen, ähnlich wie sie Czyżewski bereits in der dritten Vision von „Elektrische Visionen" artikuliert hat. Die neue Zeit brächte somit nicht nur Fortschritt und Besserung, sondern gleichermaßen Schmerz und Leid mit sich. Die Nägel sind nicht nur das Baumaterial der Zukunft, sondern gleichzeitig die Ursache des Schmerzes und der Verzweiflung.

Die Metaphern, mit denen Czyżewski in seinen Gedichten der neuen Zeit ihren Ausdruck verleiht, verbinden insgesamt häufig die Bereiche Technik und Natur miteinander ${ }^{51}$. Eine solche Metaphorik findet sich vor allem in den Gedichten „Elektrische Visionen“, „De profundis“, „Hymne an die Maschine meines Körpers“ (,Hymn do maszyny mego ciała“), „Flamme und Brunnen“ (.Płomień i studnia“) und "Transzendentales Panoptikum“ („Transcendentalne panopticum“). Hăufig werden im Rahmen dieser Metaphern der Mensch

\footnotetext{
s1 Ohne weiter in die Metaphemtheorie einzudringen, sei an dieser Stelle doch kurz auf das Verstăndnis von „Metapher”, das dem Gebrauch des Begriffs in dieser Arbeit zugrunde liegt, hingewiesen. Prinzipiell gilt, dass als .Metapher" nicht - wie bei Aristoteles - das Ersetzen eines Wortes durch ein anderes verstanden wird. sondern, dass eine metaphorische Äußerung. die auf einer pradikativen Grundstruktur basiert, zwei oder mehr Begriffe in eins setzt, diese aufeinander bezieht, wodurch eine Bedeutung entsteht, die großer ist, als die Summe der Einzelbedeutungen (vgl. Kurz 1982, 7-25). Kurz zitien an einer Stelle (23) auch August Wilhelm Schlegel: Werde doch nach dessen ,glucklicher Formulienung [durch eine Metapher; M.E.] eine "Gleichheit" angedeutet. Angedeutet heißt: eine Gleichheit wird behauptet, zugleich aber auch ihre Nichtgeltung. Im Unterschied zur nichtmetaphorischen Pradikation ist es fur die Metapher wesentlich, daß semantische Inkongruenzen nicht getilgt werden, sondern gegenwärig bleiben. Die Metapher identifiziert die Bedeutung zweier Ausdrucke [...], sie widersteht aber auch dieser Identifizierung."
} 
selbst bzw. menschliche Körperteile mit technischen Phänomenen verbunden. Beispielsweise spricht das lyrische Ich in „Elektrische Visionen“ von der „czuciowa, przepotęzna Machiny Mego Rozumu“ (1920a, 68) ${ }^{52}$. In „Hymne an die Maschine meines Körpers“, das gleich noch eigens interpretiert werden wird, ist von „elektrischen Lungen“ (,elektryczne płuca“) und „magnetischem Zwerchfell“" (,magnetyczna przepona“ - 1922c, 104) die Rede, die entsprechenden Beispiele aus „De profundis“ sind: "l'avion de mon corps adoré” oder „elektrony jęczącej Elektry piersistej.“ (1922c, 81 und 82) ${ }^{53}$. Und als bewegte Wachsfiguren aus "Transzendentales Panoptikum“ erscheinen: der „elektrische napoleon“ („elektryczny napoleon“) oder der „panoptische“ bzw. „elektrische mickiewicz“ („mickiewicz panoptyczny“ bzw. „elektryczny“ - 1922c, 111 und 112). In anderen Metaphern führt Czyżewski technische Phänomene mit Naturerscheinungen zusammen, zum Beispiel: "Wodospad magnetycznych lez" (,Wasserfall magnetischer Tränen”), „morze elektryczne“ (,elektrisches Meer“ - 1922c, 80, 81 und 82) und „elektryczne oczy“ (,elektrische Augen”) oder „elektryczny świt“ (,elektrische Morgendämmerung“ - 1920a, 68 und 70). Schließlich gibt es in den Gedichten Czyżewskis einige Metaphern, in denen das erwähnte Verhältnis von Natur und Technik nur teilweise realisiert wird und die Beziehung zwischen den einzelnen Teilen sich treffender mit "belebt“ - „unbelebt“ beschreiben ließe. Dennoch müssen sie an dieser Stelle genannt werden, da die lebensspendende Kraft meist die Elektrizität, das heißt auch ein technisches Phänomen ist, es mittels dieser Metaphern insgesamt aber um „Schöpfung“, also um einen natürlichen Prozess, geht. Hierher gehören, dem Thema des Gedichtes entsprechend, die meisten Metaphern aus „Flamme und Brunnen“, wie etwa: "manekin elektro-trup“ (,Mannequin Elektro-Leiche“), „zgalwanizowany manekin“ (,galvanisierter Mannequin“) oder „elektro-manekin“ („Elektro-Mannequin“ - alle: 1922c. 102), mit denen das Leben der künstlichen Schöpfung (,manekin“) durch Elektrizität (.,elektro“, „zgalwanizowany“) thematisiert wird. Ohne diese Kraft sind diese Schöpfungen jedoch quasi lebensunfähig (,trup“). Ähnlich verhält es sich mit den „Elektro-Mannequins“ in "Transzendentales Panoptikum“.

Ähnlich wie die Metaphern, verbinden auch die Vergleiche in Czyżewskis Gedichten häufig die Bereiche Natur und Technik miteinander, wenn es um Erscheinungen der neuen Zeit geht. Bei der Interpretation von „Elektrische Visionen“ wurde zum Beispiel auf den Vergleich einer Untergrundbahn mit einem Panther hingewiesen. Im Falle von ..Hymne an die Maschine

\$2 "fuhlenden, Obermachtigen Maschine meines Verstandes".
"Elektronen der stöhnenden vollbusigen Elektra". 
meines Körpers“ und „Der mechanische Garten“ („Mechaniczny ogród“) beruht sogar das Gedicht als ganzes auf der Idee eines solchen Vergleichs.

Zum besseren Verstăndnis der Interpretation von „Hymne an die Maschine meines Körpers“ sei eingangs das Gedicht vollständig zitiert:

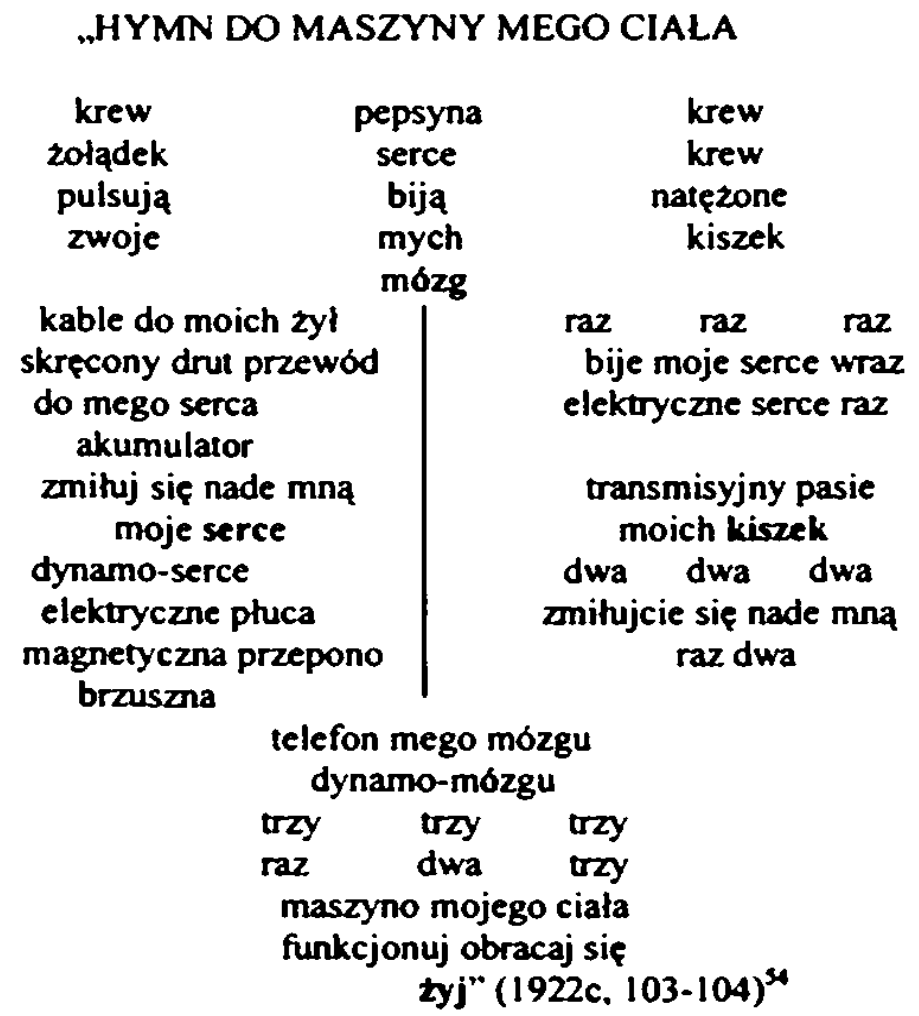

„HYMNE AN DIE MASCHINE MEINES KÖRPERS

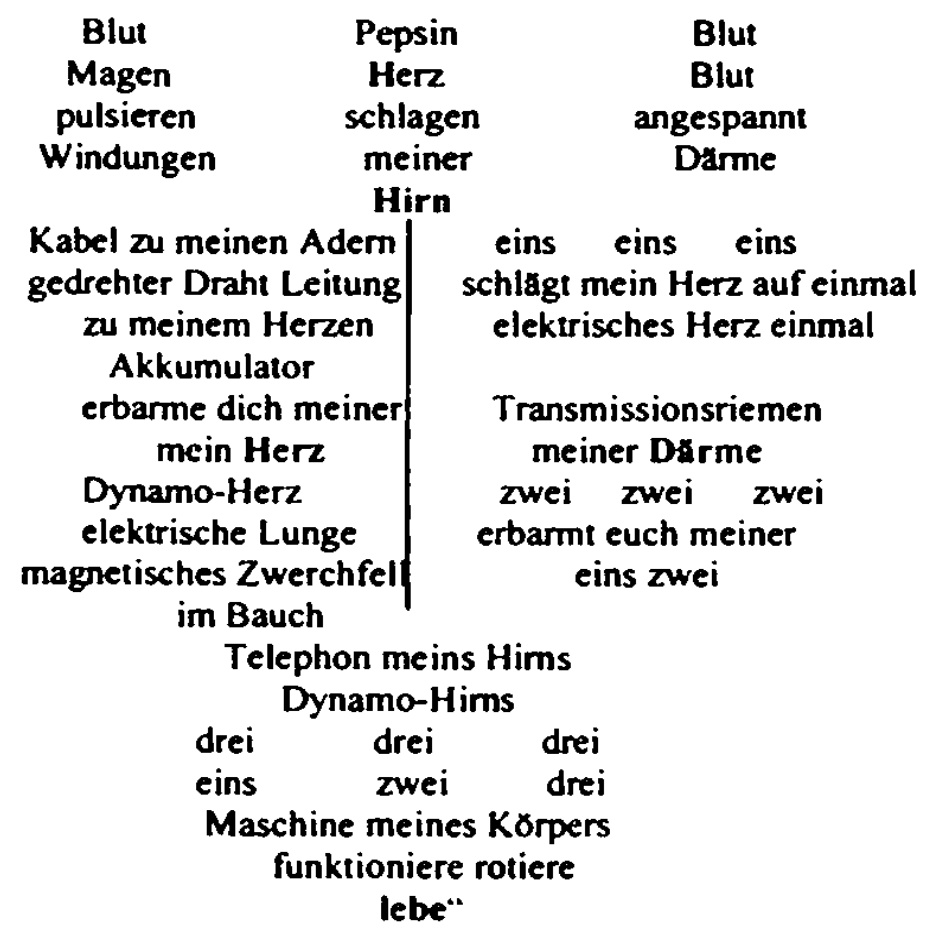

S4 Eine deutsche Übersetzung des Gedichtes findet sich auch in: Lam 1990. 189. 
Bereits aus dem Titel „Hymne an die Maschine meines Körpers“ ist erkennbar, worum es in dem Gedicht gehen soll: der menschliche Körper wird in seinem Funktionieren mit einer Maschine verglichen bzw. als Maschine begriffen. Die ebenfalls im Titel enthaltene Anspielung auf die aus der Antike stammende lyrische Form der Hymne soll dabei den feierlichen Charakter des Gedichtes sowie eine positive und emphatische Haltung dieser „Körpermaschine“ gegenüber zum Ausdruck bringen, was zum Beispiel auch die im Vokativ (,maszyno") gehaltene Hinwendung zu ihr in der drittletzten Zeile zeigt ${ }^{\text {ss. }}$

Die in-eins-Setzung von Körper und Maschine erfolgt in dem Gedicht auf zweierlei Weise: graphisch und semantisch. Im Druckbild von „Hymne an die Maschine meines Körpers“ können vier Einheiten unterschieden werden, von denen zumindest drei eindeutig einem bestimmten Körperbereich zugeordnet werden können: der erste Teil zu Beginn (vier Zeilen) steht für den Magenbereich, angedeutet durch die Begriffe: „pepsyna“, „zołądek“, „Zwoje mych kiszek". Die anschließende Zweiteilung des Mittelteils des Gedichts lässt an den Brustbereich, an die zwei Lungenflügel eines Menschen denken. Im linken Teil finden sich auch in der Tat die Begriffe "(elektryczne) płuca“, das sich darunter befindende "(magnetyczna) przepono brzuszna“ sowie dreimal „serce“ (dazu: „żł”) - einmal im Vergleich als „akumulator“. Der diesem Teil gegenüber gedruckte, durch die Linie abgetrennte, Teil ist nicht unmittelbar auf einen bestimmten Körperbereich beziehbar, dafür aber der letzte, mittig gedruckte untere Teil, der für den Kopf und das Gehirn steht. Wird nun der Versuch unternommen, in diesem aus den erwähnten Teilen konstruierten Gedicht die Figur eines Menschen wiederzuerkennen. so scheint es, dass es sich dabei um einen Torso handelt, das heißt nur Kopf und Rumpf dargestellt werden, der noch dazu auf dem Kopf steht. Durch die graphische Gestaltung des Gedichtes werden auch verschiedene Lesarten ermöglicht: horizontal und vertikal, darüber hinaus können die erwähnten Teile auch jeweils furr sich gelesen werden. Da in dem Gedicht auf jegliche Textsukzession verzichtet wird. ergibt sich somit ein simultanes Bild, das die ganze ..Körpermaschine“ gleichzeitig vor Augen führt: Wie bei einer Maschine funktionieren alle Einzelteile unabhängig voneinander, sind aber gleichzeitig Bestandteile eines gemeinsamen Organismus und als solche miteinander verbunden (,przewód“", ,transmisyjny pasie“).

In semantischer Hinsicht sind es die zahlreichen Metaphern, die Körper und Maschine eins werden lassen: die Adern als Kabel (,kable do moich żyl“), sozusagen die Leitungen, die das

\footnotetext{
"Vor allem aufgrund dieses emphatischen Grundtons von .Hymne an die Maschine meines Korpers" scheint es moglich, Czyzewskis Gedicht auch in die Tradition der europłischen Hymnendichtung zu stellen; vgl. dazu den
} 
Blut, den Strom transportieren, das Herz als Batterie, als Dynamo (,do mego serca // akumulator" und "moje serce // dynamo-serce“), als Quelle und Ursprung der Energie und das Gehirn als Telefon („telefon mego mózgu“), gewissermaßen als Steuerungszentrale des Ganzen.

Das charakteristische Merkmal dieser Körpermaschine ist ihr unablässiges Funktionieren, ihre stete Tätigkeit. In der bereits angesprochenen Apostrophe heißt es, darauf bezogen: „maszyno mego ciała // funkcjonuj obracaj się // żyj“. Dieses Funktionieren wird im Gedicht mehrmals zum Ausdruck gebracht, zum Beispiel durch entsprechende Verben: „pulsuja“" bzw. „bija“” (zweimal). Ebenso kommt ihr Arbeitstakt im Gedicht vor, zum Beispiel: „raz raz raz“, „dwa dwa dwa" usw. Das Subjekt dieses Funktionierens ist aber das Herz, das insgesamt siebenmal angesprochen wird. Das Gedicht trägt schließlich auch jener Vorstellung Rechnung, dass die Maschine auf ihre Tätigkeit bezogen für Zielgerichtetheit und Ökonomie steht. Aus diesem Grund scheint „Hymne an die Maschine meines Körpers“ fast ausschließlich aus Substantiven und Verben zu bestehen, eher selten gibt es näher beschreibende Adjektive.

Auch das Gedicht „Der mechanische Garten“ kann als Versuch gelesen werden, eine Naturerscheinung technisch zu erfassen. Entsprechend den Teilen einer Maschine, werden die „Teile“ eines Gartens, das heißt die Blumen, aber auch die Schmetterlinge, als dessen konstituierende Einzelelemente erfasst. Dies ist graphisch so dargestellt, als dass der Name einer jeweiligen Blume in einen dick umrandeten Kreis oder ein Quadrat eingeschrieben wird. die gemeinsame Verwurzelung aller so im Gedicht dargestellten Blumen in einem Garten wird durch vertikale Linien, die ein oder zwei Kreise bzw. Quadrate mit einer horizontalen Grundlinie verbinden, verbildlicht. Zwei über alle Kreise und Quadrate geschwungene Klammem am linken bzw. rechten Rand des Gedicht-Bildes symbolisieren die Geschlossenheit des mechanischen Gartens. Somit wird noch einmal die Vorstellung von der logisch konstruierten Maschine als Zusammenwirken ihrer Einzelteile deutlich, die auf den Garten übertragen wird ${ }^{56}$.

Für Czyżewski ist die Maschine, trotz seines ambivalenten Verhältnisses zu ihr, eine der charakteristischsten Erscheinungsformen der „neuen Zeit“ $(1927,230)$. Sie steht als

Eintrag ..Hymne (Neuzeit)“ von Julius Wiegand (in: Kohlschmidt/Mohr 1925-1931, 737-741) sowie den von Teresa Kostkiewiczowa (..Hymn", in: Krzyzanowski/Hemas 1984, 1/368).

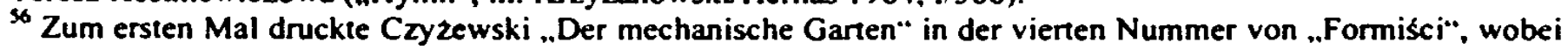
es hier - wie im Text enwăhnt - Kreise und Quadrate sind. in die die Blumennamen eingeschrieben werden (vgl. den Wiederabdruck bei: Lam 1969, I1/161). Beim Abdruck des Gedichtes in der Sammlung ..Nacht - Tag“ (1922), auf die auch die von Baluch herausgegebene Gesamtausgabe von Czyzewskis Gedichten zurickgreift (vgl. Czyzewski 1992. 97), werden hingegen nur Quadrate und Rechtecke verwendet. Nicht zutreffend ist allerdings die Anmerkung der Herausgeberin an dieser Stelle. das Gedicht sei ursprunglich in ..Zwrotnica" veroffentlicht worden, da diese Zeitschrift erst im Mai 1922 zum ersten Mal erscheinen sollte. 
herausragende Schöpfung, die durch ihren durchdachten Bau und ihr präzises Funktionieren besticht, für die Leistungsfähigkeit des modernen Menschen. So verstanden, tritt sie der Natur, als ein ihr ebenbürtiges Schöpfungsprinzip zur Seite, wie ein technisch erfasster Körper bzw. Garten zeigen. In dieser Hinsicht gewinnt die Technik, zusammen mit der Natur, die für das Ursprüngliche steht, auch Bedeutung für die „neue Kunst“ selbst, was Gegenstand des folgenden Abschnittes sein wird.

\subsubsection{Die neue Kunst}

Die neuen technischen und zivilisatorischen Errungenschaften fanden nicht nur als Themen und Motive Eingang in die Kunst und Literatur der Avantgarde, sondern auch in Hinsicht auf den unmittelbaren künstlerischen Schaffensprozess selbst. Besonders deutlich wird dieses Phänomen am Beispiel der Photographie oder des Kinos, wo eine technische Apparatur unabdingbar für das Entstehen eines Kunstwerkes ist.

In dem Gedicht „Mediumistisch-magnetische Photographie des Dichters Bruno Jasieński“ („Mediumiczno-magnetyczna fotografia poety Brunona Jasieńskiego“) beschreibt Czyżewski die Anfertigung einer Photographie des futuristischen Dichters. Eine in Klammern gesetzte letzte Zeile verrät, dass es offensichtlich er selbst ist, der das Photo macht: ,Z mediomagnetycznego fotograficznego atelier Tytusa Czyżewskiego“ (1922c. 105) ${ }^{57}$. Die Entstehung des Photos, das heißt der künstlerische Schaffensprozess selbst. wird dabei genau beschrieben:

\begin{tabular}{|c|c|}
\hline $\begin{array}{l}\text {.ja budze cie ja budze cie } \\
\text { ustawiam aparat } \\
\text { zapalam swiatlo magnetycznej zorzy } \\
\text { i widze twoje czolo } \\
\text { oswiecone z boku luna pozarów } \\
\text { kapie klisze w złotej wodzie } \\
\text { kopiuje na bromopapierze } \\
\text { i wywołuje twa widmowa twarz." }\end{array}$ & $\begin{array}{l}\text { „ich wecke dich } \\
\text { ich stelle den Apparat auf } \\
\text { entzunde das Licht der magnetischen Dammerung } \\
\text { und sehe deine Stim } \\
\text { beleuchtet von der Seite mit dem Feuerschein } \\
\text { ich bade die Platte im goldenen Wasser } \\
\text { kopiere sie auf Brompapier } \\
\text { und entwickle dein gespenstisches Gesich"“ }\end{array}$ \\
\hline
\end{tabular}

Obwohl dieses Fragment im Prinzip eine rein technische Beschreibung der Anfertigung einer Photographie ist, mit der Nennung aller dafür notwendigen Schritte (Aufstellen und Ausrichten der Kamera, die Einstellung der Beleuchtung etc.), wird gleichermaßen deutlich. dass das so entstandene Kunstwerk mehr ist, als nur ein mechanisches Produkt. Die beiden 
Metaphern („swiatło magnetycznej zorzy“ und "widmowa twarz") rücken es und dessen Entstehung ebenso in den Bereich des Geheimnisvollen ${ }^{58}$, vielleicht auch Erhabenen, wie die eher pathetisch klingenden Formulierungen „luna pożarów“ und der in seiner Wirkung noch stärkeren Wiederholung, ja budzę cię ja budzę cię". Gerade dieses „Erwecken“ der porträtierten Person ist nur in einem „wirklichen“ Kunstwerk möglich, das auf profundem Verständnis der Persönlichkeit basiert. Dies kann ein rein mechanischer Vorgang nicht gewährleisten. Dennoch ist es in diesem Gedicht eben ein technisches Verfahren, das letztendlich das Kunstwerk ermöglicht, was aber zeigt, wie Kunst und Technik ineinander greifen.

Das im ange führten Zitat verwendete Motiv des Enweckens der Person Jasieñskis (,ja budzę cię“) bezieht sich auf zwei frühere Zeilen des Gedichtes, in denen deren Tod beschrieben wird: „serce bic przestaje“ („das Herz hört auf zu schlagen“) und „przestajesz życ“ („du hörst auf zu leben“). Dieser Tod ist das Ergebnis der Auflösung des Körpers von Jasienski, die in dadaistisch-surrealistischen Bildern dargestellt wird, zum Beispiel:

\footnotetext{
.mózg jest pelen węzów i znajduje się w tej chwili

w kuchni na patelni

ametystowe oczy wielkie pływaja

razem $z$ wigilijnymi karpiami w wannie w tazience"
}

\begin{abstract}
.das Hirn ist voller Schlangen und befindet sich in diesem Augenblick in der Kache in der Pfanne die großen Amethystaugen schwimmen gemeinsam mit den Weihnachtskarpfen in der Wanne im Badezimmer'
\end{abstract}

Gleichermaßen spazieren die Hände im dunklen Saal, die Beine schwingen sich vom Sofa herab, die Finger spielen Klavier usw. Diese Wahrnehmung der Person Jasienskis in der genauen Erfassung der einzelnen Körperteile erinnert an das Gedicht „Das gesehene Gesicht“, in dem eine ähnliche Form der Wahrnehmung einer Frau beschrieben wird. Im Unterschied aber zu diesem Gedicht fehlt in „Mediumistisch-magnetische Photographie des Dichters Bruno Jasienski“ die simultane. also die gleichzeitige Darstellung aller unterschiedlichen Ansichten. die angefertigte Photographie zeigt nur das Gesicht Jasieńskis: „wywołuję twa widmową twarz". Simultan scheint im Gedicht aber die Wahrnehmung selbst zu sein, alles spielt sich zur selben Zeit ab, wie das dreimal (Zeile 4, 10 und 16) wiederholte „w tej chwili”

\footnotetext{
37 „Aus dem medio-magnetischen photographischen Atelier von Tytus Czyzewski“. Im Original kursiv. Auch alle weiteren Zitate aus diesem Gedicht stammen aus dieser Quelle, das ganze Gedicht ist auf den Seiten 104105 abgedruckt. Eine deutsche Übersetzung in: Dedecius 1996-2000, 1/1/341-342.

s Die Atmosphăre des Geheimnisvollen wird bereits zu Beginn des Gedichtes suggeriert. zum Beispiel: 
(,in diesem Augenblick“) andeutet. Das Motiv der Erweckung Jasieńskis rückt das am Ende des Gedichts entstandene Kunstwerk, eben durch die zuvor dargestellte Auflossung des Körpers bzw. dessen Tod, auch in den Kontext der Unvergänglichkeit und Überzeitlichkeit der Kunst, die der Schnelligkeit des technischen Fortschritts gegenüber stehen, sich mit jenem aber auch zu verbinden vermögen.

Als "filmisch" interpretiert Lipski einige Gedichte Czyżewskis und beschreibt Entsprechungen zwischen dessen poetischer Gestaltungsweise und der eines Films (vgl. 1993, 16-17, vgl. auch: Baluch, in: Czyżewski 1992, XLVII). Vor allem am Gedicht „Tigeraugen“ („Oczy tygrysa“) zeigt Lipski, wie dieses als Ganzes in einzelne Kameraeinstellungen auflosbar ist und die Beschreibung dabei mit einer Kamerafahrt verglichen werden kann. Im Unterschied zur bloßen Thematisierung des Phänomens Kino oder Film (vgl. „Sensation im Kino") dringe hier, so Lipski, die filmische Wahrnehmung tiefer in die poetische Gestaltung ein, insbesondere durch die Einführung visualisierender Effekte in die Dichtung.

Film und Literatur treffen ins Czyżewskis formistischen Gedichten auch in „Flamme und Brunnen“ aufeinander, das den Untertitel „elektro-kino-aero-dramo” („Elektro-Kino-LuftDrama“) trägt (1922c, 101) $)^{59}$. Vor allem wegen der darin vorkommenden Begriffe ,,kino“ und „dramo" (poln. eigentlich "dramat") kann dieser Untertitel im Sinne einer Gattungsbezeichnung für dieses Gedicht gelesen werden, wodurch es als der Versuch erscheint, die künstlerische Ausdrucksform des Filmes mit der des Theaters zusammenzuführen. Dies wird durch die Lektüre des Gedichtes bestätigt. die erkennen lässt. dass eine an ein Theaterstück erinnernde Handlung parallel zu einer Art Filmvorführung stattfindet. Zur Verdeutlichung dessen hier der Anfang des Gedichtes:

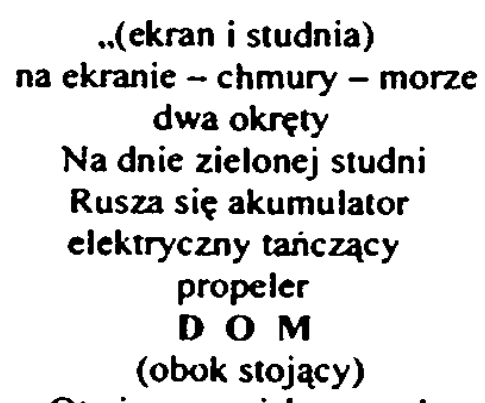

Otwiera swe iskrzace okno

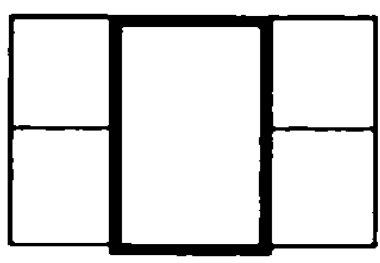

..(Bildschirm und Brunnen)

auf dem Bildschirm - Wolken - Meer zwei Schiffe

Am Boden des grünen Brunnens

Lauft ein Akkumulator

elektrischer tanzender

Propeller

HAUS

(das nebenstehende)

Offnet seine funkenspröhenden Fenster

\footnotetext{
39 Auch alle weiteren Zitate aus diesem Gedicht stammen aus dieser Quelle, das ganze Gedicht ist auf den Seiten 101-103 abgedruckt.
} 


\section{Dym Dym Dym" Rauch Rauch Rauch"}

Die im Stil eines Drehbuchs in Klammern gesetzte Anmerkung in der ersten Zeile verweist auf das angesprochene doppelte Geschehen. Der Bildschirm steht dabei für den Film, der Brunnen soll sich im Laufe des Gedichtes als Ort der dramatischen Handlung herausstellen. Zuerst setzt das filmische Geschehen ein, das sich allerdings - neben den Wolken, dem Meer und den Schiffen im Zitat - auf den Tanz von "Elektromaschinen” und "Elektrowelten” („elektro-maszyny” und „elektro-światy”) beschränkt. Es kann somit weniger als ein eigener Handlungsstrang, sondern mehr als atmosphärischer Hintergrund zur dramatischen Handlung gesehen werden, die dadurch im Kontext der modernen technisierten Welt platziert wird.

Die an ein Theaterstück erinnernde Handlung, die in „Flamme und Brunnen“ gestaltet wird. ist auch was ihre äußere Form betrifft, vom Rest des Gedichtes leicht unterscheidbar. Die Namen der handelnden Personen - Don Juan und Donna Alvarez ${ }^{60}$ - sind fett gedruckt, in Klammern gesetzt sind Regieanweisungen, wohingegen der Sprechtext normal, das heißt ohne Besonderheiten erscheint. In dieser Hinsicht muss auch ein Flugzeug zu den handelnden Personen gezählt werden, obwohl diesem kein Sprechtext, sondern bloß das Rauschen mit dem Propeller zugedacht bleibt. Wenngleich das Flugzeug aus der Luft fallt und nicht wie Don Juan und Donna Alvarez aus dem Brunnen auftaucht, verschwinden doch alle drei wieder in diesem. Dem Flugzeug kommt somit zweifelsfrei eine ästhetische Bedeutung zu. die auch aus dem eingangs angefuhrten Untertitel von „Flamme und Brunnen“ ersichtlich wird, und zwar durch den Begriff „aero“, der hier zu den „eigentlichen“ Gattungsbezeichnungen "kino" und „dramo" hinzugefügt wird. Umrahmt wird diese dramatische Handlung schließlich von einem Haus, das im Zitat angesprochen wird. Mit dem Einsetzen der dramatischen Handlung offnet dieses Haus seine .,funkensprühenden Fenster“, mit deren Ende schließt es sie wieder ${ }^{61}$.

Don Juan und Donna Alvarez werden näher als .,Mannequins” (,manekin”) bezeichnet. als weiteres Merkmal tritt noch die Elektrizităt hinzu. Beide erscheinen somit als ,nagi manekin elektro-trup” ("nackter Mannequin Elektro-Leiche“), als ,.zgalwanizowany manekin”

\footnotetext{
${ }^{60}$ Czyzewski spielt durch diesen beiden Personen zwar auf einen in der Literatur haufig gestalteten Stoff an. ubernimmt daraus aber nur die Person des Don Juan, als der des leidenschaftlichen Verfuhrers. Daneben finden sich in "Flamme und Brunnen“ keine Elemente, die aus dem Don Juan-Stoff bekannt sind. Unklar ist auch, woher Czyzewski den Namen von Don Juans Geliebter - Donna Alvarez - nimmt, da diese in vielen Gestaltungen eigentlich Donna Anna heißt (zum Beispiel bei Tirso de Molina). In Molières Bearbeitung heißt die Geliebte Elvire. Vgl. dazu: Frenzel 1962, 163-170 sowie: Makowiecki 2000, 184-185.

${ }^{61}$ Das Motiv des Hauses ist schwierig zu interpretieren, da es weder eindeutig der filmischen, noch der dramatischen Szenerie zugeordnet werden kann und es gleichfalls nicht ohne weiteres als eigenstăndiger dritter Handlungsstrang bestimmt werden kann. Vgl. for einen Vorschlag: Baluch, in: Czyzewski 1992, XLVI.
} 
(„galvanisierter Mannequin“) bzw. als „elektro-trup” („Elektro-Leiche“), Donna Alvarez daruber hinaus noch als „zgalwanizowany trup” (,galvanisierte Leiche“) und auch ihr Kind, das sie gebiert, bezeichnet sie mit "trup-elektro-manekin” („Leiche-Elektro-Mannequin“). Auffallend ist in allen Fällen die Kombination: Mannequin-Elektrizität-Leiche. Die künstliche Schöpfung des Mannequins, verglichen mit einer Leiche, wird erst durch die Kraft der Elektrizităt bewegt, scheint erst durch diese lebensfähig. In dieser Hinsicht kann der im zuvor angeführten Zitat erwähnte Akkumulator, der am Boden des Brunnens zu arbeiten beginnt, als Quelle dieser elektrischen Kraft, die die Mannequins bewegt, gesehen werden, da Don Juan und Donna Alvarez ja dem Brunnen entsteigen.

Die künstliche Schöpfung des Menschen wird so zum zentralen Thema des Gedichtes. Es handelt sich dabei sowohl um die originäre Schöpfung künstlicher Menschen. der Mannequins, als auch darum, dass diese in der Lage sind, sich selbst zu vermehren. Die dabei notwendige Kraft, die die Mannequins in Bewegung zu versetzen vermag, ist, wie gesagt. die Elektrizität, wodurch die Technik insgesamt der Natur als Quelle der Schöpfung gleichberechtigt zur Seite tritt. Denn am Ende des Gedichtes heißt es:
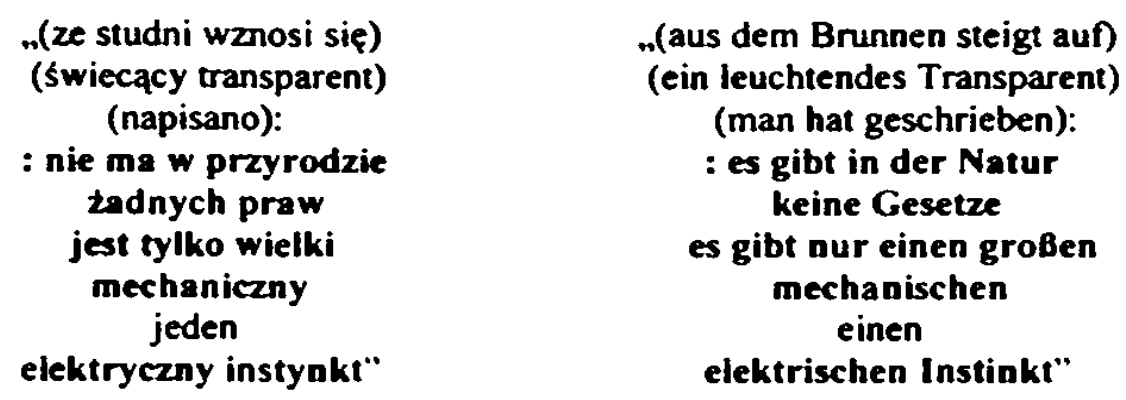

Natur und Technik finden somit ihre Symbiose, die in der Metapher vom „elektrischen Instinkt" ausgedrückt wird, die Technik bildet gewissermaßen eine Ergänzung zu den Naturgesetzen, die ihre alleinige Gültigkeit damit eingebüßt zu haben scheinen.

Diese Thematik. das heißt die Schöpfung durch Elektrizität bewegter künstlicher Menschen. findet sich auch in "Transzendentales Panoptikum“. Die in diesem Gedicht beschriebene Wachsfigurenschau besteht aus verschiedenerlei Figuren, die höchst unterschiedliche Persönlichkeiten repräsentieren: Künstler (Mickiewicz, Ibsen, George Sand, Chopin u.a.), Verbrecher (Aufschlitzer, Mörder, Straßenräuber) oder Herrscher (zum Beispiel: Maria Theresia, Katharina, Fürst Poniatowski, Napoleon). Daneben gibt es den Admiral Tegetthoff. den unbekannten Soldaten von Verdun, Hamlet und Ophelia, Blumen, Eidechsen usw., kurz: ein buntes Sammelsurium. Durch elektromechanische Vorrichtungen bzw. durch Elektrizität selbst werden diese Wachsfiguren bewegt: 
nz przyrzadem elektryczno-zegarowym nakreccany kluczem mickiewicz pisze ode do młodosci

[...]

figury $z$ wosku

figury z wosku

tanicza poruszane elektrycznoscia

[...]

rozbawieni roztańczeni

rozlalkowani zgalwanizowani" $(1922 \mathrm{c}, 110-111)^{62}$ „ein mit einem elektrischen uhrmechanismus mit einem schlussel aufgezogener mickiewicz schreibt die ode an die jugend

[...]

wachsfiguren

wachsfiguren

tanzen von elektrizită bewegt

[...]

aufgeheitert tanzlustig

puppisiert galvanisient"

Noch andere Figuren werden wie Marionetten bewegt: „dante na elektrycznych drutach”63. Der in diesem Zitat vermittelte Eindruck eines Varietés, einer Revue wird durch den Auftritt des Direktors des Panoptikums bestätigt, der zu einem Publikum spricht und diesem einzelnen Figuren vorstellt („oto elektryczny mickiewicz // piszący magnesowym piórem”) $)^{64}$ bzw. neue ankündigt. Schließlich beginnen die in Bewegung gesetzten Mannequins zu sprechen:

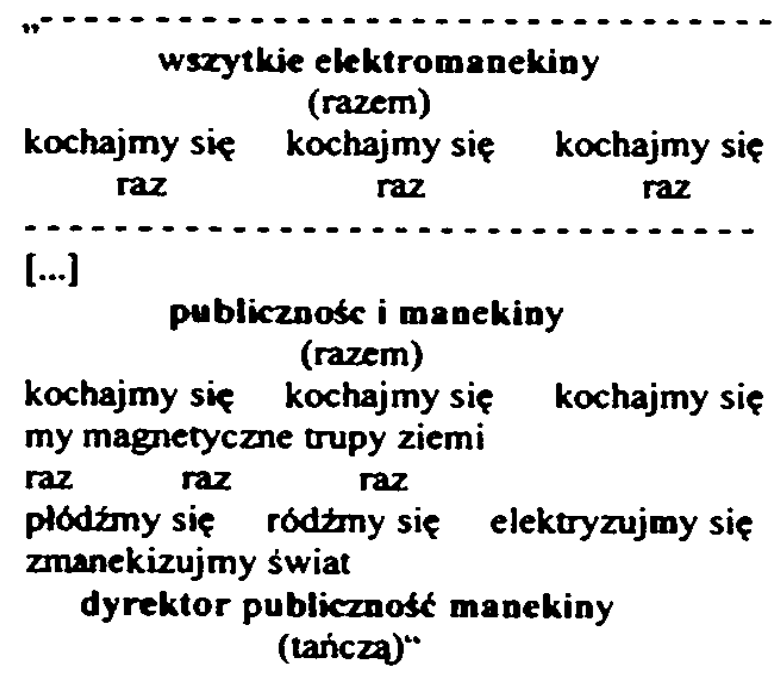

$\begin{gathered}\text { alte Elektromannequins } \\ \text { (gemeinsam) } \\ \text { lieben wir uns uns } \\ \text { eins }\end{gathered} \quad \begin{gathered}\text { eins } \\ \text { eins }\end{gathered}$
Publikum und Mannequins
(gemeinsam)
wir magnetischen Leichen der Erde
eins eins lins
zeugen wir uns gebaren wir uns elektrisieren wir uns
mannequinisieren wir die Welt
Direktor Publikum Mannequins
(tanzen)“

Wie zuvor in "Flamme und Brunnen" findet sich auch hier die Assoziation von Mannequin mit Leiche, ebenso wie das Motiv der Fortpflanzung, des Gebärens. Die künstlichen Schöpfungen, die Mannequins scheinen sich im angeführten Zitat zu diesem Zweck mit ihrem Publikum vermischen zu wollen. Lipski führt diese Faszination Czyżewskis für die technische Schöpfung von Lebewesen auf den Einfluss der italienischen Futuristen zurück, für die die „belebte Maschine“ ein vollkommeneres Geschöpf gewesen sei, als das Lebewesen selbst (vgl. 1993, 13-15) ${ }^{65}$. Und nicht zuletzt wird auch die ebenfalls aus „Flamme und Brunnen“

\footnotetext{
${ }^{62}$ Auch alle weiteren Zitate aus diesem Gedicht stammen aus dieser Quelle, das ganze Gedicht ist auf den Seiten 110-114 abgedruckt. Eine deutsche Öbersetzung bei: Lam 1990, 22 I-223.

63 "dante auf elektrischen leitungen".

os "das ist der elektrische mickiewicz // mit einem magnet-fuller schreibend".

os Lipski relativiert an dieser Stelle auch eine Kritik Wykas, die dieser im Zusammenhang mit Czyzewskis Satz: „Kochajcie elektryczne maszyny, zeńcie się z nimi i płódźcie Dynamo-dzieci - magnetyzujcie i ksztalćcie je. aby wyrosły na mechanicznych obywateli." (.Liebt elektrische Maschinen, heiratet sie und zeugt DynamoKinder - magnetisiert und bildet sie, damit sie zu mechanischen Burgern heranwachsen." - Czyzewski 1922c. 118) außert. Wyka schreibt, dass in einem technisch wenig entwickelten Land, wie es Polen direkt nach 1918
} 
bekannte Symbiose von Technik und Natur in "Transzendentales Panoptikum" an einer Stelle angesprochen: ,instynktowe zwierzęta // parzące się z błyskawicami elektronów”66.

Czyżewski gestaltet somit in beiden Gedichten einen gemeinsamen Kontext, dessen wesentlichste Elemente die Symbiose von Natur und Technik, die Bestimmung der Elektrizität als einer Elementarkraft, die Leben zu spenden vermag und die dadurch ermöglichte Schöpfung künstlicher Menschen, das heißt Mannequins, sind. Dies wird nicht zuletzt durch einige Metaphern unterstrichen, die gleichermaßen Mensch/Natur und Technik miteinander in Verbindung bringen, wie "nakręcane gwiazdy“ („aufziehbare Sterne“) oder „elektryczny mickiewicz”, ebenso wie durch die reiche mit Elektrizität assoziierbare Bildlichkeit des Gedichts. In "Transzendentales Panoptikum“ wird dieser Kontext außerdem explizit auch auf die Kunst - die Literatur und Malerei - bezogen:

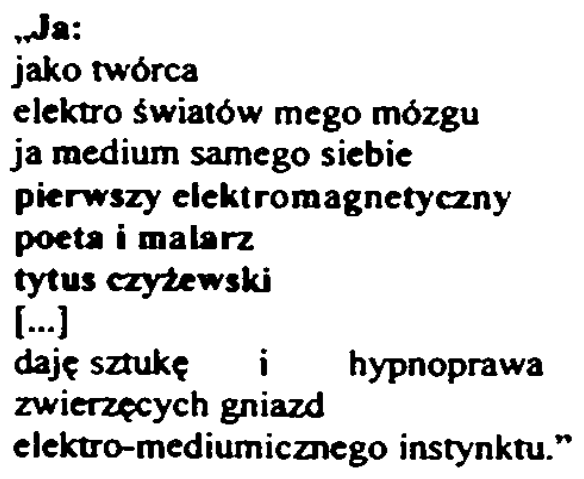

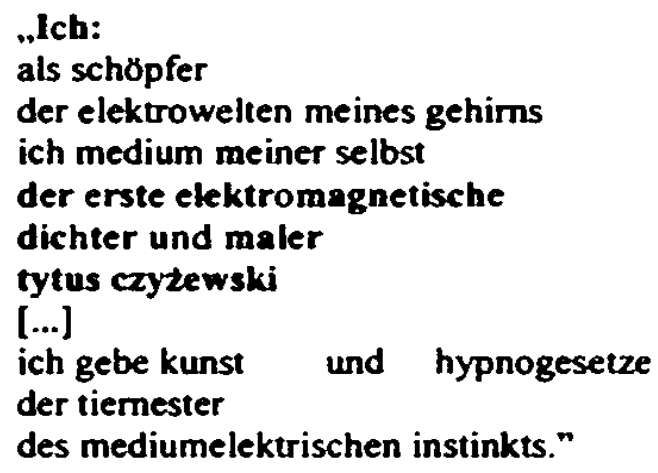

Elektrizităt und Kunst kommen schon zuvor im Gedicht miteinander in Berührung, etwa wenn der „elektrische Mickiewicz” mit einem „Magnet-Füller” schreibt. Czyżewski schreibt sich in diesem Fragment aber das Verdienst zu, als erster Künstler völlig neue Grundlagen für sein Schaffen gefunden zu haben. Dazu zählt, neben der Einbeziehung der Welt der Technik bzw. der Elektrizität („poeta i malarz elektromagnetyczny“) sowie dem Instinkt, auch die „Kunst” der Tiere (ausgedrückt durch den Hinweis auf ihre „Bauwerke“: „zwierzęcych gniazd“) sowie die Hinwendung des Künstlers zu seinen Vorstellungen bzw. zum Übersinnlichen, was unter anderem Chwistek als "visionäre Wirklichkeit" beschreibt und wovon in einem eigenen Abschnitt weiter unten noch die Rede sein wird.

Mit den Grundlagen der neuen Kunst, beschäftigt sich Czyżewski auch in seinem programmatischen Text "Von der Maschine zu den Tieren“. Ähnlich zu den hier

gewesen sei, sogar die einfachsten technischen Gerătschaften schier magische Wirkung besessen hatten und konkludiert: ..Nie dziwimy się przeto, ze maszyna zachodzi w ciąze pod piórem kogos, kto jednocześnie cały zyje podhalańska wyobraznia." (..Wundern wir uns daher nicht, dass die Maschine aus der Feder von jemandem schwanger wird. der gleichzeitig noch ganz in der volkstumlichen Vorstellungskraft der Podhale-Region verhaftet ist." - 1945/1949, 18).

\$o „instinktive Tiere // sich mit Flektronenblitzen paarend“" 
besprochenen Gedichten, bestimmt Czyżewski auch darin zwei Einflüsse, die die moderne Kunst in sich aufnehmen müsse: die Welt der Technik, der Maschinen sowie die instinktive, das heißt die ursprüngliche, Kunst der Tiere:

.Zywioł - od ogólnego mechanizmu do instynktu zwierząt - będziemy bracmi zwierząt i będziemy się uczyc ad nich instynktowej sztuki, kochac bedziemy maszyny, gdyz one nasze siostry i zwierzeta bo one nasi nauczyciele i bracia. [...]

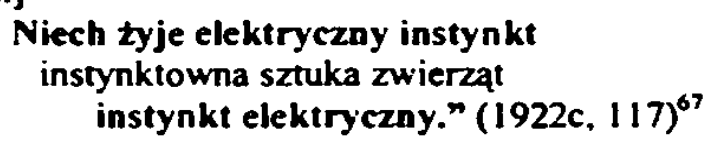

Wie zuvor in "Flamme und Brunnen" wird auch in diesem Zitat erkennbar, dass Czyżewski die Symbiose der beiden von ihm bestimmten Einflüsse im .elektrischen Instinkt” sieht: .elektryczny instynkt // (maszyna i żywioł)" (1922c, 117) ${ }^{68}$.

Wie er sich den Einfluss der Kunst der Tiere vorstellt, führt Czyżewski ebenfalls in „Von der Maschine zu den Tieren“ aus: Die Musik sei von den Vögeln, Architektur, Malerei und Bildhauerei von den tierischen Nestern und Behausungen erlembar, so Czyżewski (vgl. 1922c, 117).

Diese Thematik beschäftigt ihn auch in mehreren Gedichten, so zum Beispiel in "De profundis", besonders in dessen viertem Teil, der bereits den vielversprechenden Titel „Koralle“ (,Koral“) trägt. Die Gedanken des erwähnten Manifestes aufgreifend, wird zuerst die farbenfrohe Kunst der Tiere geschildert, zum Beispiel deren Behausungen: „Jaskółka czarnobiała // malowała swe gniazdo budowała" $(1922 \mathrm{c}, 82)^{69}$. Auch in weiteren Fällen wird das tierische Schaffen explizit mit der Person des Künstlers bzw. mit künstlerischen Tätigkeiten in Verbindung gèbracht: „artyści złoto-biali”, „malowaly się syreny korale i sepie”, ..rzeżby krokodyle i żołłwie” sowie zusammenfassend: „malowały śpiewały budowały sztukę zwierzal"70. Schließlich wird in .De profundis“ durch das lyrische Ich das Lernen des „menschlichen” Künstlers angesprochen, das ebenfalls bereits in „Von der Maschine zu den Tieren" eingefordert wurde:

„i przyszedlem ja artysta ich [=zwierzat: M.E.] uczeń ich medium ich poddany Rafael i stworzylem pó kolibra-nietoperza

${ }^{67}$, Element - vom allgemeinen Mechanismus zum Instinkt der Tiere - wir werden Brider der Tiere sein und wir werden von ihnen die instinktive Kunst lemen, lieben werden wir die Maschinen. da sie unsere Schwestem sind und die Tiere. da sie unsere Lehrer und Bruder sind. [...] Es lebe der elektrische Instinkt - die instinktive Kunst der Tiere - der elektrische Instinkt."

os "der elektrische Instinkt // (Maschine und Element)".

60 "Eine schwarz-weiße Schwalbe // sie malte ihr Nest sie baute". Auch alle weiteren Zitate aus .De profundis" sind aus dieser Quelle entnommen. der ganze vierte Teil des Gedichtes ist auf den Seiten 82-84 abgedruckt.

to .golden-weiße Kunstler", „es bemalten sich Sirenen Korallen und Tintenfische“, ..Skulpturen Krokodile und Schildkroten“ - ,sie malten sie sangen sie bauten die Kunst der Tiere“. 


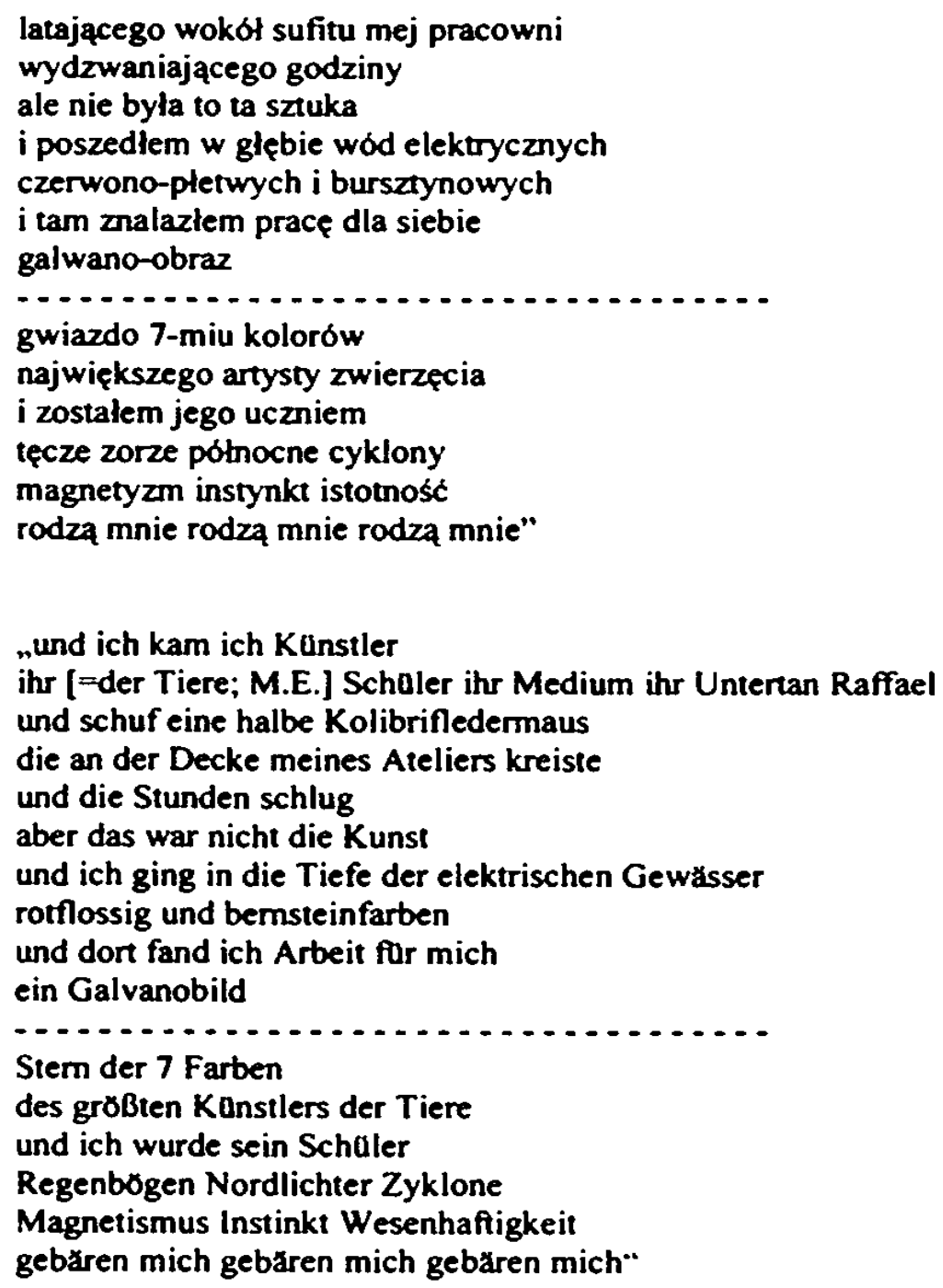

Die tierische Kunst wird in diesem Zitat höher eingeschätzt als die menschliche, für deren Tradition der Name Raffaels ins Spiel gebracht wird. Dieser ist den Tieren ebenso untergeben, wie der als lyrisches Ich auftretende Künstler, dessen Lemen und dessen Versuch, wie die Tiere zu schaffen hier thematisiert werden. Es bleibt ein wenig unklar, warum sein erster dahingehender Versuch scheitert (,ale nie byla to ta sztuka") - erst als er sein Atelier verlässt und sich in den Lebensraum der Tiere begibt (,i poszedłem w glębie wód elektrycznych"), scheint seinen Versuchen mehr Glück beschieden zu sein. Dort wird er Schüler des „größten Künstlers der Tiere“, als der hier der Seestern erscheint (poln. eig. „rozgwiazda“). Es ist vor allem der Farbenreichtum. der ihn hier fasziniert und der auch im zitierten Fragment zum Ausdruck kommt. Auffallend ist schließlich, dass Czyżewski auch in diesem Gedicht die Elektrizität (,wód elektrycznych“, „galvano-obraz“) sowie den Instinkt im Zusammenhang mit der neuen Kunst aufgreift, wie dies bereits bei den beiden Gedichten „Flamme und Brunnen“ und „Transzendentales Panoptikum" der Fall war.

Die Hinwendung zur Kunst der Tiere kann auch als die Suche nach dem Ursprünglichen verstanden werden, nach plastischen und poetischen Formen des Ausdrucks, deren eigene 
Kraft noch unverfälscht zu wirken vermag. Czyżewski thematisiert diesen Gedanken insbesondere in den Gedichten „Die Rückkehr“ („Powrót“) und „Die Uhr“ („Zegarek“).

„Die Rückkehr" scheint zu Beginn eine in naivem Ton gehaltene Hinwendung eines lyrischen Ichs an nach Süden fliegende Zugvögel zu sein, mit diesen mitfliegen zu dürfen. Erst als der erwünschte Zielor gegen Ende des Gedichtes näher beschrieben wird, wird klar, dass es sich dabei nicht um den Wunsch handelt, dem Winter zu entfliehen:

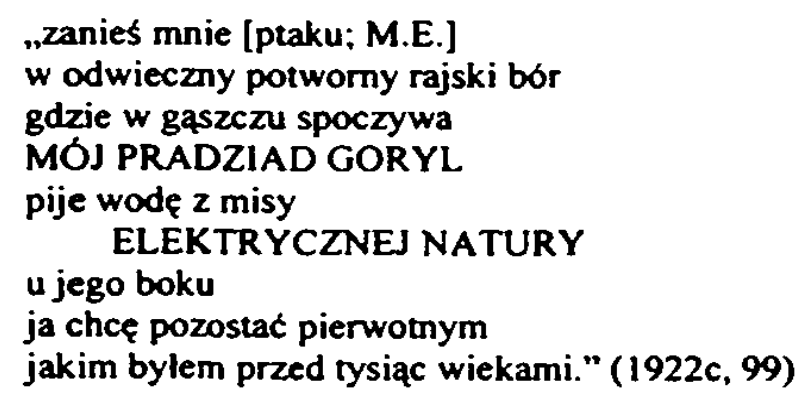

\author{
..bringe mich [Vogel; M.E.] \\ in den ewigen schrecklichen Paradieswald \\ wo im Dickicht ruht \\ MEIN URAHN GORILLA \\ er trinkt Wasser aus der Schussel \\ an seiner Seite \\ DER ELEKTRISCHEN NATUR \\ will ich ursprunglich bleiben \\ der ich war vor tausend Jahrhunderten"
}

Es ist die Sehnsucht des lyrischen Ichs (,zanieś mnie“) nach einem paradiesischen Urzustand (,ja chce pozostać pierwotnym // jakim byłem..."), der auch durch die verwendeten Temporalbestimmungen („odwieczny bör“, „przed tysiąc wiekami“) in eine möglichst große Distanz zur Gegenwart gesetzt wird. Ebenso ist ja auch der Gorilla in evolutionärer Hinsicht ein Vorfahr des Menschen (,mój pradziad goryl“). In zentraler Position erscheint in diesem Fragment jedoch die Metapher der „elektrischen Natur", eine Verbindung, die in diesem Abschnitt schon mehrfach angesprochen wurde. In diesem Zusammenhang sei noch auf einen ähnlich gebauten Vergleich hingewiesen, der im Gedicht einige Zeilen früher vorkommt und der eine Bildanalogie zwischen dem strahlenden chemischen Element Radium mit Glühwürmchen herstellt: „świeci ziarnko radium // niby świętonjański robaczek” (1922c. 99) ${ }^{71}$.

Dieser Wunsch nach dem Ursprünglichen wird schließlich auch in „Die Uhr" artikuliert. Das Gedicht kann insgesamt als Reflexion über das Wesen der zeitgenössischen Kunst gelesen werden, da zwei ihrer - in den Augen Czyżewskis - wichtigsten Merkmale thematisiert werden: die unmittelbare Hinwendung zur Gegenwart mit all ihren neuen zivilisatorischen und technischen Erscheinungsformen und eben die Suche nach der ursprünglichen Kunst der Tiere. Zwei Erlebnisse des durch die Straßen gehenden lyrischen Ichs spielen darauf an. wie schnell für die heutige Kunst neue Bedingungen geschaffen werden können, wenngleich das folgende Fragment vor allem von einem nicht zu übersehenden ironischen Unterton geprägt ist, der sich gerade auf die Avantgarde und ihre Ismen zu beziehen scheint:

" „es leuchtet ein Kornchen Radium // wie ein Gluhwürmchen“. 
"ide bokami ulicy
zawadziłem noga
o drzwi perukarza
nowa sytuacja się stwarza
i stąd nowy kierunek w poezji" (1922c, 114) „ich gehe an der Seiten der Straße ich bin mit dem Fuß gestoßen an die Tor des Peruckenmachers eine neue Situation entsteht und damit eine neue Richtung in der Poesie"

Ähnliches gilt für die moderne Malerei, wie im weiteren Verlauf beschrieben wird. Die Ironie wird im Übrigen durch die innere Zeitstruktur des Gedichtes noch verstärkt: Das im Gedicht beschriebene Geschehen spielt sich zwischen 21 Uhr abends und Mitternacht ab, das lyrische Ich scheint zu jeder Stunde auf seine Uhr zu blicken, um die Zeit abzulesen. Da die neue poetische Situation dabei um $21 \mathrm{Uhr}$, die neue malerische um $22 \mathrm{Uhr}$ entsteht, kann fast davon die Rede sein, dass die neuen Richtungen so gut wie „stündlich“ ins Leben gerufen werden, was ihren schnelllebigen Charakter noch betont.

Daneben wird in "Die Uhr" noch einmal die Suche nach dem Ursprünglichen thematisiert. Wie im zuvor besprochenen Gedicht „Die Rückkehr“ ist dabei die möglichst große zeitliche Distanz zur Gegenwart von Bedeutung:

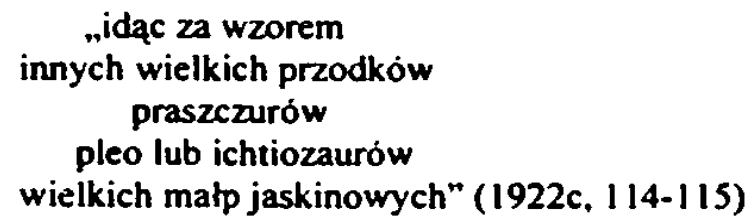

„idac za wzorem

innych wielkich przodków

praszczurów

pleo lub ichtiozaurów

wielkich matp jaskinowych" (1922c, 114-115)

\author{
.dem Vorbild folgend \\ anderer großer Vorfahren \\ Urahnen \\ Pleo- und lchthyosaurier \\ großer Hohlenaffen"
}

Was auf diese Passage folgt, ist ein Beispiel für die „Tierkunst”, in der Czyżewski ein Vorbild für die zeitgenössische Poesie sieht. Er führ dies vor allem darauf zurück, dass diese Poesie von allen inhaltlichen Zusammenhängen befreit ist und daher die einzelnen Laute rein als solche wirken können. Dieses Phänomen scheint für die Formisten insofern von Bedeutung, da es ja auch ihnen, ähnlich der Abkehr der bildenden Kunst von Naturalismus und Mimesis, um die Aufgabe der beschreibenden Funktionen der Literatur geht, was das Thema der nächsten Abschnitte sein soll.

\subsection{Das „Formistische“ in Czyżewskis Dichtung}

Die Beschreibung der theoretischen Texte einzelner Formisten im dritten Kapitel hat gezeigt, dass cs ihnen weder um eine einheitliche Theorie des Formismus, noch um Programme geht, die als „Anleitung“ zum künstlerischen Schaffen verstanden werden können. Demzufolge stellt sich auch in diesem Abschnitt weniger die Frage, ob Czyżewski in seinen Gedichten bewusst ästhetische Ansätze realisiert, die von Chwistek oder Witkacy am Material der 
bildenden Kunst entwickelt wurden. Vielmehr ist von Bedeutung, ob in diesen Gedichten künstlerische Verfahrensweisen bestimmt werden können, die auch in den theoretischen Texten thematisiert werden. Erst in dieser Hinsicht scheint es letztendlich mogglich zu sein, vom „Formistischen“ auch im Falle von Czyżewskis Lyrik sprechen zu können.

\subsubsection{Die „visionäre Wirklichkeit*}

Als gemeinsame Grundlage der Kunst aller Formisten bestimmt Chwistek, wie gezeigt, die sogenannte "visionäre Wirklichkeit". In ihr stehen nicht die Eindrücke als Abbilder des betrachteten Gegenstandes, sondern die vom Betrachter dabei entwickelten Visionen, Träume oder Halluzinationen im Vordergrund. Dies führe, so Chwistek, zu einer großen Anzahl von Bildern, die eben dadurch, dass sie nicht mehr unmittelbar an einen Gegenstand gebunden seien, besser in eine das Formale betonende Kunst integriert werden könnten, deren Ziel nicht mehr die möglichst naturgetreue Abbildung sei.

Es geht im Wesentlichen also um eine besondere Form der Betrachtung bzw. der Wahmehmung der Erscheinungen und Phänomene der äußeren Welt, die unter anderem das Visionäre, Transzendentale, Träumerische etc. betont bzw. auf diesem fußt. Eine solche Wahrnehmung wird in Czyżewskis Gedichten mehrfach thematisiert, häufig auch in Verbindung mit Übersinnlichem. In der folgenden Darstellung wird somit der Versuch unternommen, eine Charakteristik von Czyżewskis Poesie näher zu beschreiben, die ihre Entsprechung in Chwisteks Theorie der visionären Wirklichkeit findet.

Entsprechend ihrem Titel spielt das Visionäre in „Elektrische Visionen“ eine wichtige Rolle. Dabei scheint insbesondere die in der Einleitung geschilderte Begegnung zwischen dem lyrischen Ich und seinem Begleiter, der ihm die drei Einzelvisionen erschließt, einem visionären oder übersinnlichen Erlebnis gleichzukommen ${ }^{2}$. Der Gast selbst verweist nämlich in seiner Vorstellung darauf, dass er durch Rationalität nicht zu erkennen sei:

„Jak spality się twoje Mysili

Ogniem zó́tci i cynizmu Ja jestem ten o którym myślałeś Nie myśląc" $(1920 a, 65)$
„Wie deine Gedanken verbrannten

Im Feuer von Gelb und Zynismus

Ich bin der an den du dachtest

Ohne zu denken"

Die Gedanken spielen also keine Rolle für die Erkenntnis. die erst jenseits von ihnen möglich scheint. Ein weiterer Hinweis darauf, dass die in der Einleitung von „Elektrische Visionen“ 
geschilderte Szenerie sich zwischen Wach- und Traumzustand abspielt, ist die Wendung: „w przymrużona zimowa Noc" $(1920 \mathrm{a}, 65)^{73}$, und zwar durch das Motiv der halb geschlossenen Augen, das auf die Nacht übertragen wird. Dies erinnert an das Gedicht "Halbschlaf", in dem ein Soldat im Halbzustand zwischen Schlaf und Traum Visionen des Soldatentods erlebt.

Auf diese Einleitung folgen in „Elektrische Visionen“ die drei Einzelvisionen „Wizja I", "II“ und „III“, die, wie gezeigt, den Übergang zwischen der alten und der neuen Zeit beschreiben. Gerade die darin vielfach verwendete komplexe und schwer aufzulösende Bildlichkeit der poetischen Darstellung kann vielleicht als Versuch gesehen werden, diesem visionären Sehen künstlerisch zu entsprechen.

Für Chwistek ist die Bedeutung der „visionären Wirklichkeit“ für die Kunst nicht zuletzt darin gegeben, als dass diese dem Künstler die Möglichkeit bietet, seine Eindrücke, seine inneren Empfindungen etc. zum Ausdruck zu bringen. Dieser der expressionistischen Ästhetik sehr nahe Ansatz findet sich auch in Czyżewskis Lyrik und in seinen programmatischen Texten, wobei er in diesem Zusammenhang den Begriff des „Mediums“ gebraucht. So lautet etwa der letzte Satz von „Von der Maschine zu den Tieren: „instynkt elektryczny [...] wewnętrznego życia medium“ $(1922 c, 117)^{74}$. Der Künstler wird in dieser Vorstellung zum Medium seines Inneren selbst, bringt er doch dieses in seiner Kunst zum Ausdruck. So schreibt im Gedicht „Transzendentales Panoptikum“ der „erste elektromagnetische Dichter und Maler Tytus Czyżewski“" von sich selbst: ,ja medium samego siebie“ (,ich Medium meiner selbst.“- 1922c, 114).

In anderen Gedichten muss „Medium“ mehr als Bezeichnung einer Person verstanden werden, die die Fähigkeit besitzt, Verborgenes, gemeinhin nicht Fassbares sichtbar zu machen bzw. zum Ausdruck zu bringen, wodurch Czyżewski wieder stärker eine überrationale Form der Wahrnehmung bzw. Erkenntnis zu thematisiert. In diesem Sinn kann etwa der Titel von „Mediumistisch-magnetische Photographie des Dichters Bruno Jasieński“ verstanden werden, da das Gedicht den Versuch Czyżewskis beschreibt, in einer Photographie das Wesen und die Persönlichkeit Jasieńskis zum Ausdruck zu bringen. Der "medio-magnetische“ Photograph Czyżewski scheint dabei mit dem Porträtierten in einem Kontakt übersinnlicher

\footnotetext{
7 Dies deutet auch der Vers: „Ja cieszę się // ze będę po mnie” („Ich freue mich // dass ich nach mir sein werde” -1920 a, 68) an.

33 "in einer augenhalbgeschlossenen Winternache". "Mružyc" kommt im Polnischen nur in Verbindung mit den Augen, vor allem in der festen Wendung: .,mruzyć oczy" („die Augen halb schließen“). vor.

${ }^{4}$ "elektrischer Instinkt \{... $\}$ Medium des inneren Lebens".
} 
Natur zu stehen: „ty [=Jasieński; M.E.] opowiadasz mi przez sen“ („du erzählst mir im Schlaf/Traum" $-1922 \mathrm{c}, 105)^{75}$.

Auch einem Vers aus „De profundis“ scheint ein ähnliches Verständnis von Medium zugnunde zu liegen, da es wiederum um eine Form der Wahrnehmung geht, die allgemein nicht Erfassbares begreift. Es handelt sich dabei um jene, bereits zitierte, Stelle, wo ein (menschlicher) Künstler von den Tieren und ihrer Kunst lernen möchte und versuchen will, sie zu verstehen: „i przyszedłem ja arytysta // ich [=zwierzą; M.E.] uczeń ich medium [...]“ $(1922 \mathrm{c}, 83)^{76}$.

Schließlich findet sich im Band „Nacht - Tag“ noch ein eigenes Gedicht mit dem Titel „Medium“ („Medium“). Das Gedicht scheint dabei der Versuch einer Beschreibung dessen zu sein, was das Medium, das als lyrisches Ich vorkommt, wahmimmt, wie die beiden letzten Zeilen andeuten:

"to wiczialem ja medium magnetyczne

11 listcpada w potudnie 1914 r." (1922c, 95) „das sah ich magnetisches Medium am 11. November 1914 zu Mittag"

Es ist sciwierig, die übrigen Verse des Gedichtes mit dem genannten konkreten Datum in Verbindung zu bringen. es gibt zum Beispiel keine Hinweise auf den bereits begonnenen Ersten Weltkrieg. Gleichermaßen ist unbekannt, ob auch das Gedicht selbst wirklich zu dieser Zeit entsanden ist. Es ist allerdings möglich, den Beginn gewissermaßen als Abschied auf die Epoche cer Jahrhundertwende, der des ,Jungen Polens“ zu lesen:

..Ciche dżwięki jak rdzawe kwiatów zapachy

meldocie wyschłych róz które zbitych kruz budzą wspomnienia" (1922c. 95)

"Leise Tone wie der rostfarbene Duft von Blumen

Melodin vertrockneter Rosen die Erinnerungen an zerschlagene Kroge wecken“*

Mit "krıża" wird. wie Alicja Baluch vermerkt (in: Czyżewski 1992, 50), ein Art geschmükter Krug bezeichnet, der sowohl in der sezessionistischen Grafik, wie auch in der Poesie des „Jungen Polens“ hăufig vorkommt. Die Scherben dieses zerbrochenen Kruges sind wohl da: deutlichste Zeichen für das Zuende-Gehen dieser Epoche. Dieser Eindruck wird durch dit Symbole „rdzawe kwiaty“ bzw. „wyschle róże“, beides Bilder des Untergangs. des Verblühens, noch verstärkt. Schließlich sind es die geweckten Erinnerungen, die auf die vergangene Zeit verweisen. In den zitierten beiden Zeilen kommt darüber hinaus gut die Charakteistik der „visionären Wahrnehmung“ zum Ausdruck, besonders die Synästhesien

\footnotetext{
"Wie erwihnt, kann das polnische "sen" sowohl "Schlaf”, als auch „Traum” bedeuten.

${ }^{76}$ "und ichkam ich Konstler // ihr [=der Tiere; M.E.] Schuler ihr Medium“.
} 
(„ciche dżwięki“, „zapachy“, "melodie“) vermitteln anschaulich die Tiefe des inneren Erlebnisses, ebenso wie die sich durch das ganze Gedicht hindurchziehende komplexe Bildlichkeit.

Czyżewski thematisiert also in mehreren Gedichten, was Chwistek theoretisch formulier: eine Form der Wahmehmung, die auf den inneren Erlebnissen des Betrachtenden sowie auf übersinnlichen und uber das Rationale hinausgehenden Erscheinungen beruht. Denn auch Chwistek spricht in „Die Vielfalt der Wirklichkeiten in der Kunst“ (1918) von der visionären Wirklichkeit als „rzeczywistość snów, rzeczywistość halucynacji, rzeczywistość ekstaz, wizji i marzeñ“ $(1918,33)^{77}$. Für Chwistek bietet der Rückgriff der Malerei auf diese Wirklichkeit die Möglichkeit, die künstlerische Darstellung von der reinen Abbildung zu befreien und an formale Aufgaben anzunähern. Auch für Czyżewski bedeutet die Hinwendung zum „Visionären“ in seinen Gedichten die Loslösung von logischen Sinnzusammenhăngen und damit die Aufgabe einer ausschließlich über den Inhalt hergestellten Kohärenz des literarischen Werkes. Vor allem die formale Gestaltung eines Gedichtes kann so stärker ins Blickfeld gerückt werden.

\subsubsection{Die Form des Kunstwerks und die Überwindung des Inhalts}

Einer der zentralen Punkte, der in den im vierten Kapitel dieser Arbeit besprochenen literaturtheoretischen Schriften der Formisten entwickelt wird. ist die Befreiung der Dichtung von ihren deskriptiven Funktionen. Ähnlich dem Schritt von der mimetischen zur ungegenständlichen Malerei. soll auch die Literatur keine möglichst getreue Beschreibung der äußeren Wirklichkeit (mehr) sein. Ebenso dürfe, nach Meinung der Formisten. die Literatur nicht länger ausschließlich über ihren Inhalt begriffen werden, etwa als amüsante Form der Unterhaltung oder als Äußerung im politischen Sinne. Gerade darin besteht die explizite Negation einer Tradition, die in Polen seit der Romantik vertreten war, nämlich die Thematisierung der staatlichen Unfreiheit und die Stärkung des nationalen Bewusstseins durch Kunst und Literatur.

Es geht den Formisten aber nicht um eine völlige Aufgabe des Inhaltes. Sie begreifen dessen Funktion im literarischen Kunstwerk vielmehr dahingehend, dass durch eine entsprechende inhaltliche Gestaltung die formalen Qualitäten einer Dichtung stärker hervortreten können.

\footnotetext{
$n$.Wirklichkeit der Trăume. Wirklichkeit der Halluzinationen, Wirklichkeit der Ekstasen. Visionen und Tagtrăume".
} 
Chwistek spricht in diesem Zusammenhang vom „mehrdeutigem Inhalt“ bzw. von bewusster ,inhaltlicher Verschleierung“, Witkacy von der Aufnahme von „Unsinn“ in die Dichtung. Auch für Czyżewski richtete sich, wie er rückblickend auf die formistische Zeit in seinem Text „Über die Entlogisierung der Poesie“ („O odlogicznieniu poezji“) schreibt, die erste große Anstrengung der zeitgenössischen Poesie darauf, das Wort aus den ihm aufgezwungenen logischen Zusammenhängen innerhalb eines Satzes zu befreien (1936, 294) ${ }^{78}$. Schließlich kann auch Czyżewskis Betonung des Instinkts, des Ursprünglichen sowie des Übersinnlichen als Versuch verstanden werden, einen Schritt über die rationale Logik hinauszugehen. Diese „Entlogisierung der Poesie“, das heißt die Relativierung der Rolle des Inhaltes ermöglicht für die Formisten die Verwirklichung ihrer an der Form orientierten künstlerischen Absichten. Chwistek bezeichnet dieses formistische Bestreben einmal als die „Überwindung des Inhalts durch die Form“ $(1935,5)$.

Zwei Texte von Czyżewski, die einige Jahre nach dem Formismus entstanden sind, können als der Versuch gelesen werden. seine poetische Methode jener Jahre zu beschreiben: „Von der Romantik zum Zynismus“, erschienen 1927 im Band „Robespierre. Rapsodie. Cinéma. Von der Romantik zum Zynismus“ (,Robespierre. Rapsod. Cinema. Od romantyzmu do cynizmu“) sowie der bereits erwähnte Text „Über die Entlogisierung der Poesie“. Sein Bestreben. die logischen Satzzusammenhänge aufzulösen und damit eine nicht auf dem Inhalt beruhende Textkohärenz zu schaffen, bezeichnet er dabei als „Anarchisierung“:

„Kazdemu słowu $w$ mej poezji daje indiwidualne znaczenie $i$ autonomię, a zarazem przez anarchizacje (nie anarchię) słów, dzielę je na grupy analogicznych słów, z których wydobywam analogiczne zdania itd. Dlatego slowa i zdania mimo powierzchownej często alogiczności w całosci (przez kontrast wiazañ) daja spoistą istotę która zyje jak organizm w przyrodzje." $(1927,229)^{\text {x }}$

Für Czyżewski geht es demnach darum, die Kraft des einzelnen Wortes stärker zu betonen. die für ihn innerhalb eines syntaktischen Gefüges verloren zu gehen scheint. Eine neue Form des inneren Zusammenhaltes soll aber aus der Analogizität der Wörter, die miteinander assoziativ in Verbindung stehen, erwachsen. Die folgende Passage aus „De profundis“ zeigt. dass Czyżewski dies sowohl in semantischer, als auch in klanglicher Hinsicht begreift:

.ja wyszedłem z ustami pełnymi klawikordów dysonansow sonat sonatin hydroburz

\footnotetext{
77 Dieser Text entstand 1929, wurde aber erst 1936 in Czyzewskis letztem Gedichtband „Steckenpferdreiter in Wolken" (.Lajkonik w chmurach") veroffentlicht.

79 "Ich gebe jedem Wort in meiner Poesie eine individuelle Bedeutung und Autonomie, gleichzeitig teile ich sie durch Anarchisierung (nicht Anarchie) der Worter in Gruppen analoger Worter auf, aus denen ich analoge Satze hervorhole usw. Aus diesem Grund ergeben die Worter und Satze, obwohl sie scheinbar oft unlogisch sind. im Ganzen (durch einen Kontrast der Verbindungen) ein kohärentes Wesen, das lebt, wie ein Organismus in der Natur."
} 


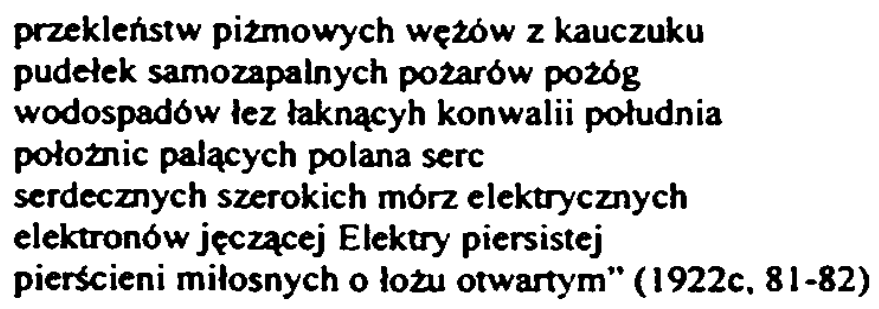

„ich ging hinaus mit einem Mund voll von Cembali

Dissonanzen Sonaten Sonatinen Hydrogewitter

Fluchen Moschusschlangen aus Kautschuk

Schachteln selbstentzandender Brande und Feuerbranste

Wasserfallen aus nach Maiglockchen des Sudens lechzender Tranen

Wochnerinnen, die Holzscheite der Herzen verbrennen

herzlicher breiter elektrischer Meere

Elektronen der stohnenden vollbusigen Elektra

Liebesringen mit einem offenen Betr

Es wäre schwierig, aus diesem Fragment ein gemeinsames Thema herauszuarbeiten oder in vielen Fällen eine gedankliche Verbindung zwischen den einzelnen Wörtern eines Verses herzustellen. Vielmehr sollte der Blick auf die angesprochene neue form des inneren Zusammenhaltes gelenkt werden, die Czyżewski durch Assoziationen erreicht. Assoziationen inhaltlicher Natur sind zum Beispiel: „Schachtel“ (Streichhölzer) - „selbstentzündend“ ..Brand“ - „Feuersbrunst” oder die Verbindungen: „Wasserfall“ - „Tränen“ und .Ring“ „liebevoll“. Häufiger sind jedoch die klanglichen Assoziationen, zum Beispiel die Alliteration: „południa // połóżnic palących polana“ oder der Gleichklang in der ersten Silbe bei: „piersistej - pierścieni“. Als figura etymologica ${ }^{80}$ sind ..dysonansów - sonat - sonatin“ und "serc - serdecznych“" zu bestimmen. Die beiden zuletzt genannten Klangfiguren werden darüber hinaus noch miteinander kombiniert: „(mórż) elektrycznych - elektronów“ mit „Elektra“. Genannt werden muss auch der erste Vers des zitierten Fragments, in dem mittels eines Vergleiches die Zähne mit den Tasten eines Cembalos miteinander verbunden werden. Festzuhalten ist außerdem, dass of das letzte Wort eines Verses mit dem ersten des darauffolgenden korrespondiert, was ebenfalls den Zusammenhalt festigt: ..poludnia // położnic“, „serc // serdecznych“, „elektrycznych // elektronów“" sowie .,piersistej // pierścieni“. Dass die zitierte Passage aus „De profundis“ über die Idee der Assoziation zusammengehalten wird, ist auch aus der grammatischen Form der einzelnen Verse ersichtlich. Es findet sich nur ein im grammatischen Sinn vollständiger Satz (,ja wyszedłem“ etc.), der Rest besteht aus Substantiven und Adjektiven, meist im Genitiv Plural. Dieser Fall.

"Ivo Braak und Martin Neubauer definieren die .,figura etymologica“ ausschließlich als Verbindung eines Zeitwortes mit einem ..stammverwandten Hauptwort als Objekt" (vgl. Braak 1965, 69). Es finden sich jedoch auch Definitionen, die den etymologischen Zusammenhang als vorrangig bestimmend ansehen, wodurch auch in 
im Polnischen: „dopełniacz“, von „dopełniać” - „voll machen, ergänzen, vervollständigen“, wird im Allgemeinen zur näheren Bestimmung eines anderen Wortes gebraucht, suggeriert als grammatische Form also einen Zusammenhang, einen - ähnlich zur Assoziation unmittelbaren zweiten Teil. Da im zitierten Fragment gerade diese inhaltliche Beziehung aber schwer herzustellen ist, wodurch, wie Czyżewski selbst betont, die Autonomie der einzelnen Begriffe gestärkt wird, entsteht hier eine eigentümliche Spannung.

Es ist somit die Auflösung „gewohnter“ Zusammenhänge, das heißt jener, die zum Beispiel auf grammatischen Strukturen oder einem logischen Gedankengang beruhen, die die Autonomie des Einzelwortes bedingt. Dank dieser Autonomie, so Czyżewski in „Von der Romantik zum Zynismus“ weiter, ermögliche dieses Einzelwort ungleich mehr neue Assoziationen (beim Rezipienten), als eines, das in feste Strukturen eingebunden sei (vgl. 1927, 229). Zu den zahlreichen im Text enthaltenen Assoziationen (vgl. die obige Interpretation des Fragmentes aus „De profundis“) treten weitere hinzu, die der Rezipient selbst herstellt. Czyżewski sieht im Eröffnen solcher gedanklichen Freiräume eine wichtige Eigenschaft der Poesie und betont, dass es vor allem der Klang der Wörter und nicht deren Bedeutung sei, der dies gewährleiste:

„Džwięki, jak np. (przypuśćmy) ai, aũo, ao itp. uzyte bez znaczenia (jako slowa logiczne), moga działać sugestywnie jako poezja [...]. Słowo jako dźwięk. czy w ogóle jako calosć autonomiczna, ma znaczenie sugestywne i tylko jako takie moze być uzyte w poezji. [...] Slowo, jako dżwięk, czy jako sugestia, jako istotny glos przyrody: spiew ptaków, glosy zwierzat, spiewy pienvotne ludów - jest podstawa poetycznej autonomii slowa która prowadzi do mozliwości zupetnie nowych i szerokich w prozie i poezji." (1936, 297) $)^{81}$

Dieses Zitat zeigt, dass Czyzewski die Laute der Tiere konkret als Poesie versteht und sie auch als Vorbild für die zeitgenössische Dichtung bestimmt. Im Gedicht „Die Uhr" findet sich eine entsprechende Stelle, in der gleichzeitig die Hinwendung zum Ursprünglichen noch einmal vergegenwärtigt wird:

$$
\begin{gathered}
\text {,idac za wzorem } \\
\text { innych wielkich przodkow } \\
\text { praszczurow } \\
\text { pleo lub ichtiozaurow } \\
\text { wielkich malp jaskinowych }
\end{gathered}
$$

\author{
..dem Vorbild folgend \\ anderer großer Vorfahren \\ Urahnen \\ Pleo- und Ichthyosaurier \\ großer Hơhlenaffen \\ und
}

\footnotetext{
der genannten Verbindung von Substantiv und Adjektiv eine .figura etymologica“ gesehen werden kann (vgl. zum Beispiel: Kulawik 1997,63).

" "Die Klănge, wie z.B. (nehmen wir an) ai, aulo, ao usw., die ohne Bedeutung (im Sinne logischer Wörner) gebraucht werden, können als Poesie suggestiv wirken. [...] Das Wort als Klang, oder aberhaupt als autonome Einheit hat eine suggestive Bedeutung und nur so kann es in der Poesie gebraucht werden. [...] Das Wort als Klang oder als Suggestion, als wesentliche Stimme der Natur: Vogelgesang. Tierstimmen, Gesănge primitiver Volker - bilden die Grundlage der poetischen Autonomie des Wortes, die zu vollig neuen und breiten Anwendungsmoglichkeiten in Prosa und Poesie fuhr."
} 

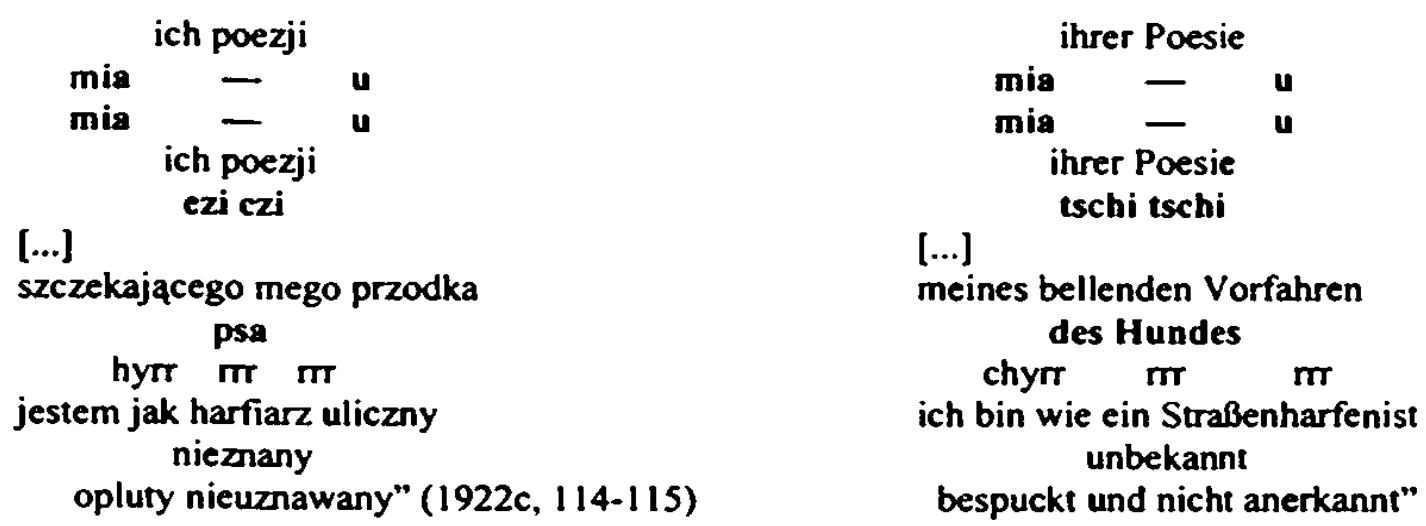

Die letzten Zeilen dieses Zitates können autobiographisch gelesen werden: Czyżewski litt sehr darunter, dass der größte Teil der polnischen Literaturkritik der Zwischenkriegszeit die formistischen und futuristischen Experimente nicht anerkannte und sich größtenteils abschätzig über sie äußerte bzw. sie mit Schweigen bedachte ${ }^{82}$.

Entsprechend dem zuvor angefuhrten Zitat aus „Über die Entlogisierung der Poesie“ versucht Czyżewski in "Die Uhr" die Laute der Tiere (,miau“, „czi“, „mт"), das heißt ihre Poesie unmittelbar in sein Gedicht aufzunehmen. Darin kann der Versuch gesehen werden, das theoretisch formulierte Postulat von der Suggestivkraft scheinbar bedeutungsloser Laute poetisch umzusetzen. Auch in anderen Gedichten realisiert Czyżewski ein ähnliches Vorhaben. So werden im Gedicht „Katzenserenade“, in dem das Liebeswerben eines Katers beschrieben wird, an mehreren Stellen dessen Laute eingefügt:

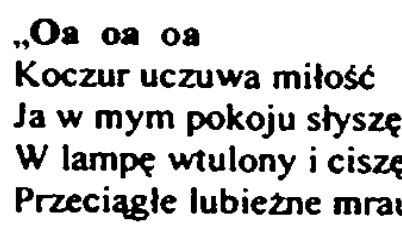

au au o - a $-u^{\prime \prime}(1920 a, 59-60)$

\begin{abstract}
.Oa oa oa
Der Kater verspür Liebe

Ich in meinem Zimmer höre

Eingehallt in Lampe und Stille

Ein langgezogenes wollustiges mrau
\end{abstract}

au au o - a - u"

Auffallend ist, dass in "Katzenserenade“, gleich wie im Zitat, die Laute des Katers stets fettgedruckt sind und sich dadurch auch graphisch vom Rest des Textes abheben. Dies kann vielleicht dahingehend verstanden werden, dass der Fettdruck nicht zuletzt das Klangvolumen dieser Laute unterstreichen soll. Tierlaute bilden schließlich auch ein konstituierendes Element der Dschungelszenerie, die im Gedicht „Tigeraugen“ dargestellt wird. Es sind hier vor allem die nervösen Laute von Papageien (.,Papugi hi hi“ - .Papageien hi hi“) und Affen („Małpy czi czi“ - „Affen tschi tschi“- 1920a, 35-36) etc. ${ }^{83}$, die einen klanglichen Kontrast zu dem auf leisen Pfoten schleichenden Tiger bilden. In anderen Gedichten von Czyzewski

\footnotetext{
"2 Vgl. zum Beispiel Czyzewskis Text ..Von der Romantik zum Zynismus“" (1927), in dem er ausfuhrlich daruber schreibt. Die Rezeption Czyzewskis in der Zwischenkriegszeit fasst Baluch (in: Czyzewski 1992, VII-1X) zusammen.
} 
finden sich. den Tierlauten ähnlich, Laute, die gleichermaßen nicht unmittelbar an eine bestimmte inhaltliche Botschaft geknüpft sind, sondern die in erster Linie für sich selbst und suggestiv wirken sollen. Dazu zählen vor allem musikalische Töne, die in den Gedichten „Der Tanz" ("Taniec“, „a-ha // Ton: - C, A.“-1920a, 39), „Stadt an einem Herbstabend“ (,fa so la si do re mi“" - 1920a, 42) oder "Singende Häuser“" (Dom fioletowy // Niski ton // Dom zółty smukły // wysoki ton" - 1920a, 49) vorkommen ${ }^{84}$. Der Vollständigkeit halber sei noch erwähnt. dass in anderen Gedichten, Töne und Laute auch als Verdeutlichung des Inhaltes Verwendung finden. Dies ist zum Beispiel der Fall in „Katzenserenade“, wo es ja der Lärm der Großstadt ist, der dem lyrischen Ich den Schlaf raubt („W bufecie piszcza flaszki // Drin drin drin“ und „Już północ biją zegary // bom bum bum bom“-1920a, 60 und 61) ${ }^{85}$. In ähnlicher Weise geschieht dies im Gedicht „Sie wusste es nicht“ („Nie wiedziała“), das in anekdotisch-amüsanter Weise die Geschichte einer Näherin erzählt, deren Schwangerschaft sie zwingt, sich zwischen zwei Männern, die sie gleichermaßen zu lieben scheint, zu entscheiden. Da ihr Lebenspartner nicht der Vater ist, befürchtet sie das Schlimmste, wenn sie an seine mögliche Reaktion denkt:

"myślicie ze się zastrzelił
Zabił ja albo rywala
Przeciez kochała go bardzo
O lala lalala lalala
On śmiał się jechal ulica i trąbil
tutu tutu tutu" (1922c, 92)

Die liedartigen Verse, von denen es noch viele weitere im Gedicht gibt, unterstützen zum einen die leichte Erzählweise, stehen zum anderen, aufgrund der in ihnen zum Ausdruck gebrachten Fröhlichkeit, in direktem Gegensatz zur Tragik des dargestellten Geschehens, wenngleich sie auch dadurch - als Kontrast - diese psychische Belastung der Näherin dem Leser noch deutlicher vor Augen führen.

Es scheint, dass Czyżewskis Absicht, die einzelnen Wörter in ihrer Autonomie zu stärken. auch die Bildlichkeit seiner Gedichte beeinflusst, wenn also zwei (oder mehrere) „autonome“ Begriffe, das heißt solche, deren Bedeutung sich allein aus ihnen selbst und nicht aus den (Satz-)zusammenhängen, in die sie eingebunden sind, ergibt ${ }^{86}$, zum Beispiel im Falle einer Metapher oder eines Vergleiches aufeinandertreffen. Dabei ist es eben gerade die

\footnotetext{
${ }^{83}$ Eine deutsche Übersetzung des Gedichtes ist bei Lam (1990, 115-116) abgedruckt.

"4 "Violettes Haus // Tiefer Ton // Schlankes gelbes Haus // Hoher Ton". Vgl. dazu außerdem die Interpretation des Gedichtes ."Die Puppe“ (.Lalka“) im weiteren Verlauf dieses Abschnittes.

"Im Buffet piepsen die Flaschen // klirr klirr klirr" und „Schon Minernacht schlagen die Uhren // bom bum bum bom".
} 
(semantische) Individualităt dieser Begriffe, die sie gegenüber anderen zu verschließen scheint. Treten sie aber trotzdem in eine Verbindung ein, so eröffnen sich dadurch ganz neue und unerwartete Sinnzusammenhänge, die von einem lebenspraktischen Standpunkt aus gesehen unlogisch erscheinen, in poetischer Hinsicht jedoch eine enorme Suggestivkraft besitzen $^{87}$.

Für die Formisten, vor allem für Czyżewski und Witkacy, sind, wie zum Teil beschrieben, solche überraschenden Kombinationen ein zentrales Element des von ihnen angestrebten neuen poetischen Ausdrucks. Czyżewski selbst bezeichnet in „Die Poesie der Expressionisten und Futuristen" Claudel und Whitman als die ersten, die „Vergleichsdissonanzen“ („dysonanse porównañ) und „unerwartete“ und „plötzliche Wendungen“ (,zwroty nieoczekiwane i nagle") in ihre Dichtung aufnahmen, deren sprachliche Bilder also keiner Logik mehr folgten (1919c, 79-80). Und auch in „Das Begräbnis der Romantik“ schreibt er über die neueste Dichtung: „Skojarzenia myślowe będa rzadkie, niespodziewane $i$ nieprzewidziane - forma barwna - wiersz jak najbardziej wolny - kontrasty myślowe jak najbardziej oddalone.“ $(1921 \mathrm{a}, 177)^{88}$. Auch für Witkacy ergibt sich die künstlerische Bedeutung von Begriffskombinationen aus der ihnen innewohnenden Spannung, die aus der Wechselwirkung zwischen den beiden scheinbar nicht zusammenpassenden Einzelteilen entsteht, wobei er, wie gezeigt, noch genauer zwischen „Grenzbegriffen“ und „asymptotischen Begriffen“ (Oxymora) unterscheidet. Die in beiden Fällen entstehende neue Bedeutung ergebe sich bei den „Grenzbegriffen“ aus der Verschmelzung der beiden Einzelteile, trotz scheinbarer Unvereinbarkeit in semantischer Hinsicht. Bei den „asymptotischen Begriffen“ sei die inhaltliche Gegensätzlichkeit der Einzelteile zu groß, um eine Symbiose zu ermöglichen, die poetische Kraft entstamme aber, so Witkacy, aus der bloßen Annäherung der einzelnen Begriffe.

Beispiele für Begriffskombinationen dieser Art finden sich in Czyżewskis formistischen Gedichten vor allem in „Elektrische Visionen“ und „De profundis“. In „Elektrische Visionen“ besteht dabei ein Teil der Verbindung oft aus einer Farbe, zum Beispiel: „gość pomarańczowego cynizmu“ („Gast des orangen Zynismus"), „głos żơłty“ (,gelbe Stimme“),

\footnotetext{
${ }^{26} \mathrm{Vgl}$. noch einmal das erste in diesem Abschnitt angefuhne Zitat, in dem Czyzewski schreibt, dass er jedem Wort eine individuelle Bedeutung verleihe.

"7ine aberraschende Wendung kann bei Czyzewski auch einen grotesken Effekt erzeugen, zum Beispiel in "De profundis": .,przjdzie do mnie Judasz // i kupi kilka obrazów" (.zu mir kommt Judas // und kauft einige Bilder" 1922c, 80).

" "Gedankliche Assoziationen werden selten, unerwartet und unvorhersehbar sein - die Form farbig - der Vers moglichst frei-die gedanklichen Kontraste moglichst weit entfernt."
} 
„kraina czamej zorzy // czerwonej trupiej czaszki“"89, „niebieski dzień“ („blauer Tag“) und „blask czarny liliowy smak” (1920a, 64, 68, 70 und 72) ${ }^{90}$. Fast alle der hier zitierten Bilder sind schwer aufzulösen, Czyżewski scheint dabei bewusst auf den traditionellen Symbolgehalt der Farben zu verzichten ${ }^{91}$. Dies zeigen, neben der Synästhesie ${ }^{92}$,lilafarbener Geschmack“, vor allem die Metaphern „oranger Zynismus“ und „gelbe Stimme“, die in "Elektrische Visionen“ mit dem "Gast" in Verbindung stehen und daher vielleicht das Übersinnliche, Nichtrationale verstärken sollen. Dasselbe gilt für die beiden Oxymora: „schwarze Dämmerung“ und „schwarzer Glanz“93.

Auch in „De profundis“ gibt es mit „pomarańczowe wiatry“ („orange Winde“-1922c, 75) eine in Bezug auf die verwendete Farbe ähnlich gebaute Metapher. Zum größten Teil wird die Bildlichkeit von „De profundis", besonders des dritten Teils „Wasserfall magnetischer Tränen“ (,Wodospad magnetycznych lez“), wie ja auch das in diesem Abschnitt bereits daraus zitierte Fragment gezeigt hat, aber von schwer bzw. nicht auflösbaren Metaphern erzeugt. Der poetische Ausdruck ist zum Teil extrem verdichtet, mehrere Metaphern verschmelzen miteinander, zum Beispiel:

,ja wyszedlem z rękami pełnymi

o świcie kalejdoskopów urano-burz" (1922c, 81) .ich ging hinaus mit vollen Hănden

zur Morgendämmerung der Kaleidoskope von

Uran-Gewittern"

Die erste Metapher besteht aus der Verbindung von „Uran“ und „Gewitter“, die wiederum in Form einer Genitivergänzung - mit den .Kaleidoskopen“ (wodurch auch hier farbliche Effekte eine Rolle spielen) zusammenhängt. Die gesamte, so geschaffene metaphorische Wendung wird schließlich noch auf die „Morgendämmerung“ zurückbezogen. Die Metapher „Uran-Gewitter" verbindet schließlich wieder die Bildbereiche Technik und Natur miteinander, ein - wie dargestellt wurde - in Czyżewskis Gedichten häufiges Phänomen.

Für Chwistek ist die überraschende Zusammenstellung ein grundlegendes gestalterisches Prinzip von Czyżewskis Lyrik, das er insbesondere im Bau der Gedichte verwirklicht sieht:

\footnotetext{
89 "das Land der schwarzen Dämmerung // des roten Totenkopfes".

90 "schwarzer Schein lilafarbener Geschmack".

91 "Die einzige Ausnahme in dieser Hinsicht konnte „blauer Tag“ sein, wenn etwa „Blau“ als die Farbe der Hoffnung etc. begriffen wird. Eine solche Lesart stunde auch im Einklang mit der in der Interpretation des Gedichtes herausgearbeiteten Struktur von .Elektrische Visionen“, da der Vers, in dem .,blauer Tag* vorkommt (."wejscie w niebieski dzien“" - „Eintritt in den blauen Tag“) gewissermaßen als Uberschrift für die zweite Vision dient, in der, nach den Schrecken der ersten Vision, nun der Beginn des besseren Morgen beschrieben wird.

${ }_{92}$ Zur Synăsthesie als Form der Metapher: vgl. Burdorf 1994, 153-154.

93 Das polnische Wort .,blask“ (,.Glanz", „Helligkeit", „Schein“) wird im Allgemeinen mit Helligkeit assoziien und taucht in Wendungen wie zum Beispiel .,blask slonca“" (..Sonnenschein“) auf.
} 
„Czyzewski pokonuje tresć przez zestawienie zdan prostych, zaczerpniętych najczęśsiej z świata wrazen wzrokowych w ten sposób, zeby słuchacz nie mógl doszukać się pomiędzy nimi myślowego związu." $(1920 \mathrm{~b}, 31)^{94}$

Auch in Chwisteks Verständnis dient die Kombination von inhaltlich weit Entferntem bzw. scheinbar Unlogischem dazu, den Inhalt in seiner Bedeutung für das ästhetische Erscheinungsbild des Kunstwerkes zu relativieren ${ }^{95}$. In vielen Gedichten Czyżewskis ist das von Chwistek beschriebene Prinzip durch den Zeilenstil umgesetzt, der es eben, wie bereits mehrfach ausgeführt, erlaubt, scheinbar unzusammenhängende Begebenheiten unmittelbar aneinander zu reihen.

Durch das Zitat von Chwistek wurde eine explizit formale Frage, die der Konstruktion des Gedichtes, angesprochen. Schließlich sollte, nach Meinung der Formisten, die „Überwindung des Inhaltes" dazu dienen. die Form des Kunstwerkes stärker und deutlicher hervortreten zu lassen. Der zurückgedrängte, nicht eindeutige bzw. unverständliche Inhalt soll die Aufmerksamkeit des Rezipienten auf die Form lenken, da umgekehrt ein eindeutiger Inhalt diese zu schnell von der formalen Gestaltung ablenken würde.

Die scheinbare inhaltliche Beziehungslosigkeit, die die Formisten anstrebten, erforder aber neue Kohärenzen, um die Einheit des Kunstwerkes dennoch zu gewährleisten. Czyżewski stellt in seiner Dichtung solche neuen Zusammenhänge zum Beispiel über Klangfiguren her.

Als erste dieser Figuren ist der Reim zu nennen. Einige der bisher durchgeführten Einzelinterpretationen haben gezeigt, dass Czyżewski in vielen jener Gedichte, in denen scheinbar miteinander unverbundene Ereignisse im Zeilenstil aneinandergereiht werden. konsequent Paarreime verwendet (zum Beispiel: „Stadt an einem Herbstabend”, „Für die Kunst und das Leben“, „Sensation im Kino“ oder „Ballade über die Kellnerin Kocia“). In „De profundis" findet sich außerdem ein Haufenreim. der nicht weniger als sechs Verse umfasst:

.i traby gór zagraly latamic mórz zajaśniały koniki polne zaśpiewaly pomaranczowe wiatry wiaty ręce i nogi oniemiały doliny rozzieleniały" (1922c, 75) ,und es spielten die Trompeten der Berge auf

die Laternen der Meere begannen zu leuchten

die Heuschrecken begannen zu singen

die orangen Winde wehten

Hande und Fuße verstummten

die Taler wurden gran"

Der zweisilbige (weibliche) Reim am Ende der Verse bindet diese eng aneinander, im Gegensatz zu deren Inhalt. In „De profundis“ gibt es darüber hinaus Beispiele für einen

\footnotetext{
"Czyzewski aberwindet den Inhalt durch Zusammenstellungen von einfachen Satzen, die meistens aus der Welt der visuellen Eindricke stammen, und zwar auf die Art, dass der Zuhorer keine gedankliche Verbindung zwischen diesen Sătzen herstellen kann.“

"s In dem Chwistek gewidmeten Gedicht ..Erkenntnis” (..Poznanie”) schreibt Czyzewski: „Wszystko mozna zrozumieć // i wszystko skojarzyc" (..Alles kann man verstehen /" und alles mit einander in Verbindung bringen" -1920a. 56). Auf deutsch ist Erkenntnis abgedruckt in: Dedecius 1996-2000. V/303-304.
} 
identischen Reim, durch den ein ebenso enger Zusammenschluss der einzelnen Verszeilen erreicht wird:
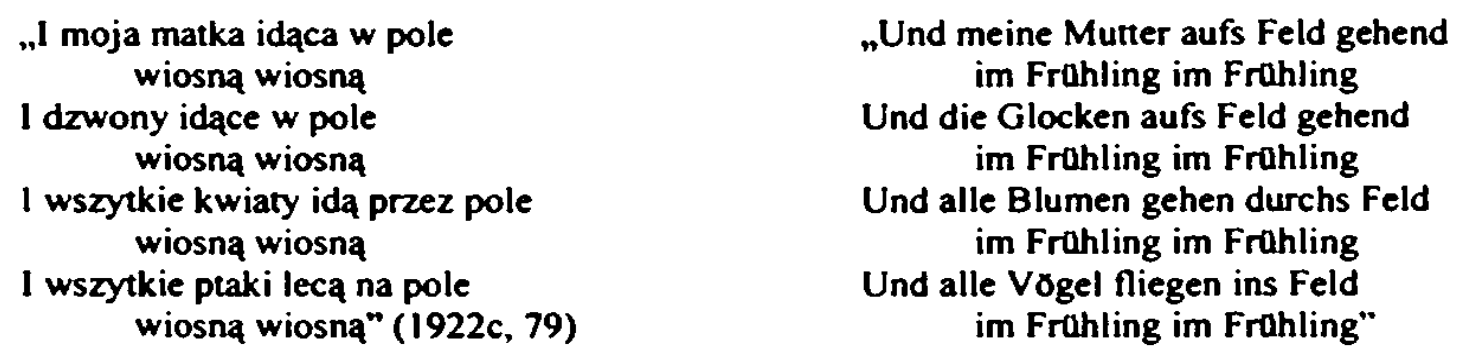

Unterstrichen wird die Kohärenz dieses Fragmentes noch durch die Anaphern sowie durch den parallelen syntaktischen Bau der vier längeren Verse. Darüber hinaus lässt sich im Falle des Subjektes des dritten und vierten längeren Verses eine Assonanz, wenn auch umgekehrt, beobachten: „kwiaty“ - „ptak $l^{*}$. Dennoch wird durch die unterschiedliche Länge der einzelnen Verse (10 bzw. 8 zu 4 Silben) der gleichmäßige Fluss innerhalb dieses Fragmentes unterbrochen, was zur Folge hat, dass die einzelnen Reime nicht in ihrer ganzen klanglichen Kraft erscheinen können.

Auch ein Fragment aus „Versenkung“ („Zapadnia“) zeigt, wie Czyzewski kleinere Einheiten eines Gedichtes über Reime organisiert:

.zapala sif ogien
płona gromnice
mgtawice swiece gromnice lice
rece źrenice
płomienie świece gromnice" (1922c, 100)

\author{
.das Feuer zindet sich an \\ Weihkerzen brennen \\ Nebelschleier Kerzen Weihkerzen Gesichter \\ Hande Pupillen \\ Flammen Kerzen Weihkerzen"
}

Am auffälligsten sind hier die zweisilbigen Reime. Die Endreime (..gromnice - lice* „źrenice“ - .gromnice“) werden dabei noch durch ebenfalls zweisilbige Binnenreime ${ }^{96}$ ergänzt: ..mglawice“, „gromnice“, wozu auch noch die einsilbigen Reime: „świece“ und „ręce“ gezählt werden könnte. Zum Teil handelt es sich dabei auch um identische Reime (.gromnice“ - ,gromnice“ - „gromnice“ und „swiece“ - ..swiece“). Somit ergibt sich eine komplexe Reim- und Klangstruktur: von den insgesamt 14 Wörtern der ersten fünf Zeilen des Zitates reimen sich neun. Allerdings finden sich die Vokale der beiden Reimsilben ,i“ und „e" auch in einigen der ungereimten Wörter wieder: „się" (nasaliert), „ogien”“ und „płomienie“" (zweimal). Zwei dieser Wörter (,płoną" - ..płomienie“) werden darüber hinaus durch eine figura etymologica miteinander verbunden.

\footnotetext{
"Vgl. zum Begriff des „Binnenreims“: Burdorf (1994, 34-35), der vorschlăgt diesen Begriff vereinfachend auf alle Arten von Reimen innerhalb eines Verses anzuwenden. um so eine aufwendige und dadurch verwirrende Terminologie (Schlagreim. Zasurreim. Mittelreim usw. - vgl. zu einer Typologie: Braak 1965, 105-107) zu vermeiden.
} 
Häufiger als regelmäßige, konsequent durchgehaltene Reimfolgen, findet sich in Czyżewskis Gedichten der ständige Wechsel zwischen ungereimten und gereimten Zeilen. Dies trifft selbstverständlich nur auf diejenigen Gedichte zu, in denen überhaupt Reimschemata erkannt werden können, da Czyżewski in sehr vielen Gedichten klangliche Strukturen anders herzustellen versucht, wovon gleich noch die Rede sein wird und zum Teil ganz auf Reime verzichtet. Als ein charakteristisches Beispiel für ein unregelmäßiges Reimschema kann jenes des Gedichtes „Katzenserenade“ angeführt werden, das sich folgendermaßen darstellen lässt:

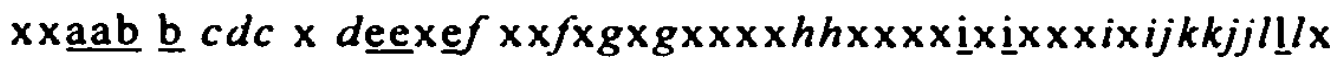

Von den insgesamt 51 Versen des Gedichtes sind 22 Waisen (mit „x" bezeichnet), 10 Verse sind einsilbig gereimt (im Schema: unterstrichen) und 19 Verse sind durch weiblichen Reim (kursiv) miteinander verbunden. Das Verhältnis zwischen ungereimten und gereimten Zeilen hält sich demnach ungefähr die Waage (22 zu 29). Außerdem fält auf, dass verschiedene Reimfolgen verwendet werden: Paarreime (ạ $\underline{b} \underline{b}$ usw.), (teilweise unterbrochene) Kreuzreime $(c d c \times d)$, umschließende Reime $(j k k j j)$. Haufenreime (eexe und vor allem $n h)$ bzw. unterbrochene Reime $(f \times x f \times g \times g$ oder $\underline{i x i}$ ). Es ist möglich, dieses, durch die relativ hohe Anzahl ungereimter Verse „geschwächte" Reimschema in Bezug zur metrischen Ordnung des Gedichtes zu setzen. bei der es sich um einen regelmäßigen tonischen Vers mit jeweils drei Betonungen handelt. Kulawik beschreibt in seiner „Poetik“ den Zusammenhang zwischen „schwachem Reim“ und tonischem Vers mit drei Betonungen (,tonik trzyzestrojowy“) als „typisch“ für dieses Metrum (vgl. 1997, 224).

Eine ăhnliche lockere Reimfolge findet sich bei Czyżewski auch in dem Gedicht „Melodie der Menge":

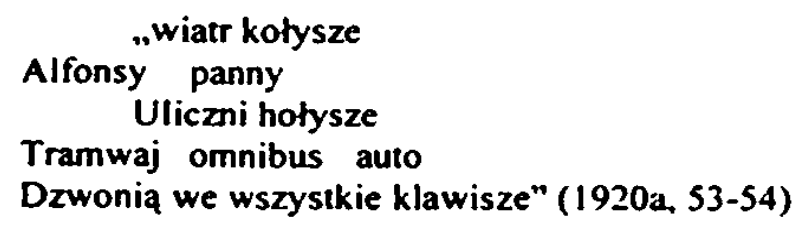

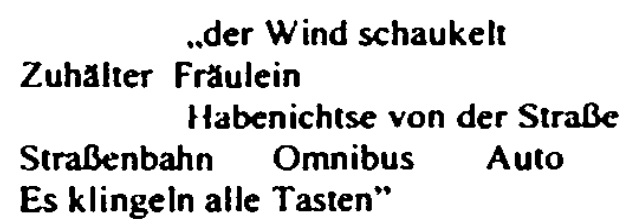

Hier ist zwischen die sich reimenden Zeilen stets eine ungereimte eingeschoben, der Reim selbst ist im ersten Fall drei-, im zweiten zweisilbig („kołysze“ - „holysze“ bzw. „klawisze“). Ein weiteres Fragment aus diesem Gedicht verdeutlicht. dass Czyżewski auch Reim und Assonanzen miteinander kombinier:

\author{
"Im Kaffeehaus \\ Grune Flote \\ Die Brust einer Frau \\ Altention
}




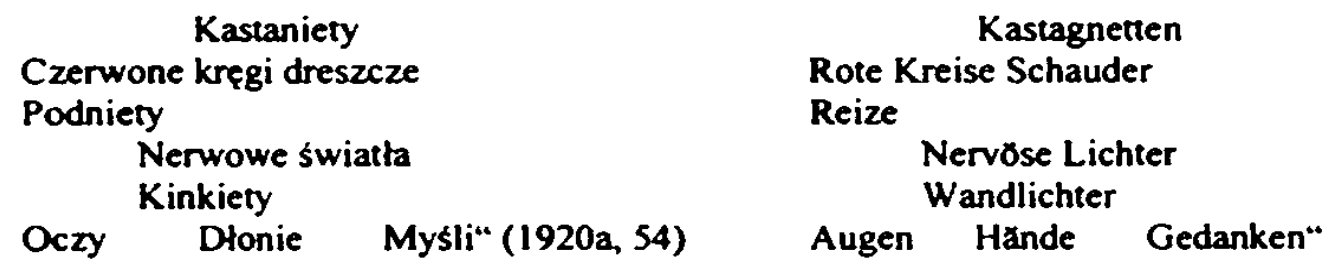

Die für den Haufenreim „kobiety“ - „kastaniety“ - „podniety“ - „kinkiety“ charakteristische Vokalverbindung ,ie“ in der jeweils betonten Silbe der einzelnen Ausdrücke, findet sich noch drei weitere Male (,zielony“, „piers“" und „dłonie“) und ist außerdem noch, in umgekehrter Reihenfolge und mit dem nasalierten "," - als "e-i" in "kręgi“ - ein weiteres Mal vorhanden. Zusătzlich zu den Reimen kommen die drei Reimvokale „e“, „i“ und „y“97 noch sieben- (,e“, .i“) bzw. viermal (,y“) vor, wodurch sich insgesamt eine in sich geschlossene Klangstruktur für dieses Fragment herauskristallisiert, die auch im Vergleich zum ersten zitierten Fragment aus „Melodie der Menge“ von ungleich höherer Dichte ist. Diese klangliche Kohärenz steht übrigens in Spannung zur im Gedicht thematisierten Form der großstädtischen Wahrnehmung, für die, wie beschrieben, wegen der Reizfülle, Auflösung und fragmentarische Eindrücke bestimmend sind.

Assonanzen und Konsonanzen sind in Czyżewskis Gedichten insgesamt häufig zu bemerken. In der Interpretation von „Halbschlaf" wurde auf die klangliche Organisation eines Teils des Gedichtes durch Konsonanzen hingewiesen. Ähnliche Strukturen finden sich, wie ebenfalls bereits erwähnt wurde, zum Beispiel auch in „Stadt an einem Herbstabend“, wo einzelne Teile des Gedichtes durch das Vorherrschen eines bestimmten Vokals in sich geschlossener erscheinen. wenngleich im Falle dieser beiden Gedichte festzustellen ist, dass die Klangstruktur die inhaltliche Aussage ergänzt bzw. deutlicher hervortreten lässt ${ }^{98}$. Die meisten Beispiele, die in diesem Abschnitt dargestellt wurden, zeigen aber, wie Czyżewski durch Klangstrukturen Kohärenzen schaff, wo dies in inhaltlicher Hinsicht, zum Beispiel durch die semantische Unvereinbarkeit der verwendeten Begriffe. nicht der Fall ist und dadurch die in der formistischen Poetik entwickelte Idee von der „Überwindung des Inhaltes durch die Form“ verwirklicht. Ein abschließend zitiertes Fragment aus „Elektrischie Visionen“, in dem mehrere Klangfiguren auftreten, soll dies noch einmal in charakteristischer Form verdeutlichen:

..Przeszła noc dzień codzień się zbliza

Pregowana pantera ryza

Elektryczne oczy strzaty świecace
„Die Nacht verging es năhert sich der Tag Alltag

Ein gestreifter rotblonder Panther

Elektrische Augen leuchtende Pfeile

\footnotetext{
97 Das ..y“" zahlt im Polnischen, unterschiedlich zum Deutschen, als Vokal.

"Auch der Beginn des vierten Teiles von „De profundis" könnte hier als Beispiel angefuhn werden - vgl. Czyzewski 1922c. 82-83.
} 
Szerokosć mózgu metro-dworzec ziemi

Czame petne energii dynamo pedzace Bez ognia koła gorace

Oa Oa Oa

\section{$\begin{array}{lll}\mathbf{R} & \mathbf{R} & \mathbf{R}\end{array}$}

Rece nagie wyciagam przed siebie

Rece moje lotne ptakoskrzydła

Widze góry rzeki macki polipa

Dotykam lasów gór dolin

Szukam chrzu święceń wyzwolin“" $(1920 a, 68)$
Die Breite des Gehirns Metrobahnhof der Erde

Ein schwarzer rasender Dynamo voll Energie Ohne Feuer heiße Răder

Oa Oa Oa

$\mathbf{R} \quad \mathbf{R}$

Bloße Hande strecke ich vor mich aus

Meine Flughande wie Vogelflugel

Ich sehe Berge Flusse Fangarme von Polypen

Ich berahre Walder Berge Taler

Ich suche Taufe Weihe Befreiung"

Als erstes fält der Endreim ins Auge. der sich durch folgendes Schema verdeutlichen lässt: „aabxbbx xxxxcc“. Es handelt sich demnach um drei Paarreime, von denen sich einer (,b“) noch ein drittes Mal, allerdings unterbrochen von einer Waise, reimt. Alle Reime sind zweisilbig. An einer Stelle wird der Endreim durch eine Assonanz ersetzt („ptakoskrzydła“ „polipa“), wobei der Gleichklang zwischen ..y“ und „i“ nicht ganz rein ist. Die auffalligste Assonanz des Fragmentes besteht allerdings in der Wiederholung der beiden Vokale „o" und „a" aus „ognia“, „koła“ und „gorące“ (nasaliert) in der folgenden Zeile: „oa oa oa“. Neben anderen, findet sich ein weiterer vokalischer Gleichklang in der drittletzten Zeile des Zitates: "widzę góry rzeki macki polipa“, wobei der dominierende Laut das „i“ ist, an einer Stelle durch das ähnlichlautende „y“ ersetzt. Als weitere Klangfiguren sind auch die Alliteration „pręgowana pantera“ sowie die Anapher ,ręce nagie... // ręce moje...“ zu nennen. In „dzień codzieñ" aus der ersten Zeile kann schließlich noch eine figura etymologica gesehen werden. Klangfiguren spielen in vielen von Czyżewskis formistischen Gedichten eine wichtige Rolle. gerade bei gleichzeitiger Zurückdrängung inhaltlicher Zusammenhänge. Die hier behandelten Fragmente, besonders jene aus „Melodie der Menge“ und das zuletzt angeführte aus "Elektrische Visionen" sollen dies als charakteristische Beispiele verdeutlichen".

Czyżewskis Umsetzung des formistischen Postulates von der „Überwindung des Inhaltes“, die er durch die "Autonomisierung" der verwendeten Wörter bzw. durch die Zusammenstellung semantisch scheinbar unvereinbarer Begriffe erreicht, fühn zu einer Auflösung der inhaltlichen Kohärenzen innerhalb des Gedichtes. Viele der in diesem Abschnitt besprochenen Textbeispiele zeigen jedoch, dass er alternative Zusammenhänge zum Beispiel über Klangstrukturen herzustellen sucht. In einigen dieser Fälle ist es daher möglich, in diesen Klangstrukturen das wichtigste Prinzip für den Aufbau. das heißt die Konstruktion des Gedichtes zu sehen. Reime. Assonanzen etc. sorgen gewissermaßen für die

Es ist, vor allem aus Platzgrunden, unmoglich, an dieser Stelle alle Gedichte Czyzewskis auf ihre Klangstrukturen hin zu beschreiben. Vor allem in eine Untersuchung miteinbezogen werden konnten noch die beiden Gedichte ..Transzendentales Panoptikum“ und ,Im Irrenhaus“" (..W szpitalu obłakanych"), in denen auch viele der in diesem Abschnitt dargesteliten Klangfiguren vorkommen. 
Geschlossenheit (bei fehlender inhaltlicher Kohärenz), sie verbinden die einzelnen Wörter oder Verse miteinander. Ein Beispiel dafür ist das zu Beginn dieses Abschnittes angeführte Zitat aus „De profundis“, in dem oft das letzte Wort eines Verses mit dem ersten des nächsten verbunden ist, wodurch ein nicht unterbrochener Textfluss vermittelt wird. In ähnlicher Weise bestimmen die zahlreichen Anaphern den Aufbau des Gedichtes „Versenkung“ (vgl. 1922c, 99-101). Hier sind die Zeilen 2 bis 13 durch gleiche Satzanfänge miteinander verbunden, in einem Fall (Zeile 12) als Inversion, ein Muster, das auch im späteren Verlauf des Gedichtes identisch noch einmal wiederholt wird (Zeilen 29-30). Neben weiteren Anaphern findet sich noch eine auffälige Korrespondenz zwischen zwei kleineren Einheiten des Gedichtes. von denen eine in diesem Abschnitt bereits beschrieben wurde. Es handelt sich dabei um ein Fragment, das durch seine komplexe Reimstruktur in sich geschlossen erscheint (Zeilen 3943). Auf dieses Fragment werden die letzten Zeilen des Gedichtes bezogen (Zeilen 51-54), in denen derselbe Reim, zum Teil mit denselben Wörtern (,żrenice“, „świece“, „gromnice“) bzw. durch neue Wörter („piwnice“, „ulice“, „lice“, „iglice“ - „Keller“, „Straßen“, "Gesichter", „Nadeln“) wieder aufgegriffen wird. Auf beide Fragmente folgen schließlich noch die zwei identischen Verse: „bezdeń bezdeń // bez dna“"100, wodurch die Beziehung zwischen diesen beiden Textelementen gleichermaßen gestärkt wird. Als letztes Beispiel für eine auf Klangstrukturen beruhende Komposition sei das Gedicht „Regiment. Eine poetische Armeeromanze“ (,Regiment. Wojskowy romans poetycki”) genannt (vgl. 1922c, 87). Hier sind es zahlreiche Parallelismen, Epiphern, Assonanzen (Konsonanzen) und Alliterationen. die kleinere Strukturen innerhalb des Gedichtes schaffen und auch einzelne, nicht unmittelbar aneinander grenzende Teile des Gedichtes, miteinander verbinden. Dadurch wird auch in diesem Fall eine, im Vergleich zum Inhalt, der durch Sprünge und überraschende Wendungen teilweise grotesk erscheint, stabile Kohärenz geschaffen, die das Gedicht in sich abgeschlossen erscheinen lässt.

In den theoretischen Texten der Formisten wird immer wieder die Bedeutung einer in sich geschlossenen Komposition, deren einzelne Teile miteinander in Beziehung stehen, für din ästhetischen Ausdruck eines Kunstwerkes hervorgehoben. Vor allem Witkacy sieht in dieser „Reinen Form“ die Voraussetzung dafü, dass das Kunstwerk beim Rezipienten die sogenannten "metaphysischen Gefühle" auslösen kann. Der Idee der Konstruktion ist auch Czyżewskis Gedicht „Die Puppe“ („Lalka“) gewidmet, das dadurch zugleich deren Bedeutung für den künstlerischen Schaffensprozess unterstreicht:

100 „bodenlos bodenlos // ohne Boden“. 
.(ANDRZEJOWI PRONASZCE)

LALKA

(telefon)

zbijam wnętrze $z$ desek

za pomoca śrub i gwoździ

maluje na szkarlatno i srebrno

umieszczam w śodku

dwa przewody telfonu aparaty

na wierzchu budowy

umieszczam glowę lalki

z ruchomymi oczami

ballo hallo

czy pani lalka dziś przyjmuje?

hallo hallo

jestem rozebrana

nieuczesana

hallo hallo

a zatem do widzenia

hallo hallo

mam $z$ pania do pomówienia

dzin dzin dzin dzin

lalo

lalo

LAL

DZIN“ (1922c, 116)

\section{,(FOR ANDRZEJ PRONASZKO)}

\section{DIE PUPPE}

(Telephon)

ich zimmere das Innere aus Brettern

mithilfe von Schrauben und Nageln

ich bemale es scharlachrot und silbern

mitten hinein platziere ich

zwei Telephonkabel

Apparate

an der Oberseite des Baus

platziere ich den Kopf einer Puppe

mit beweglichen Augen

hallo hallo

empfangen Sie heute, Frau Puppe?

hallo hallo

ich bin unbekleidet

unfrisiert

hallo hallo

also auf Wiedersehen

hallo hallo

ich habe mit Ihnen zu sprechen

ring ring ring ring

lalo lalo lalo

LAL

RING“"

In der ersten Hälfte des Gedichtes beschreibt das lyrische Ich die Anfertigung eines Kunstwerkes, wobei es sich wahrscheinlich, aufgrund der Kombination von Malerei (,maluję...") und der Verwendung von konkreten Gegenständen (,przewody telefonu“, "głowa lalki“) um eine Collage - vielleicht sogar um ein „vielebeniges Bild“ - handelt. Es ist möglich in diesem lyrischen Ich den Künstler Tytus Czyżewski zu sehen, da er sich und sein künstlerisches Schaffen ja in einigen Gedichten auch explizit nennt (,Mediumistischmagnetische Photographie des Dichters Bruno Jasieński“" „Transzendentales Panoptikum“; oder im programmatischen Text: „Tytus Czyżewski über das „Grüne Auge“ und seine Malerei (Selbstkritik -Selbstreklame)". Dass das Gedicht die Arbeit von Andrzej Pronaszko. dem es gewidmet ist, beschreibt, scheint, vor allem aufgrund der Einführung eines lyrischen Ichs, weniger wahrscheinlich ${ }^{101}$. Der beschriebene Schaffensakt beinhaltet recht konkrete Tätigkeiten, was im Einklang mit der avantgardistischen Vorstellung vom Künstler steht, der weniger einer (göttlichen) Inspiration folgt, sondern mehr einem Handwerker, der baut und konstruiert, entspricht. Auch dadurch wird noch einmal das Konstruieren eines Kunstwerkes. das als zentrales Thema dieses Gedichtes bestimmt wurde, hervorgehoben.

${ }^{101}$ Es gibt von Andrzej Pronaszko auch kein Kunstwerk, das mit dem Gedicht in einen engeren Zusammenhang gebracht werden konnte - vgl. Jakimowicz 1989. 61-62. 
Der zweite Teil von "Die Puppe“ besteht aus auf den ersten Blick belanglosen Gesprächsfetzen, die zum Beispiel aus einem Sekretariat oder einer Arztordination stammen können. Da es sich aber um ein Telefongespräch handelt und als ein Gesprächsteilnehmer wieder die Puppe aus dem ersten Teil des Gedichtes auftaucht, können diese Konversationsstücke auch insofem gedeutet werden, als dass damit die Beziehung der Einzelteile eines Kunstwerks zueinander zum Ausdruck gebracht werden soll. Die anfänglich scheinbar nicht zusammenpassenden Teile "Telephon“ und „Puppenkopf" werden durch das Telephongespräch bildlich miteinander verbunden. Dies kann als vergegenständlichte Entsprechung zu Czyżewskis überraschenden (begrifflichen) Assoziationen, von denen in diesem Abschnitt die Rede war, verstanden werden. Die nicht zusammenhängenden Gesprächsfetzen des zweiten Teiles können von sich aus, das heißt was ihren Inhalt betriff, keine Geschlossenheit herstellen, sie suggerieren im Gegenteil eher Offenheit bzw. Bruchstückhaftigkeit. Aus diesem Grund kann auch in diesem Gedicht parallel dazu eine klangliche Kohärenz bestimmt werden, die an die Laute „a“ und „"“ geknüpft ist. Es handelt sich dabei, wie unschwer zu erkennen ist, um die dominierenden Laute aus "lalka“, die darin je zweimal vorkommen, außerdem ist die „Puppe“ ja gewissermaßen auch die Hauptperson des ganzen Gedichtes, was nicht zuletzt der Titel verrät. Diese beiden Laute finden sich in dem achtmal vorkommenden "hallo“, wie auch in "lalo“ (dreimal) und in „LAL“. Die Verse. in denen diese Laute enthalten sind, sind relativ regelmäßig über den ganzen zweiten Teil des Gedichtes verteilt. Sie folgen nie direkt aufeinander, mit einer Ausnahme in der dritt- und vorletzten Zeile. Die zwischen diese Verse eingeschobenen Zeilen sind wieder durch Reime miteinander verbunden: „rozebrana“ - „nieuczesana“ bzw. „widzenia“ - „pomówienia”. Somit ergibt sich eine prägnante Klangstruktur, die nicht nur die innere Geschlossenheit des gesamten zweiten Teils des Gedichtes herstellt, sondern auch gewissermaßen „vor“ die inhaltliche Kohärenz tritt, die durch die bruchstückhafte Konversation mehr und mehr verloren zu gehen scheint.

Diese Tendenz, das heißt die immer stärker hervortretende Klangstruktur des Gedichtes, bci gleichzeitiger zunehmender inhaltlicher Zusammenhanglosigkeit, setzt sich bis zum Ende des Gedichtes fort, weshalb von einem offenen Ende gesprochen werden kann. Trotz der Ankündigung: „mam z panią do pomówienia“ besteht die darauffolgende Konversation nur mehr aus Laut- oder Klanggebilden: dem Läuten des Telephons .,dzin“ sowie .,trrr“, „lalo“, „lal“ bzw. noch einmal „dzin“. Czyżewski scheint somit jenen poetischen Ausdruck erreicht zu haben. von dem er in „Von der Romantik zum Zynismus“ bzw. in „Über die Entlogisierung der Poesie" schreibt. Schritt für Schritt wird die inhaltliche Struktur des 
Gedichtes aufgelöst, übrig bleiben am Ende „autonome Wörter", deren Suggestivkraft einzig ihrem Klang zu verdanken ist. „Die Puppe“ ist (vielleicht) deshalb bezeichnenderweise das letzte Gedicht aus „Nacht - Tag“.

Im nächsten Abschnitt, in dem die Beziehung zwischen Czyżewskis Dichtung und der bildenden Kunst untersucht wird, ist auch von einigen Gedichten die Rede, deren Bau weniger auf Klangfiguren. sondern vielmehr auf graphischen Elementen beruht. Dies ist gleichermaßen der Versuch. die Lyrik von ihrer inhaltlich deskriptiven Funktion zu befreien und neue, an der Form des poetischen Ausdrucks orientierte. Zusammenhänge zu schaffen. Auch dadurch realisient Czyzewski, ähnlich zu der in diesem Abschnitt beschriebenen Lockerung inhaltlicher Zusammenhänge durch „Autonomisierung“ der Worter, scheinbar unlogische Wortverbindungen oder durch die Aufnahme reiner suggestiv wirkender Klänge in die Dichtung, das zentrales Postulat der formistischen Poetik von der „Überwindung des Inhalts durch die Form ${ }^{102}$. Was somit entsteht, sind Gedichte mit einer in sich geschlossenen Komposition, die leben (sollen), wie ein „Organismus in der Natur” (Czyżewski 1927, 229).

\subsubsection{Literatur und Malerei im Schaffen Czyżewskis}

In der Sekundärliteratur zum Werk Czyzzewskis wird immer wieder auf die aus der Doppelbegabung des Künstlers resultierende wechselseitige Beeinflussung von Dichtung und bildender Kunst verwiesen. So werden Bilder und Gedichte Czyżewskis verglicher., in denen er dasselbe oder ein ähnliches Thema gestaltet, zum Beispiel sein ..Portrait Bruno Jasiennskis“ (,Portret Brunona Jasieńskiego“) mit dem Gedicht „Mediumistisch-magnetische Photographie des Dichters Bruno Jasieński“" ${ }^{103}$. Außerdem, und das ist für diese Arbeit vorrangig von Interesse, geht es um die Frage, welche Konsequenzen sich aus dem Beheimatetsein in zwei Kunstformen für Czyżewskis „poetische Methode“ ergeben, wie also Verfahren und Gestaltungsweisen der bildenden Kunst Czyżewskis Dichtung beeinflussen und welche Spuren sie dort hinterlassen. Zum einen fällt der Blick dabei auf visuelle Aspekte

102 Vgl. dazu auch: Baluch (1985, 72-75), wo die Autorin die „Überwindung des Inhalts“ und damit das Hervortreten der Form in Czyzewskis Poesie zum Teil ober verschiedene Arten der Wiederholung, die sich vielfach auf Klangfiguren stutzt, beschreibt.

${ }^{103}$ Besonders Pollakówna hat sich in mehreren Arbeiten mit der Doppelbegabung Czyzewskis befasst (vgl. zum Beispiel: 1963, 277-282 sowie: 1969). Vgl. dazu auch: Baluch 1985 sowie den Abschnitt ..Die Poesie als das ,Notizbuch des Malers'“ (..Poezja ,notatnikiem malarza"“) ihres Vorwortes zu: Czyzewski 1992, XXII-XXXIII. In der vorliegenden Arbeit wird der Vergleich zwischen Czyzewskis Bildern und seiner Poesie nicht weiter ausgefuhrt. Dies worde nicht nur den thematischen Rahmen dieser primär literaturwissenschaftlich konzipierten Arbeit. sondern auch die kunstwissenschaftlichen Kompetenzen des Verfassers bedeutend nherschreiten. 
in den Gedichten Czyżewskis, das heißt zum Beispiel auf deren graphische Gestaltung oder auf Farben, die die Bildlichkeit vieler Gedichte mitprägen. Zum anderen stellt sich die Frage, ob eine bestimmte, in der bildenden Kunst entwickelte Form der Wahrnehmung bzw. der künstlerischen Gestaltung dieser Wahmehmung, auch zur Grundlage des poetischen Ausdrucks werden kann. Hierbei geht es explizit um den Einfluss des Kubismus auf die Dichtung, also um Zerlegung des Dargestellten, damit verbunden um die Auflösung „gewohnter" Sinnzusammenhänge sowie um das Problem der simultanen Wiedergabe des zuvor Fragmentarisierten.

Die Rolle von Farben wurde bereits am Beispiel der Metaphorik in den Gedichten Czyżewskis ansatzweise beschrieben. Allgemein kommen Farben bei Czyżewski häufig vor und bestimmen zu einem großen Teil die Bildlichkeit vieler seiner Gedichte mit. Als ein charakteristisches Beispiel kann hier "Elektrische Visionen“ angeführt werden, in dem folgende Farben verwendet werden: wei $B$, gelb, orange, rot, blutrot, feuerrot, dämmerungsrot. rötlich-gelb, gold, grün, violett, blau. ocker, silber, silbergrau und schwarz. Dazu kommen farbähnliche visuelle Effekte, zum Beispiel Glanz oder Durchsichtigkeit (Kristalle, Eis, Diamanten. Brillanten etc.) oder Mehrfarbigkeit (Saphir). Zum Teil werden die Farben aber nicht explizit genannt, sondern zum Beispiel über Edelsteine oder Metalle zum Ausdruck gebracht.

Es ist jedoch charakteristisch für Czyżewski, dass sich in seinen Gedichten die optischen Farbeindrücke mit andern Sinnesempfindungen, vor allem mit Klängen, zu Synästhesien verbinden. Pollakówna versucht deren Rolle folgendermaßen zu erklären: „Ale najbardziej trafne jest chyba przypisywanie owych skojarzeń barw i dźwięków swoistości poetyckomalarskiej wyobraźni Czyżewskiego.“ $(1969,35)^{104}$. Neben dem Gedicht „Singende Häuser”, in dem eine Korrespondenz zwischen der Farbe der Häuser und den ihnen zugeordneten Tönen festgestellt wurde, sind es vor allem zwei Gedichte Czyzzewskis, die an dieser Stelle genannt werden müssen: "Tigeraugen" und das dem Mitformisten Jan Hrynkowski gewidmete Gedicht ..Der Tanz“. In beiden Gedichten wird das Ineinandergreifen visueller und akustischer Effekte besonders deutlich.

"Tigeraugen“ ist die Beschreibung einer Dschungelszenerie, die von der Spannung zwischen dem ruhenden. leise schleichenden und angstverbreitenden Tiger und der nervösen

104 „Aber am zutreffendsten ist es wahrscheinlich, jene Farb- und Klangassoziationen den Eigenheiten der poetisch-malerischen Vorstellungskraft Czyzewskis zuzuschreiben." Vgl. insgesamt: 33-35 sowie: Pollakówna $1963,251-252$. 
Dschungelatmosphäre lebt. Gerade letztere wird vom Geschrei der Affen und ?apageien sowie von grellen Farbeffekten charakterisiert:

"Czame pionowe linie
Źłta zieleń morze
Czi czi
Krzyk małpy
Niebieskie pręgi zieleni
Btękit zótć fiolet pal
Krzyk ptaka purpury
Na sinej tapie stapa hi hi
Olbrzymie zielone Cicho
Krwiste zielone oko to drugie
Małpy Czi-czi
Papugi hi hi“" $(1920 b, 12)^{105}$

.Schwarze senkrechte Linien Gelbes Grun Meer

Tschi tschi

Schrei eines Affen

Blaue Streifen des Grans

Himmelblau Gelb Violett Palmen Holke

Schrei des Purpur-Vogels

Auf blauer Pfote schreitet

Riesiges grunes

Blutig grü das zweite Auge

Affen Tschi-tschi

Papageien hi hi"
Rauschen de; Violetts

hi bi

Leise

Auge

Die starke optische Wirkung dieses Fragmentes wird besonders durch die Farbverbindungen, entweder durch die direkte Aufeinanderfolge von Farben („błękit żółć fiolet“) oder durch Kombinationen („krwisty zielone“), hergestellt. In dieses Farbenspiel mischt sich das Geschrei der Tiere. beide Eindrücke werden schließlich in den Synästhesien .,szum fioletu“ und „krzyk ptaka purpury“ zusammengefasst.

Eine ăhnliche Rolle spielen Farben und Klänge auch in „Der Tanz“. Doch im Unterschied zu "Tigeraugen“" wird in diesem Gedicht keine von Intensität durchdrungene Farb- und Gerăuschkulisse entworfen, die Darstellung beschränkt sich nur mehr auf fragmentarische Eindrücke:
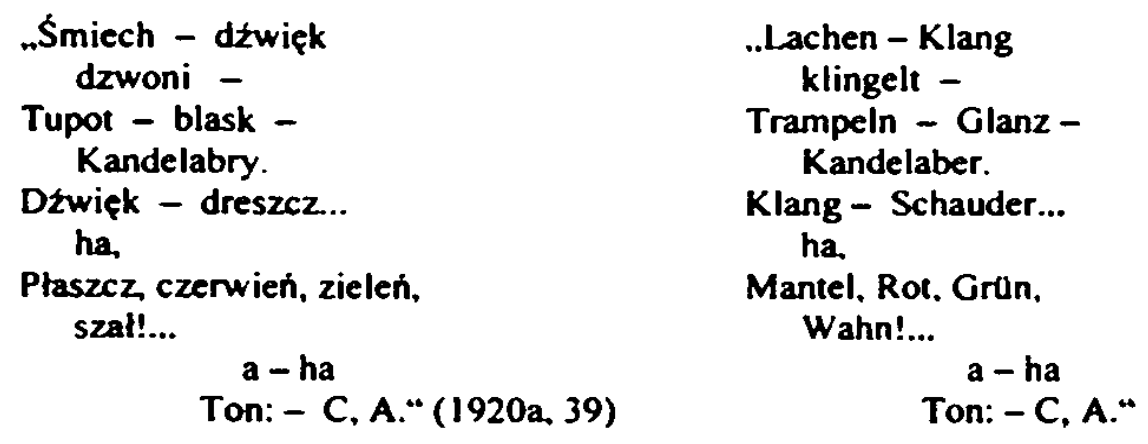

Das Gedicht scheint die Beschreibung eines, wenn auch nicht explizit genannten. lyrischen Ichs zu sein, das sich mitten im Tanzgeschehen befindet. Die daraus resultierende unablässige und schnelle Bewegung bewirkt den Fragmentcharakter ..seiner" Eindrücke, die vor allem auf akustischen („,́miech“, „dźwięk“, „dzwoni“, „tupot“) und visuell-farblichen (,blask“,

105 In der von Baluch herausgegebenen Ausgabe (Czyzewski 1992), die in der vorliegenden Arbeit ansonsten benutza wird, ist der Vers ..Na sinej lapie stapa...” mit .Na silnej lapie stapa...“ (..Auf starker Pfote schreitet...") offensichtlich unkorrekt angefuhrt. 
„kandelabry“, „czerwieñ “, „zieleñ“) Empfindungen basieren. In beiden Gedichten werden die synästhetischen Sinneseindrücke mit Emotionen in Verbindung gebracht. In "Tigeraugen“ verbreitet der ruhende Tiger, der einen Kontrast zum nervösen Dschungel darstellt. Angst („Držy małpie serce // Tajemnica puszcza krew” und „Strach drzemie“106 - 1920a, 35 und 36), in "Der Tanz" scheinen es die Fülle der Eindrücke und die Schnelligkeit der Wahmehmung zu sein, die Auslöser von „Schauder" und „Wahn" sind.

Die graphischen Elemente und ihre Rolle in Czyżewskis Gedichten hat Baluch bereits ausfuhrlich und treffend beschrieben (vgl. in: Czyżewski 1992. XLIII-XLVI). Sie sieht in vielen typographischen Gestaltungsverfahren (zum Beispiel: Fettdruck. Großbuchstaben. unterschiedliche Schriftgröße etc.) ein Mittel für die Intensivierung der Lektüre, da es sonst schwer sei, so Baluch, eine Begründung für den Einsatz dieser typographischen Variationen zu finden ${ }^{107}$. In anderen Fällen, so Baluch weiter, würden graphische Mittel auch die Eigenheiten des metrischen Baus vieler Gedichte hervorheben. Dies treffe insbesondere auf Gedichte zu, in denen Czyżewski den für ihn charakteristischen freien Vers verwende. In diesem Fall seien es die vergrößerten Abstände zwischen zwei Wörtern innerhalb eines Verses, die Verschiebung des letzten Wortes eines Verses an den Rand bzw. in die nächste Zeile oder der Einschub einer Leerzeile zwischen zwei Verse (manchmal auch ein „Vers” aus lauter Punkten), die die Autonomie des Verses - hinzufügen ließe sich: auch des einzelnen Wortes - stärkten. Dadurch würden bewusst traditionelle syntaktische und metrische Schemata aufgelöst. Dasselbe treffe auf Czyżewskis Gebrauch von Interpunktionszeichen zu, deren Funktion in vielen Gedichten der graphischer Zeichen nahe komme. Zusammenfassend stellt Baluch fest, dass die Verwendung graphischer Mittel in Czyżewskis Gedichten durchaus im Sinne der Formisten, als ..Sichtbarmachung der Form“ verstanden werden könne.

In der vorliegenden Arbeit wurde diese "Sichtbarmachung der Form" in den Gedichten Czyżewskis durch die Lockerung inhaltlicher Zusammenhänge beschrieben. Die Bemerkungen Baluchs zeigen, dass Czyżewski diese Lockerung auch über die graphische Gestaltung seiner Gedichte betreibt. Die in ihnen verwendeten graphischen Elemente „störeı““ gewissermaßen den harmonischen Textfluss, sie intensivieren nicht nur die Lektüre, sondern verleihen dem Gedicht auch ein nicht einheitliches optisches Erscheinungsbild, das sich dem Leser von selbst aufdrängt und ihn zwingt, das Gedicht nicht nur zu lesen, sondern auch zu

\footnotetext{
106 "Es zittert das Affenherz /i Das Geheimnis lăsst Blut“ - „die Angst nickert”.

107 "Als ein Beispiel kann auch hier das Gedicht „Elektrische Visionen“ aufgefuhn werden. Der Text weist dabei in typographischer Hinsicht nicht weniger als zwolf Varianten auf (Blockbuchstaben, verkleinerte bzw. vergroßente Schrift, Fettdruck, Kursivschrift usw.). Außerdem sind einzelne Worter quer zum ..normalen" Text
} 
betrachten. Dies ist gerade dann der Fall, wenn zum Beispiel einzelne, urmitelbar aufeinanderfolgende Wörter oder Verse in stark unterschiedlicher Schriftgröße gedr.uckt sind. Somit heben graphische Mittel die Form des Gedichtes nicht nur dadurch hervor, dass sie, wie Baluch zeigt, Wörter und Verse autonomisieren, sondern auch dadurch, dass sic das "traditionelle Erscheinungsbild" eines Gedichtes rein optisch verfremden und die Aufmerksamkeit des Rezipienten dadurch auf die Konstruktion des Gedichtes lenken. Beides geht Hand in Hand mit Czyżewskis Bemühungen, die in gewohnter Weise am Inhal:, das heißt an einem Thema und an dessen kohärenter Beschreibung, angelehnte Struktur des traditionellen Gedichtes aufzulösen ${ }^{108}$. Als entsprechende Beispiele können die Gedichte „Nacht - Tag“, „Hymne an die Maschine meines Körpers“ und „Der mechanische Garten“ genannt werden. Im Falle der beiden zuletzt genannten Gedichte verbindet Czyżeuski Jurch die graphische Gestaltung die Bereiche Natur und Technik miteinander. So erinnert die in „Hymne an die Maschine meines Körpers“ beschriebene „Körpermaschine“ zugleich an einen Torso mit zwei Lungenflügeln, wie an eine präzis konstruierte Maschine, deren Einzelteile für das Funktionieren des Ganzes sorgen. Der Garten von „Der mechanische Garten“ besteht aus lauter Quadraten und Kreisen, in die die Namen von Blumen eingeschrieben sind und die in drei Reihen angeordnet werden. Alle diese „Blumen“ sind darüber hinaus mit geraden Linien mit der Erde, einer horizontalen Linie, verbunden. Gerade das Beispiel dieses Gedichtes zeigt. wie die optisch-formale Gestaltung das Erscheinungsbild des Gedichtes prägt und somit die Aufmerksamkeit des Rezipienten zuerst auf sich lenkt, wiewohl dies nicht zwangsweise in eine völlige Destruktion inhaltlicher Zusammenhänge münden muss: auch der „mechanische Garten“ besteht immer noch aus verschiedenen Blumen, ebenso wie die „Körpermaschine“ aus Gedärmen, einem Herz, Adern oder einem Gehim. An dieser Stelle sei eine Bemerkung von Stanislaw Baczyński angeführt, der, ohne diese beiden Gedichte zu nennen, wohl auch an sie dachte, als er schrieb:

.Miasto, ruch, technika nie tylko jednak stwarzaja płaszczyz̨ dla ekspresji poetyckiej. W formiżmie n.p. staja się one czynnikiem mechaniki poetyckiej, dązności do układu słów na wzór technicznych

gedruckt und weitere graphische Elemente (Pfeile, weisende Hănde usw.) finden darin Verwendung. Es ist allerdings schwer, diese graphische Gestaltung mit der Interpretation des Gedichtes in Einklang zu bringen.

${ }^{100}$ Ein gutes Beispiel dafur ist das gezeichnete Fenster in .Flamme und Brunnen“ - vgl. das in 5.1.4 angefuhrte Zitat. Kritischer ist hierzu die Meinung Kazimierz Wykas: „Mechaniczne bowiem, epatujace, w niskim stopniu twórcze jest drugie nawarstwienie jego poezji: świadoma i zamierzona współczesnośc, wspótbrzmienie wyrazu poetyckiego z równoczesnym formizmem plastyki Czyzewskiego. Czyni to artysta na rózne sposoby: to zamiast powiedziec ,okno, po prostu w tekście wiersza okno rysuje [...]." (..Mechanisch hingegen, effekthascherisch und in geringem Maße kreativ ist die zweite Schicht seiner Poesie: die bewusste und beabsichtigte Modernitat, der Gleichklang des poetischen Ausdrucks mit dem Formismus in Czyzewskis bildender Kunst. Dies macht der Kunstler auf verschiedene Arten: anstatt ,Fenster' zu sagen, zeichnet er einfach im Text des Gedichtes ein Fenster [...]." - Wyka 1945/1949, 18). 
konstrukcyj, układu, w którym wyraz przestaje mieć jakkiekolwiek znaczenie, zachowując tylko swój ksztaht bez treści. [...] Próby formistów, niewatpliwie wynikajace z krancowych konsekwencyi ekspresjonizmu zawarty się w sferze abstrakcyjnej i słaby skutkiem tego mają zwiazek z procesem poetyckiej twórczosci." $(1924,42)^{109}$

Dieses Zitat zeigt, wie die Kritik am Formismus und an der formistischen Dichtung Czyzewskis, ausgehend von der falschen Annahme, den Formisten gehe es um die völlige Eliminierung des Inhaltes, häufig zu ungerechtfertigten Urteilen kommt. Auch Baczyński beschreibt in dieser Studie $(1924,16)$ über die neueste polnische Dichtung von 1924 die formistische Theorie, vor allem jene Chwisteks, als Versuch einer „Negation des Inhaltes“ („negacja treści“) und verteidigt, wie zum Beispiel Irzykowski, gewissermaßsen den ästhetischen Wert des Inhalts. Beide übersehen dabei, dass es Czyżewski, wie die Ausführungen in dieser Arbeit zeigen, um eine stärkere Hervorhebung der Form durch eine gewisse Dehierarchisierung des Inhaltes im Gedicht geht, so wie dies Chwistek in seinen theoretischen Schriften formuliert. Daher kann auch in den beiden zuletzt erwähnten Gedichten nicht davon die Rede sein, die Begriffe seien im Gedicht nur noch als graphische Zeichen ohne Bedeutung vorhanden, da es, wie gesagt, immer noch um Blumen bzw. Körperteile geht.

Die unmittelbarste Beziehung zwischen Czyżewskis Malerei und seiner Dichtung wird von vielen Autoren, die sich mit seinem Schaffen befasst haben, im Kubismus, vor allem in der besonderen Art der ,kubistischen Wahrnehmung“ gesehen. Der Kubismus war Czyżewski vor allem von seinen Paris-Aufenthalten her bekannt und ubte insgesamt einen bedeutenden Einfluss auf sein künstlerisches Schaffen aus, wenngleich in der Sekundärliteratur immer wieder die individuelle Art Czyżewskis in der Aneignung und Weiterentwicklung kubistischer Ideen betont wird (vgl. besonders: Pollakówna 1963, 32-37). Auch Czyżewskis Poesie wird häufig „,kubistisch“ genannt bzw. explizit in diesem Kontext beschrieben (vgl. zum Beispiel: Pollakówna 1969, $32-37$ und Baluch 1985, 69-70) ${ }^{110}$.

Als „kubistisch“ wird im Wesentlichen jene Poesie bezeichnet (vgl. Hutnikiewicz 1965, 60. Simonis 1967, 64-72, Baluch 1985, 69-70 sowie: Hopfinger 1993, 34-37), in der bewusst mit

109 ..Stadt. Bewegung. Technik bilden nicht nur eine Ebene fur den poetischen Ausdruck. Im Formismus z.B. werden sie zu einem Element der poetischen Mechanik, des Strebens. Worte nach dem Vorbild technischer Konstruktionen anzuordnen, wodurch das Wort jegliche Bedeutung verliert und nur seine Gestalt ohne Inhalt beibehălt. [...] Die Versuche der Formisten, die zweifellos aus den außersten Konsequenzen des Expressionismus resultieren, beschrănken sich auf die Sphăe des Abstrakten, weswegen sie wenig mit dem poetischen Schaffensprozess zu tun haben."

${ }^{110} \mathrm{Da}$ auch - ăhnlich wie dies bei den graphischen Mitteln der Fall war - die Beziehung zwischen Czyzewskis Lyrik und dem Kubismus in der erwănnten Sekundărliteratur ausfuhrlich beschrieben wurde, liegt der Schwerpunkt meiner Ausfuhrungen in erster Linie darauf, die wesentlichsten Aspekte dieser Arbeiten für die Beschreibung des Formistischen in Czyzewskis Poesie fruchtbar zu machen. 
Diskursivităt gebrochen wird. Diese Auflösung vor allem inhaltlicher Zusammenhänge fưhrt zu einer Fragmentarisierung und Zerstückelung der im Kunstwerk dargestellten Wirklichkeit, ebenso wie zu freien und überraschenden Assoziationen und, in kompositorischer Hinsicht, zum Aneinanderfügen sich voneinander stark unterscheidender, heterogener Einzelteile. Simonis beschreibt dieses künstlerische Verfahren so:

.Jenes kubistische Prinzip der Dissoziation und der Aufnahme der suggestivsten Aspekte eines Gegenstandes fuhrt zur Mißachtung der realen Dimensionen und zu einer gleichzeitigen Darbietung der verschiedenen Seiten eines Gegenstandes oder der verschiedenen Ideen, die der Phantasie des Kunstlers ein Gegenstand suggeriert, es fuhrt zum Simultaneismus und zur chaotischen Juxtaposition disparater Motive.“ (1967. 71)

Für den Rezjpienten bedeutet dies, dass er den zuvor zerstörten Zusammenhang zwischen den einzelnen Elementen, die im Kunstwerk, wie im Zitat angedeutet, simultan dargestellt werden, wieder rekonstruieren muss, um das Kunstwerk in seiner Totalität erfassen zu können.

Das Musterbeispiel dafür, wie die kubistische Wahmehmung zur Grundlage der poetischen Gestaltung bei Czyżewski werden kann. ist das Gedicht „Das gesehene Gesicht“, das mehrfach in diesem Kontext untersucht wurde (vgl. Pollakówna 1972, 110-111, Zaworska 1975, 344 sowie: Baluch. in: Czyżewski 1992, XXVII-XXXII). Gerade Pollakówna betont dabei die Gemeinsamkeiten zwischen bildender Kunst und Poesie, indem sie das Gedicht mit Czyżewskis Bild „Im Kaffeehaus“ („W kawiarni“), das auch unter dem Titel „Komposition“ (,Kompozycja“) bekannt ist, vergleicht und vor allem auf die Ähnlichkeit der Art der künstlerischen Gestaltung hinweist:

..Otóz wbrew praktyce kubistów konstruujacych przedmiot z elementów geometrycznych wedlug znanego wyrazenia Juana Grisa,$Z$ walca robię butelke', Czyzewski postępuje tak. jakby cią obraz na kawalki i po eliminacji pariii mniej istomych dokonywal kompozycji - kwintesencji pienwotnej wizji. Jest to metoda wlasciwie poetycka: dazenie do kondensacji i największej spoistości [...]. Te sama metode stosowal Czyzewski w wierszach. Jeden spośrod nich, Twar: widziana, zdradza treściowe i formalne podobienstwo do omawianej kompozycji." (1972, 110$)^{\prime \prime \prime}$

Diese Methode scheint die Wahrnehmung der Frau (durch das lyrische Ich) und deren Darstellung im Gedicht zu erklären: In der Art fragmentarisierter Eindrücke fällt der Blick auf einzelne Körperteile der Frau („biała ręka“, „oczy“, „biały zęby“ usw. - „eine weiße Hand”, „Augen“, „weiße Zähne“ usw. - Czyżewski 1920a. 58-59), die vor allem syntaktisch (kurze

\footnotetext{
'I' „Entgegen der kubistischen Praxis. einen Gegenstand aus geometrischen Elementen zu konstruieren - nach dem bekannten Satz von Juan Gris ,Aus einer Walze mache ich eine Flasche', verfahr Czyzewski so, als ob er das Bild in Stacke schneiden worde und nachdem er die weniger wichtigen Teile eliminiert hat. die Komposition vollendet - als Quintessenz seiner ursprunglichen Vision. Das ist eigentlich eine poetische Methode: nămlich das Streben nach Dichtheit und groBtmoglicher Geschlossenheit [...]. Dieselbe Methode wandte Czyzewski in seinen Gedichten an. Eines von ihnen. Das gesehene Gesicht, weist inhaltliche und formale Ähnlichkeit mit der besprochenen Komposition auf."
} 
Sătze. Ellipsen, einzelne Wörter) suggerierte Gleichzeitigkeit des Geschehens, lässt eine "Gesamtansicht" der Frau entstehen, die, wie es Pollakówna nennt, „Quintessenz der ursprünglichen Vision" "112.

Die ausführlichste Besprechung dieses Gedichtes im Kontext des Kubismus stammt von Alicja Baluch, die auch versucht, die Ansätze aus den anderen Interpretationen aufzugreifen und weiterzuentwickeln (in: Czyżewski 1992, XXX-XXXI). So geht sie dabei vor allem von der von Jan Józef Lipski beschriebenen filmischen Gestaltungsweise bei Czyżewski aus, die sie mit der kubistischen Wahrnehmung verbindet. Baluch bringt dabei die unterschiedlichen Eindrücke des lyrischen Ichs mit einem Wechsel der Perspektive, aus der heraus die Betrachtung erfolgt, in Verbindung, was an eine Kamerafahrt oder an eine subjektive Kameraführung erinnert. Am Ende zeigt sie, was Pollakówna im zuvor angeführten Zitat anspricht: die Zusammenfassung der Eindrücke in ein (kondensiertes) Bild. Dadurch erklärt sie den Vers: „widzę twarze dwie i pól“ (Czyżewski 1920a, 58) ${ }^{113}$, in dem sie die drei unterschiedlichen Ansichten vom Gesicht der Frau, die das lyrische Ich während seiner Betrachtung gewinnt. synthetisiert sieht.

Somit kann auch die Übertragung kubistischer Gestaltungsprinzipien in die Poesie mit Czyżewskis Streben nach Auflösung tradierter, vor allem inhaltlicher Strukturen und damit einhergehender „Autonomisierung“ von Wörtern und Versen in Einklang gebracht werden. Viele der hier angesprochenen Charakteristika „kubistischer Poesie“ wurden darüber hinaus bereits bei Czyżewski beschrieben: Wortkombinationen. die auf entfernten Assoziationen aufbauen oder die Juxtaposition unterschiedlicher Ereignisse in vielen Gedichten mit Zeilenstil. Die Frage, die sich an dieser Stelle jedoch abschließend stellt ist. ob Czyżewski auch in denjenigen Gedichten, die wie „Das gesehene Gesicht” auf einer kubistischen

\footnotetext{
112 Vgl. zu Czyzewskis Adaption der kubistischen Idee der Simultaneitat, die er unterschiedlich zum franzosischen Kubismus in erster Linie zeitlich und nicht räumlich versteht: Pollakówna 1969, 32 und Stopczyk 1984, 13. Am Beispiel dieser von Czyzewski in Anlehnung an den Kubismus entwickelten Art der poetischen Darstellung wird einer ihrer Kunstgriffe deutlich, dessen Wirkung zum Beispiel Lessing in der Literatur der Antike, deren Ausdrucksmittel er mit denen der Malerei ihrer Zeit vergleicht, noch vermisst: ..Nochmals also: ich spreche nicht der Rede aberhaupt das Vermogen ab, ein korperliches Ganze nach seinen Teilen zu schildern; sie kann es [...; durch sukzessive Aufzăhlung und Beschreibung dieser Teile; M.E.]: sondern ich spreche es der Rede als dem Mittel der Poesie ab, weil dergleichen wortichen Schilderungen der Korper das Tauschende gebricht, worauf die Poesie vornehmlich gehet; und dieses Tauschende, sage ich, muß ihnen darum gebrechen. weil das Koexistierende des Korpers mit dem Konsekutiven der Rede dabei in Kollision kommt, und indem jenes in dieses aufgelost wird, uns die Zergliederung des Ganzen in seine Teile zwar erleichten, aber die endliche Wiederzusammensetzung dieser Teile in das Ganze ungemein schwer, und nicht selten unmoglich macht." (1766, 100). Der erwahnte Kunstgriff Czyzewskis beruht auf der simultanen Darstellung der Einzelansichten (basierend auf dem Bruch mit der "naturlichen” Textsukzession) sowie auf dem daraus resultierenden Streben. einen synthetisierten Gesamteindruck $\mathrm{zu}$ geben. was letztendlich die von Lessing bemangelte fehlende ..Wiederzusammensetzung“ durch den Rezipienten ermoglicht, ohne dass dabei das "Tauschende", das heißt wohl die Kraft eines in sich geschlossenen poetischen Bildes, verloren ginge.

iiz "Ich sehe zweieinhalb Gesichter!"
} 
Wahmehmung und Darstellung beruhen, neue Kohärenzen innerhalb des Gedichtes herstellt. Dies scheint auch in „Das gesehene Gesicht“, um bei diesem Beispiel zu bleiben, vor allem in klanglicher Hinsicht der Fall zu sein. Die viermalige Wiederholung von "naprzeciw" (,gegenüber“), das gewissermaßen das räumliche Verhältnis zwischen dem lyrischen Ich und dem Objekt seiner Betrachtung definiert, strukturiert das Gedicht ebenso, wie die Wiederholung der Zeile „To ona“ bzw. „To nie ona“ (ebenfalls viermal - Czyżewski 1920a, 58-59) ${ }^{114}$. Dadurch bilden sich, bezogen auf die dargestellte Wahmehmung des lyrischen Ichs, innerhalb des Gedichtes kleinere Einheiten heraus, die durch die erwähnten Wiederholungen miteinander verbunden werden und somit die Geschlossenheit der Komposition des Gedichtes herstellen.

\subsubsection{Zusammenfassung: Ist Czyżewskis Lyrik „formistisch“?}

In der Sekundärliteratur zu Czyżewski, zum Formismus, aber auch allgemein zur Problematik der polnischen Avantgarde der Zwischenkriegszeit, taucht immer wieder die Frage auf, ob im Falle Czyżewskis von der Existenz einer „formistischen Lyrik“ gesprochen werden kann.

Zögernd ăußert sich zu dieser Frage zum Beispiel Pollakówna, die vielmehr versucht, Czyżewskis Poesie in den Futurismus zu integrieren: „Zasadniczo poezja Czyżewskiego lat 1917-1923 mieści się calkowicie w formule futurystycznej." $(1963,279)^{115}$. Wenngleich es in poetischer Hinsicht zweifelsfrei zahlreiche Berühungspunkte zwischen Czyżewski und dem Futurismus gibt, scheint Pollakównas Einschätzung doch zu sehr verallgemeinernd, nicht zuletzt, da Czyzewski in einigen Fällen der futuristischen Ästhetik kritisch bzw. ablehnend gegenübersteht, wie im nächsten Abschnitt gezeigt wird.

Für Hutnikiewicz resultiert die Schwierigkeit, von "formistischer Poesie“ zu sprechen, in erster Linie daraus, dass die vor allem von Chwistek formulierte Theorie des Formismus poetisch nicht realisierbar sei (vgl. 1965, 174-179). Dies begründet er damit, dass im Falle eines literarischen Werkes die Ebene der Bedeutung nie ganz ausgeschlossen werden könne. es also unmöglich sei, dieses auf rein formale, das heißt rhythmische und stilistische Qualităten zu reduzieren. Die Einschätzung Hutnikiewicz` scheint insofern unzutreffend, da es Chwistek und den Formisten, wie gezeigt, nicht um eine völlige Eliminierung des gegenständlichen Inhaltes in bildender Kunst und Literatur ging, sondern vielmehr um dessen

114 "Das ist sie" - .Das ist sie nicht".

11s "Im Prinzip entspricht Czyzewskis Poesie aus den Jahren 1917 - 1923 găzlich der futuristischen Formel.“ 
Dehierarchisierung in Bezug auf den ästhetischen Wert eines Kunstwerks, das heißt um dessen Unterordnung unter die Form. In einem Text von 1935 geht Chwistek übrigens auf diese Art von Vorwürfen seiner Theorie gegenüber ein: „Stosunek ten [=stosunek sztuki do rzeczywistości; M.E.] ująlem w formulę: przezwyciężenie treści przez formę, Formula ta była wielokrotnie błędnie interpretowana w sensie unicestwienia treści." $(1935,5)^{116}$.

Lipski äußert sich vorsichtig positiv zur Frage, ob Czyżewskis Lyrik als "formistisch“ bezeichnet werden kann (vgl. 1993, 13), betont aber vor allem die Schwierigkeit, eine klare Unterscheidung zwischen Formismus, Futurismus und Expressionismus zu treffen, gerade auch aus der Perspektive der Epoche heraus. Lipski nennt jedoch mit dem Verständnis der „Form“, die er in die aristotelische Tradition stellt, ein charakteristisches Merkmal, das dem ästhetischen Denken der Formisten. von denen er Witkacy, Chwistek und Czyżewski namentlich anfürt, gemeinsam sei: „Form“ als die Materie gestaltende Energie. Lipski überträgt seinen Gedanken nicht explizit auf Czyżewskis Lyrik, dennoch ist es möglich, gerade Czyżewskis Bemühungen, die Form seiner poetischen Aussage zu stärken, in diesem Sinne zu verstehen. In gleicher Weise scheint Lipskis Bemerkung auf die vom Künstler hergestellten neuen Beziehungen (vgl. das Gedicht „Die Puppe“) zwischen den einzelnen Teilen eines Kunstwerks anzuspielen, die dieser nicht zuletzt durch unerwartete Zusammenfügungen von Wörtern oder von Versen erreicht.

Zaworska, die als erste das "Formistische" in der Poesie Czyżewskis zu definieren versuchte (vgl. 1975, besonders: 340 und 344-345), sieht ein charakteristisches Merkmal dieser Poetik etwa im arbiträren Zusammenführen unterschiedlicher Wirklichkeitsfragmente in einem Gedicht. Viele Gedichte Czyżewskis weisen, so Zaworska, einen vielebenigen Bau auf, in dem sich diese Fragmente gegenseitig durchdringen. Als Beispiel nennt sie „Das gesehene Gesicht", in dem sich die innere (die Gedanken des lyrischen Ichs) und die äußere Wirklichkeit (seine Betrachtungen) miteinander vermischen, ebenso wie Czyżewski in anderen Gedichten Traum und Wachzustand (,Halbschlaf“) oder Phantastik und Alltägliches unmittelbar zusammenstellt. Die wichtigsten Prinzipien der poetischen Darstellung seien dabei das Verwerfen der Diskursivität zugunsten einer Lyrik freier Assoziationen und lose zusammenhängender Bilder, ebenso wie die Simultaneität, durch die Czyżewski, vor allem in den Großstadigedichten, versuche, die ganze Dynamik des moderenen Lebens festzuhalten. Schließlich beschreibt Zaworska eine gewisse präsurrealistische Tendenz in Czyżewskis

116 „Dieses Verhaltnis [=Kunst - Wirklichkeit; M.E.] fasste ich in die Formel: die Überwindung des Inhalts durch die Form. Diese Formel wurde oftmals falsch interpretien, im Sinne einer Vernichtung des Inhalts." Vgl. 
Gedichten, eine bewusste „Verfremdung“ der Alltäglichkeit, die zum Beispiel in unewarteten Bildkombinationen, freien Assoziationen und Gedankensprüngen zum Ausdruck komme. Die Anordnung dieser Bilder im Rahmen eines Gedichtes erfolge dabei, so Zaworska, durch ein vom Künstler festgelegtes Prinzip. Dieser Gedanke findet sich in vielen theoretischen Texten der Formisten, die gerade in der Konstruktion des Kunstwerks, das heißt in dessen formaler Gestaltung, das eigentlich Schöpferische der künstlerischen Arbeit erblicken.

Die Vorstellung von der vom Künstler konzipierten „Form“, die das Erscheinungsbild des Kunstwerks entscheidender zu prägen vermag, als die darin dargestellte außerkünstlerische Wirklichkeit, findet sich auch bei Baluchs Bestimmung, was „formistische Dichtung" sei (vgl. 1985, besonders: 75-78 und in: Czyżewski 1992, XLVIII-LVIII). Baluch bestimmt drei Schichten des formistischen Kunstwerks: erstens, das „Sichtbarmachen der Herrschaft des Künstlers über die Materie“ (,uwidocznieniu władzy artysty nad materia“), zweitens die Dynamisierung der zerteilten, zerstückelten und neu (gemäß der Idee des Künstlers) angeordneten Materie durch die zum Beispiel dem Film ähnliche Illusion der Bewegung und drittens den rituellen Charakter formistischer Kunstwerke. worunter die Suggestivkraft von Czyżewskis Poesie sowie deren Hinwendung zu Transrationalem und Übersinnlichem subsumiert werden könnten.

Gerade die beiden ersten von Baluch bestimmten Punkte verweisen noch einmal auf den Gedanken von Lipski zurück: Czyżewski löst in seinen Gedichten, wie auch in dieser Arbeit mehrfach beschrieben, bewusst Strukturen auf, die sich am dargestellten Objekt orientieren (zum Beispiel eine inhaltlich logische Beschreibung eines bestimmten Gegenstandes) und etabliert an ihrer Stelle solche, die sich auf die Form stützen. Das entspricht dem formistischen Verständnis von „Form" insofern, als dass sich in ihr die schöpferische Arbeit des Künstlers manifestiert. „Form“ ist das bewusst vom Künstler verwendete Verfahren, um die poetische Beschreibung zu gestalten und dadurch das Kunstwerk zu organisieren. also zu konstruieren. Bei Czyżewski geschieht dies, wie in der vorliegenden Arbeit gezeigt, durch Klangstrukturen (Wiederholungen, Reime, Assonanzen etc.), durch die Einfuhrung graphischer Elemente, insgesamt also durch die Herstellung neuer, nicht-inhaltlicher Beziehungen zwischen den einzelnen Teilen eines Kunstwerks. Dies entspricht dem zweiten Punkt von Baluch, die diese neuartige Verweis- und Beziehungsstruktur in Czyżewskis Gedichten als Bewegung der durch vorherige Auflösung und Zerstückelung leblos 
erscheinenden Materie begreift (vgl. Baluch 1985, 75 sowie: in: Czyżewski 1992, LVLVI) ${ }^{117}$.

Somit kann, die in der vorliegenden Arbeit gewonnen Erkenntnisse zusammenfassend, das "Formistische“ in Czyzzewskis Lyrik wie folgt bestimmt werden: Es ist vor allem die bewusste Auflösung logischer Bedeutungsstrukturen im Gedicht, jedoch nicht die völlige Destruktion begrifflichen Inhalts. Dies geschieht durch die „Autonomisierung“ von Wörtern und Versen sowie durch die überraschende Zusammenstellung von Begriffen, zum Beispiel in Metaphem oder Vergleichen. Mit all dem geht bei Czyżewski der Versuch einher, neue Kohärenzen im Gedicht zu schaffen, die sich, wie gezeigt, auf formale Qualitäten stützen. Darin spiegelt sich die formistische Auffassung von der Form als Produkt, Ausdruck und Wesen künstlerischen Schaffens wider und es scheint, dass dadurch auch für das formistische Postulat von der "Überwindung des Inhaltes durch die Form" eine poetische Entsprechung gefunden wurde.

In literaturhistorischer und poetologischer Hinsicht ist Czyzewskis Poesie sicher nicht exakt von parallelen Strömungen der Avantgarde abgrenzbar, wovon im folgenden Abschnitt noch die Rede ist. Sie weist Berührungspunkte nicht nur mit dem Futurismus, sondern auch mit dem Expressionismus, dem Dadaismus, der kubistischen Poesie Apollinaires und sogar mit dem erst nach dem Formismus entstandenen Surrealismus auf. Dennoch kann im „Formistischen” eine Charakteristik von Czyzewskis Poesie gesehen werden, die diese von den erwähnten Strömungen unterscheidet.

Abschließend sei eine Bemerkung von Kazimierz Wyka zitiert, in der noch eine weitere Eigenheit von Czyżewski und seiner ,formistischen Lyrik“ zur Sprache gebracht wird:

.Jego [=Czyzewskiego; M.E.] miejsce w nowatorskiej problematyce poetyckiej dwudziestolecia jest donioslejsze. anizeli się przypuszczało. Nalezal do inicjatorów, chociaz nie odegral roli przełomowej." $(1945 / 1949,22)^{118}$

Und Czyżewski selbst schreibt einmal rückblickend auf seine Poesie der frühen zwanziger Jahre: „Czy stworzyłem szkołę, czy stworzyłem styl, to zobaczy kto inny, jeśli będzie mógł lub chciał koniecznie." (1923b, 398) ${ }^{119}$. Der poetische Formismus hat mit Czyżewski erst

\footnotetext{
117 Vgl. dazu auch den Aufsatz Kryszaks uber Czyzewski (1981). Kryszak beschreibt darin die Auflosung etablierter Strukturen als zentral fur Czyzewskis formistische Dichtungen, begreift dies allerdings, in Anlehnung an den literarischen Katastrophismus, vor allem als poetischen Ausdruck fur die Dynamik des Zerfalls der Welt.

112 ..Sein [=Czyzewskis; M.E.] Platz in der innovatorischen poetischen Problematik der Zwischenkriegszeit ist wichtiger, als man annahm. Er gehorte zu den Initiatoren, obwohl er keine revolutionare Rolle spielie."

119 "Ob ich eine Schule oder einen Stil schuf, das wird ein anderer sehen. wenn er kann oder unbedingt will."
} 
einen Anfang gefunden, der Impulse gab und ein Fundament legte. Die Fortsetzung fand jedoch schon unter anderen Bezeichnungen statt ${ }^{120}$.

\subsection{Czyżewski und die europäische Avantgarde}

Die zahlreichen Berührungspunkte zwischen Czyżewski und anderen avantgardistischliterarischen Strömungen, die zum Teil während der Interpretation seiner formistischen Gedichte angesprochen wurden, verweisen auf den europäischen Kontext, in den diese eingeordnet werden können. Czyžewski verarbeitet in seiner Lyrik die verschiedenen Impulse der Futuristen. Expressionisten oder Apollinaires und fügt sie in seine eigene poetische Verfahrensweise ein. Im folgenden Überblick geht es daher weniger um das Aufzeigen von Einflüssen, sondern mehr um eine systematisierende Darstellung von Parallelen zwischen der Dichtung Czyżewskis und der europäischen Avantgarde.

\section{Czyżewski und Whitman}

Der amerikanische Dichter Walt Whitman übte durch seine 1855 zum ersten Mal veröffentlichte Gedichtsammlung „Leaves of grass“ einen großen Einfluss auf die gesamte europäische Avantgarde aus. Er thematisiert in den Gedichten dieser Sammlung die Lebensfreude eines im Diesseits verwurzelten Menschen und verbindet sogenannte erhabene und altägliche Themen miteinander. Er verzichtet größtenteils auf Reim und Metrum. wodurch er den treien Vers ansatzweise vorwegnimmt und verknüpft die einzelnen Verse vor allem klanglich miteinander ${ }^{121}$. Auch Czyżewski sieht in Whitman einen der einflussreichsten Vorgänger der modernen Poesie und streicht besonders die „biblische Einfachheit“ (..prostota biblijna“), die "neue und ehrliche Form“ (,forma nowa i szczera“), das „hohe Pathos“ („wysoki patos") sowie die „unerwarteten und plötzlichen Wendungen“ (.zwroty

\footnotetext{
${ }^{120}$ Ein moglicher Ansatzpunkt fur eine weitere Untersuchung der Frage. ob es neben Czyzewski noch andere formistische Lyriker gibt, wăre, jene in ..Formiści“ abgedruckten Gedichte zu analysieren. die von Autoren verfasst wurden, die nicht mit anderen A vantgarde-Gruppen verbunden sind, wenngleich dies im Umkehrschluss nicht automatisch ihre Verbundenheit mit dem Formismus bzw. mit der formistischen Poetik bedeutet. Dazu zahlen insbesondere die drei Gedichte, die mit .Jerzy Tom“ unterzeichnet sind (.Formisci“ [1], 14-15 und [2],7). die jedoch, wie erwăhnt, wohl von Chwisteks Schwester Emilianna verfasst wurden, wie auch die beiden Gedichte von Jan Hrynkowski (im Katalog zur 3. Krakauer Ausstellung der Formisten vom September 1919 bzw. in: „Formiści“ [4], 14).

$121 \mathrm{Vgl}$. zur Bedeutung Whitmans for die europarische Avantgarde: Drews 1983, 138-140.
} 
nieoczekiwane i nagle“) in dessen Gedichten hervor (1919c, 80). Czyżewski konnte diese wăhrend seines ersten Parisaufenthalt 1908/1909 kennen gelernt haben, da zu dieser Zeit deren franzősische Übersetzung erschien (vgl. Morawski 1961, 152). Whitman wurde aber auch in Polen selbst nach 1910 rezipiert (vgl. Prokop 1970, 29-31 bzw. 34-37 sowie: Drews 1983, 145-147), die größte Bedeutung sollte er in den zwanziger Jahren für den Warschauer "Skamander" haben. So sieht zum Beispiel der erste Autor futuristischer Gedichte in Polen, Jerzy Jankowski, in Whitmans Werk die Möglichkeit einer „Annäherung" der Literatur an die „Wirklichkeit“ („zbliženie do rzeczywistości“) und des „Verlassens des Elfenbeinturms“ („opuszczenie wieżyczka z kości słoniowej“), der fälschlicherweise - und dies scheint an die Adresse der polnischen Moderne des „Jungen Polens“ gerichtet - für das „Asyl des reinen Künstlertums“ (,asylum czystego artyzmu“) gehalten werde (zit.n.: Podraza-Kwiatkowska 1973, LXXIX). Für Czyżewski ist Whitman sicher insofern von Bedeutung, als dass er in dessen Lyrik die Hinwendung des Dichters zu seiner unmittelbaren Umwelt, was im Falle des Formisten das zwanzigste Jahrhundert mit all seinen neuen Erscheinungen bedeutet. erblickt. Was die poetische Darstellung betriff, so zeigt Whitman zum ersten Mal die freie Anordnung unterschiedlicher Ereignisse, von Momentaufnahmen, die nur mehr durch die Assoziationsgabe des Dichters miteinander verbunden sind (vgl. Allen/Davis 1971, 221-224).

Darin sieht wohl nicht nur Czyżewski, sondern - wie Ważyk schreibt $(1974,330)$ - auch Apollinaire, eine Frühform der simultanen Darstellung, die beide Dichter, unter dem Einfluss des Kubismus, später in ihrer Lyrik entwickeln.

\section{Czyzewski und Apollinaire}

Czyżewski lemte Apollinaire und dessen Texte während seiner Paris-Aufenthalte vor dem Ersten Weltkrieg kennen, er selbst bemerkt, dass dies bereits 1908-1909 geschah (vgl. Śpiewak 1939,6$)^{122}$. In Polen war Apollinaire vor 1914 vor allem als Theoretiker des Kubismus bekannt, seine Lyrik wurde erst nach 1918 übersetzt und gedruckt (vgl. Drews 1983, 204-205). Zu den ersten Übersetzern zählten Adam Bederski, dessen Übertragung von Apollinaires Gedicht „Rotsoge“ 1918 in der Zeitschrift, Zdrój“ erschien und Czyżewski (vgl. Kwiatkowski, in: Apollinaire 1975, CLXII sowie: Rylko 1968, 50-51), der darüber hinaus auch in seinem Artikel "Die Poesie der Expressionisten und Futuristen“ auf Apollinaire

\footnotetext{
${ }^{122}$ Es ist unklar, ob sich das „Kennenlemen” auf die Lekture der Texte Apollinaires oder auf einen personlichen Kontakt bezieht.
} 
verweist und ihn als "futuristisch-kubistischen“ („futurystyczno-kubistyczny“) Dichter bezeichnet (1919c, 81).

In der ersten Nummer von "Formiści" erscheint Apollinaires „Cors de chasse", allerdings noch im französischen Original („Formiści“ [1], 9). Czyżewskis Apollinaire-Übersetzungen sind im zweiten ("Océan de terre“ - „Ocean ziemi“) und im sechsten Heft („Le Tabac à priser" - „Tytoń za dwa sous“) zu finden („Formiści“ [2], 5 bzw. [6], 4). Besondere Beachtung verdient dabei die zweite Nummer: neben dem Apollinaire-Gedicht ist Czyżewskis „Melodie der Menge“ abgedruckt, eine Seite vorher „Erkenntnis“ („Poznanie“) sowie das kubistische „Portrait des Dichters Apollinaire“ („Portret poety Apollinaire“) des in Paris lebenden polnischen Malers Louis Markous (Marcoussis; eig. Ludwik Markus - „Formiści” [2], 4-5). Allerdings fehlt beim Gedicht „Erkenntnis“ noch die Widmung für Chwistek, die Czyżewski beim Abdruck in .Das grüne Auge“ hinzufügte. Schließlich widmetete Czyżewski Apollinaire noch das Gedicht „Frühling 1917“" („Wiosna 1917"“.), das vor allem den Oberleutnant Wilhelm Kostrowicki im Ersten Weltkrieg zeigt (Czyżewski 1992, 298-299) ${ }^{123}$. „Apollinaire'owi zawdzięcza Czyżewski może najwięcej““124, schreibt Lipski in seinem Aufsatz über Czyżewski $(1993,17)$ und erwähnt in diesem Zusammenhang die typographische Gestaltung der Gedichte und vor allem das Vertrauen in den poetischen Wer freier Assoziationen. Mit den Einflüssen Apollinaires auf Czyżewski sowie mit den Parallelen in einzelnen Gedichten beschäftigt sich Witold Morawski in seinem Aufsatz: „Die Poesie Tytus Czyzewskis und Apollinaire“ („Poezja Tytusa Czyżewskiego i Apollinaire“, 1961). Er nennt vor allem zwei Aspekte: die typographische Gestaltung der Gedichte und die simultane Darstellungsweise verschiedener Ereignisse.

Was die typographische Gestaltung von Gedichten betriff, so geht es dabei um die Einführung graphischer Elemente in die Gedichte sowie um die besondere Anordnung der einzelnen Verse, die sich somit zu einem Bild, das mit dem Thema des Gedichtes korrespondiert, zusammenfügen. Als Beispiele zu nennen sind einige von Apollinaires „Kalligrammen“ („Calligrammes“). etwa „Die Krawatte und die Uhr“ („La cravate et la montre“), „Die Mandoline die Nelke und der Bambus“ (..La mandoline l'oillet et le bambuou“) oder „Es regnet“ (,Il pleut“). Im Falle aller drei Gedichte stellt die typographische Anordnung der Verse oder Wörter und Buchstaben ein Bild her, das an die in den Titeln

\footnotetext{
${ }^{123}$ Das Gedicht wurde zum ersten Mal 1936 in der Zeitschrift „Prosto $z$ mostu“ (etwa: „Ohne Umschweife“) gedruckt. Apollinaires Mutter war die polnische Adelige Angelica de Kostrowitzky, die ihrem Sohn die Vornamen Guillaume Albert Wladimir Alexandre Apollinaire gab. 1897 nahm dieser dann den Namen Guillaume Apollinaire an. Vgl. dazu: Kircher 2002, $111-112$.

124 ..Das meiste verdankt Czyłtewski wohl Amollinaire"
} 
genannten Gegenstănde erinnert, das heißt zum Beispiel an eine Uhr, eine Nelke oder eine Mandoline. Beim Gedicht "Es regnet“ sind die einzelnen Buchstaben der Wörter untereinander gedruckt, wodurch der optische Eindruck von Regenschauem entsteht.

Morawski nennt und interpretiert als entsprechende Beispiele aus Czyżewskis formistischer Dichtung vor allem zwei Gedichte: „Erkenntnis“ und „Der mechanische Garten“ (vgl. 1961, 157-158) ${ }^{125}$; hinzugefügt werden könnte noch „Hymne an die Maschine meines Körpers“. Gerade in den beiden letztgenannten Gedichten, die in der vorliegenden Arbeit in dieser Hinsicht beschrieben wurden. erinnert deren graphische Gestaltung, das heißt die Anordnung der Verse an einen Garten bzw. einen menschlichen Körper. Kwiatkowski schreibt in seiner Einleitung zu Apollinaires Gedichten, dass in der Interaktion von Wort und Bild in den Bildgedichten die Sehnsucht nach Verwirklichung eines unerfullbaren Wunsches der Dichter bestehe, dass das Wort zum Ding werde (in: Apollinaire 1975, CXXX). Vielleicht kann im Gedicht „Brunnen und Flamme“ Czyżewskis Versuch erkannt werden, (sich) diesen Wunsch zu erfullen, und zwar an jenen Stellen, an denen Czyżewski ein Fenster in das Gedicht zeichnet (vgl. Czyžewski 1922c, 101 und 103).

Apollinaire (als Theoretiker und Kunstkritiker) und Czyżewski (als bildender Künstler) standen dem Kubismus nahe. In der Poesie beider Autoren finden sich bestimmte Verfahrensweisen, die mit diesem in Verbindung gebracht werden können. Dazu zählen im Falle Czyzewskis die Auflösung inhaltlicher Zusammenhänge durch freie Assoziationen und Wortverbindungen sowie die unmittelbare Aneinanderfügung von scheinbar nicht miteinander in Beziehung stehender Verse, die unterschiedliche Ereignisse beschreiben (Juxtaposition). Das wesentlichste Prinzip der poetischen Darstellung einer so bewusst fragmentarisierten Wirklichkeit ist das der Simultaneität, dank derer alles Beschriebene gleichzeitig erscheint. Eines der bekanntesten Beispiele simultaner Dichtung von Apollinaire ist sein Gedicht .Zone“, auch bei Czyzewski lassen sich, wie die einzelnen Interpretationen in dieser Arbeit gezeigt haben. zahlreiche Beispiele finden. etwa: „Hymne an die Maschine meines Körpers“,

\footnotetext{
${ }^{125}$ Wenig zutreffend zu sein scheint allerdings der Vergleich Morawskis von Czyzewskis Gedicht „Erkenntnis“ mit Apollinaires ..Il pleut", da die beiden Gedichte doch recht verschieden sind. Worauf Morawski seinen Vergleich stutza und eine .,ahnliche Wirkung" (,.podobny efekt") - in poetischer Hinsicht - konstatiert, ist der vertikale Druck des Gedichtes (..Es regnet“) bzw. eines Teils (..Erkenntnis“). Doch wăhrend sich bei Apollinaire so der optische Effekt von Regenschauern einstellt, der mit dem Thema des Gedichtes korrespondiert. geht es Czyzewski mehr darum, eine zweite Perspektive, eine zweite Sichtweise in sein Gedicht einzubauen, zu der er auch den Rezipienten zwingt, der sein Buch um $90^{\circ}$ drehen muss, um die entsprechenden Verse lesen zu konnen. Auch der Druck ist unterschiedlich: wahrend Apollinaire Buchstabe futr Buchstabe untereinander druckt. dreht Czyzewski einige Verse um, wie gesagt. $90^{\circ}$. Dadurch wird aber nicht ausgeschlossen, dass sich Czyzewski von Apollinaire auch im Falle dieses Gedichtes inspirieren ließ - dessen (møgliche) Năhe zum franzosischen Dichter zeigt, wie erwahnt. der Erstabdruck des Gedichtes in „Formiści”, nămlich neben einem Portrait von Apollinaire und noch ohne die Widmung fur Chwistek.
} 
in dem das gleichzeitige Funktionieren aller Teile dieser „Körpermaschine“ thematisiert wird. In „Mediumistisch-magnetische Photographie des Dichters Bruno Jasieński“ lässt unter anderem die dreimal wiederholte Wendung "w tej chwili“" (,in diesem Augenblick“) den Eindruck von Gleichzeitigkeit entstehen. $\mathrm{Zu}$ nennen sind auch viele jener Gedichte, in denen die Großstadt, das Großstadtleben und ihre Institutionen beschrieben werden (,Meldodie der Menge“, „Ballade über die Kellnerin Kocia“ oder „Das gesehene Gesicht“).

Eine besondere Form der poetischen Simultaneität sind die sogenannten Konversationsgedichte Apollinaires, wie zum Beispiel „Montag Rue Christine“ (,Lundi Rue Christine“). In ihnen steht, wie Tamara Trautner es formuliert „[...] nicht die Simultaneität visueller Eindrücke, sondern die Gleichzeitigkeit von aufgeschnappten Gesprächen im Vordergrund.“ (1988. 565). Die poetische Darstellung beruhe, so Trautner weiter, auf der inkohärenten Aneinanderreihung von Konversationsfetzen. Kwiatkowski interpretiert diese Gedichte Apollinaires auch als einen Versuch, die Poesie durch die Aufnahme von scheinbar Authentischem dem alltäglichen Leben anzunähern (vgl. in: Apollinaire 1975, CXXI). Auch hierfür lassen sich Beispiele aus Czyżewskis formistischen Gedichten nennen, so gibt es „authentische“ Gesprächsfragmente in „Sensation im Kino“ oder in „Ballade über die Kellnerin Kocia“. Das Gedicht "Le soir d'amour" (vgl. 1920a, 59) ${ }^{126}$, das in dieser Arbeit bislang noch nicht genannt wurde. besteht überhaupt nur aus solchen Fragmenten, die der Autor fast so, wie er sie aufgeschnappt haben dürfte. ins Gedicht übernimmt.

Ein genauerer Vergleich der Gedichte Apollinaires und Czyżewskis würde noch die Bestimmung zahlreicher weiterer Parallelen erlauben. die sich sowohl auf den thematischen, als auch auf den stilistisch-formalen Bereich beziehen (vgl. Simonis 1967, 20-21 und 62-95, Kwiatkowski, in: Apollinaire 1975, XCV1II-CXXVII sowie: Kircher 2002, 111-129). Dazu zählt zum Beispiel die Rolle von Farben und Synästhesien für den poetischen Ausdruck. Ebenso zu nennen ist das Bestreben. die Distanz zwischen lyrischem Ich und der konkreten Person des Autors zu verringern. An zwei Gedichten Czyżewskis, in denen er sich namentlich selbst nennt, wird dies besonders deutlich: "Transzendentales Panoptikum" und „Mediumistisch-magnetische Photographie des Dichters Bruno Jasieński“. Beide Dichter verbindet auch die Überzeugung, dass Poesie nicht unbedingt dem Außergewöhnlichen entspringen müsse, was sich in ihrer Hinwendung zu Alltäglichem, vor allem zur gegenwărtigen neuen Zivilisation, zeigt. Ferner sind, neben den genannten freien Assoziationen, unerwartete Wendungen und erstaunliche Kombinationen von Ereignissen ein

${ }^{126}$ Eine deutsche Übersetzung des Gedichts findet sich bei: Dedecius 1996-2000. 1/1/337 
wichtiges Gestaltungsmittel. Oftmals werden dabei scheinbar gegensätzliche Bereiche miteinander verbunden, zum Beispiel: Feierliches und Alltägliches, Tragisches und Komisches oder Religiöses und Profanes. Ein bekanntes Beispiel dafür ist eine Passage aus Apollinaires Gedicht, Zone“:

..Ist Christus der besser gen Himmel fahrt als die Flieger

Er hătt den Hohenweltrekord." $(1969,57)$

Entsprechende Beispiele finden sich in Czyżewskis Gedichten in „De profundis“ („przyjdzie do mnie Judasz // i kupi kilka obrazów“ (1922c, 80) 127 oder im Gedicht „Regiment. Eine poetische Armeeromanze", in dem gleichzeitig der Tod eines Militärs, dessen Begräbnis und das Braten eines Rühreis oder das Stopfen von Socken dargestellt werden (vgl. 1922c, 87). Was die metrische Gestaltung der Gedichte betriff, so ist bei beiden Autoren keine radikale Zerschlagung der Verse, wie sie der Futurismus propagierte, zu bemerken. Die Verse sind syntaktisch vielfach vollständig und auch die verwendeten Ellipsen, die das innere Tempo der Gedichte steigern (zum Beispiel in den Großstadtgedichten), sind noch weit entfernt von den „befreiten Wörtern“. Schließlich charakterisiert beide Autoren, bei all ihrer Zustimmung und Begeisterung, auch eine gewisse Skepsis gegenüber der neuen Zeit, was sie ebenfalls vom Futurismus trennt. So beschreibt Apollinaire in "Zone" auch die negativen Seiten der Großstadt, wie Einsamkeit und Anonymität in der Menge, was in ähnlicher Weise bei einigen Großstadtgedichten Czyżewskis deutlich wurde (zum Beispiel: „Melodie der Menge“ oder .Stadt an einem Herbstabend").

\section{Czyżewski und der Futurismus}

Zwischen den Formisten und den Krakauer Futuristen Bruno Jasieński und Stanisław Mlodozeniec gab es, wie gezeigt, hăufige Kontakte, die in Formen konkreter Zusamnenarbeit. wie gemeinsame Publikationen oder Poesie- und Vortragsabende. mündete. Währerd gerade Chwistek und Czyżewski vonseiten der Formisten diese Zusammenarbeit betrieben. standen andere Mitglieder der Gruppe dem Futurismus gleichgültig bzw. ablehnend gegenüber. Witkacy formuliert seine Vorbehalte in seinem Artikel „Einige Vorwürfe gegen den Fuurismus“ („Pare zarzutów przeciw futuryzmowi“). Er betont darin (vgl. 1922f, 316319), dsss er einige Werke der Futuristen zwar schätze, insgesamt aber seine Auffassung von 
Kunst, das heißt die Theorie der "Reinen Form", und die der Futuristen sich diametral gegenüberstünden. Darauf basiert auch Witkacys zentrale Kritik: Witkacy, für den der ästhetische Wert eines Kunstwerks in dessen formaler Konstruktion und nicht im Inhalt begründet ist, rechtfertigt in seiner Theorie die Deformation der dargestellten Gegenstände bzw. die Einführung von Unsinn in die Poesie, zur Erfullung formaler Kriterien. Den Futuristen wirft er vor, dass sie gleichermaßen die Abkehr von logischem Sinn propagierten, jedoch ohne dies für die Form des Kunstwerks fruchtbar zu machen, was im Prinzip „Realismus“ bedeute, wenn auch mit veränderten Vorzeichen (1922f, 317). In dem Artikel „Über die Folgen der Tätigkeit unserer Futuristen“ („O skutkach działalności naszych futurystów “' ${ }^{128}$ ) wiederholt Witkacy seine Kritik und bringt darüber hinaus sein Bedauern über die Mitarbeit Czyżewskis und Chwisteks an „Das Messa im Bauch“ zum Ausdruck (vgl. 1923a, 360 und 362).

Am stärksten von allen Formisten war Czyżewski mit dem Futurismus, sowohl mit dem italienischen, wie auch mit dem polnischen, verbunden. Dass er etwa mit den Manifesten Marinettis, die er zum Teil wahrscheinlich von seinen Paris-Aufenthalten her kannte, gut vertraut war, zeigt sein 1919 veröffentlichter Artikel „Die Poesie der Expressionisten und Futuristen“, in dem er unter anderem eine Passage aus dem „Technischen Manifest der futuristischen Literatur" von Marinetti zitiert, in der es um das neu entstandene Verhältnis zwischen Literatur und technisierter Welt, konkret um den Einfluss des Motors auf die Literatur, geht (vgl. Czyżewski 1919c, 80 sowie: Marinetti 1912, 285 und 286). Außerdem bezeichnet Czyżewski den futuristischen Dichter als "nervöses Kind der Großstadt“ („nervowe dziecko wielkiego miasta“), das den „allgemeinen Dynamismus der gegenwärtigen Mechanik der zivilisierten Welt“ (,powszechny dynamizm wspólczesnej mechaniki świata cywilizowanego") in sich aufgenommen hätte (1919c, 80). Wegen dieser Hinwendung zu den Erscheinungen der Gegenwart, ist der Futurismus für Czyżewski auch die Kunst, die auf den Ruinen der Epoche der „Dekadenz des Idyllischen“ („dekadencji sielankowości“) entstehe (1919c, 80). Schließlich erwähnt Czyżewski in seinem Aufsatz noch die formalen Innovationen, die die Futuristen in die Lyrik eingeführt hätten, das unkonventionelle Druckbild manch ihrer Gedichte und auch den burlesken Humor, der viele futuristische Werke kennzeichne und für den er auch einige Beispiele anführt.

Besonders Czyzewskis Lyrik aus den Jahren 1920 bis 1922 wird oft als „futuristisch“ bezeichnet und so auch im Kontext der futuristischen Poetik untersucht oder erscheint in

127 , 24 mir kommt Judas // und kauft einige Bilder.

128 Auf deutsch in: Lam 1990. 279-288. 
einschlägigen Anthologien unter diesem Etikett. Die in dieser Arbeit unternommene Beschreibung von Czyżewskis Gedichten im Kontext des Formismus schließt nicht aus, diese auch als „futuristisch“ zu untersuchen. Allerdings scheint die Beschreibung als "formistisch“ insgesamt doch adăquater, nicht nur, da sie bestimmte Ansătze aus den formistischen Theorien (vor allem das Form-Inhalt-Problem) mit einzubeziehen vermag, sondern weil es in Czyżewskis Dichtung auch zahlreiche Stilmittel und Verfahren gibt, die nicht mit der futuristischen Ästhetik zusammenhängen.

Sein Verhältnis zu den Futuristen, besonders zu den polnischen beschreibt Czyżewski so:

„Stosunek mój do moich towarzyszów futurystów nie uważam jednak za luźny lub przypadkowy. Moja działalnośc $i$ twórczośc jest zwiazana z cała grupa futurystyczną nie tylko nowymi środkami realizowania, nie znanego [sic!] dotychczas w Polsce, ale takze węzłem rozpoczynającego się nowego zycia i nowej epoki w Polsce i w swiecie." (1923b, 397)

Das Verständnis des Futurismus, das Czyżewski in diesen Zeilen entwirft, ist eng an das Bewusstsein für die neu angebrochene Ära geknüpft, die futuristische Ästhetik wird dementsprechend zum Ausdruck dieser neuen Zeit mit neuen künstlerischen Mitteln. Die futuristische Poesie sei, wie Czyżewskis noch an anderer Stelle betont $(1933,6)$, demnach nicht nur Poesie, sondern die „allgemeine Idee des Zeitgenössischen“ (,gremjalna idea wspótczesności“) sowie die Propagierung der Idee, „den Kosmos der Gegenwart , in flagranti“ festzuhalten“ („złapania wszechświata ,in flagranti` współczesności“ - im Orignial fett). In dieser Hinsicht ist Czyżewskis eigene Lyrik mit dem Futurismus verwandt. Baluch nennt als Merkmale, an denen diese poetische Verwandtschaft sichtbar wird, unter anderem: die typographische Gestalt vieler Gedichte, ihr dynamisierter Inhalt. die Simultaneităt, das Fehlen der Interpunktion, der Gebrauch „moderner“ Motive, wie der Maschine, der Mechanik etc., das Einbauen von Geräuschen der modernen Welt, zum Beispiel das Knirschen von Zahnrädern, der Lärm der Großstadt usw. Baluch geht auch auf Czyżewskis Gedicht ..Der mechanische Garten“ ein, das sie als "fast ideales futuristisches Gedicht“ („niomal idealny wiersz futurystyczny“) interpretiert (vgl. in: Czyżewski 1992, XLII-XLV), und zwar im Sinne von Marinettis Theorie der "befreiten Wörter“, das heißt Verben und Substantiva, die nicht mehr in grammatische und syntaktische Beziehungen eingebunden sind. Dennoch scheint hier eine Relativierung angebracht: Zwar besteht „Der mechanische Garten“ fast ausschließlich aus Substantiva, deren ,Autonomie“ graphisch insofern noch gesteigert wird, dass sie einzeln

129 .Mein Verhăltnis zu meinen Kollegen Futuristen halte ich jedoch nicht fur locker oder zufallig. Meine Tătigkeit und mein Schaffen sind mit der ganzen futuristischen Gruppe nicht nur durch neue, in Polen bislang unbekannte. Mittel der Verwirklichung. sondern auch durch das in Polen und auf der Welt beginnende neue Leben und die neue Epoche. verbunden." Eine deutsche Obersetzung von Czyzewskis Text bei: Lam 1990, 323325. 
in dick umrandeten Rechtecken bzw. Kreisen stehen und somit kein Teil einer syntaktischen Beziehung sind. Dennoch widerspricht die von Czyżewski gewählte kompositorische Anordnung Marinettis Forderung nach der Zerstörung der Syntax durch zufäliges Anordnen der Substantive, „so wie sie entstehen“ $(1912,282)$. Gerade durch das zuletzt genannte Beispiel wird Czyzewskis freie und kritische Rezeption des Futurismus deutlich. Außerdem verbindet die Tatsache, dass Czyżewski keine radikale Zerschlagung syntaktischer oder grammatischer Strukturen betreibt, seine Gedichte mehr mit Apollinaire, als mit den Futuristen. Als ein weiterer Differenzpunkt zum Futurismus könnte die Betonung der Form, besonders für die Konstruktion des literarischen Kunstwerks, bei Czyżewski genannt werden. ebenso wie das Verhältnis zur Maschine, die Czyżewski, wie er in „Von der Romantik zum Zynismus" schreibt, zwar als eine charakteristische Erscheinungsform der neuen Zeit, nicht aber als ein absolutes poetisches Objekt ansieht $(1927,230)$. In seinem bereits zitierten Text .Der Neonaturalismus von Marinetti“ (,Neonaturalizm Marinettiego“) schreibt Czyżewski in diesem Zusammenhang $(1933,6)$, dass die italienischen Futuristen von einer zu oberflächlichen Erfassung der neuen Zeit ausgegangen seien. sich daher mit der Thematisierung ihrer Erscheinungsformen - zum Beispiel der Maschine - begnügt hätten, ohne danach gefragt zu haben, ob die Gegenwart mit all ihren neuen Accessoires nicht auch eine neue Form der Wahmehmung bzw. ein neues Verhältnis der Menschen zu ihrer Umwelt hervorgebracht hätte.

Insgesamt kann festgestellt werden, dass sich die Parallelen bzw. Unterschiede zwischen Czyżewskis Gedichten und Manifesten ${ }^{130}$ und der futuristischen Ästhetik im Prinzip die Waage halten, worin ein weiterer Beleg für Czyżewskis kritische Rezeption gesehen werden kann.

Czyżewski und der Expressionismus

Mit der Affinität von Czyżewskis Lyrik zum Expressionismus ergibt sich noch eine weitere Verbindung zur gesamteuropäischen Avantgarde. Allerdings ist in diesem Fall weniger vom Einfluss der expressionistischen Dichtung zu sprechen, sondern mehr von Parallelen im Sinne typologischer Analogien. Die deutsche expressionistische Dichtung wurde in Polen vor 1917

\footnotetext{
130 Auch viele von Czyzewskis programmatischen Texten sind im futuristischen Duktus geschrieben und enthalten Forderungen, die an futuristische Postulate erinneren (vgl. zum Beispiel: ..Das Begrabnis der Romantik“).
} 
kaum rezipiert (vgl. Prokop 1970, 58-61), Czyzewski nennt aber in „Die Poesie der Expressionisten und Futuristen" mit Goll, Rubiner und vor allem mit dem Herausgeber der Zeitschrift „Der Sturm“ Walden einige wichtige Namen des deutschen Expressionismus (1919c, 81). Piotr Bukowski, der sich mit den expressionistischen Elementen in Czyżewskis Lyrik unlängst in dem Aufsatz "Tytus Czyżewskis formistische Lyrik und die Poetik des deutschen Expressionismus“ beschäftigte, zeigt (vgl. 2002, 167-168), dass sich Parallelen zwischen Czyżewskis Gedichten besonders zu der vom "Sturm"-Kreis entwickelten "Wortkunsttheorie“ ergeben, wenngleich er einschränkt, dass Czyżewski diese wohl nur oberflächlich kannte. Vielmehr sei es die gemeinsame Rezeption von französischer und italienischer Avantgarde, vor allem also von Apollinaire und Futurismus, auf die diese Analogien zurückgeführt werden können.

Bukowski nennt insbesondere drei Merkmale, die Czyżewskis Lyrik mit der des ..Sturm"Kreises verbinden: „Synthese, Sichtbarkeit und Rhythmus“ $(2002,168)$. Neben dem Streben nach einem poetischen Ausdruck. dessen Stärke auf Zusammenziehungen und Synthesen beruht, beziehen sich die genannten Merkmale in erster Linie auf die in den Gedichten zum Ausdruck gebrachte Bewegung und deren Rhythmus. Als entsprechendes Beispiel interpretiert Bukowski Czyżewskis Gedicht „Der Tanz“ (vgl. 2002, 170).

Neben den Parallelen in Bezug auf den poetischen Ausdruck verweist Bukowski außerdem auf gemeinsame Themen und Motive, die es erlauben. Czyżewskis Lyrik im Kontext des Expressionismus zu betrachten. Dazu zählt er neben der Großstadt, besonders die Thematisienung extremer Bewusstseinszustände, wie Fieberwahn (,Halbschlaf"), Verzweiflung. Halluzinationen. Angst und Furcht (Gedichte: „Die Angst” - „Lęk“ und „Furchr" - „Strach" - Czyżewski 1920a, 37-38 und 40-41) sowie Tod und Verfall. Gerade letztere, so Bukowski abschließend (vgl. 2002, 171-176). würden aber häufig mit Visionen der Erneuerung. der Wiederauferstehung, im Sinne des „messianistischen Expressionismus“ verknupft ${ }^{131}$. Das "Expressionistische“ in Czyżewskis Lyrik ist somit in erster Linie mit dem Ausdruck des Inneren, nicht fassbarerer Bewusstseinszustände sowie zum Teil auch mit de.n Visionăren, Nicht-Logischen verbunden. In diesem Sinne versteht auch Czyżewski selbst. wie er in „Die Poesie der Expressionisten und Futuristen“ schreibt (1919c. 81), das Wesen der expressionistischen Kunst, ebenso wie Hulewicz in seinem Vorwor zu „Das Grüne Auge“* Czyżewskis Poesie in dieser Hinsicht charakterisiert, wenn er den „inneren Ausdruck“ (,wyraz wewnętrzny“) als wesentlichstes Merkmal der neuen Kunst, die unter verschiedenen

\footnotetext{
'31 In der vorliegenden Arbeit wurden vor allem die Gedichte „Elektrische Visionen“ und „Stadt an einem Herbstabend" in dieser Hinsicht interpretiert.
} 
mehr oder weniger zutreffenden Namen wie „Expressionismus“, „Formismus“ oder „Futurismus“ auftrete, bestimmt $(1920,33)$.

Schließlich kann auch in der von Czyżewski in einigen Gedichten thematisierten Faszination am Nicht-Schönen, am Hässlichen eine Parallele zur einer Tendenz der expressionistischen Dichtung erkannt werden (vgl. dazu: Anz 2002, 163-169). So trägt „Stadt an einem Herbstabend" den Untertitel „niesielanka“ - „Nichtidylle“, im Gedicht selbst gibt es den Gesang Betrunkener, Dissonanzen, das Weinen von Kindern, wie ebenso sogenannte "gesellschaftiche Außenseiter" in Gestalt zum Beispiel einer Prostituierten auftreten. In anderen Gedichten hingegen kommen Verbrecher („Die Angst“ bzw. „Der Verrat” "Zdrada", in dem außerdem die Niederkunft einer Frau auf einer Straßenbank beschrieben wird - Czyżewski 1920a, 62-63), Diebe („Die Stadt“), wiederum Prostituierte und Zuhälter („Melodie der Menge“) oder auch Geisteskranke (,Monolog eines Narren“ - „Monolog błazna“"132 und ,Im Irrenhaus" -, W szpitalu obłąkanych") vor.

Die Parallelen zwischen Czyżew'skis formistischen Gedichten und der Lyrik Apollinaires, des Futurismus und des Expressionismus verweisen auf ihre gemeinsame Zugehörigkeit zur europäischen Avantgarde. Für Czyżewski ist dabei charakteristisch. dass er in seinen Gedichten diese verschiedenen Impulse miteinander kombiniert. Daraus ergibt sich eine weitere Parallele. die im folgenden Kapitel näher untersucht wird: denn da sich auch im Falle der frühen tschechischen und ungarischen Avantgarde eine ähnliche Rezeption und Integration in das eigene theoretische und künstlerische Schaffen der europäischen Avantgarde-Strömungen wie bei Czyżewski bzw. beim Formismus insgesamt beobachten lăsst, soll versucht werden. unter anderem von diesem Punkt ausgehend. die Spezifik der A vantgarde in Mitteleuropa ansatzweise zu verdeutlichen.

132 „Monolog eines Narren“ ist auf deutsch erschienen in: Bereska/Olschowsky 1975, 85-86. 


\section{Der Formismus und die mitteleuropäische Avantgarde}

Ein charakteristisches Merkmal der europäischen Avantgarde ist ihr übernationaler Charakter. Sie vereint in sich Strömungen, die in den unterschiedlichsten Ländern ihren Ursprung fanden. Dazu zählen in erster Linie der Futurismus aus Italien und Russland, der deutsche Expressionismus, der Dadaismus, der zuerst im Zürich des Ersten Weltkrieges entstand, der russische Konstruktivismus sowie der französische Surrealismus, die am weitesten verbreitet waren. In gleicher Weise sind hier auch die zahlreichen Strömungen der mitteleuropäischen Avantgarde zu nennen'. Diese sind zumeist unter denselben Voraussetzungen wie die zuvor genannten Strömungen entstanden, nämlich in der Absicht Kunst und Literatur radikal zu erneuern. Dennoch gibt es bei einer vergleichenden Betrachtung auch einige Unterschiede zwischen den eingangs genannten und den mitteleuropäischen Avantgarde-Strömungen, etwa was den Zeitpunkt ihres Entstehens betriff. Denn bildeten sich der Futurismus, der Expressionismus oder der an dieser Stelle ebenfalls zu nennende Kubismus, dem vor allem für die bildende Kunst große Bedeutung zukommt, bereits vor dem Ersten Weltkrieg heraus. so entstanden die meisten mitteleuropäischen Avantgarde-Gruppen erst nach dem Ersten Weltkrieg bzw. erreichten erst in den Jahren um 1920 den Höhepunkt ihres künstlerischen und theoretischen Schaffens. Wie im zweiten Kapitel dieser Arbeit gezeigt wurde, sind auch die Anfänge des Formismus, der für den Beginn der polnischen Avantgarde steht, noch vor (Austellungen der „Unabhängigen“) bzw. während des Ersten Weltkriegs (Ausstellung in Zakopane 1916) zu suchen, die Bildung der Gruppe erfolgte allerdings erst 1917/1918, als die Gruppe auch ihren eigentlichen Namen annahm. Die wichtigsten theoretischen Schriften von Chwistek und Witkacy stammen schließlich aus den Jahren 1919 bis 1922 und auch Czyżewski publizierte seine „formistischen Gedichte“ erst 1920. Auch in der tschechischen Literatur konstituierte sich die bedeutendste Avantgarde-Gruppe, der „Künstlerbund Devětsil“ offiziell erst im September 1920, ihr bekanntester ästhetisch-theoretischer Entwurf, der sogenannte ..Poetismus", wurde überhaupt erst ab 1922 entwickelt und das erste Manifest des Poetismus stammt vom Mai 1924 (vgl. Drews 1975, 75-86). Doch wie zuvor beim Formismus

\footnotetext{
' Der Begriff ..Mitteleuropa" wurde und wird, wenn auch nicht immer eindeutig, nicht nur in seiner politischen oder historischen, sondern auch in seiner kulturellen und speziell in seiner literarischen Bedeutung vielfach diskutien (zu einer Begriffsgeschichte: LeRider 1996). Gerade die Komparatistik kann hier auf eine lange Forschungstradition zurúckblicken, als Beispiele seien nur die Arbeiten von Zoran Konstantinović, Gyơrgy Mihaly Vajda und vielen anderen genannt. Angesichts des Umfangs des Materials, das zu berücksichtigen wäre. sollten alle mitteleuropäischen Avantgarden vergleichend untersucht werden. war es fur das vorliegende Kapitel notwendig. eine repräsentative Auswahl zu treffen: ich statze mich daher in meinen Ausfuhrungen, neben dem Formismus, auf die frahe ungarische und tschechische Avantgarde.
} 
sind auch in Tschechien die ersten Anzeichen der Avantgarde bereits vor dem Ersten Weltkrieg zu bemerken, und zwar in Gestalt der Gruppe, die sich um den „Almanach für das Jahr 1914" sammelte, deren weitere Tätigkeit aber durch den Weltkrieg verhindert wurde und die daher eine "unterbrochene, abgebrochene Avantgarde“ (Drews 1975, 44) blieb². Auch in der Geschichte der ungarischen Avantgarde lässt sich eine gewisse Zäsur nach dem Ersten Weltkrieg bemerken: als nämlich, nach dem Sturz der Räterepublik, viele Künstler 1919/1920 gezwungen waren, nach Wien zu emigrieren, um der ihnen drohenden Verhaftung zu entgehen. In Bezug auf die Kunst bedeutete dies das Ende des ungarischen Aktivismus, verbunden mit einer stärkeren Hinwendung zu einer mehr formal orientierten, auch stärker experimentellen Dichtung.

Die Tatsache also, dass sich die mitteleuropäische Avantgarde zeitlich um einige Jahre versetzt zu den vergleichbaren Strömungen in Westeuropa bzw. Russland entwickelte, erlaubt es, zwei Punkte zu benennen, die für ihre Genese charakteristisch zu sein scheinen. Erstens zeigt sich, dass die mitteleuropäischen Avantgardisten ihre Vorläufer in Italien oder Frankreich kannten. In einer vergleichenden Untersuchung muss daher danach gefragt werden, welche Rolle die Rezeption dieser Vorläufer für das Entstehen von Formismus oder des Devêtsil spielte, wie sie verlief, das heißt welche Aspekte in die eigenen ästhetischen Ansätze aufgenommen und welche abgelehnt wurden. Zweitens wird aufgrund der zuvor genannten Jahreszahlen deutlich, dass sich die mitteleuropäische Avantgarde unter zum Teil völlig veränderten historischen oder politischen Voraussetzungen entwickelte. wozu insbesondere der zuende gegangene Erste Weltkrieg zählt. Die unmittelbare Erfahrung seiner Gräuel, aber auch das Bewusstsein der durch ihn ausgelösten positiven politischen Veränderungen führten zu einer ambivalenten Bewertung und machten eine bedingungslose Kriegsbegeisterung, wie sie vor 1914 die italienischen Futuristen, einige deutsche Expressionisten und auch Apollinaire vertraten, völlig undenkbar. Dies heißt aber eben nicht. dass zum Beispiel der Futurismus in seiner Gesamtheit von den mitteleuropäischen Avantgarde-Gruppen abgelehnt worden wäre.

Diese bislang festgestellten Besonderheiten in der Entwicklung der mitteleuropäischen Avantgarde können als Ausgangspunkt für eine vergleichende Betrachtung ihrer einzelnen Strömungen dienen. Motiviert wird ein solcher Vergleich außerdem auch durch die lange

\footnotetext{
2 Ähnlich schreibt Pollakówna uber den Beginn des Formismus: .,Rok 1913 bylby zapewne notowany jako poczatek formizmu. gdyby nie przeszkodziła pierwsza wojna swiatowa która opóznila o cztery lata ostateczne skrystalizowanie się tego kierunku." (..Das Jahr 1913 wörde wahrscheinlich als der Beginn des Formismus getten, hatte nicht der Erste Weltkrieg die endgöltige Herausbildung dieser Richtung um vier Jahre verzogert." 1963.253).
} 
Tradition der mitteleuropäischen Komparatistik, die immer wieder auf die übernationalen Gemeinsamkeiten und geistigen Wechselbeziehungen zwischen den einzelnen Ländern hingewiesen hat sowie durch die, besonders seit Mitte der 1980er Jahre intensiv gefuhrte Diskussion über Mitteleuropa, die von den bekannten Aufsätzen von Milan Kundera (1984) und György Konrád (1986) initiiert wurde.

Das Ziel einer vergleichenden Untersuchung der mitteleuropäischen Avantgarde ist es, ihre charakteristischen Eigenheiten näher zu benennen und zu beschreiben. Diese Charakteristika können zum Beispiel auf die besonderen Entwicklungsbedingungen der mitteleuropäischen Avantgarde, wie sie zuvor genannt wurden, zurückgeführ werden. Sie sind daher in mehreren einzelnen Strömungen gleichermaßen erkennbar und ermöglichen so einen Vergleich des polnischen Formismus mit dem ungarischen Aktivismus, zum Beispiel in Bezug auf ihre Entstehung. Allerdings geht es dabei selbstverständlich nicht darum, die mitteleuropäische aus der gesamteuropäischen Avantgarde "herauszulösen“, sondern vielmehr darum, sie adäquat in diesem Kontext zu erfassen. Die mitteleuropäische ist in typologischer Hinsicht ein integrativer Teil der gesamteuropăischen Avantgarde, zum Beispiel durch das gemeinsame Bemühen, eine an den Erscheinungen der modernen Zeit orientierte Ästhetik zu entwerfen. oder durch das Bestreben. Kunst und Literatur auch direkt in gesellschaftliche und politische Prozesse einzugliedem. Dennoch scheint eine vergleichende Untersuchung der einzelnen Strömungen der mitteleuropäischen Avantgarde, die von ihren besonderen Entwicklungsbedingungen ausgeht, besser in der Lage. diese als originäre Beiträge zur Avantgarde insgesamt zu erfassen und nicht primär als Epigonen westeuropäischer und russischer Strömungen ${ }^{3}$. Der Vorteil der hier vorgeschlagenen Art der Untersuchung zeigt sich besonders etwa beim polnischen Formismus oder tschechischen Poetismus, also bei Strömungen. die ausschließlich in der mitteleuropäischen Avantgarde zu finden sind und die. anders als zum Beispiel der Futurismus, keine direkte Entsprechung in Westeuropa oder Russland haben. Ein weiteres Argument, das an dieser Stelle genannt werden kann, ist, dass aus der westeuropäischen oder russischen Avantgarde bekannte Begriffe, etwa zur Bezeichnung einer Strömung, zwar verwendet werden, im Falle mitteleuropäischer Gruppen aber oft eine ganz andere Bedeutung erfahren. So wird „Expressionismus“ von den frühen Formisten, die ihn anfangs sogar noch im Namen ihrer Gruppe führen, zum Teil anders verstanden, als zur selben Zeit in Posen oder in Berlin. Das künstlerische und theoretische Schaffen des polnischen Futurismus, besonders der Warschauer Gruppe um Anatol Stern und

${ }^{3}$ Bojtár stellt fest, dass von solchen Voraussetzungen ausgehende Untersuchungen im Prinzip lediglich in der Lage seien, die .temporal priority and superiority of the West European avant-garde" festzustellen $(1992,30)$. 
Aleksander Wat, ist in vielerlei Hinsicht mit dem Dadaismus verwandt (vgl. Turowski 1977, 100-101). Und auch Pal Deréky stellt in Bezug auf die konstruktivistischen Schriften Kassáks der frühen zwanziger Jahre fest (1991, 66-67), dass dessen literarischer Konstruktivismus wenig mit dem deutschen, holländischen oder russischen Konstruktivismus zu tun gehabt habe, sondern vielmehr als literarischer Ausdruck der sich überall in der neuen Welt manifestierenden Modernität zu verstehen sei.

Bei dieser vergleichenden Beschreibung der mitteleuropäischen Avantgarde "von innen heraus“ geht es somit nicht primär um das „Futuristische“ oder ..Expressionistische“ zum Beispiel im polnischen Formismus, sondern mehr um die Frage, wie diese Einflüsse aufgenommen und gegebenenfalls auch weiterentwickelt werden. Für die vorliegende Arbeit steht dabei, entsprechend ihrem Thema, vor allem der polnische Formismus im Zentrum der folgenden Ausführungen. Inwiefern kann er im Kontext der mitteleuropäischen Avantgarde betrachtet werden und woran kann konkret der Vergleich mit den zeitgenössischen ungarischen oder tschechischen Strömungen festgemacht werden?

\subsection{Die Herausbildung des Formismus im Kontext der mitteleuropäischen Avantgarde}

Mit Nietzsche, Bergson und vor allem Whitman sind es zum Teil dieselben Vorläufer, die sowohl das Entstehen der westeuropäischen, als auch der mitteleuropäischen und russischen Avantgarde maßgeblich beeinflussten, wenngleich die Anverwandlung of in unterschiedlicher Form geschieht (vgl. Drews 1983, 103-152). So wird zum Beispiel auf Nietzsche, von dessen „Zarathustra" gerade Marinetti und die italienischen Futuristen einige ihrer zentralen Schlagworte, wie „das Pathos des Aufbruchs, die Zertrümmerung der «alten Tafeln» und damit die Umwertung aller "Werte»" (Schmidt-Bergmann 1993, 120, vgl. auch: 58) übernehmen, in Polen vor allem von Przybyszewski und damit vom frühen Posener Expressionismus zurückgegriffen. Doch anders als die Futuristen, sieht Przybyszewski. dessen intensivste Nietzsche-Rezeption außerdem in die Jahre 1889-1898 fällt, als er in Berlin studiert, in Nietzsche vor allem den Vertreter einer dionysisch-ekstatischen Kunst des Rausches (vgl. Drews 1983, 110-111). Auch Czyżewski verweist mit Rimbaud, Mallarmé. Claudel und eben mit Whitman auf die wichtigsten gemeinsamen Vorläufer der zeitgenössischen Dichtung , auf der ganzen Welt“" (1919c, 79-80).

Ein Charakteristikum für die Herausbildung der mitteleuropäischen Avantgarde ist aber, dass diese, dank des späteren Zeitpunkts ihres Auftretens, nicht nur auf die Werke der erwähnten 
Vorgänger, sondern auch auf die Ansätze bereits existierender Avantgarde-Strömungen zurückgreifen kann. Wenngleich es nicht immer möglich ist, eindeutig zwischen genetischen Kontakten bzw. typologischen Analogien zu unterscheiden", so findet doch in allen drei Ländern, die hier stellvertretend für die mitteleuropäische Avantgarde untersucht werden, die Auseinandersetzung mit dem Futurismus oder Expressionismus statt. Dies geschieht zum Beispiel auf Reisen, bevorzugt nach Paris, durch Übersetzungen der jeweiligen Manifeste oder literarischen Werke sowie durch kritische Rezensionen in den heimischen Zeitschriften, wie dies für den Formismus im zweiten Kapitel dieser Arbeit entsprechend dargestellt wurde. Doch scheint es dabei für die mitteleuropäischen Avantgarden charakteristisch, dass die bereits existierenden ästhetischen Entwürfe einer kritischen Bewertung unterzogen werden. gerade auch im Hinblick auf die Situation und Möglichkeiten der eigenen Kunst und Literatur. So war es beispielsweise so gut wie unmöglich, die von Marinetti propagiente Poetik der „befreiten Worte“, die auf einer radikalsten Zertrümmerung jeglicher grammatischer Strukturen beruht (vgl. Marinetti 1912), in die ungarische Literatursprache um 1915 zu integrieren (vgl. Deréky 1991, 15). Oftmals werden verschiedene Einflüsse auch miteinander kombinier, wofür gerade Czyżewskis formistische Lyrik ein gutes Beispiel ist. Daher endet in allen drei Ländern die Auseinandersetzung mit den übrigen AvantgardeStrömungen nicht mit der bloßen Übernahme ausgewählter Ansätze. Vielmehr ist überall das Bestreben zu erkennen, von Futurismus, Expressionismus oder Kubismus ausgehend, den Entwurf einer wirklich neuen Ästhetik. die mit der radikal veränderten Wirklichkeit des 20. Jahrhunderts, aber auch mit dessen politischen und sozialen Gegebenheiten, im Einklang steht, zu wagen. Damit ist zugleich die zentrale Hypothese formuliert, die durch die folgenden Ausführungen weiter fundiert werden soll ${ }^{5}$.

\footnotetext{
- So schreibt zum Beispiel Drews apropos des Einflusses Apollinaires auf Nezval: „Gerade im Falle Nezvals durfte man wohl weniger von einer direkten Beeinflussung als eher von einer Art geistiger Verwandtschaft sprechen." $(1975,48)$. Als weitere Beispiele konnten die dargestellten Parallelen zwischen Czyzewskis Lyrik und der des deutschen Expressionismus genannt werden.

${ }^{3}$ Bei der Beschreibung des Formismus bzw. von Czyzewskis Poesie kommt es im Rahmen dieser Ausfuhrungen zum Teil zu Wiederholungen von Fakten und Zusammenhăngen. die bereits an anderer Stelle dieser Arbeit beschrieben wurden. Im Sinne der Einheit und Lesbarkeit dieses Kapitels wurde darauf verzichteh, die entsprechenden Passagen zu streichen. ebenso wie auf einen aufwendigen Verweisapparat. der auf die jeweiligen Stellen in den Kapiteln 2 bis 5 aufmerksam macht. Nichtsdestotrotz wurden die Wiederholungen auf ein Minimum beschräkt.
} 


\section{Der Futurismus}

Dem Futurismus kommt gerade für die Herausbildung der polnischen und der ungarischen Avantgarde eine entscheidende Bedeutung zu. In beiden Ländem wurde er noch vor dem Ersten Weltkrieg rezipiert, es erschienen mehrfach Artikel, deren Autoren sich kritisch vor allem mit den Manifesten Marinettis befassen. Dessen erstes "Manifest des Futurismus“ (1909) konnte zwei wichtigen Avantgardisten dieser Länder auch von ihren Paris-Reisen bekannt sein: Czyzewskis erster Paris-Aufenthalt fiel in die Jahre 1907 - 1909 und auch Kassák machte sich 1909 zu Fuß auf den Weg nach Paris. Allgemein wurde der Futurismus als Möglichkeit der Emeuerung und Belebung der eigenen Kunst und Literatur interpretiert. als Impuls für die Neubewertung des Verhältnisses zur heimischen Tradition sowie auch als über die Sphăre der Kunst hinaus reichende Idee, zum Beispiel in politischer Hinsicht. Positiv wurde vor allem die futuristische Begeisterung an den Erscheinungen des modernen Lebens bewertet, ebenso wie das damit einhergehende Bestreben. Kunst und Literatur mit eben dieser neuen technischen und zivilisatorischen Wirklichkeit zusammenzuführen. Deutlich kritischer wurden zum Beispiel die futuristische Begeisterung für die Maschine sowie die zum Teil radikalen Versuche, die Literatursprache zu emeuern. gesehen. Entschieden abgelehnt wurde die futuristische Kriegsbegeisterung. Auch die futuristische Forderung. Bibliotheken und Museen zu zerstören, konnte in jenen mitteleuropäischen Ländern, deren eigenes kulturelles Erbe durch die lange Zeit der Fremdherrschaft einer ständigen Bedrohung ausgesetzt war sowie darüber hinaus eine wichtige Rolle bei der Bewahrung der nationalen Identität gerade zur Zeit dieser Fremdherrschaft. die ja bis 1918 andauerte, spielte, keinesfalls auf Zustimmung stoßen ${ }^{6}$.

In Kassáks ersten programmatischen Text, der den schlichten Titel „Programm“ trägt und den er 1916 in der zehnten Nummer der von ihm ein Jahr zuvor gegründeten ersten ungarischen Avantgarde-Zeitschrift "A Tett“ („Die Tat“) veröffentlicht, halten sich, was mögliche Affinitäten zum Futurismus betriff, Zustimmung und Ablehnung die Waage. Auf der einen Seite forder Kassák für die gegenwärtige Literatur den unmittelbaren Kontakt zum Leben sowie eine starke, kraftvolle Literatur, die so zum unmittelbaren Ausdruck ihrer Zeit werden soll. So heißt es dementsprechend:

\footnotetext{
6 Vgl. zur Futurismus-Rezeption in Ungarn. vor allem zu Dezso Szabó: Deréky 1991, 12-13. In Erinnerung gerufen sei an dieser Stelle auch noch einmal das im zweiten Kapitel angefuhrte Zitat von Grabowski, der aus polnischer Sicht zur Fordenung nach der Zerstoning von Kulturgutern Stellung nimmt.
} 
„Die neue Literatur ist der Toroffner des sich befreienden Willens. [...] Sie ist verliebt in alles Unerreichbare. aber schreitet gleichgaltig aber die toten Gotter hinweg und durch den lila Nebel der Zwangsvorstellungen hindurch." (1916a, 18)

Auch diese Passage erinnert an Marinetti und an seine futuristischen Manifeste, in denen gleichermaßen das Abwerfen der Tradition und etablierter Werte sowie der unbedingte Glaube, zu allem fähig zu sein, alles erreichen zu können, zum Ausdruck kommt. Auf der anderen Seite wendet sich Kassák an zwei Stellen explizit gegen den Futurismus, und zwar vor allem gegen dessen Kriegsbegeisterung:

„Die neue Literatur kann sich zur Flagge keines Ismus bekennen. Wie sie die neuen Mrglichkeiten des Christianismus nicht akzeptieren kann, so muß sie auch gegen den Futurismus frontal vorgehen. Denn wăhrend auf der einen Seite Asketen schon seit Jahrtausenden ihren Bauchnabel bestaunen, singen auf der anderen Seite eitle Primadonnen die Apotheose des Krieges... ." (1916a, 18)

Somit blieb auch der Einfluss des Futurismus auf die frühe ungarische Avantgarde-Dichtung in stilistischer oder thematischer Hinsicht ziemlich gering. Zwar erinnert Kassáks berühmtes Antikriegsgedicht „Brrr... bum...“ (1915a) durch die häufig eingesetzte Onomatopoesie, die den Schlachtlärm wiedergeben soll, an Marinettis „Bataille Poids+Odeur“, wie es auch dessen Forderung entspricht, den Lärm in die Literatur einzuführen. Dennoch kann im Falle von Kassáks Gedicht zum Beispiel von der Zerstörung der Syntax keine Rede sein. Kassák verwendet meist grammatisch vollständige Sätze. In diese Richtung zielt auch eine Bemerkung von Dereky, der konkret zu diesem Gedicht schreibt, dass der italienische Futurismus nicht als Grundlage für die Verssprache Kassáks gedient, sondern diese nur dynamisiert habe. wie ein Vergleich mit dem erwähnten Text von Marinetti zeige (vgl. Deréky 1991, 16 sowie: 1996, 56). Zum eigentlichen Vorbild, so Deréky weiter, wurde für Kassák, davon gleich noch mehr, die Lyrik Whitmans, die bei Kassák mit dem Futurismus eine eigentümliche Symbiose eingeht.

Czyżewski sieht im Futurismus jene Kunst, in der die neue Zeit ihren adäquaten Ausdruck findet. Wenngleich er, wie beschrieben, vielen futuristischen Postulaten skeptisch gegenüber steht, finden sich in seinen eigenen Gedichten doch zahlreiche Verfahrensweisen. die aus der futuristischen Poetik bekannt sind, zum Beispiel: die typographische Gestaltung der Gedichte. das Fehlen von Interpunktion, die Einführung von Dynamik und insgesamt eine neue Motivik. die einer veränderten zivilisatorischen und technischen Wirklichkeit entspricht.

Wenngleich die futuristischen Manifeste auch in Tschechien bald nach ihrer Entstehung rezipiert wurden, blieb der Einfluss des Futurismus auf die tschechische Avantgarde bis in die zwanziger und dreißiger Jahre hinein, relativ gering (vgl. Drews 1983, 184-187). Erwähnt werden muss an dieser Stelle allerdings der 1913 entstandene Text „Offene Fenster” von 
Stanislav Kostka Neumann, der genau jene kathartische Befreiung von überholten Traditionen zu artikulieren versucht, die auch für die Futuristen charakteristisch war und, wie zuvor erwähnt, oftmals mit ihnen unmittelbar in Verbindung gebracht wurde. Im ersten Teil des Textes, dessen einzelne Absätze jeweils mit „Nieder mit“ beginnen, wendet sich Neumann vor allem gegen die Ästhetik der Moderne, zum Beispiel: „Nieder mit [...] der Schmerzenslyrik, dem Ästhetenwortschatz, [...] den Marcels, den Egons, der perversen Erotik, dem Dandytum, dem Mystizismus“ (1913, 27). Der zweite Teil, dessen Absätze jeweils mit „Es lebe" beginnen, ist hingegen ein Lobgesang auf die neue Zeit und ihre Kunst, etwa: „Doch es lebe: das befreite Wort, das neue Wort, der Fauvismus, der Expressionismus, der Kubismus, [...] die Plastik des Onomatopöismus, die Poesie des Lärms, die Zivilisation der Erfindungen“ $(1913,27)$. So ist Neumanns Text zwar ganz im futuristischen Duktus gehalten, die unmittelbar inspirierende Vorlage dürfte allerdings nicht ein Manifest von Marinetti. sondern vielmehr Apollinaires Text „L'antitradition Futuriste. Manifeste-synthèse“, der wenige Monate zuvor erschienen war, sein. Vor allem verrät dies die Form der Darstellung, auch Apollinaire unterteilt seinen Text (vgl. Apollinaire 1913, 376 und hintere Umschlagklappe) in Ablehnung (,Merde aux...”) und Zustimmung („Rose aux...“). Eine weitere Parallele zwischen Apollinaire und Neumann versteckt sich ubrigens im Detail, da sich beide nicht bedingungslos gegen jede Tradition richten, wie es der Futurismus so gerne tat: so spricht Apollinaire in seinem Text von „continuite““ (vgl. dazu: Kircher 2002, 123-124), und auch bei Neumann fehlen, wie Drews vermerkt, unter denen, die abgelehnt werden, die „großen Gestalten der tschechischen Literatur des 19. Jahrhunderts“ (1975, 44). Ein ähnliches Verhăltnis zur literatur- und kunstgeschichtlichen Tradition scheint im Übrigen auch für den Formismus charakteristisch, dem es ja auch nie um das Verwerfen der gesamten Tradition ging, sondern nur um ein kritisches Verhältnis zu ihr bzw. um ihre adäquate Weiterentwicklung im Angesicht der veränderten zeitgenössischen Wirklichkeit.

Bevor Neumann sich in den zwanziger Jahren der „proletarischen Dichtung“ zuwenden sollte - er war damals auch Vorsitzender der Kulturabteilung „Proletkult“ der Tschechischen Kommunistischen Partei KSĆ, veröffentlichte er 1918 noch den Gedichtband „Neue Gesänge“. Die darin enthaltenen Gedichte entstanden zwischen 1911 und 1914, also zur selben Zeit wie "Offene Fenster" und sind vor allem, was ihre Motivik betriff, mit dem Futurismus verwandt. das heißt durch: Telegraph, Telephon, Elektrizität. Flugzeug, Maschinen etc. (vgl. Niedziela 1979, 133-141).

Somit spielte der Futurismus für Neumann nur für einige Jahre vor dem Ersten Weltkrieg eine wichtige Rolle. Für die Avantgarde der zwanziger Jahre, den Devêtsil, vor allem für Karel 
Teige, war der Futurismus überhaupt eine Erscheinung der Vorkriegszeit, denn der Krieg selbst habe, wie dieser in „Neue Proletarische Kunst“ ausführt, diese Bewegung abgeschnitten und zerstört, wer heute noch lebe, seien „trauernde Hinterbliebene, keinesfalls die Avantgarde der Moderne, sondern schwache Wiederkäuer und bemitleidenswerte Gestrandete.“ (1922. 26).

Am Beispiel Neumanns wird aber die Rolle des Futurismus recht deutlich, die er in noch stärkerem Maße in Polen und Ungarn zu spielen vermochte. Der Futurismus inspirierte entscheidend die Bildung von avantgardistischen Gruppierungen, die Hinwendung zu einer neuen Ästhetik mit neuen Ausdrucksformen, Themen und Motiven. In diesem Sinne scheint „Futurismus“ nicht zuletzt für Chwistek die geeignetste Bezeichnung für die neue Kunst zu sein, da diese erst eine Sache der Zukunft sei $(1918,45)$. Charakteristisch für die polnische und ungarische Avantgarde ist es aber, dass der futuristische Einfluss mit anderen Impulsen. die für die Erneuerung von Kunst und Literatur fruchtbar gemacht werden, verschmolzen wird. So ist für die frühe ungarische Avantgarde-Literatur, besonders aber für Kassák, vor allem die Kombination von Futurismus mit einer von Whitman beeinflussten Dichtung charakteristisch ${ }^{7}$, bei Czyżewski hingegen tritt der Futurismus in eine Symbiose mit dem Expressionismus sowie, in noch stärkerem Maße, mit der „kubofuturistischen“ Poesie Apollinaires.

Kassák bekannte sich selbst zum Einfluss Whitmans auf seine Dichtung und schreibt, von diesem. wie auch von allen großen Dichtern, so viel gelemt zu haben, wie notwendig. Unterschiede zwischen seiner und Whitmans Lyrik sieht Kassák im Formalen: wăhrend die freien Verse Whitmans ,intuitiv geprägt“ und "impressionistisch“ seien, zeichneten sich die eigenen dadurch aus, dass sie „so streng wie möglich komponierte Ganzheiten“ seien (vgl. 1916b. 23). Wie Deréky schreibt. habe Kassák von Whitman vor allem dessen Art übernommen, den Glauben an Fortschritt und Vernunft hymnisch und breit strömend auszudrücken, wohingegen der futuristische Einfluss in der Dynamisierung von Kassäks Sprache und poetischem Ausdruck gesehen werden könne. Das Ergebnis dieser Kombinaticn bestimmend fasst Deréky schließlich zusammen:

„Die Kassáksche Synthese von futuristischen Formelementen und der Verssprache Whitmans ergab eine dynamische, kraftvolle, optimistische Dichtung. Ihre Warme. ihre feierliche Entschlossenheit erinnerte die Kritiker und Literaturhistoriker bereits ab Mitte der 20er Jahre an den Ton von Oden. Hymnen oder Rhapsodien." (1991, 16)

\footnotetext{
7 Alle Bemerkungen aber den Futurismus und Whitman und ihren Einfluss auf die ungarische Avantgarde basieren auf: Deréky 1991, 12-16 und: 1996. 56.
} 
Wenngleich die Symbiose Futurismus-Whitman zwar wohl nur für Kassák charakteristisch ist, so sei doch erwähnt, dass es zum Beispiel in Tschechien wiederum der "Futurist" Neumann war, der die Bedeutung Whitmans für die moderne Literatur erstmals erkannte, nicht nur in thematischer, sondern auch in formaler Hinsicht (vgl. Drews 1983, 147-152). Und auch in Polen war es, wie erwähnt, der erste Autor futuristischer Gedichte, Jerzy Jankowski, der noch vor dem Ersten Weltkrieg, in ähnlicher Weise wie Neumann. über Whitman schreibt.

\section{Der Expressionismus}

Neben futuristischen, finden sich auch viele Elemente in den Gedichten Czyżewskis, die eng mit der expressionistischen Poetik verbunden sind. Dazu zählt vor allem das Bestreben des Künstlers, seine Vorstellungen bzw. Empfindungen sowie zum Teil extreme Bewusstseinszustände künstlerisch zu artikulieren.

Eine gewisse Symbiose expressionistischer und futuristischer Ideen findet sich auch in dem bereits erwähnten programmatischen Text Kassáks, den er 1916 für seine Zeitschrift „A Tett“ verfasste und auf den Szabolcsi näher eingeht (vgl. 1973, 289-291). Doch ist die Beziehung von Kassák, gerade was die Jahre vor 1920 betriff, zum deutschen Expressionismus anders. als die von Czyżewski. Denn während sich für den Formisten Parallelen zum „Sturm“-Kreis und zu der von Walden. Schreyer u.a. entwickelten Theorie der "Workunst“ ergeben. gewinnt für Kassák anfangs vor allem der Aktivismus, der von Hiller, Rubiner u.a. in der Zeitschrift „Die Aktion“ propagiert wurde, an Bedeutung (vgl. Rübberdt 1993, 123-139). Dies zeigt sich am deutlichsten darin, dass Kassák ab 1919 ebenfalls einen „Aktivismus“ propagierte, den er als „revolutionäre Lebensfuhrung der unterdrückten Menschen, des nur durch eigene Kraft erlösbaren Volkes" versteht, wobei er die Kunst als das „nützlichste Instrument im großen Kampf" (1919, 50 und 53) bestimmt. Kassák wollte eine Kunst, die mit der nach kommunistischen Idealen gestalteten Gesellschaft im Einklang steht und vor allem eine Kunst für das Proletariat ist. Damit ergab sich ein unmittelbarer Zusammenhang mit der im März 1919 ausgerufenen ungarischen Räterepublik, als deren Kunst sich die Aktivisten gerne verstehen wollten. Doch es kam zum Bruch zwischen Kassák und der politischen Führung der Räterepublik. der weniger eine avantgardistische. sondern vielmehr eine agitatorische Kunst vorschwebte (vgl. Deréky 1991, 18-20). Nach dem Sturz der Räterepublik floh Kassák, wie viele andere ungarische Künstler, Anfang 1920 nach Wien. Im Mai diesen 
Jahres erschien auch wieder die erste Nummer der Zeitschrift „Ma“ („Heute“), die Kassák noch in Budapest gegründet hatte, nachdem „A Tett“ 1916 verboten worden war. Diese Zeitschrif, die teilweise auch auf deutsch erschien, wurde zu einer der bekanntesten Avantgarde-Publikationen in ganz Europa. Durch sie wurde die ungarische Avantgarde-Kunst auch im Ausland rezipiert, wie zum Beispiel nach 1922 zunehmend auch im Berliner „Sturm“, dem sich Kassák nach seiner Emigration stärker zuwandte (vgl. Rübberdt 1993, 139-141).

Ähnlich wie der Futurismus, spielte auch der Expressionismus vorwiegend für die polnische und ungarische Avantgarde eine Rolle, fưr den Devêtsil hatte er so gut wie überhaupt keine Bedeutung. Zwar publizierte Teige in der „Aktion“ bzw. im „Sturm“, dennoch lehnte er den Expressionismus selbst ab. Erst die in den zwanziger Jahren gegründete Brünner Gruppe "Literámi skupina“" stand, vorwiegend durch ihr dramatisches Schaffen, dem Expressionismus näher (vgl. Drews 1975, 51-52).

\section{Apollinaire}

Neben Futurismus und Expressionismus kann mit der, wie sie Czyżewski selbst nannte. „futuristisch-kubistischen“ (1919c, 81) Dichtung Apollinaires", eine dritte Parallele zwischen seiner formistischen Lyrik und der europäischen Avantgarde bestimmt werden. Czyżewski kombinien dabei die drei besagten Impulse miteinander, wobei sich die besondere Năhe zu Apollinaire daraus zu ergeben scheint, dass dieser, ähnlich wie auch die Formisten und Czyzewski selbst. sowohl dem Kubismus, als auch dem Futurismus in ästhetischer Hinsicht nahe stand. Dennoch waren die Formisten, ebenso wie der französische Dichter polnischer Herkunft. selten zu jener ästhetisch-innovatorischen Radikalität bereit, die Marinetti in vielen seiner Manifeste vertritt. Czyżewskis Gedichte weisen gerade zu Apollinaire viele Parallelen auf, ihm verdankte er, um einen Ausdruck von Lipski zu verwenden $(1993,17)$, wohl an meisten.

Apollinaire hatte auch eine herausragende Bedeutung für die gesamte tschechische Avantgarde. Nach Neumanns „Offene Fenster”, auf deren Affinität zu Apollinaires „L'antitradition futuriste. Manifeste-synthèse“ ja bereits weiter oben hingewiesen wurde, war

\footnotetext{
- Vgl. dazu auch Bukowski (2002. 168), der die Ähnlichkeiten zwischen Czyzewski und den deutschen Expressionisten unter anderem auch mit der gemeinsamen ... .kubo-futuristischen' Grundlage" in Gestalt Marinettis und Apollinaires erklăn.
} 
Apollinaire das unumstrittene Idol der Avantgardisten des Devětsil und später des Poetismus. Als ein Beispiel dieser Verehrung kann das Gedicht "Guillaume Apollinaire“ von Jaroslav Seifert genannt werden, das als erstes in seiner 1925 veröffentlichten Sammlung „Auf den Wellen von TSF" abgedruckt ist und in dem es - in der Nachdichtung von Gerhard Rühm unter anderem heißt:

\section{n[...]}

denn ich dachte an Sie dichter

wie Sie vorbeispazierten vor jahren und lachelnd sagten: Hirte Eiffelturm" $(1985,7)^{9}$

Seifert spielt in diesen Zeilen auf den Beginn von Apollinaires Gedicht „Zone“ an, das mit der Feststellung ,Zuletzt bist du müde dieser veralteten Welt" (,A la fin tu es las de ce monde ancien" - 1969, 54-55) beginnt und den Übergang zwischen der alten und der eben beginnenden neuen Zeit mit dem Gegensatz Hirte - Eiffelturm zum Ausdruck bringt. Apollinaire wird dadurch, wie es zuvor auch bei Czyżewski angedeutet wurde, zum Dichter der neuen Zeit, die er mit neuen Mitteln poetisch zum Sprechen bringt - zum Beispiel durch die Verdichtung, das Zusammenziehen, das auch Seifert gebraucht: „Hirte - Eiffelturm“. Schließlich lässt Seifert noch das Leichte, Spielerische in Apollinaires Dichtung anklingen, das gerade auch in der poetistischen Vorstellung von Kunst und Literatur eine zentrale Rolle einnimmt, wenn er vom „vorbeispazieren“ und „lächelnd sagen“ spricht. Wie Drews ausführt. war es vor allem die Art und Weise Apollinaires zu dichten, zum Beispiel die überraschenden Assoziationen oder die freien Juxtapositionen, die auf die tschechische Avantgarde-Dichtung den nachhaltigsten Einfluss auszuüben vermochte (vgl. Drews 1983, 209-211).

\section{Der Dadaismus}

Am geringsten blieb Apollinaires Einfluss vorerst auf die ungarische Avantgarde-Literatur, trotz gelungener Übersetzungen. die bereits um 1916 in „A Tett" veröffentlicht wurden. Deréky erklärt diesen Umstand damit. dass Apollinaires Dichtung vielfach als zu individuell, zu spielerisch oder zu unernst empfunden wurde, als dass sie sich mit dem Wunsch vieler ungarischer Avantgardisten nach einem neuen monumentalen Stil hätte vereinen lassen (vgl.

\footnotetext{
'Bei dieser Ausgabe handelt es sich um einen deutschsprachigen Reprint der tschechischen Originalausgabe von 1925. Ein Jahr zuvor - 1984 - hatte Seifert den Literaturnobelpreis erhalten.
} 
Deréky 1991, 15) ${ }^{10}$. Erst um 1921-22, in den Jahren der Wiener Emigration scheint Apollinaire, dann aber in Verbindung mit gewissen dadaistischen Tendenzen, auch im Werk Kassáks stärkere Spuren hinterlassen zu haben. Als ein Beispiel kann hier, aufgrund seiner Komposition, die durch die unmittelbare Aneinanderfügung unterschiedlicher Wirklichkeitsfragmente und Ereignisse an Apollinaires „Zone“ erinnert, das Gedicht ..Das Pferd stirbt und die Vögel fliegen hinaus“ genannt werden (vgl. Deréky 1991, 55-59). Außerdem erwähnt Kassák in diesem Gedicht, in dem er von seiner Reise nach Paris erzählt. die er $1909 \mathrm{zu}$ Fuß unternahm, den „simultaneistische[n] poet[en] guillaume apollinaire.“ (1921, 95). Der zunehmende dadaistische Einfluss auf die Dichtungen Kassáks und anderer mit dem "Ma" verbundener ehemaliger Aktivisten in den Jahren ihrer Wiener Emigration wird oft mit ihrer doppelten Enttäuschung erklärt. die sie um 1920 erlitten. Erstens, weil die Führung der Räterepublik damals nicht bereit war, die aktivistische Kunst als die „ihre“ anzuerkennen und zweitens, da sich die Räterepublik selbst kaum ein halbes Jahr halten konnte. Szabolcsi schreibt dazu: „All hope had vanished, and under the influence of despair the group moved in the direction of Dadaism." $(1973,293)^{\prime \prime}$. Der Dadaismus, gewissermaßen als „Anti-Kunst“, erscheint nach diesem Verständnis als ein möglicher Ausweg aus der politisch-engagierten Kunst des Aktivismus.

In gleicher Hinsicht steht der Dadaismus aber auch für eine Kunst des Spielerischen, der Unterhaltung und der Freude, teilweise auch des Unernsten, ebenso wie für eine Kunst, die in diesem Sinne das Leben zu ästhetisieren versucht. Damit einher geht aber die Dehierarchisienung der Kunst selbst, was gerade in den mitteleuropäischen Ländern, deren Kunst sich lange Zeit einer großen Sache verpflichtet sah, nämlich dem Kampf um nationale Souveränität. schwer mit der herrschenden Vorstellung von „Kunst“" vereinbar schien. So bildete sich zwar, vielleicht auch aus diesem Grund, in ganz Mitteleuropa keine einzige eigenständige dadaistische Gruppe heraus, dennoch lassen sich dadaistische Einflüsse in den Programmen vieler mitteleuropäischer Avantgarde-Strömungen feststellen. In diesem Sinne trifft auch speziell für die mitteleuropäische Avantgarde zu, was Bojtár bezüglich des Dadaismus in der osteuropäischen Avantgarde schreibt:

\footnotetext{
${ }^{10}$ Die Apollinaire-Übersetzungen stammten von Tivadar Raith, der in den spateren Jahren auch Versuche unternahm. die Verssprachen Apollinaires und Whitmans miteinander zu kombinieren (vgl. Deréky 1991, 47-49 bzw. 88-89).

"Vgl. auch: Deréky 1991, 34 und 44. Hier wird beschrieben. dass auch die Literaturkritik Kassáks fruhe Wiener Dichtungen gerne mit Anarchie. Unverstăndlichkeit. Nihilismus, ..kurz gesagr" eben mit Dadaismus in Verbindung brachte, was aber unter anderem zur Folge hatte. dass Kassáks aktivistische Lyrik der vorhergetenden Jahre aufgewertet wurde.
} 
.In East-Europe the great value of dadaism was that it completely destroyed the image art had of itself, of world an man. [...; Dadaism; M.E.] brought about the liberation of ant and life from rigidity, the gaiety of ,all the same', merriment, joke, masquerade, self-irony, grotesque vision. Dadaism believed in one value only: in life made still more strange, more wild, more animated and cheerful by new ideas, the rule of fantasy. In East-Europe, where dadaism was the ,silent partner', of other trends, this, at times ecstatic. cheerfulnessprogram built into other - futurist, constructivist - socially rather concepts, increasing their optimism." (1992, 39 und 41)

In dieser Hinsicht kann etwa von dadaistischen Elementen im Programm des tschechischen Poetismus gesprochen werden. So ist beispielsweise im ersten Manifest, das den Titel „Poetismus“" trägt zu lesen:

.Das Kunstwerk [...] ist in seinem Wesen ein Geschenk oder ein Spiel ohne Verpflichtungen und Folgen. [...] Die Kunst, die der Poetismus bringt, ist leger, ausgelassen, fantastisch, verspielt, unheroisch und erotisch. Es gibe keine Spur Romantismus in ihr. [...] Der Poetismus ist keine Kunst. d.h. keine Kunst im bisherigen romantischen Sinn. Er machte sich an die reguläre Liquidierung der bisherigen künstlerischen Absichten [...]. Er kann der Kunst gerade das rechte $\mathrm{Maß}$ geben, uberbewertet nicht ihre Wichtigkeit, weiß, daß sie nicht wertvoller ist als das Leben. Die Clowns und die Dadaisten haben uns diesen asthetischen Selbstskeptizismus gelehrt. [...] Der Poetismus ist vor allem ein modus vivendi." (Teige, 1924, 45, 46, 49 und 50)

Der Autor dieses im Mai 1924 veröffentlichten Manifestes, Karel Teige, schreibt übrigens in einem späteren Buch, dass die Poetisten uber die Wiener Ma-Gruppe rund um Kassák mit dem Dadaismus in Berührung gekommen seien (vgl. Bojtár 1992, 38). Aus dem angeführten Zitat wird deutlich, dass der Poetismus von seinen Repräsentanten vor allem als Haltung, die der Kunst, ihrem Wesen und ihren Aufgaben gegenüber eingenommen wird, begriffen wird. In ästhetisch-stilistischer Hinsicht wollte Teige die poetistische Kunst dem Konstruktivismus verpflichtet sehen, wie er im selben Manifest betont: ..Der Poetismus ist die Krönung des Lebens, seine Basis ist der Konstruktivismus. [...] Der Poetismus ist [...] dessen unentbehrliche Ergänzung. Er basient auf seinem Grundriß.“ (1924, 46). Dieses Bekenntnis zum Konstruktivismus erlaubt es nun, eine Parallele zwischen dem Poetismus und der polnischen Avantgarde, allerdings zur Krakauer Avantgarde mit Peiper und Przyboś, sowie, wie bereits erwăhnt, auch zu Kassák und der Wiener Ma-Gruppe zu ziehen. Auch für diese Künstler und Theoretiker nimmt in der ersten Hälfte der zwanziger Jahre der Konstruktivismus eine zentrale Position in ihrem ästhetischen Denken ein, wovon weiter unter noch die Rede sein wird.

In der polnischen Literatur war mit dem Dadaismus am stärksten die Gruppe der Warschauer Futuristen rund um Aleksander Wat und Anatol Stern verbunden. Dadaistische Losungen finden sich aber nicht nur in ihren Texten (zum Beispiel: „Gga. Erster polnischer futuristischer Almanach“ - „Gga. Pierwszy polski almanach futurystyczny“) sondern auch in den Manifesten der Krakauer Futuristen „1Tagesblatt der Futuristen“ und „Das Messa im Bauch“, an denen ja auch die Formisten Czyżewski und Chwistek mitarbeiteten. 
Wenngleich in Czyżewskis Gedichten durchaus Elemente herausgearbeitet werden könten. die mit dem Dadaismus in Verbindung gebracht werden könnten, etwa die Betonung des Spielerischen und Unterhaltsamen in der Kunst, war gerade für Chwistek, der im selben Jahr, in dem die futuristischen „Eintagesblätter“ erschienen, sein philosophisch-ästhetisches Hauptwerk über die verschiedenen Wirklichkeiten fertig gestellt und in Buchform herausgebracht hatte, ein mit dadaistischen Elementen durchsetzter Futurismus wohl kaum ein überzeugendes ästhetisches Angebot. Wie beschrieben, machte Chwistek in den dreißiger Jahren die Futuristen und deren der Öffentlichkeit verordnete „Schocktherapie“" zu einem Teil für das Scheitern des Formismus mit verantwortlich.

Auch der zweite formistische Theoretiker, Witkacy, steht, um es vorsichtig zu sagen, einer futuristisch-dadaistischen Kunst skeptisch gegenüber und bedauert in einem Aufsatz auch die Teilnahme der Formisten Chwistek und Czyżewski an den futuristischen Aktionen (1923a, 360 und 362). Doch nimmt er zum Futurismus nicht nur in kritischen Aufsätzen Stellung, in denen er vergleichend auch auf seinen eigenen Ansatz der "Reinen Form“ eingeht (zum Beispiel: 1922f), sondern versucht auch, die jungen Wilden gewissermaßen mit ihren eigenen Waffen zu schlagen. So erscheint im August 1921 in Zakopane das von Witkacy mitherausgegebene Flugblatt unter dem Titel: „Lackmuspapier. Die neueste künstlerische Neuheit!! Der Pürflunkerismus!! Die Theorie der reinen Flunkerei. Die besten Werke der Pürflunkeristen“ (,Papierek lakmusowy. Najnowsza artystyczna nowalia!! Piurblagizm!! Teoria czystej blagi. Najlepsze utwory piurblagistów” - vgl. in Auszügen: Witkiewicz 1921d. 254). In einer manifestartigen Einleitung sowie in den sich daran anschließenden „besten Werken" werden viele der von den Futuristen vertretenen Positionen in absurder Weise auf die Spitze getrieben und somit lächerlich gemacht. Dass Witkacy damit nicht selbst einen ernsthaften bzw. ernst gemeinten Beitrag zur „neuen Kunst“ leisten will, scheint sich wohl vor allem aus seiner eigenen ästhetischen Theorie zu erklären, in der er das künstlerische Schaffen ja direkt mit ".metaphysischen Fragen“ in Verbindung bringt, was im Prinzip das ziemlich genaue Gegenteil zur dadaistischen Dehierarchisierung der Kunst bedeutet. In einur Fußnote des „pürflunkeristischen“ Manifestes geht Witkacy übrigens auch auf den Formismus ein und schreibt: „Die Futurisierung und Dadaisierung der Formisten scheint die Frage von ein paar Wochen. bestenfalls Monaten zu sein, sofern diese armen aufrichtigen Mammuts am Rande des Abgrundes nicht »erwachen “.” (1921d. 254). Sah also demnach auch Witkacy, wie zuvor schon Chwistek, den Formismus vom polnischen Futurodadaismus bedroht?

Die bisherigen Ausführungen zeigen. dass die Herausbildung der mitteleuropäischen Avantgarde von der Auseinandersetzung mit den zumeist einige Jahre zuvor entstandenen 
Strömungen der westeuropäischen Avantgarde begleitet war. Es ist klar, dass die mitteleuropäische Avantgarde die bereits gemachten Erfahrungen ihrer Vorläufer nicht einfach ignorieren konnte. Somit finden futuristische oder expressionistische Ideen Eingang sowohl in die Programme, als auch in die dichterischen Werke mitteleuropäischer Avantgardisten. Charakteristisch scheint dabei aber zu sein, dass diese verschiedenen Einflüsse, nachdem sie kritisch hinterfragt wurden, vielfach miteinander kombiniert werden. Somit gilt gewissermaßen für die ganze mitteleuropäische Avantgarde, was Kassák stellvertretend bemerkt: ..During my career I have become associated with all the more important -isms, and I have learned something from each. without actually having joined any of them." (zit. n.: Szabolcsi 1973, 287).

Da nun die mitteleuropäische Avantgarde aber nicht als buntes Sammelsurium begriffen werden soll, das verschiedenste Einflüsse locker in sich vereint, muss an diesem Punkt die Frage gestellt werden, wie diese Einflüsse in die eigenen Programme integriert werden bzw. wie auf ihnen und ihren Leistungen aufbauend, der Versuch unternommen wird, eine "neue Ästhetik" zu entwerfen. zu deren Merkmalen nicht selten auch ihr ganzheitlicher bzw. synthetischer Anspruch zählt.

\subsection{Mitteleuropäische Entwürfe einer „neuen Kunst“}

Gerade in Mitteleuropa ist das für die gesamte Avantgarde charakteristische Bewusstsein, am Beginn einer ganz neuen Zeit zu stehen, einer der wesentlichsten Impulse, der die Suche nach neuen theoretischen Grundlagen von Kunst und Literatur beeinflusst. Dies betrifft sowohl die ästhetische Seite des künstlerischen Ausdrucks, wie allgemein auch die Frage nach der Funktion von Kunst und Literatur innerhalb der Gesellschaft.

Das historische Ereignis, mit dem dieser Epochenumbruch unmittelbar verknüpft wird, ist, neben der Oktoberrevolution. insbesondere der Erste Weltkrieg, auf dessen ambivalentes Verständnis eingangs bereits hingewiesen wurde. So wurde es verständlicherweise zum einen begrüßt, dass in seiner Folge wieder ein souveräner polnischer, ungarischer und tschechoslowakischer Staat entstehen konnten. Daneben stand er eben für den Beginn einer neuen Ära, in der es möglich schien, dass viele gesellschaftliche, politische und zivilisatorische Utopien realisiert werden können. zum Beispiel eine gerechte Gesellschaftsordnung. aufgebaut auf der Idee des Kommunismus oder das Zeitalter des technischen Fortschritts. Zum anderen waren die Gräuel des Krieges vielen Künstlern noch 
bewusst in Erinnerung, manchmal sogar, wie auch im Falle vieler deutscher oder französischer Künstler, von den eigenen Erlebnissen an der Front.

Diese ambivalente Einschätzung des Krieges wird in vielen dichterischen und programmatischen Werken artikuliert. Als ein Beispiel ist hier insbesondere Czyżewskis Gedicht „Elektrische Visionen“ zu nennen, das in den drei Einzelvisionen nacheinander Schrecken und Zerstörung des Krieges sowie Hoffnung und Utopie der nach seinem Ende neu angebrochenen Zeit schildert und somit ein eindrucksvolles Bild der Nachkriegswirklichkeit vermittelt. Damit verbunden ist das von Czyżewski zum Beispiel in "Stadt an einem Herbstabend” verwendete Dămmerungsmotiv, durch das er, ähnlich wie Pinthus, zugleich Ende und Anfang zum Ausdruck zu bringen vermag "2. Auch in Kassáks Gedicht "Handwerksleute“, das den Erbauern und Gestaltern der Zukunft gewidmet ist, wird das Nebeneinander von Krieg und neuer Zeit thematisiert. Nach der Schilderung von „Helden“, die mit "Hurra und Trara in die Schlacht” zogen und nun ,auf Feldern vom Blitz zerschmettert, ringsum verstreut in der ganzen Welt“ liegen sowie der Erwähnung des Todes vieler unschuldiger Menschen, des „verronnene[n] Blut[s]“”, heißt es:

„Wir aber sind von allem schon fern. [...]

Gestern weinten wir noch, und morgen vielleicht wird das Jahrhundert schon unsre Sache bewundem.

Ja! Denn aus unseren groben, klobigen Fingern drăngt schon die neue Kraft, und morgen schon feiern wir Richtfest auf neuen Mauern." (1915b, 15)

Den Krieg nun weit hinter sich lassend, beschreibt Kassák im weiteren Verlauf des Gedichtes dann diese ,neuen Mauern", wobei der Bogen von Wolkenkratzern über Brücken bis hin zu Eisenbahnen etc. reicht ${ }^{13}$. Das Gedicht endet dann schließlich mit:

,jubeln sollen die neuen Dichter, die das Antlitz der Zukunft vor uns besingen:

in Paris und Rom, in Berlin und Moskau, in London und in Budapest!" $(1915 \mathrm{~b}, 16)$

In diesen Sătzen kommt dazu Kassáks Forderung zum Ausdruck, die er auch in einigen seiner programmatischen Texte ausführt, nämlich, dass die moderne Literatur sich der gegenwärtigen Zeit zuwenden soll. Dass dies gleichermaßen für Dichter aus allen Teilen Europas gelten soll, verdeutlicht nur noch einmal den gesamteuropäischen Charakter der Avantgarde.

\footnotetext{
$12 \mathrm{Vgl}$. dazu auch: Rubberdt $(1993,40)$, die darauf verweist, dass sich dieses Motiv in der ungarischen expressionistischen Literatur nur auf den Beginn, auf den Anbruch beziehe, womit der doppeldeutige Charakter fehlt.

${ }^{13} \mathrm{Vgl}$. dazu auch Rubberdt (1993, 134-135), die bezuglich des Krieges in Kassáks frahen Gedichten ausfuhrt, dass es fur ihn charakteristisch sei, das Kriegsgeschehen in die Vergangenheit zu verbannen, hingegen aber die Zukunft in die Gegenwart zu heben. Rubberdt benennt dies auch als den wichtigsten Unterschied zur Kriegslyrik der ,Aktion“", mit der sie Kassáks Kriegsdichtungen vergleicht.
} 
Das doppelte Antlitz des Krieges ist auch einer der Leitgedanken von Tadeusz Peipers bekanntem Programmtext mit dem Titel „Der Ausgangspunkt“ („Punkt wyjścia“) aus der ersten Nummer seiner 1922 neu gegründeten Zeitschrift „Zwrotnica“. Erst durch den Krieg, so Peiper, habe sich das 20. Jahrhundert wirklich entfalten können. Nach seinem Ende sei es aber nicht nur im politischen, sondern vor allem auch im kulturellen Bereich zu grundlegenden Veränderungen bzw. Neuerungen gekommen:

"Erst der Krieg fuhrte den Menschen auf Wege, auf denen er dem Geist des Jahrhunderts begegnen und
diesem folgen sollte: Von den Zinnen der Zukunft betrachtet, war der vergangene Krieg ein bedeutsames
Ereignis auch fur die Kultur des Geistes. Wie, zerstorte er denn nicht? Er zerstorte. Aber jeder seiner
Zerstorungen ging ein gigantischer schøpferischer Akt voraus. Jeder Verlust folgte aus einer Handlung, die
Gewinn bedeutete. Seine schrecklichen Todesmaschinen kündigten die zukunftigen, măchtigen Maschinen
des Lebens an. Er zerstorte die Zivilisationsprodukte mit den Mitteln einer höheren Zivilisation." (1922c, 56)

Peiper versucht also bereits knapp vier Jahre nach dem Ende des Krieges, dessen überzeitliche Bedeutung, nämlich als Epochenumbruch zu definieren, befreit von jeglichen unmittelbaren Emotionen. Diese Bedeutung sieht er insbesondere darin, dass der Krieg dem technisierten Zeitalter, in dem die Maschinen das Leben der Menschen maßgebend beeinflussen werden, zum Durchbruch verholfen habe ${ }^{14}$. Dass Peiper in seine Argumentation eben auch das Töten des Krieges einbindet, mag nur noch einmal die zuvor angesprochene ambivalente Einstellung dem Krieg gegenüber unterstreichen.

Eine ähnliche Haltung nehmen auch Kassák und Teige ein. Doch im Unterschied zu Peiper, der sich in erster Linie mit ästhetischen Fragen beschäftigt, sehen Kassák und Teige darüber hinaus auch eine neue gesellschaftlich-politische Funktion von Kunst und Literatur, die sich ebenfalls aus den durch den Weltkrieg veränderten Verhältnissen ergibt. Nachdem Teige im "Manifest des Poetismus“ die Schrecken des Krieges noch einmal in Erinnerung gerufen hat, schreibt er, nun auf die Kunst bezogen:

„Die Kunstgeneration, die aus dem Krieg geboren worden war, vom sozialen Wellenschlag taub und hingerissen vom Kampf gegen die alte Welt, für neue Ordnungen, bekannte sich zum Schlagwort der "proletarischen Kunstu. die sich von der Sentimentalitat privater erotischer und ethischer Krisen, von der expressionistischen Dekadenz und vom ästhetischen Konfessionalismus und Exhibitionismus, vom Subjektivismus loslossen und mit der neuen Klassenrealităt, mit den typischen und kollektiven Lebensformen verschmelzen wollte." (1928, 71-72)

Wie Teige sich diese proletarische Kunst vorstellt, beschreibt er bereits einige Jahre zuvor, und zwar in seinem 1922 entstandenen Aufsatz „Neue proletarische Kunst“. Diese Kunst für die Arbeiter sei in erster Linie eine Kunst für den Menschen selbst. dessen wesentlichste

\footnotetext{
14 Im Unterschied zu fruheren Zeiten, in denen Mensch und Maschine sich feindlich gegenuberstanden, sieht Peiper seine Gegenwart von einer Umkehrung dieses Verhăltnisses geprałgt: die Maschine, gewinnt das Herz des Menschen". seit der Mensch die durch sie bewirkte Umgestaltung seines Lebens positiv zu sehen begonnen habe. was letztendlich auch die Kunst grindlegend emetrere (vgl. 1922c. 74-81).
} 
Kennzeichen „Kollektivismus" und "soziale Tendenziosität" sind (1922, 30). Während ersterer vor allem für die Nähe dieser Kunst zum Volk, zu ihrem Publikum steht (vgl. Drews 1975, 71), sei mit dem tendenziösen Charakter dieser Kunst gemeint, dass sie die kommunistischen Ideale fordemd zum Ausdruck bringt, wodurch der Dichter letztendlich, und hier beruft auch Teige sich auf den Aktivisten Hiller, „mit Worten Ereignisse beeinflussen" könne $(1922,31)$.

Und schließlich gelangte auch Kassák in seinem Text „Programm“ aus „A Tett“ zu einer ähnlichen Bestimmung der gesellschaftlichen Funktion der Literatur, die sich auch für ihn in Folge des Weltkrieges ergibt:

.Dabei warten auf die Kunst, und insbesondere auf die Literatur als den Inhaber der am unmittelbarsten wirksamen Ausdrucksmittel, bei der Gestaltung des Menschen der kommenden Generation große Aufgaben. [...]

Die neue Literatur (zu deren Kraftigung und Entwicklung von der weltspleenigen Stimmungstăndelei der vorangegangenen Generation zur Lyrik des bewussten Willens der Krieg wesentlich beigetragen hat. wenngleich sie nicht im Krieg entstand) muß als notwendige gesellschaftliche Erscheinung stăndig den Kontakt zu allen progressiven wirtschaftlichen und politischen Bewegungen halten, und ihre fuhrenden Vertreter mússen wie die kommerziellen, industriellen und politischen Faktoren eine fuhrende Rolle bei der Lenkung der Staatsmaschinerie, bei der Revision der bestehenden und der Formulierung der neuen Gesetze fordern. $*$ (1916a, 17-18)

Sowohl Kassák. als auch Teige, fordem in den angeführten Zitaten eine von rein ästhetischformalen Spielereien abgegrenzte, politisch engagierte Kunst, wobei beide dem Kommunismus nahe stehen. Im Zentrum ihrer Kunst steht der (neue) Mensch, der Gestalter der Zukunft, selbst - (neue) Literatur und Kunst dienen dabei seiner geistigen Entwicklung und Formung. was Kassák zum Beispiel in seinem Text "Aktivismus" in die Formel „Erschaffung des neuen Menschen durch die neue Kunst" $(1919,53)$ fasst und was als Leitgedanke in vielen programmatischen Texten Kassáks immer wieder auftauch (zum Beispiel auch in seinem Vorwort zum „Buch neuer Künstler”). Doch trotz ihrer Nähe zur Politik und ihrer Forderung nach tendenziöser, engagierter Kunst, wollen sowohl Kassák, als auch Teige die kreative Autonomie der Kunst bewahren und sprechen sich dezidiert gegen eine agitatorische, von Parteikalkül beeinflusste Kunst aus. Für Kassák bedeutete dies, wie schon erwähnt, auch das Zerwürfnis mit der politischen Führung der ungarischen Räterepublik. der er seine aktivistische Kunst ja als offizielle Kunst anbieten wollte, für Teige und den Devẽtsil die Abgrenzung von Neumanns Proletkult.

Dass sich die Frage nach der politisch-gesellschaftlichen Rolle von Kunst und Literatur nach dem Ersten Weltkrieg in Mitteleuropa als drängend erwies, ist aber nicht nur in der neuen politischen Situation, in der sich die nun wieder souveränen Staaten Polen. die Tschechoslowakei. Ungarn und andere, nach 1918 befanden, begründet. Die Frage stellte sich 
auch deswegen, da Kunst und Literatur gerade in Mitteleuropa seit der Romantik eng mit politischen Angelegenheiten, vor allem mit der Sache der nationalen Unabhängigkeit, verknüpft waren. Auch aus diesem Grund scheint es 1918 notwendig, das Verhältnis zwischen Politik und Literatur neu zu überdenken.

Allerdings unterscheidet sich in diesem Fall die Lösung, die die Formisten anbieten. grundlegend von der Kassáks oder Teiges. Wie Chwistek. Czyżewski und Witkacy in ihren Schriften betonen, betrachten sie gerade durch die Unabhängigkeit die „nationale“ bzw. „politische“ Frage für Kunst und Literatur als erledigt, was nun ausschließlich interessiere, seien rein formal-ästhetische Probleme: „My bez programu dążymy do stworzenia nowej ery wartości estetycznych, tj. wartości sztuki“, schreibt Czyżewski (1921a, 176) in „Das Begräbnis der Romantik“"15.

Aber auch für Kassák und Teige wurde im weiteren Verlauf der zwanziger Jahre zunehmend die ästhetische Seite der Kunst wichtiger, als deren politisches Engagement. Kassák verarbeitete, wie erwähnt, seine politische Enttäuschung nach 1920 in der Wiener Emigration und auch Teige betont in seinen poetistischen Manifesten immer stärker, wie Drews es formulier, den „Eigencharakter der Kunst. [...] ihr Eigenleben innerhalb der Gesellschaft.“ $(1975,77)$. So gelingt es beiden. Kunst im Rahmen ihrer konstruktivistischen Ansätze, die sie ab 1922 entwickeln, als autonomes, jedoch im gesellschaftlichen Sinne relevantes, Handeln zu begreifen.

Im Bewusstsein einer neuen Zeit und einhergehend mit der Neubestimmung von Aufgabe und Funktion der Kunst, werden nach 1918 neue ästhetische Ansätze in der mitteleuropäischen Avantgarde entwickelt. Dies geschieht auch, wie schon zuvor angedeutet. in der kritischen Auseinandersetzung mit den früheren westeuropäischen (und russischen) AvantgardeStrömungen, als deren Fortsetzung sich die in Mitteleuropa neu entstandenen Gruppen betrachten. Ihr Wunsch, ihre Kunst in einen gesamteuropäischen Kontext zu stellen, wird dadurch gleichermaßen deutlich.

In seinem Aufsatz „Der Formismus” von 1919 beschäftigt sich Chwistek mit der angesprochenen Problematik (vgl. 1919a, 94-99, besonders: 96-99). Er stellt unter anderem fest, dass Expressionismus. Kubismus und Futurismus zwar selbst zu keinen großen künstlerischen Leistungen geführt hätten, jedoch durch ihre wichtigen Experimente die Möglichkeiten der künstlerischen Darstellung der Wirklichkeit bedeutend erweitert hätten. Dadurch habe sich die gegenwärtige Kunst von einer mimetisch-naturalistischen

is „Ohne Programm streben wir danach. eine neue Ära asthetischer Werte, d.h. Werte der Kunst, zu schaffen." Eine ahnliche Meinung vertitt auch Chwistek (vgl 1919a, 98). 
Kunstauffassung lösen sowie von viel störendem Ballast befreien können, insbesondere im thematisch-motivischen Bereich. Die westeuropäischen Strömungen hätten damit, so Chwistek, die notwendigen „Vorarbeiten“ für das Streben nach einem „,neuen Stil“ geleistet. dem der Formismus sich zu nähern versuche: „Formizm jest próbą stworzenia nowego stylu na podstawie pojęć realizmu i piękna, które rozwinęły się z doświadczeń kubistów, futurystów i ekspresjonistów.“ $(1919 a, 99)^{16}$. Demzufolge ist die formistische Kunst in stilistischer Hinsicht auch mit ihren Vorläufern verwandt, wie Chwistek ebenfalls ausführt: durch die „nüchternen und einfachen Formen“ („formy surowe i proste“) mit dem Kubismus, durch das „Streben, die Bildfläche mit einheitlichen Gegenständen auszufüllen“ („dążenie do wypełnienia plótna przedmiotami o charakterze jednolitym “), mit dem Futurismus und durch die „Tendenz zur synthetischen Erfassung der Bewegung“ („tendencja do syntetycznego ujęcia ruchu“) mit dem Expressionismus (1919a, 99). Deutlich wird somit Chwisteks Bemühen erkennbar, den Einfluss der westeuropäischen Strömungen auf den Formismus genau zu bestimmen, dadurch zugleich aber auch festzulegen, wo das genuin „Formistische“ beginnt. Damit erreicht er eben zweierlei: neben der Betonung der Eigenständigkeit des Formismus auch dessen Kontextualisierung innerhalb der europäischen Avantgarde.

Sehr ähnlich, und daher gut mit Chwisteks Aufsatz vergleichbar, ist das Vorwort Kassáks zum „Buch neuer Künstler”, das er 1922 in Wien auf deutsch herausbrachte. Kassák versucht darin, genau wie zuvor Chwistek, die einzelnen westeuropäischen Avantgarde-Strömungen als Wegbereiter und Vorläufer des von ihm nun verfolgten konstruktivistischen Ansatzes zu bestimmen. Der Futurismus, als die erste der „,neuen Richtungen“ habe dabei die „rohen, noch richtungslosen“ Kräfte aus den Fesseln der klassischen Ästhetik befreit (1922a, 100). Als Reaktion darauf sei der Expressionismus entstanden, den Kassák vor allem als Dichtung, die das Innerste des Menschen zum Ausdruck bringt, beschreibt, allerdings - und das mag, nicht zuletzt wegen Kassáks eigener expressionistischer Vergangenheit, doch ein wenig verwundern - ziemlich abwertend: so ist dabei von "Ichkrankheiten“ einer „tödlich verliebten kleinbürgerlichen Seele“ ebenso die Rede, wie von den expressionistischen Schöpfungen ais „verschüttete Empfindungspfüzen im Mondschein.“(1922a, 100). Erst im Kubismus sieht Kassák nun die ..erste Kunstrichtung des modernen Zeitalters“ (1922a, 100), was er insbesondere mit der rationalen Konstruktion und der Komponiertheit kubistischer Kunstwerke in Verbindung bringt. Gescheitert sei der Kubismus allerdings noch an seiner

\footnotetext{
16 "Der Formismus ist der Versuch, einen neuen Stil auf der Grundlage der Begriffe des Realismus und des Schönen zu schaffen, die sich aus den Erfahrungen der Kubisten, der Futuristen und der Expressionisten entwickelt haben."
} 
analytischen Methode. Im Dadaismus schließlich sieht Kassák die notwendige Kraft, die durch ihr revolutionäres Zerstörertum die neue Zeit vom drückenden Balast der Vergangenheit habe befreien können:

..Der Kubismus kam zur emeuerten Menschheit, um etwas zu bauen und vergaß, daß die Raum: noch mit den Trammern von gestem uberfullt waren. [...], so mußte der Dadaismus als Gegner aufteten, uf daß die Bahn frei wird und der Flieger mit dem Ballast der Zweckmaßigkeit nicht auch die Leichen ter Ahnen mitzuschleppen braucht. Was der Kubismus uns vermachte, ist der Glaube des Suchens und die Sehnsucht nach Reinheit. Was wir vom Dadaismus bejahen, ist der Fanatismus der Vernichtung.“ (1922a. 10 l)

In diesem Zitat wird noch einmal der „Vorläufercharakter” von Kubismus und Didaismus deutlich, wobei, wie zuvor Chwistek, auch Kassák genau benennt, worin dieser Einfluss besteht. Beide verweisen in ihren Texten darüber hinaus noch auf den experinentellen. fragmentarischen Charakter futuristischer oder dadaistischer Kunstwerke, die aber gerade auch in dieser Hinsicht für die gegenwärtige Kunst von Bedeutung sein können. Bei Kassák kommt schließlich daran anknüpfend noch sein Bekenntnis zu der neuen, gegerwärtigen Epoche der Menschheit, dem „Zeitalter der Konstruktivität“(1922a, 102), zum Ausduck.

Und schließlich stellt auch Teige in seinen Programmen den Poetismus als letztes Gked in die Entwicklung der Kunst des (bisherigen) 20. Jahrhunderts. Dies zeigt sich zum Beispiel im ersten Satz des „Manifestes des Poetismus", das er 1928, vier Jahre nach der ersten Proklamation, verfasst und in dem er die Anfänge des Poetismus noch einmal beschreibt:

.im Augenblick, als das letze Aufflackern der ismen, des Dadaismus, Futurismus, Expretsionismus, Kubismus. Suprematismus erlosch, in einer Zeit der finsteren Verwirtung und peinlichen Stagnaton in allen Ateliers und Arbeitszimmern. [...] in Prag. [...], in den Jahren 1923 und 1924, also vor vier iunf Jahren wurde der Poetismus protlamiert." $(1928,70)$

Was Chwistek und Kassák also noch mit dem Experimentalcharakter der frühen AvantgardeStrömungen beschreiben, deutet Teige hier als deren Stagnation - sie seien zu einem Punkt gekommen, an dem sie sich nicht mehr hätten weiterentwickcln können. Teige betont in seinem Manifest außerdem den europăischen Kontext, in dem der Poetismus verstanden werden müsse: „Wir haben uns in den Rhythmus des kollektiven europäischen Schaffens eingeglieder, in einen Rhythmus, dessen Metronom Paris war [...].“ (1928, 75). Damit artikuliert Teige seine Überzeugung, dass die gegenwärtige tschechische wie eưopäische Kunst und Literatur auf denselben Grundlagen basiert, die er im Anschluss daran auch bestimmt. So befasst er sich in weiteren Verlauf seines Manifestes unter anderem mit Poe, Baudelaire, Verlaine, Mallarmé und schließlich ausführlich mit Marinetti und Apollinaire, wobei Teiges Text in mancher Hinsicht an Czyżewskis Aufsatz ..Die Poesie der 
Expressionisten und Futuristen" erinnert, gerade wenn es um die Grundlagen geht, von denen die gegenwärtige Dichtung ausgeht.

Vor diesem Hintergrund betrachtet, wird, zum Beispiel im Falle der formistischen Theorien von Chwistek und Witkacy, ihre Motivation verständlich, völlig neue Grundlagen der Ästhetik zu suchen. Chwistek bestimmt insgesamt vier Wirklichkeiten, die er auf die Kunst überträgt und durch die er das künstlerische Schaffen insgesamt zu erfassen versucht, wobei er, wie im dritten Kapitel ausgeführt wurde, davon ausgeht. dass die unterschiedlichen künstlerischen Schulen (Realismus, Impressionismus etc.) auf einer jeweils anderen Konzeption der Wirklichkeit basieren. Für die neueste Kunst, und das gilt gleichermaßen für alle avantgardistischen Strömungen, bestimmt er dabei die sogenannte „visionäre Wirklichkeit". Dem Künstler, der sich dieser Wirklichkeit verpflichtet sieht, geht es nicht mehr um Mimesis, sondern darum, sein eigenes Schaffen, seine Wahrnehmung der Wirklichkeit zum Ausdruck zu bringen. Eine zentrale Rolle spielt dabei die Form der Kunstwerke, die zur Grundlage und Essenz dieser neuen Ästhetik wird. Auch Witkacy bestimmt in seiner Theorie der "Reinen Form“ ein prinzipielles Verständnis von Kunst. nämlich, wie ebenfalls im dritten Kapitel ausgeführt, als Objektivierung der existenzbezogenen „metaphysischen Gefühle". Beide wollen die Kunst von ihr wesensfremden Tendenzen, wie politischer Vereinnahmung, Berauschung der Sinne, leichter Unterhaltung etc.. befreien und diese gleichermaßen von der Verpflichtung der möglichst naturgetreuen Abbildung entbinden, um somit das Wesen einer neuen formal orientierten Ästhetik zu offenbaren. Bei Witkacy heißt es dazu:

.Na stworzeniu systemu o minimalnej ilości koniecznych do przyjęcia pojęć, z zupełnym wyeliminowaniem pojęcia przedmiotu jako takiego przez uświadomienie jego istotnego znaczenia, polegać powinna wedlug nas praca dzisiejszych estetyków." (1922d. 215)"

Somit kann im Formismus der Versuch einer grundlegenden Neubestimmung des Verhältnisses zwischen Inhalt und Form im Kunstwerk gesehen werden. Die Formisten wollen keine abstrakte Kunst, sondern die kreative Leistung des Künstlers, die sich ihrcr Meinung nach in den Einzelformen des Kunstwerks und vor allem in dessen Komposition manifestiert, stärker betonen. In der Literatur, in Czyżewskis Gedichten aus der formistischen Zeit, zeigt sich dieses Bestreben in der Lockerung - nicht Zerstörung - inhaltlicher Zusammenhänge. Die Einheit eines Gedichtes wird nicht mehr auf eine semantisch fundierte

17 .Die Arbeit der heutigen Ästhetiker sollte unserer Meinung nach auf der Schaffung eines Systems beruhen, das mit einer minimalen Anzahl notwendig vorausgesetzter Begriffe auskommt, unter volligem Ausschluss des Begriffs des Gegenstandes als solchen durch das Bewusstmachen seiner wesentlichen Bedeutung." 
Textsukzession gestützt, sondem durch andere Kohärenzen hergestellt, die auf formalen Qualităten, wie zum Beispiel Klangfiguren, beruhen.

Der Gedanke, eine neue Kunst fur eine neue Zeit zu entwerfen, kommt in ähnlicher Weise, wenn auch etwas anders formuliert, bei Kassák und Teige zum Ausdruck. Denn es geht bei ihnen nicht mehr ausschließlich um eine neue Ästhetik, sondern darüber hinausgehend bereits um eine von ihr durchdrungene neue Welt, wie es zum Beispiel Teige formuliert:

„Die Konstruktivisten kommen nămlich oberhaupt nicht mit Entwärfen für eine neue Kunst, sondern mit Plänen fur eine neue Welt, mit einem Programm fur ein neues Leben. Sie realisieren nicht irgendwelche asthetischen Theorien, sondern schaffen eine neue Welt." $(1925,56)$

In dieser Vorstellung fält und fiel der Kunst die Rolle zu, diese neue Welt zu errichten, mitzuhelfen, sie zu erbauen. Ganz ähnliche Ideen finden sich auch in Kassäks Text „Bildarchitektur" (1922b). Diese Ansätze von Kassäk und Teige stehen aber bereits im Zeichen des Konstruktivismus, der in Polen mit der Krakauer Avantgarde rund um Peiper und Przyboś ab 1921/22 seine Repräsentanten fand, also nachdem sich die formistische Gruppe aufgelöst hatte.

Gemeinsam für die an dieser Stelle besprochenen Ansätze und Texte ist der Gedanke an eine völlig neue Kunst, dessen Bestimmung für eine vergleichende Untersuchung der mitteleuropäischen Avantgarde fruchtbar gemacht werden kann. Die im Folgenden zitierte Bemerkung Derékys über die ungarische Avantgarde-Literatur kann somit als ein Wesenszug der mitteleuropäischen Avantgarde insgesamt festgehalten werden:

.,[...] und es zeigte sich, daß trotz etlicher Werke, die nach ihren poetischen Losungen sehr wohl als zum Futurismus, Expressionismus, Dadaismus bzw. zum Surrealismus gehorig genannt werden konnen, die ungarische Avantgarde-Dichtung eher durch die umfassende Idee einer neuen Dichtung. als durch einzelne Ismen bestimmt ist." (1991, 27-28)

\subsection{Zusammenfassung}

Ein Kernpunkt in der Diskussion über Mitteleuropa, die in den achtziger Jahren von Konrád und Kundera angestoßen wurde, war, das Bewusstsein für den zentralen Teil Europas wieder (neu) zu schaffen, und zwar in seiner gesamteuropäischen Perspektive. Europa sollte nicht länger als in zwei Sphären geteilt begriffen werden. Somit wurden mit der Zeit auch die Umrisse Mitteleuropas immer deutlicher, jenem Teil Europas, der in kultureller Hinsicht gleichermaßen mit dem Westen, wie auch mit dem Osten verbunden ist. Mit den politischen Umwälzungen von 1989 wurden viele notwendige Voraussetzungen geschaffen. die eine 
ideologie- und wertfreie Erforschung des kulturellen Erbes Mitteleuropas prinzipiell ermöglichten. Darauf können heute viele nach 1989 entstandene Forschungseinrichtungen, die sich explizit mit Mitteleuropa beschäftigen sowie grenzüberschreitende Projekte und Vorhaben, wie zum Beispiel Zeitschriften, aufbauen.

Auch die Erforschung der mitteleuropäischen Avantgarde gliedert sich gut in diesen Rahmen ein. Mit den neunziger Jahren wurde diese immer häufiger thematisiert, wie die wachsende Zahl von Ausstellungen und Publikationen beweist. Das jüngste Beispiel ist die in die Los Angeles erarbeitete Ausstellung „Central-European Avant-Gardes. Exchange and transformation 1910-1930", die 2002 auch in Deutschland zu sehen war ${ }^{18}$. Gerade in dieser Ausstellung bzw. in den Beiträgen zum Katalog wird versucht, die mitteleuropäische Avantgarde zum einen in ihren inneren Zusammenhängen zu erfassen, zum anderen aber auch die gesamteuropäischen Bezüge deutlich zu machen (vgl. in: Benson 2002).

Diese Absicht lag auch den Ausführungen in diesem Kapitel zugrunde. Es sollten die gemeinsamen Voraussetzungen, unter denen sich die mitteleuropäische Avantgarde herausgebildet hat, erarbeitet werden. Als solche wurden bestimmt: der, im Vergleich zu einigen westeuropäischen Avantgarde-Strömungen, spätere Zeitpunkt ihrer Herausbildung, das Bewusstsein, am Beginn einer neuen historischen und, was ihre Erscheinungsformen betriff, zivilisatorischen Epoche zu stehen sowie die damit verbundene Absicht, die Grundlagen von Kunst und Literatur theoretisch neu zu definieren. Letzteres war auch verbunden mit einer Neubestimmung des Verhältnisses zwischen Kunst/Literatur und Gesellschaft, wobei sich hier besonders in Mitteleuropa die Auseinandersetzung mit einer von der Romantik herrührenden Tradition zeigte. Wichtig für diese ästhetische Neuorientienung war schließlich auch die kritische Aneignung früherer Avantgarde-Strömungen, woran sich der Versuch knüpfte, deren Ansätze fortzuführen. Dadurch kam auch der Wunsch zum Ausdruck, sich mit dem eigenen Schaffen im gesamteuropäischen Kontext zu bewegen.

\footnotetext{
18 Erwahnt werden muss in diesem Zusammenhang auch die große Bonner Ausstellung von 1994, vgl. Stanisławski'Brockhaus 1994.
} 
Pot

rich

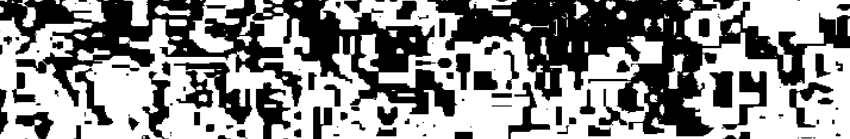

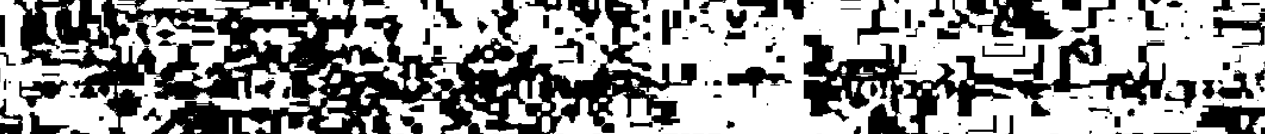

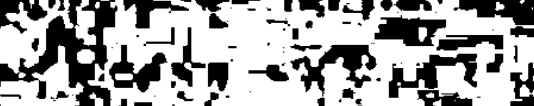

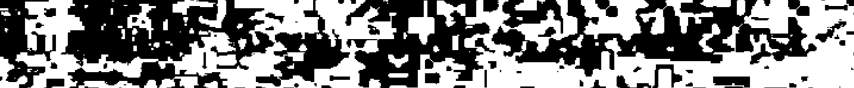

(

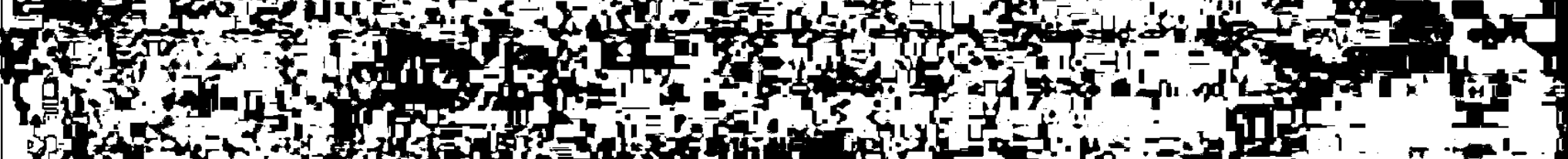

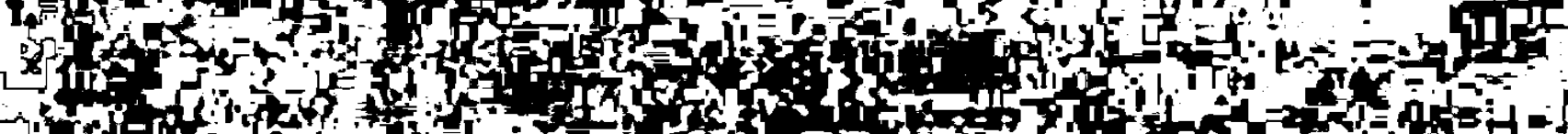

5 -

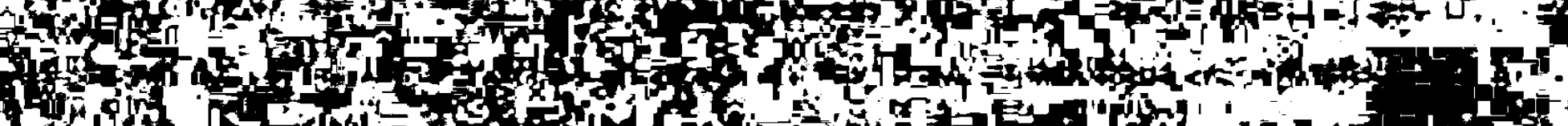

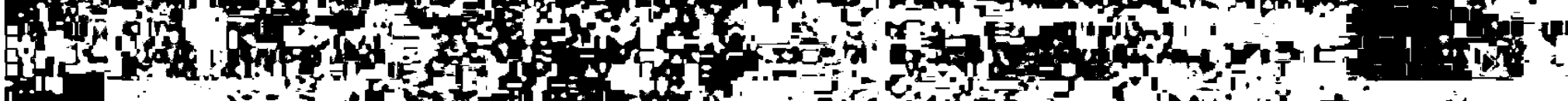

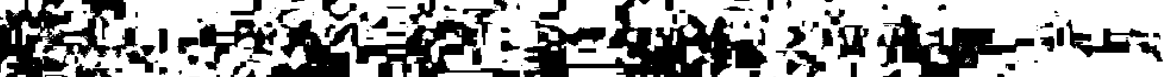

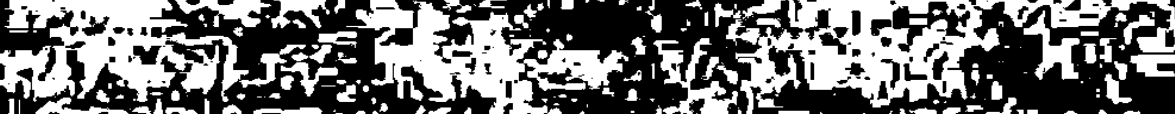

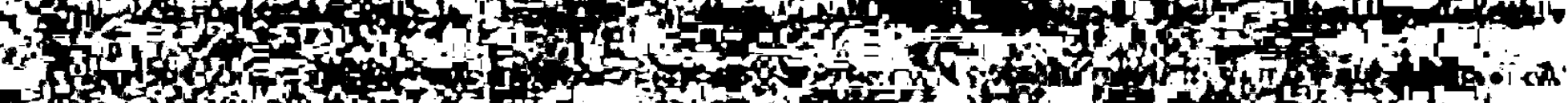

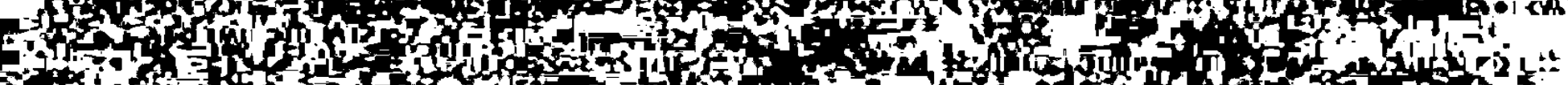
S. it EN

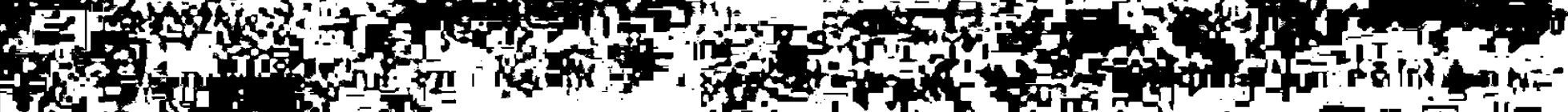

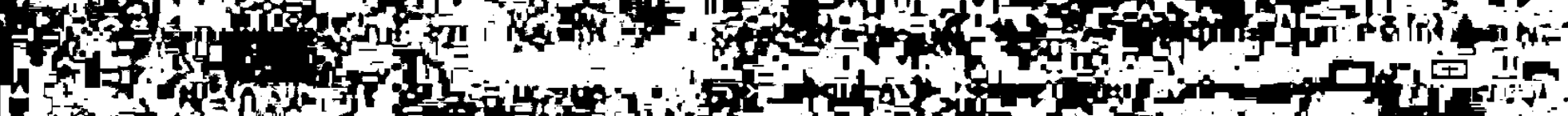

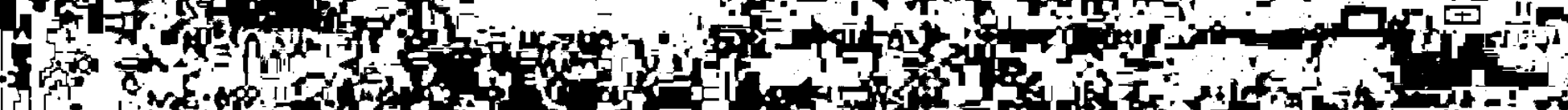

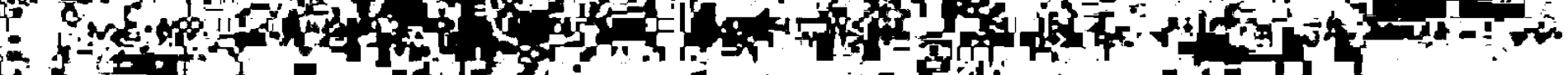

30 is

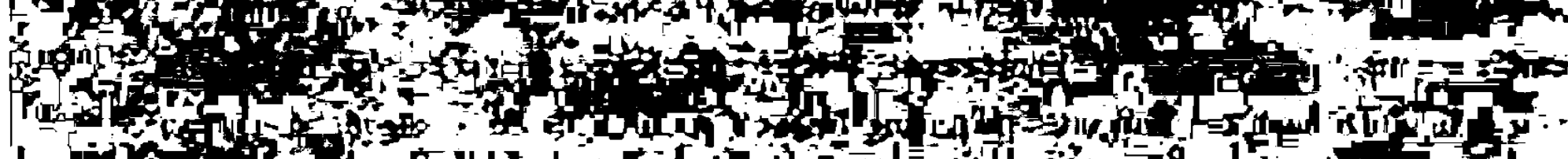

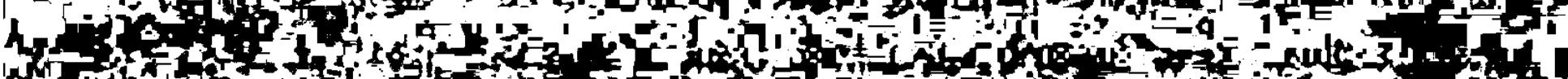

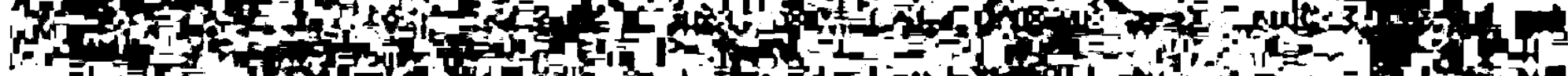

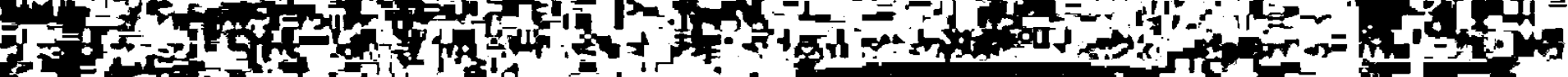
14.

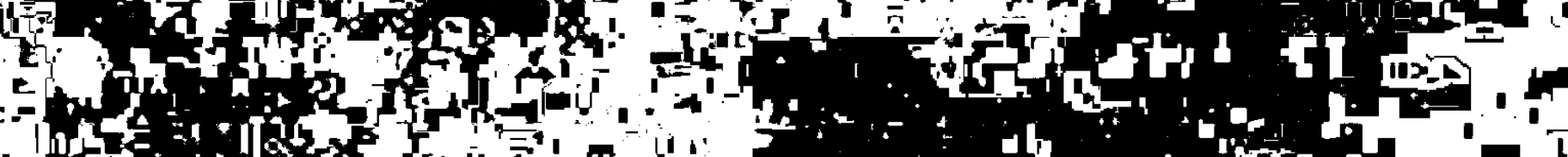
10

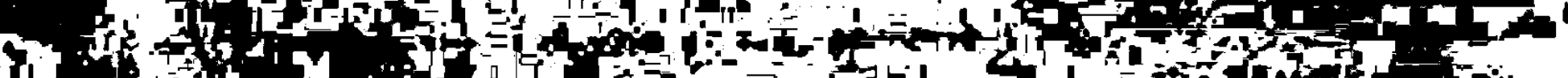
d

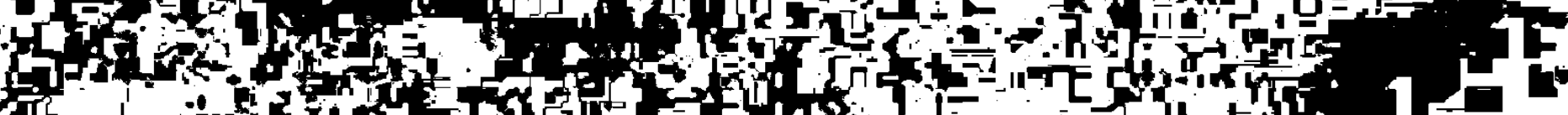

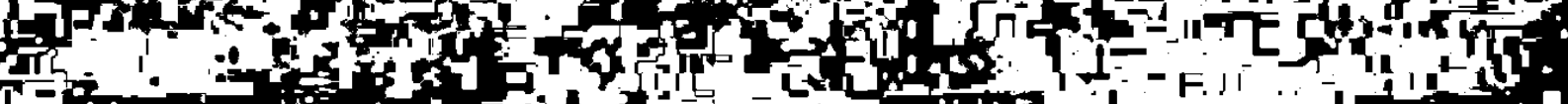
W. 


\section{Ausblick}

Helena Zaworska bemerkt einmal $(1975,339)$, dass es bei der Erforschung der frühen polnischen Avantgarde wichtiger sei, diese, trotz ihrer Gegensätze, als Einheit zu erfassen. anstatt sie präzise in einzelnen Ismen zu unterteilen, was letztendlich ohnehin nicht exakt möglich sei. In diesem Sinne können auch die Ergebnisse dieser Arbeit für weitere Untersuchungen fruchtbar gemacht werden. Die Bestimmung der Eigenständigkeit des literarischen Formismus sollte nicht zu dessen Isolation im Kontext der frühen polnischen Avantgarde führen. Deren Spezifik besteht gerade zu einem großen Teil darin, dass die Grenzen zwischen Expressionismus, Futurismus und Formismus fließend sind, was nicht nur die engen Kontakte der Formisten zur Zeitschrift „Zdrój“ und zur Gruppe „Bunt”, sondern auch zu den Futuristen zeigen, die in dieser Arbeit nur ansatzweise behandelt werden konnten'. Doch so wie in diesem Zusammenhang futuristische oder expressionistische Elemente in der formistischen Lyrik Czyzewskis beschrieben wurden, ließe sich umgekehn auch die Frage nach formistischen Elementen zum Beispiel in der Poesie der Futuristen Jankowski, Jasieński, Wat und - vor allem - Młodożeniec stellen (vgl. auch: Zaworska 1975, 339). Somit scheint es durch die Kenntnis des „Formistischen“ möglich, die Zusammenhänge innerhalb der frühen polnischen Avantgarde genauer zu erfassen. Davon ausgehend kann diese polnische Avantgarde der ersten Nachkriegsjahre als Ganzes in ihrer Beziehung zur zeitgenössischen gesamteuropäischen Kunst und Literatur, etwa in Hinsicht auf ihre Besonderheiten, treffender beschrieben werden. Diese Besonderheiten ließen sich schließlich auch durch eine genauere Untersuchung der literatur- und kunstkritischen polnischen Publizistik der Jahre nach dem Ersten Weltkrieg herausarbeiten. Mit Irzykowski, Doda oder Baczyński wurden in der vorliegenden Arbeit nur einzelne Autoren behandelt. für den Formismus würde sich außerdem eine kritische Analyse der Rezensionen zu den einzelnen Ausstellungen anbieten. Ebenso wäre es von Interesse, die formistischen Ansätze von Chwistek oder Witkacy mit den formalästhetischen Theorien ihrer Zeit zu vergleichen: neben denen der russischen Formalisten existieren auch in der polnischen Literaturwissenschaft Arbeiten, auf die ein solcher Vergleich zurückgreifen könnte (vgl. Markiewicz 1982).

Im Anschluss an die Feststellung „formistischer Elemente“ in der Lyrik von Czyżewskis „avantgardistischen Zeitgenossen“, das heißt jener Dichter, deren Gedichte noch zur Zeit des

\footnotetext{
' Vgl. dazu auch: Glowiński (1998, 202), der einen gewissen Synkretismus im Bereich der Poetik fur alle polnischen literarischen Gruppen. die unmittelbar nach 1918 entstanden sind, also auch fur den „Skamander”, als
} 
Formismus publiziert wurden, stellt sich auch die Frage nach den Spuren der formistischen Poetik bei Autoren der späteren polnischen Avantgarde. Der Einfluss des Formismus könnte hier besonders auf die Krakauer Avantgarde rund um Peiper und Przyboś sowie auf Ważyk herausgearbeitet werden. Im Falle des zuletzt genannten spielten dabei die sogenannten präsurrealistischen Tendenzen in Czyżewskis Gedichten eine zentrale Rolle. Die von Czyżewski vollzogene Auflösung inhaltlicher Zusammenhänge, das heißt der Bruch mit der Diskursivität oder seine in Anlehnung an den Kubismus entwickelte simultane Darstellung zuvor dekonstruierter Gegenstände waren auch für die Lyrik der Surrealisten wichtig. Diese Verfahren bildeten die Grundlage dafür, weit entfernte Bereiche oder scheinbar nicht zusammenpassende Ereignisse im Gedicht unmittelbar nebeneinander zu stellen (vgl. auch: Baluch 1985, 69-70 und Lipski 1993, 18). Somit zeigt sich eine Entwicklungslinie vom Kubismus hin bis zum Surrealismus, die auch Ważyk selbst beschreibt (vgl. 1964). Weitere Parallelen zwischen Czyzewski und dem Surrealismus ergeben sich auch aus der Abkehr vom Rationalen sowie in der Sehnsucht nach dem Ursprünglichen (vgl. Pollakówna 1969, 39).

Das „Formistische“, das in der vorliegenden Arbeit an den Gedichten Czyżewskis beschrieben wurde, könnte als poetischer Ansatz auch in Beziehung zu seinen avantgardistischen Dramoletten gesetzt werden, die zwischen 1918 und 1922 entstanden sind. Hier bietet sich auch der Vergleich mit Witkacy an, der die „Reine Form“, neben der Malerei, ja auch - und gerade - im Theater zu verwirklichen suchte ${ }^{2}$.

Die meisten Anknüpfungspunkte für weitere Untersuchungen bietet aber, so ist zumindest die Hoffnung des Verfassers, das Kapitel über die mitteleuropäische Avantgarde. Was in dieser Arbeit geleistet werden konnte, war ein erstes Aufzeigen von Gemeinsamkeiten. Der hier angedeutete Vergleich avantgardistischer Strömungen könnte nicht nur in räumlicher, zum Beispiel auf die südslawischen Literaturen. sondern auch in zeitlicher Hinsicht, das heißt unter Einbeziehung von Erscheinungen der späten zwanziger und dreißiger Jahre, erweitert werden. Auch die Rolle der Volkskunst für die einzelnen mitteleuropäischen Avantgarden könnte in einem eigenen Vergleich thematisier werden ${ }^{3}$. Auf die Bedeutung der volkstümlichen Kunst aus der Podhale-Region für die Formisten wurde in dieser Arbeit hingewiesen, wenngleich dieser Aspekı nicht explizit ausgeführt wurde. Im Falle Czyżewski

charakteristisch erachtet und dies unter anderem mit der Umbruchssituation. sowohl in politischer, als auch in asthetisch-literarischer Hinsicht erklär.

${ }^{2}$ Wahrend die dramatischen Arbeiten von Czyzewski bislang eher selten untersucht wurden (vgl. zum Beispiel auf deutsch: Kunstmann 1965, 32-34). gibt es zum formistischen Theater und zur ..Reinen Form" Witkacys im Theater eine Folle von Untersuchungen in mehreren Sprachen. Vgl. in deutscher Sprache die erwahnte Arbeit .Form und Deformation“ von Anna Schmidt (1992). Ein Vergleich von Czyzewski und Witkacy im Bereich des Dramas ist mir bislang jedoch nicht bekannt. 
wäre dabei aber nicht nur seine Malerei und Lyrik aus der Zeit des Formismus zu berücksichtigen, sondern gerade auch die 1925 in Paris veröffentlichte Gedichtsammlung „Weihnachstlieder" („Pastoralki“").

Eine Untersuchung avantgardistischer Literatur darf sich keinesfalls nur auf die programmatischen Texte konzentrieren, sondern muss vor allem die literarischen Kunstwerke ins Auge fassen. Dienen erstere einer groben Orientierung, und in diesem Sinne wurden sie für den Vergleich der mitteleuropäischen Avantgarden in der vorliegenden Arbeit gelesen, so ist es erst anhand der Gedichte möglich, wirklich fundiert über ästhetische Parallelen und gemeinsame künstlerische Verfahrensweisen zu sprechen. Hinter einer vergleichenden Erforschung der mitteleuropäischen Avantgarde steht aber nicht nur der Wunsch, die inneren literarischen und künstlerischen Beziehungen dieses zentralen Teils Europas zu erforschen. sondern auch deren Verankerung im gesamteuropäischen Kontext aufzuzeigen.

\footnotetext{
${ }^{3}$ Vgl. zum Beispiel fur die ungarische Avantgarde: Szabolcsi 1973, 287 und 293 sowie: Deréky 1991, 15.

"Vor allem Wyka sah in Czyzewskis .Weihnachtsliedern" eine gelungene Verbindung von Avantgarde und Volkskunst: vgl. Wyka 1945/1949, 19-21. Vgl. zu diesem Aspekt auch den Beitrag von: KrzysztoforskaDoschek (1996).
} 
(5)

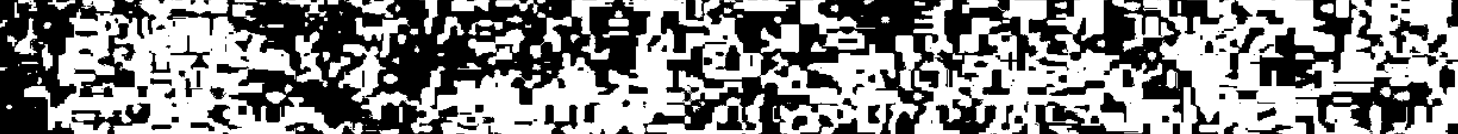

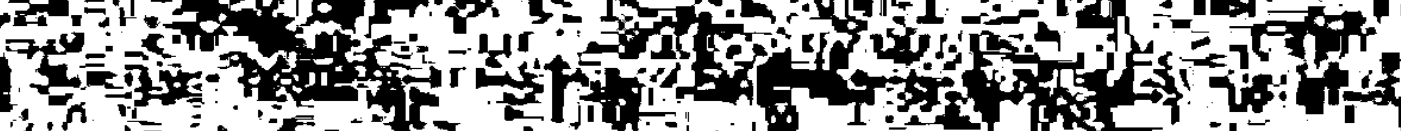

$\therefore=11$ 


\section{Bibliographie}

\subsection{Formismus}

\subsection{1 primär}

\subsubsection{Texte von Czyżewski}

1919a: „Salome“ (Obraz wielopłaszczyznowy). In: Wianki (1), 17-19.

1919b: O najnowszych prądach w sztuce polskiej. In: Wianki (1-3), 6-7; 11; 10-12.

1919c: Poezja ekspresjonistów i futurystów. In: Andrzej Lam: Polska awangarda poetycka.

Programy lat 1917-1923. Tom drugi: Manifesty i Protesty. Antologia. Kraków 1969, 7881.

1920a: Zielone oko. Poezje formistyczne. Elektryczne wizje. In: Tytus Czyzewski: Poezje i próby dramatyczne. Hrsg. von Alicja Baluch. Wroclaw u.a. 1992, 31-72.

1920b: Zielone oko. Kraków.

1921 a: Pogrzeb romantyzmu - uwiąd starczy symbolizmu - śmierć programyzmu. In:

Andrzej Lam: Polska awangarda poetycka. Programy lat 1917-1923. Tom drugi: Manifesty

i Protesty. Antologia. Kraków 1969, 175-177.

1921b: Od maszyny do zwierząt - kto się gniewa na nas? In: Andrzej Lam: Polska awangarda poetycka. Programy lat 1917-1923. Tom drugi: Manifesty i Protesty. Antologia. Kraków 1969, 177-178.

1922a: Monsalwat czy lupanar. In: Zwrotnica (2), 21.

1922b: List z Paryża. In: Zwrotnica (3), 73-74.

1922c: Noc-Dzien. Mechaniczny instynkı elektryczny. In: Tytus Czyżewski: Poezje i próby

dramatyczne. Hrsg. von Alicja Baluch. Wroclaw u.a. 1992, 73-119.

1923a: List z Paryża. In: Zwrotnica (4), 115-116.

1923b: Mój futuryzm. In: Andrzej Lam: Polska awangarda poetycka. Programy lat 1917-

1923. Tom drugi: Manifesty i Protesty. Antologia. Kraków 1969, 396-399.

1927: Robespierre. Rapsod. Cinema. Od romantyzmu do cynizmu. In: Tytus Czyżewski:

Poezje i próby dramatyczne. Hrsg. von Alicja Baluch. Wrocław u.a. 1992, 202-232. 1928: Monografia o formizmie. In: Kurier Polski (201), 22.07., 7.

1933: Neonaturalizm Marinettiego. In: Wiadomości literackie (17), 16.04., 6. 
1936: Lajkonik w chmurach. In: Tytus Czyżewski: Poezje i próby dramatyczne. Hrsg. von Alicja Baluch. Wroclaw u.a. 1992, 233-297.

1938: Mój Formizm. In: Glos Plastyków (8-12), 11-14.

1979: Poezje wybrane. Hrsg. von Joanna Pollakówna. Warszawa.

1987: Poezje. Hrsg. von Krzysztof Karasek. Warszawa.

1992: Poezje i próby dramatyczne. Hrsg. von Alicja Baluch. Wrocław u.a. (=Biblioteka Narodowa, Seria I, Nr. 273)

\subsubsection{Texte der anderen Formisten}

Chwistek, Leon (1918): Wielość rzeczywistości w sztuce. In: Leon Chwistek: Wielość rzeczywistości w sztuce $\mathrm{i}$ inne szkice literackie. Hrsg. von Karol Estreicher. Warszawa 1960. 24-50.

-Ders. (1919a): Formizm. In: Leon Chwistek: Wielość rzeczywistości w sztuce $\mathrm{i}$ inne szkice literackie. Hrsg. von Karol Estreicher. Warszawa 1960, 94-99.

-Ders. (1919b): Wrogowie formizmu $\mathrm{i}$ ich psychologia. In: Leon Chwistek: Wielośc rzeczywistości w sztuce i inne szkice literackie. Hrsg. von Karol Estreicher. Warszawa 1960, 89-93.

-Ders. (1920a): Formizm. In: Leon Chwistek: Wielość rzeczywistości $w$ sztuce $i$ inne szkice literackie. Hrsg. von Karol Estreicher. Warszawa 1960. 100-104.

-Ders. (1920b): [Zdanie, jako dwoisty utwór...]. In: Tytus Czyżewski: Poezje i próby dramatyczne. Hrsg. von Alicja Baluch. Wroclaw u.a. 1992, 31-32.

-Ders. (1921 a): Wielość rzeczywistości. ln: Leon C'hwistek: Pisma filozoficzne i logicznc. Hrsg. von Kazimierz Pasenkiewicz. Band 1. Warszawa 1961. 30-105.

-Ders. (1921b): Zagadnienia wspólczesnej architektury. In: Leon Chwistek: Wielośc rzeczywistości w sztuce $\mathrm{i}$ inne szkice literackie. Hrsg. von Karol Estreicher. Warszawa 1960, 77-88.

-Ders. (1921c): O poezji. In: Andrzej Lam: Polska awangarda poetycka. Programy lat 19171923. Tom drugi: Manifesty i Protesty. Antologia. Kraków 1969, 234-236.

-Ders. (1922a): Nowa poezja polska. Cztery wykłady o poezji futurystycznej uygloszone na kursach literackich w Krakowie. In: Nowa Sztuka. Czasopismo artystyczne (2). 11-13.

-Ders. (1922b): Tytus Czyżewski a kryzys formizmu. In: Leon Chwistek: Wielość 
rzeczywistości w sztuce i inne szkice literackie. Hrsg. von Karol Estreicher. Warszawa $1960,107-112$.

-Ders. (1922c): Teatr przyszłości. In: Leon Chwistek: Wielość rzeczywistości w sztuce i inne szkice literackie. Hrsg. von Karol Estreicher. Warszawa 1960, 171-182.

-Ders. (1922/1924): [Rozważania abstrakcynje na temat...]. In: Karol Estreicher (1969): Na marginesie wspomnienia o pewnej dyskusji zakopiańskiej. In: Bydgoski Rocznik Muzealny (1), 97-105.

-Ders. (1924): Wielość rzeczywistości w sztuce. Nachdruck aus Przegląd Współczesny (24), Kraków.

-Ders. (1935): Moja walka o nową formę w sztuce. In: Wiadomości literackie (51-52), 20.12., 5.

-Ders. (1938): Twórcza siła formizmu. In: Głos Plastyków (8-12), 113-124.

Formiści (1-2; 4-6). Kraków 1919-1921.

Katalog 1. Wystawy Ekspresyonistów Polskich. Kraków 1917.

Katalog Wystawy Grafiki Polskiej i Ekspresyonistów Polskich. Lwów 1918.

Katalog I-ej Wystawy Formistów Polskich. Warszawa 1919.

[Katalog] Wystawa Formistów i Buntu w Poznaniu. Poznań 1919.

Pronaszko, Andrzej (1938): [Rok 1913 w Krakowie...]. In: Głos Plastyków (8-12), 29.

-Ders. (1976): Zapiski scenografa. Wspomnienia - artykuły - listy. Hrsg. von Jerzy

Timoszewicz. Warszawa.

Pronaszko, Zbigniew (1914): Przed wielkim jutrem. In: Rydwan (1-2), 125-129.

-Ders. (1918): O Ekspresyoniżmie. In: Maski (1), 15-16.

-Ders. (1938): Jak to było właściwie?... In: Głos Plastyków (8-12), 31-32.

Winkler, Konrad (1921a): Bez programu. In: Formiści (4), 1-2.

-Ders. (192lb): [Każdy nowy a spontaniczny odruch...]. In: Formiści (5), 16.

-Ders. (1921c): Na nowych drogach sztuki. In: Formiści (6), 2-3.

-Ders. (1921d): Formizm na tle współczesnych kierunków w sztuce. Kraków.

-Ders. (1927): Formiści Polscy. Warszawa. (=Monografje Artystyczne XIV)

-Ders. (1938): Exegi Monumentum. In: Glos Plastyków (8-12), 37-39.

-Ders. (1947): Tytus Czyżewski. Artysta z instynktu i wyobrażni. In: Głos Plastyków (12), 13-17.

Witkiewicz, Stanisław Ignacy (1919a): Nowe formy w malarstwie i wynikające stąd nieporozumienia. In: Stanislaw lgnacy Witkiewicz: Nowe formy w malarstwie i inne pisma estetyczne. Hrsg. von Jan Leszczyński. Warszawa 1959, 11-170. 
-Ders. (1919b): Wstęp objaśniający. In: Katalog I-ej Wystawy Formistów Polskich. Warszawa, o.S.

-Ders. (1920): Wstęp do teorii Czystej Formy w teatrze. In: Stanisław Ignacy Witkiewicz: Nowe formy $w$ malarstwie $i$ inne pisma estetyczne. Hrsg. von Jan Leszczyński. Warszawa 1959, 263-282.

-Ders. (1921 a): Formista o formizmie. IV Wystawa Formistów w Krakowie. In: Stanisław Ignacy Witkiewicz: Nowe formy w malarstwie $\mathrm{i}$ inne pisma estetyczne. Hrsg. von Jan Leszczyński. Warszawa 1959, 313-315.

-Ders. (1921b): Z powodu krytyki IV-tej wystawy Formistów. In: Formiści (4). 5-8.

-Ders. (1921c): Bliższe wyjaśnienia w kwestii Czystej Formy na scenie. In: Stanisław lgnacy Witkiewicz: Nowe formy $w$ malarstwie $i$ inne pisma estetyczne. Hrsg. von Jan Leszczyński. Warszawa 1959, 283-310.

-Ders. (1921d): Lackmuspapier. Das erste künstlerische Frühgemüse. In: Ryszard Stanisławski/Christoph Brockhaus (Hrsg.): Europa. Europa. Das Jahrhundert der Avantgarde in Mittel- und Osteuropa. Band 3: Dokumente. Bonn 1994, 254.

-Ders. (1922a): Pojęcie piękna. In: Stanisław Ignacy Witkiewicz: Nowe formy w malarstwie i inne pisma estetyczne. Hrsg. von Jan Leszczyński. Warszawa 1959, 175-183.

-Ders. (1922b): O pojęciu formy. In: Stanisław Ignacy Witkiewicz: Nowe formy w malarstwie $i$ inne pisma estetyczne. Hrsg. von Jan Leszczyński. Warszawa 1959, 184-192.

-Ders. (1922c): O «treści» obrazów i ich tytułach i o problemie imitacji trójwymiarowości na płaszczyżnie. In: Stanisław Ignacy Witkiewicz: Nowe formy w malarstwie i inne pisma estetyczne. Hrsg. von Jan Leszczyński. Warszawa 1959, 202-207.

-Ders. (1922d): O tak zwanej «deformacji» ksztaltów świata zewnętrznego na obrazach malarıy współczesnych. In: Stanisław Ignacy Witkiewicz: Nowe formy w malarstwie i inne pisma estetyczne. Hrsg. von Jan Leszczyński. Warszawa 1959, 208-218.

-Ders. (1922e): Krytyka teorii sztuki Leona Chwistka. In: Stanisław Ignacy Witkiewicz: Nowe formy $w$ malarstwie $i$ inne pisma estetyczne. Hrsg. von Jan Leszczyński. Warszawa 1959, 246-259.

-Ders. (1922f): Parę zarzutów przeciw futuryzmowi. In: Stanislaw Ignacy Witkiewicz: Nowe formy w malarstwie i inne pisma estetyczne. Hrsg. von Jan Leszczyński. Warszawa 1959. 316-319.

-Ders. (1922-23): Nowe Wyzwolenie. Dramat w jednym akcie. In: Zwrotnica (3-4). 56-61; 94-97.

-Ders. (1923a): O skutkach działalności naszych futurystów. In: Andrzej Lam: Polska 
awangarda poetycka. Programy lat 1917-1923. Tom drugi: Manifesty i Protesty. Antologia. Kraków 1969, 354-363.

-Ders. (1923b): Mątwa czyli Hyrkoniczny Światopogląd. In: Zwrotnica (5), 127-138.

-Ders. (1923c): Dalszy ciagg polemiki z Leonem Chwistkiem. In: Stanisław Ignacy

Witkiewicz. Pisma filozoficzne i estetyczne. Tom 1: Nowe formy w malarstwie. Szkice estetyczne. Teatr. Hrsg. von Jan Leszczyński. Warszawa 1974, 410-425.

Zamoyski, August (1920): Wstęp objaśniający. In: Katalog Wystawy Formistów i Buntu w Poznaniu. Poznań, o.S.

-Ders. (1938): O Formiźmie. In: Głos Plastyków (8-12), 43-46.

-Ders. (1968): Jak i dlaczego wyroslem $z$ formizmu. In: Poezja (1-2), 17-32; 32-47.

\subsection{2 sekundär}

\subsubsection{Formismus (allgemein)}

Ankieta o ekspresyoniżmie. Ekspresyonizm w sztuce plastycznej. Ankieta Gazety Wieczornej (1918). In: Gazeta Wieczoma (4232), 03.07., 5 und (4276), 28.07., 1-10.

Bołoz-Antoniewicz, Jan (1920): Podstawy formizmu. In: Gazeta Wieczorna (5275), 12.06., 34; (5277), 13.06, 3; (5279), 15.06., 3; (5281), 16.06., 3; (5283). 17.06., 3; (5285), 18.06., 6 und (5287), 19.06., 3.

Cybis, Jan (1938): Polski formizm. In: Głos Plastyków (8-12), 5.

Doda. Wiktor (1925): Na rozdrożach polskiego formizmu. Tarnów.

Jakimowicz. Irena (Hrsg., 1989): Formiści. Warszawa.

Kostyrko, Teresa (1996): Formizm. In: Grzegorz Dziamski (Hrsg.): Od awangardy do postmodernizmu. Warszawa, 203-220.

Morawski, Stefan (1973): Ankieta o formistach polskich. (Opracowanie i wnioski). In:

Rocznik Historii Sztuki (18), 299-335.

Peiper. Tadeusz (1922a): Rozłam w formizmie. In: Zwrotnica (1), 16.

-Ders. (1922b): Zbigniew Pronaszko. In: Zwrotnica (1), 16.

Pollakưna. Joanna (1966): W przededniu formizmu. Polska krytyka artystyczna o wspólczesnych prądach europejskich. In: Biuletyn Historii Sztuki (1). 62-66.

-Dies. (1968): Pierwsze wstapienie formistów. Wokół wystawy 1917r. In: Przegląd Humanistyczny (4), 73-90. 
-Dies. (1971): Malarze i podpalacze. In: Maria Gantzowa (Hrsg.): Sztuka XX Wieku.

Materiały Sesji Stowarzyszenia Historyków Sztuki. Słupsk, pażdziemik 1969. Warszawa, 189-201.

-Dies. (1972): Formiści. Wroclaw u.a.

Szczepińska, Joanna (1954): Historia i program grupy „Formiści Polscy” w latach 1917 1922. In: Materiały do studiów i dyskusji z zakresu teorii i historii sztuki, krytyki artystycznej oraz badań nad sztuką (3-4), 201-250.

-Dies. (1973): O polskim formizmie. Warszawa.

Terlecki, Władysław (1922): Formiści lwowscy. In: Zwrotnica (2), 47.

\subsubsection{Literatur zu Czyżewski}

Baluch, Alicja (1985): O formizmie w malarstwie i poezji Czyżewskiego. In: Miesięcznik literacki (1), 69-78.

Bukowski. Piotr (2002): Tytus Czyżewskis formistische Lyrik und die Poetik des deutschen Expressionismus. Prolegomena zu einer integrativen Vergleichsstudie. In: Hartmut Kircher u.a (Hrsg.): Avantgarden in Ost und West. Literatur, Musik und bildende Kunst um 1900. Köln u.a., 159-176.

Hulewicz, Jerzy (1920): [Niezmierzone i niepoliczone są drogi...]. In: Tytus Czyżewski:

Poezje i próby dramatyczne. Hrsg. von Alicja Baluch. Wroclaw u.a. 1992, 33-34.

Kryszak, Janusz (1981): Harfiarz uliczny. In: Janusz Kryszak: Urojona perspektywa. Szkice literackie. Lódż, 29-56.

Krzysztoforska-Doschek. Jolanta (1996): Reflexe urslawischer Dichtung in der futuristischen Lyrik Tytus Czyżewskis. In: Wiener Slawistisches Jahrbuch (42), 123-127.

Lipski, Jan Józef (1993): Tytus Czyżewski. In: Irena Maciejewska u.a. (Hrsg.): Literatura polska w okresie międzywojennym. Band 3. Kraków, 7-40.

Młodożeniec, Stanisław (1922): Tytus Czyżewski: „Noc-Dzień“, „Osioł i słonce w metamorfozie“, „Wlamywac z z lepszego towarzystwa“, „Waz, Orfeusz i Eurydyka“. In: Zwrotnica (2), 46.

-Ders. (1959): Tytus Czyżewski, pierwszy w awangardzie. In: Orka (6), 08.02., 6. Morawski, Witold (1961): Poezja Tytusa Czyżewskiego i Apollinaire. In: Przegląd Humanistyczny (4), 151-166.

Pollakówna. Joanna (1963): Tytus Czyżewski - Formista. In: Juliusz Starzyński (Hrsg.): Z 
zagadnień plastyki polskiej w latach 1918-1939. Wrocław u.a., 241-291. (= Studia z historii sztuki IX)

-Dies. (1969): Spełnienia dwoiste (Uwagi o twórczości Czyżewskiego). In: Poezja (1), 27-48. Stopczyk, Stanisław (1984): Tytus Czyżewski. Warszawa.

Stur, Jan (1921): Tytus Czyżewski: Zielone oko. In: Jan Stur: Na przelomie. O nowej i starej poezji. Lwów, 171-174.

Śpiewak, Jan (1939): Jak się kształtował polski futuryzm. Rozmowa z Tytusem Czyżewskim. In: Czas (187), 09.07., 5.

Wyka, Kazimierz (1945): O Tytusie Czyżewskim. In: Kazimierz Wyka: Rzecz wyobraźni. Warszawa² 1977, 13-16.

-Ders. (1945/1949): Czyżewski - Poeta. In: Kazimierz Wyka: Rzecz wyobrażni. Warszawa ${ }^{2}$ 1977, 17-22.

-Ders. (1947): «Pastorałki» Czyzewskiego. In: Kazimierz Wyka: Rzecz wyobraźni. Warszawa² 1977, 23-29.

Wyka. Marta (1978): Tytus Czyżewski. In: Twórczość (1), 90-102.

-Dies. (1982): Dynamomaszyny i pastorałki - Tytus Cyżewski, in: Irena Maciejewska (Hrsg.): Poeci dwudziestolecia międzywojennego. Band 1. Warszawa, 211-235.

Zaleski, Marek (1980): „W imię ducha motoru amen”. In: Twórczość (7), 117-119.

Zaworska, Helena (1975): Formizm. In: Alina Brodzka u.a. (Hrsg.): Literatura Polska 19181975. Tom 11918 - 1932. Warszawa 2 1991, $337-349$.

\subsubsection{Literatur zu den anderen Formisten}

[ohne Autor] (1921): Leon Chwistek. Wielość rzeczywistości. In: Nowa sztuka. Miesięcznik artystyczny (1), 30-31.

[ohne Autor] (1926): Rozmowa z Leonem Chwistkiem. In: Gazeta Literacka (9-10), 2.

Baluch, Alicja (1984): Leon Chwistek w stulecie urodzin. In: Odra (12), 106-107.

Blumówna, Helena (1958): Z. Pronaszko. Warszawa.

Estreicher, Karol (1971): Leon Chwistek. Biografia artysty (1884 - 1944). Kraków.

Folga-Januszewska, Dorota (1982): Leon Chwistek's multitude of realities. In: Projekt (2). 2 11.

-Dies. (1984): Wirklichkeit und Stil in der Kunsttheorie von Leon Chwistek. In: Micha! Bristiger u.a. (Hrsg.): Karol Szymanowski in seiner Zeit. München, 39-47. 
Grzeniewski. Ludwik Bohdan (1968): O „Pałacach Boga“ Leona Chwistka. In: Ludwik

Bohdan Grzeniewski: Leona Chwistka Pałace Boga. Próba rekonstrukcji. Warszawa² 1979, 5-29.

Irzykowski, Karol (1922): Na Giewoncie Formizmu (Teoria p. Chwistka). In: Karol

Irzykowski: Wybór pism krytycznoliterackich. Hrsg. von Wojciech Głowała. Wroclaw u.a. $1975,444-471$.

-Ders. (1929): Treść i forma. Studium z literackiej teorii poznania (Polemika ze Stanisławem Ignacym Witkiewiczem. In: Karol Irzykowski: Wybór pism krytycznoliterackich. Hrsg. von Wojciech Głowała. Wrocław u.a. 1975, 265-320.

-Ders. (1975): Wybór pism krytycznoliterackich. Hrsg. von Wojciech Glowala. Wrocław u.a. Jakimowicz, Irena (1978): Witkacy. Chwistek. Strzemiński. Myśli i obrazy. Warszawa.

Kostyrko, Teresa (1966): Poglądy estetyczne Leona Chwistka. In: Studia estetyczne (3), 205221.

-Dies. (1995): Leona Chwistka filozofia sztuki. Warszawa.

Kotarbinski, Tadeusz (1922): Leon Chwistek: Wielość rzeczywistości. In: Przegląd Warszawski (6), 426-428.

Kunstmann, Heinrich (1962): Leon Chwistek: Wielość rzeczywistości w sztuce i inne szkice literackie. Wybral i przedmową poprzedzil Karol Estreicher. Warszawa Czytelnik 1960. 258 S. In: Die Welt der Slawen. Vierteljahresschrift für Slawistik (7), 222-224.

Puzyna, Konstanty (1999): Pojęcie Czystej Formy. In: Konstanty Puzyna: Witkacy. Hrsg. von Janusz Degler. Warszawa, 113-125.

Schmidt. Anna (1992): Form und Deformation. Zum kunsttheoretischen und dramatischen

Werk von Stanisław Ignacy Witkiewicz. München. (=Slavistische Beiträge, Band 294)

Skowroński. Jarosław (1979): O teorii poezji S. I. Wikkiewicza. In: Teksty (5). 128-135.

Soin, Maciej (1995): Filozofia Stanisława Ignacego Witkiewicza. Wroclaw.

Szymariska, Beata (1971): Teoria poezji Stanisława Ignacego Witkiewicza. In: Studia

Estetyczne (8), 173-188.

Wat, Aleksander (1922): Stanislaw Ignacy Witkiewicz: Szkice estetyczne. In: Nowa Sztuka.

Czasopismo artystyczne (2), 29-30.

Witkiewicz, Stanisław Jan (1977): Stanisław Ignacy Witkiewicz w Rosji. In: Miesięcznik Literacki (8), 66-74. 


\subsection{Polnische Kunst und Literatur (allgemein)}

Baczyński, Stanisław (1923): Sztuka walcząca. Lwów.

-Ders. (1924): Syty Paraklet i glodny Prometeusz (Najmłodsza poezja polska). Kraków/ Warszawa.

Balcerzan, Edward (1984): Dialektyka polskiego dwudziestolecia międzywojennego. In:

Tomasz Weiss (Hrsg.): Prace ofiarowane Henrykowi Markiewiczowi. Kraków, 265-279. Baranowicz, Zofia (1979): Polska awangarda artystyczna 1918-1939. Warszawa.

Bereska, Henryk/Heinrich Olschowsky (Hrsg., 1975): Polnische Lyrik aus funf Jahrzehnten. Berlin/Weimar 1977.

Brodzka. Alina u.a. (Hrsg., 1975): Literatura Polska 1918 - 1975. Tom 11918 - 1932. Warszawa ${ }^{2} 1991$.

Brzękowski, Jan u.a. (1934): O sztuce nowoczesnej. Lódż.

Dedecius, Karl (Hrsg., 1964): Polnische Poesie des 20. Jahrhunderts. Übertragen von Karl Dedecius. München.

-Ders. (Hrsg., 1978): Polnisches Lesebuch des 20. Jahrhunderts. Deutsch von Karl Dedecius. München.

-Ders. (Hrsg., 1995): Hundert polnische Gedichte. Sto wierszy polskich. Ausgewăhlt und übertragen von Karl Dedecius. Kraków.

-Ders. (Hrsg., 1996-2000): Panorama der polnischen Literatur des 20. Jahrhunderts. 5 Abteilungen in 7 Bänden. Zürich.

Dobrowolski, Tadeusz (1976): Malarstwo polskie ostatnich dwustu lat. Wroclaw u.a. Estreicher, Karol (1973): Historia sztuki w zarysie. Kraków 1982.

Gazda. Grzegorz (1974): Futuryzm w Polsce. Wroclaw u.a. (=Z dziejów form artystycznych w literaturze polskiej, tom XXXV)

Glowiński. Michal (1998): Grupa literacka a model poezji (przykład Skamandra). In: Michał Glowiński: Dzieło wobec odbiorcy. Szkice z komunikacji literackiej. Kraków, 190-206. Gryglewicz. Tomasz (2002): Cracow. In: Timothy O. Benson (Hrsg.): Central-European avant-gardes. Exchange and transformation 1910-1930. Los Angeles. 328-332.

Hopfinger, Maryla (1993): W laboratorium sztuki XX wieku. O roli slowa i obrazu.

Warszawa.

Hutnikiewicz, Artur (1965): Od czystej formy do literatury faktu. Glównie teorie i programy literackie XX stulecia. Warszawa ${ }^{5} 1988$.

Hutniekiewicz. Artur/Andrzej Lam (Hrsg., 2000): Literatura polska XX wieku. Przewodnik 
encyklopedyczny. Warszawa.

Jarosiński, Zbigniew (1985): Postaci poezji. Warszawa.

Jarosiński, Zbigniew/Helena Zaworska (Hrsg.. 1978): Antologia polskiego futuryzmu i Nowej

Sztuki. Wroclaw u.a. (=Biblioteka Narodowa, Seria I, Nr. 230)

Jasieński, Bruno (1921): Mańifest w sprawie ortografji fonetycznej. In: Andrzej Lam: Polska awangarda poetycka. Programy lat 1917-1923. Tom drugi: Manifesty i Protesty. Antologia. Kraków 1969, 219-221.

Kębłowski, Janusz (1987): Dzieje sztuki polskiej. Panorama zjawisk od zarania do współczesności. Warszawa.

Krzyżanowski, Julian/Czesław Hernas (Hrsg., 1984): Literatura Polska. Przewodnik encyklopedyczny. 2 Bände. Warszawa.

Kunstmann, Heinrich (1965): Moderne polnische Dramatik. Köln/Graz.

Kużma, Erazm (1976): Z problemów świadomości literackiej i artystycznej ekspresjonizmu w Polsce. Wroclaw u.a. ( $Z$ Z dziejów form antystycznych w literaturze polskiej, tom XLIV) Lam, Andrzej (1962): Poczatek swiadomości ekspresjonistycznej w Polsce. In: Przegląd Humanistyczny (2), 1-30.

-Ders. (1969): Polska awangarda poetycka. Programy lat 1917-1923. 2 Bände. Kraków. -Ders. (Hrsg., 1990): Die literarische Avantgarde in Polen. Dichtungen - Manifeste Theoretische Schriften. Tübingen 1990. (=Deutsche Textbibliothek. Band 9) Lukaszewicz, Piotr/Jerzy Malinowski (1996): Ekspresjonizm w sztuce. In: Grzegorz

Dziamski (Hrsg.): Od awangardy do postmodernizmu. Warszawa. 221-242.

Malinowski, Jerzy (1991): Sztuka i nowa współnota. Zrzeszenie artystów Bunt 1917-1922. Wrocław.

Markiewicz, Henryk (Hrsg., 1982): Problemy teorii literatury w Polsce międzywojennej.

Wroclaw u.a.

Olschowsky, Heinrich (Hrsg., 1986): Der Mensch in den Dingen. Programmtexte und Gedichte der Krakauer Avantgarde. Leipzig.

Ostrowski, Jan K. (1989): Die polnische Malerei vom Ende des 18. Jahrhunderts bis zum Beginn der Moderne. München.

Peiper, Tadeusz (1922c): Der Ausgangspunkt. In: Heinrich Olschowsky (Hrsg.): Der Mensch in den Dingen. Programmtexte der Krakauer Avantgarde. Leipzig 1986, 56-59.

-Ders. (1922d): Miasto. Masa. Maszyna. In: Andrzej Lam: Polska awangarda poetycka.

Programy lat 1917-1923. Tom drugi: Manifesty i Protesty. Antologia. Kraków 1969. 307324. 
-Ders. (1974): O wszytkim i jeszcze o czymś. Artykuly, eseje, wywiady (1918-1939). Hrsg. von Stefan Góra u.a. Kraków.

Podraza-Kwiatkowska, Maria (Hrsg., 1973): Programy i dyskusje literackie okresu Młodej Polski. Wroclaw u.a. (=Biblioteka Narodowa, Seria I, Nr. 212)

Prokop, Jan (1970): Z przemian w literaturze polskiej lat 1907-1917. Wroclaw u.a. (=Prace Komisji Historycznoliterackiej 24)

Przybylski, Ryszard (1975): Ekspresjonizm poznański. In: Alina Brodzka u.a. (Hrsg.):

Literatura Polska 1918 - 1975. Tom 11918 - 1932. Warszawa ${ }^{2}$ 1991, 261-271.

Przybyszewski, Stanisław (1918): Powrotna fala. Naokoło ekspresjonizmu. In: Andrzej Lam: Polska awangarda poetycka. Programy lat 1917-1923. Tom drugi: Manifesty i Protesty. Antologia. Kraków 1969, 46-56.

-Ders. (1990): De profundis und andere Erzählungen. Hrsg. von Michael Matthias Schardt und Hartmut Vollmer. Paderborn.

Ratajczak, Józef (1967): Programy „Zdroju”. In: Przegląd Humanistyczny (1), 83-95.

-Ders. (Hrsg., 1987): Krzyk i ekstaza. Antologia polskiego ekspresjonizmu. Poznań.

Tarnogórska, Maria (1997): Poemat międzywojenny. Wroclaw.

Trzynadlowski, Jacek (1977): Futuryzm polski. In: Józef Heistein (Hrsg.): Futuryzm i jego warianty w literaturze europejskiej. Wroclaw, 97-112.

Ważyk, Adam (1964): Miejsce kubizmu. In: Adam Ważyk: Eseje literackie. Warszawa 1982, 199-204.

-Ders. (1974): Dziwna historia awangardy. In: Adam Wažyk: Eseje literackie. Warszawa $1982,307-381$.

Witkowska, Alina (Hrsg., 1995): Idylla Polska. Antologia. Unter Mitarbeit von Izabela Jarosinska. Wroclaw u.a. (=Biblioteka Narodowa, Seria I, Nr. 284)

Wojciechowski, Aleksander (Hrsg., 1967): Polskie życie artystyczne w latach 1890-1914. Wrocław u.a.

-Ders. (Hrsg., 1974): Polskie życie artystyczne w latach 1915-1939. Wrocław u.a.

Zawada. Andrzej (1998): Dwudziestolecie literackie. Wrocław.

Zaworska, Helena (1963): O Nową Sztukę. Polskie programy artystyczne lat 1917 - 1922. Warszawa. (=Historia literatury 9)

Zeleński Boy, Tadeusz (1983): Znaszli ten kraj?... (Cyganeria krakowska) oraz inne wspomnienia o Krakowie (Wybór). Hrsg. von Tomasz Weiss. Wrocław u.a. (=Biblioteka Narodowa. Seria I, Nr. 246) 


\subsection{Europäischer und mitteleuropäischer Kontext}

Anz, Thomas (2002): Literatur des Expressionismus. Stuttgart/Weimar.

Apollinaire, Guillaume (1913): „L'antitradition futuriste. Manifeste-synthèse“. In: Apollinaire zur Kunst. Texte und Kritiken 1905-1918. Hrsg. von Hajo Düchting. Köln 1989, 376 und hintere Umschlagklappe.

-Ders. (1969): Poetische Werke. Cuures poétiques. Hrsg. von Gerd Henninger. Neuwied/Berlin.

-Ders. (1975): Wybór poezji. Hrsg. von Jerzy Kwiatkowski. Wrocław u.a. (=Biblioteka Narodowa, Seria II, Nr. 176)

-Ders. (1989): Apollinaire zur Kunst. Texte und Kritiken 1905-1918. Hrsg. von Hajo Düchting. Köln.

Bahr, Hermann (1920): Expressionismus. München.

Benson, Timothy O. (Hrsg., 2002): Central-European avant-gardes. Exchange and transformation, 1910-1930. Los Angeles.

Bojtár, Endre (1992): East-European Avant-Garde Literature. Budapest.

Bürger, Peter (1974): Theorie der Avantgarde. Frankfurt (Main) ${ }^{13} 1993$.

Chvatik, Kvetoslav (1970): Der Poetismus. In: Kvetoslav Chvatik: Strukturalismus und Avantgarde. München, 50-69.

Deréky, Pál (1991): Ungarische Avantgarde-Dichtung in Wien 1920-1926. Thre zeitgenössische literaturkritische Rezeption in Ungam sowie in der ungarischen Presse Österreichs, Rumäniens, Jugoslawiens und der Tschechoslowakei. Wien u.a.

-Ders. (Hrsg., 1996): Lesebuch der ungarischen Avantgardeliteratur (1915-1930). A Magyar avantgárd irodalom (1915-1930) olvasókönyve. Wien u.a.

Drews, Peter (1975): Devětsil und Poetismus. Künstlerische Theorie und Praxis der tschechischen literarischen Avantgarde am Beispiel Vitezzslav Nezvals, Jaroslav Seiferts und Jił̌ Wolkers. München. (=Slavistische Beiträge, Band 89)

-Ders. (1983): Die slawische Avantgarde und der Westen. Die Programme der russischen. polnischen und tschechischen literarischen Avantgarde und ihr europäischer Kontext. München. (=Forum Slavicum, Band 55)

Duplessis, Yvonne (1992): Der Surrealismus. Berlin. (=Schriften zur Kunsttheorie VIII) Gazda, Grzegorz (1996): Awangarda. In: Grzegorz Dziamski (Hrsg.): Od awangardy do postmodernizmu. Warszawa. 21-32.

Hein, Manfred Peter (Hrsg., 1991): Auf der Karte Europas ein Fleck. Gedichte der 
osteuropäischen Avantgarde. Zürich.

Jaworski, Stanisław (1992): Awangarda. Warszawa.

Kassák, Lajos (1915a): Brrr...bum... . In: Lajos Kassák: Lasst uns leben in unserer Zeit.

Gedichte, Bilder und Schriften zur Kunst. Hrsg. von József Vadas. Budapest 1989, 9-10.

-Ders. (1915b): Handwerksleute. In: Lajos Kassák: Lasst uns leben in unserer Zeit. Gedichte,

Bilder und Schriften zur Kunst. Hrsg. von József Vadas. Budapest 1989, 15-16.

-Ders. (1916a): Programm. In: Lajos Kassák: Lasst uns leben in unserer Zeit. Gedichte, Bilder und Schriften zur Kunst. Hrsg. von József Vadas. Budapest 1989, 17-19.

-Ders. (1916b): Die neue Literatur. In: Lajos Kassák: Lasst uns leben in unserer Zeit.

Gedichte, Bilder und Schriften zur Kunst. Hrsg. von József Vadas. Budapest 1989, 21-25.

-Ders. (1919): Aktivismus. In: Lajos Kassák: Lasst uns leben in unserer Zeit. Gedichte, Bilder und Schriften zur Kunst. Hrsg. von József Vadas. Budapest 1989, 50-54.

-Ders. (1921): Das Pferd stirbt und die Vögel fliegen hinaus. In: Lajos Kassák: Lasst uns leben in unserer Zeit. Gedichte, Bilder und Schriften zur Kunst. Hrsg. von József Vadas. Budapest 1989, 81-97.

-Ders. (1922a): Buch neuer Künstler (Vorwort). In: Lajos Kassák: Lasst uns leben in unserer Zeit. Gedichte, Bilder und Schriften zur Kunst. Hrsg. von József Vadas. Budapest 1989, 98-102.

-Ders. (1922b): Bildarchitektur. In: Lajos Kassák: Lasst uns leben in unserer Zeit. Gedichte, Bilder und Schriften zur Kunst. Hrsg. von József Vadas. Budapest 1989, 105-110.

Kircher, Hartmut (2002): Guillaume Apollinaire - ein Avantgardist nicht ohne Tradition. In:

Hartmut Kircher u.a. (Hrsg.): Avantgarden in Ost und West. Literatur, Musik und Bildende Kunst um 1900. Köln u.a., 111-129.

Konrád, György (1986): Der Traum von Mitteleuropa. In: Erhard Busek/Gerhard Wilfinger

(Hrsg.): Aufbruch nach Mitteleuropa. Rekonstruktion eines versunkenen Kontinents. Wien, 87-97.

Konstantinović, Zoran (Hrsg., 1978): „Expressionismus“ im europäischen Zwischenfeld.

Innsbruck. (=Innsbrucker Beiträge zur Kulturwissenschaft, Sonderheft 43)

-Ders. (2000): Grundlagentexte der Vergleichenden Literaturwissenschaft aus drei

Jahrzehnten. Hrsg. von Beate Burtscher-Bechter u.a. Innsbruck u.a. (=Comparanda. Band 1)

Kundera, Milan (1984): Un occident kidnappé oder Die Tragödie Zentraleuropas. In:

Kommune. Forum für Politik und Ökonomie (7), 43-52.

Magnuszewski, Józef (1976): Typologiczno-porównawcze spojrzenie na literatury polską i 
czeską okresu międzywojennego (Zarys problematyki). In: Scholastyka Bartoszczak-Gadaj (Hrsg.): Z problemów współczesnych języków i literatur słowniańskich. Warszawa. 139154.

Marinetti, Fillippo T. (1912): Technisches Manifest der futuristischen Literatur. Supplement zum Technischen Manifest der Futuristischen Literatur. In: Hansgeorg Schmidt-Bergmann: Futurismus. Geschichte, Ästhetik, Dokumente. Reinbek bei Hamburg 1993, 282-293.

Mešs'an. Antonin (1984): Geschichte der tschechischen Literatur im 19. und 20. Jahrhundert. Köln/Wien.

Neumann, Stanislav Kostka (1913): Offene Fenster. In: Ryszard Stanislawski/Christoph Brockhaus (Hrsg.): Europa, Europa. Das Jahrhundert der Avantgarde in Mittel- und Osteuropa. Band 3: Dokumente. Bonn 1994, 27.

Niedziela, Zdzisław (1979): Futurystyczny epizod twórczości S. K. Neumanna. In: Zdzisław Niedziela (Hrsg.): Literatury słowianiskie w okresie awangardowego przełomu, Wrocław u.a., 133-141.

Passuth, Krisztina (1988): Les Avant-Gardes de l'Europe Centrale 1907-1927. Paris.

-Dies. (2003): Treffpunkte der Avantgarden Ostmitteleuropa. Budapest/Dresden.

Pinthus, Kurt (Hrsg., 1920): Menschheitsdämmerung. Ein Dokument des Expressionismus. Hamburg 1959.

LeRider, Jacques (1996): Mitteleuropa. Auf den Spuren eines Begriffs. Wien.

Rübberdt, Irene (1993): Einheit im Widerstreit. Zur ungarischen Lyrik der Moderne und Avantgarde. Budapest. (=officina hungarica II)

Ryłko, Zdzisław (1968): Apollinaire i teorie polskiej awangardy poetyckiej. In: Przegląd Humanistyczny (6), 49-81.

Schamschula, Walter (1996): Geschichte der tschechischen Literatur. Band II: Von der Romantik bis zum Ersten Weltkrieg. Köln u.a.

Schmidt-Bergmann. Hansgeorg (1993): Futurismus. Geschichte. Ästhetik, Dokumente. Reinbek bei Hamburg.

Seifert. Jaroslav (1985): Auf den Wellen von TSF. Gedichte. Hrsg. von Eva H. Plattner und Peter Weibel. Wien.

Simonis, Ferdinand (1967): Die Lyrik Guillaume Apollinaires. Inspiration zwischen Erinnerung und Prophetie. Bonn. (=Abhandlungen zur Kunst-, Musik- und Literaturwissenschaft, Band 47)

Stanisławski, Ryszard/Christoph Brockhaus (Hrsg., 1994): Europa. Europa. Das Jahrhundert der Avantgarde in Mittel- und Osteuropa. 4 Bände. Bonn. 
Szabolcsi, Miklós (1973): Expressionism in Hungary. In: Ulrich Weisstein (Hrsg.):

Expressionism as an international literary phenomenon. Paris/Budapest, 289-291.

-Ders. (1979): Avantgarde, Neo-Avantgarde, Modernismus. Fragen und Vorschläge. In:

Karlheinz Barck u.a. (Hrsg.): Künstlerische Avantgarde. Annäherungen an ein unabgeschlossenes Kapitel. Berlin (Ost), 23-38.

Teige, Karel (1922): Neue proletarische Kunst. In: Karel Teige: Liquidierung der $>$ Kunst $<$.

Analysen, Manifeste. Mit einem Nachwort von Paul Kruntorad. Frankfurt (Main) 1968, 743.

-Ders. (1924): Poetismus. In: Karel Teige: Liquidierung der $>$ Kunst $<$. Analysen, Manifeste. Mit einem Nachwort von Paul Kruntorad. Frankfurt (Main) 1968, 44-52.

-Ders. (1925) : Der Konstruktivismus und die Liquidienung der >Kunst<. In: Karel Teige:

Liquidierung der $>$ Kunst $<$. Analysen, Manifeste. Mit einem Nachwort von Paul Kruntorad. Frankfurt (Main) 1968, 53-69.

-Ders. (1928): Manifest des Poetismus. In: Karel Teige: Liquidienung der $>$ Kunst<. Analysen,

Manifeste. Mit einem Nachwort von Paul Kruntorad. Frankfurt (Main) 1968, 70-111.

Trautner, Tamara (1988): Apollinaire - Calligrammes. Poèmes de la paix et de la guerre. In:

Walter Jens (Hrsg.): Kindlers Neues Literatur Lexikon. Band 1. München, 564-565.

Turowski, Andrzej (1977): Dada-Polen. In: Stephan Waetzoldr/Verena Haas (Hrsg.):

Tendenzen der Zwanziger Jahre. 15. Europäische Kunstausstellung Berlin 1977. Berlin, 3/100-101.

-Ders. (1998): Awangardowe marginesy. Warszawa.

Weisgerber, Jean (Hrsg., 1984): Les Avant-Gardes littéraires au XX' siécle. 2 Bände.

Budapest.

Wilhelmi, Christoph (2001): Künstlergruppen im östlichen und südlichen Europa seit 1900.

Ein Handbuch. Stuttgart.

\subsection{Sonstige Primār- und Sekundărliteratur}

Allen, Gay Wilson/Charles T. Davis (1971): Einfuhrung in ein kritisches Studium von Walt Whitmans Gedichten. In: Gerhard Hoffmann (Hrsg.): Amerikanische Literatur des 19. Jahrhunderts. Frankfurt (Main), 217-238.

Best, Otto F. (1994): Handbuch literarischer Fachbegriffe. Definitionen und Beispiele.

Frankfurt (Main). 
Die Bibel. Altes und Neues Testament. Einheitsübersetzung. Freiburg u.a. 2003. Borghesi, Silvia (1999): Paul Cézanne. Köln. (=Berühmte Maler auf einen Blick) Braak, Ivo (1965): Poetik in Stichworten. Literaturwissenschaftliche Grundbegriffe. Eine Einführung. 7., überarbeitete und erweiterte Auflage von Martin Neubauer. Unterägeri ${ }^{7}$ 1990.

Burdorf, Dieter (1994): Einfuhrung in die Gedichtanalyse. Stuttgart-Weimar 21997. -Ders. (2001): Poetik der Form. Eine Begriffs- und Problemgeschichte. Stuttgar-Weimar. Cézanne, Paul (1957): Über die Kunst. Gespräche mit Gasquet und Briefe. Hrsg. von Walter Hess. Hamburg. (=Rowohlts Klassiker der Literatur und der Wissenschaft 6) Chrząstowska, Bożena/Seweryna Wyslouch (1978): Poetyka stosowana. Warszawa 2000. Durišin, Dionýz (1972): Vergleichende Literaturforschung. Versuch eines methodischtheoretischen Grundrisses. Berlin (Ost). (=Sammlung Akademie Verlag 18, Literatur) Faron, Bolesław (1995): Jama Michalika. Przewodnik literacki. Kraków 2002.

Frenzel Elisabeth (1962): Stoffe der Weltliteratur. Ein Lexikon dichtungsgeschichtlicher Längsschnitte. Stuttgart ${ }^{8} 1992$.

Grimm, Jürgen (Hrsg., 1989): Französische Literaturgeschichte. Stuttgart. Haverkamp. Anselm (Hrsg., 1983): Theorie der Metapher. Darmstadt 2996. Ingarden, Roman (1937): Sprawa formy i treści w dziele literackim. In: Życie literackie (5), 153-167.

Kawyn, Stefan (1946): Zagadnienie grupy literackiej. Lublin. (=Towarzystwo Naukowe KUL, wykłady i przemówienia 9)

Kerényi, Karl (1966): Die Mythologie der Griechen. 2 Bände. München ${ }^{8} 1985$.

Kohlschmidt, Werner/Wolfgang Mohr (Hrsg., 1925-1931): Reallexikon der deutschen Literaturgeschichte. 2 Bände. Berlin 21958.

Koopmann, Helmut (1970): Das Junge Deutschland. Analyse eines Selbstverständnisses. Stuttgart. (=Germanistische Abhandlungen 33)

Kopalinski, Wladysław (1990): Słownik symboli. Warszawa.

Kulawik, Adam (1997): Poetyka. Wstęp do teorii dziela literackiego. Kraków.

Kurz, Gerhard (1982): Metapher, Allegorie, Symbol. Göttingen ${ }^{3} 1993$.

Lessing, Gotthold Ephraim (1766): Laokoon oder über die Grenzen der Malerei und Poesie.

In: Gotthold Ephraim Lessing: Werke. Band II. Kritische Schriften. Philosophische Schriften. Hrsg. von Jost Perfahl. München 1974, 7-166.

Makowiecki, Andrzej Z. (2000): Słownik postaci literackich. Warszawa. Molière (1971): CEuvres complètes II. Hrsg. von Georges Louton. Paris. 
de Molina, Tirso (1870): Don Juan. In: Moritz Knapp (Hrsg.): Spanisches Theater. Fünfter Band: Schauspiele von Tirso de Molina. Hildburghausen 1870, 33-150.

Purchla, Jacek (1993): Krakau unter österreichischer Herrschaft 1846-1918. Faktoren seiner Entwicklung. Wien u.a.

Richard, Lionel (1993): Cabaret Kabarett. Von Paris nach Europa. Leipzig.

Richter, Horst (1998): Geschichte der Malerei im 20. Jahrhundert. Stile und Künstler. Köln. Sławiński, Janusz (Hrsg., 1994): Podręczny słownik terminów literackich. Warszawa.

-Ders. (Hrsg., 1976): Słownik terminów literackich. Wrocław u.a. ${ }^{3} 1998$. Sprengel, Peter/Gregor Streim (1998): Berliner und Wiener Moderne. Vermittlungen und Abgrenzungen in Literatur, Theater, Publizistik. Mit einem Beitrag von Barbara Noth.

Wien u.a. (=Literatur in der Geschichte, Geschichte in der Literatur 45)

Tyrowicz, Marian (1991): Wspomnienia o życiu kulturalnym i obyczajowym Lwowa 1918 1939. Wroclaw u.a.

Weisstein, Ulrich (1992): Einleitung. Literatur und bildende Kunst: Geschichte, Systematik, Methoden. In: Ulrich Weisstein (Hrsg.): Literatur und bildende Kunst. Ein Handbuch zur Theorie und Praxis eines komparatistischen Grenzgebietes. Berlin, 11-31. 


\section{Slavistische Beiträge}

Herausgegeben von Peter Rehder

408. Huterer, Andrea: Die Wortbildungslehre in der Anweisung zur Erlernung der Slavonisch-Rußischen Sprache (1705-1729) von Johann Werner Paus. 2001. 327 S. 26.59 €. (3-87690-805-1)

409. Vickery, Walter N.: M. Iu. Lermontov: His Life and Work. 2001. VIII, 422 S. $29.65 \in$. (387690-813-2)

410. Slavistische Linguistik 2000. Referate des XXVI. Konstanzer Slavistischen Arbeitstreffens. Hamburg, 26.-28.9.2000. Herausgegeben von Volkmar Lehmann und Jessica Schamberg. 2001.277 S. $26.59 \in$. (3-87690-814-0)

411. Berwanger, Katrin: Die szenische Poetik Božena Němcovás. Theatralische Medialität in ihren Briefen, Reiseskizzen und Erzählwerken. 2001. 201 S. 23.52 €. (3-87690-815-9)

412. Swiderska, Małgorzata: Studien zur literaturwissenschaftlichen Imagologie. Das literarische Werk F.M. Dostoevskijs aus imagologischer Sicht mit besonderer Berücksichtigung der Darstellung Polens. 2001. 495 S. 29.65 €. (3-87690-816-7)

413. Widera, Steffi: Richard Weiner. Identität und Polarität im Prosafrühwerk. 2001. 296 S. 26.- $€$. (3-8769)-818-3)

414. Szucsich, Luka: Nominale Adverbiale im Russischen. Syntax, Semantik und Informationsstruktur. 2002. 255 S. 24.- €. (3-87690-819-1)

415. Breuer, Astrid Yvonne: Asyndese? Zum Problem einer 'negativen' Kategorie. 2002. 291 S. 26.- $\epsilon$. (3-87690-822-1)

416. Townsend, Ch.E., Laura A. Janda: Gemeinslavisch und Slavisch im Vergleich. Einführung in die Entwicklung von Phonologie und Flexion. Vom Frühurslavischen über das Spätgemeinslavische bis in die slavischen Einzelsprachen, mit besonderer Berücksichtigung des Russischen, Polnischen, Tschechischen. Serbischen/Kroatischen. Bulgarischen. Übersetzung. Redaktion und Layout P. Rehder. 2002. 237 S. 10.- $€$. (3-87690-831-0) (= Studienhilfen. 12.)

417. Stegherr, Marc: Das Russinische. Kulturhistorische und soziolinguistische Aspekte. 2003. XII, 529 S. 58.- €. (3-87690-832-9)

418. Bayer, Lenka: Sprachgebrauch vs. Spracheinstellung im Tschechischen. Eine empirische und soziolinguistische Untersuchung in Westböhmen und Prag. 2003. 328 S. 26.- €. (3-87690-838-8)

419. Shull, Sarah: The Experience of Space. The Privileged Role of Spatial Prefixation in Czech and Russian. 20()3. X. 239 S. 24.- $\epsilon .(3-87690-839-6)$

420. Hurtig. Claudia. Taccjana Ramza: Belarussische Grammatik in Tabellen und Übunbgen. besaруска граматыка уे табліцах и практыкаваннях. 2003. $267 \mathrm{~S} .20 .-\epsilon .(3-87690-850-7)$

421. Belyavski-Frank. Masha: The Balkan Conditional in South Slavic. A Semantic and Syntactic Siudy. 2003. IV, X, 310 S. 26.- €. (3-87690-851-5)

422. Slavistische Linguistik 2001. Referate des XXVII. Konstanzer Slavistischen Arbeitstreffens, FrankfurvFriedrichsdorf 11.-13.9.2001. Herausgegeben von Holger Kuße. 2003. 359 S. 28.€. (3-87690-853-1)

423. Böhler, Claudia: Das russisch-deutsche Wörterbuch von Iwan Pawlowsky - eine metalexikographische Analyse. 2003. X. 208 S. 24.- 6. (3-87690-854-6)

424. Reese, Hella: Ein Meisterwerk im Zwielicht: Ivan Bunins narrative Kurzprosaverknüpfung Temnye allei zwischen Akzeptanz und Ablehnung - eine Genrestudie. 2003. 411 S. 30,- $€$. (3$87690-870-1)$

425. Deschler, Jean-Paul: Kleines Wörterbuch der kirchenslavischen Sprache. Wortschatz der gebräuchlichsten liturgischen Texte mit deutscher Übersetzung. 2003. 347 S. 28,- $€$. (3-87690)$871-X)$

426. Waszink, Paul: Don't Weep a Gold Chain. Observations on Primary and Secondary Systems in Russian Classical and Romantic Art and Literature. 2(0)3. X. 309 S., I5 Abb. 28.- €. (38769()-872-(0)

427. Schorlemmer, Uta: Die Magie der Annäherung und das Geheimnis der Distanz. Krystian Lupas Recherche »neuer Mythen« im Theater. 2003. X. 265 S., 10 Abb. 26.- $€$. (3-87690-873-6)

428. Smola, Klavdia: Formen und Funktionen der Intertextualität im Prosawerk von Anton Čechov. 2004. 235 S. 24.- Є. (3-87690-877-9)

429. Eberharter, Markus: Der poetische Formismus Tytus Czyżewskis. Ein literarischer Ansatz der frühen polnischen Avantgarde und sein mitteleuropäischer Kontext. 2004. 243 S. 24,- $€$. (38769()-878-7)

\section{Verlag Otto Sagner $\cdot 80328$ Minchen e-mail: postmaster@kưbonn-ságnetr.đe e}

